Hendrik Suermann

\title{
Einkommensteuerliche Behandlung von Währungsgewinnen und -verlusten
}

Eine finanzwissenschaftliche Analyse des Steuerrechts in den USA und in Deutschland 


\section{Hendrik Suermann}

\section{Einkommensteuerliche Behandlung von Währungsgewinnen und -verlusten}

Durch die internationale Kapitalallokation entstehen bei flexiblen Wechselkursen Währungsgewinne und Währungsverluste. Diese müssen bei der einkommensteuerlichen Behandlung grenzüberschreitend eingesetzten Kapitals berücksichtigt werden. Der Autor zeigt, wie Kursgewinne und -verluste unter der Zielsetzung von Kapitalexport- beziehungsweise Kapitalimportneutralität besteuert werden sollten. Außerdem werden mit Hilfe der Optionsbewertungstheorie die Auswirkungen asymmetrischer Besteuerung durch das Anrechnungsverfahren auf die Kapitalallokation analysiert. Dabei wird auch der Frage der steuerrechtlichen Quelle von Währungsgewinnen und -verlusten nachgegangen. Vor dem Hintergrund der gewonnenen Erkenntnisse wird das Steuerrecht der USA und Deutschlands betrachtet. In den USA wurde mit der Steuerreform von 1986 eine gesetzliche Grundlage für die einkommensteuerliche Behandlung von Währungsgewinnen und -verlusten geschaffen. In Deutschland ist dieser Bereich der Besteuerung im Gesetzestext nicht erwähnt.

Hendrik Suermann studierte Volkswirtschaftslehre an der Universität Hamburg. Zwischen 1994 und 1998 Promotion bei Prof. Dr. G. Krause-Junk. Seit 1997 bei einer Wirtschaftsprüfungsgesellschaft tätig. 


\section{Einkommensteuerliche Behandlung \\ von Währungsgewinnen und -verlusten}




\section{FINANZWISSENSCHAFTLICHE SCHRIFTEN}

Herausgegeben von den Professoren

Albers, Krause-Junk, Littmann, Oberhauser, Pohmer, Schmidt

Band 92

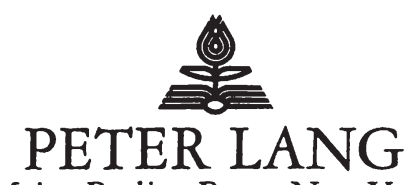

Frankfurt am Main - Berlin - Bern - New York · Paris - Wien 


\section{Hendrik Suermann}

\section{Einkommensteuerliche Behandlung von Währungsgewinnen und -verlusten}

Eine finanzwissenschaftliche Analyse des Steuerrechts in den USA und in Deutschland

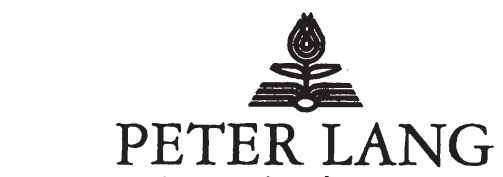

Europäischer Verlag der Wissenschaften 
Die Deutsche Bibliothek - CIP-Einheitsaufnahme

Suermann, Hendrik:

Einkommensteuerliche Behandlung von Währungsgewinnen und -verlusten : eine finanzwissenschaftliche Analyse des Steuerrechts in den USA und in Deutschland / Hendrik Suermann. - Frankfurt am Main ; Berlin ; Bern ; New York ; Paris ; Wien : Lang, 1999

(Finanzwissenschaftliche Schriften ; Bd. 92)

Zugl.: Hamburg, Univ., Diss., 1998

ISBN 3-631-34393-0

Open Access: The online version of this publication is published on www.peterlang.com and www.econstor.eu under the international Creative Commons License CC-BY 4.0. Learn more on how you can use and share this work: http://creativecommons. org/licenses/by/4.0.

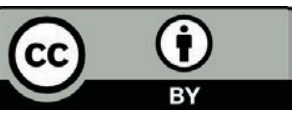

This book is available Open Access thanks to the kind support of ZBW - Leibniz-Informationszentrum Wirtschaft.

Gedruckt auf alterungsbeständigem, säurefreiem Papier.

\author{
D 18 \\ ISSN 0170-8252 \\ ISBN 3-631-34393-0 \\ ISBN 978-3-631-75217-3 (eBook) \\ (C) Peter Lang GmbH \\ Europäischer Verlag der Wissenschaften \\ Frankfurt am Main 1999 \\ Alle Rechte vorbehalten.
}

Das Werk einschließlich aller seiner Teile ist urheberrechtlich geschützt. Jede Verwertung außerhalb der engen Grenzen des

Urheberrechtsgesetzes ist ohne Zustimmung des Verlages unzulässig und strafbar. Das gilt insbesondere für Vervielfältigungen, Übersetzungen, Mikroverfilmungen und die Einspeicherung und Verarbeitung in elektronischen Systemen.

Printed in Germany 124567 


\section{Inhaltsverzeichnis}

$\begin{array}{ll}\text { Abkürzungsverzeichnis } & 8\end{array}$

Symbolverzeichnis $\quad 9$

I. Symbole 9

II. Indizes 9

A. Einleitung 11

B. Theoretische Überlegungen zu einer effizienten Besteuerung
von Währungsgewinnen und -verlusten

I. Allokative Effizienz 16

1. Effizienz der Kapitalmärkte 16

2. Allokative Effizienz bei Besteuerung 18

a) Kapitalexportneutralität $\quad 19$

b) Kapitalimportneutralität $\quad 20$

c) Zur Kritik an beiden Ansätzen in der Literatur 21

II. Zur Bedeutung von Währungsrisiko und Besteuerung bei den
Investitions- und Finanzierungsentscheidungen der Unternehmen

1. Zahlen zum Währungsrisiko 24

2. Definitionen für Währungsrisiken in Unternehmen 26

a) Transaktionsrisiko $\quad 27$

$\begin{array}{ll}\text { b) Buchrisiko } & 27\end{array}$

c) Das ökonomische Risiko $\quad 28$

3. Irrelevanz der Währung für die Finanzierung 29

4. Währungsrisiko 32

5. Konkretisierung der Kapitaleinkommensteuer 33

a) Zur Finanzierungsneutralität $\quad 33$

b) Investitionsneutralität $\quad 34$

$\alpha)$ Unvollkommener Verlustausgleich als Optionsposition 34

ß) Kapitalwertabschreibung $\quad 36$

6. Zu inframarginalen Gewinnen $\quad 37$

III. Optimale Kapitaleinkommensbesteuerung

1. Kaufkraftparitätenhypothesen:

Gleichgewichtsbeziehungen der Gütermärkte $\quad 39$

2. Zinsparitätenhypothese:
Gleichgewichtsbeziehung der internationalen Kapitalmärkte

3. Implikationen für neutrale Besteuerung 46

a) Besteuerung nach dem Wohnsitzlandprinzip 48

$\alpha)$ Nominalwertprinzip $\quad 48$

$\begin{array}{lr}\beta) \text { Freistellung von Scheingewinnen } & 52\end{array}$

b) Besteuerung nach dem Quellenlandprinzip $\quad 55$

IV. Asymmetrische Besteuerung ausländischen Kapitaleinkommens
und unerwartete Wechselkursänderungen

1. Anrechnungsverfahren bei isolierter Betrachtung 59

2. Anrechnungsverfahren mit Verlustausgleich 67

a) Bedeutung des Verlustabzugverbots in der isolierten Betrachtung 67

b) Verlustausgleich beim Anrechnungsverfahren 68

3. Anrechnungsverfahren mit Abzugsmethode als Wahlrecht 69

4. Gegenüberstellung der Ergebnisse 71

V. Zur Quelle von Währungsgewinnen und -verlusten 72

VI. Zusammenfassung $\quad 77$ 
C. Währungsgewinne und -verluste im U.S.-amerikanischen Steuerrecht 80

I. Grundlagen zur Besteuerung ausländischer Einkünfte 81

$\begin{array}{ll}\text { 1. Steuersubjekte der U.S.-Einkommensteuer } & 81\end{array}$

2. Besteuerung von Kapitaleinkommen 83

a) Ordentliches Einkommen („Ordinary Income“) 84

$\begin{array}{ll}\text { b) Veräußerungsgewinne und -verluste } & 87\end{array}$

3. Quelle und Arten von Einkünften 88

4. Zurechnung von Zinsaufwendungen 90

5. Anrechnung ausländischer Steuern 92

II. Die einkommensteuerliche Behandlung
von Währungsgewinnen und -verlusten

1. Grundlagen zur steuerrechtlichen Ermittlung 96

a) Umsatzmethode (,Separate Transaction Method“) 97

b) Stichtagmethode (",Profit and Loss Method") 100

c) Fristigkeitmethode („Net Worth Method") 101

2. Der Kern der Steuerreform von 1986: Stichtagmethode reformiert 104

a) Qualifizierte wirtschaftliche Einheiten
("Qualified Business Units")

b) Die Bestimmung der funktionalen Währung (,Functional Currency“) 106

c) Bestimmung des steuerpflichtigen Erfolgs der QBU
in U.S.-Dollar

d) Umrechnung der Gewinn- und Verlustrechnung:
Durchschnitts- oder Stichtagskurs?

e) Zurechnung von Zinsaufwendungen 111

f) Kapitalherabsetzungen und Entnahmen 111

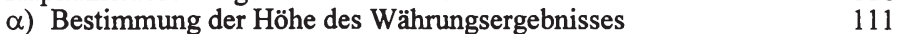

ß) Quelle und Art des Währungsergebnisses 114

g) Besonderheiten bei Ausschüttungen
ausländischer Tochtergesellschaften 116

$\alpha)$ Währungsgewinne und -verluste bei der Ausschüttung
von einbehaltenen Gewinnen

$\begin{array}{ll}\beta) \text { Anrechnung ausländischer Steuern } & 120\end{array}$

3. Eine Variante der „Net Worth Method“:

Spezielle Rechtsverordnungen für stark inflationäre Währungen 123

a) Theoretische Überlegungen 124

$\begin{array}{ll}\text { b) Die geltende Rechtslage } & 127\end{array}$

4. Umsatzmethode mit Neuerungen: „Section 988 Transactions“ 131

a) Zu nichtmonetären Aktiva 133

b) Anlage- und Finanzierungsinstrumente
mit Fremdkapitalcharakter

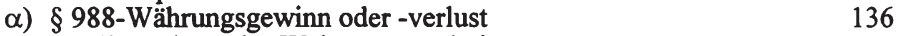

B) Quelle und Art des Währungsergebnisses $\quad 139$

c) Währungstermingeschäfte 141

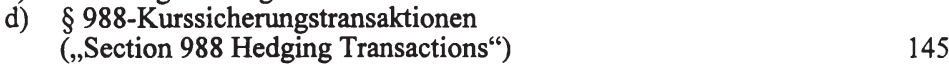

5. Privatvermögen 149

III. Zusammenfassende Beurteilung 150

D. Währungsgewinne und -verluste im deutschen Steuerrecht 155

I. Grundlagen zur Besteuerung ausländischer Einkünfte 156

1. Steuersubjekte und Steuersätze 156

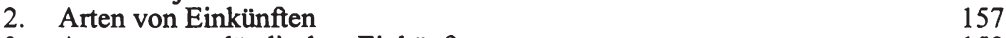

3. Arten von ausländischen Einkünften 159

$\begin{array}{ll}\text { 4. Zurechnung von Betriebsausgaben } & 161\end{array}$

5. Anrechnungs-, Freistellungs- und Abzugsmethode 161

6. Eine Anmerkung zum Solidaritätszuschlag 165 
II. Die einkommensteuerliche Behandlung

von Währungsgewinnen und -verlusten

1. Elementare Grundsätze ordnungsmäßiger Buchfuihrung 165

2. Transaktionen von Steuerinländern

a) Anschaffungskosten und Veräußerungszeitpunkt 169

b) Quelle des Währungsergebnisses

c) Teilwertabschreibungen bei wechselkursbedingten Wertminderungen

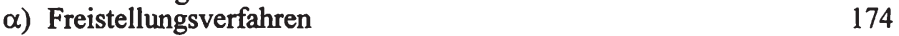

ß) Anrechnungsverfahren 176

d) Währungstermingeschäfte 177

e) Einzelbewertungsgrundsatz, Bewertungseinheiten und Kurssicherungstransaktionen $\quad 178$

3. Ausländische Betriebstätten 182

a) Zulässigkeit der Umrechnungsmethoden 182

b) Quelle des Währungsergebnisses 185

c) Wechselkursbedingte Wertminderungen 188

a) Freistellungsverfahren $\quad 188$

ß) Anrechnungsverfahren $\quad 189$

4. Wesentliche Beteiligungen an ausländischen Kapitalgesellschaften $\quad 190$

a) Freistellungsverfahren 191

b) Anrechnungsverfahren 192

5. Zur Umrechnung ausländischer Steuern im Anrechnungsverfahren 193

6. Einnahmenüberschußrechnung und Privatvermögen 194

III. Wirkung der deutschen Besteuerung

bei erwarteten Wechselkursänderungen

1. Zur erwarteten Währungsentwicklung 196

$\begin{array}{ll}\text { 2. Zur Quelle von Währungsgewinnen und -verlusten } & \\ \text { im Freistellungsverfahren } & 198\end{array}$

3. Anrechnungsverfahren und stark inflationäre Währungen 201

4. Exkurs: Freistellungsverfahren weltweit 201

IV. Zusammenfassende Beurteilung im Vergleich
zu der Besteuerung in den USA

$\begin{array}{ll}\text { E. Zusammenfassung } & 207\end{array}$

Anhang $\quad 211$

$\begin{array}{ll}\text { Literaturverzeichnis } & 233\end{array}$ 


\section{Abkürzungsverzeichnis}

\begin{tabular}{|c|c|}
\hline a.a.O. & am angegebenen Ort \\
\hline Abs. & Absatz \\
\hline Abschn. & Abschnitt \\
\hline AIG & Auslandsinvestitionsgesetz \\
\hline $\mathrm{AO}$ & Abgabenordnung \\
\hline AStG & Außensteuergesetz \\
\hline Aufl. & Auflage \\
\hline $\mathrm{BFH}$ & Bundesfinanzhof \\
\hline bzw. & beziehungsweise \\
\hline d.h. & das heißt \\
\hline DASTM & Dollar Aproximate Separate Transactions Method \\
\hline Diss. & Dissertation \\
\hline E\&P & Earnings and Profits \\
\hline ebda. & ebenda \\
\hline erw. & erweiterte \\
\hline EStDV & Einkommensteuer-Durchführungsverordnung \\
\hline EStG & Einkommensteuergesetz \\
\hline EStR & Einkommensteuerrichtlinien \\
\hline f., ff. & folgende, fortfolgende \\
\hline FASB & Financial Accounting Standards Board \\
\hline FG & Finanzgericht \\
\hline Fn. & Fußnote \\
\hline HGB & Handelsgesetzbuch \\
\hline Hrsg. & Herausgeber \\
\hline i. S. d. & im Sinne des \\
\hline IDW & Institut der Wirtschaftsprüfer in Deutschland e.V. \\
\hline IRC & Internal Revenue Code \\
\hline Jg. & Jahrgang \\
\hline KStG & Körperschaftsteuergesetz \\
\hline m.w.N. & mit weiteren Nachweisen \\
\hline n-rkr & nicht rechtskräftig \\
\hline Nr. & Nummer \\
\hline o. Jg. & ohne Jahrgang \\
\hline o. V. & ohne Verfasser \\
\hline OECD-MA & OECD-Musterabkommen \\
\hline Prop. Reg. & Proposed Treasury Regulations \\
\hline QBU & Qualified Business Unit \\
\hline Reg. & Treasury Regulations \\
\hline rkr & $\begin{array}{l}\text { rechtskräftig } \\
\text { Randziffer }\end{array}$ \\
\hline Sp. & Spalte \\
\hline u. & und \\
\hline u.a. & und andere \\
\hline überarb. & überarbeitete \\
\hline v. & vom \\
\hline vgl. & vergleiche \\
\hline
\end{tabular}




\section{Symbolverzeichnis}

\section{Symbole}

$\begin{array}{cl}\sigma & \text { Standardabweichung } \\ \tau & \text { Quellensteuersatz } \\ \text { AM } & \text { „ausländische Währung“: Bezeichnung der fiktiven ausländischen } \\ \text { C } & \text { Währung } \\ E & \text { Opeis einer Kaufoption } \\ \text { e } & \text { nominaler Devisenkurs } \\ \text { EK } & \text { Eigenkapital } \\ \text { f } & \text { Devisenterminkurs } \\ \text { FK } & \text { Fremdkapital } \\ \text { ge } & \text { nominaler Grenzertrag } \\ \text { GK } & \text { Gesamtkapital } \\ \text { gp } & \text { nominale Grenzproduktivität } \\ \text { i } & \text { Inflationsrate } \\ \text { IM } & \text {,inländische Währung“: Bezeichnung der fiktiven inländischen } \\ & \text { Währung } \\ \text { k } & \text { Ausübungspreis einer Option, aber auch Kapitalkosten } \\ N & \text { Operand für kumulative Normalverteilung } \\ \mathrm{n} & \text { Zeitraum in Perioden } \\ \mathrm{P} & \text { Preis einer Verkaufoption } \\ \mathrm{r} & \text { nominales risikofreies Marktzinsniveau } \\ \mathrm{T} & \text { Steuereinnahme beziehungsweise Steuerlast } \\ \mathrm{t} & \text { Steuersatz im Wohnsitzland, aber auch Zeitpunkt } \\ \mathrm{V} & \text { Vermögen }\end{array}$

\section{Indizes}

+1 kennzeichnet einen Zeitraum von einer Periode

* kennzeichnet Variable und Parameter des Auslands

AM kennzeichnet monetäre Größen in ausländischer Währung

e kennzeichnet eine Steuer auf Devisenkursänderungen

IM kennzeichnet monetäre Größen in inländischer Währung

n kennzeichnet eine Steuer auf nominale Erträge

r kennzeichnet reale Größen 
Hendrik Suermann - 978-3-631-75217-3

Downloaded from PubFactory at 01/11/2019 06:58:26AM

via free access 


\section{A. Einleitung}

Vor zehn Jahren haben die USA als erste bedeutende Industrienation eine umfassende gesetzliche Grundlage für die einkommensteuerliche Behandlung von Währungsgewinnen und -verlusten geschaffen. Im Rahmen der Steuerreform von 1986 wurde mit Wirkung zum 1.1.1987 das Einkommensteuergesetz - der „Internal Revenue Code“ - um einen Unterabschnitt erweitert, der ausschließlich Fremdwährungsgeschäfte zum Inhalt hat.

Überlegungen zu einer angemessenen Quantifizierung von Währungsgewinnen und -verlusten wurden in den Vereinigten Staaten aber schon früher angestellt. Für die Rechnungslegung wurden erste Empfehlungen bereits 1931 veröffentlicht. ${ }^{1}$

Im Bereich der Einkommensbesteuerung gab Ravenscroft 1973 eine umfangreiche Zusammenstellung der rechtskräftigen Urteile in den USA zur Besteuerung von Währungsgewinnen und der buchhalterischen Methoden für eine periodische Ermittlung des (steuerlichen) Erfolgs von Aktivitäten in mehreren Währungsräumen heraus. ${ }^{2}$

In Reaktion auf des Werk von Ravenscroft schreibt P. Musgrave 1975:

„Sowohl die Umrechnung von Auslandseinkünften in U.S.-Dollar als auch die steuerliche Behandlung von Währungsgewinnen und -verlusten ist [...] ein wichtiger Teil des Besteuerungsprozesses. Dessen ungeachtet existieren nicht nur kein geschriebenes Recht, welches die Umrechnungsmethoden spezifiziert, sondern auch nur wenige Richtlinien des Finanzministeriums, die dem Steuerpraktiker eine eindeutige Anleitung geben. Ein außenstehender Betrachter gewinnt den Eindruck, daß sich die meisten Praktiken nahezu ohne systematische Analyse in den gewohnheitsrechtlichen Gebrauch eingeschlichen haben, und daß sowohl der Steuerverwaltung als auch dem Steuerpflichtigen ein übermäßiger Ermessensspielraum bleibt. Es ist offensichtlich, daß das Gesetz in diesem wichtigen und zunehmend bedeutenden Feld konkreter sein sollte".3

In den folgenden Jahren setzte eine intensive Diskussion um neue buchhalterische und steuerliche Ansätze für eine ökonomisch plausible und praktikable Erfassung wechselkursbedingten Einkommens ein. Währenddessen unterlag der U.S.-Dollar in der Folge des endgültigen Scheiterns des Festkurssystems von Bretton Woods 1973 erstmals starken Schwankungen; die internationale Verflechtung der Kapital- und Gütermärkte nahm zu und ebenso die Irritation über die geltende Rechtslage. ${ }^{4}$

Der „Financial Accounting Standards Board (FASB)“ verfaßte 1975 die Richtlinie Nr. 8 zur Umrechnung ausländischer Währungen in Buchführung und Bilanzierung. ${ }^{5}$ Die Richtlinie wurde später durch Richtlinie Nr. 52 ersetzt, ${ }^{6}$ die umfangreiche Änderungen insbesondere hinsichtlich des Zeitpunkts der Erfassung nicht realisierter Währungsgewinne und -verluste bei ausländischen Betriebstätten und Tochtergesellschaften beinhaltete. 1980 erarbeitete das U.S.amerikanische Finanzministerium erste umfassende Reformvorschläge des Steuerrechts in

1 Vgl. American Institute of Certified Public Accountants, Foreign Exchange Losses, in: The Bulletin of the American Institute of (Certified Public) Accountants, Nr. 92 v. 15. Dezember 1931.

2 D.R. Ravenscroft, Taxation and Foreign Currency: The Income Tax Consequences of Foreign Exchange Transactions and Exchange Rate Fluctuations, Cambridge, Mass. 1973.

3 P.B. Musgrave, Exchange Rate Aspects in the Taxation of Foreign Exchange Income, In: National Tax Journal, 28.Jg. (1975), S.405 (eigene Übersetzung).

4 F.E. White, Taxation of Foreign Currency Transactions under the Tax Reform Act of 1986, in: International Bureau of Fiscal Documentation Bulletin, 41.Jg. (1987), S.206f..

5 Vgl. FASB, Statement of Financial Accounting Standards No.8.: Accounting for the Translation of Foreign Currency Transactions and Foreign Currency Financial Statements, Stamford 1975.

6 Vgl. FASB, Statement of Financial Accounting Standards No.52.: Foreign Currency Translation, in: Dies., Accounting Standards, Original Pronouncemants, Stamford 1982, S. 1390-1422. 
diesem Bereich. ${ }^{7}$ Die angeregten Verbesserungen fußen in wesentlichen Teilen auf der Richtlinie Nr. 52 des FASB.

Konkrete Vorschläge zu einer gesetzlichen Regelung der Besteuerung von Währungsgewinnen beinhalteten die 1985 von Präsident Reagan unterzeichneten Reformvorschläge „The Presidents Tax Proposals to the Congress for Fairness, Growth and Simplicity" 8 und die zeitgleiche Initiative zu einer Neugestaltung des Steuersystems aus dem „House Ways and Means Committee“, dem Finanzausschuß des Repräsentantenhauses. ${ }^{9}$

Als Ergebnis wurde mit der weitreichenden U.S.-Steuerreform des Jahres 1986 der Unterabschnitt J (,Subpart J“) neu in das Einkommensteuergesetz eingeführt. Allerdings stellt Unterabschnitt J nur einen groben Rahmen dar und die Steuerbehörden waren gefordert, diesen Rahmen durch detailliertere Steuerrichtlinien ("Treasury Regulations“) mit Leben zu füllen. ${ }^{10}$ Letztere haben im Laufe der letzten zehn Jahre respektable Ausmaße angenommen.

Ein weiterer Aspekt der Steuerreform von 1986 ist aber ebenfalls von Bedeutung: ${ }^{11}$ Die Angleichung des Steuersatzes für Veräußerungsgewinne an die übrigen Einkommensteuersätze. Unlängst wurde dieser Schritt allerdings zurückgenommen. Am 5. August 1997 unterzeichnete Präsident Clinton den sogenannten „Tax Payer Relief Act of 1997“. Damit wurde unter anderem die Steuer auf Veräußerungsgewinne im Privatvermögen wieder gesenkt.

Im Gegensatz dazu wird in dem deutschen Einkommen- und Körperschaftsteuergesetz die Besteuerung von Währungsgewinnen und -verlusten nicht ausdrücklich erwähnt. Das geltende Recht fußt in Deutschland auf dem Handelsrecht - und zwar vor allem auf ungeschriebenem Recht, nämlich den Grundsätzen ordnungsmäßiger Buchführung und Bilanzierung. In den letzten Jahren wurden einige Monographien veröffentlicht, die Interpretationen dieser Grundsätze und des allgemeinen Einkommensteuerrechts im Hinblick auf die Ermittlung und Besteuerung von Währungsgewinnen in Deutschland bieten.

Außerdem haben der Bundesfinanzhof und die Finanzgerichte der Länder in einer Reihe von Urteilen die steuerliche Behandlung des Währungsergebnisses präzisiert.

Veränderungen der deutschen Rechtslage sind durch Bestrebungen der Europäischen Union zu einer Vereinheitlichung des Bilanz- und Steuerrechts denkbar. In der 4. und 7. EG-Bilanzrichtlinie mußte die Währungsumrechnung von Auslandsinvestitionen allerdings aufgrund unüberwindlicher Meinungsverschiedenheiten und der unterschiedlichen Praxis in den Mitgliedsländern ausgeklammert werden. ${ }^{12}$ Möglich war auf europäischer Ebene bisher nur die Formulierung einer - nicht verbindlichen - Stellungnahme zur Umrechnung von Einzelabschlüssen. ${ }^{13}$

7 U.S. Department of the Treasury, Foreign Exchange Discussion Draft, Washington, DC. 1980.

8 R. Reagan, The Presidents Tax Proposals to the Congress for Fairness, Growth and Simplicity, Washington, DC. 1985, S. $409-422$.

9 U.S. House Ways and Means Committee, Tax Reform Bill of 1985, in: Standard Federal Tax Reports -Extra Edition-, 72.Jg. (1985), Heft 52, Sp.467-478.

10 D.P. Zaiken u.a., Handling the Treatment of Foreign Currency under Tax Reform, in: Journal of Taxation, 54.Jg. (1987), S.168.

11 J. Isenbergh, International Taxation, Teil II, Boston u.a. 1990, S. 282.

12 D. Ordelheide, Gefährdung der Nominalkapitalerhaltung durch die Währungsumrechnung von Auslandsinvestitionen, in: Zeitschrift für betriebswirtschaftliche Forschung, 46.Jg. (1994), S.795-818; Adler/Düring/ Schmaltz, Rechnungslegung und Prüfung der Unternehmen, Teilband 1, 6. Aufl. Stuttgart 1995, §253 HGB, Rz. 90.

13 Vgl. Beratendes Forum für Rechnungslegung der Europäischen Kommission, Umrechnung von Fremdwährungsposten, Hrsg. Europäische Kommission, Brüssel u. Luxemburg 1995. 
Die Frage nach einer adäquaten Umrechnungsmethode wird aber auch in Deutschland nach wie vor kontrovers diskutiert. ${ }^{14}$ „Die Unsicherheit des Gesetzgebers über eine angemessene Regelung dieser Bilanzierungsfrage " 15 kommt in den besonderen Vorschriften zur Erläuterung der Währungsumrechnung im Anhang der Jahresabschlüsse von Unternehmen zum Ausdruck. ${ }^{15}$

Die aktuellen Diskussionen um eine internationale Vereinheitlichung der Bilanzierung ${ }^{16}$ und die Reform der Unternehmensbesteuerung in Deutschland ${ }^{17}$ betreffen mittelbar einen anderen Aspekt der Besteuerung von Währungsgewinnen und - insbesondere - Währungsverlusten. In beiden Fällen steht nämlich die Anwendung des Vorsichtsprinzips der deutschen Rechnungslegung auf dem Prüfstand. Es ist unklar, inwieweit auch künftig Verluste vor ihrer Realisierung steuerlich berücksichtigt werden dürfen. Die Bildung von Rückstellungen ist für bestimmte drohende Verluste seit der jüngsten, am 9. September 1997 Gesetz gewordenen, Steueränderung nicht mehr zulässig.

Die vorliegende Arbeit untersucht die Rechtslage in den USA und in Deutschland aus finanzwissenschaftlicher Perspektive.

Im Mittelpunkt steht die Frage:

- Welchen Einfluß auf die Kapitalallokation haben die konkreten Regelungen zur Besteuerung von Währungsgewinnen und -verlusten in den USA und in Deutschland?

Daraus leiten sich die nachfolgend behandelten Aspekte ab, nämlich

- ob Währungsgewinne und -verluste überhaupt besteuert werden sollten;

- welche quantitativen Auswirkungen Währungsschwankungen bei asymmetrischer Besteuerung im Anrechnungsverfahren haben;

- welcher Quelle wechselkursbedingte Gewinne und Verluste steuerrechtlich zugerechnet werden sollten: dem Belegenheits- oder dem Wohnsitzstaat;

- und schließlich, wann Währungsgewinne und -verluste besteuert werden sollten.

Die Arbeit gliedert sich in drei Teile. In dem nachfolgenden Teil B werden theoretische Überlegungen zu einer effizienten einkommensteuerlichen Behandlung von Währungsgewinnen und -verlusten angestellt. Die Teile C und D beleuchten anschließend das geltende Recht in den USA und in Deutschland.

Die Erhebung von Steuern auf Kapitaleinkommen wird dabei als gegeben unterstellt. ${ }^{18}$ Untersucht wird, wie unter dieser Voraussetzung die größtmögliche Entscheidungsneutralität hinsichtlich der Herkunft oder dem Einsatzort von Kapital gewährleistet werden kann.

14 J. Baetge, Konzernbilanzen, 2. überarb. u. aktualisierte Aufl., Düsseldorf 1995, S.153.

15 G. Gebhardt u. N. Breker, Bilanzierung von Fremdwährungstransaktionen im handelsrechtlichen Einzelabschluß - unter Berücksichtigung von §340h HGB, In: Der Betrieb, 44. Jg. (1991), S.1529.

16 Vgl. z.B. o.V., Der Kapitalmarkt bestimmt die Rechnunglegung, in: Börsen-Zeitung v. 2.10.1997.

17 Vgl. z.B. o.V., Die Wirtschaftsprüfer sehen das Vorsichtsprinzip gefährdet, in: Frankfurter Allgemeine Zeitung v. 6.10.1997.

18 Eine Analyse zur neutralen Besteuerung von Währungsgewinnen wurde von Mertens durchgeführt. Vgl. J.B. Mertens, Translation Rules and Tax Neutrality: The Effects of the Taxation of Foreign Exchange Gains and Losses on the Profit Maximizing Decisions of Firms, Diss., Emroy Univ. 1992. Auf der Grundlage einer Reingewinnsteuer, das heißt bei ökonomischer Abschreibung und Freistellung der marktüblichen Verzinsung für alle Finanzierungsformen, zeigt Mertens, warum sowohl beim Quellenlandprinzip als auch bei Besteuerung im Wohnsitzland Währungsgewinne und -verluste wie andere Kapitalkosten von der Besteuerung ausgenommen werden müssen. Die Reingewinnsteuer ist in der Analyse von Mertens neutral, da sie impliziert, Investitionsmöglichkeiten seien standortgebunden. Könnte das Unternehmen entscheiden, in welchem Land eine bestimmte Investition durchgeführt wird, für die ein zu versteuernder Reingewinn erwartet wird, wäre auch die Höhe des Steuersatzes entscheidungsrelevant. Vgl. G. Krause-Junk, Körperschaftsteuerharmonisierung in Europa, unveröffentlichte Notizen zur Vorlesung im Wintersemester 1993/94, S. 23 f.. 
In dem theoretischen Teil wird der Frage nachgegangen, ob Gewinne oder Verluste besteuert werden sollten, deren Ursache in erwarteten Wechselkursänderungen liegt. Zu diesem Zweck werden die Prinzipien der Kapitalexportneutralität und der Kapitalimportneutralität vor dem Hintergrund der Zins- und der Kaufkraftparität betrachtet.

Außerdem wird analysiert, welche Folgen das Risiko unerwarteter Kursänderungen hat. Das wesentliche Problem ist hier die asymmetrische Besteuerung von Währungsgewinnen und -verlusten im Anrechnungsverfahren. Die inländische Steuerlast wird als Optionsposition modelliert und in zwei Beispielen berechnet. Dabei findet auch Berücksichtigung, daß das Steuerrecht möglicherweise den Abzug ausländischer Verluste von inländischen Einkünften oder die Wahl des Abzugsverfahrens einräumt.

Mit Hilfe der Ergebnisse wird schließlich abgewogen, ob das Währungsergebnis den inländischen oder den ausländischen Einkünften zugerechnet werden sollte.

Der Schwerpunkt der anschließenden Analysen des geltenden Steuerrechts in den USA und Deutschland ist Kapitalexport in Form von Direktinvestitionen durch Betriebstätten und durch Tochtergesellschaften. Dieser Aspekt bildete einen Mittelpunkt der Gesetzesreform in den USA. Außerdem fallen mit der maßgeblichen Kontrolle des Steuerinländers über die Investition auch Währungsgewinne und -verluste im Inland an. ${ }^{19}$ Einbezogen werden daneben andere Formen grenzüberschreitenden Kapitaleinsatzes und Termingeschäfte. Bei diesen Geschäften ist aber die Währung, auf die die Positionen lauten, wahlfrei. Das Währungsrisiko kann prinzipiell sowohl im Quellen- als auch im Wohnsitzstaat (oder auch in einem dritten Land) anfallen.

Unberücksichtigt bleiben der Bankensektor und Unternehmensstrukturen, die mehr als zwei Stufen umfassen.

Im U.S.-Steuerrecht wurden spezielle Steuerrichtlinien für Direktinvestitionen in stark inflationären Währungsräumen geschaffen. Die Richtlinien werden in Teil C untersucht. Ein Vergleich dieser Umrechnungsmethode mit dem in den USA ansonsten vorgeschriebenen Verfahren zur Gewinnermittlung bei grenzüberschreitenden Investitionen veranschaulicht Probleme der Quantifizierung von Währungsgewinnen und -verlusten. Zudem sind die Richtlinien seit 1986 mehrfach revidiert worden.

Demgegenüber werden in Deutschland Gewinne in solchen Ländern nicht nach einer besonderen Methode bestimmt. Wie in Teil D deutlich werden wird, ist dies, mit Einschränkungen, auch nicht erforderlich.

Die Teile enden mit einer Beurteilung des Steuerrechts in den USA und in Deutschland; zum Abschluß des Teils $D$ werden außerdem die Regelungen beider Länder verglichen.

19 Für den Begriff der Direktinvestition sind unterschiedliche Definitionen geprägt worden. Hier ist aber entscheidend die steuerrechtliche Abgrenzung des jeweils betrachteten Landes für die Gewinnermittlung und für die Zulässigkeit der Anrechnung von Steuern im Belegenheitsstaat. Vgl. A.J. Weichenrieder, Besteuerung und Direktinvestition, Schriften zur angewandten Wirtschaftsforschung Nr.70, Tübingen 1995, S.4f.. u. S.5-8 für einen Überblick über die Motive für Direktinvestitionen. 


\section{B. Theoretische Überlegungen zu einer effizienten Besteuerung von Währungsgewinnen und -verlusten}

In diesem Teil werden die theoretischen Überlegungen dargelegt, auf deren Grundlage nachfolgend die Besteuerung von Währungsgewinnen und -verlusten als Teil des Kapitaleinkommens in den USA und in Deutschland beurteilt werden wird.

Ausgangspunkt sind die in der Finanzwissenschaft bekannten Prinzipien der Kapitalexportund der Kapitalimportneutralität. Diese Konzepte für eine neutrale Besteuerung grenzüberschreitender Investitionen basieren auf einem Arbitragegleichgewicht auf den internationalen Kapitalmärkten.

In der monetären Außenwirtschaftstheorie wird das Arbitragegleichgewicht auf den internationalen Kapitalmärkten bei flexiblen Wechselkursen durch die Hypothesen der Zins- und der Kaufkraftparität beschrieben.

Die Ansätze werden hier zunächst kritisch eingefuihrt und danach integriert. Es wird darstellt, wie erwartete Währungsgewinne und -verluste steuerlich zu behandeln sind, um bei flexiblen Wechselkursen ein kapitalexportneutrales oder ein kapitalimportneutrales Arbitragegleichgewicht zu ermöglichen. Dabei wird auch die Frage beantwortet, ob es notwendig ist, sogenannte Scheingewinne freizustellen, oder ob Kapitalexport- und Kapitalimportneutralität im Rahmen des Nominalwertprinzips möglich sind.

Der Blick in die Wirklichkeit zeigt indes, daß ein wesentliches Problem für die Besteuerung in dem Risiko unerwarteter Wechselkursänderungen liegt. Das Währungsrisiko führt im Anrechnungsverfahren zu einer asymmetrischen Behandlung, wenn Kursgewinne im Inland steuerpflichtig sind, Kursverluste dagegen aufgrund eines Anrechnungsüberhangs die Steuerbelastung nicht mindern. Die Wirkung auf den erwarteten Endwert einer Investition im Ausland wird hier anhand von zwei Beispielen berechnet. Dabei wird zunächst das Anrechnungsverfahren isoliert betrachtet und anschließend auch (i) der Abzug eines Währungsverlustes von der inländischen Bemessungsgrundlage und (ii) die Abzugsmethode als Wahlrecht zugelassen. Für folgende drei Fälle werden die Resultate verglichen:

(1) Währungsgewinne und -verluste werden zur Gänze in das Anrechnungsverfahren einbezogen;

(2) nur ex ante erwartete Währungsgewinne und -verluste werden im Anrechnungsverfahren berücksichtigt oder

(3) Währungsgewinne und -verluste werden im Wohnsitzland besteuert, doch nicht in das Anrechnungsverfahren einbezogen.

Die genannten Fälle lassen sich in der Realität umsetzen, indem das Währungsergebnis entweder den inländischen oder ganz oder teilweise den ausländischen Einkünften zugerechnet wird. Daher wird zum Abschluß abgewogen, welche steuerrechtliche Quelle von Währungsgewinnen und -verlusten zweckmäßig ist.

Die Analyse beschränkt sich in diesem Teil auf ein einperiodiges Modell. Außerdem wird von den Unterschieden möglicher Finanzierungsformen abstrahiert und eine Grenzproduktivität und ein Grenzertrag für jedes Land unterstellt. Dabei werden die Voraussetzungen für die zweite Unterstellung ausführlich dargelegt.

Basis der Überlegungen in dieser Arbeit ist die Annahme, daß die Devisenmärkte als Bestandteil der internationalen Kapitalmärkte ihre Funktion der Allokation des Faktors Kapital effizient erfüllen. Auf Grund dessen beginnt der Teil mit einer Überprüfung der Effizienzmarkthypothese. 


\section{Allokative Effizienz}

\section{Effizienz der Kapitalmärkte}

Die Preisbildung auf Kapitalmärkten wird durch Erwartungen über zukünftige Entwicklungen bestimmt. Das trifft auch auf die Bildung der Devisenkurse zu, da Devisenmärkte Bestandteil der internationalen Kapitalmärkte sind.

In dieser Arbeit werden rationale Erwartungen unterstellt. Die Hypothese rationaler Erwartungen wurde erstmals 1961 von Muth ${ }^{1}$ in der Ökonomie angewendet. Ihr zufolge ist zwar die Prognose eines einzelnen Wirtschaftssubjektes subjektiv und in der Regel unvollständig, da die ökonomische Entwicklung auch von unvorhersehbaren Zufallseinflüssen bestimmt wird. Es wird aber behauptet, Wirtschaftsubjekte würden ihre Erwartungen über die künftige Entwicklung auf der Grundlage des ihnen bekannten „wahren“ Modells bilden. Im Durchschnitt sind die subjektiven Erwartungen der Wirtschaftseinheiten bezüglich einer Variablen $\mathbf{x}, \mathbf{x}_{+1}^{e}$, für einen in der Zukunft liegenden Zeitpunkt infolgedessen richtig; sie stimmen mit dem objektiven Erwartungswert $E\left[\mathrm{x}_{t+1}\right]$ überein:

$$
\mathbf{x}_{+1}^{\mathbf{e}}=E\left[\mathbf{x}_{+1}\right]
$$

Die Hypothese rationaler Erwartungen ist Voraussetzung für die Existenz effizienter Kapitalmärkte: Die Bedingung für effiziente Kapitalmärkte erfordert, daß der Preis zu jedem Zeitpunkt alle verfügbaren Informationen richtig reflektiert. Dann vermittelt der Preis die richtigen Signale für eine optimale Allokation der Ressourcen. ${ }^{2}$ Zwar handeln auf den Märkten eine Vielzahl verschiedener Individuen mit heterogenen Erwartungen. Meinungsverschiedenheiten über die Interpretation gegebener Informationen allein implizieren aber nicht die Ineffizienz des Marktes. Erforderlich wäre, daß einzelne Marktteilnehmer regelmäßig zu einer besseren Bewertung der Informationen gelangen als die aggregierte Meinung der anderen Teilnehmer, die sich in dem aktuellen Kurs ausdrückt. ${ }^{3}$ Der Wettbewerb um Gewinne, die mit einer besseren Interpretation gegebener Informationen verbunden sind, sollen die Effizienz des Marktes sicherstellen. Ist ein Marktteilnehmer nicht in der Lage, die Entwicklung richtig einzuschätzen, würde er aufgrund anhaltender Verluste aus dem Markt ausscheiden. ${ }^{4}$

Entwickelt wurde die Hypothese für Wertpapiermärkte geschlossener Volkswirtschaften, und Modelle der Preisbildung wurden auch hierfür zunächst empirisch überprüft. Zwar erscheint die These aus dem wirtschaftswissenschaftlichen Blickwinkel zunächst unmittelbar einleuchtend. ${ }^{5}$ Dennoch hat sich die empirische Forschung seit den $70 \mathrm{er}$ Jahren sehr intensiv mit dieser Hypothese auseinandergesetzt.

Die Hypothesen rationaler Erwartungen und effizienter Kapitalmärkte werden in gleicher Weise für die Wechselkursentwicklung unterstellt: Ist der Devisenmarkt effizient, werden in den Wechselkursen alle verfügbaren Informationen sofort und korrekt ausgedrückt. Es

1 J.F. Muth, Rational Expectations and the Theory of Price Movements, in: Econometrica, 29.Jg. (1961), S. $316 \mathrm{ff}$.

2 E.F.Fama, Efficient Capital Markets: A Review of Theory and Empirical Work, in: Journal of Finance, 25.Jg. (1970), Nr.2, S.383.

3 E.F.Fama, Efficient Capital Markets: A Review, a.a.O., S.388.

4 Das gilt allerdings nicht notwendigerweise: Immerhin ist denkbar, daß die Rendite eines Portfolios zwar unterhalb der marktüblichen Verzinsung liegt, aber nicht die Substanz aufzehrt. Solange einzelne Marktteilnehmer die Risikoprämie für ihr Portfolio nicht korrekt abschätzen und deshalb ihre geringe Rendite nicht erkennen, werden sie nicht aus dem Markt ausscheiden. Kapitalaufbringung und Kapitaleinsatz sind dann nicht vollkommen effizient.

5 W.F.Sharpe, Discussion, Kommentar zu E.F. Fama, Efficient Capital Markets: A Review, a.a.O., S. 418. 
existieren keine Möglichkeiten, mit Anlagen in einer bestimmten Währung systematisch eine Rendite zu erzielen, die Erträge anderer Anlageformen mit gleichem Risiko übertrifft. ${ }^{6}$

Beide Theorien sind allerdings umstritten. So argumentiert Dornbusch beispielsweise: ,[...] Tatsache bleibt, daß vieles von dem, was Kapitalverkehr genannt wird, nichts mit der gesamtwirtschaftlich produktiven Allokation von Ressourcen zu tun hat. Vielmehr wären die Märkte von dem Bedürfnis gleichsam sofortiger Kapitalerträge geprägt."7 So könnten ungerechtfertigt hohe Revisionen der Kurserwartungen im Lichte neuer Nachrichten, Gerüchte oder Ankündigungen überhöhte Korrekturen der gegenwärtigen Kurse auslösen und zu einer ineffizienten Informationsverarbeitung führen. ${ }^{8}$

Auch die Ergebnisse empirischer Forschungen sind widersprüchlich. Überwiegend bestätigend ist das Urteil von Fama in seiner umfangreichen Kritik an Untersuchungen nationaler Kapitalmärkte. ${ }^{9}$ Vorbehalte äußert er nur bei Tests über lange Zeiträume von mehreren Jahren. ${ }^{10}$ Andere Untersuchungen können indessen nicht ausschließen, daß die Effizienzmarkthypothese zumindest für den Devisenmarkt nicht völlig uneingeschränkt gilt. In einer Zusammenfassung von Analysen der Devisenmärkte kommt Gaab zu der Schlußfolgerung, $\mathrm{da} ß$,Zumindest kurzfristig auch irrationale und massenpsychologische Einflüsse eine Rolle zu spielen scheinen und dieses umso eher je unsicherer die Erwartungen sind, während längerfristig fundamentale Einflußfaktoren mit einem größeren Gewicht in die Erwartungsbildung einfließen."11 Zweifel an einer effizienten Informationsverarbeitung auf den Devisenmärkten äußern neben Anderen beispielsweise auch McDonald und Taylor. ${ }^{12}$

Trotz der gewissen Vorbehalte empirischer Untersuchungen wird nachfolgend aber von der Gültigkeit der Effizienzmarkthypothese ausgegangen.

6 W.Filc, Anmerkungen zur Effizienz des Devisenmarktes, in: Aspekte der Geldpolitik in offenen Volkswirtschaften, Hrsg. C. Köhler und R. Pohl, Berlin 1987, S.79.

7 R. Dornbusch, The Dollar and the Deficit, in: Internationales Währungssystem und weltwirtschaftliche Entwicklung, Hrsg. C. Dräger u. L. Späth, Baden-Baden 1988, S. 106 (eigene Übersetzung).

Schon Keynes wandte ein: Sie sind nicht daran interessiert, was eine Investition für jemanden, der diese kauft, um sie ,zu behalten', wirklich wert ist, sondern, wie der Markt sie unter dem Einfluß von Massenpsychologie in drei Monaten oder einem Jahr bewerten wird. Für eine erfolgreiche Spekulation wäre es notwendig, rechtzeitig zu erkennen, wenn die Meinung der Mehrheit der Marktteilnehmer umschwenkt und kurz vor der folgenden Kursreaktion richtig zu handeln. Bekannt ist Keynes' Vergleich mit einem Schönheitswettbewerb, bei dem ein Gewinn denjenigen zugesprochen wird, die die Meinung aller Beteiligten am besten schätzen. Das Ergebnis wird nicht die zusammengefaßte Meinung aller Beteiligter sein, sondern die zusammengefaßte Meinung aller Beteiligter über die Meinung der anderen. J.M. Keynes, The General Theory of Employment, Interest, and Money, London, New York u.a., 1936, S.155f.

8 J. Frenkel u. M. Goldstein, A guide to target zones, in: International Monetary Fund Staff Papers, 33.Jg. (1986), S.640.

9 E.F. Fama, Efficient Capital Markets: II, in: Journal of Finance, 46. Jg. (1991), S.1575-1617.

10 E.F. Fama, Efficient Capital Markets: II, a.a.O., S. 1578.

11 W. Gaab, Möglichkeiten und Grenzen des Erkennens spekulativer Bubbles an den Devisenmärkten, in: Kooperation, Autonomie und Devisenmarkt. Veröffentlichungen des Instituts für Empirische Wirtschaftsforschung Bd. 26, Hrsg. Wolfgang Filc und Claus Köhler, Berlin 1990, S.93.

12 R.McDonald u. M.P.Taylor, Exchange Rate Economics: A Survey, in: International Monetary Fund Staff Papers, 39.Jg. (1992), S.32f.

Statistische Tests sind allerdings schwierig. Es ist nicht möglich, die Hypothesen rationaler Erwartungen und effizienter Märkte getrennt zu überprüfen. Außerdem muß eine Wahrscheinlichkeitsverteilung unterstellt werden. Für die Preisbildung auf den Devisenmärkten wird in diesem Zusammenhang auf das sogenannte ,Peso Problem" hingewiesen. Es besagt, daß die Normalverteilungsannahme dann nicht zulässig ist, wenn die Marktteilnehmer in jeder Periode mit einer kleinen Wahrscheinlichkeit eine große Wechselkursänderung erwarten und dieses Ereignis aufgrund der Begrenztheit der Stichprobe tatsächlich nicht eintritt. W.S. Krasker, The „Peso" Problem in Testing the Efficiency of Forward Exchange Markets, in: Journal of Monetary Economics, 6.Jg. (1980), S.271. 
Zudem beeinflussen auch die institutionellen Rahmenbedingungen die Preisbildung am Devisenmarkt. Staatliche Restriktionen und Reglementierungen an den Devisen- und Finanzmärkten, wie beispielsweise Bestimmungen für die Ausfuhr von Devisen oder die Höhe staatlich festgelegter Wechselkurse, ${ }^{13}$ werden hier jedoch ausgeschlossen.

$\mathrm{Zu}$ den institutionellen Rahmenbedingungen zählt aber auch die Einkommensteuer.

\section{Allokative Effizienz bei Besteuerung}

Maßstab für die Bewertung der Effizienz einer Steuer ist deren Wirkung auf die Güter- und Faktorallokation. ${ }^{14}$ Durch die Erhebung der Steuer werden Einkommens- und möglicherweise auch Substitutionseffekte ausgelöst. Der Einkommenseffekt ist unausweichlich, da es schließlich ein Ziel der Besteuerung ist, dem Staat ein Aufkommen zu verschaffen. Bei der Betrachtung allokativer Wirkungen wird dieser Effekt durch die Unterstellung ausgeklammert, das Steueraufkommen werde pauschal erstattet. Denn würden „diese Effekte bei der Analyse der Allokationswirkungen der Besteuerung mitberücksichtigt, so liefe man Gefahr, die Unterschiede zwischen den verschiedenen Steuern zu verwässern und ein verzerrtes Bild von der Struktur eines unter Effizienzgesichtspunkten attraktiven Steuersystems zu erhalten."15

Für die Effizienz sind Substitutionseffekte entscheidend. Sie treten immer dann ein, wenn die Steuer die relativen Preise verändert und Steuerpflichtige sich deswegen anders verhalten als ohne Steuer. Diese Wirkung kann erwünscht sein, wenn die Steuer mit dem Ziel der Korrektur eines Marktversagens eingesetzt wird. Marktversagen ist für die Kapitalmärkte hier aber ausgeschlossen, da die Effizienzmarkthypothese eine Grundlage der Arbeit ist.

Der Substitutionseffekt führt zu einer steuerlich bedingten Mehrbelastung (,excess burden“), weil die Steuerpflichtigen das belastete Gut oder das belastete Verhalten substituieren und so der Steuer ausweichen. Durch ihre Reaktion auf die Veränderung der Preisrelationen realisieren die Wirtschaftssubjekte ein niedrigeres Nutzenniveau, dem kein Steueraufkommen gegenübersteht; die Besteuerung bewirkt damit einen Wohlfahrtsverlust. Allokativ optimal ist eine Steuer, wenn sie keinen Substitutionseffekt zur Folge hat. Sie wird dann als neutral in bezug auf das Verhalten der Steuerpflichtigen bezeichnet.

13 Unsicherheit über die Rahmenbedingungen beeinflussen natürlich auch die Preisbildungsvorstellungen rationaler Marktteilnehmer.

14 Unbeachtet bleiben hier verteilungspolitische Überlegungen. Zumindest die Kriterien der horizontalen und der vertikalen Gleichbehandlung können in riskanter Umwelt aufgrund der unterschiedlichen Zeitbezogenheit der Konzepte im Widerspruch zur Effizienzanforderung stehen. Die Beurteilung der Effizienz einer Einkommensteuer muß realistischerweise an erwartete Erträge anknüpfen. Die Frage ist, inwieweit eine in der Zukunft anfallende Besteuerung die Gegenwartswerte verschiedener Anlagen beeinflußt. Die Gerechtigkeit der Steuer muß gegenwartsbezogen beurteilt werden. Entscheidend ist hier, wie leistungsfähig ein Steuersubjekt zum Zeitpunkt der Steuererhebung ist. Ein Konflikt besteht zB. bei progressiver Einkommensbesteuerung. Mit den Zielen der Gleichbehandlung ist es vereinbar, daß ex post auf Gewinne riskanter Investitionen, die die Erwartungen übertroffen haben, ein höherer Steuersatz angewendet wird als auf niedrigere Erträge einer unsicheren oder sicheren Anlage. Effizient ist ein progressiver Steuersatz dagegen nicht, da er den Gegenwartswert von Investitionen umso stärker reduziert, je höher deren Risiko ist.

15 H.-W. Sinn, Kapitaleinkommensbesteuerung, Tübingen 1985, S.5. 


\section{a) Kapitalexportneutralität}

Um die weltweit effiziente Allokation des Faktors Kapital nicht zu behindern, „sollten Steuern die Wahl zwischen der Investition im In- oder Ausland oder die Aufteilung von Auslandsinvestitionen auf verschiedene Länder nicht beeinträchtigen."16

Die Wahl der Kapitalanbieter wird durch das Steuersystem nicht beeinflußt, wenn Kapitaleinkommen unabhängig davon, wo es erzielt wird, steuerlich gleich behandelt wird. Die Steuer ist dann neutral in bezug auf den Einsatzort von Kapital, das heißt sie ist kapitalexportneutral ${ }^{17}$. Bei Vernachlässigung nichtsteuerlicher Einflüsse und unter der Annahme abnehmender Grenzerträge wird sich unter diesen Umständen die Grenzproduktivität des Faktors Kapital vor Steuern weltweit angleichen. Denn sollte die Grenzproduktivität in einem Land höher sein, werden dessen Inländer ihr gesamtes Kapitalangebot im eigenen Land einsetzen und Ausländer ihr Kapital in das Land exportieren. Damit steigt der Kapitaleinsatz in dem Land und die Grenzproduktivität sinkt dort.

Die Grenzerträge der Sparer gleichen sich international indes nur bei identischen Steuersätzen in den Ländern an:

Es mögen gp und gp die Grenzproduktivitäten und ge und ge die Grenzerträge im In- und im Ausland darstellen. Die Kapitalerträge der in- und ausländischen Sparer werden am Wohnsitz mit dem Satz von $\tau$ beziehungsweise $\tau$ * besteuert. Wenn $\tau \neq \tau^{*}$, dann gilt im Gleichgewicht unter den oben genannten Bedingungen $\mathrm{gp}=\mathrm{gp}^{*}$ und $\mathrm{ge}=(1-\tau) \cdot \mathrm{gp}=(1-\tau) \cdot \mathrm{gp}^{*} \neq \mathrm{ge}^{*}=\left(1-\tau^{*}\right) \cdot \mathrm{gp}^{*}=$ $\left(1-\tau^{*}\right) \cdot$ gp. Die Grenzerträge stehen in der folgenden Beziehung zueinander:

$$
\begin{aligned}
& \frac{\text { ge }}{\operatorname{ge}^{*}}=\frac{(1-\tau)}{\left(1-\tau^{*}\right)} \\
\Leftrightarrow & \operatorname{ge} \cdot \frac{\left(1-\tau^{*}\right)}{(1-\tau)}=\mathrm{ge}^{*}
\end{aligned}
$$

Das Wohnsitzlandprinzip, das heißt die Besteuerung sämtlichen Kapitaleinkommens am Wohnsitz des Steuerpflichtigen, ${ }^{18}$ ist der einfachste Weg zu diesem Ziel. Es ist aber nicht notwendige Voraussetzung, denn es ist irrelevant, welchem Staat die Steuereinnahmen zufließen, solange nur die Summe der Steuerlast unabhängig von der Quelle der Kapitalerträge ist.

Tatsächlich wird Kapitalexportneutralität regelmäßig durch die Anrechnung im Ausland gezahlter Steuern auf die inländische Steuer angestrebt. Die inländische Steuerlast auf Erträge ausländischer Herkunft wird um die im Ausland gezahlte Steuer gemindert. Eingeschränkt wird die kapitalexportneutrale Wirkung des Anrechnungsverfahrens jedoch durch sogenannte Anrechnungsüberhänge. Übersteigt die Steuerlast im Ausland die inländische Steuerschuld vor der Anrechnung, werden im Ausland gezahlte Steuern nämlich nur bis zur Höhe dieser inländischen Steuerschuld berücksichtigt. Für diesen Anrechnungshöchstbetrag gilt folglich die Beziehung: 19

16 R.A.Musgrave, Fiscal Systems, New Haven, London 1969, S.248f. (eigene Übersetzung).

17 Vgl. zu den Kriterien der Kapitalexport- sowie der Kapitalimportneutralität auch A.J. Weichenrieder, Besteuerung und Direktinvestition, a.a.O., S.12-25.

18 R. Peffekoven, Probleme der internationalen Finanzordnung, in: Handbuch der Finanzwissenschaft, Bd. IV, Tübingen 1983, S.242.

19 Vgl. z.B. R. Peffekoven, a.a.O., S.248; J. Bourne Wahl, Taxation of Foreign Exchange Gains and Losses, Office of Tax Analysis Papers Nr.57, Washington, DC. 1987, S. 7; Arthur Andersen \& Co., Tax Reform 1986, Chicago 1986, S.189. 


\begin{tabular}{|c|c|c|}
\hline \multirow{2}{*}{$\begin{array}{l}\text { Anrechnungs- } \\
\text { höchstbetrag }\end{array}$} & $\begin{array}{l}\text { steuerpflichtiges } \\
\text { auslăndisches Einkommen }\end{array}$ & \multirow{2}{*}{$\begin{array}{c}\text { Steuerschuld im } \\
\text { Wohnsitzland in Bezug } \\
\text { - auf das Welteinkommen } \\
\text { vor der Anrechnung } \\
\text { ausländischer Steuern }\end{array}$} \\
\hline & $\begin{array}{l}\text { steuerpflichtiges } \\
\text { Welteinkommen }\end{array}$ & \\
\hline
\end{tabular}

Das Anrechnungsverfahren kann für ein einzelnes Land außerdem im Widerspruch zu dem Ziel nationaler Effizienz stehen. Denn durch das Verfahren mag der Ertrag des einzelnen Sparers zwar unabhängig von dem Einsatzort des Kapitals identisch sein. Gleichwohl wird das Kapitaleinkommen der Volkswirtschaft bei Kapitalexport um die ausländische Steuer reduziert. Unter Umständen ist deshalb für ein Land der Verzicht auf das Anrechnungsverfahren der bessere Weg. ${ }^{20}$ Das Ziel nationaler Effizienz wird in dieser Arbeit jedoch nicht weiter verfolgt, da es im Widerspruch zu weltweit optimaler Kapitalallokation steht. Statt dessen gilt im Zusammenhang mit dem Anrechnungsverfahren die Unterstellung, die Summe aus in- und ausländischer Steuerbelastung werde im Wohnsitzland pauschal erstattet.

\section{b) Kapitalimportneutralität}

Werden Kapitalerträge unabhängig davon, wer sie empfängt, steuerlich gleich behandelt, ist das Steuersystem neutral in bezug auf den Ursprung des eingesetzten Kapitals. Mit anderen Worten: die Besteuerung ist kapitalimportneutral, denn die Kapitalnachfrager sind indifferent gegenüber der Herkunft des Faktors. ${ }^{21}$

Dies ist durch das Quellenlandprinzip möglich. Direkte Steuern werden hiernach nur an der Quelle, das heißt am Einsatzort des Kapitals, unabhängig von dessen Herkunft erhoben; im Wohnsitzland sind ausländische Erträge von einer Besteuerung freigestellt. Wird wiederum von nichtsteuerlichen Einflüssen abstrahiert und außerdem für die Kapitalanbieter ein abnehmender Grenznutzen der Transformation von Gegenwarts- in Zukunftskonsum angenommen, werden sich die Grenzerträge der Sparer nach Steuern weltweit angleichen, denn alle Sparer bieten Kapital zu gleichen Bedingungen an.

Kapitalimportneutralität gewährleistet also die weltweit optimale Aufbringung des Faktors Kapital, weil sich die Zeitpräferenzraten der Sparer überall angleichen können. Durch eine veränderte Aufbringung des gegebenen Kapitals lassen sich dann unter sonst gleichen Umständen die Kapitalkosten nicht mehr reduzieren. ${ }^{22}$

Die Grenzproduktivitäten des Faktors gleichen sich bei diesem Besteuerungsprinzip international aber nur an, wenn die Steuersätze in den Ländern identisch sind:

Im In- und Ausland werde eine Quellensteuer von $t$ beziehungsweise $t^{*}$ erhoben. Dann gilt für die inländische Nachfrage nach Kapital $(1-t) \cdot g p=g e=g e *$ und analog für die ausländische Kapitalnachfrage $\left(1-t^{*}\right) \cdot \mathrm{gp}^{*}=\mathrm{ge}^{*}=$ ge. Im Gleichgewicht stehen die Grenzproduktivitäten in folgender Beziehung zueinander:

$$
g p \cdot \frac{(1-t)}{\left(1-t^{*}\right)}=g p^{*}
$$

20 Vgl. R.A.Musgrave, Fiscal Systems, a.a.O., S.249f.; R.A. Musgrave, P.B. Musgrave u. L. Kullmer, Die öffentlichen Finanzen in Theorie und Praxis, 3. Band, 4.Aufl., Tübingen 1992, 202 u. S. 205 f..

21 R.A.Musgrave, Fiscal Systems, a.a.O., S. 254.

22 Vgl. z.B. A.J. Weichenrieder, Besteuerung und Direktinvestition, a.a.O., S.16f.. 


\section{c) Zur Kritik an beiden Ansätzen in der Literatur}

Die zwei Neutralitätsanforderungen lassen sich gleichzeitig offensichtlich nur unter sehr restriktiven und deswegen unrealistischen Voraussetzungen erfüllen. Es müßten (i) die Steuersätze in den Ländern gleich sein. Weiterhin ist es (ii) erforderlich, daß überall das gleiche Besteuerungsprinzip angewendet wird und (iii) die Bemessungsgrundlagen identisch sind. Infolgedessen sind die Vor- und Nachteile beider Ansätze in der Literatur ausgiebig diskutiert worden.

Ein Urteil wird in dieser Arbeit zwar nicht angestrebt. Die Ansätze sollen aber die Grundlage der theoretischen Herleitung effizienter Besteuerung von Währungsgewinnen bilden, da sie mit den beiden weltweit praktizierten Ansätzen der Anrechnung und der Freistellung im internationalen Steuerrecht korrespondieren. Die Bedeutung des Konfliktes um die beiden Ansätze - der keineswegs entschieden ist -, zeigt sich daran, daß sich die Außenbesteuerung und hier insbesondere auch die Forderungen in Verhandlungen um Doppelbesteuerungsabkommen in den Ländern unterscheiden. Die angelsächsischen Länder und auch Japan präferieren das Anrechnungsverfahren. Andere europäische Länder differenzieren zwischen Direkt- und Portfolioinvestitionen. Zumindest für Direktinvestitionen wird aber dem Freistellungsverfahren der Vorrang gegeben.

Aus diesem Grund werden die wesentlichen Argumente kurz zusammengefaßt.

In der volkswirtschaftlichen - besonders der englischsprachigen - Literatur wird überwiegend Kapitalexportneutralität für den besseren Ansatz gehalten. Die Argumentation konzentriert sich auf die allokativen Vorzüge der vermuteten internationalen Angleichung der Grenzproduktivitäten, also darauf daß eine unterschiedliche Höhe der direkten Steuern an verschiedenen Standorten keinen Einfluß auf die Investitionsentscheidung hat. ${ }^{23}$

Von den Kritikern wird gegen Kapitalexportneutralität eingewandt, sie sei nicht mit dem Äquivalenzprinzip in Einklang zu bringen. ${ }^{24}$ Ein direkter Zusammenhang der Höhe des Steuersatzes zu der Versorgung mit intermediären öffentlichen Gütern könne in einer offenen Volkswirtschaft nur durch kapitalimportneutrale Steuern hergestellt werden. Nicht die Herkunft des Kapitals sei entscheidend, sondern die Kosten der staatlichen Leistungen im Investitionsland. Ein Optimum aus dem Blickwinkel des Äquivalenzprinzips, in dem die Grenzproduktivität der öffentlichen Güter gerade der Summe der Grenzkosten für die Unternehmen in Form des inländischen Grenzsteuersatzes entsprechen, ${ }^{25}$ wäre nicht möglich, wenn in einem

23 Vgl. O. Gandenberger, Einfluß der Einkommen- und Körperschaftsteuer, Der Einfluß der Einkommen- und Körperschaftsteuer auf die internationalen Wirtschaftsströme, in: Grundfragen des Internationalen Steuerrechts, Hrsg. K. Vogel, Köln 1985, S.33-48, S. 43 f. und die dort genannte Literatur.

24 P.B. Richman, Taxation of Foreign Investment Income. An Economic Analysis, Baltimore 1963, S.7; O. Gandenberger, Kapitalexportneutralität versus Kapitalimportneutralität, a.a.O., S.21f.; K. Vogel, Harmonisierung des Internationalen Steuerrechts in Europa als Alternative zur Harmonisierung des (materiellen) Körperschaftsteuerrechts, in: Steuer und Wirtschaft, 70. Jg. (1993), S.387f. .

25 „Steuern [...] sind durch die Rechtsordnung eines Staates vorgegebene Transaktionskosten. Öffentliche Güter andererseits, die einem Unternehmen zugute kommen [...], mindern die Transaktionskosten.“ K. Vogel, Harmonisierung des internationalen Steuerrechts, a.a.O., S.387. Vogel verbindet im Ergebnis Äquivalenz- und Leistungsfähigkeitsprinzip, indem er weiter schreibt: „Die staatlich induzierten Transaktionskosten einer Investition bestehen demgemäß in der Differenz zwischen den zu leistenden Abgaben und den empfangenen öffentlichen Gütern." Ebda. . Dieser Saldo wäre die relevante Größe für die Standortentscheidung der Kapitalgeber. Konkret bedeutet dies: weltweite Effizienz setzt nicht gleiche Steuersätze voraus. Ein Land mit effizienter Verwaltung wird ökonomisch sinnvoll handeln, wenn es mehr - relativ produktivere - öffentliche Güter anbietet und dafür auch eine höhere Steuerschuld einfordert. „Effizienz' ist daher zu definieren als optimale Faktorallokation bei Minimierung der staatsinduzierten Transaktionskosten." Ebda. . 
Wohnsitzland ausländischer Kapitalanbieter dieser Steuersatz nicht gelten würde. ${ }^{26}$ Allerdings ist ein öffentliches Gut definitionsgemäß nicht knapp und die Nutzung damit nicht mit zusätzlichen Kosten verbunden.27

Jede Aussage auf der Grundlage des Äquivalenzprinzips steht außerdem vor dem Problem, daß nur ein unrealistisch aufwendiges Steuersystem die intersektorale Neutralität nicht verletzten würde: Standorte mit zwar vergleichsweise hoher Steuerlast, aber auch umfangreicher Versorgung mit öffentlicher Infrastruktur, werden im internationalen Vergleich attraktiv sein für Investitionen in Sektoren, deren Produktivität stärker von diesen öffentlichen Gütern abhängt. ${ }^{28}$

Ein weiteres Argument gegen Kapitalexportneutralität fußt auf der Umsetzung der Anforderung im Steuerrecht der Länder. Schon genannt wurden Anrechnungsüberhänge. Hinzukommt ein Problem bei Beteiligungen an ausländischen Kapitalgesellschaften, die sich aus deren Eigenschaft als eigenes Steuersubjekt ableitet. Das internationale Steuerrecht gestattet es nämlich dem Wohnsitzstaat im Grunde nicht, Gewinne zu besteuern, die nur wirtschaftlich das Einkommen der Steuersubjekte in der Periode erhöhen, aber nicht tatsächlich zufließen, da das Unternehmen im Quellenland sie thesauriert. ${ }^{29}$ Die Besteuerung ist eigentlich erst dann möglich, wenn Gewinne ausgeschüttet werden oder der Kapitalgeber seine Anteile veräußert. ${ }^{30}$

Im Ergebnis gewährt der inländische Staat durch diese Steuerstundung einen zinsgünstigen Kredit - vorausgesetzt der Steuersatz ist im Ausland niedriger als im Inland. Die steueraufschiebende Wirkung der Thesaurierung in ausländischen Kapitalgesellschaften wird in der Literatur häufig als „deferral“ bezeichnet. Kapitalexportneutralität wird hierdurch verletzt, denn nicht ausgeschüttete Gewinne unterliegen nur der Besteuerung im Quellenland. Die quantitative Bedeutung ist abhängig von der Differenz der Steuersätze in beiden Ländern und der Dauer der Thesaurierung.

Allerdings sind die Möglichkeiten zu einer Steuerstundung auf diesem Wege mittlerweile von vielen Ländern durch sogenannte Zugriffbesteuerungen am Wohnsitz eingeschränkt worden.

Kritisiert wird schließlich der partialanalytische Charakter der beiden Neutralitätskriterien. „Export- ebenso wie Importneutralität bedeuten lediglich das Fehlen bestimmter Einflüsse, sie

26 O. Gandenberger, Kapitalexportneutralität versus Kapitalimportneutralität, a.a.O., S.22; K. Vogel, Harmonisierung des internationalen Steuerrechts, a.a.O., S.387f..

27 „Ein Argument für das Quellenlandprinzip läßt sich daher für den Fall öffentlicher Güter nicht konstruieren.“ A.J. Weichenrieder, Besteuerung und Direktinvestition, a.a.O., S.19f..

28 Außerdem stellt auch das Kapitalexportland mittelbar öffentliche Güter bereit, die dem Kapitalimportland zugute kommen. P.B. Musgrave, United States Taxation of Foreign Investment Income. Issues and Arguments. Cambridge, Mass. 1969, S.116. Im übrigen scheitert das Äquivalenzprinzip schon daran, daß weder die Bereitstellung noch die Inanspruchnahme offentlicher Güter hinreichend genau ermittelt werden kann. G. Krause-Junk, Die Bedeutung der Steuerharmonisierung für die Errichtung eines Gemeinsamen Marktes, Institut für Ausländisches und Internationales Finanz- und Steuerwesen, Hamburg 1984, S.7.

29 Ziel des internationalen Steuerrechts ist nur die Vermeidung von Doppelbesteuerung. Diese ist im Kommentar zum OECD Muster für zwischenstaatliche Abkommen definiert als „Erhebung vergleichbarer Steuern in zwei (oder mehreren) Staaten von denselben Steuerpflichtigen für denselben Steuergegenstand und denselben Zeitraum“. Bei Einlegern und Kapitalgesellschaft ist keine Subjektidentität gegeben. J.M. Mössner, Die Methoden zur Vermeidung der Doppelbesteuerung - Vorzüge, Nachteile, aktuelle Probleme, in: Grundfragen des Internationalen Steuerrechts. Hrsg. Klaus Vogel, 1985, S. $139 \mathrm{f}$.

30 Unter extremen Annahmen wandelt sich das Anrechnungsverfahren bei begrenzter Anrechnung zum Freistellungsverfahren. Denn ist der ausländische Steuersatz geringer als der inländische Satz, kommt es dann nicht zur Steuerpflicht im Wohnsitzland, wenn das Kapital und die Erträge darauf nicht repatriiert oder veräußert werden; ist er höher, kommt es nicht zur Anrechnung.

A.J. Wilensky, Future Directions of U.S. International Tax Policy, in: Taxes, 70.Jg. (1992), S. 1002. 
sind keine wirkliche Neutralität." ${ }^{11}$ Die Theorie des Zweitbesten zeige, daß Effizienzkriterien die Maximierung der Wohlfahrt nicht mehr gewährleisten, wenn auch nur ein Markt unvollkommen ist. Infolgedessen ist es dann auch nicht sinnvoll, die verbleibenden Bedingungen zu erfüllen.

Horst $^{32}$ weist darauf hin, daß Kapitalexportneutralität nur bei vollkommen zinsunelastischem Kapitalangebot optimal ist und Kapitalimportneutralität allein bei nicht zinsreagibler Kapitalnachfrage. ${ }^{33}$ Sind aber sowohl Sparen als auch Investieren Funktionen des Zinsniveaus, läßt sich der geringstmögliche Wohlfahrtsverlust erst durch das Verletzen beider Neutralitätskriterien erreichen. Mit anderen Worten, der Steuersatz auf grenzüberschreitende Erträge muß von dem Satz für inländisches Kapitaleinkommen abweichen. ${ }^{34}$ Dabei läßt sich zeigen, daß zumindest kleine Länder mit dem Ziel der Maximierung der eigenen Wohlfahrt autonom die Steuersätze wählen werden, die auch das weltweite Optimum herstellen, wenn das Ziel eines fixen Steueraufkommens für ein betrachtetes Land unterstellt wird. ${ }^{35}$

Das Optimum hängt von Variablen ab, die nicht bestimmbar und auch nicht notwendigerweise im Zeitablauf konstant sind. Deshalb ist es problematisch, eine konkrete Handlungsanweisung für die Besteuerung grenzüberschreitender Investitionen abzuleiten. ${ }^{36}$ Die Analysen zeigen aber, daß dies in nicht geringerem Maße für die Forderungen nach Kapitalexport- oder Kapitalimportneutralität gilt ${ }^{37}$; sie legen es nahe, die damit verbundenen zwischenstaatlichen Verhandlungen und Abkommen überhaupt in Frage zu stellen.

Das Ziel dieser Arbeit ist aber bescheidener. Im Rahmen der gegebenen Regelungen des internationalen Steuerrechts wird gezeigt, wie Währungsgewinne und -verluste behandelt werden sollten. Und die Realität der internationalen Besteuerung sind die Verfahren der Anrechnung und der Freistellung.

31 K. Vogel, Harmonisierung des internationalen Steuerrechts, a.a.O., S.386; so auch G. Krause-Junk, Die Bedeutung der Steuerharmonisierung, a.a.O., S.7.

32 T. Horst, A Note on the Optimal Taxation of International Investment Income, in: Quarterly Journal of Economics, 95.Jg. (1980), S.793-798.

33 T. Horst, A Note on the Optimal Taxation of International Investment Income, a.a.O., S.796.

34 Ist die Kapitalnachfrage im kapitalexportierenden Land und das Angebot im kapitalimportierenden Land fix, sind internationale Kapitalerträge steuerfrei zu stellen. Ist das Angebot im exportierenden und die Nachfrage im importierenden Land fix, sind internationale Kapitalerträge mit dem Satz des Wohnsitzlandes auf den verbleibenden Ertrag nach Abzug der Steuer des Auslands (Abzugsverfahren) zu belasten. In allen übrigen Fällen liegt der optimale Satz zwischen diesen Extrema. Vgl. T. Horst, A Note on the Optimal Taxation of International Investment Income, a.a.O., S.796f..

35 Vgl. W. Laux-Meiselbach, Ein einfaches Modell der optimalen Besteuerung internationaler Kapitalerträge, Hefte zur internationalen Besteuerung, Institut für Ausländisches und Internationales Finanz- und Steuerwesen Nr.34, Hamburg 1987, S.12-24; G. Krause-Junk, Körperschaftsteuerharmonisierung in Europa, a.a.O..

36 W. Laux-Meiselbach, a.a.O., S.31.

37 T. Horst, A Note on the Optimal Taxation of International Investment Income, a.a.O., S. 796f. . 


\section{Zur Bedeutung von Währungsrisiko und Besteuerung bei den Investitions- und Finanzierungsentscheidungen der Unternehmen}

Für einen Kapitalgeber sind die unmittelbaren Auswirkungen einer Schwankung des Wechselkurses auf sein grenzüberschreitend eingesetztes Kapital leicht erkennbar: ein Kursgewinn erhöht das Vermögen in der Währung seines Wohnsitzes, ein Kursverlust mindert es. Handelt es sich bei dem Kapitalexport aber nicht um die Bereitstellung von Fremdkapital, sind daneben auch mittelbar auf die Wechselkursänderung zurückzuführende Gewinne oder Verluste zu erwarten, die sich aus währungsbedingten Änderungen von Beschaffungs- und Absatzpreisen ergeben. Müssen hier Wechselwirkungen bei einer Analyse der Kapitaleinkommensbesteuerung beachtet werden?

Dies ist eine Frage, der in diesem Abschnitt nachgegangen wird. Währungsergebnis und Wechselkursrisiko werden am Einsatzort des Kapitals - im Unternehmen - präzisiert. Zu diesem Zweck werden Begriffsbestimmungen für das Währungsrisiko aus der Betriebswirtschaftslehre eingeführt. Schwerpunkt ist hier der Begriff des ökonomischen Risikos, bei dem die genannten Formen der unmittelbaren und der mittelbaren wechselkursbedingten Gewinne und Verluste unterschieden werden können. Wie gezeigt wird, sind letztere für das Thema dieser Arbeit unerheblich.

Darauf aufbauend kann das Steuersystem hinsichtlich Finanzierungs- und Investitionsneutralität für die Analyse der Besteuerung von Währungsgewinnen und -verlusten in Abschnitt III konkretisiert werden. Gezeigt wird, unter welchen Voraussetzungen vom Unternehmen so weit abstrahiert werden kann, daß Erträge aus Direkt- und Portfolioinvestitionen bei der Analyse der Besteuerung in diesem Teil B nicht mehr unterschieden werden müssen.

Zunächst aber Zahlen zur Abbildung der Währungsentwicklung in den letzten Jahren:

\section{Zahlen zum Währungsrisiko}

Daß die Entwicklung des Wechselkurses Auswirkungen auf den Erfolg von Unternehmen haben wird, die - aus welchen Gründen auch immer - von anderen Währungen abhängig sind, verdeutlicht schon ein Blick auf die tatsächlichen Kursverläufe. Bekannt sind die Extrema des bilateralen Wechselkurses zwischen der Deutschen Mark (DM) und dem amerikanischen Dollar (U.S.-\$) seit dem Ende des Festkurssystems von Bretton-Woods von 1,73 DM/U.S.-\$ im Jahre 1979; 3,15 DM/U.S.-\$ in 1985 und 1,39DM/U.S. $\$$ in 1992. Bis zum 31.7.1997 ist der Kurs dann wieder auf 1,84DM/U.S.-\$ angestiegen. Hinzukommt die zeitweise starke Volatilität um die längerfristigen Durchschnittskurse. Schwankungen von über $5 \%$ innerhalb von 20 Handelstagen und bis zu 20\% innerhalb eines Jahres sind keine Seltenheit, wie auf der Abbildung B1 auf der folgenden Seite für den Wechselkurs zwischen DM und U.S.-\$ erkennbar ist.

Die jährliche Volatilität - gemessen als einfache Standardabweichung der Kursänderung in einer Periode von 260 Handelstagen über den dargestellten Zeitraum - beträgt 10,1\%. ${ }^{38}$

38 Vgl. auch Deutsche Bundesbank, Finanzmarktvolatilität und ihre Auswirkungen auf die Geldpolitik, in: Monatsbericht, April 1996, S.54-70. 
Abb. B1: Prozentuale Veränderung des U.S.-\$ gegenüber der DM im Verlauf von 20 Handelstagen und im Verlauf eines Jahres zwischen dem 1.1.1991 und dem 31.7.1997.

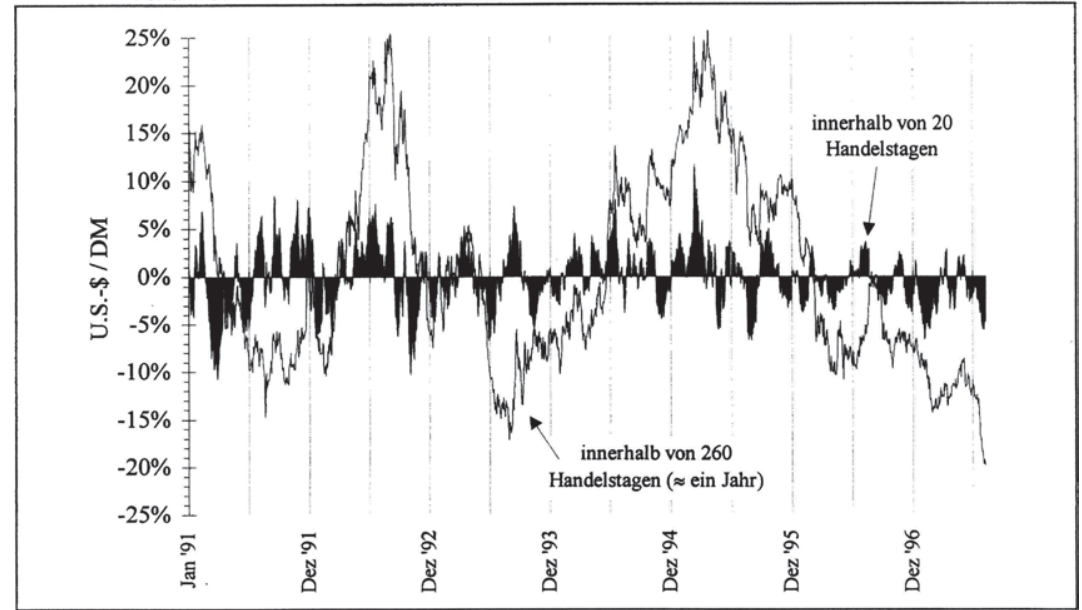

Quelle: $\quad$ Eigene Darstellung mit Daten der Federal Reserve Bank of Chicago.

Geringer sind die Schwankungen der DM gegenüber den Währungen des Europäischen Währungssystems. Die Wechselkursänderungen gegenüber dem Französischen Franken (FF) zeigt die nachstehende Abbildung B2. Sie betrugen weniger als 5\% innerhalb von 20 Handelstagen und maximal 5,4\% innerhalb eines Jahres. Seitdem die Bandbreiten zum 2. August 1993 von $\pm 2,25$ auf $\pm 15 \%$ erweitert wurden, ist die Volatilität des FF gegenüber der DM gestiegen, und zwar - bezogen auf die Periode von 260 Handelstagen - von 0,8\% auf knapp 2,1\%.

Abb. B2: Prozentuale Änderung des Französischen Franken (FF) gegenüber der DM im Verlauf von 20 Handelstagen und eines Jahres zwischen dem 1.1.1991 und dem 31.7.1997.

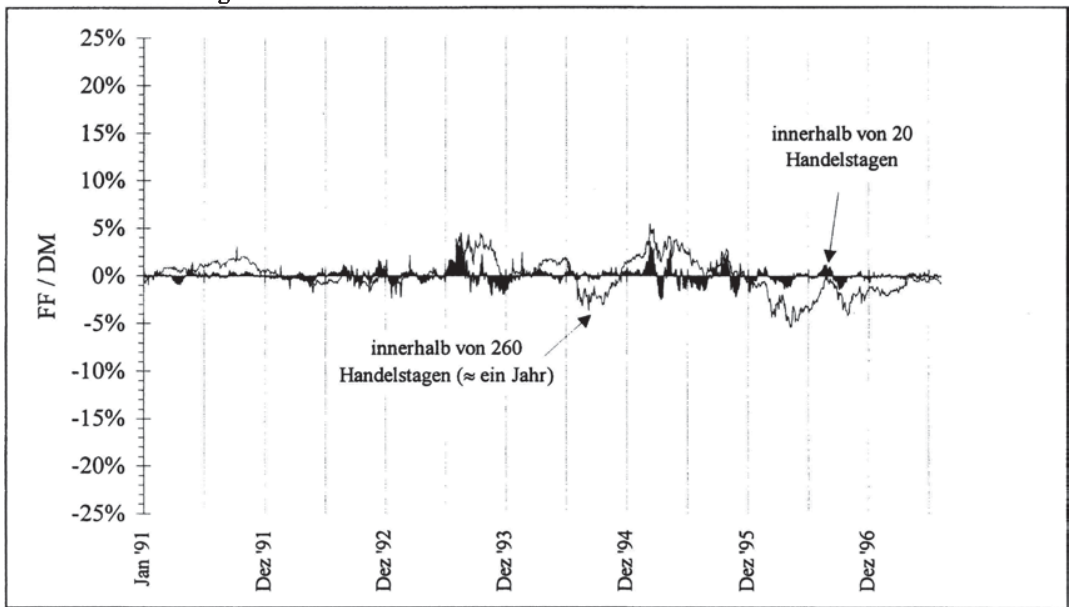

Quelle: $\quad$ Eigene Darstellung mit Daten der Federal Reserve Bank of Chicago. 
Im Vergleich zur Kursentwicklung des U.S.-\$ gegenüber der DM geringer sind auch die Schwankungen zwischen dem U.S.-\$ und der Währung des benachbarten Kanada. Dies veranschaulicht abschließend Abbildung B3. Für den betrachteten Zeitraum errechnet sich eine Volatilität für die Periode von 260 Handelstagen von $4,2 \%$.

Abb. B3: Prozentuale Änderung des kanadischen Dollar (CAN-\$) gegenüber dem U.S.-\$ im Verlauf von 20 und 260 Handelstagen zwischen dem 1.1.1991 und dem 31.7.1997.

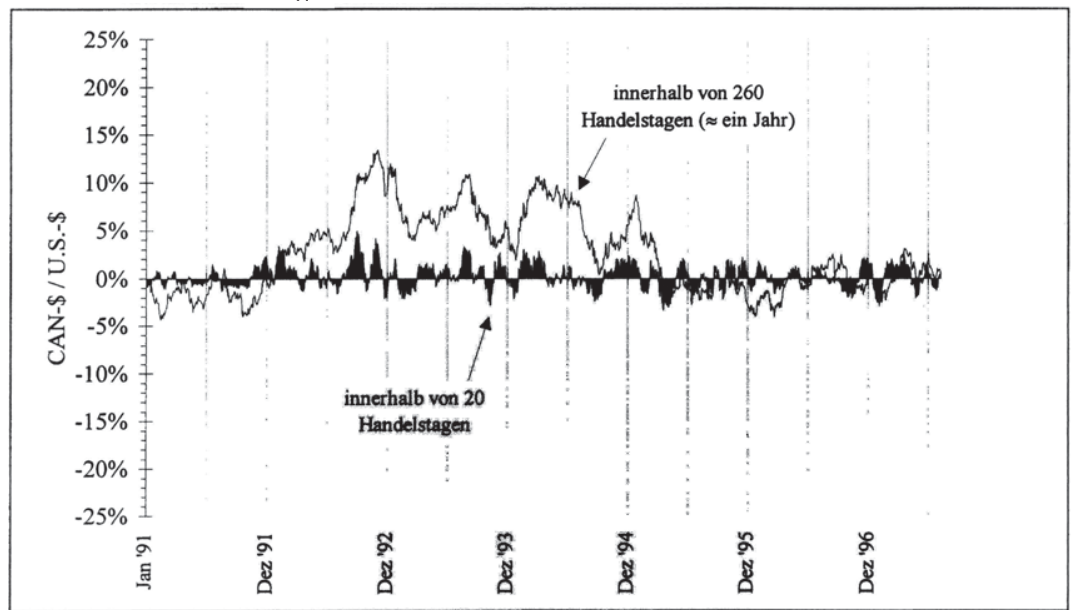

Quelle: $\quad$ Eigene Darstellung mit Daten der Federal Reserve Bank of Chicago.

\section{Definitionen für Währungsrisiken in Unternehmen}

Bei der Beurteilung des Währungsrisikos muß genau differenziert werden, wie der Ertrag beeinflußt werden kann. In der Literatur sind zu diesem Zweck eine Reihe von Definitionen geprägt worden.

Zunächst ist aber der Begriff des Risikos zu charakterisieren: Als Risiko wird die Möglichkeit einer zufallsbedingten positiven oder negativen Abweichung einer Zielgröße von ihrem Erwartungswert bezeichnet. Um das Risiko verschiedener Situationen vergleichbar zu machen, wird es häufig als Standardabweichung definiert. Dafür ist allerdings Voraussetzung, daß die Funktion der Wahrscheinlichkeit der zufälligen Abweichungen von der Zielgröße die Form einer Normalverteilung um ihrem Erwartungswert bildet.

Risiko besteht ex ante. Ex post ist eines der Ereignisse aus der Verteilung sicher eingetreten: hier ein (positiver oder negativer) Gewinn in einer bestimmten Höhe.

Bei Untersuchungen der Bedeutung von Unsicherheit über die Wechselkursentwicklung für Unternehmungen ist in der Literatur die folgende Abgrenzung gebräuchlich ${ }^{39}$ :

39 R.M. Rodrigues u. E.E. Carter, International Financial Management, 2.Aufl. Englewood Cliffs 1979, S.228241; D.K. Eiteman u. A.I.Stonehill, Multinational Business Finance, 5.Aufl., Reading (Mass.) 1989; G. Franke, in: Handwörterbuch Export und Internationale Unternehmung. Hrsg. K. Macharözina und M.K. Welge, Stuttgart 1989, Sp.2197; T. Finne, Bilanzierung von Fremdwährungsgeschäften und internationale Doppelbesteuerung, Baden-Baden 1991, S.39-47; H.E. Büschgen, Internationales Finanzmanagement, 


\section{a) Transaktionsrisiko}

Das Transaktionsrisiko bezieht sich auf die jeweiligen Zahlungszeitpunkte, zu denen ein Währungsgewinn oder -verlust realisiert wird. Es ist das Risiko einer unerwarteten Entwicklung des Wertes in der inländischen Währung von bestehenden Auslandsforderungen und -verbindlichkeiten zwischen Vertragsabschluß, Lieferung und Zahlungseingang beziehungsweise Erhalt der Ware und Fälligkeit der Zahlungsverpflichtungen. Dazu zählen auch schwebende Geschäfte in fremden Währungen, das heißt Geschäftsvorfälle, bei denen vertragliche Verpflichtung und Erfüllung zeitlich auseinanderfallen. Beispiele sind Devisentermingeschäfte und auch Verträge, bei denen der Betrag in fremder Währung vor Lieferung oder effektiver Zahlung fest vereinbart wird, bei denen also eine Verpflichtung für die Zukunft besteht, in der Gegenwart aber noch keine Forderung oder Verbindlichkeit. ${ }^{40}$

\section{b) Buchrisiko}

An zweiter Stelle wird in der Regel das Buchrisiko genannt, das sich auf den Jahresabschluß bezieht. Es kann definiert werden als das Risiko von Auswirkungen der Wechselkursänderungen auf den bilanziellen Gewinn oder Verlust, die sich aus der Umrechnung der auf fremde Währungen lautenden Positionen bei der Aufstellung von Bilanz und Gewinn- und Verlustrechnung ergeben. ${ }^{41}$ Der Begriff umfaßt damit die Gesamtheit aller mit unerwarteten Wechselkursänderungen verbundenen Buchrisiken, die (noch) nicht finanzwirksam wurden. Gemäß dieser Definition kann auch das Transaktionsrisiko einbezogen sein bei Geschäften, die an einem Bilanzstichtag noch nicht abgeschlossen waren. Ob dies tatsächlich so ist, hängt davon $\mathrm{ab}$, ob nicht realisierte Währungsgewinne oder -verluste bilanziert werden.

Das Ausmaß des Buchrisikos ist von der Wahl der Methode für die Umrechnung von Fremdwährungspositionen im Jahresabschluß abhängig. Da hierfür aber verschiedene Methoden angewendet werden, kann das Buchrisiko offensichtlich das tatsächliche Risiko nicht treffend erfassen. Außerdem ist es - wie die Bilanz überhaupt - vergangenheitsorientiert ${ }^{42}$. Aus diesen Gründen erscheint die Position von Buckley überzeugend, „daß das Buchrisiko für alle praktischen Belange ignoriert werden kann" $" 43$.

Andererseits setzt auch die Einkommensteuer eine jährliche Ermittlung des Einkommens voraus. Auch die hier anzuwendenden Ansätze zur Umrechnung basieren auf Grundsätzen, die für Buchführung und Bilanzierung entwickelt wurden. In Deutschland ist die Handelsbilanz sogar maßgeblich. Die Steuerbilanz ist lediglich die „auf steuerliche Belange zugeschnittene

2. Überarb. Aufl, Frankfurt a.M. 1993, S.228ff.. Allerdings ist die Abgrenzung der Begriffe in der Literatur nicht einheitlich.

40 T. Finne, a.a.O., S.39-47; E. Flood u. D.R. Lessard, On the Measurement of Operating Exposure to Exchange Rates: A Conceptual Approach, in: Financial Management, 15.Jg. (1986), S.26.

41 T. Finne, a.a.O., S.44 m.w.N.. In der Literatur sind unterschiedliche Begriffsbestimmungen geschaffen worden. Insbesondere wird der Begriff teilweise nur auf die Konsolidierung ausländischer Tochtergesellschaften bezogen. So z.B. K. Pohle, Management von Währungsrisiken, in: Finanzierungshandbuch, Hrsg. F.W. Christians, 2.Aufl., Wiesbaden 1988, S.771;

42 „In the economist's jargon, historical figures are sunk costs!" R.M. Rodrigues, u. E.E. Carter, a.a.O., S.239.

43 A. Buckley, Multinational Finance, Oxford 1986, S.132 (eigene Übersetzung). Vgl. auch E. Pausenberger u. M. Glaum, Management von Währungsrisiken, in: Handbuch des Finanzmanagements: Instrumente und Märkte der Unternehmensfinanzierung, Hrsg. G. Gebhardt u.a., München 1993, S.770 und die dort angegebene Literatur. 
Handelsbilanz des Unternehmers“. ${ }^{44}$ Damit kann auch das Buchrisiko materielle Auswirkungen haben.

Doch ist das aus der Bilanzierung resultierende Risiko für eine finanzwissenschaftliche Analyse nicht der richtige Ausgangspunkt.

\section{c) Das ökonomische Risiko}

Das ökonomische Risiko ist hier das Risiko einer Marktwertänderung eines Unternehmens infolge unerwarteter Wechselkursänderungen. ${ }^{45}$ Grundlage ist demgemäß der Barwert des gesamten zukünftigen Zahlungsstromes durch die Unternehmung, der auch die Erfolgswirkungen von wechselkursbedingten Preisänderungen auf den Absatz- und Beschaffungsmärkten einschließt. ${ }^{46,47}$ Deshalb ist es zweckmäßig, das ökonomische Risiko in einen Wettbewerbs- und einen Umwechslungseffekt aufzuteilen, ${ }^{48}$ wie in der Abbildung B4 auf der folgenden Seite dargestellt.

Der Wettbewerbseffekt erfaßt die Auswirkungen von zukünftigen Änderungen der Devisenkurse $e_{1}, \ldots, e_{n}$ verschiedener Währungen auf die Preise für Vorleistungen und die Ausbringung in der lokalen Währung des Unternehmens. Da es das Ziel ist, alle Effekte auf den Marktwert der Unternehmung zu kalkulieren, sollten auch die optimalen Preis-Mengen-Reaktionen des Unternehmens auf allen Märkten in den Funktionen $f_{1}, \ldots, f_{4}$ berücksichtigt werden. ${ }^{49}$ Der Effekt stellt somit die Folgen der Währungsfluktuation auf den Marktwert des Unternehmens (beziehungsweise der Tochtergesellschaft oder Betriebstätte) in der Währung des Einsatzortes des Kapitals dar. Diese Änderung des Marktwertes ist unabhängig von dem Ursprungsort des eingesetzten Kapitals ein einkommenswerter Vermögenszuwachs oder -rückgang, der mittelbar durch die Wechselkursentwicklung verursacht ist.

Demgegenüber beziffert der Umwechslungseffekt die Auswirkung der Kursentwicklung auf den Marktwert in der Währung des Ursprungsortes des eingesetzten Kapitals (freilich nur, soweit Ursprungs- und Einsatzort nicht identisch sind)..$^{50}$

44 E. Littmann, H. Bitz u. J.P. Meincke, Das Einkommensteuerrecht, Kommentar, 15. Aufl., Stuttgart 1989, $\S \S 4,5, \mathrm{Rz}, 367$.

45 R.M. Rodrigues, u. E.E. Carter, a.a.O., S.236f.; D.K. Eiteman u. A.I. Stonehill, a.a.O., S.172.

46 Häufig wird der Begriff „Marktwert“ auf den Wert des Eigen- und nicht - wie hier - auf den des Gesamtkapitals bezogen. So z.B. H.-W. Sinn, Kapitaleinkommensbesteuerung, a.a.O., S.22.

47 Externe Analysen der Wechselkursänderungsreagibilität des Marktwertes von Aktien werden deshalb auch durch Regressionsanalysen mithilfe historischer Daten durchgeführt. M. Adler u. B. Dumas, Should Exposure Management Depend on Translation Accounting Methods?, in: Euromoney, 1981, S. 132.

48 E. Flood u. D.R. Lessard, a.a.O., S. 26.

49 R.M. Rodrigues, u. E.E. Carter, a.a.O., S.239. Dies betrifft auch Preise in Stammlandwährung, beispielsweise wenn das Risiko besteht, daß ein Konkurrent aus einem fremden Währungsraum infolge der Wechselkursentwicklung einen Preis ändert. So gesehen sind auch Unternehmen, deren Zahlungsströme ausschließlich in einer Währung bewertet werden, dem ökonomischen Risiko ausgesetzt. D.K. Eiteman u. A.I. Stonehill, a.a.O., S.183.

Vgl. auch die Analyse von E. Flood u. D.R. Lessard, a.a.O., S.29-36 über die Bedeutung der Angebots- und Nachfrageelastizitäten auf Märkten verschiedener Währungsräume für das Ausmaß des ökonomischen Risikos einer Unternehmung.

50 In der Literatur werden die aus der Möglichkeit von Kursänderungen resultierenden Risiken für verschiedene Währungen unter dem Begriff als ,net exposure" zusammengefaßt. Das ökonomische Risiko einer Unternehmung errechnet in diesem Fall sich aus den Salden der Fremdwährungspositionen verschiedener Währungen und der Korrelation der einzelnen Währungen. Es ist aber fraglich, ob die Korrelationen zuverlässig ermittelt werden können. 
Abb. B4: Die Bestandteile des ökonomischen Risikos: Wettbewerbs- und Umwechslungseffekt

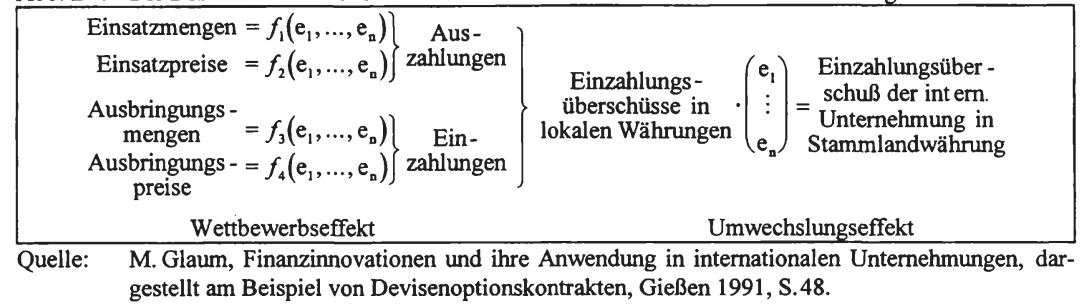

Ein kurzes Beispiel: Ein Kapitalgeber exportiere Kapital in das Ausland, um dort ein Gut zu produzieren, das er in sein Wohnsitzland importiere. Fällt nun der Kurs der ausländischen Währung, wird unter sonst gleichen Umständen der Marktwert seiner Unternehmung in der Währung des Quellenlandes zunehmen, da der Umsatzerlös steigt (Wettbewerbseffekt). Gleichzeitig mindert der Kursrückgang den Marktwert des eingesetzten Kapitals in der Währung des Wohnsitzlandes (Umwechslungseffekt).

Die Darstellung des ökonomischen Risikos gibt einen Eindruck davon, wie vielschichtig die Konsequenzen einer Änderung des Wechselkurses für Kapitaleinkommen sein können. Die Wirkungen des Wettbewerbseffektes beziehungsweise Wechselwirkungen zwischen Wettbewerbs- und Umwechslungseffekt sind für das Thema dieser Arbeit jedoch unerheblich. Unter den nachfolgend erläuterten Gründen ist es möglich und sinnvoll, das nur mittelbar auf Kursänderungen zurückführbare Einkommen hier nicht zu beachten.

\section{Irrelevanz der Währung für die Finanzierung}

Modigliani und Miller haben 1958 gezeigt, daß der Marktwert jeder Kapitalgesellschaft in einer geschlossenen Volkswirtschaft unabhängig von der Wahl der Kapitalstruktur ist. ${ }^{51}$ Voraussetzungen sind rational handelnde Marktteilnehmer auf einem vollkommenen Kapitalmarkt ${ }^{52}$ und das Fehlen von Steuern. ${ }^{53}$ Die Argumentation basiert auf einfachen Arbitrageüberlegungen; der Beweis wird an dieser Stelle nicht wiederholt. ${ }^{54} \mathrm{Im}$ Kern besagt die These aber: unter den genannten Voraussetzungen können Kapitalgeber ceteris paribus jede Finanzierungsentscheidung der Unternehmensleitung rückgängig machen. ${ }^{55}$ Sie werden deshalb für keine bestimmte Kapitalstruktur eine geringere Rendite fordern als für irgend eine andere Alternative. Folglich können auch die Kapitalkosten für keine spezifische Kombination aus Eigen- und Fremdkapital minimal sein. Entscheidend für den Marktwert eines Unternehmens

51 F. Modigliani u. M.H. Miller, The Cost of Capital, Corporation Finance and the Theory of Investment, in: American Economic Review, 48.Jg. (1958), S.265-270.

52 Insbesondere dürfen keine Kosten durch Konflikte zwischen der Unternehmensleitung, den Fremd- und den Eigenkapitalgebern entstehen (,agency costs" und ,moral hazzard") und es muß für funktionierende Arbitrage gewährleistet sein, daß Anlage- und Aufnahmezins (nahezu) identisch sind.

53 F. Modigliani, Debt, Dividend Policy, Taxes, Inflation and Market Valuation, in: Journal of Finance, 37.Jg. (1982), S.255f. .

54 Vgl. z.B. F. Modigliani u. M.H. Miller, Reply to Heins and Sprenkle, in: American Economic Review, 59. Jg. (1969), S.592-595; J. Drukarczyk, Theorie und Politik der Finanzierung, 2., völlig neugestaltete Aufl., München 1993, S.131-140.

55 Dies gilt bei unveränderten Aktiva oder der Finanzierung einer zusätzlichen Investition gleicher Risikoklasse, das heißt, deren erwartete Zahlungsüberschüsse perfekt positiv korreliert sind mit den erwarteten Zahlungsüberschüssen der bestehenden Aktiva. 
oder auch einer Investition sind nicht die Präferenzen einzelner Kapitalgeber, sondern die Opportunitätskosten: das Zinsniveau sowie die Risikoprämien vergleichbarer Anlagen. ${ }^{56}$ Auf vollkommenen Märkten sind diese Preise für einzelne Wirtschaftssubjekte und für einzelne Investitionen Daten.

Die Logik des Satzes von Modigliani und Miller ist nicht nur auf die Alternativen Eigen- und Fremdkapital anwendbar. Der Satz gilt prinzipiell für alle Kombinationen verschiedener Finanzierungsformen. In einer offenen Volkswirtschaft zählen hierzu auch die Möglichkeiten einer Finanzierung in fremder Währung. Dies veranschaulicht folgende Überlegung: ${ }^{57}$

Unterstellt sei ein inländisches eigenfinanziertes Unternehmen, das seine Aktiva zu einem Teil mit Eigenkapital (EK) und zu einem Teil mit Fremdkapital ${ }^{58}$ (FK) finanziert hat. Das Eigenkapital der Unternehmung sei Teil des Vermögens der inländischen Anleger, das Fremdkapital Bestandteil der Ersparnis ausländischer Kapitalgeber. Der Wert des Unternehmens ergibt sich aus dessen Gesamtkapital (GK), das zu jedem Zeitpunkt dem Marktwert der Aktiva entsprechen muß.

Zunächst habe die Unternehmung das Fremdkapital in der inländischen Währung (IM) aufgenommen. Da die inländischen Anleger das Eigenkapital $\mathrm{EK}_{\mathrm{IM}}=\mathrm{GK}_{\mathrm{IM}}-\mathrm{FK}_{\mathrm{IM}}$ des Unternehmens halten, haben sie Anspruch auf den Unternehmensgewinn nach Abzug der Kosten für das Fremdkapital. Die ausländischen Kapitalgeber tragen das Wechselkursrisiko und erhalten Fremdkapitalzinsen.

Jetzt entscheide das Unternehmen unter sonst gleichen Bedingungen, das Fremdkapital $\mathrm{FK}_{\mathrm{IM}}$ durch einen Kredit in der ausländischen Währung $\mathrm{AM}\left(\mathrm{FK}_{\mathrm{AM}}\right)$ zu ersetzen. Folge ist, daß das Währungsrisiko nicht von den ausländischen Anlegern, sondern vom Unternehmen und damit mittelbar durch die inländischen Eigenkapitalgeber getragen wird $\left(\mathrm{EK}_{\mathrm{IM}}=\mathrm{GK}_{\mathrm{IM}}-\mathrm{FK}_{\mathrm{AM}}\right)$. Sowohl die inländischen als auch die ausländischen Kapitalgeber werden gegenüber der Entscheidung des Unternehmens aber indifferent sein. Dessen Marktwert und dessen Kapitalkosten werden sich durch diese Finanzierungsentscheidung nicht verändern.

Warum? Die in- und ausländischen Kapitalgeber können sich so stellen, als sei die Finanzierung des Unternehmens in inländischer Währung erfolgt. Um die Zahlungsströme der Ausgangssituation zu duplizieren, müssen die inländischen Eigenkapitalgeber auch das Fremdkapital $\mathrm{FK}_{\mathrm{AM}}$ übernehmen und mit einem Kredit in inländischer Währung finanzieren. Den Kredit stellen die ausländischen Sparer zur Verfügung. So entspricht die Situation der ausländischen Anleger offenkundig der Ausgangslage - vorausgesetzt der Kredit an inländische Kapitalgeber wird als risikofrei angesehen.

Aber auch für die Eigenkapitalgeber ist die Vermögenslage unverändert. Denn Währungsverluste (oder auch höhere Kapitalkosten) aus der Fremdkapitalposition müssen immer einem Währungsgewinn bei den Finanzierungskosten des Unternehmens entsprechen. Der Marktwert des Eigenkapitals wird sich somit bei einer Bewegung des Wechselkurses ceteris paribus ${ }^{59}$ gerade so entwickeln, daß er die Änderung des Barwertes der Zahlungsströme des Fremdkapitals $\mathrm{FK}_{\mathrm{AM}}$ kompensiert.

56 F. Modigliani u. M.H. Miller, The Cost of Capital, a.a.O., S.264.

$57 \mathrm{Vgl}$. hierzu K.A.Froot, Multinational Corporations, Exchange Rates, and Direct Investment, in: International Policy Coordination and Exchange Rate Fluctuations, Hrsg. W.H. Branson u.a., Chicago und London 1990, S.309-313.

58 Aus Gründen der einfacheren Darstellung sei der Anteil des Fremdkapitals hinreichend gering, um als ausfallrisikofrei angesehen werden zu können.

59 Dies bezieht sich beispielsweise auf die Absatzmöglichkeiten oder auch auf eine möglicherweise mit der Bewegung des Wechselkurses einhergehende Änderung des inländischen Zinsniveaus. Beides wird indes die Vermögenssituation der Kapitalgeber in den Fällen (a) und (b) gleichermaßen berühren. 
Das Resultat ist unabhängig von dem Risiko der erwarteten Erträge des Gesamtkapitals der Firma. Für jeden möglichen künftigen Zahlungsstrom ist hier keine bestimmte Form der Finanzierung gegenüber einer anderen Form dominant. Das heißt, daß unter den genannten Annahmen der Marktwert der ganzen Unternehmung auf der Aktivseite der Bilanz geprägt wird.

Wie die Erkenntnisse von Modigliani und Miller implizieren, hat das Ergebnis auch bei anderen Kombinationen von Finanzierungsformen Gültigkeit. Internationale Diversifikation von Finanzierungsquellen auf Seiten der Unternehmung bietet Kapitalanbietern keinen zusätzlichen Nutzen und hat demzufolge keine Wirkung auf den Marktwert. ${ }^{60}$ Ebenso erhöht eine unmittelbare Minderung des aus dem oben definierten Umwechslungseffekt resultierenden Risikos - beispielsweise durch Termingeschäfte - nicht den Marktwert. ${ }^{61}$

Schließlich verdeutlicht ein Vergleich der Finanzierungsalternativen auch, daß alle ökonomischen Variablen identisch sind. Wechselkurserwartungen, Risikoprämien und Produktivität des Faktors Kapital bleiben unverändert. Sie brauchen deshalb an dieser Stelle nicht weitergehend betrachtet zu werden.

Für diese Arbeit entscheidend ist eine weitere Schlußfolgerung: Bestehen nämlich keine Interdependenzen zwischen der Gestaltung der Passivseite und der Aktivseite der Bilanz eines Unternehmens, ist die Vorteilhaftigkeit unternehmerischer Entscheidungen auf den Absatzund Beschaffungsmärkten unabhängig von Finanzierungsalternativen. Hierunter fallen auch Positionen, die im Zusammenhang mit der laufenden Geschäftstätigkeit stehen, wie zum Beispiel Lieferantenkredite in einer fremden Währung. Denn das Unternehmen kann sich prinzipiell des Risikos zu einem objektiven Marktpreis entledigen, indem es die Positionen mittels Factoring veräußert oder durch Termingeschäfte sichert. Geringe Transaktionskosten, die dabei entstehen können, werden an dieser Stelle vernachlässigt.

Ausschlaggebend ist an dieser Stelle deshalb auch der Saldo der Positionen in einer bestimmten Währung zu einem bestimmten Zeitpunkt und nicht deren ursächliche Zusammensetzung. Nur dieser Saldo stellt für die Kapitalgeber das Währungsrisiko im Sinne des Umwechslungseffektes dar. Und nur dieser Saldo ist ausschließlich abhängig von dem Wohnsitz der Kapitalanbieter. ${ }^{62}$

Der Wettbewerbseffekt ist dagegen in der Weise unabhängig von der Herkunft des Kapitals, $\mathrm{da}$ er für alle Kapitalanbieter gleichermaßen ein Risiko darstellt. Ein Unternehmen kann einen Verlust an Konkurrenzfähigkeit nicht mit alternativen Finanzierungsformen (einschließlich Termingeschäften) kompensieren. Es mag - je nach der Vollkommenheit der übrigen Märkte, auf denen es operiert - die gewinnmaximalen Kombinationen aus Preis und Menge auf den Absatzmärkten anpassen, sein Vermarktungskonzept revidieren oder Vorleistungen aus anderen Währungsräumen beziehen ${ }^{63}$ oder aber sich aus dem Markt zurückziehen.

60 A.C. Shapiro, Financial Structure and Cost of Capital in the Multinational Corporation, in: Journal of Financial and Quantitative Analysis, 13.Jg. (1974), S.222.

Davon zu unterscheiden ist aber internationale Portfoliodiversifikation der Kapitalgeber. Dies kann den Nutzen risikoaverser Sparer erhöhen, indem sie das Portfoliorisiko mindert. Um zu vermeiden, daß sich die Darstellung erheblich verkompliziert, wird dieser Aspekt hier nicht ausdrücklich betrachtet. Weiter unten wird deshalb von risikoneutralen Präferenzen ausgegangen.

61 M. Adler u. B. Dumas, a.a.O., S.134. Tatsächlich legt eine Studie auf dem Jahr 1978 nahe, daß die Wirkung von Marktimperfektionen in diesem Zusammenhang gering ist. R.E. Dukes, The Empirical Investigation of the Effects of FASB Statement No.8. on Security Return Behaviour. Financial Accounting Standards Board, Dezember 1978, zitiert nach M. Adler u. B. Dumas, a.a.O., S.133.

62 Genau genommen besteht diese Abhängigkeit im Hinblick auf die Währung, in der die Sparer ihre Allokationsentscheidungen treffen. Auf die Probleme mit dem Vorgehen, hierbei von dem Wohnsitz auszugehen, wird im Abschnitt III auf Seite 54 im Zusammenhang mit neutraler Besteuerung noch einmal eingegangen.

63 E. Flood u. D.R. Lessard, a.a.O., S.27. Vgl. hierzu die Beispiele in D.K. Eiteman u. A.I. Stonehill, a.a.O., S.177-181. 
Derartige Handlungen beeinflussen die Produktivität des Unternehmens und auf Grund dessen auch das Kapitaleinkommen. Andererseits kann das Faktoreinsatzverhältnis variieren, wenn sich die Kapitalkosten ändern. Nur trifft dies auf alle Arten der Finanzierung in gleichem Maße zu.

Da die resultierenden Gewinnveränderungen unabhängig von der Wahl der Finanzierungsstruktur eintreten, sollen sie hier auch nicht als positiver oder negativer Währungserfolg verstanden werden. Die Ertragsmöglichkeiten sollten von der Unternehmensleitung in jedem Fall also losgelöst von dem Umfang des Saldos von Fremdwährungsforderungen beziehungsweise -verbindlichkeiten - realisiert werden. ${ }^{64}$ Dies ist entscheidend für die folgenden Überlegungen zur einkommensteuerlichen Behandlung von Währungsgewinnen und -verlusten. Es bedeutet nämlich: der Wettbewerbseffekt ist irrelevant für die Herstellung von Kapitalexport- und Kapitalimportneutralität unter Berücksichtigung von Währungsfluktuationen.

\section{Währungsrisiko}

Der Umwechslungseffekt beschreibt deshalb für diese Arbeit eine angemessene Abgrenzung des Begriffs des Wechselkursrisikos ${ }^{65}$. Das Transaktionsrisiko greift zu kurz, da es die Möglichkeit von Währungsgewinnen beziehungsweise -verlusten bei Forderungen und Verbindlichkeiten mit längeren Restlaufzeiten sowie Direktinvestitionen, Beteiligungen und Betriebstätten nicht einschließt. Das ökonomische Risiko als Ganzes trennt nicht zwischen dem unternehmerischen Risiko im allgemeinen und dem Währungsrisiko im engen Sinne. Das Buchrisiko schließlich erfaßt gar keine Risiken.

Unter Verwendung der Begriffe des Wohnsitz- und Quellenlandes wird in der folgenden für diese Arbeit gültigen Definition der Umwechslungseffekt auf den Barwert der Zahlungsreihe bezogen: Als Wechselkursrisiko wird hier das Risiko benannt, daß sich der Barwert einer Zahlungsreihe nach der Umrechnung in die Währung des Wohnsitzlandes eines Kapitalgebers erhöht oder vermindert, weil in der Währung eines Quellenlandes unverändert anfallende Zahlungen der Reihe sich infolge einer nicht erwarteten Entwicklung des Austauschverhältnisses, in inländischer Währung gemessen, ändern.

Auch Devisentermingeschäfte stellen eine Zahlungsreihe mit einem Barwert dar und werden deshalb durch diese Begriffsbestimmung erfaßt. Für Unternehmungen oder Betriebstätten ist zu jedem Zeitpunkt nur der Saldo aus Forderungen und Verbindlichkeiten in einer bestimmten Währung interessant. Schließlich verkörpern offene Fremdwährungspositionen einer ausländischen Unternehmung, die auf die Währung der Kapitalgeber lauten, für diese kein Währungsrisiko.

64 Vgl. auch die Ausführungen von Stützel zur funktionsanalytischen Bilanztheorie: W. Stützel, Bemerkungen zur Bilanztheorie, Wiesbaden 1967; ders. Entscheidungstheoretische Elementarkategorien als Grundlage einer Begegnung von Wirtschaftswissenschaft und Rechtswissenschaft, in: Zeitschrift für Betriebswirtschaft, 36. Jg. (1966), S.765-789 insb. S.778f..

65 Häufig wird zwischen Wechselkurs- und Währungsrisiko unterschieden. Letzteres umfaßt dann zusätzlich Unsicherheit über die Einführung oder Änderung staatlicher Restriktionen und Reglementierungen an den Devisen- und Finanzmärkten und seltener der Besteuerung von Devisentransaktionen. H.E. Büschgen, Internationales Finanzmanagement, a.a.O., S.167. Konvertier- und Transferrisiken werden hier aber nicht betrachtet. Diese Differenzierung ist hier deshalb nicht erforderlich. 


\section{Konkretisierung der Kapitaleinkommensteuer}

\section{a) Zur Finanzierungsneutralität}

Die Irrelevanz der Kapitalstruktur wird durch die Einkommensbesteuerung dann nicht verletzt, wenn Erträge aller Finanzierungsalternativen von der Steuer gleichermaßen betroffen sind; das Steuersystem ist damit finanzierungsneutral:

Das inländische Unternehmen habe in einer Periode einen Bruttogewinn in Höhe von g · GK erwirtschaftet. Für das Fremdkapital müssen Kapitalkosten von k · FK gezahlt werden. Zunächst sei das Quellenlandprinzip unterstellt und der Steuersatz auf Zinserträge betrage $t_{\mathrm{k}}$. Wird auf Selbstfinanzierung verzichtet, werden an die Anteilseigner vor Steuern Gewinne im Umfang von $\mathrm{g} \cdot \mathrm{GK}-\mathrm{k} \cdot \mathrm{FK}$ ausgeschüttet, auf die ein Steuersatz von $\mathrm{t}_{\mathrm{g}}$ erhoben werde. Ist $t_{g}=t_{k}=t$, ist der Vermögenszuwachs $\Delta V$ inländischer Kapitalgeber insgesamt

$$
\begin{aligned}
\Delta \mathrm{V} & =\mathrm{k} \cdot \mathrm{FK} \cdot\left(1-\mathrm{t}_{\mathrm{k}}\right)+(\mathrm{g} \cdot \mathrm{GK}-\mathrm{k} \cdot \mathrm{FK}) \cdot\left(1-\mathrm{t}_{\mathrm{g}}\right) \\
& =(\mathrm{g} \cdot \mathrm{GK}) \cdot(1-\mathrm{t}) .
\end{aligned}
$$

Er ist - wie behauptet - unabhängig von der Zusammensetzung des Kapitals.

Dabei ist es unerheblich, ob das internationale Steuerrecht auf dem Prinzip der Kapitalimportneutralität fußt oder aber Kapitalexportneutralität angestrebt wird. Zwar weichen die Grenzproduktivitäten an verschiedenen Standorten beziehungsweise die Grenzerträge bei Kapital unterschiedlicher Herkunft voneinander ab. Für das Unternehmen an einem Standort besteht in steuerlicher Hinsicht dennoch Neutralität in bezug auf die Finanzierungsform. ${ }^{66}$

Finanzierungsneutralität ist aber weder für Kapitalimport- noch für Kapitalexportneutralität notwendige Voraussetzung. Gilt beispielsweise in Gleichung [B5] $t_{g}>t_{k}$, dann ist bei einem von inländischen Kapitalgebern geforderten Ertrag von $\Delta V$ (der bei Kapitalimportneutralität dem Vermögenszuwachs $\Delta \mathrm{V}^{*}$ ausländischer Anleger entspricht) der notwendige Bruttogewinn $\mathrm{g} \cdot$ GK umso geringer, je stärker das Unternehmen fremdfinanziert ist:

$$
\Delta \mathrm{V}=\mathrm{g} \cdot \mathrm{GK} \cdot\left(1-\mathrm{t}_{\mathrm{g}}\right)+\mathrm{k} \cdot \mathrm{FK} \cdot\left(\mathrm{t}_{\mathrm{g}}-\mathrm{t}_{\mathrm{k}}\right) \text {. }
$$

Er erreicht sein Minimum bei vollständiger Fremdfinanzierung. Für die Analyse der internationalen Effizienz einer Steuer würde es deshalb ausreichen, den Steuersatz für Erträge aus Fremdkapital zugrunde zu legen. Für dieses Minimum müßte freilich $\mathrm{k}=\mathrm{g}$ gelten, ein Ergebnis, das zwar ex ante erwartet, ex post jedoch bei unsicheren Investitionen nur zufällig eintreffen wird. Deshalb ist es einfacher, weiterhin anzunehmen, der Anteil des Fremdkapitals sei hinreichend gering, um als risikofrei angesehen werden zu können. ${ }^{67}$

Analog dazu ist auch Kapitalexportneutralität nicht verletzt, wenn im Wohnsitzland eine Form der Kapitalanlage diskriminiert wird und die Anbieter im In- und Ausland zur Gänze auf die geringer besteuerte Anlageform ausweichen. Voraussetzung ist natürlich, daß die Finanzierungsform wird auf Seiten der Anbieter unabhängig vom Einsatzort des Faktors benachteiligt wird.

66 F. Modigliani u. M.H. Miller, Reply to Heins and Sprenkle, a.a.O., S.593f.; A.B. Atkinson u. J.E. Stieglitz, Lectures on Public Economics, London u.a. 1980, S. 132f.; T.E. Copeland u. J.F. Weston, Financial Theory and Corporate Policy, 3.Aufl. Reading, Mass. u.a. 1988, S.451 f.; H.-W. Sinn, Die Bedeutung des Accelerated Cost Recovery System für den internationalen Kapitalverkehr, in: KYKLOS, 37.Jg. (1984), S. 553 .

67 Notwendig ist diese Einschränkung nicht, auf die Demonstration der Gültigkeit der Aussage unter Berücksichtigung riskanten Fremdkapitals und anderer Finanzierungsformen wird hier aber verzichtet. Vgl. T.E. Copeland u. J.F. Weston, a.a.O., S.462-464 (und auch S.464-481). Notwendig ist aber der Ausschluß von zusătzlichen Kosten im Falle eines Konkurses. 
Daraus folgt: solange international die Rangfolge der Steuersätze auf Erträge aus Eigen- und Fremdfinanzierung identisch ist, ${ }^{68}$ ist der geringere Steuersatz für die Analyse allokativer Folgen heranzuziehen. Die auf Seite 30 dargestellten Arbitrageüberlegungen gelten dann unverändert.

Ausgeschlossen werden müssen aber Kosten, die durch Konflikte zwischen Eigen- und Fremdkapitalgebern, zwischen Eigenkapitalgebern und Unternehmensleitung oder durch Zahlungen an Dritte außer dem Staat verursacht werden können. ${ }^{69}$

\section{b) Investitionsneutralität}

Ein Steuersystem kann aber nicht nur die Finanzierung, sondern auch die Investitionsentscheidung beeinflussen. Wenn der identische Barwert der Zahlungsreihen unterschiedlicher Grenzinvestitionen nach Berücksichtigung der Besteuerung nicht mehr gleich ist, ist das Steuersystem nicht investitionsneutral. Die relative Vorteilhaftigkeit einer Investition wird insbesondere verändert, wenn (i) der Steuersatz nicht unabhängig von der Höhe des Ertrags ist, oder (ii) der Zeitpunkt der Besteuerung nicht dem Zeitpunkt der Entstehung des Einkommens entspricht.

\section{๙) Unvollkommener Verlustausgleich als Optionsposition}

Neutralität in bezug auf die Investitionsentscheidung ist deshalb nicht gewährleistet, wenn die Steuer nicht symmetrisch ist, das heißt der Tarif nicht proportional und ein voller sofortiger Verlustausgleich nicht gestattet ist.

Die Wirkung eines Steuersystems mit unzureichendem Verlustausgleich wurde auf anschauliche Weise von Majd und Myers mit Hilfe der Optionstheorie gezeigt. ${ }^{70}$

Die Optionstheorie ermöglicht es, asymmetrische Erwartungsstrukturen zu dem für die allokativen Folgen ausschlaggebenden Zeitpunkt der Investitionsentscheidung zu bewerten. Die Belastung durch eine nicht symmetrische Steuer wird zumindest in Form der formalen und der Anstoßinzidenz auch quantifizierbar und kann so mit der Last bei symmetrischer Besteuerung

68 Die Überlegungen gelten bei Selbstfinanzierung nicht analog: Die Finanzierungsform ist zwar dominant, wenn der Steuersatz auf einbehaltene Gewinne geringer ist als auf ausgeschüttete Gewinne oder Fremdkapitalzinsen. Die Finanzierungskosten der Grenzinvestition entsprechen aber jenen der Fremd- oder Eigenfinanzierung, denn die Opportunitätskosten werden hier auf dem Kapitalmarkt determiniert. Darüber hinaus ist Selbstfinanzierung nur für Firmen eine Alternative, die Gewinne erwirtschaftet haben. H.-W. Sinn, Die Bedeutung des Accelerated Cost Recovery System, a.a.O., S.553f.

69 Außerdem muß von Gestaltungsmöglichkeiten der Unternehmen bezüglich des Ortes der Einkommensentstehung abstrahiert werden. Hierzu zählt beispielsweise die Wahl von Tranferpreisen oder von Preisen für Patente und Lizenzen. A.C. Shapiro, a.a.O., S.213.

70 S. Majd u. S. Myers, Valuing the Government's Tax Claim on Risky Corporate Assets, NBER Working Paper Series Nr.1553, Cambridge, Mass. 1985. Vgl. hierzu auch J.A. Schnabel u. E. Roumi, A Contingent Claims Analysis of Partial Loss Offset Taxation and Risk-Taking, in: Public Finance, 45. Jg. (1990), S.304-320, die die Wirkungen eines begrenzten Verlustausgleichs auf den Marktwert der Aktien von Unternehmungen bei Berücksichtigung (risikobehafteter) Fremdfinanzierung analysieren.

Optionstheoretisch wurde von Constantinides außerdem die Möglichkeit bewertet, Veräußerungsverluste sofort zu realisieren, Kursgewinne aber hinauszuschieben. Vgl. G.M. Constantinides, Capital Market Equilibrium with Personal Taxes, in: Econometrica, 51.Jg. (1983), S.611-612. Estache und van Wijnbergen haben die Wirkung einer Mindeststeuer (insbesondere für Brasilien) auf diesem Weg analysiert. Vgl. A. Estache u. S. van Wijnbergen, Evaluating the Minimum Asset Tax on Corporations: An Option Pricing Approach, CEPR Discussion Paper Series Nr.684, London 1992. Vgl. zur Mindeststeuer in den USA Fußnote 42 auf Seite 87. 
und bei anderen asymmetrischen Steuersystemen verglichen werden. Der Übertragung auf die Realität steht nur noch das Problem der Bestimmung der Parameter im Weg, insbesondere des Risikos.

Dieser Gedanke wird an späterer Stelle dieses Teils zur Analyse asymmetrischer einkommensteuerlicher Behandlung von Währungsgewinnen und -verlusten aufgegriffen werden und deshalb hier am Beispiel einer einfachen einperiodigen Grenzinvestition in einem Steuerregime ohne Verlustausgleich allgemein erläutert:

Eine symmetrische Steuer mindert das Einkommen des Steuerpflichtigen in jeder Periode um den Steuersatz, ganz gleich, ob es positiv oder negativ ist. Der Staat beteiligt sich also auch im Fall eines Verlusts anteilig.

Ohne Verlustausgleich partizipiert der Staat an einem positiven Ergebnis, der Steuerpflichtige muß den Verlust dagegen allein tragen. Diese ökonomische Situation des Kapitalgebers ist interpretierbar als Position eines Verkäufers einer Kaufoption („Stillhalter“) auf den Anteil des Gesamtkapitals einer Unternehmung in Höhe des Steuersatzes. ${ }^{71}$

Ein Käufer einer Kaufoption erwirbt - gegen Zahlung einer Prämie - das Recht, eine bestimmte Menge eines bestimmten Gutes nach einem im voraus festgelegten Zeitraum zu einen im voraus festgelegten Preis - dem sogenannten Basis- oder Ausübungspreis - zu kaufen. ${ }^{72}$ Ist der tatsächliche Preis dieses Gutes zum Erfüllungszeitpunkt höher, ist es sinnvoll, die Option auszuüben. Ist er indes niedriger, ist es günstiger, das Gut direkt zu erwerben und die Option verfallen zu lassen. Die Optionsprämie ist dann verloren.

Der Stillhalter ist der Verkäufer der Option; er übernimmt die Verpflichtung, den Vertrag durch Lieferung des Gutes zu erfüllen. Er erhält die Optionsprämie als Ausgleich dafür, gegebenenfalls das Gut zu dem im Vergleich zum Marktwert höheren vereinbarten Preis liefern zu müssen.

Hier ist „Käufer“ der Optionen der besteuernde Staat: ${ }^{73}$ im Falle einer positiven Entwicklung der Investition übt er sein Recht aus, mit dem Anteil in Höhe des Steuersatzes am Gewinn beteiligt zu sein. Das Ergebnis entspricht einer Transaktion, bei der der Staat am Periodenende den Anteil an der Investition zu den Anschaffungskosten erwirbt und zu dem höheren Endwert an einen Dritten veräußert.

Der „Kaufpreis“ der Optionen ist bei einer Grenzinvestition der Gegenwartswert dieser Steuerforderung zum Zeitpunkt der Investitionsentscheidung. Die Anschaffungskosten sind der „Ausübungspreis“, weil eine positive Differenz zwischen den Anschaffungskosten und dem tatsächlichen Endwert steuerpflichtig ist. Bei einer negativen Differenz läßt dagegen der Staat seine Option verfallen; der Verlust verbleibt beim Steuerpflichtigen.

Ist der erwartete Endwert höher als die Anschaffungskosten, ist die Optionsposition ,im Geld". Sie hat dann auch im Fall des sicheren Einzahlungsüberschusses einer risikofreien Investition einen Wert. Dies ist folgerichtig, denn schließlich ist es das Ziel der Steuer, dem Staat ein Aufkommen zu verschaffen. Besteht kein Verlustrisiko, entspricht der Preis der Optionen gerade dem Barwert der am Ende der Periode fälligen Steuerlast ${ }^{74}$ und es ergeben sich keine neuen Erkenntnisse.

71 Auch hier sind natürlich einschränkende Annahmen erforderlich. Wesentlich ist, die Möglichkeit auszuschließen, daß der ex ante zugrundegelegte künftige Zahlungsstrom von der Unternehmensleitung in der Zukunft mit dem Ziel der Steuerminimierung verändert wird. S. Majd, u. S. Myers, a.a.O., S.12f..

72 Neben diesen sogenannten „Europäischen Optionen“ gibt es auch „Amerikanische Optionen“, bei denen die Ausübung während der Laufzeit möglich ist. In diesem Zusammenhang ist ein solches Recht aber nicht gegeben.

73 S. Majd, u. S. Myers, a.a.O., S. 8-10.

74 Vgl. allgemein J.C. Cox u. M. Rubinstein, Option Markets, Englewood Cliffs, NJ. 1985, S.216. 
Anders ist dies bei einer riskanten Investition. Hier ist einerseits ein höherer Ertrag mit der Folge einer hohen Steuerlast möglich. Andererseits besteht die Gefahr eines Verlusts, den die Kapitalgeber allein zu tragen haben. Da diese Gefahr umso größer ist, je höher das Risiko ist, ist auch der Wert der Eventualforderung seitens des Staates zum ausschlaggebenden Zeitpunkt der Investitionsentscheidung umso größer, je unsicherer der Gewinn der Anlage ist. ${ }^{75}$

Die Differenz zwischen dieser Forderung und dem Barwert bei symmetrischer Besteuerung ist genau die zusätzliche Belastung durch die Verweigerung eines Verlustausgleichs. Das Steuersystem ist daher dann nicht investitionsneutral, wenn es nicht symmetrisch ist. Riskante Investitionen werden umso stärker diskriminiert, je unsicherer die Einzahlungsüberschüsse sind.

Freilich bleibt die Ermittlung des Risikos einer einzelnen Investition hier ein kaum lösbares Hindernis.

Ist im Steuerrecht die Verrechnung von Verlusten mit positiven Einkünften aus anderen Investitionen oder anderen Perioden zulässig, ist zwar die Verletzung der Investitionsneutralität geringer. Die Wahrscheinlichkeit des Eintritts eines nicht ausgleichbaren Verlusts ist dann andererseits umso größer, je weniger Verluste aus einer Investition mit Gewinnen aus anderen Projekten ausgeglichen werden können. Dadurch werden kleine Unternehmen diskriminiert. ${ }^{76}$

\section{ß) Kapitalwertabschreibung}

Voraussetzung für investitionsneutrale Besteuerung ist neben der effizienten Berücksichtigung von Verlusten auch die ökonomisch korrekte Ermittlung der Bemessungsgrundlage. Für die Ermittlung des Kapitaleinkommens müßte hierfür jede Wertänderung des Kapitals in der Periode ihrer Entstehung in Form von Ab- oder auch Zuschreibungen steuerlich berücksichtigt werden. Nicht nur Wertminderungen infolge von zum Beispiel Abnutzung oder technischem Fortschritt, sondern jede Marktwertänderung der materiellen und immateriellen Aktiva der Unternehmung oder der Anteile seitens der Kapitalgeber zählen dazu. Wie Johansson gezeigt hat, ist nur dann gewährleistet, daß die Einkommensteuer Erträge und Aufwendungen proportional mindert und infolgedessen die Rangfolge der Investitionsalternativen nicht verändert. ${ }^{77}$ Gewährleistet das Steuersystem nicht die Erfassung einkommenswerter Veränderungen an ökonomischer Verfügungsmacht zum Zeitpunkt ihrer Entstehung, ist das Steuersystem wiederum nicht investitionsneutral. Die Ursache hier ist vergleichbar mit dem oben genannten Argument des ,deferral“: Wird ein Wertzuwachs zu spät oder eine Wertminderung zu früh berücksichtigt, entstehen dem Steuerpflichtigen Zinsvorteile durch die Steuerstundung; umgekehrt fällt die Steuer zu hoch aus, wenn Wertzuwächse zu früh oder Wertminderungen zu spät erfaßt werden. ${ }^{78}$

75 J.C. Cox u. M. Rubinstein, a.a.O., S.216.

76 „Our calculations show that tax asymmetries can have a significant impact on project values, even when carry forwards and carry backs are allowed. This distortion is particularly severe for high risk assets that stand alone or that are part of an undiversified firm." S. Majd, u. S. Myers, a.a.O., S.31f.. Aus diesem Grund ist ein vollkommener Verlustausgleich nicht „eine Pervertierung der Körperschaftsteuer“, wie Sinn meint. H.-W. Sinn, Kapitaleinkommensbesteuerung, a.a.O., S.105.

77 S.-E. Johansson, Income Taxes and Investment Decisions, in: Swedish Journal of Economics, 71.Jg. (1969), S. $105 f$.

78 A.B. Atkinson u. J.E. Stieglitz, a.a.O., S. 142f.; R. A. Musgrave, P.B. Musgrave u. L. Kullmer, Die öffentlichen Finanzen in Theorie und Praxis, 2. Band, 5.Aufl., Tübingen 1993, S.262f.. 
Für ein richtiges Verständnis der ökonomischen Abschreibung ist insbesondere zu beachten, daß Wertänderungen im Sinne ökonomischer Verfügungsmacht nicht Ein- oder Auszahlungen entsprechen müssen.

Beispielsweise erkennt ein Unternehmen die Möglichkeit einer Investition, die Gewinne erwarten läßt, die den Grenzertrag des Faktors Kapital für Anlagen mit gleichem Risiko übertrifft. Der positive Nettobarwert, der sich aus der Diskontierung dieser erwarteten inframarginalen Gewinne errechnet, wäre bei ökonomisch korrekter Abschreibung schon zu dem Zeitpunkt zuzuschreiben, zu dem er erkannt wird. Zu spät wäre es, ihn zu besteuern, wenn die Verfügungsmacht dem Steuersubjekt tatsächlich monetär zufließt; zu spät wäre es sogar, ihn zum Zeitpunkt der Investition zuzuschreiben, denn es mag - aus welchen Gründen auch immer - sinnvoll sein, das Projekt nicht sofort durchzuführen. ${ }^{79}$

Die offensichtlichen praktischen Probleme ${ }^{80}$ bei der Erfüllung dieser Anforderung an das Steuersystem werden bei der internationalen Besteuerung bei flexiblen Wechselkursen um einen zusätzlichen Aspekt erweitert: Wie ist das Steuersystem zu gestalten, wenn sich die Maßstäbe, nämlich die (Außen-)Werte der Währungen, im Zeitablauf unterschiedlich entwikkeln?

\section{Zu inframarginalen Gewinnen}

Der Rahmen der nachfolgenden Analyse konzentriert sich allerdings im Einklang mit den Prinzipien der Kapitalimport- und der Kapitalexportneutralität ausschließlich auf die Grenzproduktivität des Kapitaleinsatzes sowie auf den Grenzertrag der Kapitalanbieter. Inframarginale Gewinne, die darüber hinausgehen, werden nicht beachtet.

Aber kann es inframarginale Gewinne für den Faktor Kapital überhaupt geben?

Dem Denkmodell rational handelnder Marktteilnehmer folgend, muß diese Frage verneint werden. Wenn für den Faktor Kapital inframarginale Gewinne identifiziert werden, ist dies Folge einer nicht zutreffenden Zuordnung der Wertschöpfung, also einer Marktunvollkommenheit. Leistungsfähig sind nur Personen. Überrenditen sind aber das Ergebnis überragender Leistungen im Wettbewerb, das heißt sie sind gebunden an Personen. Auf funktionierenden Märkten werden demgemäß die Gewinne diesen Personen zufallen - und zwar unabhängig von deren Kapitaleinsatz. Infolgedessen müssen derartige Erträge dem Faktor Arbeit zugesprochen werden.

Die Schwierigkeit der Zuordnung von inframarginalen Gewinnen mag aber auch das Motiv dafür sein, daß in der Literatur häufig bei Kapitalexport und Kapitalimport zwischen Direktinvestitionen und sogenannten Portfolioinvestitionen differenziert wird. Erstere werden dann durch ein unmittelbares Engagement eines Kapitalgebers auf dem Boden eines anderen

79 Dies wird deutlicher, wenn unterstellt wird, die Investition werde in einer Aktiengesellschaft geplant. Die Wirkung auf die ökonomische Verfügungsmacht der Anteilseigner kommt dann im Zuwachs des Marktwertes der Anteile unmittelbar zum Ausdruck. Der Wert wird auch als „timing option" („option to wait and learn") bezeichnet. Vgl. R.A. Brealey u. S.C. Myers, Principles of Corporate Finance, 4.Aufl., International Edition 1991, S.521 f.. Einen sehr guten Überblick über die Optionstheorie als Instrument zur Präzisierung solcher immateriellen Werte bei der Investitionsentscheidung bieten A.K. Dixit u. R.S. Pindyck, The Options Approach to Capital Investment, in: Harward Business Review, 73.Jg. (1995), S. 105-115.

80, ,[...] die praktischen Probleme sind derart groß, daß Abweichungen von den ökonomisch richtigen Werten nicht die Ausnahme, sondern die Regel sind. Dies liegt teilweise natürlich auch daran, daß Steuergesetzgeber und Verwaltung aus Hilflosigkeit oder auch absichtsvoll gar nicht mehr den Versuch einer ökonomisch richtigen Bewertung unternehmen." G. Krause-Junk, Außenwirtschaftliche Konsequenzen beschleunigter Abschreibung, in: Finanzarchiv, 46.Jg. (1988), S.253. 
Staates charakterisiert. ${ }^{81}$ Wertpapiere und nicht wesentliche Beteiligungen an Unternehmen sind dagegen Beispiele für Portfolioinvestitionen. Sie sind charakterisiert durch ,eine weniger enge ökonomische Verbindung des Einkunftsempfängers mit dem Ort der Wertschöpfung und damit der Einkomensentstehung" 82.83

Da hier die Position vertreten wird, eine Grenzbetrachtung für Kapitaleinkommen sei ausreichend, wird dem Blickwinkel einer derartigen Abgrenzung nicht gefolgt. Portfolio- und Realinvestitionen unterscheiden sich dann nur darin, daß bei ersteren ein Finanzintermediär etwa eine Bank oder auch eine Anlagegesellschaft - die Eigenschaften der Kapitalanlage verändert. Dadurch kann der Umfang des Risikos und des Investitionsvolumens und die Handelbarkeit oder auch die Fristigkeit der Realinvestition den Präferenzen der letzten Gläubiger anpaßt werden. „Würden die letzten Schuldner (mit anderen Worten, die Wirtschaftssubjekte, die Auszahlungsüberschüsse planen) sich direkt an die letzten Gläubiger (die Einheiten mit Einzahlungsüberschüssen) wenden, ließen sich Finanzierungswünsche und Anlagewünsche häufig nicht in Einklang bringen"84. Solange diese Dienstleistung der Intermediation nicht Auswirkungen auf die Steuerlast bei verschiedenen Investitionen hat, weil im Steuerrecht zwischen Portfolio- und Realinvestitionen unterschieden wird, wird der Einsatz des Faktors Kapital dadurch nicht (negativ) beeinflußt.

\section{Optimale Kapitaleinkommensbesteuerung bei erwarteten Wechselkursänderungen}

Die Analyse einer Kapitaleinkommensbesteuerung bei flexiblen Wechselkursen gliedert sich in drei Teilbereiche. In diesem Abschnitt wird zunächst im Rahmen des Wohnsitzland- und des Quellenlandprinzips gezeigt, wie Währungsgewinne oder -verluste steuerlich behandelt werden sollten, die infolge erwarteter Wechselkursänderungen entstehen. Unerwartete Kursänderungen können an dieser Stelle vernachlässigt werden, indem am Ursprungs- oder Einsatzort ein symmetrisches Steuersystem unterstellt wird. Die Darstellung konzentriert sich hier bei beiden Besteuerungsprinzipien auf grenzüberschreitende Finanzierungsbeziehungen, bei denen das Währungsergebnis beim Kapitalgeber anfällt. Mit anderen Worten: der Kapitalnachfrager finanziert sich nur in der Währung seines Landes.

Die Erwartungsbildung wird aus zwei Hypothesen der Außenwirtschaftstheorie abgeleitet: der Kaufkraftparitätentheorie als Begründung für die langfristige Währungsentwicklung und der Zinsparitätentheorie zur Erklärung kurzfristiger Kursänderungen. Da die Ansätze aber nicht

81 O. Gandenberger, Einfluß der Einkommen- und Körperschaftsteuer, a.a.O., S.42.

82 O. Gandenberger, Kapitalexportneutralität versus Kapitalimportneutralität, a.a.O., S.2.

$83 \mathrm{Zu}$ der Frage, was ausländische Direktinvestitionen überhaupt sind, merkt Froot an: „Die Bezeichnung läßt vermuten, daß sie zum einen internationalen Kapitaltransfer und zum anderen eine wirkliche Investitionsausgabe umfaßt. Tatsächlich beinhaltet es indes weder das eine noch das andere: Ausländische Direktinvestitionen sind im wesentlichen eine Ausweitung unternehmerischer Kontrolle über nationale Grenzen hinweg. Wenn Ford die beherrschende Mehrheit des britischen Unternehmens Jaguar, plc. übernimmt, ist Kapitalexport von Ford oder nach Großbritannien nicht erforderlich. Die Übernahme kann ausschließlich innerhalb Großbritanniens durch Fremdfinanzierung von Dritten erfolgen. In so einem Fall werden lediglich Anteile übertragen; eine Investitionsausgabe (die in der Zahlungsbilanzen erfaßt würde) findet nicht statt.“ K.A. Froot, Comment zu: J. Slemrod, The Impact of the Tax Reform Act of 1986 on Foreign Direct Investment to and from the United States, in: Do Taxes Matter? Hrsg. Joel Slemrod, Cambridge, Mass. 1990, S. 198.

$84 \mathrm{H}$. Schmidt, Liquidität von Finanztiteln als integrierendes Konzept der Bankbetriebslehre, in: Zeitschrift für Betriebswirtschaft, 49.Jg. (1979), S.713. 
unumstritten sind und bislang empirisch nicht zweifelsfrei bewiesen werden konnten, werden deren Voraussetzungen zunächst dargestellt.

Die Hypothesen beschreiben ein Arbitragegleichgewicht auf den internationalen Kapitalmärkten. Ein solches Arbitragegleichgewicht muß (bei Vernachlässigung nichtsteuerlicher Einflüsse) auch gewährleistet sein, damit die oben formulierten Ziele der internationalen Besteuerungsprinzipien erreicht werden können, nämlich eine weltweit effiziente Kapitalallokation bei kapitalexportneutraler Besteuerung oder eine weltweit optimale Kapitalaufbringung bei kapitalimportneutraler Besteuerung. Deshalb werden die Ansätze hier integriert. Zur Vereinfachung der Darstellung werden dabei Länder unterstellt, zwischen denen sich ohne Besteuerung und ohne Wechselkursänderungen die Grenzproduktivitäten beziehungsweise Grenzerträge angleichen.

Die Annahme symmetrischer Besteuerung wird in dem nachfolgenden Abschnitt IV aufgehoben werden. Dort wird der Schwerpunkt der Untersuchung auf den Auswirkungen nicht erwarteter Wechselkursänderungen liegen. Abschnitt V behandelt abschließend die Frage nach der steuerrechtlichen Quelle eines Währungsergebnisses.

\section{Kaufkraftparitätenhypothesen: Gleichgewichtsbeziehungen der Gütermärkte}

Die Kaufkraftparitätentheorie wurde Anfang dieses Jahrhunderts von Gustav Cassel in verschiedenen Formen entwickelt. In ihrer einfachsten Form erklärt sie Devisenkursänderungen durch unterschiedliche Entwicklungen der Höhe des Preisniveaus in verschiedenen Ländern. Die Kaufkraft des Geldes wäre demnach überall gleich..$^{85}$ Der Devisenkurs e muß dann dem Verhältnis von Inlandspreisniveau in Inlandswährung $\mathbf{P}$ und Auslandspreisniveau in Auslandswährung $\mathrm{P}^{*}$ entsprechen:

$$
\mathrm{e}=\frac{\mathrm{P}}{\mathrm{P}^{*}} .
$$

Bei Preisunterschieden für gleiche Güter oder Faktoren an verschiedenen Orten würde eine Form internationaler Güterarbitrage zu einem Ausgleich der Preise führen. ${ }^{86}$

Die Gleichgewichtsbedingung für ein Gut $i$ in zwei Währungsräumen ist $P_{i} \stackrel{!}{=} e \cdot P_{i}^{*} \cdot{ }^{87}$ Eine Aggregation dieser Bedingung für einzelne Güter zu Gleichung [B7] ist aber nur zulässig, wenn das Gewicht jedes Gutes im Preisindex in beiden Staaten identisch ist. Außerdem ist die Handelbarkeit von Gütern aufgrund von Transaktionskosten im internationalen Handel, z.B. durch Transport, Informationskosten ${ }^{88}$ oder durch Zölle und unter Umständen auch indirekte

85 J.Kay u. J.King, Taxing Currency Fluctuation?: The Tax Treatment of Foreign Exchange Gains and Losses, Institute for Fiscal Studies Report Series Nr.18, London 1985, S.12.

86 K. Rose u. K. Sauernheimer, Theorie der Außenwirtschaft, 11., völlig überarb. und erw. Aufl., München 1992, S.177f..

87 G.Giovannetti, A Survey of Recent Empirical Tests of the Purchasing Power Parity Hypothesis, in: BNL Quarterly Review, 1992, S.82.

88 Hierzu können auch direkte Steuern zählen. Komplizierte zwischennationale Steuerregeln erhöhen die Markteintrittskosten ausländischer Konkurrenten: „Financing and investment decisions inevitably become blurred in the face of corporate taxation. In this field, multinationals operate in an extremely complex environment and spend a great deal of resources in tax planning." K.A.Froot, Multinational Corporations, a.a.O., S.331. 
Steuern ${ }^{89}$, eingeschränkt oder unmöglich und der Faktor Arbeit nahezu immobil. Infolgedessen wird zwischen handelbaren und wegen zu hoher Transaktionskosten nicht handelbaren Gütern und Dienstleistungen unterschieden. Je stärker die Handelbarkeit eingeschränkt ist, umso geringer sind offenbar die Arbitragemöglichkeiten. Preisunterschiede bei nicht handelbaren Gütern haben keine direkten Auswirkungen auf den Wechselkurs.

Unvollkommene Märkte und eine unvollständige internationale Integration der nationalen Gütermärkte begünstigen Preisunterschiede. Der beschränkte Wettbewerb gibt Unternehmen Preissetzungsspielräume auf einzelnen Märkten. Ist die Preiselastizität der Nachfrager in zwei Regionen ungleich, ist es für ein marktwertmaximierendes Unternehmen vorteilhaft, unterschiedliche Preise zu fordern. Diese Preise sind innerhalb bestimmter Grenzen unabhängig von der Entwicklung des Devisenkurses.

Kurz- und mittelfristig sind nach einer Untersuchung von Engel tatsächlich Preisänderungen zwischen zwei ungleichen Gütern innerhalb eines Währungsraumes in den allermeisten Fällen geringer als zwischen zwei gleichen Gütern in verschiedenen Ländern. Ausnahmen bilden lediglich einfache, homogene Güter. ${ }^{90}$

Diesen Einschränkungen versucht eine komparative beziehungsweise schwache Form der Kaufkraftparitätentheorie Rechnung zu tragen. Die genannten Beschränkungen der güterwirtschaftlichen Arbitragemöglichkeiten werden zwar berücksichtigt. Es wird aber unterstellt, ihr Einfluß auf den Wechselkurs sei im Zeitablauf gleichbleibend und Gleichung [B7] um einen konstanten Faktor $\Omega$ ergänzt: ${ }^{1}$

$$
\mathrm{e}=\Omega \cdot \frac{\mathrm{P}}{\mathrm{P}^{*}} .
$$

Eine Änderung des Devisenkurses zwischen zwei Zeitpunkten entspricht dann der Entwicklung des relativen Preisniveaus während der Periode. ${ }^{92}$

Problematisch ist bei diesem Ansatz die Bestimmung der korrekten Basisperiode, von der an die Entwicklung fortgeschrieben wird. ${ }^{93}$ Für die Argumentation in dieser Arbeit wichtiger ist aber, daß Beschränkungen der Handelbarkeit von Gütern nicht nur das Niveau, sondern auch die Entwicklung des realen Wechselkurses beeinflussen können:

In einer Volkswirtschaft mit ausgelasteten Faktoren seien in den Sektoren handelbarer Güter die Produktivitätsfortschritte größer als in Sektoren nationaler Güter - beispielsweise, weil der Wettbewerb durch ausländische Konkurrenten auf diesen Märkten intensiver ist. Die Preiselastizität der Nachfrage sei für nicht handelbare Güter gering, für handelbare Produkte

89 Dies gilt bei einer Mehrwertsteuer auf der Grundlage des Ursprungslandprinzips, das allerdings kaum noch angewendet wird. Bei verschiedenen Sătzen im Rahmen des Bestimmungslandprinzips werden die Bruttopreisrelationen zwischen Konsum- und Investitionsgütern unterschiedlich beeinflußt. H.-W. Sinn, Kapitaleinkommensbesteuerung, a.a.O., S.159f..

90 C.Engel, Real Exchange Rates and Relative Prices, in: Journal of Monetary Economics, 32.Jg. (1993), S.3748.

91 R.M. Levich, Empirical Studies of Exchange Rates: Price Behavior, Rate Determination and Market Efficiency, in: Handbook of International Economics, Bd. II., Hrsg. R. W. Jones und P.B. Kenen, Amsterdam u.a. 1985, S.984; R. Dornbusch, Rurchasing Power Parity, in: ders., Exchange Rates and Inflation, Cambridge, Mass. u. London 1988, S.267.

92 R.M. Levich, a.a.O., S.984; K. Rose u. K. Sauernheimer, a.a.O., S.179.

93 B.Balassa, The Purchasing-Power-Parity Doctrine: A Reappraisal, in: Journal of Political Economy, 72. Jg. (1964), S. 584. 
dagegen hoch. Schließlich gebe es kurz- und langfristig nur geringe Möglichkeiten, den international immobilen Produktionsfaktor Arbeit durch Kapital zu substituieren. ${ }^{94}$

Die Preise für nicht handelbare Güter werden dann relativ schneller ansteigen. Die Entwicklung der Arbeitsproduktivität in den Sektoren internationaler Güter ermöglicht eine real zunehmende Entlohnung des Faktors Arbeit bei konstanten Preisen für die Produkte dieses Sektors. Produzenten nationaler Güter dagegen werden die steigenden Faktorkosten nur durch höhere Preise aufbringen können. Je größer der Anteil des vor ausländischer Konkurrenz geschützten Sektors ist, umso stärker kann die nationale Inflationsrate von der Geldentwertung in anderen Ländern abweichen.

Das Ergebnis ist bei statischem Vergleich verschiedener Länder ein umso höheres Preisniveau, je größer das Bruttoinlandsprodukt pro Kopf ist: Preise für handelbare Güter sind international identisch, nichthandelbare Güter dagegen umso teurer, je höher der Entwicklungsstand (je höher die Arbeitsproduktivität in den handelbaren Sektoren) eines Landes ist. Entwickelte Länder werden einen absoluten Vorteil in der Produktion aller Güter haben. Folge der hier getroffenen Annahmen ist aber ein relativer Vorteil bei der Herstellung handelbarer Güter. ${ }^{95}$ Ein unterschiedliches Niveau der Produktivität in verschiedenen Ländern kann auf diesem Weg langfristige Unterschiede der realen Devisenkurse - gemessen auf der Grundlage umfassender Preisindizes - zur Folge haben. ${ }^{96}$

Dynamisch betrachtet muß die Kaufkraft in Ländern mit im Vergleich stärker wachsendem Inlandsprodukt schneller sinken, da der Preis der nationalen Güter dieser Länder relativ schneller zunimmt.

Aus diesem Grund wird die Gültigkeit der Hypothese gleicher Kaufkraft häufig auf Preise für handelbare Güter eingeschränkt. ${ }^{97}$ Allerdings wäre dies bei der schwachen Form der Kaufkraftparitätenhypothese nur notwendig, wenn das Wachstum der betrachteten Volkswirtschaften unterschiedlich ausgeprägt ist. Auch dann aber erreichen diese unterschiedlichen Preisentwicklungen eine Grenze, wenn die Preisunterschiede in verschiedenen Währungsräumen so groß sind, daß die Güter (und Dienstleistungen) handelbar werden. ${ }^{98}$

Dennoch: die Integration einer Kaufkraftparitätenhypothese der Wechselkursentwicklung in die Theorie einer international neutralen Einkommensbesteuerung ist deshalb umso kritischer anzusehen, je stärker sich zwei betrachtete Volkswirtschaften in ihrer Struktur und ihrem Entwicklungsstand unterscheiden.

Diese Einschränkung triff jedoch auf die meisten Arbeiten zum Thema internationaler Neutralität der Besteuerung zu. ${ }^{99}$ Die Möglichkeit der Überwälzung direkter Steuern auf die Güterpreise wird in der Argumentation über ihre weltweite Effizienz in der Regel per An-

94 Der Sektor nichthandelbarer Güter wird häufig mit Dienstleistungen gleichgesetzt. Wird weiterhin unterstellt, Dienstleistungen seien relativ arbeitsintensiv, verstärkt sich die Wirkung auf das nationale Preisniveau. B.Balassa, a.a.O., S.585f.. Allerdings sind die meisten Konsumgüter Kuppelprodukte. Der Preis schließt auch kaum handelbare Leistungen (Distribution, Vermarktung und ähnliches) ein.

95 B.Balassa, a.a.O., S.585.

96 Ein nachfrageorientierter Erklärungsansatz ergänzt diese auf unterschiedlichen Produktivitäten basierende Argumentation: Unterstellt wird, daß die Einkommenselastizität für nichthandelbare Güter größer und für handelbare Güter kleiner als eins ist. S.B. Linder, An Essay on Trade and Transformation, New York 1961, S.95. Nichthandelbar seien mehrheitlich Luxusartikel, handelbar dagegen Gebrauchsgüter. Infolgedessen muß das Preisniveau umso höher sein, je höher das Bruttoinlandsprodukt in einer Region ist. J.H. Bergstrand, Structural Determinants of Real Exchange Rates and National Price Levels: Some Empirical Evidence, in: American Economic Review, 81. Jg. (1991), S.325.

97 Notwendig ist dies auch, wenn der Anteil handelbarer Güter am Bruttoinlandsprodukt in zwei Ländern unterschiedlich groß ist.

98 Ein Beispiel ist der Tourismus. B.Balassa, a.a.O., S. 596.

99 Eine differenzierte Analyse führt beispielsweise P. Musgrave durch. P.B. Musgrave, United States Taxation of Foreign Investment Income, a.a.O., S.111-115. 
nahme ausgeklammert. ${ }^{100}$ Zumindest wenn Kapitalimportneutralität ${ }^{101,102}$ und gleiche indirekte Steuern unterstellt werden, ist dies nur denkbar bei einer Güterarbitrage in der Weise, wie sie hier als Voraussetzung für die Gültigkeit der Kaufkraftparität beschrieben wurde.

Die Bedeutung der Hypothese ist bei der Betrachtung von Währungsgewinnen freilich größer. Es werden nicht nur indirekte Wirkungen durch die Überwälzung der Steuer berührt, da Wechselkursänderungen die Gewinne grenzüberschreitenden Kapitaleinsatzes direkt beeinflussen.

Langfristig kann die Kaufkraftparitätenhypothese aber als die beste Annäherung an eine Beschreibung der gleichgewichtigen Entwicklung von Wechselkursen angesehen werden. Eine systematische Beziehung zwischen Preisniveau und Wechselkurs wurde allerdings noch nicht zweifelsfrei nachgewiesen. ${ }^{103}$ Dies mag auch schlicht daran liegen, daß der Zeitraum flexibler Devisenkurse zu kurz ist, um eindeutige empirische Resultate errechnen zu können ${ }^{104}$ und daran, daß sich Güter, Faktoren und auch die Märkte im Zeitablauf zu stark ändern. Trotz der gewichtigen Einschränkungen ist insofern die Kaufkraftparität bislang der einzige theoretische und empirische Anhaltspunkt für eine Begründung einer langfristig gleichgewichtigen Kursentwicklung. ${ }^{105}$

\section{Zinsparitätenhypothese: Gleichgewichtsbeziehung der internationalen Kapitalmärkte}

Für die Bestimmung einer neutralen Einkommensteuer kann ein langfristiges Gleichgewicht aber nicht alleiniger Maßstab sein. Interessanter ist die Frage, ob vorübergehende Abweichungen von einer Gleichgewichtssituation die Neutralität verletzen können. Die Vielzahl von empirischen Analysen zur Gültigkeit der Kaufkraftparität in den letzten dreißig Jahren zeigen nämlich eindeutig, daß die Wechselkursentwicklung kurzfristig keinem Preisniveau folgt. ${ }^{106}$ Schon ein flüchtiger Blick auf die tatsächliche Devisenkursentwicklung macht zumindest kurz- und mittelfristige Abweichungen von der Kaufkraftparität deutlich, wie die Abbildung B5 auf der folgenden Seite beispielhaft für die nominalen und die realen effektiven Außenwerte der DM und des U.S.-\$ zeigt.

Nominaler und realer Außenwert der Währungen schwanken weithin parallel. Neben den schon genannten Argumenten wird als Ursache für diese Schwankungen vor allem angeführt, daß

${ }^{100}$ Kritisch äußert sich hierzu O. Gandenberger, Kapitalexportneutralität versus Kapitalimportneutralität, a.a.O., S.15f..

${ }^{101}$ Notwendig ist auch die Annahme eines nicht vollkommen preisunelastischen Arbeitsangebotes.

102 Dies gilt nicht für kapitalexportneutrale Besteuerung, wenn die Faktorkosten für Kapital international identisch sind.

${ }^{103}$ R.A. Meese u. K. Rogoff, Was it real?, The Exchange Rate-Interest Differential Relation, 1973-1984, NBER Working Paper Series Nr.1732, Cambridge, Mass. 1985, S.10f. u. S.13f.; H. J. Edison u. B.D. Pauls, A Reassessment of the Relationship Between Real Exchange Rates and Real Interest Rates: 1974-1990, in: Journal of Monetary Economics, 31.Jg. (1993), S.184. Einen guten Überblick über empirische Studien zur Kaufkraftparität geben G. Giovannetti, A Survey, a.a.O., S.81-97; R. MacDonald u. M.P. Taylor, a.a.O., S.157.

${ }^{104}$ P. Krugman, Equilibrium Exchange Rates, in: International Policy Coordination and Exchange Rate Fluctuations, Hrsg. W.H. Branson u.a., Chicago u. London 1990, S.162ff. .

${ }^{105}$ Vorbehalte bleiben aber bei Volkswirtschaften mit stark unterschiedlichem Niveau beziehungsweise stark unterschiedlicher Entwicklung des Inlandsprodukts.

${ }^{106}$ R.C. Marston, Real and Nominal Exchange Rate Variability, in: Empirica - Austrian Economic Papers, 16.Jg. (1989), S.147. 
Devisenmärkte Bestandteil der internationalen Kapitalmärkte sind. ${ }^{107}$ Nur sehr mittelbar determinieren die Gütermärkte die Kursentwicklung. Entscheidend sind vielmehr Arbitragetransaktionen zwischen Anlagealternativen in verschiedenen Währungen.

Abb. B5: Entwicklung des nominalen und des realen effektiven Außenwertes der DM und des U.S.-\$ zwischen 1975 und 1996 (Basis: $1975=100$ ).

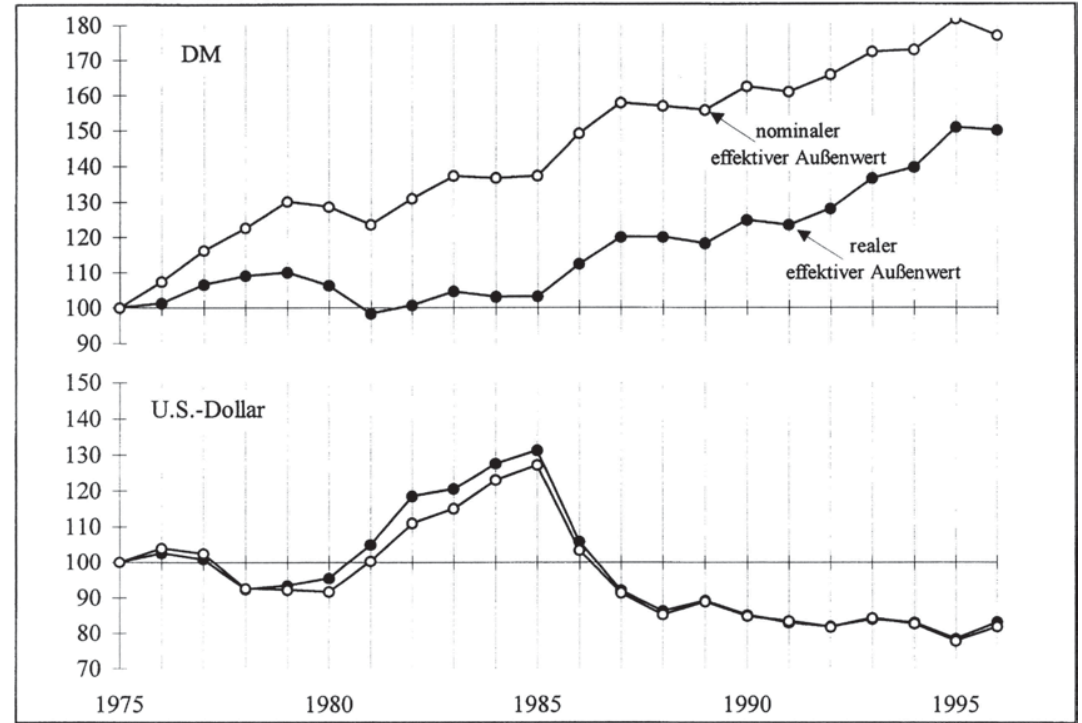

Quellen: International Monetary Fund, International Financial Statistics Yearbook 1995, Washington, D.C., 1995, S.386f. u. S.776f.; ders. International Financial Statistics June 1997, Washington, D.C., 1997, S.304f. u. S.712f..

In einer Reihe von Modellen wurde versucht, die unterschiedlichen Eigenschaften der Güterund Kapitalmärkte in einen Zusammenhang mit der Devisenkursentwicklung zu bringen. Wesentlich ist die zeitliche Ausrichtung: Die Preisentwicklung auf den Gütermärkten reagiert langsam und mit zeitlicher Verzögerung auf Änderungen der Faktorpreise und der Nachfrage. Güterpreise werden aufgrund dessen als vergangenheitsorientiert angesehen.

Auf der anderen Seite werden die Preise auf den Kapitalmärkten von neuen Informationen über erwartete zukünftige Ereignisse determiniert. Kurzfristige Preisunterschiede für verschiedene Anlagen gleicher Qualität werden durch Arbitragetransaktionen von Marktteilnehmern sofort ausgeräumt. Insbesondere die Devisenmärkte werden wegen der Vielzahl „kleiner“ Marktteilnehmer und der Homogenität der gehandelten Güter häufig als nahezu vollkommene Märkte bezeichnet.

Wie die Anpassungsprozesse tatsächlich verlaufen, ist für den Inhalt dieser Arbeit nicht relevant. Entscheidend ist aber, daß die meisten Modelle zur Erklärung der Wechselkursentwicklung auf der Annahme eines langfristigen Gleichgewichts basieren und daß dieses Gleich-

107 Vgl. J.A. Frenkel u. M.L. Mussa, The Efficiency of Foreign Exchange Markets and Measures of Turbulence, in: American Economic Review, Papers and Proceedings, 70.Jg. (1980), S.374-381. Frenkel und Mussa relativieren die starke Volatilität der Wechselkurse, die auch in den Abbildungen B1 bis B3 auf den Seiten 25f. zum Ausdruck kommt, indem sie darauf hinweisen, daß deren Schwankungen im Zeitraum zwischen 1973 und 1979 geringer waren als die der Aktienmärkte. Ebda., S.375 u. S.378. 
gewicht durch eine Form der Kaufkraftparität auf den Gütermärkten determiniert wird. Die tatsächliche Entwicklung wird als Abweichung von diesem Gleichgewicht infolge realer oder monetärer Schocks erklärt. Diese Annahmen werden hier übernommen.

Der bekannteste Erklärungsansatz ${ }^{108}$ ist vermutlich das Modell von Dornbusch ${ }^{109}$, demzufolge eine Expansion der Geldmenge in einer kleinen offenen Volkswirtschaft ceteris paribus sofort zu einer starken Abwertung der heimischen Währung fuihrt. Die Abwertung geht dem Anstieg der inländischen Preise zeitlich voraus und übertrifft ihn in seinem Umfang. Der Devisenkurs „überschießt"110 das neue Gleichgewicht vorübergehend.

Wenngleich langfristig die gleichgewichtige Devisenkursentwicklung durch die Kaufkraftäquivalenz determiniert wird, ist kürzerfristig damit das nominale Zinsniveau in verschiedenen Währungsräumen entscheidend. Erwartete Kursänderungen werden unmittelbar auf den Kapitalmärkten durch eine internationale Parität der Zinssätze bestimmt.

Die Zinsparitätentheorie beschreibt also im Unterschied zur Kaufkraftparität ein Arbitragegleichgewicht, das nur auf Ausgleichstransaktionen auf Kapitalmärkten basiert. Der Devisenkurs wird hiernach durch Portfolioentscheidungen der Marktteilnehmer bestimmt. Diese gründen sich auf die Ertragserwartungen und das Risiko verschiedener Anlagen. Gemäß der Zinsparitätenhypothese wird der gleichgewichtige Wechselkurs auf den Kapitalmärkten zu jedem Zeitpunkt dadurch charakterisiert, daß Devisenkursänderungserwartungen gerade die unterschiedlichen Eigenschaften von Anlageformen in verschiedenen Währungsräumen kompensieren. Steigt beispielsweise das Zinsniveau in einem Land, werden diese Anlagen relativ zu Alternativen in anderen Währungsräumen attraktiver. Der Außenwert dieser Währung wird infolgedessen - durch tatsächliche Transaktionen oder auch nur durch Neubewertung der Bestände - steigen, bis ein neues transitorisches Gleichgewicht erreicht ist, in dem Anleger gegenüber den Investitionsalternativen indifferent sind.

$\mathrm{Zu}$ den Eigenschaften von Fremdwährungsanlagen gehört allerdings auch ein Devisenkursrisiko, da die erwartete Devisenkursänderung unsicher ist. Allgemein wird in der Kapitalmarkttheorie von riskoaversen Präferenzen ausgegangen. Infolgedessen muß auch der erwartete Ertrag von Anlageformen in fremden Währungen eine Prämie für das Risiko einer Devisenkursänderung beinhalten. Die Bestimmung einer derartigen Prämie bereitet bislang aber sowohl theoretisch als auch empirisch Schwierigkeiten. ${ }^{11}$ An dieser Stelle wird sie deshalb durch die Annahme risikoneutraler Anleger ausgeklammert. Da die Frage nach der Existenz einer Risikoprämie aber auch für eine neutrale Devisengewinnbesteuerung von Bedeutung ist, wird das Problem weiter unten kurz aufgegriffen.

Das Ausmaß der Angleichung der Ertragsraten hängt außerdem vom Grad der Kapitalmobilität ab. In dem Extremfall vollkommener Kapitalmobilität und risikoneutraler Anleger kommt es - wenn keine Kapitaleinkommensteuern bestehen ${ }^{112}$ - zum Ausgleich der Ertragsraten in beiden Ländern. Mit anderen Worten: es besteht offene oder ungedeckte Zinsparität. Ist dies der Fall, wird ein inländischer Kapitalgeber indifferent gegenüber einer Anlage im Inoder Ausland sein, wenn er eine Kursentwicklung erwartet, bei der ein Währungsgewinn oder -verlust die unterschiedliche Verzinsung des eingesetzten Kapitals gerade ausgleicht. Bei

\footnotetext{
108 P.R.Krugman, a.a.O., S. 162.

${ }^{109} \mathrm{Vgl}$. R.Dornbusch, Expectations and Exchange Rate Dynamics, in: Journal of Political Economy, 84. Jg. (1976), S. 1161-1176.

${ }^{110}$ R. Dornbusch, Expectations and Exchange Rate Dynamics, a.a.O., S.1169.

${ }^{111}$ R.M. Levich, a.a.O., S.1024.

112 Vgl. zum Einfluß der Ertragsbesteuerung auf die Zinsparität M.B. Levi, Taxation and "Abnormal" International Capital Flows, in: Journal of Political Economy, 85. Jg. (1977), S.635-646.
} 
einem Zinsniveau im Inland von $\mathrm{r}$ und im Ausland von $\mathrm{r}^{*}$ muß die erwartete Rate der Devisenkursänderung $\mathrm{e}_{+1}^{\mathrm{e}} / \mathrm{e}$ der Beziehung

$$
1+r=\frac{e_{+1}^{e}}{e} \cdot\left(1+r^{*}\right)
$$

entsprechen. ${ }^{113}$ Dabei steht e für den aktuellen und $\mathrm{e}_{+1}^{\mathrm{e}}$ für den für das Periodenende erwarteten Devisenkurs. ${ }^{114}$

Beispiel B1:

Beträgt das Zinsniveau im Inland $r=10 \%$ und im Ausland $r^{*}=7 \%$, ist der inländische Kapitalgeber indifferent, wenn er eine Währungsentwicklung mit der Rate

$$
\frac{\mathrm{e}_{+1}^{\mathrm{e}}}{\mathrm{e}}=\frac{1+\mathrm{r}}{1+\mathrm{r}^{*}}=\frac{1,1}{1,07}=1,02804
$$

erwartet, das heißt einen Anstieg des Devisenkurses um 2,804\%. Liegt der Kurs aktuell bei $\mathrm{e}=1$, wird er für das Ende der Periode einen Anstieg des Kurses auf $\mathrm{e}_{+1}^{\mathrm{e}}=1,02804$ antizipieren. Der mit diesem Anstieg verbundene Gewinn kompensiert ihn genau für die niedrigere Ertragsrate in der ausländischen Währung.

Spiegelbildlich ist die Situation für den ausländischen Sparer. Aus seiner Sicht stellt der von dem Inländer erwartete Kursanstieg einen Rückgang des Wechselkurses dar, und zwar auf $1,02804^{-1}=0,973$. Bei dieser Kursentwicklung ist er indifferent gegenüber den beiden Anlagen, denn dann beträgt der erwartete Ertrag für ihn auch bei Kapitalexport in das Inland $7 \%$.

Da Gleichung [B9] für inländische und für ausländische Markteilnehmer in gleicher Weise gültig ist, ${ }^{115}$ kann in einer Welt ohne Steuern offensichtlich eine erwartete Währungsentwicklung existieren, die ein Arbitragegleichgewicht auf dem Devisenmarkt ermöglicht.

Entscheidend für dieses Gleichgewicht ist die Form der Erwartungsbildung durch die Marktteilnehmer. Wie schon an früherer Stelle auf den Seiten 16 bis 17 begründet, wird in dieser Arbeit mit der Hypothese rationaler Erwartungen argumentiert. ${ }^{116}$ Demnach stimmen die subjektiven Erwartungen der einzelnen Anleger über die Devisenkursentwicklung $e_{+1}^{e}$ mit dem objektiven Erwartungswert $E\left[\mathrm{e}_{+1}\right]$ überein. Erwartungsfehler haben ihre einzige Ursache darin, daß neue kursbeeinflussende Informationen zwischen dem Zeitpunkt der Erwartungsbildung und dem Zeithorizont - hier dem Periodenende - bekannt werden. Sie werden aufgrund dessen in der Literatur auch als Nachrichten (,news“) bezeichnet. Hierzu zählen beliebige Schocks, die Auswirkungen auf das Zinsniveau in den Ländern und auf den Wechselkurs haben, beispielsweise sich ändernde Einschätzungen über die Entwicklung der Inflationsraten in den Ländern. Entscheidend für das kurzfristige Verhalten des Devisenkurses sind diese neuen Informationen über zukünftige Ereignisse, die den Außenwert der Währung berühren und infolgedessen kurzfristig die Erwartungen über ein geändertes Gleichgewicht beeinflussen.

${ }^{113}$ Die Trennung von Währungsgewinn und Zinsertrag ist durch die folgende Umformung möglich: [B9b]

$$
r-r^{*}=\left(1+r^{*}\right) \cdot\left(\frac{\epsilon_{1}^{*}}{e}-1\right)
$$

Die rechte Seite der Gleichung quantifiziert den Währungsgewinn bei Zinsertrag und investiertem Kapital. M.B. Levi, a.a.O., S.636.

${ }^{114}$ Vgl. zur ungedeckten Zinsparität auch P.Isard, Uncovered Interest Parity, IMF Working Paper Nr.51, 1991. Tatsächlich läßt sich anhand dieser Identität eine ganze Zeitstrukturkurve erwarteter Devisenkurse herleiten, denn für jeden Anlagehorizont $t+i, i=1,2, \ldots, n$ existiert eine gleichgewichtige Kursentwicklung.

115 Vgl. aber die Anmerkung in Fußnote 129 auf Seite 48 dieser Arbeit.

${ }^{116}$ Die Zinsparität ist auch mit regressiven Erwartungen konstruierbar. Marktteilnehmer würden in diesem Fall eine Devisenkursentwicklung hin zu einem ,normalen Niveau“ prognostizieren. 
Vorhersehbar sind zu jedem Zeitpunkt indes nur Devisenkursentwicklungen, die sich direkt aus der Zinsparität ableiten. ${ }^{117}$

Im Unterschied zur offenen Zinsparität beschreibt die gedeckte Zinsparität das risikofreie Arbitragegleichgewicht zwischen den Alternativen einer inländischen und einer ausländischen Anlage, bei der das Wechselkursrisiko durch ein Devisentermingeschäft gleicher Laufzeit mit dem Terminkurs $f_{+1}$ abgesichert ist: 118

$$
1+r=\frac{f_{+1}}{e} \cdot\left(1+r^{*}\right)
$$

In gleicher Weise wie bei der ungedeckten Zinsparität steht der Terminkurs ${ }_{t} f_{t+1}$ in einer Arbitragebeziehung zu den Zinssätzen der beiden Länder. Sollte allerdings die gedeckte Zinsparität [B9b] nicht erfüllt sein, wäre im Unterschied zu Gleichung [B9] risikofreie Arbitrage möglich. Erwartungsgemäß ist deshalb die Gültigkeit dieser Beziehungen auch empirisch weitgehend gesichert.119

Im Rahmen der bislang getroffenen Annahmen - besonders der Annahme der Risikoneutralität der Marktteilnehmer - ist ein positiver oder negativer Gewinn durch einen vom Kassakurs abweichenden Terminkurs steuerlich anderen wechselkursbedingten Gewinnen oder Verlusten gleichzustellen. ${ }^{120,121}$ Wäre dies nicht gegeben, bestünde die Möglichkeit der Steuerarbitrage, indem auf dem Kassa- und dem Terminmarkt gegenläufige Positionen eingegangen werden. In den Teilen $\mathrm{C}$ und $\mathrm{D}$ wird deshalb auch betrachtet, wie Gewinne und Verluste aus Devisentermingeschäften steuerlich behandelt werden.

\section{Implikationen für neutrale Besteuerung}

Welche Schlußfolgerungen lassen sich aus der Kaufkraftparitäten- und Zinsparitätentheorie für die Besteuerung von Währungsgewinnen und -verlusten ableiten?

Wie die bisherigen Ausführungen zeigen, wird das Arbitragegleichgewicht, bei dem Anbieter und Nachfrager indifferent gegenüber der Anlage beziehungsweise Aufnahme von Kapital im

${ }^{117}$ Die Preisbildung im Rahmen der ungedeckten Zinsparität ist deshalb von einem reinen Zufallsprozeß der Kursbildung zu unterscheiden. Bei einem ,random walk“-Modell ist jedwede Devisenkursänderung unvorhersehbar. Wie [B9] verdeutlicht, wäre dies bei vollkommener Substitutionalität von Anlagen in verschiedenen Währungen nur dann korrekt, wenn das Zinsniveau in beiden Ländern identisch ist. Ein ,random walk“ ist weder eine notwendige, noch eine hinreichende Bedingung für Devisenmarkteffizienz. R. E. Cumby u. M. Obstfeld, A Note on Exchange-Rate Expectations and Nominal Interest Differentials: A Test of the Fisher Hypothesis, in: Journal of Finance, 36.Jg. (1981), S.609; R. MacDonald, Floating Exchange Rates. Theories and Evidence, London u.a. 1988, S.176.

118 P.Isard, a.a.O., S.1.

119 Vgl. M.B. Levi, a.a.O., S.636.

${ }^{120}$ Empirische Untersuchungen über die Effizienz des Devisenmarktes haben häufig zum Inhalt, zu hinterfragen, in wieweit der Terminkurs $f_{+1}$ tatsächlich eine unverzerrte Vorhersage des erwarteten künftigen Wechselkurses darstellt. Die Gültigkeit der Effizienzmarkthypothese erfordert nämlich, daß der Terminkurs eine unverzerrte Vorhersage des zuküntigen Kassawechselkurses darstellt. Das bedeutet aber nicht, daß diese Vorhersage in Zeiten großer Unsicherheit besonders gut ist, sondern nur, daß der Terminkurs der beste verfügbare Prognosewert ist. R. MacDonald u. M.P. Taylor, a.a.O., S.34. Froot und Frankel fassen hierzu zusammen: „Most of the studies that test the unbiasedness hypothesis reject it, and they generally argee on the direction of bias. They tend to disagree, however, about whether the bias is evidence of a risk premium or of a violation of rational expectations.“ K.A. Froot u. J.A. Frankel, Forward Discount Bias: Is it an Exchange Risk Premium?, in: Quarterly Journal of Economics, 104.Jg. (1989), S.139.

${ }^{121}$ Die Frage nach der Effizienz der Devisenmärkte ist hier deshalb von zusätzlicher Bedeutung: Würde die ungedeckte Zinsparität die Wechselkursentwicklung nicht korrekt beschreiben, wären die im folgenden formulierten Besteuerungsvorschläge möglicherweise nicht richtig. 
In- oder Ausland sind, auch in den hier unterstellten Ländern nicht zu jeder Zeit durch weltweit gleiche Grenzproduktivitäten und Grenzerträge charakterisiert. Daher kann die Möglichkeit eines solchen Gleichgewichts nicht Kriterium für die Beurteilung der internationalen Neutralität einer Steuer sein. ${ }^{122}$ Statt dessen müßte auch unter dem Einfluß der Besteuerung die erwartete Währungsentwicklung (i) die von den Kapitalanbietern jedes Landes erwarteten Grenzerträge und (ii) die von den Kapitalnachfragern antizipierte erforderliche Grenzproduktivität für Kapital weltweit angleichen können. Nur dann wirkt das Steuersystem nicht verzerrend auf die Entscheidungen der Sparer und der Kapitalnachfrager. Da diese Voraussetzungen sehr restriktiv und deswegen unrealistisch sind, wird hier anhand der Eigenschaften der Kapitalexport- und der Kapitalimportneutralität untersucht, wie Währungsgewinne und -verluste steuerlich behandelt werden sollten.

Dies geschieht zunächst im Rahmen des Nominalwertprinzips, das besagt, „daß Geld weder der Wert von Gold, noch der einzelner Güter oder Leistungen, sondern als Zahlungsmittel und Wertmesser ein Gut eigener und deshalb nur sich selbst gleicher Art ist" ${ }^{123}$ Die Steuersysteme der meisten Länder beruhen auf diesem Prinzip, ${ }^{124}$ obwohl es immer wieder kritisiert wird. ${ }^{125}$ Dies gilt insbesondere für die USA im Zusammenhang mit der dortigen Veräußerungsgewinnbesteuerung. ${ }^{126}$

Anschließend wird das Nominalwertprinzip aufgehoben und die Freistellung von sogenannten Scheingewinnen zugelassen. Unter dem Begriff des Scheingewinnes wird eine durch Geldwertverschlechterung entstandene Differenz zwischen den nominalen und den realen Gewinnen einer Unternehmung verstanden. ${ }^{127}$ Die Bezeichnung ist genaugenommen bei einer Argumentation auf der Grundlage der Annahme rationaler Wirtschaftssubjekte ungeeignet, da ja ein „Schein“ nicht bestehen kann. Die erwartete Geldentwertung wird ex ante von den Kapitalanbietern bei ihrer Ertragsforderung nicht übersehen beziehungsweise ex post nicht als wirklicher Gewinn interpretiert werden. Andererseits ist sie allgemein geläufig und wird deshalb in dieser Arbeit übernommen. ${ }^{128}$

122 Vgl. auch H.-W. Sinn, Kapitaleinkommensbesteuerung, a.a.O., S. 170 u. Fn.9.

${ }^{123}$ K. Lange, Die Bedeutung des Grundsatzes der Steuergerechtigkeit für die Erfolgsbesteuerung der Aktien- und der Zinsanlage unter dem Einfluß der Inflation und Konsequenzen für das geltende Steuerrecht, Diss., Univ. Hamburg 1982, S. 15.

${ }^{124}$ Es ist einer der tragenden Grundsätze der deutschen Rechts- und Wirtschaftsordnung überhaupt, da es in $\S 3$ des Währungsgesetzes als gesetzliche Norm festgeschrieben ist. Vahlens großes Wirtschaftslexikon, Band I (A-K), Hrsg. E. Dichtel u. O. Issing, München 1987, S.837.

125 So schon E. Schmalenbach, Die steuerliche Behandlung der Scheingewinne, 2., unveränd. Aufl., Jena 1922; vgl. auch Sachverständigenrat zur Begutachtung der gesamtwirtschaftlichen Entwicklung, Jahresgutachten 1982/83. Stuttgart 1982, S.180-186.

126 So die Republikanische Partei in ihrem Steuerreformentwurf „Contract with America“. Allerdings scheint die Forderung nach Freistellung von Scheingewinnen hier primär als Argumentationshilfe für das eigentliche Ziel der Minderung der Veräußerungsgewinnsteuer zu dienen. Vgl. M. Feldstein, Why Capital Gains Taxes Are Unfair, in: Wall Street Journal v. 21.11.1994; J. Calmes, Tax Cuts Aplenty Are to Be Pledged In GOP's Manifesto, in: Wall Street Journal v. 22.09.1994; G. Graham, Republican Tax Plans Challenged, in: Financial Times v. 12.01.1995. In dem aktuellen Wahlprogramm der Partei wird eine Halbierung des Spitzensteuersatzes auf Veräußerungsgewinne gefordert. The 1996 Republican Platform: Building a Better America, angenommen am 12. August 1996.

${ }^{127}$ Sachverständigenrat zur Begutachtung der gesamtwirtschaftlichen Entwicklung, a.a.O., S.181.

${ }^{128}$ In diesem Teil B wird jeder inflationär bedingte Kapitalertrag auch als Scheingewinn benannt, unabhängig davon, ob die Steuer an der Quelle oder beim Sparer erhoben wird. Andere Definitionen beziehen den Begriff auf die Entwertung des Eigenkapitals einer Unternehmung durch den inflationären Preisanstieg. K.D. Haase, Geldentwertung und Ertragsbesteuerung der Unternehmung, in: Die Unternehmung in ihrer gesellschaftlichen Umwelt, Hrsg. P. Mertens, Wiesbaden 1975, S.283. Er wird auch für den Teil des inflationsbedingten Gewinnes verwendet, „der mit Rücksicht auf die Erhaltungserfordernisse an die Unternehmung gebunden werden sollte“. D. Börner, Bilanzpolitik und Unternehmenserhaltung bei geltendem Steuerrecht, in: Die Unter- 


\section{a) Besteuerung nach dem Wohnsitzlandprinzip}

Die Besteuerung allein nach dem Wohnsitzlandprinzip behindert - wie oben dargelegt - die weltweit effiziente Allokation des Faktors Kapital nicht, wenn jedes Land sein Kapitaleinkommen aus allen Quellen gleichermaßen belastet. Schließt dies Währungsgewinne und -verluste ein?

\section{a) Nominalwertprinzip}

Bei Besteuerung nach dem Wohnsitzlandprinzip wird auf Seiten des Kapitalanbieters, nicht aber bei den Kapitalnachfragern eine Steuer erhoben. Deshalb entsprechen die beobachteten Marktzinssätze $r$ und $r$ in dieser Umwelt den Grenzproduktivitäten des Kapitaleinsatzes im Inland gp und im Ausland gp*.

Zur Vereinfachung der Darstellung wird Sicherheit hinsichtlich ihrer Höhe unterstellt. Da in diesem Abschnitt von einer symmetrischen Besteuerung des Währungsergebnisses ausgegangen wird, ist es hier auch unproblematisch, die gleiche Annahme über die Entwicklung des Wechselkurses zu treffen: Der Devisenkurs wird sich mit der Rate $\Delta \mathrm{e}=\mathrm{e}_{+1} / \mathrm{e}$ ändern. ${ }^{129}$

Notwendige Voraussetzung für weltweit effizienten Kapitaleinsatz ist unter den hier getroffenen Annahmen, daß die Grenzproduktivitäten des Faktors in einer Beziehung zueinander stehen, die durch die Zinsparität - also durch Gleichung [B9] - beschrieben wird, da an der Quelle keinerlei Steuern erhoben werden. Es muß deshalb gelten:

$$
1+\mathrm{gp}=\Delta \mathrm{e} \cdot\left(1+\mathrm{gp}^{*}\right)
$$

Der inländische Kapitalanbieter werde nun aber mit einer Kapitaleinkommensteuer in Höhe von $\tau$ belastet. Die einperiodige Grenzinvestition dieses Sparers im eigenen Land wird deshalb einen Endwert ergeben, der neben dem eingesetzten Kapital einen Grenzertrag ge umfaßt, der der um die Steuer geminderten Grenzproduktivität entspricht, beziehungsweise

$$
\mathrm{ge}=\mathrm{gp} \cdot(1-\tau) \text {. }
$$

Der Ertrag bei grenzüberschreitendem Einsatz seines Kapitals hat demgegenüber zwei Bestandteile, nämlich zum einen den ausländischen Gewinn und zum anderen einen Währungsgewinn oder -verlust beim exportierten Kapital:

Auf eine Einheit exportierten Kapitals erzielt der inländische Anbieter im Falle der Grenzinvestition einen Gewinn in ausländischer Währung von genau $\mathrm{gp}^{*}$. In der inländischen Währung wird dieses Ergebnis durch die Rate der Wechselkursänderung erhöht oder reduziert. Es verbleiben $\Delta \mathrm{e} \cdot \mathrm{gp}$, die am Wohnsitz der Kapitaleinkommensteuer unterliegen.

nehmung in ihrer gesellschaftlichen Umwelt, Hrsg. P. Mertens, Wiesbaden 1975, S.240; so auch P. Gurtner, Inflation, Nominalwertprinzip und Einkommensteuerrecht, 1.Aufl., Bern u. Stuttgart 1980., S.87.

129 Diese Annahme ist nicht ganz unproblematisch. Gemäß dem sogenannten Siegel-Paradox gilt nämlich bei Unsicherheit aus der Sicht ausländischer Marktteilnehmer: $E\left[\mathrm{e} / \mathrm{e}_{+1}\right]>\mathrm{e} / E\left[\mathrm{e}_{+1}\right]$. J.J. Siegel, Risk, Interest Rates and the Forward Exchange, in: Quarterly Journal of Economics, 86.Jg. (1972), S.304. Deshalb ist bei positiver Varianz der Erwartungswert der Wechselkursänderung aus der Sicht der Inländer nicht identisch mit dem Erwartungswert aus dem Blickwinkel ausländischer Kapitalanbieter. Beispielsweise bedeutet ein Anstieg des Devisenkurses um $10 \%$ aus der Sicht inländischer Kapitalanbieter für ausländische Sparer einen geringeren Rückgang des Devisenkurses um nur $1,1^{-1}=9,1 \%$. Allerdings wird diese Differenz als vernachlässigbar klein angesehen. J.H. McCulloch, Operational Aspects of the Siegel Paradox, in: Quarterly Journal of Economics, 89.Jg. (1975), S. 172. 
Die Wechselkursänderung beeinflußt aber auch den Endwert des exportierten Kapitals. Von einer Einheit eingesetzten Kapitals verbleibt am Periodenende genau $\Delta \mathrm{e}$. Der daraus resultierende Währungsgewinn oder -verlust von $(\Delta \mathrm{e}-1)$ werde im Wohnsitzland mit einem Steuersatz $\tau_{e}$ belastet. Dessen Höhe steht hier in Frage.

Der Endwert des inländischen Sparers bei einer ausländischen Grenzinvestition ergibt sich durch Zusammenfügen der beiden Teile des Gewinns:

[B11b]

$$
\text { ge }=(\Delta \mathrm{e}-1) \cdot\left(1-\tau_{\mathrm{e}}\right)+\Delta \mathrm{e} \cdot \mathrm{gp} \cdot(1-\tau)
$$

Der Kapitalanbieter ist nur dann indifferent gegenüber der in- und der ausländischen Anlagealternative, wenn der zu erwartende Gewinn in beiden Fällen identisch ist. Deshalb resultiert die Arbitragebedingung des risikoneutralen inländischen Sparers durch Gegenüberstellung des Grenzertrags der in- und ausländischen Investition:

$$
\mathrm{gp} \cdot(1-\tau) \stackrel{!}{=}(\Delta \mathrm{e}-1) \cdot\left(1-\tau_{\mathrm{e}}\right)+\Delta \mathrm{e} \cdot \mathrm{gp}^{*} \cdot(1-\tau) \text {. }
$$

Es ist hier offenkundig, daß ein Gleichgewicht genau dann gegeben ist, wenn das Währungsergebnis wie andere Kapitalgewinne im Wohnsitzland der Einkommensteuer unterliegt, wenn also $\tau_{e}=\tau$ gilt. ${ }^{130}$ Denn nur in einem solchen Steuerregime ist das Kriterium für Kapitalexportneutralität, Gleichung [B10] erfüllt. Dies wird durch einfaches Herauskürzen der Steuersätze $\tau$ und $\tau_{\mathrm{e}}$ sichtbar.

Dieses Ergebnis leuchtet ein: Führt in einer Welt ohne Steuern bei Gleichgewicht auf dem Devisenmarkt das kleine Inland eine Einkommensteuer ein, besteht für den risikoneutralen Kapitalanbieter danach kein Anreiz zur Substitution von Anlagealternativen, wenn alle Bestandteile des Einkommens - also auch das Währungsergebnis - in gleichem Maße reduziert werden. ${ }^{131}$ Er trägt die Last der Steuer allein und Kapitalexportneutralität ist gewahrt.

${ }^{130}$ M.B. Levi, a.a.O., S.641; J. Bourne Wahl, Taxation of Foreign Exchange Gains and Losses, a.a.O., S.4-6; Vgl. auch R.H. Gordon, Taxation of Investment and Savings in a World Economy, in: American Economic Review, 76.Jg. (1986), S.1090; J.S. Alworth, The Finance, Investment and Taxation Decisions of Multinationals, New York 1988, S.147; A. Giovannini, National Tax Systems versus the European Capital Market, in: Economic Policy, 8.Jg. (1989), S.365.

${ }^{131}$ Die Annahme risikoneutraler Marktteilnehmer bleibt unbefriedigend. Würde aber statt dessen Risikoaversion unterstellt, würde eine Analyse der Neutralitätskriterien sehr komplex werden und nur noch von theoretischem Interesse sein können. Hinzukommt, daß ,keine einheitliche Meinung über die grundsätzliche Natur des Wechselkursrisikos besteht, daß es keine adäquate Methode gibt, es zu messen und kein Modell, da $\beta$ eine angemessene gleichgewichtige Risikoprämie determiniert.“ R. M. Levich, a.a.O., S. 1024.

Sind Kapitalanbieter risikoavers, werden sie eine Anlage mit sicherer Rendite einer unsicheren Alternative mit gleichem Erwartungswert vorziehen. Unsichere Investitionen werden dann nur durchgeführ, wenn der erwartete Gewinn höher ist als die risikofreie Verzinsung. Diese Risikoprämie ist abhängig von der Unsicherheit über den erwarteten Ertrag und den Präferenzen der Sparer. Die Prämie ist eine positive Funktion des Risikos. K.J. Arrow, The Theory of Risk Taking, in: Essays in The Theory of Risk Bearing, Hrsg. K.J. Arrow, Amsterdam u.a. 1970, S.90-120.

Die Kapitalallokation ist bei Risikoaversion von zwei Parametern abhängig, da Kapitalanbieter ihre Anlageentscheidungen anhand ihrer Zeit- und ihrer Risikopräferenzen treffen. Wie E.D. Domar, u. R.A. Musgrave, Proportional Income Taxation and Risk-Taking, in: Quarterly Journal of Economics, 59.Jg. (1944), S.388-422 gezeigt haben, hat eine allgemeine Einkommensteuer Einfluß auf beide Parameter. Für die Wirkung der Steuer ist - neben der Ausgestaltung der Verlustausgleichsmöglichkeiten - das Vorzeichen der zweiten Ableitung der Präferenzfunktion bezüglich des Risikos entscheidend, das heißt die Elastizität der Risikobereitschaft der Kapitalanbieter in Bezug auf die Risikoprämie (beziehungsweise die Ertragserwartungen). Vgl. auch D. Schneider, Gewinnbesteuerung und Risikobereitschaft: Zur Bewährung quantitativer Ansätze in der Entscheidungstheorie, in: Zeitschrift für betriebswirtschaftliche Forschung, 29. Jg. (1977), S.433-466; K.A. Konrad, Kapitaleinkommensteuer und beschleunigte Abschreibungen bei Unsicherheit, Münchener wirtschaftswissenschaftliche Beiträge, Nr.89-08, München 1989. 
Würden indes Währungsgewinne nicht oder geringer als andere Kapitaleinkünfte besteuert beispielsweise weil sie als Veräußerungsgewinne qualifiziert werden -, wäre die grenzüberschreitende Investition relativ zur Anlage im Inland attraktiver, wenn ein ansteigender Kurs antizipiert wird. Der Vorteil des steuerfreien Währungsgewinns fällt dem inländischen Sparer zu, da sich ihm unbegrenzte Anlagemöglichkeiten im Ausland bieten. Im Extremfall würde er infolgedessen sein Kapital zur Gänze exportieren. Der inländische Kapitalnachfrager muß dann auf das ausländische Angebot zurückgreifen, was hier freilich ebenfalls ohne Einschränkung und zu konstanten Kapitalkosten zur Verfügung steht.

Wird der Devisenkurs zurückgehen, wäre andererseits zunächst die Investition im Inland günstiger, weil der Währungsverlust nicht durch die Besteuerung entsprechend gemindert wird. $\mathrm{Ob}$ dies tatsächlich zu einer Belastung der Anbieter oder aber zu einer Begünstigung der inländischen Nachfrager führt, bleibt dabei allerdings offen:

Ist das Land Nettoimporteur von Kapital, können die Kapitalanbieter ihre gesamte Ersparnis im Inland einsetzen. Auch wenn dies geschieht, sind die Kapitalnachfrager aber auf den Import des Faktors angewiesen. Sie werden sich daher im Wettbewerb um das knappe inländische Angebot solange überbieten, bis die Kapitalkosten das Niveau bei ausländischer Finanzierung erreichen. Die formale Belastung durch Freistellung von Währungsverlusten hat also keine materiellen Auswirkungen, da Kursverluste gar nicht anfallen müssen. Sind die alternativen Kapitaleinsatzmöglichkeiten homogen, was hier unterstellt wird, ist Kapitalexportneutralität durch die inländische Besteuerung nicht verletzt.

Ist das Land dagegen Nettokapitalexporteur, sinken die Kapitalkosten inländischer Nachfrager in Abhängigkeit des Währungsverlusts. Die letzte Einheit des inländischen Angebots muß in dieser Situation nämlich im Ausland eingesetzt werden. Deshalb werden die Sparer um die knappen inländischen Anlagemöglichkeiten konkurrieren. Der Nachteil des steuerfreien Währungsverlusts wird hier zum Vorteil auf Seiten der Nachfrager im Wohnsitzland.

Die Wirkung der Steuer auf die Kapitalallokation ist auf Grund dessen eine Funktion der erwarteten Währungsentwicklung.

Der Grundgedanke ist einfach: Ist der Staat mittels der Ertragsteuer an Gewinnen und Verlusten einer Investition beteiligt, reduziert sich das Risiko der Kapitalgeber. Offen bleibt die Frage, welche Folgen das Risiko in staatlichen Händen hat. Die Annahme einer pauschalen Rückzahlung funktioniert hier nicht, da dieser Zahlungsstrom unsicher sein muß und deshalb nicht nur einen Einkommenseffekt zur Folge haben wird.

Ist die erwartete Wechselkursentwicklung unsicher, müßte Kapitalexport und Kapitalimport nur stattfinden können, wenn der erwartete Ertrag von Auslandsinvestitionen um eine angemessene Risikoprämie höher ist als die Verzinsung im Inland. Die Existenz einer solchen Prämie würde implizieren, daß der aus der - sicheren gedeckten Zinsparität resultierende Terminkurs $f_{+1}$ niedriger ist als der erwartete Devisenkurs $E\left[e_{+1}\right]$. R.M. Levich, a.a.O., S.1032; R. MacDonald u. M.P. Taylor, a.a.O., S.29f.. Eine derartige Prämie ist aber nur aus der Sicht eines Landes denkbar, denn eine positive Prämie im Inland impliziert für ausländischer Sparer eine negative Prämie.

Andererseits gilt, ,jede internationale Geldleihe muß immer zugleich auch internationale Güterleihe sein." O. Sievert, Gibt es eine Alternative zu flexiblen Wechselkursen?, in: Wirtschaftsdienst, 66. Jg. (1986), S.338. Infolgedessen müßte sich die intertemporale internationale Kapitalallokation wenigstens teilweise an den Präferenzen in Abhängigkeit der erwarteten Güterpreise zum geplanten Konsumzeitpunkt orientieren. Eine Risikoprämie für Auslandsinvestitionen wäre dann abhängig von der Kovarianz der gesamten Rendite aus der Anlage mit dem Grenznutzen des Zukunftskonsums von Gütern, die in der Anlagewährung gehandelt werden. Auf gleiche Weise hätte aber auch Unsicherheit über die Entwicklung der Preise alternativer inländischer Konsumgüter Einfluß. Vgl. R.M. Levich, a.a.O., S.1033 und die dort angegebene Literatur, sowie D.T. Breeden, An Intertemporal Asset Pricing Model with Stochastic Consumption and Investment Opportunities, in: Journal of Financial Economics, 7.Jg. (1979), S.265-296. „Dieses Modell legt nahe, daß die Risikoprämie kurzfristig das Vorzeichen wechseln kann“. R.M. Levich, a.a.O., S.1033. Die Prämie müßte dann auch geringer sein, als es die isolierte Betrachtung der Volatilität der Devisenkurse nahelegt. Und etwaige Auswirkungen der Besteuerung dieser Risikoprämie auf die internationale Allokationsneutralität einer Einkommensteuer bleiben unbestimmt. 
Ist aber mit der Besteuerung des Währungsergebnisses im Inland schon gewährleistet, daß international effizienter Kapitaleinsatz nicht behindert wird? Diese Anforderung ist für ein Land notwendig. Sie ist aber nicht mehr hinreichend, sobald in den anderen Staaten Kapitaleinkommen ebenfalls steuerpflichtig ist. Auch das Einkommen der ausländischen Sparer aus grenzüberschreitendem Einsatz des Faktors wird durch die Wechselkursentwicklung beeinflußt. Auch im Ausland müssen deshalb Währungsgewinne und -verluste wie Kapitaleinkommen besteuert werden. Andernfalls ist es im Falle einer Kursänderung nicht denkbar, daß sowohl inländische als auch ausländische Kapitalanbieter indifferent gegenüber dem Einsatzort ihres Kapitals sind. Es existiert kein Arbitragegleichgewicht, das die Alternativen der vier Marktteilnehmer - der in- und ausländischen Kapitalbieter und Kapitalnachfrager - zum Ausgleich bringt. ${ }^{132}$ Lediglich wenn ein konstanter Wechselkurs antizipiert würde, wäre die steuerliche Behandlung des Währungsergebnisses offensichtlich irrelevant.

Die Zusammenhänge werden durch das folgende Beispiel deutlich:

Beispiel B2:

Das Einkommen des inländischen Sparers aus Beispiel B1 (Seite 45) wird am Wohnsitz mit einer Steuer in Höhe von $\tau=0,35$ belastet. Das Ausland erhebt eine entsprechende Steuer von $\tau^{*}=0,55$ auf das Einkommen seiner ausländischen Kapitalanbieter. Das steuerpflichtige Einkommen umfaßt bei beiden Ländern auch Währungsgewinne und -verluste.

Da auf Seiten der Kapitalnachfrager nicht besteuert wird, entspricht das unterstellte Zinsniveau im Inland von $10 \%$ und im Ausland von $7 \%$ der jeweiligen Grenzproduktivität. Die beiden Werte werden durch die Steuer nicht verzerrt, wenn sie in einer Beziehung entsprechend der Zinsparität zueinander stehen, das heißt wenn wiederum

$$
\Delta \mathrm{e}=\frac{1+\mathrm{gp}}{1+\mathrm{gp}^{*}}=\frac{1,1}{1,07}=1,02804
$$

Bei dieser Kursentwicklung ist der inländische Kapitalanbieter indifferent hinsichtlich des Einsatzortes seines Kapitals, denn der Grenzertrag beträgt sowohl für die inländische Investition

als auch für die ausländische Alternative

$$
\mathrm{ge}=\mathrm{gp} \cdot(1-\tau)=0,1 \cdot(1-0,35)=6,5 \%
$$

$$
\begin{aligned}
\text { ge } & =(\Delta \mathrm{e}-1) \cdot(1-\tau)+\Delta \mathrm{e} \cdot \mathrm{gp}^{*} \cdot(1-\tau) \\
& =0,2804 \cdot(1-0,35)+1,2804 \cdot 0,07 \cdot(1-0,35)=6,5 \% .
\end{aligned}
$$

In der gleichen Situation sieht sich der ausländische Sparer. Bei einer Anlage im eigenen Land wird er einen Grenzertrag von

$$
\mathrm{ge}^{*}=\mathrm{gp}^{*} \cdot\left(1-\tau^{*}\right)=0,07 \cdot(1-0,55)=3,15 \%
$$

und ebenso bei der grenzüberschreitenden Investition von

$$
\begin{aligned}
\text { ge }^{*} & =\left(\Delta \mathrm{e}^{-1}-1\right) \cdot\left(1-\tau^{*}\right)+\Delta \mathrm{e}^{-1} \cdot \mathrm{gp} \cdot\left(1-\tau^{*}\right) \\
& =-0,0273 \cdot(1-0,55)+0,9727 \cdot 0,1 \cdot(1-0,55)=3,15 \%
\end{aligned}
$$

erzielen können.

Das Arbitragegleichgewicht der gefundenen Daten in diesem Beispiel wird in der folgenden Abbildung B6 veranschaulicht:

132 Vgl. M.D. Levi, a.a.O., S.638-643. 
Abb. B6: Arbitragegleichgewicht bei Wohnsitzland- und Nominalwertprinzip

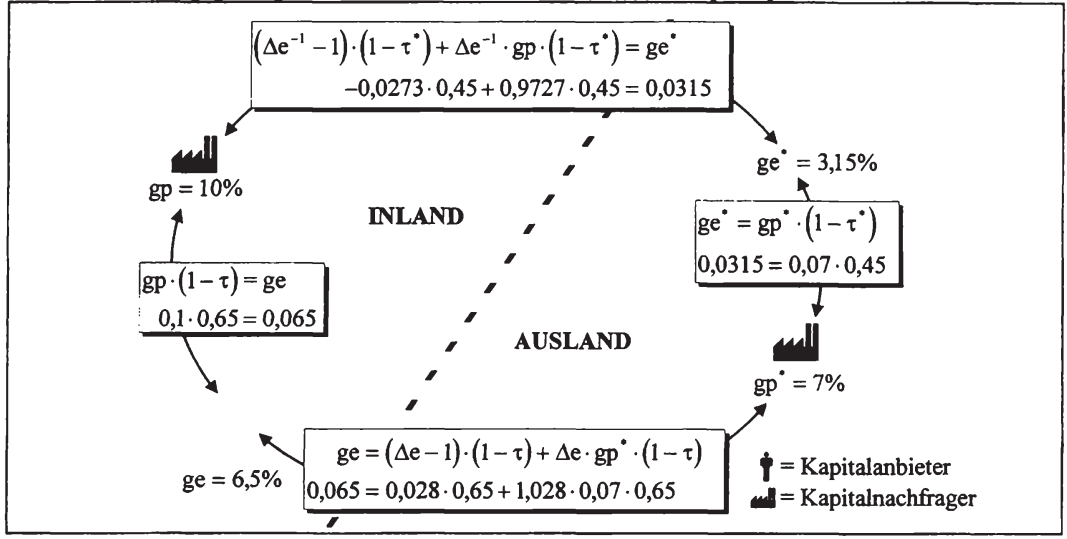

Quelle: Eigene Darstellung.

Die Kapitalnachfrager sind indifferent gegenüber der Herkunft des Kapitals, da die Währungsentwicklung die Unterschiede der Kosten für Kapital in- und ausländischer Herkunft kompensiert. Auch die Sparer sehen hier keinen Anlaß zur Substitution. Dies verdeutlicht, daß die Form der Besteuerung ein Gleichgewicht zwischen den Marktteilnehmern ermöglicht. Es bestehen keine Konflikte zwischen den Arbitragemöglichkeiten.

Wäre das Währungsergebnis in einem der beiden Länder dagegen steuerfrei, könnte der Kreis nicht geschlossen werden. Eine effiziente Allokation des Faktors Kapital würde unter diesen Umständen durch die Besteuerung nur dann nicht behindert, wenn für die Kapitalgeber dieses Landes Kapitalexport weder notwendig, noch die Substitution inländischer gegen ausländische Anlagen attraktiv ist: wenn ein Kursrückgang antizipiert wird und das Land Nettokapitalimporteur ist.

\section{ß) Freistellung von Scheingewinnen}

Der Wechselkurs ist das Austauschverhältnis zweier Währungen. Es liegt also nahe, auch der Frage nachzugehen, wie Neutralität in einem Steuersystem möglich ist, das im Inland solche Erträge nicht besteuert, die nur durch den Kaufkraftverlust der Währungen im Verlauf der Besteuerungsperiode begründet sind. ${ }^{133}$

Zur Klärung der Frage ist zunächst erforderlich, das nominale Zinsniveau in die zwei Teile Kompensation für die Überlassung des Kapitals und für die Geldentwertung - aufzuspalten. Gemäß der Fisher-Hypothese ist das reale Zinsniveau $r^{r}$ unabhängig von der Inflationsrate. ${ }^{134}$ Demgemäß errechnet sich die nominale Ertragsrate $1+r^{n}$ durch multiplikative Verknüpfung des realen Zinsniveaus $1+r^{s}$ mit der Inflationsrate $1+i$ :

133 Die Belastung von inflationsbedingten Scheingewinnen wurde von Gandenberger als Argument gegen Kapitalexportneutralität angeführt. O. Gandenberger, Kapitalexportneutralität versus Kapitalimportneutralität, a.a.O., S. 13.

134 I. Fisher, The Theory of Interest. New York 1930. 


$$
1+\mathrm{r}^{\mathrm{n}}=(1+\mathrm{i}) \cdot\left(1+\mathrm{r}^{\mathrm{r}}\right) \cdot 135
$$

Der inländische Kapitalanbieter muß in diesem Steuersystem nur auf seine realen Kapitaleinkünfte am Wohnsitz Einkommensteuer zahlen. Als Endwert der einperiodigen Grenzinvestition im Inland ergibt sich aus dessen Sicht:

$$
\begin{aligned}
1+\mathrm{ge} & =(1+\mathrm{i}) \cdot\left(1+\mathrm{gp}^{\mathrm{r}} \cdot(1-\tau)\right) \\
& =1+\mathrm{gp}^{\mathrm{n}} \cdot(1-\tau)+\mathrm{i} \cdot \tau,
\end{aligned}
$$

wobei $\mathrm{gp}^{\mathrm{r}}$ die reale und $\mathrm{gp}^{\mathrm{n}}$ die nominale inländische Grenzproduktivität darstellen. Trotz der multiplikativen Verknüpfung der Raten der realen Grenzproduktivität und der Inflation ist die Freistellung von Scheingewinnen bei der inländischen Investition einfach durch Abzug der Geldentwertung von der Bemessungsgrundlage zu erreichen, wie Gleichung [B12] nach der Umstellung in der zweiten Zeile zeigt.

Es liegt deshalb die Schlußfolgerung nahe, daß auch im Falle einer ausländischen Investition des inländischen Kapitalgebers so zu verfahren ist. Das heißt, die inländische Geldentwertung muß von dem ausländischen Gewinn - dem nominalen im Ausland erzielten Kapitaleinkommen und dem Währungsergebnis - abgezogen werden. Formal: die Arbitragebeziehung inländischer Kapitalanbieter, Gleichung [B11], wird auf beiden Seiten um i $\cdot \tau$ erweitert.

Wie im Rahmen des Nominalwertprinzip gezeigt wurde, ist es zur Wahrung von Kapitalexportneutralität notwendig, Währungsgewinne und -verluste zu besteuern. Unter diesen Umständen reduziert die Einkommensteuer den Gewinn bei in- und ausländischen Investitionsalternativen proportional, und die Gültigkeit der Zinsparität wird durch die Steuer nicht verletzt. Eine Freistellung von Scheingewinnen kann auf Grund dessen aber auch nur an die inländische Inflation anknüpfen, weil nur eine gleiche Veränderung des Ergebnisses aller Anlagealternativen das Arbitragegleichgewicht nicht verändert. ${ }^{136}$ Die Steuerbelastung der Gewinne aller Anlagealternativen wird in diesem Fall um einen Betrag in absolut gleicher Höhe gemindert, der sich aus der inländischen Inflationsrate, multipliziert mit dem Steuersatz, errechnet.

Die Rate der Geldentwertung im Ausland ist für kapitalexportneutrale Besteuerung im Inland somit irrelevant.

Deshalb ist das mit kapitalexportneutraler Besteuerung angestrebte Ziel, die effiziente Allokation des Faktors Kapital nicht zu behindern, auch dann erreichbar, wenn die Staaten in bezug auf die Behandlung von Scheingewinnen unterschiedlich verfahren. Würde beispielsweise das Ausland auf dem Nominalwertprinzip bestehen, würde lediglich der Grenzertrag des ausländischen Kapitalanbieters für alle Anlagealternativen in Abhängigkeit der dortigen Inflationsrate geringer ausfallen. Hinsichtlich der einkommensteuerlichen Behandlung des Währungsergebnisses gelten ansonsten die Überlegungen des vorangegangenen Unterabschnitts $\alpha$ ) analog.

135 V. Tanzi, Inflation and the Personal Income Tax: An International Perspective, Cambridge, Mass. u.a., 1980, S.52f..

Der Endwert einer Investition mit einem Barwert $\mathrm{BW}$ beträgt in $\mathrm{t}=1$ zum Geldwert von $\mathrm{t}=0: \mathrm{EW}=\mathrm{BW} \cdot\left(1+\mathrm{r}^{\mathrm{r}}\right)$; der nominale Endwert beträgt: $E^{n}=B W \cdot\left(1+r^{n}\right)$. Somit muß auch gelten: $E W^{r} \cdot\left(1+r^{n}\right)^{-1}=E^{n} \cdot\left(1+r^{n}\right)^{-1}$. Die Beziehung zwischen realen und nominalen Größen ist $E^{n}=E W^{r} \cdot(1+i)$. Deshalb folgt: $1+r^{n}=(1+i) \cdot\left(1+r^{n}\right)$.

136 Wenn beide Länder das Währungsergebnis freistellen, werden - bei Annahme einer Währungsentwicklung gemäß Kaufkraftparität - in dem Land mit der höheren Inflationsrate auch die realen Kapitalkosten höher sein: Ist z.B. die Inflationsrate im Inland höher, werden inländische Kapitalanbieter versuchen, ihr Kapital im Ausland einzusetzen, weil grenzüberschreitender Kapitaleinsatz durch den steuerfreien Währungsgewinn begünstigt wird. Aber auch ausländische Sparer wollen in ihrem Land investieren, um steuerlich unwirksame Währungsverluste zu vermeiden. Ein Gleichgewicht ist hierbei nicht möglich, eine Angleichung der Ertragsraten setzt gleichwohl eine höhere Grenzproduktivität im Inland voraus. R. H. Gordon, a.a.O., S. 1090f.. 
Deshalb ist auch die Freistellung von Scheingewinnen in einer offenen Volkswirtschaft mit dem Ziel der Kapitalexportneutralität wenigstens unter den in diesem Teil getroffenen Annahmen nicht mit zusätzlichen Problem behaftet.

Unbeantwortet bleiben kann hier ebenfalls die Frage nach der Ermittlung der Rate der inländischen Geldentwertung, weil der Betrag, um den die Steuerlast gemindert wird, nicht abhängig vom Einsatzort des Kapitals ist.

Unbedeutend ist in diesem Zusammenhang aber auch, daß die Entwicklung des Außenwertes einer Währung in Grenzen nur durch die Preisänderungen handelbarer Güter geprägt wird, neutral in bezug auf die Präferenzen der Kapitalanbieter dagegen eine Indexierung anhand der Inflationsrate ist, die deren Warenkorb widerspiegelt (soweit sie überhaupt zinselastisch sind): Vergleichbar mit den Überlegungen zu dem Wettbewerbs- und dem Umwechslungseffekt auf Seiten der Unternehmung sind nämlich auch an dieser Stelle die Entscheidungen über die Verwendung der Ersparnis und über den Einsatzort des Kapitals zu trennen. Im ersten Fall ist die Grundlage ein gegebenes Güterbündel zu einem Zeitpunkt. Die relativen Preise sind in diesem Moment unabhängig von der Währungsentwicklung. Im zweiten Fall steht ein Entschluß für einen Zeitraum an. Die antizipierte Wechselkursänderung ist hier wirtschaftlich betrachtet Bestandteil der Kompensation für die Überlassung des Kapitals in einem bestimmten Währungsraum. Würde etwa ein Währungsgewinn antizipiert, der den Gesamtgewinn ausländischer Anlagen gegenüber inländischen Alternativen attraktiver erscheinen läßt, werden rational handelnde (risikoneutrale) Kapitalanbieter diese Alternative unabhängig von ihren Präferenzen bezüglich der Nachfrage nach Gütern und Dienstleistungen realisieren wollen. ${ }^{137}$

Nicht geklärt ist in dem Zusammenhang dieser Arbeit allerdings noch der Begriff des Wohnsitzes bei Kapitalanbietern, die Lebensmittelpunkte in mehr als einem Währungsraum haben. Müßte für diese Personen die Änderung an Kaufkraft von Einkommen und Vermögen durch (i) Inflation und (ii) Wechselkursentwicklung in beiden Währungsräumen gegenübergestellt werden und der geringere Verlust an Geldwert bei der Bemessung des einkommensteuerpflichtigen Zuwachses an ökonomischer Verfügungsmacht abgezogen werden?

Gleiches gilt für Personen, die in der Nähe der Grenze zwischen zwei Währungsräumen wohnen oder gar Grenzpendler sind. Diesem Gedanken folgend müßte die Indexierung sich an der für die Steuerpflichtigen günstigeren Entwicklung von (i) und (ii) orientieren. Zölle und andere Transaktionskosten wären allerdings zu berücksichtigen. ${ }^{138}$

Eine ähnlich gelagerte Schwierigkeit tritt auch im Nominalwertprinzip auf, weil ein Währungsgewinn oder -verlust augenscheinlich von der Währung abhängig ist, in der er gemessen wird. Dies müßte die Währung sein, in der der Sparer seine Allokationsentscheidung trifft. Im allgemeinen - und davon wird in dieser Arbeit ausgegangen - ist dies das Zahlungsmittel des Wohnsitzlandes. Ist ein Lebensmittelpunkt eindeutig identifizierbar, spielt es keine Rolle, ob der Steuerpflichtige plant, einzelne Güter oder Dienstleistungen in einer anderen Währung nachzufragen. Der Grund hierfür wurde schon genannt: die Entscheidungen über die Verwendung der Ersparnis und über den Einsatzort des Kapitals sind voneinander unabhängig. Im Kern ist geht es dabei nämlich auch um die Frage nach der Ermittlung der den individuellen Präferenzen entsprechenden Rate der Geldentwertung - gemessen in der Währung, in der die Steuer zu entrichten ist.

${ }^{137}$ Diese Schlußfolgerung ist für risikoaverse Kapitalanbieter nicht zwingend. Denkbar ist, daß sie ihre Anlageentscheidungen auch im Hinblick auf ihren geplanten Konsum treffen. Planen sie, einen Teil der Güter in einer fremden Währung nachzufragen, kann das Wechselkursrisiko reduziert werden, indem schon die Ersparnis in diesem Währungsraum eingesetzt wird. Vgl. auch Fußnote 131 auf Seite 49 dieser Arbeit.

138 Vgl. hierzu auch P. Musgrave, Exchange Rate Aspects, a.a.O., S.409 f.. 
Im besonderen kann dies bei Wirtschaftssubjekten, die keinen eindeutigen Lebensmittelpunkt in einem Währungsraum haben, dennoch kritisch sein. Der Maßstab der Allokationsentscheidung ist unbestimmt. Es kann nicht ausgeschlossen werden, daß ein Währungsgewinn oder -verlust in den Augen des Steuerpflichtigen gar keine Veränderung an Verfügungsmacht darstellt, weil er die Verfügungsmacht in der aus der Sicht des besteuernden Staates fremden Währung ausüben will.

Aber: auch diese Frage berührt nicht die Entscheidung über den Kapitaleinsatz, sondern die intertemporalen Folgen der Kapitaleinkommensbesteuerung und Fragen hinsichtlich der Steuergerechtigkeit. Denn ungeachtet des Lebensmittelpunktes des Steuerpflichtigen werden die Erträge aller Anlagealternativen dieses Kapitalanbieters in gleichem Maße belastet, wenn die Bemessungsgrundlage in einer Währung ermittelt wird.

Deshalb ist es in dieser Arbeit legitim, von einem einzigen Wohnsitz auszugehen.

\section{b) Besteuerung nach dem Quellenlandprinzip}

Die Besteuerung nach dem Quellenlandprinzip behindert die weltweit optimale Aufbringung des Faktors Kapital nicht, wenn jedes Land die Erträge des in seinem Land eingesetzten Kapitals gleichermaßen belastet. Inwieweit aber sollten dabei auch Währungsgewinne und -verluste einbezogen werden?

Die Steuer wird hier an der Quelle auf Seiten der Kapitalnachfrager erhoben. Im Wohnsitzland bleibt das Einkommen der Kapitalanbieter steuerfrei. Die beobachtbaren Marktzinssätze im Inland $\mathrm{r}$ und im Ausland $\mathrm{r}^{*}$ sind somit jetzt die relevanten Sätze aus der Sicht der Kapitalanbieter, das heißt sie entsprechen in einer Umwelt der Kapitalimportneutralität den Grenzerträgen ge beziehungsweise ge des im jeweiligen Land angebotenen Kapitals.

Auch hier wird mit dem Ziel einer einfacheren Darstellung Sicherheit hinsichtlich der Grenzproduktivitäten und der Währungsentwicklung unterstellt.

Notwendige Voraussetzung für eine Besteuerung, die die optimale Aufbringung des Faktors Kapital nicht behindert, ist hier, daß die Grenzerträge des Kapitaleinsatzes in allen Ländern in einem Verhältnis zueinander stehen, das durch die Zinsparitätenbeziehung -also durch Gleichung [B9] - beschrieben wird. Deshalb muß gelten:

$$
1+\mathrm{ge}=\Delta \mathrm{e} \cdot\left(1+\mathrm{ge}^{*}\right) \text {. }
$$

Bei dem Kapitalnachfrager im Inland werde nun eine Quellensteuer mit einem Satz von t erhoben. Ist das Land wiederum klein, sind für den Investor die Kapitalkosten auf dem Weltmarkt konstant. Da die inländischen Kapitalanbieter nicht besteuert werden, können sie dieser Quellensteuerlast ausweichen, indem sie ihr Kapital im Ausland einsetzen. Das heißt, daß allein der inländische Kapitalnachfrager die Last der Steuer tragen muß. Wenn das Kapital in der Währung des Quellenlandes aufgenommen wurde, ist für eine Besteuerung von Währungsgewinnen oder -verlusten deshalb hier kein Raum, denn die übrigen Marktteilnehmer bleiben von der Steuer unberührt. Im Vergleich zur steuerfreien Ausgangslage sind ja nur die Kapitalkosten des inländischen Investors angestiegen. ${ }^{139}$

${ }^{139}$ Falls dagegen (Fremd-)Kapital in der Währung des Auslandes aufgenommen wird, sind Kursgewinne und -verluste bei der Besteuerung des Kapitalnachfragers zu berücksichtigen. Analog zu der Argumentation im Text hier kann im übrigen gezeigt werden, daß im Rahmen des Wohnsitzlandprinzips bei der entsprechenden Finanzierungsbeziehung ein Währungsergebnis im Quellenland nicht zu besteuern ist. Wie einleitend gesagt, werden 
Dabei ist es gleichgültig, ob die Quellensteuer auf die realen Gewinne beschränkt wird, oder ob sie auch Scheingewinne einschließt. Im zweiten Fall ist lediglich die Belastung des inländischen Kapitalnachfragers in Abhängigkeit von der Höhe der Inflationsrate entsprechend höher.

Freilich wäre die Besteuerung eines solchen Währungsergebnisses im Quellenland nicht unbedingt naheliegend, wenngleich durchaus möglich. Eher schon könnte dies im Wohnsitzstaat geschehen. ${ }^{140}$ Wäre im Inland das Währungsergebnis auf Seiten der Kapitalgeber trotz der Freistellung ausländischer Einkünfte steuerpflichtig - etwa weil es als (nicht freigestellte) Veräußerungsgewinne qualifiziert oder den inländischen Einkünften zugerechnet wird-, wären die Auswirkungen spiegelbildlich zu den Folgen der Freistellung im Rahmen des Wohnsitzlandprinzips. Der Nachteil wird hier durch einen steuerpflichtigen Kursanstieg und nicht durch einen steuerfreien Kursrückgang verursacht. Die Steuer wäre in diesem Fall deshalb nur dann irrelevant, wenn für die Kapitalgeber des Inlands Kapitalexport weder notwendig, noch die Substitution inländischer gegen ausländische Anlagen attraktiv ist, also wenn das Land Nettokapitalimporteur ist und ein ansteigender Devisenkurs antizipiert wird.

Daß derartige antizipierte Währungsgewinne im Rahmen des Quellenlandprinzips nicht besteuert werden sollten, impliziert indes nicht zwingend eine generelle Freistellung von Währungsgewinnen. Notwendig ist lediglich, Erträge nicht zu besteuern, die durch die erwartete Devisenkursänderung $\Delta \mathrm{e}$ anfallen. Darüber hinausgehende Währungsgewinne könnten durchaus belastet werden, wenn Verluste - also alle kursänderungsbedingten positiven oder negativen Erträge, die infolge einer von $\Delta \mathrm{e}$ abweichenden Wechselkursentwicklung anfallen entsprechend uneingeschränkt steuermindernd geltend gemacht werden können. ${ }^{141}$ Mit anderen Worten: ist ein Währungsgewinn geringer als ex ante erwartet wurde, muß der Differenzbetrag zwischen dem erwarteten und dem ex post realisierten Gewinn die Bemessungsgrundlage reduzieren. Ist dies der Fall, bliebe der Erwartungswert unberührt und die Zinsparität würde nicht verletzt.

Allerdings erscheint ein derartiges Steuersystem kaum als praktikabel. Zwar wäre denkbar, antizipierte kursänderungsbedingte Erträge mit Hilfe der Terminkurse zu errechnen. Die Bestimmung der Bemessungsgrundlage ist aber sehr aufwendig, und zumindest für längere Zeiträume wird die Ermittlung eines fristenkongruenten Terminkurses schwierig sein. ${ }^{142}$

Auch für die Beurteilung des kapitalimportneutralen Steuersystems ist jedoch die Betrachtung eines Landes nicht hinreichend. Notwendig ist darüber hinaus ein entsprechendes Vorgehen im Ausland. Auch dort darf das Währungsergebnis nicht besteuert werden. Andernfalls ist ein Arbitragegleichgewicht nur denkbar, wenn Währungsgewinne oder -verluste nicht anfallen, also bei einem konstanten Kurs.

Beispiel B3:

Der Kapitalertrag wird im Inland und im Ausland mit einem Quellensteuersatz von $t=0,35$ beziehungsweise $t^{*}=0,55$ belastet.

Auf Seiten der Kapitalanbieter wird keine Steuer erhoben. Das Marktzinsniveau entspricht deshalb hier dem Grenzertrag ge beziehungsweise ge in den Ländern. Es liegt im Inland bei 6,5\% sowie im Ausland bei 3,15\% nominal.

diese Varianten im Text nicht erörtert. Sie spielen in der steuerrechtlichen Diskussion kaum eine Rolle und sind auch für die nachfolgende Analyse asymmetrischer Besteuerung nicht erforderlich.

${ }^{140}$ Diese Möglichkeit ist durchaus real existent, wie Teil D zum deutschen Steuerrecht zeigen wird.

${ }^{141}$ Das Ergebnis steht deshalb auch nicht im Widerspruch zu der in Fußnote 18 der Einleitung genannten Arbeit von Mertens (S.13), die ja von einer Reingewinnsteuer ausgeht. J.B. Mertens, a.a.O..

$142 \mathrm{~J}$. Bourne Wahl, Tax Treatment of Foreign Exchange Gains and Losses and the Tax Reform Act of 1986, in: National Tax Journal, 42.Jg. (1989), S.61. 
Eine optimale Aufbringung des Faktors ist deshalb gemäß Gleichung [B13] gewährleistet, wenn der Devisenkurs bis zum Ende der Periode mit der Rate

$$
\Delta \mathrm{e}=\frac{1+\mathrm{ge}}{1+\mathrm{ge}^{*}}=\frac{1,065}{1,0315}=1,03248
$$

ansteigt.

Wie die Berechnungen in der folgenden Abbildung B7 zeigen, existiert bei dieser Kursentwicklung ein Arbitragegleichgewicht zwischen den vier Marktteilnehmern im In- und Ausland. ${ }^{143}$ Die geforderte Grenzproduktivität beträgt unabhängig von der Herkunft des Faktors bei Kapitaleinsatz im Inland $\mathrm{gp}=10 \%$ und für Investitionen im Ausland $\mathrm{gp}^{*}=7 \%$.

Abb. B7: Arbitragegleichgewicht bei Quellenland- und Nominalwertprinzip

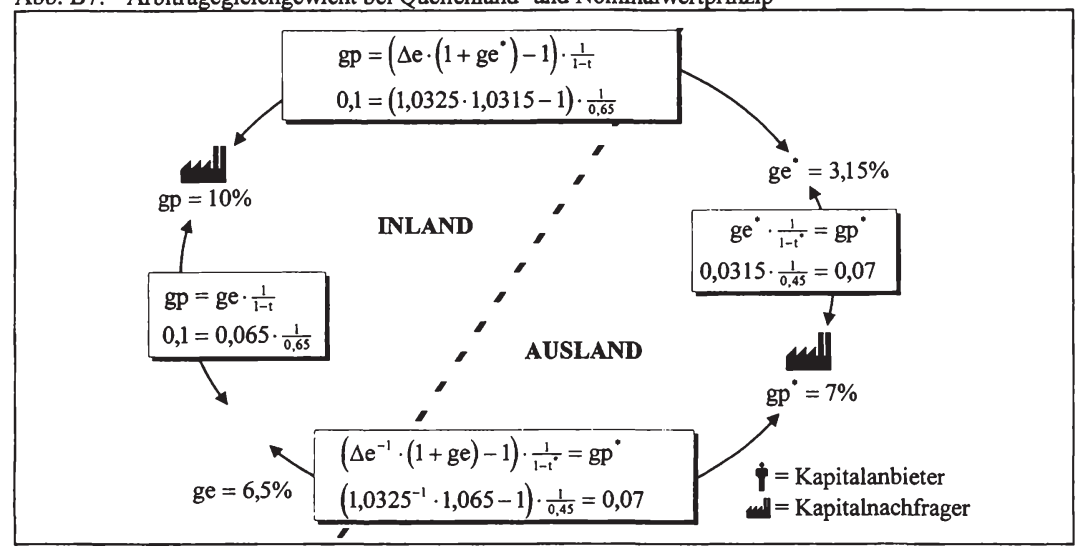

Quelle: Eigene Darstellung.

Bemerkenswert ist ein Vergleich dieser Ergebnisse mit dem Beispiel B2 auf Seite 52. Obgleich hier das Quellenlandprinzip und im anderen Fall das Wohnsitzlandprinzip unterstellt wird, sind im In- und Ausland die Grenzproduktivitäten mit 10\% beziehungsweise 7\% und die Grenzerträge mit $6,5 \%$ beziehungsweise $3,15 \%$ in beiden Rechnungen identisch. Nur die unterstellte Wechselkursentwicklung ist verschieden. In dem Beispiel B2 wurde ein Kursanstieg von 2,804\% unterstellt, hier hingegen ein stärkerer Anstieg von 3,25\%.

Ohne die Berücksichtigung flexibler Wechselkurse ist dieses Ergebnis nicht denkbar; bei Einführung einer Einkommensteuer in einem kleinen Land an der Quelle muß in entsprechender Höhe die Grenzproduktivität zunehmen, bei der Besteuerung des Sparers der Grenzertrag zurückgehen, weil die inländischen Marktteilnehmer Preisnehmer sind. Doch wie die Beispiele zeigen, ist es bei flexiblen Wechselkursen wenigstens rechnerisch möglich, daß die Währungsentwicklung die Unterschiede zwischen den beiden Besteuerungsprinzipien ausgleicht. Sowohl kapitalimportneutrale als auch kapitalexportneutrale Besteuerung wäre dann international neutral, falls weltweit einheitlich verfahren würde. Die Frage ist freilich, ob ein solcher Vergleich der Beispiele legitim ist. Mit anderen Worten: Ist die unterstellte Währungsentwicklung sinnvoll?

${ }^{143}$ Bei einer Quellensteuer gilt für die inländische Investition $1+\mathrm{gp} \cdot(1-\mathrm{t})=1+\mathrm{ge}$, daraus folgt $\mathrm{gp}=\mathrm{ge} \cdot \frac{1}{1-\mathrm{t}}$. Für die ausländische Investition gilt $\left.1+\mathrm{gp}^{-1} \cdot\left(1-\mathrm{t}^{*}\right)\right) \cdot \Delta \mathrm{e}=1+\mathrm{ge}, \mathrm{bzw} . \mathrm{gp}=\left(\Delta \mathrm{e}^{-1} \cdot(1+\mathrm{ge})-1\right) \cdot \frac{1}{1-t^{*}}$. 
Langfristig ist dies eindeutig zu verneinen: Langfristig wird die Währungsentwicklung - wie oben dargelegt - durch die Raten der in- und ausländischen Geldentwertung determiniert. Die Kaufkraftparität ist eine Arbitragebeziehung der Gütermärkte und als solche durch eine Kapitaleinkommensteuer zumindest direkt nicht veränderbar. In einem langfristigen Gleichgewicht, in dem das reale risikofreie Zinsniveau in den Ländern übereinstimmt, wird eine Form von Kaufkraftparität unabhängig von der Besteuerung des Kapitaleinkommens die Währungsentwicklung determinieren.144,145 Deshalb wird durch Wohnsitzlandbesteuerung auch hier langfristig lediglich der weltweit effiziente Kapitaleinsatz und durch Quellenbesteuerung die weltweit optimale Kapitalaufbringung nicht behindert.

Kurzfristig, bei einem vorübergehenden Auseinanderfallen des in- und ausländischen realen Zinsniveaus infolge eines exogenen Schocks, ist die Antwort nicht so eindeutig: Verursacht durch die trägen Preisreaktionen auf den Gütermärkten ist auch eine Veränderung des Zeitpfades der Wechselkursentwicklung hin zu dem neuen Gleichgewicht durch die Gewinnbesteuerung nicht auszuschließen.146 Die Wechselkursentwicklung gleicht gemäß Zinsparitätentheorie Kapitalkosten und Ertragsraten auf dem Kapitalmarkt an. Eine Steuer kann die unmittelbaren Auswirkungen eines Schocks auf den Außenwert der Währung und das Zinsniveau beeinflussen, wenn zur Angleichung der in- und ausländischen Grenzerträge beziehungsweise der Grenzproduktivitäten die Erwartung einer größeren periodischen Kursänderung gefordert wird. Ausschlaggebend hierfür sind die kurzfristigen Zinselastizitäten der Kapitalanbieter und -nachfrager.

Die Beziehung des Niveaus von Kapitalkosten beziehungsweise -ertragsraten in einem Land zu den entsprechenden Größen des Auslands wird allerdings vor allem durch makroökonomische Zusammenhänge bestimmt, die hier nicht näher betrachtet werden können.

\section{Asymmetrische Besteuerung ausländischen Kapital- einkommens und unerwartete Wechselkursänderungen}

In der Realität ist die einkommensteuerliche Behandlung von Währungsgewinnen und -verlusten nicht symmetrisch. Typische Asymmetrien und ihre quantitative Bedeutung werden in diesem Abschnitt betrachtet.

Dabei wird weiterhin unterstellt, daß die Kapitalanbieter ihre Erwartungen hinsichtlich der Währungsentwicklung auf der Grundlage von Zins- und Kaufkraftparitätentheorie bilden. Die Analyse konzentriert sich aber auf die Auswirkungen nicht erwarteter Kursänderungen auf den antizipierten Ertrag von grenzüberschreitendem Kapitaleinsatz unter dem Einfluß der Besteuerung.

Ausgangspunkt sind die Ergebnisse des letzten Abschnitts zum Wohnsitzlandprinzip. Mit Hilfe der oben eingefuihrten Optionstheorie werden zunächst isoliert das Anrechnungsverfahren und der Verlustabzug analysiert. Die Resultate werden danach zusammengefügt, um

\footnotetext{
144 Würde sich die Arbitragebeziehung auf den Kapitalmärkten in einer Gleichgewichtssituation mit unterschiedlichen Steuersätzen auf eine andauernde $\mathrm{Zu}$ - oder Abnahme des Wechselkurse stützen, müßte dieses Verhältnis der Währungen entweder gegen null oder gegen unendlich streben. Beide Ergebnisse sind bei identischen Inflationsraten ökonomisch unsinnig. Bei Gütersteuern ist denkbar, daß das Niveau des Wechselkurses unterschiedliche Steuersätze kompensiert. Für eine Angleichung der Ertragsraten nach Einkommensbesteuerung wäre aber eine andauernde Änderung des Niveaus erforderlich.

${ }^{145}$ Bei einer Wechselkursänderung von $\Delta e=1,028$, wie sie in Beispiel B2 unterstellt wurde, wären hier in Beispiel B3 sowohl die inländische Grenzproduktivität mit $g p=9,3 \%$ als auch der inländische Grenzertrag mit ge = $6,04 \%$ niedriger.

146 Vgl. auch J.S. Alworth, a.a.O., S.166.
} 
das Anrechnungsverfahren zu beurteilen. Abschließend wird auch die Möglichkeit einbezogen, daß ein Steuerrecht die Anwendung des Abzugsverfahrens als Wahlrecht einräumt. Die Wirkungen werden anhand der Beispiele des letzten Abschnitts III für das Inland und das Ausland berechnet und verglichen.

Die durch die Optionstheorie erzielbaren quantitativen Ergebnisse machen es möglich, noch einer weiteren Frage nachzugehen, die in der steuerrechtlichen Diskussion des Themas einigen Raum einnimmt: Ist die Benachteiligung von Kapitalexport in den betrachteten asymmetrischen Steuersystemen geringer, wenn das Währungsergebnis steuerrechtlich als im Wohnsitzland oder im Quellenland entstanden angesehen wird? Die Antwort wird in dem folgenden Abschnitt $\mathrm{V}$ gesucht.

Die Nutzung der Optionsbewertungstheorie verkürzt aber nicht zuletzt auch die Darstellung. Die Wirkungsweise relevanter Parameter ${ }^{147}$ ist unmittelbar auf die erwartete Steuerlast übertragbar. Eine Herleitung ist hier deshalb entbehrlich.

\section{Anrechnungsverfahren bei isolierter Betrachtung}

Verzichtet das Quellenland nicht auf die Besteuerung von Einkünften, die auf seinem Hoheitsgebiet entstehen, ist - wie oben schon erwähnt - Kapitalexportneutralität durch das Anrechnungsverfahren realisierbar. Das Wohnsitzland besteuert in diesem Fall zwar die Welteinkünfte der inländischen Kapitalgeber zunächst unabhängig von deren Herkunft. Die tatsächliche Steuerpflicht kann aber um Steuern gemindert werden, die im Quellenland gezahlt werden müssen.

Auch die Berücksichtigung flexibler Wechselkurse verletzt Kapitalexportneutralität bei dieser Vorgehensweise nicht, wenn Währungsgewinne und -verluste in Höhe des Steuersatzes im Sitzstaat der Kapitalanleger effektiv belastet werden. Für die Allokationsentscheidung ist es dabei gleichgültig, ob ein Teil dieser Gesamtsteuerlast tatsächlich an den inländischen oder den ausländischen Staat gezahlt werden muß.

In der Realität ist freilich die Anrechnung von im Ausland gezahlten Steuern im Wohnsitzstaat regelmäßig nur maximal bis zur Höhe der inländischen Steuerforderung vor der Anrechnung zulässig. Darüber hinausgehende ausländische Steuern führen zu den schon genannten Anrechnungsüberhängen, die im Wohnsitzland unberücksichtigt bleiben. Kapitalexportneutralität ist damit verletzt.

Bei Unsicherheit über die Entwicklung des Wechselkurses ist die Betrachtung der Steuersätze (und der Bemessungsgrundlagen) aber nicht hinreichend, um das Ausmaß der Verzerrung durch die Beschränkung der Anrechnung abschätzen zu können, wie die folgende Analyse zeigt:

Der Ertrag aus Investitionen im Ausland wurde im vorangegangenen Abschnitt III in zwei Komponenten aufgeteilt: einen Währungsgewinn oder -verlust, der infolge der Änderung des Außenwertes des zum Zeitpunkt $t$ exportierten Kapitals entsteht, sowie den im Ausland erwirtschafteten Gewinn (dessen Wert für die Kapitalgeber natürlich auch von der Wechselkursentwicklung abhängig ist).

Die im Ausland erhobene Steuer ist unabhängig von der Wechselkursentwicklung ein konstanter Anteil der zweiten Komponente des Ertrags, soweit bei der Umrechnung für beide Positionen der gleiche Wechselkurs zur Anwendung kommt, was hier unterstellt wird. Ist der Grenzertrag im Ausland beispielsweise geringer als im Inland, ist auch die ausländische

${ }^{147}$ Erwartete Währungsentwicklung, Währungsrisiko, in- und ausländisches Zinsniveau, Länge der Periode und (mit Einschränkungen) die Höhe der Steuersătze. 
Steuerlast entsprechend niedriger. Dies impliziert aufgrund der Zinsparitätenhypothese allerdings auch die Erwartung einer Aufwertung der Währung des Landes.

Die Aufwertung erhöht die ausländische Abgabe für Inländer aber vergleichsweise geringfügig und nicht relativ zum Ertrag. ${ }^{148}$ Für die Angleichung der Ertragsraten ist der Währungsgewinn beim investierten Kapital bedeutender. Dieser Gewinn bleibt im Ausland indessen regelmäßig steuerfrei.

Das heißt: aus der Sicht des inländischen Kapitalanbieters ist die effektive ausländische Belastung geringer als die Tarifbelastung. Deshalb fuhrt bei Investitionen in einem Land mit aufwertender Währung auch ein in diesem Land im Vergleich zum Sitzland des Kapitalgebers höherer Steuersatz nicht notwendigerweise zu einem Anrechnungsüberhang. Erst wenn der Steuersatz im Quellenland so hoch ist, daß die dortige Steuerpflicht auch die aus dem Währungsgewinn resultierende Steuer am Wohnsitz des Steuerpflichtigen übertrifft, entsteht ein Überhang. Andererseits kann bei Investitionen in einem Land mit einer abwertenden Währung auch ein im Vergleich zum Quellenland geringerer Steuersatz im Wohnsitzland einen Anrechnungsüberhang zur Folge haben. ${ }^{149}, 150$

Kapitalexportneutral ist dieses Steuersystem mit beschränkter Anrechnung aber in beiden Fällen nicht. Bei flexiblen Wechselkursen diskriminiert die Besteuerung gegenüber Kapitalexport nicht nur, wenn der Steuersatz im Wohnsitzstaat niedriger als im Quellenland ist. Auch im umgekehrten Fall ist die Neutralität nicht gewahrt.

Die Ursache hierfür liegt in der Unsicherheit über die tatsächliche Entwicklung des Devisenkurses. Infolgedessen besteht auch Unsicherheit über die relative Höhe der inländischen Steuerpflicht. Eine Situation, in der ein unerwarteter Währungsverlust zu einer höheren Steuerpflicht im Ausland als im Inland führt, kann nicht ausgeschlossen werden. Da andererseits aber die Möglichkeit einer geringeren Steuerlast im Ausland als Folge der Währungsentwicklung nicht entstehen kann, ist das Steuersystem nicht symmetrisch.

Dies wird nachfolgend unter Zuhilfenahme der Daten des Beispiels B2 von Seite 51 veranschaulicht:

Beispiel B4a:

Abbildung B8 zeigt die Ergebnisfunktion inländischer Kapitalanbieter bei Investitionen im Ausland in Abhängigkeit von dem tatsächlich eintretenden Devisenkurs am Ende der Periode, (1) wenn die Steuer des Auslands bis zur Höhe der Steuer im Wohnsitzland anrechenbar ist, sowie (2) wenn nur das Inland eine Steuer erhebt oder (3) nur das Ausland den dort entstandenen Gewinn besteuert.

Grundlage der Graphik bilden die Daten des Beispiels B2; darüber hinaus wurde der Steuersatz des Auslands von 0,55 auch für dessen Quellensteuer unterstellt $\left(t^{*}=0,55\right)$. Der ausländische Steuersatz ist somit also höher als derjenige im Inland $(\tau=0,35)$.

148 Vgl. J. Bourne Wahl, Taxation of Exchange Gains and Losses, a.a.O., S.13f..

149 J. Bourne Wahl, Tax Treatment of Foreign Exchange Gains and Losses and the Tax Reform Act of 1986, a.a.O., S. $67 \mathrm{f}$..

${ }^{150}$ Falls (Fremd-)Kapital in der Währung des Wohnsitzlandes aufgenommen wird, kommt es nicht wechselkursbedingt zu asymmetrischer Besteuerung, wenn das Steuersystem im Quellenland vollen Verlustabzug zuläßt: Im Wohnsitzland fallt kein Währungsergebnis an. Im Quellenland ist ein Währungsgewinn oder -verlust auf der Ebene des Unternehmens zunächst wie andere Finanzierungsaufwendungen abziehbar (vgl. Fußnote 139 auf Seite 55 dieser Arbeit). Ein Wăhrungsverlust mindert diese Aufwendungen und damit die Steuerlast, ein Währungsgewinn erhöht sie. Das heißt: ex ante entsprechen die Finanzierungskosten denen bei Kreditaufnahme in der Quellenlandwährung. Zum Zeitpunkt der Zinszahlung wird (möglicherweise) eine Quellensteuer erhoben. Diese Steuer ist aber ja unabhängig von der Wechselkursentwicklung, soweit bei der Umrechnung von Kapitalertrag und Quellensteuer der gleiche Wechselkurs zur Anwendung kommt, was im Text unterstellt wird. Deshalb ist bei der Betrachtung des Anrechnungsüberhangs kein Währungsergebnis zu beachten. 
Abb. B8: Ergebnisfunktion inländischer Kapitalanbieter bei Sitzstaat- und Quellenbesteuerung

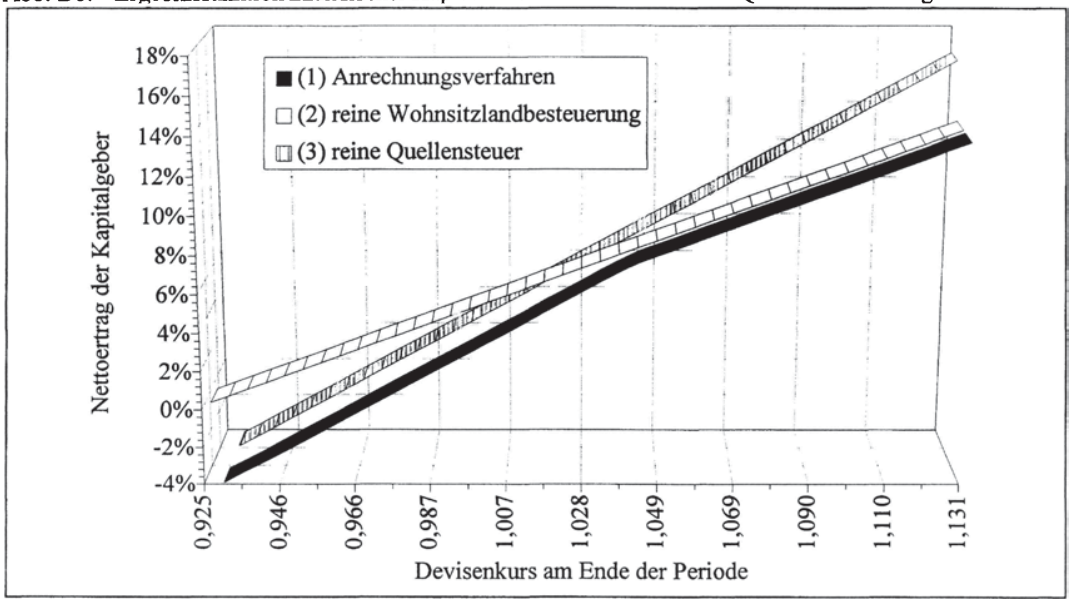

Quelle: Eigene Darstellung.

Allgemein ist die Anrechnungsgrenze immer dann erreicht, wenn die ausländische und die inländische Steuerlast die gleiche Höhe haben. Hier muß also gelten:

$$
\mathrm{r}^{*} \cdot \mathrm{t}^{*} \cdot \Delta \mathrm{e}=\left(\Delta \mathrm{e}-1+\Delta \mathrm{e} \cdot \mathrm{r}^{*}\right) \cdot \tau
$$

Für das Beispiel ergibt die Auflösung dieser Gleichung [B14] nach $\Delta \mathrm{e}$ :

$$
\frac{1}{r^{*} \cdot\left(1-\frac{t^{*}}{\tau}\right)+1}=\frac{1}{0,07 \cdot\left(1-\frac{0,55}{0,35}\right)+1}=1,0417 \text {. }
$$

Solange der Devisenkurs um nicht mehr als 4,17\% ansteigt, ist der Quellensteuersatz maßgebend, da ein Anrechnungsüberhang entsteht. Erst ein stärkerer Kursanstieg hat eine Steuerpflicht auch im Inland zur Folge. Wird dieser Kurs übertroffen, ist die Gesamtsteuerlast auch dann größer als bei ausschließlicher Quellenbesteuerung, wenn der Steuersatz im Wohnsitzland niedriger als im Quellenland ist, da der zusätzliche Währungsgewinn im Inland steuerpflichtig wird. In Abbildung B8 wird dies deutlich: Die Steigung der Ertragsfunktion in einem Steuersystem mit beschränkter Anrechnung ist geringer in dem Bereich, in dem der Wechselkurs über die Grenze von 1,0417 hinaus ansteigt.

Fraglich ist, welche Möglichkeiten das inländische Steuerrecht einräumt, wenn die Summe aus positivem - um die Quellensteuer geminderten - ausländischen Gewinn und einem Währungsverlust zu einem Verlust für den inländische Kapitalgeber führt. Da aber das Ziel dieses Unterabschnitts die isolierte Betrachtung der Wirkung eines Anrechnungshöchstbetrages bei flexiblen Wechselkursen ist, sei hier die Verrechnung von Verlusten mit positiven Welteinkünften aus anderen Quellen ausgeschlossen. Unter dieser Annahme ist es möglich, die Auswirkung des Anrechnungshöchstbetrags auf den Erwartungswert des Nettoertrags einer Auslandsinvestition zu quantifizieren, indem der Gewinn einer ausländischen Anlage in zwei Bestandteile zerlegt wird:

- in den Ertrag nach Abzug der ausländischen Steuerpflicht und

- in eine Eventualforderung des inländischen Staates. 
Nur wenn die Differenz aus rechnerischer Steuerlast bei reiner Wohnsitzlandbesteuerung und ausländischer Steuerpflicht positiv ist, fordert der inländische Staat diesen Unterschiedsbetrag auch tatsächlich ein.

Algebraisch lautet diese Aufteilung für den Nettoertrag in Abhängigkeit der Wechselkursentwicklung $\mathrm{R}[\Delta \mathrm{e}]$ :

$$
\begin{aligned}
\mathrm{R}[\Delta \mathrm{e}]=[1 & \left.+\mathrm{r}^{*} \cdot\left(1-\mathrm{t}^{*}\right)\right] \cdot \Delta \mathrm{e}-1 \\
& \quad-\max \left\{\left(\Delta \mathrm{e}-1+\Delta \mathrm{e} \cdot \mathrm{r}^{*}\right) \cdot \tau-\mathrm{r}^{*} \cdot \mathrm{t}^{*} \cdot \Delta \mathrm{e} ; 0\right\}
\end{aligned}
$$

Es ist leicht, den Erwartungswert der ersten Komponente zu bestimmen. Für eine Beurteilung der Bedeutung des zweiten Teils muß allerdings auf die Erkenntnisse der Optionsbewertungstheorie zurückgegriffen werden.

Die Optionsbewertungstheorie ist in diesem Zusammenhang besonders geeignet, da Währungsrisiken quantifizierbar sind. Währungen werden rund um die Uhr gehandelt und das Risiko ist, zumindest in der Form historischer oder impliziter Volatilitäten ${ }^{151}$, meßbar. Die auf diesem Weg errechneten Werte sind daher realistisch. ${ }^{152}$

Die Eventualforderung des Staates läßt sich als Kaufoption interpretieren. Der inländische Staat nimmt am Ende der Periode ein Besteuerungsrecht nur dann wahr, wenn der Devisenkurs den aus Gleichung [B14] folgenden Wert - den „Ausübungspreis“ - übersteigt. Andernfalls ist die zweite Komponente in Gleichung [B15] null. Die Höhe der inländischen Steuerforderung ist also nur im ersten Fall eine positive Funktion des tatsächlichen Wechselkurses. Der Staat ist deshalb „Käufer“ von Kaufoptionen auf die ausländische Währung. Die Anleger haben die Position des „Stillhalters“ dieser Optionen.

Der Wert der Optionen zum Anlagezeitpunkt ist der entscheidungsrelevante Betrag für die allokativen Folgen dieses Steuersystems, denn der „Kaufpreis“ der Optionen stellt den Barwert der Steuerforderung des inländischen Staates dar und mindert demgemäß den erwarteten Nettoertrag für inländische Kapitalgeber. Es wird an dieser Stelle darauf verzichtet, die Einzelheiten der Berechnung darzulegen; die Schritte werden in Anhang I ab Seite 212 anhand der im Beispiel unterstellten Daten beschrieben. Das Ergebnis hebt aber die Bedeutung der Möglichkeit eines Anrechnungsüberhangs für die internationale Kapitalallokation bei flexiblen Wechselkursen hervor:

Wird eine Standardabweichung des erwarteten Devisenkurses von $\sigma[\Delta \mathrm{e}]=0,1$ unterstellt, beträgt der erwartete Ertrag 4,87\% und ist damit um 1,63 Prozentpunkte geringer als der für Kapitalexportneutralität erforderliche Wert von 6,50\%. Er ist aber insbesondere um 1,17 Prozentpunkte geringer als der theoretische Nettogewinn von $6,04 \%{ }^{153}$, wenn Sicherheit hinsichtlich der Währungsentwicklung angenommen wird, das heißt wenn am Wohnsitz aufgrund des Anrechnungsüberhangs nicht besteuert wird.

Der Preis der Kaufoptionsposition ${ }^{154}$ - der Erwartungswert der Steuerpflicht im Inland - ist bei gegebenen Steuersätzen in den Ländern umso höher, je größer die Wahrscheinlichkeit eines Wechselkurses ist, bei dem eine zusätzliche Steuerlast im Inland anfällt, also

151 Vgl. hierzu z.B. Deutsche Bundesbank, Finanzmarktvolatilität und ihre Auswirkungen auf die Geldpolitik, a.a.O., S.54f. u. S.67-70.

152 Allerdings entspricht die Annahme einer Normalverteilung der erwarteten Wechselkursänderung nicht empirischen Untersuchungen. Vgl. R.M. Levich, a.a.O., S.995-997 sowie auch Fußnote 12 auf Seite 17 dieser Arbeit. Infolgedessen ist eine exakte theoretische Berechnung von Wăhrungsoptionen - wie im übrigen auch von Zinsoptionen - ein schwieriges Problem.

${ }^{153} \Delta \mathrm{e} \cdot\left(1+\mathrm{gp} \cdot\left(1-\mathrm{t}^{\circ}\right)\right)=1,028 \cdot(1+0,07 \cdot 0,45)=0,0604$

154 Die Wirkungen der nachfolgend genannten Einflußfaktoren lassen sich unmittelbar aus den Erkenntnissen der Optionsbewertungstheorie ableiten. Auf deren Herleitung wird hier deshalb verzichtet. Vgl. hierzu J.O. Grabbe, 
- je höher die Standardabweichung des erwarteten Wechselkurses $\sigma[\Delta \mathrm{e}]$ ist $^{155}$,

- je niedriger der „Ausübungspreis“ und

- je höher der am Periodenende erwartete Devisenkurs sind und schließlich

- tendenziell, je länger die Periode ist.

Der „Ausübungspreis“ ist - wie auch in Gleichung [B14] nachvollzogen werden kann - wiederum umso höher, je niedriger das ausländische Zinsniveau, je niedriger der ausländische und je höher der Steuersatz im Wohnsitzland ist. Alle drei Einflußfaktoren mindern nämlich die ausländische Steuer relativ zu der Last im Inland, das heißt sie erhöhen die Anrechnungsgutschrift.

Besonderes Gewicht hat indes der Einfluß der Länge der Periode, denn insbesondere die Entscheidung über eine Direktinvestition wird realistischerweise für einen Zeitraum von mehr als einem Jahr getroffen werden. ${ }^{156}$

Andererseits ist die diskriminierende Wirkung der Steuer umso schwächer, je höher der inländische Zinssatz ist. Denn der „Preis“ der Optionsposition ist auch relativ zur Steuerlast bei inländischen Erträgen zu sehen.

Um die Beeinflussung des Anrechnungshöchstbetrages durch Währungsverluste zu verhindern, wird vorgeschlagen, das Währungsergebnis den inländischen Einkünften zuzurechnen. ${ }^{157}$

Ein Währungsgewinn oder -verlust, der infolge der Änderung des Außenwertes des exportierten Kapitals entsteht, wird damit nicht in das Anrechnungsverfahren einbezogen. Die ausländischen Einkünfte, die darauf entrichteten Quellensteuern und die Steuer am Wohnsitz werden dann durch eine Wechselkursänderung proportional verändert. Das Währungsergebnis kann davon unabhängig im Inland einer (symmetrischen) Besteuerung unterliegen.

Infolge des höheren ausländischen Steuersatzes würde in dem oben eingeführten Beispiel der ausländische Gewinn im Ergebnis mit dem ausländischen Steuersatz belastet, der Währungsgewinn beim exportierten Kapital indes mit dem inländischen Satz:

$$
\begin{gathered}
(\Delta \mathrm{e}-1) \cdot(1-\tau)+\Delta \mathrm{e} \cdot \mathrm{r}^{*} \cdot\left(1-\mathrm{t}^{*}\right) \\
=0,028 \cdot 0,65+1,028 \cdot 0,07 \cdot 0,45=0,0506 .
\end{gathered}
$$

Der erwartete Nettoertrag ist mit $5,06 \%$ zwar geringer als zur Wahrung von Kapitalexportneutralität erforderlich wäre. Er ist aber höher als in einem Steuersystem, das in die begrenzte Anrechnung auch Währungserträge einbezieht.

Eine dritte Möglichkeit wurde in den USA diskutiert. ${ }^{158}$ Vorgeschlagen wurde, nur ex ante erwartete Währungsgewinne oder -verluste sollten bei der Anrechnungsgrundlage berücksichtigt werden. Einkünfte, die auf unerwartete Kursänderungen zurückzuführen sind, sollten da-

The Pricing of Call and Put Options on Foreign Exchange, in: Journal of International Money and Finance, 2.Jg. (1983), S.249f.; J.C. Cox u. M. Rubinstein, a.a.O., S.215-217.

155 Die quantitative Bedeutung der Volatilität in dem hier gewählten Beispiel wird durch die Abbildung B10 auf Seite 71 dieser Arbeit graphisch veranschaulicht.

${ }^{156}$ Hierbei ist allerdings anzumerken, daß diese Aussage nicht uneingeschränkt zutrifft. Denkbar ist bei einem im Vergleich zum Inland sehr hohen Zinsniveau im Ausland auch mit zunehmender Haltedauer ein abnehmender Optionspreis. Vgl. J.O. Grabbe, a.a.O., S.250.

${ }^{157}$ Vgl. R. Henrey, H.R. 3838 and Foreign Currency Rules Reform: Comments and Recommendations, in: Tax Management International Journal, 15.Jg. (1986), S.173, der aufgrund ähnlicher Überlegungen fordert, Währungserfolge im U.S.-Steuerrecht als inländische ordentliche Einkünfte zu interpretieren.

Vgl. ebenso Institut „Finanzen und Steuern“" e.V. (Hrsg.), Währungsschwankungen und die Methoden zur Vermeidung der Internationalen Doppelbesteuerung, Heft 125, Bonn 1988, S. $19 \mathrm{f}$;; O.H. Jacobs, Internationale Unternehmensbesteuerung, 3.Aufl., München 1995, S.241. Für Beispielrechnungen zum deutschen Steuerrecht vgl.: T. Finne, a.a.O., S.275-282; N.-P. Schoss, Die ertragsteuerlichen Konsequenzen von Wechselkursänderungen bei Direktinvestitionen deutscher multinationaler Unternehmen, Bergisch Gladbach 1993, zugl. Diss., Univ. Siegen 1992, S.137-141.

${ }^{158}$ R. Reagan, The Presidents Tax Proposals, a.a.O., S.413. J. Bourne Wahl, Taxation of Foreign Exchange Gains and Losses, a.a.O., S.8f. u. S.15-19. Vgl. auch Seite 135 dieser Arbeit. 
gegen inländischen Einkünften zugerechnet werden. Soweit der ausländische Gewinn nicht unsicher ist, entsteht hier praktisch keine Eventualforderung, wenn die unerwarteten Währungsgewinne beziehungsweise -verluste einer symmetrischen Besteuerung im Inland unterliegen.

Für das Beispiel bedeutet diese Variante:

Der erwartete Währungsgewinn in Höhe von 0,028 wäre hier ausländischen Erträgen zuzurechnen. Der effektive Steuersatz für ausländische Gewinne beträgt dann nicht $t^{*}=0,55$, sondern etwa 0,4. ${ }^{159} \mathrm{Da}$ er immer noch über dem Satz des Wohnsitzlandes liegt, entsteht auch hier ein Anrechnungsüberhang, und es entfällt eine Steuerpflicht im Wohnsitzland. Der Nettoertrag entspricht demzufolge dem Wert, der oben unter der Annahme von Sicherheit über die Währungsentwicklung ermittelt wurde, nämlich 6,04\%.

Das Ergebnis kommt in dem hier gewählten Beispiel dem bei Wahrung von Kapitalexportneutralität geforderten Betrag am nächsten. Inwieweit dieses Fazit allgemein gültig ist, wird weiter unten analysiert, nachdem die Werte der hier betrachteten Steuersysteme für die ausländischen Kapitalanbieter berechnet wurden.

Zum Vergleich werden die Resultate noch einmal gegenübergestellt:

Erwartungswert des Nettoertrags am Ende der Periode einer

- inländischen Anlage:

- Anlage im Ausland bei

- kapitalexportneutraler Besteuerung:

- beschränkter Anrechnung der ausländischen Steuer bei der inländischen Steuer auf den ausländischen Gewinn

- beschränkter Anrechnung der ausländischen Steuer bei der inländischen Steuer auf den ausländischen Gewinn und auf den erwarteten Währungsgewinn 6,04\%

- beschränkter Anrechnung der ausländischen Steuerbei der gesamten inländischen Steuer und Unsicherheit über die Währungsentwicklung:

$4,87 \%$

Die Ergebnisse aus der Sicht ausländischer Kapitalanbieter sind noch interessanter, denn die isolierte Betrachtung der Steuersätze (Quellensteuersatz $\mathrm{t}=0,35$; Steuersatz im Wohnsitzland $\left.\tau^{*}=0,55\right)$ läßt hier keinen Anrechnungsüberhang vermuten:

Beispiel B4b:

Tatsächlich entsteht - wie leicht nachgerechnet werden kann - trotz der Aufwertung der Währung des Auslandes kein Anrechnungsüberhang, wenn der aus ausländischer Sicht erwartete Devisenkurs von 0,973 tatsächlich eintrifft.

Die Höhe der ausländischen Steuer wird gemäß analoger Anwendung der Gleichung [B14] erst $\mathrm{ab}$ einem Devisenkurs von

$$
\left[\mathrm{r}^{*} \cdot\left(1-\frac{\mathrm{t}}{\mathrm{\tau}^{*}}\right)+1\right]^{-1}=\left[0,1 \cdot\left(1-\frac{0,35}{0,55}\right)+1\right]^{-1}=0,9649
$$

relevant, wie auch in der folgenden Abbildung B9 erkennbar ist. Die Abbildung zeigt die Ergebnisfunktion ausländischer Kapitalanbieter bei Investitionen im Inland in Abhängigkeit von dem tatsächlich eintretenden Wechselkurs am Ende der Periode, (1) wenn die Steuer des Quellenlands bis zur Höhe der Steuer am Wohnsitz angerechnet wird, (2) bei Besteuerung nur am Wohnsitz und (3) bei Besteuerung im Quellenland. Dies ist in der Abbildung auf der folgenden Seite erkennbar.

Die optionstheoretische Ermittlung des Erwartungswertes des Nettoertrags der grenzüberschreitenden Anlage im Anhang I ergibt bei einer Standardabweichung des erwarteten Devisenkurses von $\sigma[\Delta \mathrm{e}]=0,1$ in diesem Beispiel B5 den Wert 1,16\%. Erforderlich wären bei Kapitalexportneutralität 3,15\%.

${ }^{159}$ Die Nettoertrag im Ausland beträgt $0,07 \cdot 0,45=0,0315$. Zuzüglich des erwarteten Währungsgewinnes von 0,028 sind dies 0,0595 . Der Bruttoertrag liegt bei 0,1 . Daraus ergibt sich der im Text genannte effektive Steuersatz: $1-0,0595 / 0,1 \approx 0,4$. 
Abb. B9: Ergebnisfunktion ausländischer Kapitalanbieter bei Sitzstaat- und Quellensteuer

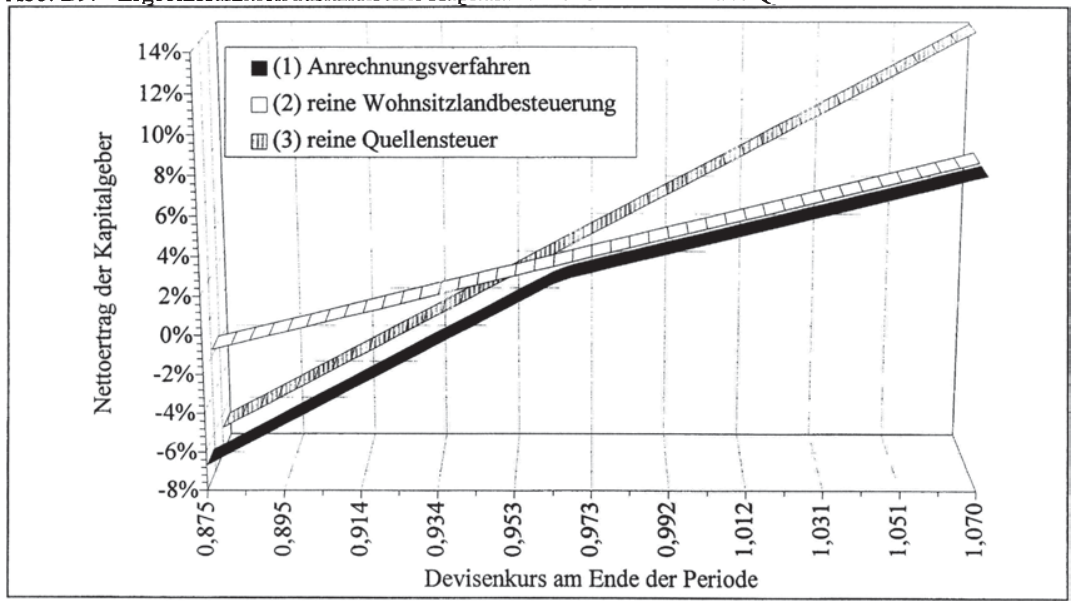

Quelle: Eigene Darstellung.

Der zu erwartende Gewinn wird durch Unsicherheit über die Währungsentwicklung noch stärker gemindert als im Fall des Beispiels B3a für das Inland. Die Ursache ist zum einen der hier höhere Steuersatz im Wohnsitzland. Hinzukommt zum anderen, daß bei Eintritt des erwarteten Währungsverlusts der Anrechnungshöchstbetrag nur knapp überschritten wird. Schon bei einem geringfügig höheren Währungsverlust wird hier ein Anrechnungsüberhang entstehen, der allein von dem Steuerpflichtigen zu tragen ist. Demgegenüber führt eine positive Abweichung vom erwarteten Wechselkurs zu einer entsprechend höheren Steuerbelastung im Wohnsitzland.

Ein höherer Erwartungswert des Nettoertrags ist deshalb auch hier für grenzüberschreitende ausländische Kapitalgeber möglich, wenn das Währungsergebnis den inländischen Einkünften zugerechnet wird. Der Erwartungswert des Währungsverlustes bei dem exportierten Kapital wird durch die Steuer dann genau in Höhe der inländischen Tarifbelastung reduziert, weil Gewinne und Verluste symmetrisch behandelt werden (wiederum vorausgesetzt ein Währungsverlust kann die Steuerbelastung proportional mindern). Da das Währungsergebnis den Anrechnungshöchstbetrag in diesem Fall nicht relativ verändert, ist auf Grund des geringeren ausländischen Quellensteuersatzes ein Überhang ausgeschlossen. Der Gewinn entspricht dem Ergebnis bei symmetrischer Anrechnung und Kapitalexportneutralität ist gewahrt.

Dies trifft auch für die dritte Alternative zu, bei der nur ex ante erwartete Währungsgewinne oder -verluste zur Anrechnung zugelassen werden:

Der Währungsverlust mindert zwar den Ertrag grenzüberschreitender Investitionen (und in geringem Maße auch die anrechenbare Quellensteuer). Der im Vergleich hohe Steuersatz im Wohnsitzland hat aber dennoch eine Steuerpflicht auch dort zur Folge. Denn der effektive Quellensteuersatz für diese Erträge liegt zwar nicht bei $t=0,35$, sondern bei etwa $0,46.160 \mathrm{Er}$ ist indessen immer noch geringer als der entscheidende Steuersatz im Wohnsitzland $\left(\tau^{*}=0,55\right)$.

${ }^{160}$ Die Nettoertrag im Inland beträgt hier $0,1 \cdot 0,65=0,065$. Nach Abzug des Währungsverlustes von 0,027 verbleiben ausländischen Kapitalanbietern 0,038. Dessen Bruttoertrag läge bei 0,07 . Daraus ergibt sich der im Text genannte effektive Steuersatz: $1-0,0377 / 0,07 \approx 0,46$. 
Kapitalexportneutralität ist bei dieser Besteuerungsalternative im Fall eines im Vergleich zum Quellenland höheren Steuersatzes im Wohnsitzland auch dann gegeben, wenn ein Währungsgewinn erwartet wird, wenn also das Zinsniveau im Quellenland relativ niedriger ist. ${ }^{161}$

Ist es damit aus theoretischer Sicht vorteilhaft, zwischen erwarteten und nicht erwarteten Währungsgewinnen und -verlusten zu differenzieren?

Der eindeutige Vorteil, den dieses Verfahren hinsichtlich einer möglichst geringen Diskriminierung von Kapitalexport bei der Beispielrechnung für das Inland ergeben hat, ist nicht allgemein gültig. Denn in einer Situation eines antizipierten Währungsverlustes kann die Methode auch dann zu einem Anrechnungsüberhang führen, wenn der ausländische Steuersatz geringer ist, da auf diesem Wege die ausländischen Einkünfte gemindert werden. Dies ist offensichtlich nicht möglich, wenn das gesamte Währungsergebnis inländischen Einkünften zugerechnet wird.

Allein wenn die Quellensteuer niedriger ist als die Tarifbelastung im Wohnsitzland und ein Währungsgewinn antizipiert wird, dann fällt die Gesamtbelastung geringer aus. Dies war in der ersten Rechnung weiter oben der Fall: Der Währungsgewinn wurde nur anteilig besteuert, da er einen Teil des Anrechnungsüberhangs bei dem ausländischen Gewinn aufgezehrt hat.

Eine Differenzierung des Währungsergebnisses führt somit in mehr Situationen zu einer Diskriminierung von Kapitalexport. Andererseits ist im Falle einer Benachteiligung deren Höhe geringer. Die Höhe ist unter den hier getroffenen Annahmen für die allokativen Auswirkungen aber unerheblich. Die Methode ist demzufolge nicht sinnvoll.

Die Umkehrung dieses letzten Aspektes hat allerdings überhaupt zu dem Vorschlag gefuihrt. Es sollte damit eine gezielte Manipulation von Anrechnungshöchstbeträgen durch Steuerpflichtige mittels antizipierter Währungserfolge verhindert werden. ${ }^{162}$ Die Möglichkeit ist dann gegeben, wenn Einkünfte und darauf entrichtete Steuern mehrerer Währungsräume verrechnet werden können - also insbesondere in den USA.

Auch die Resultate der Berechnungen für das Ausland werden abschließend nochmals gegenübergestellt:

Erwartungswert des Nettogewinns ausländischer Kapitalgeber am Periodenende bei einer

- Anlage in ihrem Land

- grenzüberschreitenden Anlage bei

- kapitalexportneutraler Besteuerung:

$3,15 \%$

- beschränkter Anrechnung der ausländischen Steuer bei der inländischen Steuer auf den ausländischen Ertrag

$3,15 \%$

- beschränkter Anrechnung der ausländischen Steuer bei der inländischen Steuer auf den ausländischen Gewinn und auf den erwarteten Währungsgewinn 3,15\%

- beschränkter Anrechnung der ausländischen Steuer bei der gesamten inländischen Steuer und Unsicherheit über die Währungsentwicklung: $\quad \underline{1,16 \%}$

Die Problematik der einkommensteuerlichen Behandlung von nicht antizipierten Währungsgewinnen und -verlusten als ausländische Einkünfte zeigt sich hier besonders deutlich. Nur in diesem Steuerregime wird Kapitalexport diskriminiert.

${ }^{161}$ Eine gewisse Unsicherheit besteht, wenn der ausländische Steuersatz geringer ist als der des Inlands. Die überschüssige Anrechnungsgutschrift ist nämlich eine Funktion der Währungsentwicklung. Wird ex ante ein geringer Währungsgewinn erwartet, ist damit unklar, ob ein Anrechnungsüberhang entstehen wird. Diese Abweichung wird hier aber vernachlässigt.

162 J. Bourne Wahl, Taxation of Foreign Exchange Gains and Losses, a.a.O., S.8f. und Teil C. 


\section{Anrechnungsverfahren mit Verlustausgleich}

\section{a) Bedeutung des Verlustabzugverbots in der isolierten Betrachtung}

Eine zweite denkbare Asymmetrie eines Steuersystems ist die Beschränkung oder die Verweigerung des Ausgleichs von Verlusten bei der Bemessung der Steuerpflicht im Wohnsitzland ${ }^{163}$, etwa wenn Währungsverluste steuerlich den Veräußerungsverlusten zugerechnet werden und diese nicht mit anderen Arten von Einkünften verrechnet werden dürfen. ${ }^{164}$ Bezüglich des Gewinnes in der Währung des Einsatzortes wird dabei weiterhin Sicherheit unterstellt.

Auch die Auswirkung fehlender Verlustausgleichsmöglichkeiten auf den erwarteten Ertrag einer einperiodigen Auslandsinvestition läßt sich optionstheoretisch bestimmen: Die inländische Steuerschuld ist als einfache Währungs-Kaufoptionsposition interpretierbar. Die kapitalexportierenden Sparer sind Stillhalter in den Optionen.

Der „Ausübungspreis“ ist der Devisenkurs, bei dem der Währungsverlust dem im Ausland erwarteten Gewinn in inländischer Währung entspricht, das heißt wenn gilt:

$$
\Delta \mathrm{e} \cdot\left(1+\mathrm{r}^{*}\right)=1 \text {. }
$$

In diesem Fall ist nämlich der Gesamtgewinn des Auslandsengagements genau null; der Währungsverlust zehrt den ausländischen Gewinn auf. Der besteuernde Staat ist als „Käufer“ der Optionen im Falle einer positiven Entwicklung der Investition mit dem Anteil des Steuersatzes am Ertrag beteiligt, bei einem Verlust dagegen nicht.

Das erwartete Nettoeinkommen in Abhängigkeit der Währungsentwicklung $R[\Delta \mathrm{e}]$ setzt sich demgemäß wie folgt zusammen:

$$
\begin{aligned}
\mathrm{R}[\Delta \mathrm{e}]=(1 & \left.+\mathrm{r}^{*}\right) \cdot \Delta \mathrm{e}-1 \\
& -\max \left\{\left(\Delta \mathrm{e}-1+\Delta \mathrm{e} \cdot \mathrm{r}^{*}\right) \cdot \tau ; 0\right\}
\end{aligned}
$$

Wie gesagt, werden Währungsoptionen auf effizienten Märkten gehandelt. Der auf diesem Weg errechnete Erwartungswert der Steuerlast ist insofern (nahezu) objektiv.

Für die Daten des Beispiels B2 dieses Teils und einer unterstellten Standardabweichung des erwarteten Devisenkurses von $\sigma[\Delta \mathrm{e}]=0,1$ werden im Anhang wiederum die Berechnungen durchgeführt (in Anhang II ab Seite 216).

Das Ergebnis für den inländischen Kapitalanbieter:

Bei reiner Wohnsitzlandbesteuerung ohne Verlustausgleich mindert die Steuer den erwarteten Grenzertrag einer Auslandsinvestition des inländischen Anbieters von 6,50\% bei symmetrischer Besteuerung mit dem Satz von $\tau=0,35$ auf $6,15 \%$.

Der Wert wird durch den Ausschluß des Verlustausgleichs somit nur um etwa 0,35\% gemindert. Die Ursache hierfür liegt in der geringen Wahrscheinlichkeit eines Verlustes. Erwartet wird ja ein Devisenkurs von 1,028. Ein Verlust würde aber erst bei dem um $9 \%$ geringeren Kurs von weniger als $\left(1+r^{\prime \prime}\right)^{-1}=1,07^{-1}=0,935$ - dem „Ausübungspreis“ der Optionsposition entstehen.

Für den ausländischen Anleger, der sein Kapital ins Inland exportieren will, wird der erwartete Gewinn durch den nicht gestatteten Verlustausgleich stärker reduziert. Gegenüber einem erwarteten Ertrag von 3,15\% bei symmetrischer Besteuerung mit den Satz $\tau$ * $=0,55$ sinkt er um 0,0085 auf etwa $2,3 \%$.

\footnotetext{
${ }^{163}$ Die Ausführungen dieses Unterabschnitts a) lassen sich unmittelbar auf eine asymmetrische steuerliche Berücksichtigung von Finanzierungsaufwendungen im Rahmen des Quellenlandprinzips übertragen (vgl. Fußnote 139 auf Seite 55). Die Resultate gelten spiegelbildlich, ansonsten aber unverändert.

164 J.B. Mertens, a.a.O., S.235f. u. S.254.
} 
Die diskriminierende Wirkung ist hier erheblich größer, denn „Ausübungspreis“ ist der Devisenkurs von 0,91 und der erwartete Kurs liegt bei 0,973. Ein Verlust ist auf Grund dessen bei gleicher Standardabweichung der erwarteten Währungsentwicklung wahrscheinlicher; er tritt schon bei einem Kursrückgang um knapp 6,5\% ein. Zusätzlich ist auch der Steuersatz höher.

Grundsätzlich beeinflussen folgende Faktoren das Ausmaß der zusätzlichen Belastung durch das Fehlen von Verlustausgleichsmöglichkeiten:

Die Minderung des erwarteten Ertrags ist umso größer, je niedriger das Zinsniveau im Wohnsitzland ist. Denn gemäß der Zinsparitätenhypothese ist die Summe aus Währungsergebnis und den ausländischen Einkünften in inländischer Währung entsprechend geringer. Infolgedessen führt schon ein kleinerer Devisenkursrückgang zu einem insgesamt negativen Ergebnis. Unter sonst gleichen Umständen ist daher ein währungsbedingter Verlust wahrscheinlicher.

Darüber hinaus reduziert eine größere Standardabweichung - das Maß der Unsicherheit über die Währungsentwicklung - den erwarteten Nettoertrag.

Auch ein höherer Steuersatz im Wohnsitzland erhöht die diskriminierende Wirkung grenzüberschreitenden Kapitaleinsatzes. Der Staat ist zwar sowohl an inländischen als auch an ausländischen Gewinnen gleichermaßen stärker beteiligt, aber nicht an Währungsverlusten.

\section{b) Verlustausgleich beim Anrechnungsverfahren}

Aus den Ergebnissen des vorangegangenen Unterabschnitts a) läßt sich auch die Antwort auf ein noch offenes Problem im Zusammenhang mit dem Anrechnungsverfahren unmittelbar ableiten. Die Wirkung eines flexiblen Wechselkurses wurde analysiert, wenn (i) die Anrechnung einer ausländischen Steuer nur bis zu einem Höchstbetrag zulässig ist und (ii) das Währungsergebnis als ausländischen Ursprungs qualifiziert und damit bei der Anrechnung einbezogen wird. Um welchen Betrag wird aber in diesem Steuersystem der Erwartungswert der Steuerlast gemindert, wenn außerdem ein ausländischer Verlust bei der Quantifizierung der im Inland steuerpflichtigen Welteinkünfte abgezogen werden kann?

Der Barwert dieser Steuererleichterung entspricht betragsmäßig genau der zusätzlichen Belastung durch das Vorenthalten eines Verlustabzugs im Vergleich zur symmetrischen Besteuerung, die im vorangegangenen Unterabschnitt ermittelt wurde. Der Steuerpflichtige ist hier „Käufer“, der Staat „Stillhalter“ von Währungs-Verkaufoptionen.

Warum? Wie oben hat ein Währungsverlust durch eine ausländische Investition erst dann Auswirkungen auf die inländische Steuerlast, wenn der Verlust den ausländischen Gewinn in inländischer Währung aufzehrt; ausländische Steuern sind dabei nicht abziehbar. Dieser Kurs ist deshalb auch hier der „Ausübungspreis“. Nur wird nicht, wie oben, bei jedem Prozent, das der tatsächliche Kurs am Ende der Periode darunter liegt, der Verlust im Vergleich zu einer symmetrischen Steuer um den Anteil des Steuersatzes erhöht. Das Gegenteil ist der Fall: der inländische Staat beteiligt sich ab diesem Kursniveau an dem Mißerfolg des Steuerpflichtigen in Höhe des Steuersatzes. ${ }^{165}$ Würde diese Beteiligung in der obigen Situation einer reinen Wohnsitzlandbesteuerung ohne Verlustausgleich auch gewährt, wäre dort das Ergebnis ein symmetrisches Steuersystem. Die ex ante erwartete Gesamtsteuerlast wird hier somit durch

165 Außerdem beteiligt sich der inländische Staat natürlich weiterhin an einem Gewinn, soweit dieser die Höhe der Anrechnungsgrenze übertrifft. 
die Eventualforderung, die dem Steuerpflichtigen durch den inländischen Staat eingeräumt wird, in entsprechender Weise gesenkt.

Insgesamt sieht sich der Steuerpflichtige in einem Steuersystem mit begrenzter Anrechnung und Verlustausgleich somit in der Position des Käufers und des Stillhalters in Kaufoptionen für die Währung des Landes, in dem er das Kapital einsetzt:

Der Endwert in ausländischer Währung und die auf den Gewinn zu entrichtende Quellensteuer sind fix, der Wechselkurs flexibel. Die ausländische Steuer wird im Anrechnungsverfahren berücksichtigt, nicht aber beim Verlustabzug. Sie bestimmt den oberen Punkt der Freistellung im Inland; die Höhe des ausländischen Gewinns determiniert den unteren Punkt. Zwischen diesen Punkten ist der Währungsgewinn oder -verlust im Wohnsitzstaat steuerfrei. In dem Bereich darüber und darunter bestimmt das Land des Steuerpflichtigen die Be- oder Entlastung für eine Einheit zusätzlichen Gewinns beziehungsweise zusätzlichen Verlusts in inländischer Währung bei der Auslandsinvestition.

Algebraisch hat dies für das erwartete Nettoeinkommen $\mathrm{R}[\Delta \mathrm{e}]$ das folgende Aussehen:

[B18]

$$
\begin{aligned}
\mathrm{R}[\Delta \mathrm{e}]=[1 & \left.+\mathrm{r}^{*} \cdot\left(1-\mathrm{t}^{*}\right)\right] \cdot \Delta \mathrm{e}-1 \\
& -\max \left\{\left(\Delta \mathrm{e}-1+\Delta \mathrm{e} \cdot \mathrm{r}^{*}\right) \cdot \tau-\mathrm{r}^{*} \cdot \mathrm{t}^{*} \cdot \Delta \mathrm{e} ; 0\right\} \\
& -\min \left\{\left(\Delta \mathrm{e}-1+\Delta \mathrm{e} \cdot \mathrm{r}^{*}\right) \cdot \tau ; 0\right\} .
\end{aligned}
$$

Für die Steuerpflichtigen des Beispiels dieses Abschnitts VI bedeutet dies:

Der Verlustabzug ist aus der Sicht des inländischen Steuerpflichtigen zulässig ab einem Endwert von $\Delta \mathbf{e} \cdot\left(1+\mathbf{r}^{*}\right)=1$, also ab einem Rückgang des Kurses auf 0,935 . Durch die Einräumung dieses Rechts im Rahmen des Anrechnungsverfahrens wird der erwartete Gewinn der Auslandsinvestition aus dem Beispiel B4a dieses Teils um 0,0035 erhöht, nämlich von knapp $4,9 \%$ auf 5,2\%. 166

Analog wird der erwartete Gewinn der grenzüberschreitenden Investition des ausländischen Steuerpflichtigen des Beispiels B4b um 0,0085 erhöht, und zwar von 1,16\% auf 2,0\%. ${ }^{167}$

Bedingung ist hier freilich - im Unterschied zur isolierten Betrachtung der Wirkung eines Anrechnungshöchstbetrages - das Vorliegen positiver Einkünfte aus anderen Quellen, mit denen die Verluste gegebenenfalls verrechnet werden können.

\section{Anrechnungsverfahren mit Abzugsmethode als Wahlrecht}

Das Außensteuerrecht einiger Länder - und dazu zählen auch die USA und Deutschland gestattet unter gewissen Voraussetzungen aber auch die Wahl der Abzugsmethode anstelle der Anrechnung ausländischer Steuern.

Bei der Abzugsmethode sind ausländische Einkünfte im Wohnsitzland steuerpflichtig, im Ausland gezahlte Steuern werden aber von der inländischen Bemessungsgrundlage auf die Welteinkünfte abgezogen.

Die Abzugsmethode ist für den Steuerpflichtigen im allgemeinen attraktiv, wenn sein gesamtes Einkommen der Periode negativ oder wenn die Steuerbelastung im Ausland sehr hoch ist. ${ }^{168}$ Im besonderen ist sie hier genau dann vorzuziehen, wenn die ausländischen Einkünfte - ein-

\footnotetext{
$166 \mathrm{Vgl}$. Seite 64 dieser Arbeit.

$167 \mathrm{Vgl}$. Seite 66 dieser Arbeit.

168 Vgl. R. Peffekoven, a.a.O., S.243; L. Fischer u. P. Warneke, Internationale Betriebswirtschaftliche Steuerlehre, 3., überarb. Aufl. 1988, S.149; T. Finne, a.a.O., S. 281 f..
} 
schließlich dem Währungsverlust - geringer sind als die ausländische Steuer. In diesem Fall wird durch den Abzug der Quellensteuer das steuerpflichtige Einkommen in stärkerem Maße reduziert als es durch die damit notwendige Hinzurechnung der ausländischen Einkünfte erhöht wird. ${ }^{169}$ Ist der Währungsverlust niedriger, sind die ausländischen Gewinne durch das Anrechnungsverfahren von einer Besteuerung im Wohnsitzland freigestellt. Das Abzugsverfahren würde in diesem Fall eine größere Belastung herstellen.

Es muß also gelten:

$$
\begin{aligned}
& \Delta e \cdot \mathbf{t}^{*} \cdot \mathbf{r}^{*}=\Delta e \cdot\left(1+\mathbf{r}^{*}\right)-1 \\
\Leftrightarrow & \Delta \mathrm{e}+\Delta \mathrm{e} \cdot \mathbf{r}^{*} \cdot\left(1-\mathrm{t}^{*}\right)=1 .
\end{aligned}
$$

Damit wird die ex ante erwartete Gesamtsteuerlast bei Vorliegen einer Quellensteuer mehr gemindert als durch den Verlustabzug, der ja die ausländische Steuer außer acht läßt.

Ein gewisser kompensierender Effekt ist zwar dadurch gegeben, daß der (negative) Grenzsteuersatz auf Währungsverluste etwas niedriger ist, denn hier schmälert die ausländische Steuer auch die inländische Bemessungsgrundlage. Ein um eine Einheit geringerer Kurs führt im Inland folglich zu einer geringeren Entlastung als durch den Verlustabzug, da auch die abziehbare ausländische Steuer schrumpft. Dieser Effekt kann aber nicht überwiegen, solange die ausländische Belastung positiv ist.

Der erwartete Endwert wird somit im Rahmen des Anrechnungsverfahrens durch das Recht, im ungünstigen Fall auf das Abzugsverfahren zurückgreifen zu können, umso stärker erhöht, je höher die ausländische Steuer ist.

Im übrigen ist sie in ihrer Wirkungsweise aber vergleichbar mit dem oben berechneten Verlustabzug. Deshalb läßt sich in gleicher Weise die Optionstheorie bemühen, um den Folgen konkrete Werte für den hier wesentlichen Zeitpunkt der Allokationsentscheidung zuzuordnen. Der Steuerpflichtige ist nämlich auch hier „Käufer“ und der Staat „Stillhalter“ von WährungsVerkaufoptionen. Wenn sich der Steuerpflichtige für die Abzugsmethode entscheidet, verringert - bei gegebenem ausländischen Gewinn - der Währungsverlust die Belastung im Wohnsitzland proportional; der Staat ist in Höhe seines Steuersatzes daran beteiligt. Der Wechselkurs, ab dem diese Entscheidung sinnvoll ist, wird durch Gleichung [B19] determiniert; er ist hier der „Ausübungspreis“.

Formal heißt das für das erwartete Nettoeinkommen $\mathrm{R}[\Delta \mathrm{e}]$ hier:

$$
\begin{aligned}
\mathrm{R}[\Delta \mathrm{e}]=[1 & \left.+\mathrm{r}^{*} \cdot\left(1-\mathrm{t}^{*}\right)\right] \cdot \Delta \mathrm{e}-1 \\
& \quad \max \left\{\left(\Delta \mathrm{e}-1+\Delta \mathrm{e} \cdot \mathrm{r}^{*}\right) \cdot \tau-\mathrm{r}^{*} \cdot \mathrm{t}^{*} \cdot \Delta \mathrm{e} ; 0\right\} \\
& \quad \min \left\{\left(\Delta \mathrm{e}-1+\Delta \mathrm{e} \cdot \mathrm{r}^{*} \cdot\left(1-\mathrm{t}^{*}\right)\right) \cdot \tau ; 0\right\} .
\end{aligned}
$$

Für die Daten des Beispiels B2 dieses Teils wirkt sich das folgendermaßen aus:

Die Anwendung der Abzugsmethode wird für den inländischen Kapitalanbieter sinnvoll, bei einem Devisenkursrückgang auf weniger als 0,969; dies entspricht einem Rückgang um 5,7\%. Die Möglichkeit des Methodenwechsels erhöht den Erwartungswert des Nettogewinns am Ende der Periode um 0,062, und zwar von 4,87\% - dem Erwartungswert beim Anrechnungsverfahren ohne Verlustausgleich - auf 5,49\%.

Für den ausländischen Anleger ist die Abzugsmethode vorteilhaft, wenn der Kurs aus deren Sicht wenigstens auf das gegenüber dem Erwartungswert um etwa 3,5\% niedrigere Niveau von 0,939 zurückgeht. Die mit dem Wahlrecht gewährte Option erhöht den erwarteten Ertrag um 0,136 von 1,16\% auf 2,52\%.

Die Berechnungen hierzu werden in Anhang III ab Seite 219 durchgeführt.

${ }^{169}$ Vgl. auch Flick/Wassermeyer/Becker, §34c EStG, Rz. 147. 
Sind Währungsgewinne und -verluste dagegen inländische Einkünfte, ist der Stellenwert der Abzugsmethode unabhängig von der Wechselkursentwicklung. Da die ausländischen Einkünfte, sowie die darauf zu entrichtende ausländische und inländische Steuerlast bei einem Kursrückgang proportional reduziert werden, bewirkt die Abzugsmethode unter der hier getroffenen Annahme eines sicheren ausländischen Gewinns insbesondere keine asymmetrische Besteuerung. Damit ändern sich auch die oben errechneten Beispielwerte durch die Berücksichtigung dieses Wahlrechts nicht.

\section{Gegenüberstellung der Ergebnisse}

Der Nettoertrag für den inländischen und den ausländischen Kapitalanleger in den Beispielen wird in der folgenden Graphik noch einmal gegenübergestellt, wenn im Rahmen des Anrechnungsverfahrens (1) der Verlustabzug nicht zulässig ist, (2) ein Verlustabzug gestattet ist und (3) der Steuerpflichtige die Abzugsmethode wählen kann. Die Abbildung B10 zeigt außerdem die Auswirkung der Höhe der Standardabweichung des erwarteten Devisenkurses auf den erwarteten Gewinn in den drei Steuersystemen:

Abb. B10: Ergebnisfunktionen einperiodiger grenzüberschreitender Investitionen in Abhängigkeit von der Volatilität des Wechselkurses bei beschränkter Anrechnung, wenn Währungsgewinne steuerrechtlich ausländischen Ursprungs sind und Verlustausgleich im Wohnsitzland (1) gestattet oder (2) nicht gestattet ist, oder (3) die Wahl der Abzugsmethode zulässig ist.

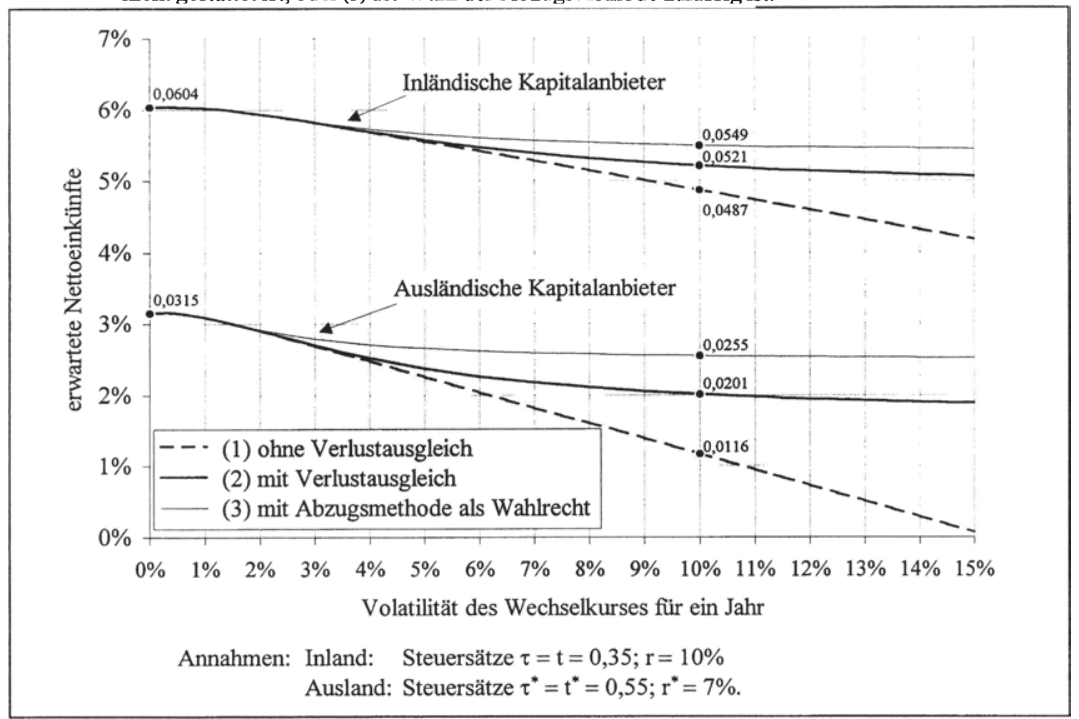

Quelle: Eigene Darstellung.

Es ist erkennbar, wie in beiden Fällen schon eine geringe Volatilität durch die Gefahr eines höheren Anrechnungsüberhangs zu einer Minderung des erwarteten Nettoertrags führt. Die Zunahme der Bedeutung des Risikos eines Überhangs in Abhängigkeit der Standardabweichung des Wechselkurses - die negative Steigung der Funktion - ist für die ausländischen Kapitalan- 
bieter größer, weil zum einen der Steuersatz an deren Wohnsitz höher ist und zum anderen dort infolge von Währungsschwankungen ein Anrechnungsüberhang erst möglich wird.

Kompensierend wirken die Optionen des Verlustabzugs beziehungsweise der Abzugsmethode bei stärkerer Volatilität, sobald auch ein währungsbedingter Verlust aus einer grenzüberschreitenden Investition nicht mehr ganz unwahrscheinlich ist.

Ein Effekt wird in Abbildung B10 nicht sichtbar, der aber aus theoretischem Blickwinkel interessant ist: Mit sehr hoher Volatilität steigen die Funktionen (2) und (3) wieder an. Der Grenzwert bei unendlicher Standardabweichung des Wechselkurses ist in beiden Steuersystemen der Nettogewinn bei ausschließlicher Wohnsitzlandbesteuerung. Die Quellensteuer wird irrelevant und Kapitalexportneutralität ist damit wiederhergestellt. Praktische Bedeutung hat dieser Aspekt jedoch wohl nicht.

Im Rahmen des Anrechnungsverfahrens bringt die Abzugsmethode als Wahlrecht die geringsten Verzerrungen durch Unsicherheit über die Währungsentwicklung mit sich, zumindest wenn das Währungsergebnis zu den ausländischen Einkünften gezählt wird. Allerdings ist es in der Realität des Steuerrechts jedenfalls für die hier betrachteten Länder nicht korrekt, von einem wirklichen Wahlrecht zu sprechen. Auf das Abzugsverfahren kann nur unter bestimmten und restriktiven Voraussetzungen zurückgegriffen werden.

Im Hinblick auf die Frage nach dem Ursprung des Währungsergebnisses zeigt aber auch schon ohne Berücksichtigung der Abzugsmethode ein Vergleich der Ergebnisse dieses Teils, daß jedenfalls der Kapitalgeber des Inlands bei einer grenzüberschreitenden Investition einen höheren Nettogewinn erwarten kann, wenn das Währungsergebnis nicht den inländischen Einkünften zugerechnet wird, nämlich 5,2\% anstelle der zuvor auf Seite 63 ausgerechneten $5,1 \%$.

Die Differenz von hier $0,1 \%$ ist freilich gering. Sie nimmt jedoch bei geringerer Volatilität zu. Ist der Ursprung der Währungserfolge das Inland, erhöht die Allokationseffizienz des Steuersystems bei begrenzter Anrechnung infolgedessen nicht zwingend. Die Frage nach der Quelle derartiger Einkünfte im Sinne des Steuerrechts ist noch unbeantwortet.

\section{Zur Quelle von Währungsgewinnen und -verlusten}

Wo entstehen Währungsgewinne und -verluste? Gleicht die Wechselkursentwicklung gerade den unterschiedlichen Kaufkraftverlust der Währungen aus, entsteht kein ökonomischer Gewinn. Somit kann auch keine Quelle im eigentlichen Sinne existieren. Ist dagegen die Kaufkraftparität verletzt, ist die Bestimmung eines wirtschaftlichen Entstehungsortes kaum möglich. Dies ist hier aber auch nicht erforderlich, denn die Frage nach der Quelle hat im Steuerrecht das Ziel, Besteuerungsansprüche aufzuteilen. Und da solche Gewinne oder Verluste nur in einem Land sichtbar werden und deshalb eine Überschneidung von Besteuerungsansprüchen verschiedener Staaten in der Realität nicht entsteht, kann die Antwort durch eine ergebnisorientierte Herangehensweise gesucht werden.

Dabei ist es im Rahmen von Kapitalimportneutralität aus der Sicht des Wohnsitzstaates sicherlich sinnvoll, das Währungsergebnis dem Einsatzort des Kapitals zuzurechnen. So wird rechtssystematisch auf einfachem Weg deren Freistellung im Wohnsitzland erreicht.

Auch im reinen Wohnsitzlandprinzip ergibt sich hier kein Problem. Das Welteinkommen ist auf Seiten der Kapitalanbieter steuerpflichtig. Es ist irrelevant, wo der Ursprung ist.

Die Frage stellt sich realistischerweise also nur aus der Sicht des Sitzlandes und nur, wenn dort Quellensteuern begrenzt anrechenbar sind. 
Die Beispielrechnungen der vorangegangenen Unterabschnitte haben für das Inland ergeben, daß der erwarte Nettoertrag (geringfügig) höher ist, wenn das Währungsergebnis ausländischen Ursprungs ist - trotz der asymmetrischen Eigenschaften dieses Steuersystems.

Zur Klärung, inwieweit diese Aussage allgemeingültig ist, verhilft die folgende Abbildung B11. Dort werden die erwarteten Nettoeinkünfte in Abhängigkeit des ausländischen Steuersatzes für drei Alternativen abgebildet, nämlich (1) wenn Währungserfolge inländischen Ursprungs sind, (2) wenn das Währungsergebnis den ausländischen Einkünften zugerechnet wird und (3) wenn es zwar ausländische Einkünfte sind, aber hinsichtlich des Devisenkursanstiegs für die Periode Sicherheit unterstellt wird. Ein ausländischer Verlust sei im Wohnsitzland von den Welteinkünften des Steuerpflichtigen abziehbar.

Abb. B11: Ergebnisfunktion einer einperiodigen grenzüberschreitenden Investition in Abhängigkeit von der Höhe des ausländischen Steuersatzes bei beschränkter Anrechnung, wenn (i) ein ansteigender Devisenkurs erwartet wird und (ii) die Quelle des Währungsergebnisses steuerrechtlich entweder das Inland oder das Ausland ist.

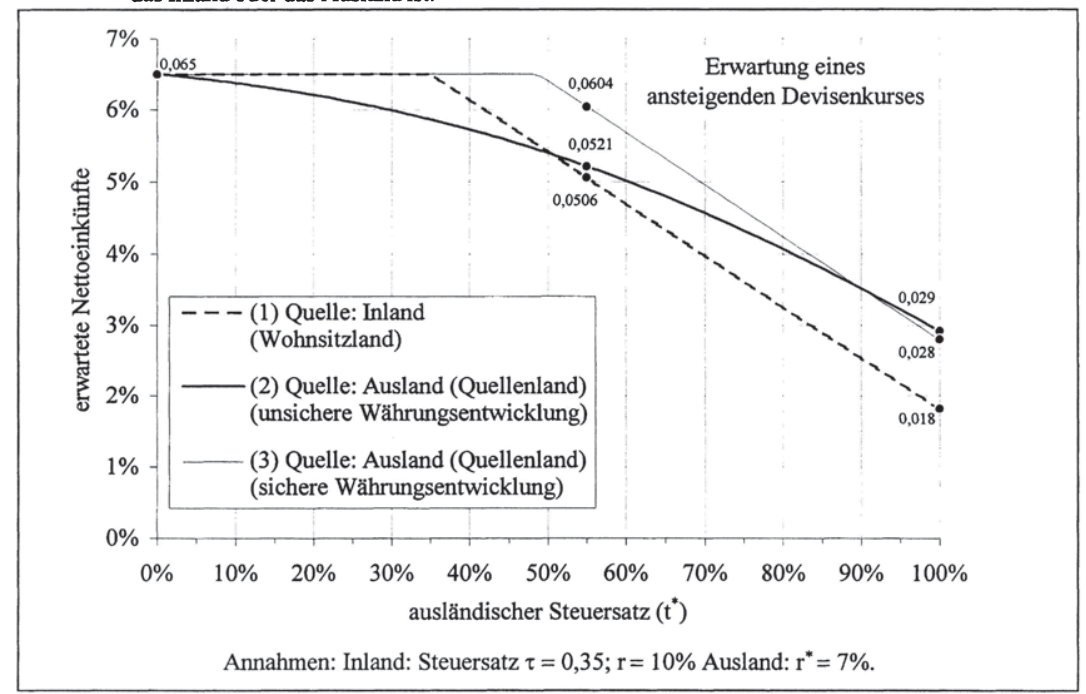

Quelle: Eigene Darstellung.

Die Randpunkte bei einem ausländischen Steuersatz von 0 und von 100 Prozent sind schnell erklärt: Bei einem ausländischen Steuersatz von $t^{*}=0$ ist ein Anrechnungsüberhang ausgeschlossen. Es gilt das Wohnsitzlandprinzip. Soweit die Abziehbarkeit von Währungsverlusten nicht eingeschränkt ist, muß das zu erwartende Ergebnis deshalb unabhängig von der Quelle des Währungserfolgs für in- und ausländische Anlagen identisch sein, hier also $6,5 \%$ betragen.

Bei einem ausländischen Steuersatz von $t^{*}=1$ fließen dem Steuerpflichtigen im Ausland keine Einkünfte zu, da sie zur Gänze als Steuer einbehalten werden. Ist das Währungsergebnis inländischen Ursprungs, wie in der gestrichelten Funktion (1) unterstellt, kann der Steuerpflichtige nur einen versteuerten Währungsgewinn erwarten, und zwar $0,028 \cdot(1-0,35)=1,8 \%$.

Günstiger ist die Situation in der zweiten Alternative. Denn der Währungsgewinn erhöht hier die ausländischen Einkünfte. Dadurch wird die Quellensteuer zu einem größeren Teil anrechenbar. Im Ausland wird der gesamte Gewinn von 0,07 durch den Staat einbehalten; in inländischer Währung sind dies $0,07 \cdot 1,028=0,072$. Die Quellensteuer ist höher als die erwartete Steuer im Wohnsitzland vor der Anrechnung von $0,035(=0,1 \cdot 0,35)$. Im Inland 
fällt damit keine Steuer an. Bei Sicherheit hinsichtlich der Währungsentwicklung beläuft sich der Nettogewinn auf $0,1-0,072=2,8 \%$. Der Währungsgewinn ist de facto steuerfrei.

Die Berücksichtigung von Währungsrisiko führt in diesem Steuersystem zu einer weiteren Erhöhung des erwarteten Endwertes, wie ein Vergleich der Funktionen (2) und (3) in Abbildung B11 bei einem Quellensteuersatz von 100\% zeigt. Infolge der Möglichkeit eines Verlustabzugs im Wohnsitzland geht mit einem Währungsverlust nämlich eine Minderung der inländischen Steuer einher, wenn der Devisenkurs am Ende der Periode weniger als 0,935 beträgt, also um etwa 9\% unter dem Erwartungswert von 1,028 liegt. Der Anrechnungshöchstbetrag ist gemäß Gleichung [B14] auf Seite 61 bei einem Kurs von 1,149 erreicht. Eine zusätzliche Steuer im Wohnsitzland entsteht somit erst bei einem Kursanstieg um knapp 12\%. ${ }^{170}$ Das quantitative Gewicht dieses Effekts ist hier mit 0,1\% allerdings sehr gering und seine praktische Bedeutung auch angesichts der unterstellten Höhe der Tarifbelastung im Ausland fraglich.

Demgegenüber ist die Chance, eine Anrechnungsgutschrift auf Kursgewinne anwenden zu können, maßgeblich dafür, daß die Zurechnung des Währungsergebnisses zu den ausländischen Einkünften vorteilhaft sein kann. Wie die Verläufe der Funktionen in Abbildung B11 zeigen, ist das hier bei hoher Quellensteuerbelastung der Fall.

Wird nochmals Sicherheit hinsichtlich der Währungsentwicklung unterstellt, liegt dies auf der Hand. Der ausländische Steuersatz ist höher und außerdem wird der Devisenkurs ansteigen. Es kommt deshalb offensichtlich zu einer geringeren Verzerrung, wenn Währungsgewinne den ausländischen Einkünften zugerechnet werden, weil derartige Gewinne in das Anrechnungsverfahren einbezogen werden. Funktion (3) der Abbildung B11, der die Annahme eines sicheren Kursgewinns nach Maßgabe der Zinsparität zugrunde liegt, zeigt dementsprechend höhere Nettoeinkünfte, sobald der Steuersatz im Ausland größer ist als im Inland von 35\%.

Die Berücksichtigung von Währungsrisiko reduziert den erwarteten Endwert von ausländischem Kapitaleinsatz bei asymmetrischer Besteuerung durch die Zurechnung des Währungsergebnisses zu den ausländischen Einkünften. Durch Vergleich des Verlaufs der Funktion (3) mit Funktion (2) in Abbildung B11 ist dies auch hier wieder erkennbar. Die Entlastung durch den Verlustabzug ist gering und unabhängig von der Höhe der Quellensteuer. ${ }^{171}$ Das Risiko eines Anrechnungsüberhangs ist demgegenüber abhängig von der Höhe der ausländischen Steuer. Die Benachteiligung ist umso größer, je niedriger die Abgabe im Quellenland, solange ohne Währungsrisiko kein Anrechnungsüberhang entstehen würde. Danach verringert sich der Abstand freilich wieder, da bei sicherer Kursentwicklung die Abgabe am Einsatzort für die Gesamtsteuerlast nicht mehr relevant ist.

Interessanter ist der Vergleich der Funktionen (1) und (2), also der erwarteten Steuerlast unter dem Einfluß des Währungsrisikos bei Zurechnung der Kursgewinne und -verluste zu inländischen beziehungsweise $\mathrm{zu}$ ausländischen Einkünften. Die Höhe der diskriminierenden Belastung der grenzüberschreitenden Investition steht hier im Spannungsfeld der Benachteiligung durch volle Besteuerung des Währungsergebnisses im ersten Fall und durch den unsicheren Anrechnungsüberhang im zweiten Fall. Bei der in den letzten Abschnitten unterstellten Tarifbelastung im Quellenland von $t^{*}=0,55$ überwiegt-wie auch schon in Abschnitt IV gesagt - der zweite Effekt: Die Zurechnung zu den ausländischen Einkünften führt zu einer geringeren Diskriminierung. Aber schon bei einem nur geringfügig niedrigeren Steuersatz kehrt sich die Rangfolge um. Eine Zurechnung zu den inländischen Einkünften

${ }^{170}$ Kompensierend wirkt aber, daß der effektive Steuersatz auf Währungsgewinne mit hier 33,6\% geringer ist als die Erstattung von $37,5 \%$ bei Währungsverlusten. Der effektive Satz ergibt sich aus der Anzahl der Optionen, die in den Anhängen I und II berechnet wurden.

${ }^{171}$ In der Abbildung B11 bedeutet dies, daß Funktion(2) um den Betrag der Minderung des erwarteten Endwertes parallel nach unten verschoben wird, wenn dieser Verlustabzug nicht gestattet ist. 
wäre vergleichsweise günstiger. Wenn der Steuersatz im Ausland nicht größer ist als im Inland, kommt es augenscheinlich überhaupt nicht zu einer Diskriminierung.

Der Schnittpunkt der beiden Funktionen (1) und (2) ist zum einen abhängig von der Höhe des Währungsrisikos. Die Perspektive, eine Anrechnungsgutschrift auf Kursgewinne anwenden zu können und so die Steuerlast im Wohnsitzland zu mindern, ist umso unbedeutender, je niedriger die Schwankung des Kurses ist. Für Abbildung B11 bedeutet dies: die Konvexität der Funktion (2) ist umso größer, je niedriger die Wechselkursschwankung, bis sie - bei sicherer Kursentwicklung - der Funktion (3) entspricht. Dagegen ist die Volatilität bei der Zurechnung des Währungsergebnisses zu den inländischen Einkünften unerheblich.

Der Schnittpunkt ist zum anderen abhängig von der antizipierten Kursentwicklung.

Das verdeutlicht die nachfolgende Abbildung B12. Dort werden die Funktionen aus der Sicht des ausländischen Kapitalanbieters dargestellt, der bei der grenzüberschreitenden Investition einen höheren Gewinn als in seinem eigenen Währungsraum erzielt und demgemäß einen zurückgehenden Devisenkurs erwartet.

Abb. B12: Ergebnisfunktion einer einperiodigen grenzüberschreitenden Investition in Abhängigkeit von der Höhe des ausländischen Steuersatzes bei begrenzter Anrechnung, wenn (i) ein zurückgehender Devisenkurs erwartet wird und (ii) die Quelle des Währungsergebnisses steuerrechtlich entweder das Inland oder das Ausland ist

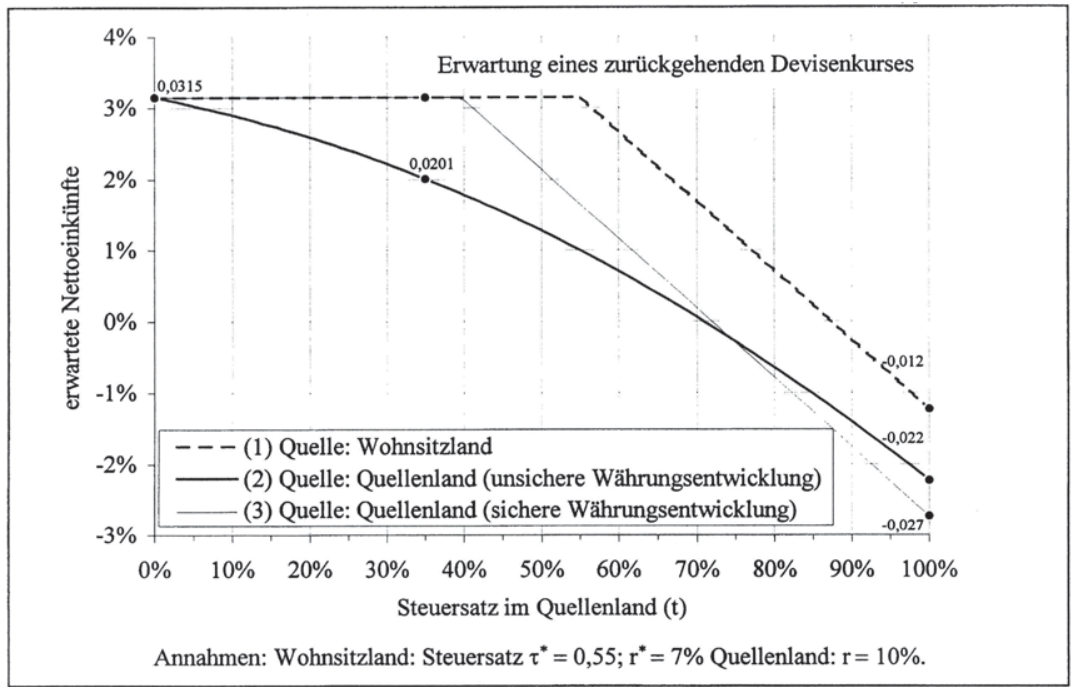

Quelle: Eigene Darstellung.

Schon wenn Sicherheit hinsichtlich der Wechselkursentwicklung unterstellt wird, zeigt sich, daß die Benachteiligung von Kapitalexport bei einem geringeren Quellensteuersatz eintritt, falls das Währungsergebnis ausländischen Quellen zugerechnet wird (Funktion (3)). Da ein Kursverlust sicher eintreten wird, ist in dieser Situation eine Reduzierung der ausländischen Einkünfte relativ zur ausländischen Steuerlast die Folge.

Die asymmetrische Besteuerung des Währungsergebnisses erhöht die Benachteiligung zusätzlich und umso mehr, je größer das Währungsrisiko ist. Deshalb sind in diesem Fall für alle denkbaren ausländischen Steuersätze die Nettoeinkünfte eindeutig höher, wenn als Quelle des Währungsgewinnes das Inland bestimmt wird. 
Allerdings wirft dieser Fall ein Problem anderer Natur auf: Wird das Währungsergebnis den inländischen Einkünften zugerechnet, beinhaltet dies nämlich im Ergebnis eine Erstattung von im Ausland gezahlten Steuern durch den inländischen Staat. Denn die Höhe des steuerpflichtigen ausländischen Gewinnes und des erwarteten Währungsverlustes stehen zumindest bei der Grenzinvestition in ökonomischem Zusammenhang zueinander. Dennoch muß der inländische Staat im Falle eines Währungsverlustes eine negative Steuerzahlung auf diese Einkünfte akzeptieren. Zwar ist die Beziehung hier nicht so offensichtlich wie bei der allokativ optimalen symmetrischen Anrechnung, die eine direkte Erstattung durch das Inland erfordern würde. Dennoch bewirkt auch die Lokalisierung von Währungsverlusten im Wohnsitzland mittelbar das, was die Staaten durch die Begrenzung der Anrechnung gerade verhindern wollen.

Wenn das Wohnsitzland das Währungsergebnis als ausländische Einkünfte charakterisiert, besteht zudem für das Quellenland ein Anreiz, die eigene Steuer auf Kapitaleinkünfte ausländischer Anbieter zu reduzieren. Aus der Sicht des Quellenlandes ist die Höhe der eigenen Steuer für Kapitalimport hiernach nicht irrelevant, solange das Niveau niedriger ist als im Herkunftsland. Denn es kommt nicht nur zu einer Verlagerung von Steuereinnahmen, wenn das Quellenland die Einkommensteuer bis auf das Niveau des Ursprungslandes anhebt. Ist die Besteuerung im Wohnsitzland nicht symmetrisch, verursacht bei Währungsrisiko schon eine geringe Quellensteuer eine Benachteiligung von Kapitalimport. Aber auch bei einem symmetrischen Steuersystem im Ausland ist die erwartete Währungsentwicklung zu beachten.

Aus den Überlegungen in diesem Abschnitt V anhand der beiden Beispiele lassen sich folgende allgemeine Aussagen ableiten:

Die relevanten Parameter für die Bestimmung der steuerrechtlichen Quelle von Währungsgewinnen und -verlusten sind der erwartete Devisenkurs und die relative Höhe des Quellensteuersatzes im Vergleich zur Belastung im Wohnsitzland.

Ist der Quellensteuersatz nicht größer als der Satz im Wohnsitzland und die Kursentwicklung nicht sicher, dann ist die Belastung immer geringer, wenn das Währungsergebnis inländischen Ursprungs ist, weil ein Anrechnungsüberhang hier nicht erwartet wird.

Das gleiche Ergebnis trifft zu, wenn ein rückläufiger Devisenkurs erwartet wird, da der antizipierte Währungsverlust nur mit Sicherheit steuermindernd geltend gemacht werden kann, falls das Währungsergebnis den Einkünften aus dem Wohnsitzland zugerechnet wird. Hier kann zwar der oben beschriebene Effekt kompensierend wirken, daß ein abziehbarer Währungsverlust wahrscheinlicher ist als ein steuerpflichtiger Währungsgewinn, wenn bei dem Gewinn im Ausland ein sehr hoher Anrechnungsüberhang entsteht. Diese Möglichkeit wird indes keine praktische Bedeutung haben, da sie einen unrealistischen Quellensteuersatz voraussetzt und geringe quantitative Auswirkungen hat.

Übrig bleibt die problematische Kombination einer Investition in einen Währungsraum mit einer höheren Quellensteuer und der gleichzeitigen Erwartung eines steigenden Wechselkurses. Sind Währungsgewinne ausländische Einkünfte, wird hier eine Minderung der Steuerlast auf Währungsgewinne durch den Anrechnungsüberhang bei den ausländischen Gewinnen antizipiert werden. Je geringer das Währungsrisiko und je höher der Abstand der Steuersätze in Quellen- und Wohnsitzland, umso wahrscheinlicher ist es, daß damit der Nachteil asymmetrischer Besteuerung in den Hintergrund tritt und der Ursprung des Währungsergebnisses im Ausland eine geringere zusätzliche Belastung durch das Anrechnungssystem bewirkt.

Für die Formulierung einer allgemeinen Regel kann also die Position unterstützt werden, dernach das Währungsergebnis aus allokativen Überlegungen den inländischen Einkünften zugerechnet werden sollte. In der überwiegenden Mehrzahl denkbarer Situationen führt dieses 
Vorgehen zu einer geringeren zusätzlichen Belastung von grenzüberschreitenden Investitionen als bei Zurechnung zu ausländischen Einkünften.

Diese Aussage gilt umso mehr, als zumindest mit Blick auf die Grenzinvestition die Diskriminierung an sich und nicht deren Höhe entscheidend ist. Denn in allen Fällen ist zumindest bis zu dem Punkt eines Anrechnungsüberhangs Kapitalexportneutralität nur dann gewahrt, wenn Währungsgewinne und -verluste einkommensteuerlich als inländische Einkünfte angesehen werden.

Aus allokativem Blickwinkel ist allerdings auch zu beachten, wo die mit der asymmetrischen Besteuerung verbundene zusätzliche Last tatsächlich anfällt. Dabei wurde weiter oben festgestellt, daß zumindest in dem abstrakten Analyserahmen dieses Teils die Diskriminierung von Kapitalexport überhaupt nur allokative Folgen haben muß, wenn Kapitalexport notwendig ist, wenn also das betrachtete Land Nettokapitalexporteur ist. Ist dies der Fall, wird der Versuch der inländischen Kapitalgeber, die diskriminierte ausländische Investitionen durch Anlagen im Inland zu substituieren, im Ergebnis eine Begünstigung der inländischen Investoren zur Folge haben.

\section{Zusammenfassung}

In diesem Teil wurde die Besteuerung von Währungsgewinnen und -verlusten als Bestandteil des Einkommens aus einperiodigem grenzüberschreitenden Kapitaleinsatz analysiert.

Ausgangspunkt war in Abschnitt I die Frage, ob die Kapitalmärkte ihre internationale Allokationsfunktion für den Faktor Kapital effizient erfüllen. Obgleich die Effizienzmarkthypothese in der Literatur nicht unumstritten ist und empirisch bislang nicht zweifelsfrei bestätigt werden konnte, wird in dieser Arbeit die Position vertreten, daß die Hypothese plausibel ist.

Auf der Grundlage dieser Annahme konnte der Gedanke einer international neutralen Besteuerung des Faktors Kapital dargestellt und die Ansätze der Kapitalexport- und der Kapitalimportneutralität eingefuihrt werden.

In Abschnitt II wurde der Blickwinkel gewechselt und der Stellenwert des Währungsrisikos bei der Investitions- und Finanzierungsentscheidung der Unternehmen betrachtet. So konnten zunächst zwei Arten von Risiken als Folge flexibler Wechselkurse unterschieden werden. Gewinn und Marktwert einer Unternehmung können sich durch wechselkursbedingte Preisänderungen auf den Beschaffungs- und Absatzmärkten in der Währung ihres Belegenheitslandes ändern (der Wettbewerbseffekt). Daneben kann der Marktwert, ausgedrückt in der Währung eines ausländischen Kapitalgebers, infolge einer Wechselkursänderung steigen oder sinken (der Umwechslungseffekt).

Für die internationale Kapitalallokation ist der Wettbewerbseffekt als eine Determinante der Produktivität des Faktors am Einsatzort zu verstehen. Das Risiko wird von allen Kapitalgebern unabhängig von deren Wohnsitz getragen. Ein Umwechslungseffekt dagegen berührt nur ausländische Kapitalgeber und wird deshalb hier als das Währungsrisiko bezeichnet.

Damit konnte sich der Blick auf die Passivseite der Bilanz einer Unternehmung beschränken. Es wurde gezeigt, daß unter bestimmten Voraussetzungen nicht nur von verschiedenen Formen der Finanzierung abstrahiert werden kann, sondern daß auch die Währung der Finanzierung für den Marktwert irrelevant ist.

Voraussetzung ist insbesondere eine nicht diskriminierende Besteuerung.

Die einkommensteuerliche Behandlung von Währungsgewinnen und -verlusten war das Thema der Abschnitte III bis V. 
In Abschnitt III wurde gefragt, wie Gewinne und Verluste besteuert werden sollten, die durch erwartete Wechselkursänderungen entstehen. Das Währungsrisiko wurde an dieser Stelle noch durch die Annahme symmetrischer Besteuerung ausgeklammert. Kapitalanbieter und Kapitalnachfrager bildeten ihre Erwartung bezüglich der Kursentwicklung anhand der Kaufkraft- und der Zinsparitätenhypothese. Die Kaufkraftparität war Anker für die langfristig gleichgewichtige Beziehung der Währungen zueinander und die Zinsparität die Arbitragebeziehung auf den Kapitalmärkten bei Abweichungen von diesem Gleichgewicht.

Ein solches Arbitragegleichgewicht muß bei Vernachlässigung nichtsteuerlicher Einflüsse auch gegeben sein, wenn die Ziele einer kapitalexport- oder einer kapitalimportneutralen Besteuerung - der effiziente Einsatz beziehungsweise die optimale Aufbringung des Faktors Kapital - erreicht werden. Die Ansätze wurden deshalb zusammengeführt.

Die Alternativen des einperiodigen Kapitaleinsatzes im kleinen Inland oder im Ausland wurden aus dem Blickwinkel der Allokationsentscheidung, das heißt ex ante auf Grund der erwarteten Erträge und Kapitalkosten verglichen. Für die Länder galt, daß sich ohne Besteuerung und Wechselkursänderungen die Grenzproduktivitäten beziehungsweise -erträge angleichen. Unterstellt wurden zudem risikoneutrale Präferenzen der Marktteilnehmer sowie vollkommene internationale Kapitalmobilität.

Ergebnis: Ein Arbitragegleichgewicht ist bei kapitalexportneutraler Besteuerung des Einkommens dann möglich, wenn das Währungsergebnis wie andere Kapitalerträge im Wohnsitzland belastet wird. Für kapitalimportneutrale Besteuerung ist ein solches Gleichgewicht nur denkbar - vorausgesetzt die Investition wurde nicht durch (Fremd-) Kapital in der Währung des Ursprungslandes finanziert -, wenn Währungsgewinne oder -verluste weder im Quellen- noch im Wohnsitzland steuerpflichtig sind.

Sollen zudem noch inflationär bedingte Gewinne freigestellt werden, braucht lediglich die Bemessungsgrundlage um die Rate der Geldentwertung in dem jeweils besteuernden Land gekürzt zu werden. Auf Grund dessen ist sowohl das Ziel kapitalexport- als auch kapitalimportneutraler Besteuerung auch dann realisierbar, wenn die Staaten hinsichtlich der Behandlung von Scheingewinnen unterschiedlich verfahren.

Im Mittelpunkt des Abschnitts IV standen die Auswirkungen des Risikos unerwarteter Wechselkursänderungen in einem Steuersystem, das das Währungsergebnis asymmetrisch besteuert und in Abschnitt V wurde der Frage nach einer sinnvollen Quelle von Währungsgewinnen und -verlusten im Sinne des Steuerrechts nachgegangen.

Es wurde zunächst das Anrechnungssystem und der Verlustabzug isoliert betrachtet und die Ergebnisse danach zusammengefuihrt. Außerdem wurde die Möglichkeit einbezogen, daß das Steuerrecht auch die Anwendung des Abzugsverfahrens als Wahlrecht zuläßt.

Asymmetrie besteht im Anrechnungsverfahren durch die Gefahr von Anrechnungsüberhängen als Folge nicht erwarteter Währungsverluste. Im Gegensatz dazu erhöhen Währungsgewinne die Steuerlast im Wohnsitzland, wenn der Anrechnungshöchstbetrag überschritten wird. Dieser Effekt kann reduziert werden durch einen Verlustabzug und stärker noch durch die Perspektive, auch das Abzugsverfahren wählen zu können.

Die Bedeutung der verschiedenen Formen asymmetrischer Besteuerung wurde anhand von zwei Beispielen durch Berechnung der erwarteten Endwerte der Alternativen mit Hilfe der Optionsbewertungstheorie veranschaulicht. Die Optionstheorie bietet ein bislang wenig genutztes Hilfsmittel zur Beurteilung der Folgen asymmetrischer Steuern. Die Höhe der Steuerlast kann bestimmt werden und die Wirkungsrichtung von Einflußfaktoren läßt sich ohne weitere Herleitung aus der Theorie übernehmen. Hier ist die Optionstheorie besonders geeignet, da das Währungsrisiko in Form historischer oder impliziter Volatilitäten gemessen werden kann.

Es zeigte sich, daß der erwartete Endwert grenzüberschreitenden Kapitaleinsatzes in nicht zu vernachlässigender Höhe gemindert wird - und zwar sowohl wenn nach Maßgabe der zu 
erwartenden Währungsentwicklung ein Anrechnungsüberhang antizipiert werden muß als auch wenn dies nicht so ist. Das Ausmaß der Diskriminierung von Kapitalexport ist umso größer, je höher die Wahrscheinlichkeit eines Anrechnungsüberhangs, das Währungsrisiko und der am Periodenende erwartete Devisenkurs sind.

Die ungleiche Besteuerung nicht erwarteter Gewinne und Verluste hat ihre Ursache in der unterstellten Zurechnung des Währungsergebnisses zu ausländischen Quellen.

In der Literatur wurde deshalb vorgeschlagen,

(1) nur erwartete Währungsgewinne oder -verluste in das Anrechnungsverfahren einzubeziehen oder

(2) das Währungsergebnis steuerrechtlich generell den inländischen Einkünften zuzurechnen. Aus allokativem Blickwinkel ist die erste Alternative abzulehnen. Der zweite Vorschlag fuihrt dagegen in der überwiegenden Mehrzahl denkbarer Situationen zu einer geringeren zusätzlichen Belastung von grenzüberschreitenden Investitionen als die Zurechnung des Währungsergebnisses zu den ausländischen Einkünften. Für die Formulierung einer allgemeinen Regel wird die Position deshalb hier unterstützt.

Zwei Argumente relativieren diese Aussage allerdings: Zum einen kann dies im Ergebnis die Erstattung von Quellensteuern durch den Fiskus des Wohnsitzlandes implizieren. Die Zurechnung zu ausländischen Einkünften bildet dagegen einen Anreiz, international diskriminierende Quellensteuern zu reduzieren. Zum anderen hat zumindest innerhalb des hier gewählten Analyserahmens die Diskriminierung von Kapitalexport überhaupt nur allokative Folgen, wenn Kapitalexport notwendig ist, wenn also das betrachtete Land Nettokapitalexporteur ist. 


\section{Währungsgewinne und -verluste im U.S.-amerikanischen Steuerrecht}

Die theoretischen Überlegungen des vorangegangenen Teils B haben den Stellenwert von Währungsgewinnen und -verlusten im Rahmen der Besteuerung des Kapitaleinkommens bei der internationalen Kapitalallokation aufgezeigt. In diesem Teil ist nun zu prüfen, welche allokativen Folgen sich daraus in Bezug auf das in den USA seit der Steuerreform von 1986 bestehende Recht ableiten lassen.

Mit der Steuerreform wurde erstmalig eine umfassende gesetzliche Grundlage für diesen Bereich des Außensteuerrechts geschaffen. Doch fußen die darin verankerten Methoden zur Ermittlung und Umrechnung der Gewinne in wichtigen Bereichen auf der früheren Rechtslage. Die zuvor gebräuchlichen Verfahren sind deshalb auch der Ausgangspunkt der nachfolgenden Untersuchung. Es waren namentlich die Umsatz-, die Stichtag- und die Fristigkeitmethode.

Die Stichtagmethode ist seither in der Regel für Direktinvestitionen im Ausland maßgeblich, wurde allerdings für Auslandsengagements in stark inflationären Währungsräumen mittlerweile wieder aufgehoben. Statt dessen sind Richtlinien erlassen worden, die sich an die Fristigkeitmethode anlehnen aber verkürzte Bilanzperioden vorsehen.

Daneben gilt eine Form der Umsatzmethode für einzelne Fremdwährungsgeschäfte, welche nicht mit einem unmittelbaren Engagement im Ausland verbunden sind. Hauptsächlich sind dies die Bereitstellung von Fremdkapital sowie Währungstermingeschäfte und Kurssicherungstransaktionen.

Abschließend wird auch die Besteuerung von Privatvermögen kurz betrachtet. Hier veränderte die Steuerreform jedoch die Behandlung von Währungsgewinnen und -verlusten im wesentlichen nur durch die - inzwischen wieder aufgehobene - Angleichung der Tarifbelastung auf Veräußerungsgewinne und ordentliches Einkommen.

Ansonsten wurde im Gesetzeswerk und den erlassenen Steuerrichtlinien mit den Umrechnungsmethoden Charakter und Entstehungsort der Einkünfte und auch der Zeitpunkt der Besteuerung von Währungsgewinnen und -verlusten genau festgelegt.

Der letzte Aspekt - der Zeitpunkt der Erhebung der Steuer - stellt ein elementares Problem der Besteuerung im allgemeinen und auch der Besteuerung von Währungsgewinnen und -verlusten im besonderen dar. In Teil B wurde dies durch die Annahme einperiodiger Investitionen ausgeblendet. Die Auswirkungen einer Besteuerung zum falschen Zeitpunkt sind ja bekannt und nicht spezifisch für das Thema dieser Arbeit. Bei einer Analyse geltenden Steuerrechts läßt sich diese Annahme aber dennoch nicht aufrecht erhalten. Der Besteuerungszeitpunkt und die damit in Zusammenhang stehende Abgrenzung der Bemessungsgrundlage ist ein Schwerpunkt der Regelungen, der sich nicht trennen läßt. Dies trifft insbesondere auf die erwähnte Umsatzmethode zu, weil dabei Transaktionen einer ausländischen Niederlassung noch keinen Anlaß zur Besteuerung von Kursgewinnen der inländischen Kapitalgeber bieten. Deshalb wird der Aspekt hier, bezogen auf die tatsächliche Rechtslage, berücksichtigt.

Andererseits muß der Blickwinkel in einem Punkt eingeschränkt werden: Es können nur Auswirkungen der Besteuerung auf den Kapitalexport der USA betrachtet werden, da sich Teil C auf das U.S.-Steuersystem konzentriert. Eine Untersuchung, die auch Kapitalimport einschließt, wäre zu umfangreich. Sie ist zudem nicht realistisch, da die zusammengefaßte Belastung der U.S.-Quellenbesteuerung und der Steuer am Wohnsitz aller übrigen Länder betrachtet werden müßte. Formal läßt sich diese Einschränkung erreichen, indem für den Rest der Welt kapitalexportneutrale Besteuerung unterstellt wird: dort sei das Einkommen der 
Kapitalanbieter symmetrisch und ohne zeitliche Verzögerung steuerpflichtig. Kapitalnachfrager können hiernach immer auf das Angebot des Weltmarkts ausweichen.

Darstellung und Analyse der Besteuerung von Währungsgewinnen und -verlusten ist Abschnitt II dieses Teils $\mathrm{C}$ vorbehalten, der sich vom Aufbau her an die Struktur der durch die Steuerreform von 1996 geschaffenen Regelungen anlehnt. Vorangestellt werden in dem nachfolgenden Abschnitt I aber relevante Grundlagen zum Verständnis des U.S.-Steuerrechts. Der Teil endet mit einer zusammenfassenden Beurteilung in Abschnitt III.

\section{Grundlagen zur Besteuerung ausländischer Einkünfte}

Um die Besteuerung von Währungsgewinnen und -verlusten durch die USA verstehen zu können, ist die Kenntnis einiger Grundlagen des dortigen Steuerrechts notwendig:

Steuersubjekte der U.S.-Einkommensteuer werden nach Steuerinländern und -ausländern unterschieden. Deren Kapitaleinkommen kann entweder als sogenanntes ordentliches Einkommen oder als Veräußerungsgewinn in den USA steuerpflichtig sein.

Einkommen, das Steuerinländer im Ausland erzielen, ist in den USA steuerpflichtig. Die Steuer wird auf Gewinne, welche durch eine ausländische Kapitalgesellschaft erwirtschaftet wurden, vom Grundsatz her zum Zeitpunkt Ausschüttung erhoben. Daneben ist aber eine weitreichende Zugriffsbesteuerung zu beachten.

Abgaben, die auf das ausländische Einkommen am Entstehungsort erhoben werden, sind unter bestimmten Voraussetzungen anrechenbar. Zu diesem Zwecke werden zunächst die Bruttoeinkünfte nach in- und ausländischen Quellen getrennt. Anschließend müssen die bei der Erzielung der ausländischen Einkünfte entstandenen Aufwendungen zugerechnet werden. Die Bestimmung des Entstehungsortes ist dabei für Bruttoeinkünfte und Aufwendungen nach gänzlich unterschiedlichen Regelungen vorzunehmen. In einem dritten Schritt sind die Einkünfte aus allen ausländischen Quellen in sogenannten Körben zusammenzufassen. Für jeden der Körbe muß die anrechenbare ausländische Steuerlast separat errechnet werden.

Diese soeben genannten Aspekte der Besteuerung in den USA werden nachfolgend beschrieben.

\section{Steuersubjekte der U.S.-Einkommensteuer}

Das amerikanische Einkommensteuergesetz - der „Internal Revenue Code“ - erhebt in seinem ersten Paragraphen (IRC §1) den Anspruch, eine progressive Steuer auf das Einkommen jeder natürlichen Person zu erheben. In IRC §11(a) wird ein ebensolches Recht für das Einkommen juristischer Personen formuliert. Diese umfassende Forderung wird an späterer Stelle des Gesetzestextes für ausländische juristische und natürliche Personen freilich eingeschränkt: sie sind in den Vereinigten Staaten beschränkt steuerpflichtig mit ihrem Einkommen, das auf dem Gebiet der USA entsteht. ${ }^{1}$

Ein Steuerinländer ist dagegen mit seinen Welteinkünften unbeschränkt steuerpflichtig.

1 Für natürliche Personen IRC §871 oder §877 i.V.m. IRC §2(d); für juristische Personen IRC §11(d). 
Der Begriff des Steuerinländers umfaßt bei Einzelpersonen Gebietsansässige und darüber hinaus außerdem sämtliche weiteren Staatsbürger des Landes. ${ }^{2}$

Unternehmen werden zur Besteuerung in den USA nach drei Typen unterschieden: ${ }^{3}$ Wird die Gesellschaft als Kapitalgesellschaft (,corporation“")4 eingeordnet, ist sie als juristische Person selbständige Einheit und damit steuerpflichtig. Bei einer Personengesellschaft (,partnership“) $)^{5}$ werden dagegen die Gesellschafter mit ihrem Anteil am Gewinn der Gesellschaft besteuert.

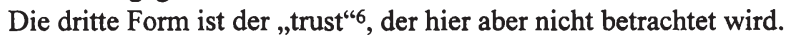

Die Besteuerung einer Kapitalgesellschaft richtet sich nach dem Ort ihrer Gründung. Ist die Gründung nach den zivilrechtlichen Gesetzen der USA beziehungsweise eines dessen Bundesstaaten vollzogen worden, ist die Körperschaft Steuerinländer und mit ihren Welteinkünften dort unbeschränkt steuerpflichtig.?

Die Definition einer Gesellschaft als Steuersubjekt ergibt sich allerdings nicht zwingend aus ihrer zivilrechtlichen Einordnung als Kapitalgesellschaft. Dies ist eine Folge der föderalistischen Struktur des Rechtssystems der USA. Zwar ist der IRC Gesetz der Vereinigten Staaten und infolgedessen für Steuerpflichtige aller Gliedstaaten gleichermaßen gültig, die zivilrechtliche Gesetzgebung liegt jedoch weitgehend in den Händen der einzelnen Bundesstaaten. Prinzipiell wird aber jede Gesellschaft, die nach den Gesetzen eines Bundesstaates als Kapitalgesellschaft gegründet wurde, auch im Steuerrecht als solche angesehen. ${ }^{8}$ Darüber hinaus kann allerdings eine Personengesellschaft bundessteuerrechtlich als ,association" eingeordnet werden, ${ }^{9}$ wenn sie wesentliche Merkmale einer typischen Kapitalgesellschaft aufweist. ${ }^{10}$ Sie wird dann steuerlich wie eine Körperschaft behandelt.

In gleicher Weise wird bei der Einordnung ausländischer Gesellschaften vorgegangen. Demzufolge wird steuerrechtlich eine ausländische Kapitalgesellschaft"1 (,foreign corporation“)

2 Es kommt hier das Nationalitätsprinzip zur Anwendung, denn der umfassende Besteuerungsanspruch in IRC § 1 wird an keiner Stelle grundsätzlich eingeschränkt für Personen, die zwar Staatsbürger der Vereinigten Staaten sind, ihren Lebensmittelpunkt jedoch in einer anderen Nation haben. J. Isenbergh, International Taxation, Teil I, Boston u.a. 1990, S.15.

3 E. Boles, Gesellschaften im US-Einkommensteuerrecht, München 1993, S. 3.

4 IRC $\S 11$.

5 IRC $\S 701$.

6 IRC $\S 641$.

7 IRC §7701(a)(4) und auch IRC §7701(a)(5); J. Isenbergh, International Taxation, Teil I, a.a.O., S.16.

8 P.R. McDaniel, H.J. Ault, M.J. McMahon, Jr. u. D.L. Simmons, Federal Income Taxation of Business Organizations, Westbuy, NY. 1991, S.308.

9 IRC $\S 7701(a)(14)$ i.V.m. IRC $\$ 7701(a)(1)$, IRC $\S 7701(a)(3)$.

10 Mindestens vier der folgenden sechs Merkmale einer typischen Kapitalgesellschaft müssen erfüllt sein: (1) die Beteiligung von Gesellschaftern; (2) ein Absicht der Weiterführung der Geschäftstätigkeit mit dem Ziel, Gewinne zu erwirtschaften; (3) die unbegrenzte Lebensdauer des Unternehmens (unabhängig von Tod, Rücktritt usw. einzelner Gesellschafter); (4) eine zentralisierte Geschäftsleitung (es dürfen nicht alle Gesellschafter an der Geschäftsführung beteiligt sein); (5) eine Haftungsbeschränkung und schließlich (6) die freie Übertragbarkeit der Eigentumsrechte. Reg. §301.7701-1 u. Reg. \$301.7701-2; P.R. McDaniel, H.J. Ault, M.J. McMahon, Jr. u. D.L. Simmons, a.a.O., S.27. Die („Check-the-Box“-)Regelungen wurden mit Wirkung zum 1.8.1998 durch die Einführung eines Wahlrechts für in den USA gegründete Personengesellschaften und „Limited Liability Companies" sowie für die meisten ausländischen Gesellschaften liberalisiert und vereinfacht. Vgl. Eli H. Fink, Final 'Check-the-Box' Regulations Issued, in: Intertax, 25.Jg. (1997), S.106; M. Apelt, Der abkommensrechtliche Nutzungsberechtigte aus US-Sicht - Neue Quellensteuerrichtlinien des IRS, in: Internationales Steuerrecht, 6.Jg. (1997), S.235f.

11 Im Unterschied zu einer in einem U.S.-Bundesstaat gegründeten Gesellschaft werden nach ausländischem Recht gegründete Körperschaften nicht prinzipiell steuerrechtlich als solche eingeordnet. Vgl. E. Boles, a.a.O., S.106-137. Beispielsweise wurde eine deutsche $\mathrm{GmbH}$ in den USA steuerrechtlich nicht regelmäßig als Körperschaft eingeordnet, wenn die Merkmale nicht vorlagen. Vgl. ebda., S.107f. m.w.N.. 
identifiziert, wenn die Unternehmung (i) nach U.S.-Steuerrecht als Kapitalgesellschaft eingeordnet werden kann ${ }^{12}$ und (ii) im Ausland gegründet wurde. ${ }^{13}$

Im Unterschied zu Kapitalgesellschaften ist für Personengesellschaften das Vorhandensein eines Handels oder Gewerbes („trade or business") auf dem Boden der Vereinigten Staaten einzige Voraussetzung, um als inländischer Steuerpflichtiger eingestuft $\mathrm{zu}$ werden. ${ }^{14}$ Den Begriff eines ausländischen Handels oder Gewerbes gibt es nicht.

Neben dem Bund erheben auch die Gliedstaaten Einkommensteuern nach eigenem Recht. Sie erreichen maximal $10,75 \%{ }^{15}$ und können von der Bemessungsgrundlage für die Einkommensteuer des Bundes abgezogen werden. ${ }^{16}$ Wegen der Verschiedenheit des Rechts in den Bundesstaaten ist es aber nicht möglich, diese Steuer zu berücksichtigen.

\section{Besteuerung von Kapitaleinkommen}

Die Bedeutung der Einstufung einer Gesellschaft als Kapital- oder Personengesellschaft wird durch einen Blick auf die Struktur der Körperschaftsteuer sichtbar. In den USA unterliegen Gewinne aus Beteiligungen an einer Körperschaft einer vollen wirtschaftlichen Doppelbesteuerung. ${ }^{17}$ Sowohl die Kapitalgesellschaft als auch die Anteilseigner sind als Steuersubjekt einkommensteuerpflichtig; eine Anrechnung der Körperschaftsteuer auf der Ebene der Kapitalgeber ist nicht zulässig.

Körperschaft- und Einkommensteuer werden nach einem progressiven Tarif erhoben. Der Spitzensteuersatz für Kapitalgesellschaften liegt derzeit bei $35 \%$ für Gewinne, die zehn Millionen U.S.-Dollar übersteigen. ${ }^{18}$ Natürliche Personen werden mit einem Satz von höch-

12 Im Gegenzug zu der in der vorstehenden Fußnote 10 angesprochenen Vereinfachung der Einordnung einer Gesellschaft ist aber eine kraft Doppelbesteuerungsabkommen durch die USA gewährte Minderung von Quellensteuern nunmehr von der Zurechnung der steuerpflichtigen Einkünfte nach ausländischem Recht abhängig. Konkret bedeutet dies beispielsweise: ist nach dem Recht eines Landes eine dort belegene (Zwischen-) Gesellschaft Personengesellschaft, ist das Abkommen der USA mit diesem Land unerheblich, wenn die Eigentümer in einem dritten Land ansässig sind. Taxpayer Relief Act of 1997, §1054(a); M. Apelt, aaO, S.236f.; Deloitte \& Touche LLP (Hrsg.), Promises Kept: The 1997 Tax Act, A Tax News\&Views Special Report, 1997, Internet: http:/www.dtonline.com/promises/chap6.htm; V.K. Jacobs, Taxpayer Relief Act: Statement of the Managers, Internet: http://www.rpifs.comt/t97index.htm, Stand: 29.7.1997.

13 E. Boles, a.a.O., S.106f..

14 IRC §864(b); Reg. §1.861-2(a)(2).

15 In 1997 erheben sieben Staaten keine Einkommensteuer; der höchste Satz von 12\% gilt in North Dakota. Der niedrigste Spitzensteuersatz der Körperschaftsteuer liegt bei $5 \%$ in fünf Staaten, der höchste bei $12 \%$ und zwar in Iowa . Vgl. Federation of Tax Administrators, State Tax Rates \& Structure, Washington, D.C. 1997, Internet: http://sso.org/fta/ind inc.html, http://sso.org/fta/corp inc.html.

16 I. Müssener, Vereinigte Staaten von Amerika, in: A. Mennel, Steuern in Europa, USA, Kanada und Japan, Herne u. Berlin, Loseblatt, Stand 32. Ergänzungslieferung (Mai 1997), S.13.

17 J.F. Chown, Tax Efficient Foreign Exchange Management, New York u.a. 1990, S. 154.

Dies gilt zumindest ex ante bei der Entscheidung über die Finanzierung einer Erweiterungsinvestition mittels Fremd- oder zusätzlichem Eigenkapital. Zur Selbstfinanzierung vgl. den Einwand in H.-W. Sinn, Taxation and the Cost of Capital: The „Old" View, the „New" View, and Another View, in: NBER Working Paper Series Nr.3501, Cambridge, Mass. 1990.

18 Die Höhe der Körperschaftsteuer in den USA errechnet sich gemäß IRC §11(b) aus der Summe aus:

- $15 \%$ der steuerpflichtigen Gewinne von bis zu $\$ 50.000$,

- $25 \%$ der steuerpflichtigen Gewinne über $\$ 50.000$ bis $\$ 75.000$,

- $34 \%$ der steuerpflichtigen Gewinne über $\$ 75.000$ bis $\$ 10.000 .000$ sowie weiterer

$5 \%$ der Gewinne über $\$ 100.000$ bis $\$ 235.000$ und

- $35 \%$ der Gewinne, die über $\$ 10.000 .000$ hinausgehen. 
stens $39,6 \%$ belastet $^{19}$ und die Tarifstufen in jedem Jahr in Anlehnung an die Rate der Geldentwertung des U.S.-Dollar angepaßt. ${ }^{20}$

Die maximale Tarifbelastung eines Steuerinländers durch Einkommen- und Körperschaftsteuer des Bundes beträgt somit knapp 61\%. Aus dieser Doppelbesteuerung ergeben sich allerdings unmittelbar keine grundsätzlichen Besonderheiten, die die Präferenz des Kapitalgebers hinsichtlich des Einsatzortes seines Kapitals durch die Unternehmung beeinflussen. Die Belastung auf der Ebene des Kapitalgebers ist Folge der Rechtsformwahl; nach der Entstehung der Gewinne wird dort nicht differenziert. Insbesondere ist deren Besteuerung unabhängig davon, ob die Kapitalgesellschaft in- oder ausländische Einkünfte erzielt hat. Deshalb wird die Einkommensteuer auf Einkünfte, die durch eine inländische Kapitalgesellschaft erzielt wurden, in dieser Arbeit nicht ausdrücklich betrachtet.

Auch auf eine Analyse der progressiven Tarifstruktur im Zusammenwirken mit Fluktuationen von Wechselkursen wird hier verzichtet, denn es ist bekannt, daß ein progressiver Einkommensteuertarif gegenüber riskanten Investitionen diskriminierend wirkt, weil der positive Ausgang unsicheren Kapitaleinsatzes mit einem höheren Steuersatz belastet wird als ein Mißerfolg. ${ }^{21}$ Erhöht die Volatilität der Wechselkurse das Gesamtrisiko eines Auslandsengagement, wird deshalb Kapitalexportneutralität verletzt.

\section{a) Ordentliches Einkommen („Ordinary Income“)}

Einkommensteuerobjekt einer Kapitalgesellschaft und der Mitinhaber einer Personengesellschaft ist der nach den steuerrechtlichen Vorschriften zu ermittelnde Gewinn.

Auch hier ist das Steuerrecht ein in sich geschlossenes Regelwerk; es gilt - analog zur Definition des Steuersubjektes - eine strikte Trennung der Gewinnermittlung zum Zwecke der Besteuerung einerseits, die nahezu ausschließlich auf steuergesetzlichen Regelungen beruht, und dem handelsrechtlichen Bilanzergebnis andererseits. ${ }^{22,} 23$

19 Die Einkommensteuer für das Jahr 1996 beträgt zB. für unverheiratete Einzelpersonen laut IRC § 1(c):

- $15 \%$ bei Einkünften von bis $\mathrm{zu} \$ 24.000$,

- $28 \%$ auf darüber hinausgehende Einkünfte bis zu $\$ 58.150$,

- $31 \%$ auf Einkünte über $\$ 58.150$ bis $\$ 121.300$,

- 36\% auf Einkünfte über $\$ 121.300$ bis $\$ 263.750$ und

- $39,6 \%$ auf Einküntte, die über $\$ 263.750$ hinausgehen.

20 IRC $\S 1(\mathrm{f})$.

21 Vgl. z.B. D. Schneider, Gewinnbesteuerung und Risikobereitschaft, a.a.O., S.651-653.

22 Einerseits ist die Trennung die logische Konsequenz der Erkenntnis, daß Bilanzen im Spannungsfeld teilweise konkurrierender Bilanzziele stehen. Vgl. W. Stützel, Bemerkungen zur Bilanztheorie, a.a.O.. Dies kommt in der Urteilsbegründung des US Supreme Court zu dem Fall ,Thor Power Tool Co. versus Commissioner' zum Ausdruck: „Oberstes Ziel der Handelsbilanz ist es, die Unternehmensleitung, die Anteilseigner, die Kreditgeber und andere näher Interessierte mit nützlichen Informationen zu versorgen. Die ausschließliche Pflicht des Bilanzerstellers besteht darin, die genannten Personen vor einer Irrefuhrung zu bewahren. Das oberste Ziel des Steuersystems ist jedoch die angemessene Erzielung von Steuereinnahmen. Den Steuerbehörden obliegt die wichtige Aufgabe, den Fiskus zu schützen. Entsprechend ihren Zielen und Aufgaben folgt die Handelsbilanz dem Prinzip der Vorsicht, d. h. mögliche Bewertungsfehler sollten eher zu einer Unter- als zu einer Überbewertung von Einkommen und Aktivposten führen. Wegen der deutlich abweichenden Ziele und Verpflichtungen der Steuererhebung darf die Verminderung von Einkommen nicht zum leitenden Gesichtspunkt werden. Aufgrund dieser unterschiedlichen, ja sogar gegensätzlichen Aufgaben, ist eine vermutete Gleichstellung zwischen Handels- und Steuerbilanz unannehmbar." Thor Power Tool Co. vs. Commissioner of Internal Revenue Nr. 77920 (1979), deutsche Übersetzung von H. Menkhaus, Der oberste Gerichtshof nimmt Stellung zum Verhältnis von Handels- und Steuerrecht, in: Juristenzeitung, 34.Jg. (1979), S.359; K. Vogel, Ausländische Entscheidungen als Anregung für den deutschen Steuerrechtler, in: Steuer und Wirtschaft, 59.Jg. (1982), S.69. 
Ausgangspunkt der Bemessung des steuerpflichtigen Gewinnes sind die Bruttoeinkünfte (,gross profits"). Diese werden um die abziehbaren Aufwendungen („deductions") gemindert, die in Teil VI des IRC erschöpfend aufgezählt sind. ${ }^{24}$ Hierzu zählen insbesondere die Betriebsausgaben (,trade or business expenses“). Auf das Ergebnis, den zu versteuernden Gewinn, wird der Körperschaft- beziehungsweise Einkommensteuersatz angewendet. ${ }^{25}$

Es besteht die Möglichkeit, im Ausland gezahlte Einkommensteuern bei der Bemessung im Inland anzurechnen. $\mathrm{Zu}$ diesem Zwecke sind die Bruttoeinkünfte nach in- und ausländischen Quellen zu trennen; ebenso müssen die erlaubten Abzüge separat zugerechnet werden. Das Vorgehen wird weiter unten in den Unterabschnitten c) und d) beschrieben.

Ein Verlust kann mit steuerpflichtigen Gewinnen verrechnet werden; eine negative Steuer im Falle eines Verlusts sieht das U.S.-amerikanische Steuerrecht freilich nicht vor. Negative Einkünfte können nur die Steuerpflicht bei anderen Gewinnen oder in anderen Perioden mindern. $\mathrm{Da}$ Steuerinländer mit ihrem Welteinkommen steuerpflichtig sind, wird hierbei nicht zwischen in- und ausländischen Verlusten unterschieden. Ein Verlustrücktrag ist seit der Steueränderung von 1997 für zwei Jahre und ein Verlustvortrag für 20 Jahre in unbegrenzter Höhe zulässig. ${ }^{26}$ Zuvor betrugen die Zeiträume drei beziehungsweise 15 Jahre. ${ }^{27}$

Einbehaltene Gewinne einer Kapitalgesellschaft erhöhen deren sogenannte „earnings and profits“ (E\&P). Als E\&P wird die Summe der thesaurierten Nettogewinne vergangener Jahre und des laufenden Jahres bezeichnet. ${ }^{28}$ Eine genaue Beschreibung dieses Begriffs des U.S.-amerikanischen Steuerrechts ist allerdings inzwischen eine Wissenschaft für sich. ${ }^{29} \mathrm{Er}$ ist im Gesetz nicht definiert, sondern das Produkt von Regelungen der Steuerbehörden und richterlichen Entscheidungen.

Andererseits ist , $\mathrm{zu}$ beachten, daß durch Bewertungsvariationen und damit durch Variation des als ,Gewinn“ bezeichneten Betrags [...] zugleich die Kompetenzverteilung variiert wird“. W. Stützel, Entscheidungsorientierte Elementarkategorien, a.a.O., S.788. Deshalb liegt ein Nachteil der Trennung von Handels- und Steuerbilanz in den USA vermutlich darin, daß politischen Entscheidungsträgern und Interessengruppen größere Kompetenzen bei der steuerrechtlichen Gewinnfeststellung eingeräumt werden. Denn das heißt auch, daß Partikularinteressen leichter in das Steuergesetz einfließen können. Vgl. auch: M. Friedman, U.S. Tax Bill Won't Reform U.S. Politics, in: Wall Street Journal Europe v. 8.7.1986.

23 Ein zaghafter Versuch der Anknüpfung der Besteuerung an das in der Handelsbilanz ausgewiesene Ergebnis wurde mit der Einführung der sogenannten alternativen Mindeststeuer unternommen. H. Debatin, Reagans Steuerreform: Ein Experiment - kein Vorbild, in: Frankfurter Allgemeine Zeitung v. 28.2.1987 (die alternative Mindeststeuer wird in Fußnote 42 auf Seite 87 noch einmal angesprochen). Der Ansatz ist in den USA aber auf Unverständnis gestoßen: „Es ist eine seltsame Vorstellung, den Versuch zu unternehmen, Steuergesetze an Bucherträge zu binden." B.C. O'Brien, Zitiert in H. Gleckman u. B. Starr, The Minimum Tax: It's the Bottom Line that Counts, in: Business Week v. 16.6.1986 (eigene Übersetzung).

24 IRC $§ 161-180$.

25 Neben der Gewinnermittlung nach der Methode des Betriebsvermögensvergleichs (,accrual method") kann auch eine Einnahmenüberschußrechnung (,cash method“) zulässig sein. Soweit nichts anderes gesagt wird, basieren die Ausführungen zur Unternehmensbesteuerung hier aber auf der Methode des Betriebsvermögensvergleichs.

26 Taxpayer Relief Act of 1997, §1082; KPMG Peat Marwick LLP. (Hrsg.), Taxpayer Relief Act of 1997 Booklet, 1997, Internet: http://www.us.kpmg.com/taxact/booklet/5business.html.

27 IRC §172(b)(1)(A); G. J. Yost, III, 1996 International Tax Summaries, New York u.a. 1996, S.U-38. Desweiteren dürfen Verluste aus passiven Tätigkeiten nicht mit aktiven, aber zeitlich unbefristet mit passiven Gewinnen verrechnet werden. I. Müssener, a.a.O., S. 19.

28 U. Woywode, Fremdwährungsumrechnung nach US-Steuerrecht, in: Recht der Internationalen Wirtschaft, 37.Jg. (1991), S.699.

29 Vgl. z.B. D.C. Broenen, Foreign Corporation Earnings and Profits, Tax Management Portfolio Nr.932., Washington,D.C. 1990 für eine detaillierte Darstellung der Ermittlung der E\&P einer ausländischen Kapitalgesellschaft. 
Deshalb hier nur so viel: Eine Zahlung der Gesellschaft an die Eigenkapitalgeber wird steuerlich als Dividende angesehen, soweit sie aus den E\&P finanziert wurde. ${ }^{30}$ Reichen die E\&P nicht aus, ist der Differenzbetrag als Kapitalrückzahlung oder als Veräußerungsgewinn zu werten. ${ }^{31}$ Wesentliches Ziel des Konzeptes ist also die Abgrenzung einer Dividende von anderen Zahlungen an die Anteilseigner.

Die E\&P sind somit weder vergleichbar mit den kumulierten versteuerten Gewinnen der Gesellschaft, weil auch steuerbefreite Erträge zu den E\&P gerechnet werden, ${ }^{32}$ noch entsprechen sie notwendigerweise dem handelsrechtlich ermittelten einbehaltenen Gewinn. Die E\&P stimmen aber auch nicht mit dem ökonomischen Gewinn überein, da unter anderem nicht realisierte Gewinne oder Verluste nicht erfaßt werden. ${ }^{33}$

E\&P und Ausschüttungen sind für inländische und für ausländische Kapitalgesellschaften mit inländischen Anteilseignern nach überwiegend gleichen steuerlichen Grundsätzen zu bestimmen. ${ }^{34}$

Gewinne einer ausländischen Körperschaft sind im allgemeinen von einer Besteuerung durch die USA abgeschirmt, solange sie nicht an steuerinländische Eigenkapitalgeber ausgeschüttet werden. ${ }^{35}$ Wenn allerdings die Voraussetzungen des Unterabschnitts F des IRC erfüllt sind, werden auch einbehaltene Gewinne einer ausländischen Kapitalgesellschaft Steuerinländern der USA zugerechnet. Die Gewinne sind dann in der Periode der Entstehung in den USA einkommensteuerpflichtig; sie unterliegen einer Zugriffsbesteuerung. Der Fiskus greift dann auf diese Erträge pro rata $\mathrm{zu},{ }^{36}$ wenn

- die ausländische Unternehmung als abhängige ausländische Tochtergesellschaft (,controlled foreign corporation") anzusehen ist, das heißt wenn in den USA unbeschränkt Steuerpflichtige einen Anteil von über $50 \%$ des Eigenkapitals halten ${ }^{37}$ und

- der Steuerpflichtige über mindestens $10 \%$ der Stimmrechte dieser ausländischen Gesellschaft verfügt ${ }^{38}$ und außerdem

- die Gewinne als sogenanntes „subpart F income“"39 anzusehen sind. Prinzipiell sind dies Einkünfte und Veräußerungsgewinne durch passive Aktiva. ${ }^{40}$ Hierzu zählen unter anderem Dividenden, Zinsen und Mieteinnahmen sowie Veräußerungsgewinne bei Wertpapieren, Immobilien und Warentermingeschäften.

Auch ein positiver Saldo aus Währungsgewinnen und -verlusten durch bestimmte Fremdwährungstransaktionen der ausländischen Unternehmung fällt darunter, wenn diese nicht im Zusammenhang mit der gewöhnlichen Geschäftstätigkeit der Gesellschaft stehen. ${ }^{41}$

30 IRC $\S 316(a)$.

31 J. Isenbergh, International Taxation, Teil I, a.a.O., S.463.

32 So erhöhen z.B. steuerfreie Zinseinkünfte aus bestimmten Staatsanleihen die E\&P und Verluste mindern sie unabhängig davon, ob sie steuerlich abziehbar sind. J. Isenbergh, International Taxation, Teil I, a.a.O., S.463.

33 J. Isenbergh, International Taxation, Teil I, a.a.O., S. $463 \mathrm{f}$.

34 U. Woywode, a.a.O., S.699.

35 J.F. Chown, a.a.O., S.160f..

36 IRC $\S 951$.

37 IRC $§ 957(a)$.

$38 \mathrm{Ab}$ dieser Grenze ist die indirekte Anrechnung ausländischer Einkommensteuern zulässig. Vgl. Seite 93.

39 IRC $\S 952$.

40 Im wesentlichen umfaßt Einkommen nach Unterabschnitt F gemäß IRC §954(a)(1),Foreign Base Company Income", das wiederum hauptsächlich Gewinne sind, die in IRC §553(a) als Einkünfte einer sogenannten personenbezogenen ausländischen Holdinggesellschaft (,foreign personal holding company“, FPHC) gemäß IRC $\$ 552$ definiert werden. Eine FPHC ist aber eigentlich eine Gesellschaft, deren Anteile sich zu mehr als $50 \%$ in den Händen von höchstens fünf Steuerinländern befinden und deren Gewinne zu wenigstens $60 \%$ durch passive Tätigkeiten erwirtschaftet werden.

41 IRC $\S 954(c)(1)(D)$. 
Zum Zeitpunkt der tatsächlichen Ausschüttung werden Einkünfte, die der Zugriffsbesteuerung unterlagen, aber nicht ein zweites Mal besteuert. ${ }^{42}$

Eine Personengesellschaft ist demgegenüber nicht als solche Steuersubjekt, sondern dient nur als Durchgangsleitung, durch welche steuerpflichtige Einkünfte oder Verluste den einzelnen Gesellschaftern zugerechnet werden. Jeder Gesellschafter hat seinen Anteil an den Gewinnen der Personengesellschaft der Besteuerung zu unterwerfen, unabhängig davon, ob sie ausgeschüttet werden.

\section{b) Veräußerungsgewinne und -verluste}

Ein Veräußerungsgewinn oder -verlust im Sinne des U.S.-Steuerrechts ist ein Gewinn beziehungsweise ein Verlust aus einem Verkauf oder Tausch von Vermögenswerten. ${ }^{43}$ Er ist prinzipiell zum Zeitpunkt der Realisierung steuerpflichtig. Dabei ist es gleichgültig, ob sich das veräußerte Wirtschaftsgut im Privatvermögen befand oder Teil eines Gewerbebetriebes war.

Allerdings gelten eine ganze Reihe von Ausnahmen. ${ }^{44}$ Hervorzuheben sind an dieser Stelle Gewinne und Verluste bei der Veräußerung von Aktiva im Rahmen der gewöhnlichen Geschäftstätigkeit. Diese werden den ordentlichen Einkünften zugerechnet. Außerdem sind Veräußerungsgewinne aus einem Verkauf von Beteiligungen an ausländischen Unternehmen dann, wenn (i) der Steuerpflichtige in den letzten fünf Jahren davor wenigstens $10 \%$ der Stimmrechte der Gesellschaft gehalten hat und (ii) die Gesellschaft eine abhängige Auslandsgesellschaft ist, bis zur Höhe der E\&P ordentliche Einkünfte. ${ }^{45}$ Zweck der Vorschrift ist es, die

42 Seit 1978 gibt es in den Vereinigten Staaten außerdem eine sogenannte Mindeststeuer. Sie soll die Untergrenze der effektiven Steuerbelastung aller Steuerpflichtigen sicherstellen, die nur vom Einkommen des Steuerjahres abhängig ist. Mit der Steuerreform von 1986 wurden die Sätze angehoben (derzeit gemäß IRC §55(b)(1) für natürliche Personen höchstens $28 \%$, für Kapitalgesellschaften $20 \%$ ) und vor allem die Bemessungsgrundlage erheblich ausgeweitet. Vom Grundprinzip her ist sie jetzt das steuerbare Einkommen der Person mit Hinzurechnung der Steuervergünstigungen. Darüber hinaus ist die Hälfte des Mehrbetrages, um den das handelsrechtliche Bilanzergebnis den ermittelten steuerpflichtigen Gewinn übersteigt, zusätzlich in die Besteuerungsgrundlage einzubeziehen. Die seither mit dem Begriff „alternativ“ergänzte Mindeststeuer ist somit tatsächlich ein zweites paralleles Einkommensteuersystem, das für eine Anzahl von Unternehmen - insbesondere für kapitalintensive Betriebe - die wirkliche Steuerbelastung festlegt. Allerdings kann eine Differenz zwischen regulärer Körperschaftsteuer und tatsächlich zu zahlender alternativer Mindeststeuer zeitlich unbegrenzt vorgetragen werden. Die Abgabe stellt somit im Ergebnis eine - unverzinsliche - Steuervorauszahlung dar. H. Debatin, Reagans Steuerreform: Ein Experiment - kein Vorbild, a.a.O.; W. Treumann, M. Peltzer u. A.M. Kuehn, US Business Law, 2. neubearb. u. erw. Aufl., Köln 1990, S. 394 f.. Die Steuer hat gegenüber ihrer Einführung 1986 zudem an Bedeutung verloren, da deren Sätze im Unterschied zu den regulären Steuern seither nicht erhöht wurden.

Die alternative Mindeststeuer ist im Zusammenhang mit der Besteuerung von Währungserfolgen aber nicht ganz unbedeutend. Es gibt trotz der Tatsache, daß die steuerlichen Regelungen auf dem Konzept des FASB fußen, im Ergebnis Abweichungen der handels- und steuerrechtlichen Vorschriften. Probleme mit der Mindeststeuer sind bei größeren Währungsverlusten im Zusammenhang mit der Veräußerung einer ausländischen Niederlassung nicht ganz unwahrscheinlich. R.A. Gordon u. D.S. Lange, International Effects of the Corporate AMT Book Income Regulations, in: Tax Management International Journal, 16. Jg. (1987), S.370-373 (der Text berücksichtigt aber noch nicht die Bestimmungen für Investitionen in hochinflationären Währungsräumen). Probleme können außerdem bei Fremdwährungstransaktionen auftreten. Nach handelsrechtlichen Maßstäben sind nämlich Währungsgewinne oder -verluste an jedem Bilanzstichtag zu berücksichtigen (unter Umständen aber nur außerhalb der Bilanz auszuweisen), im Steuerrecht demgegenüber meist erst bei Realisierung. Ebda., S.173f..

43 IRC $\$ 1222$.

44 IRC $\S 1221$.

45 IRC §1248(a). 
Möglichkeit zu verbauen, kumulierte E\&P der Auslandsgesellschaft in Kapitalgewinne umzuqualifizieren. ${ }^{46}$

Wie in der Einleitung schon erwähnt, wurde seit dem Inkrafttreten der Steuerreform von 1986 auf realisierte weltweite Nettoveräußerungsgewinne der gleiche Steuertarif wie auf andere Einkünfte angewendet. Sie waren bei der Ermittlung der einkommensteuerlichen Bemessungsgrundlage einzubeziehen, aus dessen Gesamtbetrag sich der anzuwendende Steuersatz ergibt. ${ }^{47}$ Mit der in diesem Jahr verabschiedeten Steueränderung wird die Angleichung des Tarifs nach längerer Diskussion für derartige Gewinne im Privatvermögen ${ }^{48}$ wieder zurückgenommen. Künftig gilt ein reduzierter Satz von maximal $20 \%$ für Gewinne aus dem Verkauf von Vermögensgegenständen, die sich mehr als 18 Monate in den Händen des Steuerpflichtigen befanden. ${ }^{49}$ Für langfristige Veräußerungsgewinne wird eine Steuer von höchstens noch $18 \%$ erhoben werden, wenn die Haltedauer mehr als fünf Jahre betrug (und der Vermögensgegenstand nach dem Jahr 2000 angeschafft wurde). Nur die kurz- und mittelfristigen Gewinne - bei einer Veräußerung innerhalb von zwölf Monaten beziehungsweise nach zwölf bis 18 Monaten - sind unverändert voll steuerpflichtig.

Nettoveräußerungsverluste dürfen nicht von anderen steuerbaren Gewinnen abgezogen werden. ${ }^{50}$ Die Verrechnung mit Veräußerungsgewinnen ist für Kapitalgesellschaften durch einen Verlustrücktrag um bis zu drei Jahre und einen Vortrag für fünf Jahre möglich. Natürliche Personen können Veräußerungsverluste in jedem Steuerjahr mit bis zu maximal $\$ 3.000$ ordentlichen Einkommens verrechnen ${ }^{51}$ und im übrigen unbegrenzt vortragen ${ }^{52}$.

\section{Quelle und Arten von Einkünften}

Ausgangspunkt für die U.S.-amerikanische Besteuerung grenzüberschreitender Einkünfte ist die Quelle der Bruttoeinkünfte. Die Quellenregeln (,source rules“) bestimmen für acht verschiedene Einkunftarten, wann eine inländische und wann eine ausländische Quelle vorliegt. ${ }^{53}$

46 T.J. O'Neil, Federal Income Tax Treatment of Foreign Currency Transactions after the Tax Reform Act of 1986, in: Tax Notes, 33.Jg. (1986), S. 190, Fn.34.

47 Die Besteuerung von Kapitalgewinnen wird in den IRC $\$ 1001-1288$ beschrieben.

48 Der Gesetzesentwurf des Repräsentantenhauses sah auch vor, die Steuer zu senken für Kapitalgesellschaften auf Gewinne durch die Veräußerung von Vermögenswerten, die länger als acht Jahre gehalten wurden. Tax Payer Relief Act of 1997: Text of H.R. 2014 as Passed by the House of Representatives on June 26, 1997, $\$ 321$; V.K. Jacobs, a.a.O..

49 Die im Text genannten Sätze gelten bei einer Tarifbelastung des ordentlichen Einkommens von $28 \%$. Beträgt die Tarifbelastung des ordentlichen Einkommens 15\%, werden Veräußerungsgewinne nur mit $10 \%$ beziehungsweise $8 \%$ besteuert. Taxpayer Relief Act of 1997, §311(a).

50 IRC $\S 165($ f) i.V.m. IRC $\S 1211$.

51 IRC $\$ 1211$ (b).

52 IRC $§ 1212$ (b). Die systematische Trennung von Kapitalgewinnen und ordentlichen Einkünften bestand im Einkommensteuergesetz auch vor dem Taxpayer Relief Act of 1997. Sie wurde 1986 nicht aus dem Gesetz gestrichen, um - wie in dem Bericht des Vermittlungsausschusses des Kongresses zur damaligen Steuerreform begründet wurde - eine Ausnahme von Kapitalgewinnen bei einer denkbaren späteren Erhöhung der Steuersätze zu erleichtern. M.J. Graetz, Federal Income Taxation, 2.Aufl. 1988, New York 1988, S.12 u. S.664f.. Bis 1986 wurden langfristige Kapitalgewinne bei Vermögenswerten, die sich länger als sechs Monate im Besitz des Steuerpflichtigen befanden, in der Periode ihrer Realisierung zu $40 \%$ des Steuersatzes für ordentliches Einkommen besteuert.

53 IRC $\S 861$ legt die inländische Quelle fest, $\S 862$ Einnahmen aus ausländischer Quelle, IRC $\S 863$ unter anderem Einkünte, die sich aus mehreren Einkunftarten zusammensetzen und/oder aus mehreren Quellen stammen; mit der Steuerreform 1986 wurde außerdem $§ 865$ eingefügt, der die Besteuerung von Einkünten aus der Veräußerung beweglichen Vermögens gesondert regelt. 
Der Begriff der Quelle wird dabei sowohl zur Bestimmung der geographischen Herkunft von Einkommen als auch zur Differenzierung der Art der ausländischen Einkünfte verwendet. ${ }^{54}$

Die acht Einkunftarten sind im einzelnen:55 (1) Zinsen, (2) Dividenden, (3) Dienstleistungen, (4) Mieten und Lizenzgebühren, (5) Verfügung über Grundeigentum, (6) Verkauf und Tausch beweglichen Vermögens, (7) Versicherungsprämien und (8) Sozialversicherungsbezüge. Die Bezüge aus (3), (7) und (8) sind für die Fragestellung dieser Arbeit nicht relevant.

Zur Bestimmung der Quelle von Zinszahlungen ist der Wohnsitz des Kreditnehmers maßgeblich. ${ }^{56}$ Dies gilt vom Grundsatz her sowohl für Ausländer als auch für Staatsbürger der Vereinigten Staaten, gleichgültig, ob der Kreditnehmer eine Körperschaft ${ }^{57}$ oder eine natürliche Person ist (Wohnsitz einer Personengesellschaft ist, wie gesagt, der Standort ihres Handelsoder Gewerbes). 58

Demgemäß sind Zinserträge von Steuerinländern der USA ausländische Einkünfte, wenn der Schuldner dort seinen Wohnsitz hat beziehungsweise sein Handels- oder Gewerbebetrieb im Ausland belegen ist.

Die Quelle von Dividenden ist prinzipiell der Ort der Gründung der Körperschaft. ${ }^{59}$

Eine Ausnahme bilden ausländische Kapitalgesellschaften, deren Gewinn in jedem der letzten drei Jahre vor der Festsetzung der Dividende zu mindestens $25 \%$ in tatsächlichem Zusammenhang stand mit dem Betrieb eines Handels oder Gewerbes innerhalb der USA. Ist dies der Fall, ist der Teil der Gewinne, der in tatsächlichem Zusammenhang mit dem Handel oder Gewerbe in den USA steht, steuerlich inländischen Ursprungs. ${ }^{60}$

Einkünfte aus Vermietung fallen dort an, wo das Wirtschaftsgut eingesetzt wird. ${ }^{61}$

Veräußerungsgewinne aus dem Verkauf immobiler Aktiva haben ihre Quelle an dem Ort, an dem das Realkapital installiert ist. ${ }^{62}$ Bei beweglichen Vermögenswerten wird dagegen als Quelle der Wohnsitz der verkaufenden Person unterstellt.63, 64 Abweichend davon fallen reine

54 Zur Bedeutung des Begriffs „source“ vgl. K. Vogel, „Source“ und „Jurisdiction“ im Steuerrecht der Vereinigten Staaten und im deutschen Recht, in: Aktuelle Themen im U.S.-Deutschen Steuer- und Handelsrecht, Hrsg. Henry S. Conston, Osnabrück 1988, S. 104-108 und J. Isenbergh, International Taxation, Teil I, a.a.O., S.93.

55 IRC §861(a)(1)-(8), §862(a)(1)-(7); G.C. Hufbauer u. J.M. van Rooij, U.S. Taxation of International Income: Blueprint für Reform, Washington, DC. 1992, S.203-207; K. Vogel, „Source“ und „Jurisdiction" im Steuerrecht der Vereinigten Staaten und im deutschen Recht, a.a.O., S.101.

56 IRC $\S 861(a)(1), \S 862(a)(1)$.

57 Zinszahlungen einer inländischen Kapitalgesellschaft sind aber dann ausländischen Quellen zuzurechnen, wenn in jedem der letzten drei Jahre vor der Zahlung mindestens $80 \%$ der gesamten Einkünfte der Gesellschaft (,\$0-20 corporation“) durch aktive Tätigkeiten im Ausland erzielt wurden und der Gläubiger keine verbundene Person (,related person") ist. IRC §861(a)(1)(A) u. IRC §861(c). Fließen die Zinszahlungen einer verbundenen Person zu, ist die steuerrechtliche Quelle nicht zu 100\% im Ausland, sondern nur zu dem Prozentsatz, zu dem auch die Erträge der Gesellschaft im Ausland entstanden sind. IRC §861(c)(2)(B). Eine verbundene Person ist ein Steuerinländer auch hier, wenn er zu mindestens $10 \%$ an der Kapitalgesellschaft direkt beteiligt ist. IRC $\S 954(d)(3)$.

58 Reg. $\S 1.961-2(a)(2)$.

59 IRC $\S 861(\mathrm{a})(2)(\mathrm{A}), \S 862(\mathrm{a})(2)$.

60 IRC $\S 861(\mathrm{a})(2)(B)$; J. Isenbergh, International Taxation, Teil I, a.a.O., S. $109 \mathrm{f}$.

61 IRC §861(a)(4), wenn dies die USA sind bzw. IRC §862(a)(4), wenn es im Ausland eingesetzt wird.

62 IRC $\S 861$ (a)(5), wenn der Ort in den USA bzw. IRC §862(a)(5), wenn er im Ausland liegt.

63 IRC $\S 865$ (a). Bei abnutzbarem Vermögen ist zu berücksichtigen, daß die Quelle für Veräußerungsgewinne nur dann das Ausland ist, wenn sie zuvor vorgenommene Abschreibungen übersteigen, die das Einkommen des Steuerpflichtigen aus U.S.-Quellen minderten. IRC $\S 865(\mathrm{c})$.

64 Die Möglichkeit, Immobilien in eine Kapitalgesellschaft einzubringen und so in mobile Beteiligungstitel umzuwandeln, wurde erst durch die Steuerreform 1986 ausgeräumt. IRC §861(a)(5) i.V.m. IRC §897(c). 
Veräußerungsgewinne bei Inventar (,,inventory") steuerrechtlich dort an, wo der Verkauf stattfindet. 65

Für bewegliche Aktiva gelten aber wieder eine Reihe von Ausnahmen, unter anderem: ${ }^{66}$

Ist ein Veräußerungsgewinn einem Büro oder einer anderen festen Geschäftseinrichtung („office or other fixed place of business“) im Ausland zurechenbar, ist auch dessen Quelle in jenem Land. ${ }^{67}$

Der Veräußerungsgewinn, den eine U.S.-amerikanische Kapitalgesellschaft bei dem Verkauf von Anteilen an einer ausländischen Konzerngesellschaft erzielt, ist dann ausländischen Ursprungs, wenn (i) die Tochtergesellschaft während der letzten drei Jahre vor dem Verkauf wenigstens die Hälfte ihrer Bruttogewinne aus einer aktiven Tätigkeit durch den Betrieb eines Handels oder Gewerbes außerhalb der USA erzielt hat und (ii) der Verkauf in dem Staat stattfindet, in dem die ausländische Konzerngesellschaft ${ }^{68}$ in den drei Jahren vor dem Verkauf mehr als die Hälfte der Bruttoeinkünfte erwirtschaftete. ${ }^{69}$

Kursgewinne bei der Veräußerung von Aktien werden dann ausländischen Quellen zugerechnet, wenn dies in einem Doppelbesteuerungsabkommen der USA vereinbart wurde und der Steuerpflichtige sich zur Anrechnung ausländischer Ertragsteuern entscheidet. ${ }^{70}$

Wird eine ausländische Kapitalgesellschaft liquidiert, werden Gewinne wie bei einem Verkauf der Beteiligung zugerechnet. ${ }^{11}$

\section{Zurechnung von Zinsaufwendungen}

Von den Quellenregeln unterschieden werden die Bestimmungen über die Zurechnung beziehungsweise Aufteilung von Aufwendungen, wenn diese im Zusammenhang mit der Erzielung von Einkünften entstanden sind (,expense allocation and apportionment rules 6$)^{62} .{ }^{73}$

Die Bestimmungen sind rechtssystematisch der zweite Prüfungsschritt, denn die Aufwendungen werden von den zuvor bestimmten Bruttoeinkünften abgezogen, um zum steuer-

65 IRC $\S 861(a)(6)$ bei Veräußerung in den USA; IRC $\S 862(a)(6)$ bei Veräußerung im Ausland; vgl. auch J. Isenbergh, International Taxation, Teil I, a.a.O., S.137. Anhaltspunkt für die Bestimmung des Ortes ist die Übertragung der Eigentumsrechte. Arthur Andersen \& Co., a.a.O., S. 199.

66 Für eine detaillierte Behandlung dieser Quellenregeln vgl. z.B. J. Isenbergh, International Taxation, Teil I, a.a.O., S. 123-146 u. S.155f..

67 IRC $\S 865(\mathrm{e})$. Die Gewinne müssen aber gemäß IRC $\S 865(\mathrm{e})(1)(B)$ darüber hinaus im Ausland einer Quellensteuer von mindestens $10 \%$ unterliegen.

68 Eine ausländische Konzerngesellschaft ist hierfür definiert als eine Gesellschaft, an der die U.S.-Körperschaft zu mindestens $80 \%$ direkt oder über verbundene Dritte beteiligt ist. IRC §865(i)(4) i.V.m. IRC §1504(a)-(b).

69 IRC $\S 865(f)$; D.P. Zaiken, F.E. Woodridge u. D.L. Renfroe, Revisions to Income-Sourcing Rules Likely to Increase U.S. Tax on Foreign Income, in: Journal of Taxation, 68.Jg. (1988), S.122.

70 IRC $\S 865(\mathrm{~h})$

71 IRC $\S 331$ i.V.m. $§ 861(a)(2)$ bzw. $§ 862(a)(2)$. Ein geringes Maß an Unsicherheit verbleibt allerdings aufgrund des umstrittenen Urteils des Bundesberufungsgerichts aus dem Jahre 1944 im Fall Hay vs. Commissioner. Dort wurde nämlich der Gewinn eines Steuerausländers aus der Liquidation seiner U.S.-amerikanischen Gesellschaft mit einer Ausschüttung gleichgestellt und deshalb dem Sitz der liquidierten Unternehmung zugerechnet. Hay vs. Commissioner, 145 F.2d 1001 (4th Cir. 1944); J. Isenbergh, International Taxation, Teil I, a.a.O., 155.

72 IRC §864(e), derzeit vor allem aber die Temporary Regulations Reg. §1.861-9T.

73 Vgl. J. Isenbergh, International Taxation, 1994 Supplement, a.a.O., S.88ff. u. ders., International Taxation, Teil I, a.a.O., S.195ff.. 
pflichtigen Einkommen zu gelangen. ${ }^{74} \mathrm{Zu}$ diesem Zwecke ist der Gesamtbetrag aller Einnahmen eines Steuerpflichtigen in Ertragskategorien (,classes of income") aufzuteilen. ${ }^{75}$

Für die Analyse der Besteuerung von Währungsgewinnen und -verlusten sind vorrangig Regelungen zur Abziehbarkeit von Fremdkapitalkosten wichtig, zumal hierunter auch Gewinne und Verluste anderer Finanzierungsinstrumente erfaßt werden, ${ }^{76}$ soweit sie die Kosten der Kreditfinanzierung berühren. ${ }^{77}$

Die Bestimmungen im Steuerrecht der USA fußen auf dem Gedanken, „daß Geld fungibel ist und daß Zinsaufwendungen allen Aktivitäten und Vermögenswerten zurechenbar sind, ungeachtet des spezifischen Motivs, das zur Aufnahme des Fremdkapitals führte, für das Zinsen gezahlt werden. [...] Dieser Ansatz erkennt, daß alle Aktivitäten und Vermögenswerte Kapital erfordern, und daß den Entscheidungsträgern ein hohes $\mathrm{Maß}$ an Flexibilität hinsichtlich der Herkunft und der Verwendung dieses Kapitals offensteht."

Hieraus wird die Schlußfolgerung abgeleitet, daß

,die Summe der Abzüge für Fremdkapitalkosten in allen Fällen in Beziehung zu allen einkommenerzeugenden Aktivitäten und Vermögenswerten des Steuerpflichtigen gesetzt werden sollte".78

Innerhalb der gesetzlich vorgegebenen Kategorien von Einkünften erfolgt die Zurechnung von Zinsaufwendungen deshalb vom Grundprinzip her auf indirektem Wege. Nach dem Ort der Entstehung des Einkommens wird nicht gefragt. Als Schlüssel dient statt dessen die geographische Aufteilung des Vermögens eines Steuerpflichtigen (,,asset method“) ${ }^{79}$. Das heißt: die weltweiten Fremdkapitalkosten werden zunächst insgesamt quantifiziert und dann in dem Verhältnis auf die Einkünfte aus den verschiedenen Quellen aufgeteilt, das sich aus dem Anteil des dort gehaltenen Vermögens am Gesamtvermögen ergibt.

Für die Zurechnung von Fremdkapitalkosten werden dabei die folgenden Kategorien unterschieden:

Die Finanzierungsaufwendungen einer Einzelperson ${ }^{80}$ werden in vier Kategorien aufgeteilt:81 (i) Zinsen, die einem Handel oder Gewerbe des Steuerpflichtigen zurechenbar sind; (ii) Aufwendungen zur Erzielung von Kapitaleinkommen, soweit es nicht aus einer sogenannten passiven Aktivität (,passive activity") stammt; (iii) Aufwendungen zur Erzielung von Kapitaleinkommen durch passive Aktivitäten und schließlich (iv) Hypothekenzinsen auf den ersten und zweiten Wohnsitz. Weitere Schuldzinsen, die in (i) bis (iv) nicht erfaßt werden, sind grundsätzlich überhaupt nicht steuermindernd vom Einkommen einer Einzelperson abziehbar.

74 IRC §§862(b), 863(a); Reg. §1.861-8(a)(1).

75 Vgl. Reg. §1.961-8(a)(3) für deren Aufzählung. Für Aufwendungen, bei denen eine eindeutige Zuordnung in eine Kategorie nicht gelingt, sind die Bruttoeinkünfte außerdem zu Gruppen zusammenzufassen. Reg. §1.961-8(a)(4). Eine sogenannte Restgruppe (,residual grouping“) steht für verbleibende Abzüge bereit, für die ein Zusammenhang mit bestimmten Einkünften nicht herstellbar ist. Diese werden schlicht anteilmäßig auf alle Welteinkünfte der Steuerpflichtigen aufgeteilt.

76 So z.B. Gewinne und Verluste aus Termingeschäften und Swaps, auch wenn der Einsatz eine Minderung des Währungsrisikos von Fremdwährungsverbindlichkeiten zum Ziel hat. Reg. §1.861-9T(b)(1)(i)-(ii).

77 Vgl. J. Isenbergh, International Taxation, 1994 Supplement, a.a.O., S.90f..

78 Reg. §1.861-9T(a) (eigene Übersetzung).

79 Reg. $\$ 1.861-9 \mathrm{~T}(\mathrm{~g})(1)(\mathrm{i})$.

80 Soweit die ausländischen Einkünfte in einer Periode nicht $\$ 5.000$ übersteigen, können gemäß Reg. §1.861-9T(d)(1) sämtliche Zinsaufwendungen inländischen Erträgen zugerechnet werden.

81 Reg. §1.861-9T(d)(1)(i)-(iv), die Aufteilung basiert auf IRC §163(h)(2)(A)-(D).

Vgl. Reg. §1.861-9T(d)(1)(v) für ein Beispiel zur Veranschaulichung. 
Zinsaufwendungen einer Personengesellschaft werden entsprechend ihrem Anteil den beteiligten Partnern ${ }^{82}$ zugerechnet. Ist der Partner eine Einzelperson, sind die Aufwendungen ihrem Charakter nach den genannten Kategorien (i) bis (iii) zuzuordnen. Ist er eine Kapitalgesellschaft, finden die entsprechenden Regelungen für Kapitalgesellschaften Anwendung. ${ }^{83}$

Ausgenommen sind Fremdkapitalkosten, die in einer unmittelbaren Beziehung zu einem Aktivum stehen. Die Kosten können dann direkt den Bruttoerträgen der Einkunftart und -quelle zugewiesen werden. ${ }^{84}$

Für Kapitalgesellschaften gilt die Allokation der Zinsaufwendungen nach Maßgabe der Eigenschaften der Einkünfte und der geographischen Aufteilung des Vermögens nur noch eingeschränkt. Soweit die Methode in der geschilderten Weise anwendbar ist, können deren Vermögenswerte hierfür wahlweise zu den steuerrechtlichen Buchwerten oder aber auch zu Marktwerten quantifiziert werden. 85

U.S.-amerikanische Gesellschaften eines internationalen Konzerns (,affiliated group“86) müssen ein weitaus komplizierteres Verfahren anwenden. Im Gesetzestext heißt es, Fremdkapitalkosten eines Konzerns seien entsprechend dem Wert der Aktiva ${ }^{87}$ zwischen den jeweiligen Einzelgesellschaften aufzuteilen, ,als seien alle Unternehmen des Konzerns eine einzige Gesellschaft".88

Dies führt gleichwohl nicht einfach zur indirekten Zurechnung von Zinsaufwendungen innerhalb des gesamten Konzerns. Denn einbezogen werden können nur die Aktiva der Unternehmungen einer Gruppe, die ihren Sitz in den USA haben. Hierzu zählen zwar auch deren Beteiligungen an ausländischen Konzerngesellschaften; auf diesem Wege werden Finanzierungskosten der inländischen Gesellschaften auf die in- und ausländischen Bruttoeinkünfte aufgeteilt. Es werden aber keinerlei Zinsaufwendungen ausländischer Gesellschaften der Gruppe berücksichtigt, die U.S.-Unternehmen Beteiligungskapital bereitgestellt haben. ${ }^{89}$

\section{Anrechnung ausländischer Steuern}

Die um die abziehbaren Aufwendungen reduzierten Bruttoeinkünfte aus ausländischen Quellen sind in den USA steuerpflichtig. Dabei besteht aber die Möglichkeit, im Ausland gezahlte Einkommensteuern bei der Bemessung im Inland anzurechnen, um eine doppelte Belastung von Einkünften durch eine Besteuerung im Inland und im Ausland zu mindern.

Die Verwendung des Anrechnungsverfahrens leitet sich in den USA direkt aus dem ersten von fünf Zielen des Außensteuerrechts ab. Unter dem Postulat ökonomischer Effizienz heißt es nämlich, das Steuerrecht solle keine Anreize bieten, eine Investitionsalternative einer anderen vorzuziehen. ${ }^{90}$ Gleichwohl findet das darin zum Ausdruck kommende Ziel der Kapitalexport-

82 Dies gilt für Kommanditisten nur, soweit sie zu mindestens $10 \%$ an der Gesellschaft beteiligt sind. Andernfalls können diese Personen Zinsaufwendungen direkt von den ihnen zufließenden Bruttoerträgen der Gesellschaft abziehen. Reg. §1.861-9T(e)(3), (4).

83 Reg. §1.861-9T(e)(3), (2).

84 Reg. $\S 1.861-10 \mathrm{~T}(\mathrm{~b})(2)$.

85 Reg. §1.861-9T(g)(1)(ii).

86 IRC $\$ 1504$. Wesentliche Eigenschaft ist die Verbindung der Unternehmen untereinander durch Beteiligungen und Stimmrechte in Höhe von mindestens $80 \%$ und eine gemeinsame Dachgesellschaft.

87 IRC $§ 864(e)(2)$.

88 IRC $\$ 864(\mathrm{e})(1)$ (eigene Übersetzung).

89 J. Isenbergh, International Taxation, 1994 Supplement, a.a.O., S.107. Auf S.112-116 werden die Bestimmungen der Reg. $\$ 1.861-10(\mathrm{e})$ weitergehend dargestellt.

90 R. Reagan, The Presidents Tax Proposals, a.a.O., S.383; G.C. Hufbauer u. J.M. van Rooij, a.a.O., S.49. 
neutralität schon hier seine Grenze bei dem zweiten Anspruch an das Außensteuerrecht: der Sicherung des Steueraufkommens. ${ }^{91}$

Der Konflikt beider Ziele wurde zugunsten der Sicherung des Steueraufkommens entschieden; die Anrechnung ausländischer Steuern ist bis zur Höhe der Steuerforderung der USA zulässig. Und zwar ist eine direkte Anrechnung zulässig, wenn Subjektidentität vorliegt, wenn also das Steuersubjekt der ausländischen Steuern auch Steuerpflichtiger der U.S.-Einkommensteuer ist. 92

Die Möglichkeit einer indirekten Anrechnung (,deemed paid credit") wird darüber hinaus für gezahlte Steuern ausländischer Tochtergesellschaften eingeräumt, bei denen Kapitalgesellschaften mit Sitz in den USA einen Anteil von mindestens $10 \%$ des Stimmrechts besitzen. ${ }^{93}$ Anrechenbar sind diese Steuern zum Zeitpunkt der Besteuerung durch die USA, also nach der Ausschüttung an die Muttergesellschaft, oder wenn die Gewinne der Zugriffsbesteuerung gemäß Unterabschnitt F unterliegen. ${ }^{94}$

Die wesentlichsten Elemente der rechtlichen Gestalt des Anrechnungsverfahrens in den USA $^{95}$, das inzwischen ,wahrlich barocke Dimensionen angenommen hat" 96 :

Im Unterschied zu der in Teil B dargestellten allgemeinen Form des Anrechnungsverfahrens ist in den USA der Anrechnungshöchstbetrag für etliche Einkunftarten getrennt zu bestimmen. Die Einkünfte aus allen ausländischen Quellen werden in sogenannten Körben (,,baskets“) zusammengefaßt. Für jeden der Körbe ist nach der Gleichung [B3] auf Seite 20 die maximal anrechenbare ausländische Steuerlast zu errechnen:

[C1] $\begin{gathered}\text { Anrechnungs- } \\ \text { höchstbetrag für } \\ \begin{array}{c}\text { Einkünfte } \\ \text { dieses Korbes }\end{array}\end{gathered}=\frac{\begin{array}{c}\text { steuerpflichtige ausländische } \\ \text { Einkünfte eines Korbes }\end{array}}{\text { steuerpflichtige }} \begin{gathered}\begin{array}{c}\text { Steuerschuld im } \\ \text { Wohnsitzland auf die } \\ \text { Welteinkünfte }\end{array} \\ \begin{array}{c}\text { Welteinkünfte vor } \\ \text { der Anrechnung } \\ \text { ausländischer Steuern }\end{array}\end{gathered} .97$

Es ist somit für die Bemessung des anrechenbaren Betrags in den USA nicht relevant, aus welchen ausländischen Quellenländern die Einkünfte stammen. Ausländische Steuern auf die Einkünfte eines bestimmten Korbes können die Steuerforderung des U.S.-amerikanischen Fiskus aber nur auf die gesamten Einkünfte der jeweiligen Gruppe mindern. Innerhalb jedes Korbs sind gemäß der Quellenregeln in- und ausländische Bruttoeinkünfte zu trennen und die Abzüge zuzurechnen, um den Betrag der steuerpflichtigen ausländischen Einkünfte des Korbs in [C1] $\mathrm{zu}$ bestimmen. ${ }^{98}$

Mit der Steuerreform 1986 wuchs die Zahl der einzelnen Körbe auf mindestens zehn; unter anderem: 99,100

91 Weitere Ziele sind: Erhaltung der Wettbewerbsfähigkeit, Einfachheit und die Kompatibilität mit den internationalen Besteuerungsnormen. Vgl. A.J. Wilensky, a.a.O., S.1000f..

92 Ausländische Steuern können gemäß IRC §905(a) im Inland dann angerechnet werden, wenn die Forderung im Ausland entsteht oder wenn sie tatsächlich gezahlt werden.

93 IRC §902(a); S.R. Marcuse u. D.L. Paul, The U.S. Foreign Tax Credit - A Practical Handbook -, London 1993, S.39.

94 IRC §901(a), IRC §902(a) bzw. §960(a) i.V.m. IRC §78.

95 Für einen guten Überblick über das U.S.-amerikanische Anrechnungsverfahren vgl. S.R. Marcuse u. D.L. Paul, a.a.O. und M. Zarnitz, Die Wirkung der Einführung der separaten Limitierung in das US-amerikanische Außensteuerrecht auf die internationale Kapitalallokation, Diss., Univ. Hamburg 1994, S.29-74.

96 J. Isenbergh, International Taxation, Teil I, a.a.O., S.456.

97 Arthur Andersen \& Co., a.a.O., S. 193.

98 Für eine detaillierte Aufstellung der Prüfungsreihenfolge vgl. S.R. Marcuse u. D.L. Paul, a.a.O., S.3-18.

99 IRC §904(d); Arthur Andersen \& Co., a.a.O., S.190f., in deutscher Übersetzung auch bei E.K. Briner, Änderungen im amerikanischen Steuerrecht, in: Steuer Revue, 43. Jg. (1988), S.20-23.

Diese Liste gilt für alle Steuerpflichtigen infolge IRC §954(c)(A),(B) i.V.m. §904(d)(2)(A)(i). 
(A) Passive Einkünfte, die dem Steuerpflichtigen entweder zufließen oder bei ihm der Abzugsbesteuerung unterliegen, insbesondere

- Dividenden aus Beteiligungen, die weniger als $10 \%$ betragen;

- Zinserträge und vergleichbare Einkünfte, ${ }^{101}$ soweit sie nicht in dem Korb (B) aufgenommen werden;

- Gewinne aus der Veräußerung von Vermögenswerten, deren Erträge als passiv eingestuft würden, also auch Kursgewinne oder -verluste bei dem Verkauf von Aktien und Anleihen und

- Nettowährungsgewinne bei bestimmten Transaktionen, 102

soweit der Steuerpflichtige nicht nachweist, daß der ausländische effektive Steuersatz auf diese Einkünfte mindestens $90 \%$ des Satzes der USA beträgt. In diesem Fall können die Einkünfte dem nachstehend genannten Korb (I) zugewiesen werden (,kickout rule"). ${ }^{103}$ Damit ist es (nahezu) ausgeschlossen, mit im Ausland niedrig besteuerten passiven Erträgen die Steuerlast in den USA auf andere Arten ausländischer Einkünfte zu mindern. Umgekehrt ist es aber möglich, Anrechnungsgutschriften in Korb (I) auf passive Einkünfte anzuwenden.

(B) Ausländische Zinserträge, auf die eine „hohe Quellensteuer“ von mindestens fünf Prozent erhoben wurde.

(E) Dividenden von jeder nicht abhängigen Auslandsgesellschaft, an denen der Steuerpflichtige zu mindestens zehn Prozent beteiligt ist, in einem separaten Korb. 104

(I) Den globalen Korb (,overall basket“) für alle weiteren ausländischen Erträge, die in keinen der anderen Körbe hineingehören.

Anrechnungsüberhänge können bis zu maximal zwei Jahre zurück- und fünf Jahre vorgetragen werden. Eine Verrechnung von Anrechnungsüberhängen in einzelnen Körben mit inländischen Steuerforderungen auf Einkünfte in anderen Körben ist aber natürlich nicht zulässig. ${ }^{105}$

Das steuerpflichtige Einkommen aus ausländischen Quellen umfaßt auch Veräußerungsgewinne der Periode. Einbezogen wird indes nur der geringere Betrag von (i) den Nettoveräußerungsgewinnen aus Quellen außerhalb der Vereinigten Staaten oder (ii) den weltweiten Nettoveräußerungsgewinnen des Steuerpflichtigen. ${ }^{106}$ Ein Veräußerungsverlust im Inland mindert den weltweiten Veräußerungsgewinn und demnach auch den Veräußerungsgewinn aus ausländischen Quellen. Ausländische Nettoveräußerungsverluste bleiben hiernach bei der Berechnung anrechenbarer ausländischer Steuern unberücksichtigt.

Die Verrechnung ordentlicher ausländischer Verluste mit inländischen Gewinnen in einer Periode ist - wie gesagt - möglich. Anrechenbare ausländische Ertragsteuern können aber nur

100 Weiterhin bestehen Körbe für: (C) Einkünfte aus Bankgeschäften, Finanzierungen, Versicherungen und vergleichbaren Tätigkeiten; (D) Einkünfte aus Schiffahrtsgesellschaften; (F) „domestic international sales corporation“ (DISC) Dividenden; (G) ,foreign sales corporations“ (FSC) Erträge und $(\mathrm{H})$ FSC Ausschüttungen und gemäß IRC $\$ 907$ ein Korb für Einkünfte aus der Förderung von Rohöl.

101 Vgl. zu den vergleichbaren Einkünten Reg. §1.954-2(h).

102 Vgl. die Seiten 131 ff. dieser Arbeit.

${ }^{103}$ IRC §954(b)(4); Arthur Andersen \& Co., a.a.O., S. 195.

104 Sogenannte „10-50 corporations“. Infolge dieser Anforderung, für jede Beteiligung an einer nicht abhängigen Auslandsgesellschaft durch einen getrennten Korb (E) anzurechnen, gilt für Beteiligungen zwischen zehn und 50 Prozent de facto eine „per country limitation“. Durch die Steueränderung von 1997 wird diese Trennung zugunsten eines einzigen Korbes aufgehoben werden. Die Vereinfachung gilt allerdings erst ab dem Jahr 2003. Taxpayer Relief Act of 1997, §1105(a); KPMG Peat Marwick LLP. (Hrsg.), a.a.O., Internet: http:// www.us.kpmg.com/taxact/ booklet/7foreign.html; M. Cooper, A. Shapiro u.a., Tax Payer Relief Act of 1997 Introduces Changes to International Tax Provisions, in: Tax Notes International, 15.Jg. (1997), S.414f..

105 IRC $\S 904(c)$.

106 IRC $\S 904(\mathrm{~b})(2),(\mathrm{b})(3)(\mathrm{A})$. 
inländische Steuern auf ausländische Gewinne kürzen. ${ }^{107}$ Das heißt: ist ein Steuerpflichtiger in der Situation, in einem Jahr einen negativen Ertrag bei der Summe seiner ausländischen Engagements feststellen zu müssen, so mindern diese negativen Einkünfte sein Welteinkommen in der Periode und damit die Steuerlast in den USA. Positive Einkünfte in späteren Perioden werden aber zur Bemessung des Anrechnungsbetrags bis zur Höhe des Verlustes als inländische Einkünfte umgedeutet. ${ }^{108}$ Ausländische Abgaben auf diese Einkünfte sind mithin nicht anrechenbar; der Fiskus der USA gewinnt auf die Weise die im Jahr des ausländischen Verlusts gekürzte Steuer zurück (,recapture“). Für den Steuerzahler ist allerdings ein Anrechnungsüberhang sehr wahrscheinlich. ${ }^{109}$ Prinzipiell analog wird verfahren, wenn sich ein Verlust in einem Korb herausstellt. Dieser Betrag ist aber zunächst proportional von den Gewinnen in anderen Körben und nur ein danach verbleibender Rest von inländischen Einkünften abzuziehen. Umgekehrt werden anschließend positive Erträge in dem Korb, in dem der Verlust eintrat (,loss basket“) zunächst den übrigen Körben zugerechnet. ${ }^{110}$

Die Anrechnung ausländischer Steuerzahlungen ist ein Wahlrecht. ${ }^{111}$ Verzichtet ein Steuerpflichtiger auf die Anrechnung, verbleibt die Möglichkeit des Abzugs dieser Aufwendungen. ${ }^{112}$ Die Wahl des Anrechnungsverfahrens ist für jedes Jahr getrennt zu treffen. Natürlich kann aber nicht in einem Steuerjahr in einem Land für den Abzug, in einem anderen Währungsraum dagegen für die Anrechnung von im Ausland gezahlten Steuern optiert werden. ${ }^{113}$

\footnotetext{
${ }^{107}$ Verluste aus den ,überflüssigen passiven Aktiva“ gemäß Unterabschnitt F können nur innerhalb der Tochtergesellschaft mit Gewinnen verrechnet werden. Die Abzugsbesteuerung dieser Verluste - und damit die Verrechnung mit positiven Erträgen aus anderen Tochtergesellschaften und anderen Ländern im Korb (A) - ist nicht möglich. J.F. Chown, a.a.O., S.161.

${ }^{108}$ IRC $\S 904(f)(1)$. Der in einem Steuerjahr als inländische Einkünfte umgedeutete Betrag kann begrenzt werden auf $50 \%$ der gesamten ausländischen Erträge des Jahres.

${ }^{109}$ M. Zarnitz, a.a.O., S. 90 .

110 IRC $\$ 904(f)(5)$.

${ }^{111}$ IRC $\$ 901(a)$.

112 IRC \$164(a)(3).

113 IRC §275(a)(4)(A).
} 


\section{Die einkommensteuerliche Behandlung von Währungsgewinnen und -verlusten}

Die Besteuerung von Gewinnen und Verlusten aus Wechselkursfluktuationen ist in den USA seit der Steuerreform von 1986 explizit im Steuergesetz im Unterabschnitt J (,Subpart J-Foreign Currency Transactions') des Einkommensteuergesetzes in den Paragraphen 985 bis 989114 und den dazugehörenden Durchführungsverordnungen geregelt. ${ }^{115}$ Zum Zwecke der Erhebung der Bundeseinkommensteuer durch die USA werden Zeitpunkt der Erfassung, Charakter und die geographische Quelle der meisten - aber nicht aller - realisierten Währungsgewinne oder -verluste, die Umrechnungsmethode für ausländische Einkünfte und die Umrechnung anrechenbarer ausländischer Steuern in den Gesetzen maßgebend festgelegt. 116

In Paragraph 989 wird dem Finanzministerium darüber hinaus ein weitreichender Spielraum zur Interpretation des Gesetzestextes eingeräumt. Dies ist in den erlassenen Regelungen („Treasury Regulations“) geschehen.

\section{Grundlagen zur steuerrechtlichen Ermittlung}

Vor der Steuerreform von 1986 wurden fünf Umrechnungsmethoden zur Ermittlung steuerlichen Gewinnes im Inland unterschieden. Die drei wesentlichen Ansätze sind:

- die Umsatzmethode (,the transaction method"),

- die Stichtagmethode (,the profit and loss method") $)^{117}$ und

- die Fristigkeitmethode (,the net worth method“) ${ }^{118}$.

Hinzu kamen zwei weitere Verfahren, die „foreign corporation method"119 und die „section 964 method" ${ }^{120}$, die im Ergebnis Kombinationen der übrigen drei Methoden sind, aber infolge der rechtlichen Selbständigkeit ausländischer Tochterkapitalgesellschaften und der auch damals schon praktizierten Zugriffsbesteuerung unterschieden wurden.

Die Ansätze unterscheiden sich im wesentlichen in folgenden Punkten: ${ }^{121}$

- Die ausländische Währung wird in unterschiedlichem Umfang zur Ermittlung des in den USA steuerpflichtigen Gewinnes angewendet.

- Bilanzpositionen sind teilweise zu historischen Kursen, teilweise zu Stichtagskursen umzurechnen.

\footnotetext{
${ }^{114} \mathrm{Vgl}$. Anhang VI auf Seite 224.

${ }^{115} \mathrm{Zu}$ den Inhalten der Reform der Besteuerung von Währungsgewinnen und -verlusten vgl. W.S. Corey u.a., Tax Treatment of Foreign Currency Under $\$ \S 985-989$, in: The Tax Management International Journal, 16.Jg. (1987), S.375-399 (Teil I) und S.127-146 (Teil II); International Bureau of Fiscal Documentation, Tax Treatment of Exchange Gains and Losses, Amsterdam, 1988, S.129-137; D.P. Zaiken u.a., Handling the Treatment of Foreign Currency under Tax Reform, a.a.O., S.168-178; C.E. Muller u.a., Foreign Currency Regulatory Guidance, in: Tax Management International Journal, 17.Jg. (1988), S.371-393; R. Henrey, International Tax Aspects of Foreign Currency Transactions, in: International Bureau of Fiscal Documentation Bulletin, 43.Jg. (1989), S.312-326; R.P. Keck u. J.F. Montgomery, US Federal Tax Aspects of Foreign Currency Transactions, in: Intertax, o.Jg. (1994), S. 149-158 und in deutsch: U. Woywode, a.a.O., S.695-704.

${ }^{116}$ R.P. Keck u. J.F. Montgomery, a.a.O., S.149;

117 Rechtliche Grundlage war Reverent Ruling 75-107, 1975-1 CB32.

${ }_{118}$ Rechtliche Grundlage war Reverent Ruling 75-106, 1975-1 CB31.

${ }^{119}$ Für das Verfahren wird auch der Begriff, „section 902 method" verwendet.

${ }^{120}$ Auch „combination method“" genannt. Reg. §1.964-1, insbesondere Reg. §1.964-1(e).

${ }^{121}$ D. R. Ravenscroft, a.a.O., S.14.
} 
- Die Umsätze werden entweder einzeln umgerechnet oder aber nur das Betriebsergebnis der Tochtergesellschaft oder Betriebstätte.

- Der Überschuß wird im Jahr der Entstehung oder im Jahr des Transfers in das Inland besteuert.

Es ist offensichtlich, daß aus diesen Bewertungsunterschieden Auswirkungen auf die Höhe der steuerlichen Bemessungsgrundlage und den Zeitpunkt der Belastung resultieren. ${ }^{122} \mathrm{Da}$ sich die anzuwendende Verfahrensweise aus der rechtlichen Erscheinungsform des Auslandsengagements ableitete und auch hierbei zum Teil Wahlrechte eingeräumt wurden, verblieb erheblicher und viel kritisierter Ermessensspielraum auf Seiten von Steuerverwaltung und Steuerpflichtigen.

Das Grundprinzip der Methoden, die in den Jahren durch richterliche Entscheidungen und Durchführungsverordnungen der Finanzverwaltung $\mathrm{zu}$ geltendem Steuerrecht der USA wurden, wird auf den folgenden Seiten kurz vorgestellt und bewertet.

Elementarer Ausgangspunkt der steuerrechtlichen Folgen von Wechselkursänderungen war und ist die Interpretation von Beständen in ausländischen Währungen als Vermögen (,property“) und nicht als Zahlungsmittel. Erträge daraus sind damit steuerrechtlich prinzipiell wie andere Vermögenswerte zu behandeln.

Das bedeutet, der Erwerb einer fremden Währung stellt immer einen Kauf (,purchase“) dar, deren Veräußerung - ganz gleich ob durch Tausch gegen Güter oder Dienstleistungen oder aber gegen andere Währungen - einen Verkauf (,sale or exchange").

„Infolgedessen ist der Genuß eines Cappuccinos, der von einem U.S.-Touristen einem Café in Florenz in italienischer Lire bezahlt wurde, theoretisch ein Anlaß zur Feststellung eines steuerpflichtigen Gewinnes": der Differenz zwischen dem Wechselkurs der Lire zum Zeitpunkt des Erwerbs und ihres Tausches durch das Bezahlen des Cappuccinos. ${ }^{123}$

Die Differenzierung zwischen dem U.S.-Dollar und ausländischen Zahlungsmitteln wird begründet mit der Beobachtung, daß andere Währungen gegenüber dem U.S.-Dollar im Wert schwanken, wohingegen der Dollarwert des U.S.-Dollar natürlich konstant bleibt. ${ }^{124} \mathrm{Im}$ Ergebnis kommt darin die Anwendung des Nominalwertprinzips für das U.S.-Zahlungsmittel im Steuerrecht des Landes zum Ausdruck. Allerdings wird das Nominalwertprinzip an keiner Stelle explizit zur Grundlage des Steuersystems der USA erklärt.

Wenn Fremdwährungsbestände als Vermögen anzusehen sind, impliziert dies aber zweitens auch die Anwendung des Realisationsprinzips („realization principle“). Das heißt, die Besteuerung von Währungsgewinnen und -verlusten ist nicht früher als zum Zeitpunkt der Realisierung durch Tausch oder Verkauf möglich.

\section{a) Umsatzmethode (,Separate Transaction Method“)}

Die steuerrechtliche Interpretation von Beständen in ausländischen Währungen als Vermögen ist der Anknüpfungspunkt der Umsatzmethode - auch Transaktionsmethode (,(separate) transaction method") genannt. ${ }^{125}$

122 D. R. Ravenscroft, a.a.O., S. 14 ff.; P. B. Musgrave, Exchange Rate Aspects, a.a.O., S.406.

123 J. Isenbergh, International Taxation, Teil II, a.a.O., S. 280 u. S.280, Fn. 1 (eigene Übersetzung).

124 So z.B. T. J. O'Neil u. C. Lee, Federal Income Tax Treatment of Foreign Currency Denominated Debt, a.a.O., S.11.; J. Isenbergh, International Taxation, Teil II, a.a.O., S. 280.

125 S.R. Lainoff u. T.Y. McArthur, The Final Functional Currency Regime for U.S. Taxpayers Operating in Hyperinflationary Environments: Mandatory DASTM, in: Tax Management International Journal, 23.Jg. (1994), S.583. 
Nach dem sogenannten "separate transactions principle" waren die Transaktionen in einer fremden Währung in der Regel in zwei Elemente zu zerlegen: die Geschäftstätigkeit und das Währungsrisiko. Die U.S.-amerikanischen Finanzgerichte hatten bis 1986 übereinstimmend erklärt, diese zwei Elemente seien steuerrechtlich als separate Transaktionen anzusehen. ${ }^{126}$ In dem Fall ,Church's English Shoes, Ltd. versus Commissioner', der den Kauf von Schuhen von einem englischen Verkäufer auf Kredit in britischen Pfund zum Inhalt hatte, begründete das Finanzgericht beispielsweise, daß ,zum Zwecke der Buchführung und der Besteuerung zwei Transaktionen vorlagen, zum einen der Kauf und Verkauf von Schuhen und zum anderen eine ,Spekulation' in einer fremden Währung." 127,128

Ob nun „Spekulation“ die richtige Bezeichnung ist, sei dahingestellt. Es ist jedenfalls ökonomisch plausibel, einen Währungsgewinn oder -verlust aus Kauf, Verkauf oder Tausch der Fremdwährungsposition einerseits und den Ertrag aus beziehungsweise die Aufwendung für eine Leistung andererseits zu trennen. ${ }^{129}$ Die Vorgehensweise basiert auf der „Fiktion der sofortigen Zahlung bei Lieferung und gleichzeitiger Fremdwährungskreditaufnahme" 130 und entspricht damit der Definition des Währungsrisikos in Teil B.

Steuerrechtliche Folge ist zum einen die Möglichkeit der Zuteilung des Währungsgewinns oder -verlustes zu einer anderen Quelle und auch in einem anderen Anrechnungskorb als die zugrundeliegende Geschäftstätigkeit - beispielsweise zusammen mit Zinserträgen oder als inländische Einkünfte. Zum anderen können der Zeitpunkt der Realisation des Erfolgs aus der Geschäftstätigkeit und des Währungsgewinnes oder -verlustes auseinanderfallen.

Folge ist allerdings auch die Notwendigkeit der getrennten buchhalterischen Erfassung der beiden Vorgänge: zur Bestimmung des steuerlichen Gewinnes ist jede Transaktion einer Bilanzperiode separat zum jeweils aktuellen Devisenkurs umzurechnen. Das heißt, die Bücher sind in U.S.-Dollar zu führen. Der Währungsgewinn oder -verlust wird demgemäß dann steuerpflichtig, wenn die Transaktion abgeschlossen ist. ${ }^{131}$

Beispiel C1:

Ein amerikanisches Unternehmen kauft ein Grundstück im Ausland in der Währung des Landes (AM) für 10.000 AM. Umgerechnet zum Zeitpunkt des Kaufs seien dies $\$ 10.000$. Am Ende des Jahres wird es für 10.700 AM veräußert. Der Kurs der AM liege an diesem Tag bei $\$ 1,028$. Der Gewinn von 700 AM vor der Umrechnung ist somit für das amerikanische Unternehmen infolge der Währungsentwicklung tatsächlich ein Gewinn von $\$ 1.000$.

Dieser Erfolg von $\$ 1.000$ ist für die Bemessung der Steuerlast der Periode maßgeblich, unabhängig davon, ob das Vermögen am Tag der Veräußerung in U.S.-Dollar transferiert wird.

Wird das Grundstück statt dessen erst am ersten Tag der nächsten Periode verkauft, bleibt der Gewinn in der Bilanz der ersten Periode unberücksichtigt, da keine Transaktion stattfand, bei der der Ertrag realisiert wurde. Der Steuerpflichtige muß das Aktivum zum Anschaffungspreis in U.S.-Dollar bilanzieren.

${ }^{126}$ T.J. O'Neil u. C. Lee, a.a.O., S.12; S.R. Lainoff u. T.Y. McArthur, a.a.O., S. 584.

${ }^{127}$ Church's English Shoes, Ltd., 24 T.C. 56 (1955), zitiert nach: T.J. O'Neil u. C. Lee a.a.O., S. 12 (eigene Übersetzung).

${ }^{128}$ Im Unterschied hierzu wird bei dem sogenannten integrierten Ansatz (,integrated approach“) der Währungsgewinn oder -verlust dem Verkaufserlös oder dem Kaufpreis zugerechnet, indem die Transaktion im Zeitpunkt des Zahlungsein- beziehungsweise Zahlungsausgangs gebucht wird. J.J. Costello, Tax Impact of Currency Exchange Rate Fluctuations, in: Tax Lawyer, 26.Jg. (1973), S.430ff.; FASB, An Analysis of Issues Related to Accounting of Foreign Currency Translation; FASB-Discussion Memorandum, Stamford 1974, S. 2 f.

${ }^{129}$ Vgl. auch T.J. O'Neil u. C. Lee, a.a.O., 13.

${ }^{130}$ G. Gebhardt u. N. Breker, a.a.O., S. 1531.

131 P. B. Musgrave, Exchange Rate Aspects, a.a.O., S.406; J.B. Mertens, a.a.O., S. 28. 
Dies ist freilich soweit nichts Neues. Es ist ein Faktum des Realisationsprinzips, daß es den Steuerpflichtigen einen Zinsvorteil durch den Aufschub des Besteuerungszeitpunktes gewährt und das Wahlrecht des Zeitpunktes der Realisation einräumt, der im Fall eines Währungsverlustes auch zum Nachteil werden kann.

Wenn auf in- und ausländische Gewinne der gleiche Steuersatz zur Anwendung kommt, ist in dem hier gewählten Beispiel Kapitalexportneutralität indes nicht verletzt. Denn wird eine Währungsentwicklung gemäß der Zinsparitätenhypothese erwartet, wäre der Vorteil durch den Steueraufschub für Kapitalanbieter eines jeden Landes bei allen Investitionsalternativen gleich groß - solange die Anlage während der Haltedauer keine Ein- oder Auszahlungen auslöst.

Hierin liegt eine Schwäche der Umsatzmethode. Hätte nämlich in der oben geschilderten Investition der ökonomische Ertrag in der ausländischen Währung auch eine Einzahlung in Höhe von 700AM am Ende der ersten Periode zur Folge - beispielsweise durch Mieteinnahmen -, wäre diese zum Wechselkurs zum Zeitpunkt der Zahlung umzurechnen. Steuerpflichtig wären somit $\$ 720(=700 \mathrm{AM} \cdot 1,028$ \$/AM). Der weitere Währungsgewinn im Umfang von $\$ 280$ wäre demgegenüber erst in der folgenden Periode zu versteuern, wenn das Grundstück über die Jahresfrist hinaus gehalten wird. Eine sonst gleiche inländische Anlage mit einer steuerpflichtigen Einzahlung von $\$ 1.000$ in der ersten Periode wird infolgedessen diskriminiert, beziehungsweise - im umgekehrten Fall eines Währungsverlustes - begünstigt.

Letzteres wird verstärkt, wenn das Steuersystem nicht symmetrisch ist. Kommt das Realisationsprinzip zur Anwendung, erscheinen die Auswirkungen einer eingeschränkten steuerlichen Berücksichtigung von Verlusten in einem etwas anderen Licht als in der einperiodigen Analyse des Teils B. Denn es sind Währungsverluste mehrerer Perioden kumuliert in dem Steuerjahr der Veräußerung des Aktivums in der Bemessungsgrundlage einer ausländischen Investition zu berücksichtigen.

Beispiel C2:

Ein amerikanisches Unternehmen kauft nun ein Grundstück für $\$ 10.000$ beziehungsweise $10.000 \mathrm{AM}$ in einem Land, dessen Währung jährlich um $0,973 \%$ gegenüber dem U.S.-Dollar abwertet. Es werden in jedem Jahr Mieteinnahmen von 1.000 AM erzielt, der Marktwert des Grundstücks bleibt in AM aber konstant.

Das Grundstück wird am Ende des vierten Jahres veräußert. Der Erlös von 10.000 AM entspricht dann einem Wert von $\$ 8.950$, es wird also ein Währungsverlust von $\$ 1.050$ realisiert. Dem stehen Mieteinnahmen von $\$ 895$ in der Periode gegenüber, insgesamt verbleibt also ein Verlust von $\$ 155$.

Der Erwartungswert des Ertrags der Investition zum Zeitpunkt der Investitionsentscheidung wird bei asymmetrischer Besteuerung durch das Risiko eines noch größeren wechselkursbedingten Verlustes zusätzlich gemindert.

Eine weitere Schwäche ist, wie schon angedeutet, der buchhalterische Aufwand, da die Methode die Umrechnung jeder einzelnen Transaktion erfordert. Deshalb wird sie nur für Unternehmen mit wenigen derartigen Umsätzen, die keine ausländische Betriebstätte unterhalten und insbesondere deren Buchhaltung in heimischer Währung geführt wird, als geeignet angesehen. Wenn ausländische Betriebstätten diesen Ansatz anwenden, müßten sie ihre Bücher faktisch in der Währung des Stammhauses führen. ${ }^{132}$

132 J.B. Mertens, a.a.O., S. 28. 


\section{b) Stichtagmethode („Profit and Loss Method“)}

Das Umrechnen jeder Einzelposition wird bei der Stichtagmethode vermieden. Die Bücher der ausländischen Unternehmung des inländischen Steuerpflichtigen werden in diesem Ansatz in der Währung ihres Standortes geführt; die ausländische Währung fungiert mithin als eigene Maßeinheit. ${ }^{133}$ Deshalb ist es bei der Stichtagmethode möglich, auch für nichtmonetäre Vermögenswerte einen Wertzuwachs - gemessen in der Währung des Standorts - und einen Währungsgewinn getrennt zu quantifizieren.

Dieser Aspekt ist wesentlich zum Verständnis der unterschiedlichen steuerrechtlichen Vorgehensweisen bei beiden Methoden der Umsatz- und der Stichtagmethode.

Zum Zwecke der Besteuerung im Inland ist das Ergebnis der Gewinn- und Verlustrechnung in die inländische Währung umzurechnen. In der Regel - allerdings nicht immer - ist zur Umrechnung des steuerpflichtigen Bilanzgewinnes der Wechselkurs am Bilanzstichtag maßgeblich. Ebenfalls in der Regel sind Kapitalrückfuihrungen oder weiterer Kapitalexport zum Kurs zum Zeitpunkt der Transaktion zu berücksichtigen. ${ }^{134}$

Beispiel C3:

Im Unterschied zum vorhergehenden Unterabschnitt verwendet das amerikanische Unternehmen $\$ 10.000$ beziehungsweise $10.000 \mathrm{AM}$ nun als Einlage für eine ausländischen Niederlassung. Am Ende der gleichen Periode verkauft die Muttergesellschaft die Unternehmung für 10.700 AM; der Wechselkurs zu diesem Zeitpunkt betrage auch dieses Mal $1,028 \mathrm{~S} / \mathrm{Am}$. Um das Beispiel nicht unnötig kompliziert zu machen, wird angenommen, der

Marktwert der Aktiva entspreche auch zu diesem Zeitpunkt ihrem Buchwert.

Zugegebenermaßen ist der Fall nicht spektakulär. Hier ist der einzige Gegensatz zum Beispiel des vorangegangenen Unterabschnitts, daß der Marktwertzuwachs das Ergebnis einer Vielzahl von Einzeltransaktionen der Betriebstätte in der ausländischen Währung sein wird. Freilich wurde die Problematik der Investitionsneutralität des Steuersystems - die Umsetzung der Ertragswertabschreibung - durch die Annahme der Identität von Markt- und Buchwerten kurzerhand ausgeklammert.

Die Parallelen werden noch deutlicher, wenn der Fall - wiederum analog zum vorangegangenen Unterabschnitt - umgeschrieben wird:

Beispiel C4:

Die Niederlassung in Beispiel C3 wird erst zu Beginn der zweiten Periode veräußert.

Zum Ende der ersten Periode wurde eine Gewinn- und Verlustrechnung erstellt, die ein

Plus von $700 \mathrm{AM}$ auswies.

$700 \mathrm{AM} \cdot 1,028 \mathrm{~S} / \mathrm{AM}=\$ 720$ sind auch hier in der ersten Periode im Inland steuerpflichtig. Der darüber hinausgehende Währungsgewinn von $\$ 280$ wird in der Gewinn- und Verlustrechnung nicht erfaßt. Er ist deshalb auch erst zum Zeitpunkt der Realisierung zu versteuern. Zumeist ist dies dann ganz oder teilweise der Fall, wenn die ausländische Betriebstätte veräußert beziehungsweise Kapital entnommen wird.

So erscheint die Stichtagmethode als eine logische Erweiterung der Umsatzmethode für Auslandsengagements mit komplexen Zahlungsreihen, wie etwa eine ausländische Betriebstätte. Ein zentraler Unterschied zur Umsatzmethode ist, daß hier die ausländische Unternehmung als wirtschaftliche Einheit betrachtet wird. ${ }^{135,136}$ Nicht die Einzeltransaktion innerhalb der Einheit wird betrachtet, sondern nur die Transaktionen des inländischen Steuerpflichtigen. ${ }^{137}$

133 S. R. Lainoff u. T.Y. McArthur, a.a.O., S. 583.

134 P. B. Musgrave, Exchange Rate Aspects, a.a.O., S.406.

135 J. Walmsley, The Foreign Exchange Handbook: A Users Guide, New York u.a. 1983, S.373. 
Hieraus leitet sich aber auch zusätzliche Kritik ab, denn die Stichtagmethode ist im Vergleich zur Umsatzmethode aus dem Blickwinkel ökonomischer Effizienz nicht vorzuziehen. Wäre nämlich der Erwerb des Grundstücks des ersten Beispiels Teil der Geschäftstätigkeit der Betriebstätte, würde der Verkauf am Anfang der zweiten Periode nicht zu der Realisierung des Währungsgewinnes oder -verlustes (in Höhe von hier \$280) führen. Einbezogen würde bei der Bemessung der Steuerlast im Inland immer nur ein Veräußerungsgewinn der ausländischen wirtschaftlichen Einheit, der zum Kurs am darauffolgenden Bilanzstichtag umgerechnet werden würde.

Im umgekehrten Fall eines rückläufigen Devisenkurses würde sich darüber hinaus bei begrenzten Verlustausgleichsmöglichkeiten auch in stärkerem Maße eine diskriminierende Wechselwirkung mit dem Realisationsprinzip auswirken können.

Allgemein formuliert: Die Begünstigung (Benachteiligung) von Kapitalexport durch einen Aufschub der Besteuerung von Währungsgewinnen (Verlusten) ist umso größer, je stärker der erwartete Gesamtertrag des Auslandsengagements durch eine erwartete Wechselkursänderung geprägt ist. In einem nicht symmetrischen Steuersystem ist die Benachteiligung außerdem umso größer, je mehr Unsicherheit über die erwartete Währungsentwicklung besteht.

Sehr schwierig ist eine schlüssige ökonomische Beurteilung von Abschreibungen für Abnutzung. Das Problem wird zurückgestellt und erst auf Seite 124 im Zusammenhang mit der Besteuerung von Investitionen in stark inflationären Währungsräumen angesprochen.

\section{c) Fristigkeitmethode (,Net Worth Method“)}

Bei der „Net Worth Method“ ist nicht die Gewinn- und Verlustrechnung, sondern der Jahresabschluß der ausländischen wirtschaftlichen Einheit Anknüpfungspunkt zur Bestimmung der Steuerlast im Inland. Prinzipiell ist der steuerpflichtige Gewinn die Differenz zwischen dem in inländischer Währung ausgedrückten Wert des bilanziellen Reinvermögens am Beginn und am Ende der Bilanzperiode - korrigiert um Transfers im Verlauf der Periode. Letztere werden in gleicher Weise wie auch bei der Umsatzmethode bewertet, nämlich zum Kurs zum Zeitpunkt der Übertragung. ${ }^{138}$

Zur Umrechnung der Bilanzpositionen ist allerdings nicht in jedem Fall der Wechselkurs am Bilanzstichtag maßgeblich. Der Stichtagskurs ist nur bei Positionen des Umlaufvermögens („current assets") und kurzfristigen Verbindlichkeiten anzuwenden. Das Anlagevermögen (,noncurrent assets") ist statt dessen, ebenso wie langfristige Verbindlichkeiten, zum historischen Kurs des Datums der Anschaffung in inländischer Währung zu bilanzieren. Die „Net Worth Method" ist deshalb als eine sogenannte Fristigkeitmethode anzusehen.

In der Rechnungslegung wird deshalb der Begriff der lokalen Perspektive („local perspective") verwendet. Im Unterschied dazu bezeichnet die globale Perspektive Umrechnungsmethoden - wie z.B. die Umsatzmethode -, bei das Auslandsengagement als integraler Bestandteil der weltweiten Aktivitäten des inländischen Steuerpflichtigen angesehen wird. Vgl. z.B. K. Küting u. C.-P. Weber, Der Konzernabschluß, 3.Aufl., Stuttgart 1991, S.117-128.

${ }^{136}$ Der Begriff „wirtschaftliche Einheit“ wird hier auch als deutsche Übersetzung des in der amerikanischen Literatur und im U.S.-Steuerrecht weit verbreiteten Wortes ,entity“ gebraucht.

${ }^{137}$ Die Stichtagmethode ist im Steuerrecht der USA aber nicht eine logische Erweiterung der Umsatzmethode. Denn bei der Stichtagmethode wird ein Währungserfolg bei Beteiligungskapital getrennt berechnet, bei der Umsatzmethode dagegen bei nichtmonetären Aktiva, und dazu zählen auch Aktien ausländischer Unternehmen in den Händen inländischer Steuerpflichtiger, nicht. Dieser Aspekt - und Kritikpunkt - wird an späterer Stelle ausführlicher behandelt.

138 P. B. Musgrave, Exchange Rate Aspects, a.a.O., S.406; T. Horst, Foreign Exchange Gains and Losses: What are the Issues?, in: Tax Notes, 28. Jg. (1985), S.1396. 
An dieser Stelle ist ein kurzer Exkurs zur begrifflichen Klarstellung angebracht. Für die handelsbilanzielle Umrechnung werden nämlich andere Begriffe verwendet als die hier genannten des U.S.-Steuerrechts; darüber hinaus sind im englischen und im amerikanischen Sprachraum unterschiedliche Bezeichnungen gebräuchlich:

Prinzipiell wird zwischen den Umrechnungsmethoden mit differenzierten Kursen (,net worth“ oder ,balance sheet methods") und der Stichtagmethode (,current-“"oder ,closing-rate method") unterschieden.

$\mathrm{Zu}$ ersteren zählt die Fristigkeitmethode, die in der Rechnungslegung auch als „currentnoncurrent method" bezeichnet wird. Die sogenannte Nominal-/Sachwertmethode (,monetarynonmonetary method") knüpft demgegenüber nicht an der Fristigkeit, sondern der Geldnähe der Bilanzpositionen an. Der Hauptunterschied zur Fristigkeitmethode ist demnach, daß langfristige Verbindlichkeiten zum aktuellen, Aktien beispielsweise dagegen zum historischen Kurs umzurechnen sind. ${ }^{139}$ Als eine Weiterentwicklung der Nominal-/Sachwertmethode wird die Zeitbezugmethode („temporal method"140) angesehen, die besonders in Deutschland Anwendung findet und deshalb dem nächsten Teil $\mathrm{D}$ vorbehalten bleibt.

Neben der hier beschriebenen Stichtagmethode gibt es noch die modifizierte Form, bei der nicht nur die Gewinn- und Verlustrechnung umgerechnet wird, sondern auch der Jahresabschluß. Dabei ist nur das Eigenkapital mit dem historischen Kurs zu konvertieren. Eine dadurch entstehende Umrechnungsdifferenz zwischen der Eröffnungs- und der Schlußbilanz ist der Nettowährungserfolg der Eigenkapitalgeber bei den Beständen. Er wird in dem Zahlenwerk in inländischer Währung erfolgswirksam (oder auch erfolgsneutral) erfaßt. ${ }^{141}$

Schließlich wird die Umsatzmethode ebenfalls den Umrechnungsmethoden mit differenzierten Kursen zugeordnet. ${ }^{142}$

Auch die Fristigkeitmethode steht mit der Umrechnung der Bilanzpositionen im Widerspruch zum Realisationsprinzip, da zumindest teilweise Währungsgewinne steuerlich berücksichtigt werden, ohne daß es zu einer Transaktion kommen muß.143

Die Methode läßt sich darüber hinaus schlecht in das bestehende Außensteuerrecht der USA einflechten, da die Systematik des Verfahrens eine Differenzierung nach Einkunftarten nicht vorsieht, denn es werden ja Bestände umgerechnet. Hieraus ergeben sich Probleme für die Anwendung der oben beschriebenen Quellenregeln und für die diversen Anrechnungskörbe. ${ }^{144}$ Die Methode hat ihren gedanklichen Ursprung in den zwanziger Jahren und kommt aus der Rechnungslegung. Sie wurde unter vergleichsweise stabilen Wechselkursverhältnissen entwickelt, in denen Schwankungen um einen konstanten Durchschnittswert überwogen. Deshalb wurden für langfristige Bilanzpositionen historische Kurse gewählt. Für Positionen, die kurze

${ }^{139}$ In der U.S.-Rechnungslegung wurde allerdings schon 1965 die Fristigkeitmethode abgewandelt. Sie glich danach - bis auf eine unterschiedliche Umrechnung von Vorräten - dem Nominal-/Sachwertverfahren. G. Langenbucher, Umrechnung von Fremdwährungsabschlüssen, in: K. Küting u. C.-P. Weber (Hrsg.), Handbuch der Konzernrechnungslegung, Stuttgart, 1989, S.452, Rz.988. Steuerrechtlich wurde die Abwandlung aber nicht nachvollzogen.

${ }^{140}$ Vgl. L. Lorensen, Reporting Foreign Operations of U.S. Companies in U.S. Dollars, Accounting Reseach Study No.12, New York 1972, S.11-16.

141 G. Langenbucher, Umrechnung von Fremdwährungsabschlüssen, a.a.O., S.455, Rz 996.

142 Vgl. z.B. J.E. Connor, Accounting for the Upward Float in Foreign Currencies, in: The Journal of Accountancy, 133. Jg. (1972), S.39-44; FASB, An Analysis of Issues Related to Accounting of Foreign Currency Translation, a.a.O., S.ii-ix; J. Kay u. J. King, a.a.O., S.21 -23; W. Zillessen, Zur Praxis der Währungsumrechnung deutscher Unternehmen, in: Betriebswirtschaft, 42.Jg. (1982), S.534-536; O.H. Jacobs, Internationale Unternehmensbesteuerung, a.a.O., S.323 f.; W. Ossadnik, Umrechnung von Fremdwährungsposten bei der Konzernrechnungslegung, in: Deutsches Steuerrecht, 32.Jg. (1994), S.1393-1395.

143 J. Isenbergh, International Taxation, Teil II, a.a.O., S.287; M. Zollo, The Search for Clarity And Consistency in Foreign Currency Translation, in: Taxes, 71.Jg. (1993), S.973.

144 J. Isenbergh, International Taxation, Teil II, a.a.O., S.287; M. Zollo, a.a.O., S.974. 
Zeit in den Büchern der ausländischen Unternehmung standen, erschien demgegenüber der Stichtagkurs als angemessener. ${ }^{145}$

Diese Situation bestand bis zum Ende des Festkurssystems von Bretton-Woods im Jahre 1971. Das Verfahren gewährleistet dennoch in der Regel eine bessere Näherung des steuerpflichtigen an den ökonomischen Ertrag einer Periode als die Stichtagmethode, da wenigstens die Aktiva des Umlaufvermögens zum Wechselkurs am Bilanzstichtag bewertet werden.

Wäre etwa das Grundstück der ausländischen wirtschaftlichen Einheit in dem Beispiel des vorangegangenen Unterabschnitts Teil des Umlaufvermögens, wäre somit ein Währungsgewinn in Höhe von 10.000 AM 1,028 \$/AM 1 \$ / $\$$ M $\$ 280$ am Ende der ersten Periode im Inland steuerpflichtig - allerdings unabhängig von dem tatsächlichen Marktwert des Grundstücks am Bilanzstichtag. Denn die Abkehr vom Realisationsprinzip betrifft nur Währungsgewinne oder -verluste, nicht aber Marktwertänderungen der Bilanzpositionen in der ausländischen Währung. ${ }^{146}$ Für die Erstellung der Bilanz der ausländischen wirtschaftlichen Einheit gelten die steuerrechtlichen Vorschriften der USA und dazu zählt die Bilanzierung zu Anschaffungskosten.

Hieraus leitet sich die Ausnahme von der Regel einer besseren Bestimmung des tatsächlichen Erfolges ab. Hätten nämlich die Aktiva des Umlaufvermögens an Wert verloren, wäre ein Währungsgewinn zu versteuern, obgleich möglicherweise insgesamt ein Verlust vorliegt.

Die Wechselwirkungen zwischen Wertänderungen in der fremden Währung und der Wechselkursentwicklung sind besonders problematisch, wenn die Rate der Geldentwertung im Ausland im Vergleich zum Wohnsitzland hoch ist. Auch dieses Problem wird zunächst zurückgestellt und im Zusammenhang mit der Besteuerung von Investitionen in stark inflationären Währungsräumen weiter unten erörtert.

Wäre das Grundstück der ausländischen wirtschaftlichen Einheit indes Teil ihres Anlagevermögens, ergäbe die Anwendung der Fristigkeitmethode bezüglich des Währungsgewinnes oder -verlustes das gleiche Ergebnis wie die Umsatzmethode: er wäre dann im Inland steuerpflichtig, wenn das Aktivum veräußert wird. Bei der Stichtagmethode würde er demgegenüber im Inland - wie gesagt - erst zum Zeitpunkt der Repatriierung des Verkaufserlöses berücksichtigt.

Ein Gewinn in Form einer Einnahme (etwa die Mieteinnahme des Beispiels in Höhe von $700 \mathrm{AM})$ ist im übrigen bei allen Methoden in derselben Periode auch im Inland steuerpflichtig. Er wird aber bei Anwendung der Fristigkeitmethode - im Einklang mit der Stichtagaber im Gegensatz zur Umsatzmethode - zum Wechselkurs am Bilanzstichtag konvertiert.

Aus der Sicht inländischer Steuerpflichtiger gilt folglich prinzipiell: die Fristigkeitmethode ist günstiger, wenn ein Rückgang, die Stichtagmethode dagegen, wenn ein Anstieg des Devisenkurses erwartet wird. Nicht verwunderlich ist deshalb, daß Steuerpflichtige, die sich in Ländern mit schwacher Währung betätigten - das heißt deren Außenwert infolge einer vergleichsweise hohen Inflation zurückgeht und für die dies auch in Zukunft erwartet wird -, vor der Steuerreform überwiegend die Fristigkeitmethode wählten, soweit sie ein Wahlrecht hatten. Steuerpflichtige, die andererseits in Gebieten mit fester Währung - deren Binnenwert also relativ zum U.S.-Dollar stabil ist und von deren Außenwert deshalb erwartet wird, er würde zunehmen - operierten, griffen lieber auf die Stichtagmethode zurück. ${ }^{147}$ In beiden

\footnotetext{
145 G. Langenbucher, Umrechnung von Fremdwährungsabschlüssen, a.a.O., S.450, Rz.983; A.G. Coenenberg, Jahresabschluß und Jahresabschlußanalyse: Betriebswirtschaftliche, handels- und steuerrechtliche Grundlagen. 14., überarb. Aufl., Landsberg/Lech 1993, S.383.

146 P. B. Musgrave, Exchange Rate Aspects, a.a.O., S.406.

147 W.S. Corey u.a., a.a.O., Teil II, S. 137; S.R. Lainoff u. T.Y. McArthur, a.a.O., S. 584.
} 
Situationen hätte allerdings die Fristigkeitmethode eine bessere (und die Umsatzmethode die beste) Näherung an das ökonomisch korrekte Ergebnis ergeben. ${ }^{148}$

Die Wahl der Methode wurde bis 1987 bei ausländischen Betriebstätten allgemein freigestellt. ${ }^{149}$ Für abhängige Auslandsgesellschaften, die einer Zugriffsbesteuerung unterlagen, fand demgegenüber eine Kombination aus Umsatz- und Fristigkeitmethode Anwendung (die schon erwähnte „full section 964 method"). ${ }^{150}$ Das Vorgehen bei den übrigen Beteiligungen entsprach der Stichtagmethode, bis auf eine wesentliche Ausnahme: Der rechtlichen Selbständigkeit der ausländischen Kapitalgesellschaft entsprechend, wurde naturgemäß nicht das Bilanzergebnis einer Periode umgerechnet. Steuerpflichtig waren im Inland nur Ausschüttungen, die zum Wechselkurs zum Zeitpunkt der Übertragung bewertet werden mußten (,foreign corporation method"). ${ }^{151}$

Gewichtiger (und auch umstrittener) als das Ausmaß der Berücksichtigung nicht realisierter Währungsgewinne war indessen die Frage, welche Währungsgewinne sich steuerrechtlich vielleicht als Veräußerungsgewinne auslegen ließen. Denn Veräußerungsgewinne wurden in den USA ja in jener Zeit sowohl bei natürlichen als auch bei juristischen Personen geringer besteuert als Zinsen und Dividenden. Seit der Angleichung der Steuersätze für die Arten von Einkünften hat dieser Aspekt zumindest für Kapitalgesellschaften aber nur historische Bedeutung.

\section{Der Kern der Steuerreform von 1986: Stichtagmethode reformiert}

Mit der Steuerreform von 1986 entschied sich die Legislative der USA gegen die Fristigkeitmethode. Im Mittelpunkt steht statt dessen die Stichtagmethode zur Umrechnung von Betriebstättenergebnissen und zur Erhebung der Abzugsbesteuerung bei abhängigen Auslandsgesellschaften. ${ }^{152}$ Der Ansatz bietet darüber hinaus auch die Grundlage für die Besteuerung von Ausschüttungen ausländischer Tochtergesellschaften im Inland. Denn Ziel der Neuregelung der Besteuerung von Währungsgewinnen war - neben der Schaffung von Rechtsklarheit und -vereinfachung - auch, für Tochtergesellschaften und andere wirtschaftliche Einheiten eine gleiche Behandlung von Einflüssen einer Wechselkursänderung auf den Ertrag zu erreichen. ${ }^{153}$

148 Vgl. J.B. Mertens, a.a.O., S.27-55 für ein ausführlicheres Beispiel zur Begründung dieser Feststellung.

149 P.B. Musgrave, Exchange Rate Aspects, a.a.O., S.405f.. Aufgrund der schwierigen Buchfuihrung wurde aber die Umsatzmethode von ausländischen Betriebstätten kaum angewendet. D. P.Zaiken u.a., Handling the Treatment of Foreign Currency under Tax Reform, a.a.O., S. 170.

$150 \mathrm{Vgl}$. U. Woywode a.a.O., S.699 - 701 für eine gute Zusammenfassung der Methode.

151 Oder ,section 902 method“. P. B. Musgrave, Exchange Rate Aspects, a.a.O., S.406f. .

152 Vier Argumente wurden angeführt: (1) Die Stichtagmethode sei besser als die Fristigkeitmethode mit dem Konzept der funktionalen Währung vereinbar; (2) die Stichtagmethode würde eine enge Beziehung zu dem nach ausländischem Steuerrecht qualifizierten steuerpflichtigen Einkommen gewährleisten; (3) der buchhalterische Aufwand der getrennten Umrechnung jeder Bilanzposition bliebe erspart und (4) eine getrennte Ausweisung einzelner Bestandteile des Gewinnes zum Zwecke separater Besteuerung sei bei der Fristigkeitmethode schwierig. U. S. Senate Finance Committee, Report on H.R. 3838, General Explanation, in: Standard Federal Tax Reports - Extra Edition-, 73.Jg. (1986), S.454.

Entscheidend wird indes noch ein weiterer Aspekt gewesen sein: Die Stichtagmethode wurde durch FASB Statement No.52 seit 1981 für die Rechnungslegung festgeschrieben. Dieser Beschluß folgte einer heftigen Diskussion. Zuvor war nämlich - in FASB Statement No.8 aus dem Jahre 1975 die Fristigkeitmethode angeordnet worden. Sie wurde verworfen, weil die erfolgswirksame Bilanzierung nichtrealisierter Kursgewinne und -verluste durch Umrechnung der Bilanzpositionen (unerwünscht) starke jährliche Schwankungen des Gewinnes zur Folge hatte. T. Horst, Foreign Exchange Gains and Losses, a.a.O., S. 1397; FASB, Statement of Financial Accounting Standards No.8. a.a.O., dies. Statement of Financial Accounting Standards No.52, a.a.O..

153 U.S. Department of the Treasury, Foreign Exchange Discussion Draft, a.a.O., S.4; R. Reagan, The Presidents Tax Proposals, a.a.O., S.416. M.J. Cooper, Proposed Tax Reform Act of 1985 Changes Rules for Taxing Exchange Gains or Losses, in: Tax Management International Journal, 15.Jg. (1986), S.57. 


\section{a) Qualifizierte wirtschaftliche Einheiten ("Qualified Business Units")}

Die wesentliche Neuerung ist die Einfuihrung des Begriffs der "functional currency“, der funktionalen Währung, der aus der Richtlinie Nr. 52 des FASB ${ }^{154}$ übernommen wurde. Alle Schritte, die auf dem Weg zur Bestimmung der Steuerpflicht in den Vereinigten Staaten nach den Regeln des Unterabschnitts J vorgenommen werden, sind in der funktionalen Währung zu kalkulieren, soweit nicht im Gesetzestext ausdrücklich anderes vorgeschrieben wird. ${ }^{155}$ Damit wird im Gesetz erstmalig nicht mehr nur der U.S.-Dollar namentlich zur Festlegung der Steuerpflicht zugrunde gelegt.

Freilich ist in der Regel der U.S.-Dollar die funktionale Währung. Wenn dies aber nicht der Fall ist, dann ist die Stichtagmethode zur Bestimmung des Erfolgs einer Periode anzuwenden. Die Bestimmung der funktionalen Währung spielt deshalb eine „kritische Rolle“ bei der Ermittlung der Bemessungsgrundlage. ${ }^{156}$ Das Ergebnis der Prüfung der zutreffenden funktionalen Währung entscheidet über die Anwendung der Stichtagmethode. 157

Aber nicht nur die Funktion der ausländischen Währung als eigene Meßgröße, sondern auch die Interpretation eines Auslandsengagements als wirtschaftliche Einheit wurde im Gesetz explizit definiert. Die Reform des IRC führte nämlich den Begriff „qualifizierte wirtschaftliche Einheit" („qualified business unit", QBU) ein.

Nach dem Wortlaut des Gesetzes ist eine QBU für den Unterabschnitt J definiert als ,jede separate und eindeutig bestimmte Einheit eines Handels oder Gewerbes eines Steuerpflichtigen, die eigene Bücher und Aufzeichnungen führt."158 Weitere Erläuterungen werden in den Durchführungsverordnungen geliefert: Demzufolge ist eine steuerrechtlich als Kapitalgesellschaft eingeordnete Gesellschaft ohne Zweifel immer eine QBU, eine Einzelperson dagegen nicht; wohl aber können Aktivitäten einer Einzelperson eine QBU begründen, wenn sie der genannten Definition des IRC entsprechen. Deshalb ist beispielsweise eine Personengesellschaft als eine QBU der beteiligten Person zu verstehen. ${ }^{159}$

Ein Handel oder Gewerbe ist in diesem Zusammenhang jede Unternehmung, mit der eigenständig Einkünfte erwirtschaftet werden können. ${ }^{160}$ Nachrangige, wirtschaftlich unselbständige Einheiten und auch abhängig Beschäftigte sind dagegen nicht als QBU anzusehen. Eine vertikal, funktional oder geographisch getrennte Abteilung eines Handels oder Gewerbes kann für diesen Zweck aber als eigener Handels oder eigenes Gewerbe interpretiert werden, wenn die Aktivitäten der Abteilung ansonsten einen solchen Betrieb begründen. ${ }^{161}$

\footnotetext{
${ }^{154} \mathrm{Vgl}$. FASB, Statement of Financial Accounting Standards Nr.52, a.a.O., Abs.4-10.

155 IRC §985(a).

${ }^{156}$ U.S. Department of the Treasury, Foreign Exchange Discussion Draft, a.a.O., S.2.

${ }^{157}$ U.S. Department of the Treasury, Foreign Exchange Discussion Draft, a.a.O., S.2; J. Isenbergh, International Taxation, Teil II, a.a.O., S.288.

158 IRC $\S 989$ (a) (eigene Übersetzung).

${ }^{159}$ Reg. $\$ 1.989(\mathrm{a})-1(\mathrm{~b})(2)$.

${ }^{160}$ Reg. $\$ 1.989$ (a)-1(c); R.P. Keck u. J.F. Montgomery, a.a.O., S.149.

${ }^{161}$ Reg. \$1.989(a)-1(c). Die QBU ist infolgedessen nicht gleichzusetzen mit einem Handel oder Gewerbe, der auf der Grundlage von IRC §446(d) separate Bücher führen darf.
} 


\section{b) Die Bestimmung der funktionalen Währung („Functional Currency“)}

Die funktionale Währung ist der U.S.-Dollar, ${ }^{162}$ oder ,im Falle einer qualifizierten wirtschaftlichen Einheit die Währung der ökonomischen Umwelt, in der ein wesentlicher Teil der Aktivitäten dieser Einheit abgewickelt und die Bücher und Aufzeichnungen geführt werden." 163 Die Bestimmung der funktionalen Währung einer QBU ist deshalb zumeist unproblematisch, denn in der Regel ist vom U.S.-Dollar oder der Währung des Sitzlandes der QBU auszugehen. Nur wenn eine QBU in mehr als einer Währung operiert und insbesondere, wenn der U.S.-Dollar eine der ausländischen Währungen der wirtschaftlichen Einheit ist, ergeben sich Schwierigkeiten. Ausgangspunkt ist dann die Währung, in der Bücher und Geschäftspapiere geführt werden. ${ }^{164}$ Darüber hinaus ist die ökonomische Umwelt der QBU „unter Berücksichtigung aller Fakten und Umstände" zu untersuchen. ${ }^{165}$ Und es gilt auch hier: die amerikanischen Grundsätze ordnungsmäßiger Buchführung sind als Begründung nicht hinreichend. ${ }^{166}$ Als Anhaltspunkte werden in den Richtlinien genannt: 167

(A) die Währung des Landes, in der die QBU ihren Sitz hat;

(B) die Währungen, in der die QBU ihre Ein- und Auszahlungen abwickelt;

(C) die Währungen, in der der wesentliche Teil der Einnahmen und Ausgaben der QBU erzielt werden;

(D) die hauptsächliche Kapitalanlage- und Kapitalaufnahmewährung der QBU;

(E) die Währungen der Absatzmärkte der QBU;

(F) die Währungen in denen die Preis-, Finanz- und Investitionsentscheidungen getroffen werden;

(G) die Dauer der Geschäftstätigkeit der QBU und

(H) das Gewicht und/oder das Volumen der eigenständigen Aktivitäten der QBU.

Ausdrücklich wird darauf hingewiesen, daß die Inflationsrate für die Ableitung der funktionalen Währung aus der ökonomischen Umwelt der QBU keine Bedeutung hat. ${ }^{168}$ Gleichwohl kann eine QBU gezwungen sein, anstelle der so ermittelten funktionalen Währung den U.S.-Dollar einzusetzen, wenn die Preisniveausteigerung sehr hoch ist. Auf die Regelungen im Fall einer Hyperinflation der funktionalen Währung wird aber erst an späterer Stelle gesondert eingegangen.

Außerdem wird festgelegt, wann unabhängig von der Buchführungswährung der U.S.-Dollar als funktionale Währung zugrunde zu legen ist; nämlich unter anderem, wenn der Steuerpflichtige nicht als QBU anzusehen ist - dies umfaßt vor allem Einzelpersonen -; wenn die QBU Einkommen oder Verluste erwirtschaftet, die in tatsächlichem Zusammenhang mit einem Handel oder Gewerbe auf dem Boden der USA stehen und wenn der Sitz der QBU selbst in den Vereinigten Staaten liegt. ${ }^{169}$

Die Freiheitsgrade einer Unternehmung bei der Festsetzung der funktionalen Währung sind somit gering. Ein Wahlrecht bleibt dem Steuerpflichtigen nur, wenn für eine QBU tatsächlich

${ }^{162}$ IRC $\S 985$ (b)(1)(A).

${ }^{163}$ IRC $\$ 985(\mathrm{~b})(1)(\mathrm{B})$ (eigene Übersetzung).

${ }^{164}$ Reg. §1.985-1(c)(1), (3).

${ }^{165}$ Reg. $\$ 1.985-1(\mathrm{c})(2)$ (eigene Übersetzung). In der Stellungnahme des Finanzausschusses des Senats heißt es: ,Der Ansatz der funktionalen Währung geht von einer langfristigen Bindung an eine spezifische ökonomische Umwelt aus“. U.S. Senate Finance Committee, Report on H.R. 3838, a.a.O., S. 456 (eigene Übersetzung).

${ }^{166}$ Reg. $\$ 1.985-1(c)(5)$.

${ }^{167}$ Reg. $\$ 1.985-1(c)(2)(i) ;$ U. Woywode, a.a.O., S. 697.

${ }^{168}$ Reg. $\S 1.985-1$ (c)(2)(ii).

${ }^{169}$ Reg. $\$ 1.985-1(\mathrm{~b})(1)(\mathrm{i})$, (v) und (iii). 
mehr als ein Zahlungsmittel den Punkten (A) - (H) entspricht ${ }^{170}$ - ein Fall, der in der Realität eher selten sein dürfte. ${ }^{171}$

Der Wechsel der funktionalen Währung ist überdies nicht unproblematisch. Erforderlich ist nicht nur die Genehmigung durch die Steuerbehörden. ${ }^{172}$ Erforderlich ist vor allem die Umrechnung der Bilanzpositionen zum Wechselkurs am Bilanzstichtag des ausgehenden Steuerjahres. ${ }^{173}$ Für Steuerpflichtige mit einer QBU in einem Währungsraum, der in der Vergangenheit abgewertet hat, mag dies durchaus ein Anreiz sein: Sie könnten die Währungsverluste steuermindernd geltend machen, ohne nicht realisierte (nominale) Gewinne versteuern zu müssen.

Auch eine ausländische Tochtergesellschaft ist eine QBU. Deshalb ist auch deren Gewinn zur Besteuerung in den USA in einer funktionalen Währung zu ermitteln - genau gesagt, in nur einer Währung. Denn die Gesellschaft kann durchaus aus mehreren qualifizierten wirtschaftlichen Einheiten mit unterschiedlichen funktionalen Währungen bestehen. Die aus der Perspektive des Steuerpflichtigen in den USA maßgebliche Währung ist dann nach den Kriterien des wirtschaftlichen Umfeldes der ausländischen Gesellschaft einschließlich aller dazugehörenden weiteren wirtschaftlichen Einheiten ausfindig zu machen (,integral extension rule"). ${ }^{174}$ Es ist hierbei zu bedenken, daß die Kapitalgesellschaft kraft Rechtsform immer eine QBU ist, ganz gleich ob die Tätigkeiten, die auf der Ebene der Tochtergesellschaft ausübt werden, einen Handel oder ein Gewerbe begründen. ${ }^{175}$ Die zivilrechtlichen Strukturen der Unternehmung wurden in diesem Zusammenhang in den Vorschriften übergangen. Beispielsweise kann die Währung einer Betriebstätte der Gesellschaft in einem dritten Land als funktionale Währung zugrunde zu legen sein, wenn diese die ökonomische Umwelt der gesamten Gesellschaft dominiert. ${ }^{176}$ Damit ist auch bei der Stichtagmethode eine Situation nicht ausgeschlossen, bei der die Tochtergesellschaft den Periodengewinn für die Besteuerung in den USA in einer anderen Währung als für die Besteuerung durch den Belegenheitsstaat bemessen muß.

\section{c) Bestimmung des steuerpflichtigen Erfolgs der QBU in U.S.-Dollar}

Soweit ein Steuerpflichtiger über eine oder mehrere QBU mit einer funktionalen Währung verfügt, die nicht der U.S.-Dollar ist, ist das steuerpflichtige Einkommen in drei Schritten zu kalkulieren, nämlich indem ${ }^{177}$

(1) der zu versteuernde Gewinn oder Verlust separat für jede qualifizierte wirtschaftliche Einheit in dessen funktionaler Währung nach U.S.-amerikanischem Steuerrecht ${ }^{178}$ bestimmt wird;

(2) der unter (1) ermittelte Gewinn oder Verlust jeder QBU separat mit dem sogenannten angemessenen Wechselkurs (,appropriate exchange rate") umgerechnet wird und

\footnotetext{
${ }^{170}$ Reg. $\$ 1.985-1(c)(4)$.

171 F.E. White, a.a.O., S. 209.

172 Reg. §1.985-4(a).

173 Reg. $\$ 1.985-5$ (c) bis (e).

${ }^{174}$ Reg. $\$ 1.985-1(d)(1)$; L.G. Stodghill, Coordination Between Foreign Currency Rules and Other Substantive Rules, in: International Tax Journal, 15.Jg, (1987), S.23.

${ }^{175}$ R. Henrey, International Tax Aspects, a.a.O., S.313.

176 Vgl. Beispiele (7) und (8) des Reg. §1.985-1(f).

Dies gilt natürlich nicht, wenn die Tochterkapitalgesellschaft ihren Sitz in den USA hat.

177 IRC $\$ 987$ (1) bis (3).

178 R.P. Keck u. J.F. Montgomery, a.a.O., S. 153.
} 
(3) das Ergebnis aus (2) sachgemäß korrigiert wird, insbesondere betreffend den Transfer von Vermögenswerten zwischen verschiedenen QBU eines Steuerpflichtigen in der Bilanzperiode.

Der „angemessene Wechselkurs“ ist für den Fall der Umrechnung der Gewinn- und Verlustrechnung einer QBU im Gesetzestext definiert als „,er gewichtete durchschnittliche Wechselkurs für das Steuerjahr der qualifizierten wirtschaftlichen Einheit" 179 beziehungsweise, für die Zugriffsbesteuerung nach Unterabschnitt F des IRC, der ausländischen Kapitalgesellschaft. Von einer Gewichtung wird in den Richtlinien allerdings abgesehen, denn dort wird weitergehend ausgefuihrt, unter dem angemessenen Kurs sei der einfache Durchschnitt aller werktäglichen Kassakurse innerhalb der Besteuerungsperiode zu verstehen. ${ }^{180}$

Die Bestimmungen des Unterabschnitts $J$ haben für ausländische Kapitalgesellschaften, an denen U.S.-Steuerpflichtige beteiligt sind, vom Grundsatz her in gleicher Weise Gültigkeit wie für Betriebstätten. Ist die QBU des inländischen Steuerpflichtigen aber eine Tochterkapitalgesellschaft mit wiederum mehreren funktionalen Währungen, ist der Erfolg schrittweise zu ermitteln. Zunächst ist der Gewinn jeder QBU in deren funktionaler Währung soweit dies nicht der U.S.-Dollar ist ${ }^{181}$ - nach den Regeln des Unterabschnitts J zu quantifizieren. Die Ergebnisse sind in die funktionale Währung der ausländischen Kapitalgesellschaft umzurechnen und in deren Gewinn- und Verlustrechnung aufzunehmen. Werden die Gewinne durch die Tochtergesellschaft einbehalten, sind sie auf die Anrechnungskörbe aufzuteilen und zu deren E\&P zu addieren. ${ }^{182}$ Auch hier gilt: eine Ausschüttung ist zur Besteuerung zum Kassakurs zum Zeitpunkt des Transfers in die USA umzurechnen. Gewinne, die nicht ausgeschüttet werden, aber wegen der Zugriffbesteuerung nach Unterabschnitt $F$ in den USA dennoch steuerpflichtig sind, sind dagegen so zu bemessen wie der Erfolg anderer QBU, nämlich zum jahresdurchschnittlichen Wechselkurs. Allgemein: die E\&P sind zu behandeln wie andere E\&P der ausländischen Tochtergesellschaft. ${ }^{183}$ Ausgenommen hiervon sind U.S.-Dollar-Aktivitäten der ausländischen Kapitalgesellschaft, für die besondere Vorschriften gelten.

Außerdem bestehen natürlich Regelungen zur Umrechnung von Ausschüttungen von Gewinnen früherer Perioden und die indirekte Anrechnung der im Sitzland darauf gezahlten Einkommensteuern. Hierauf wird ab Seite 116 eingegangen werden.

\section{d) Umrechnung der Gewinn- und Verlustrechnung: Durchschnitts- oder Stichtagskurs?}

In der Reform von 1986 wurde zur Umrechnung des Ergebnisses der QBU als angemessener Wechselkurs ein jahresdurchschnittlicher Kurs für nicht transferierte Gewinne festgeschrieben. In dem Bericht des Finanzausschusses des Senats heißt es dazu: „die Verwendung des Wechselkurses des Jahresendes verzerrt das Einkommen und reflektiert nicht die Tatsache, daß der Gewinn oder Verlust kontinuierlich im Laufe des Jahres realisiert wurde." 184 Die Anwendung des durchschnittlichen Kurses ist auch in der Literatur befürwortet worden. ${ }^{185} \mathrm{Als}$

\footnotetext{
${ }^{179}$ IRC $\S 989(\mathrm{~b})(4)$ (eigene Übersetzung).

180 Reg. $\$ 1.989$ (b)-1.

${ }^{181}$ Reg. $\$ 1.985-1(\mathrm{~d})(1)(\mathrm{ii})$.

182 R. Henrey, International Tax Aspects, a.a.O., S.314.

183 Reg. $§ 1.985-1$ (d)(2); vgl. außerdem Beispiele (9) bis (11) des Reg. $\$ 1.985-1(\mathrm{f})$.

184 U.S. Senate Finance Committee, Report on H.R. 3838, a.a.O., S.454 (eigene Übersetzung); U.S. House Ways and Means Committee, House Ways and Means Committee Report, In: Standard Federal Tax Reports -Extra Edition-, 72. Jg. (1985) Heft 53, S.469.

185 M. Zollo, a.a.O., S.973.
} 
Begründung wurde außerdem darauf verwiesen, die Zuordnung eines Wechselkurses für nicht transferierte Erträge sei ,in jedem Fall eine willkürliche Angelegenheit“, da die Wahl eines Jahres zur Bestimmung des Einkommens ebenfalls willkürlich ist. ${ }^{186}$

Dies sind jedoch keine recht überzeugenden Argumente, nicht den Bilanzstichtagskurs zugrunde zu legen. ${ }^{187}$ Der Rückgriff auf einen Durchschnittskurs mit der Argumentation, Einkommen sei durch einzelne Transaktionen im Verlauf des ganzen Jahres entstanden, mag zwar dem buchhalterischen Charakter der Gewinn- und Verlustaufstellung als Zeitraumrechnung entsprechen. Es widerspricht aber dem Charakter erwarteter Wechselkursänderungen, die mit Zinseinkünften vergleichbar sind, denn es mißachtet zwei Aspekte:

Erstens muß unterstellt werden, daß sich das Einkommen innerhalb einer Periode exponentiell entwickelt, da Einzahlungen im Ausland reinvestiert werden, soweit kein Transfer ins Inland stattfindet. Das Ergebnis der Gewinn- und Verlustrechnung der QBU ist Ausdruck der kumulierten Einnahmenüberschüsse zwischen zwei Stichtagen; es ist ein Stromsaldo und stellt damit den (realisierten) Bestandszuwachs in der ausländischen Währung dar.

Zweitens ist dieser Bestandszuwachs in der inländischen Währung zu jedem Zeitpunkt gerade so viel wert, wie aus der Konvertierung zum Wechselkurs in diesem Moment resultiert. Es ist irrelevant, welche zeitliche Struktur die Zahlungsreihe des Einkommensentstehungsprozesses hatte.

Ein Beispiel mit drei alternativen Zahlungsreihen verdeutlicht den Zusammenhang:

Beispiel C5:

Eine QBU, deren funktionale Währung die AM ist, investiert ihr gesamtes Dotationskapital von 10.000 AM am Anfang einer Periode in eine einjährige Anleihe in der Währung ihres Sitzstaates. Am letzten Tag der Bilanzperiode wird die Anleihe einschließlich einer Verzinsung von $7 \%$, also $700 \mathrm{AM}$, zurückgezahlt.

Die Plausibilität der Anwendung des Stichtagskurses ist hier offensichtlich.

Nun investiert die QBU die 10.000 AM für ein Jahr in täglich fälliges Termingeld. Die Buchhaltung der wirtschaftlichen Einheit wird täglich Einkommen in Höhe der Verzinsung des Kapitals für einen Tag aufzeichnen. Bei der Annahme einer horizontalen Zeitstruktur der Zinssätze in dem Land wird gleichwohl ebenfalls ein Endwert von 10.700 AM erwartet werden.

Zwar ist das Einkommen sichtbar „im Verlauf des ganzen Jahres entstanden“. Warum aber sollte deshalb ein durchschnittlicher Wechselkurs zur Umrechnung herangezogen werden?

Schließlich investiert die QBU 10.000 AM in eine Anleihe mit einer Laufzeit von genau einem Jahr und zwei Zinszahlungszeitpunkten. Die erste Zahlung von 344 AM wird nach sechs Monaten realisiert. Am Fälligkeitstag - am Anfang der zweiten Bilanzperiode werden Einkünfte von wiederum $344 \mathrm{AM}$ und von $11 \mathrm{AM}$ aus der Wiederanlage des Ertrages des sechsten Monats verbucht.

Da ein Teil des Gewinnes nicht in der Bilanzperiode zu einer Einzahlung wird, würde ein nicht realisierter Währungsgewinn in Höhe von 344AM $1,028 \%$ / $-344 \mathrm{AM} \cdot 1,014 \mathrm{~S} / \mathrm{AM}$

$\$ 4,82$ in die inländische Bemessungsgrundlage einfließen, wenn der Stichtagskurs verwendet würde und die erwarteten Wechselkurse von 1 \$/AM, 1,014 \$/AM und 1,028 \$/AM am Anfang der Periode, im sechsten Monat beziehungsweise am Bilanzstichtag eintreffen. Das Realisa-

\footnotetext{
186 P. B. Musgrave, Exchange Rate Aspects, a.a.O., S.411.

187 Vgl. auch G. Gebhardt, Währungsumrechnung im Einzelabschluß und bei der Aufstellung konsolidierter Abschlüsse, Arbeitsbericht Nr.39 des Instituts für Unternehmensführung und Unternehmensforschung der Ruhr-Universität Bochum, Bochum 1986, S.47.
} 
tionsprinzip wäre hierdurch streng genommen verletzt. Der ermittelte Gewinn stellt aber eine (etwas) bessere Näherung an den tatsächlichen Ertrag dar. ${ }^{188}$

Der andere Fall: Würde der Gewinn mit dem jahresdurchschnittlichen Kurs, hier 1,014\$/AM, konvertiert und wäre der Zinsertrag von 356 AM schon am Ende der ersten Periode auch eine Einnahme, wäre faktisch ein realisierter Währungsgewinn im Inland nicht steuerpflichtig; in diesem Fall \$4,98.

Beide Ansätze sind aus dem Blickwinkel buchhalterischer Grundsätze somit genau betrachtet unbefriedigend. Die Anwendung des Wechselkurses am Bilanzstichtag liefert aber das ökonomisch bessere Ergebnis.

Diese Schlußfolgerung wird durch einen letzten Gedanken untermauert: Würde nämlich nicht auf die Verwendung des Stichtagskurses zurückgegriffen, bestünde ein Anreiz, den Gewinn dann zu repatriieren, wenn der Wechselkurs am Stichtag niedriger ist als der kalkulatorische Durchschnittswert, ihn aber in der QBU zu belassen, wenn das Gegenteil der Fall ist. ${ }^{190}$ Denn zum Zeitpunkt der Kapitalrückführung wird der Währungserfolg steuerlich erfaßt, wie an späterer Stelle geschildert werden wird.

Nicht zum durchschnittlichen Kurs, sondern zum Kurs zum Zeitpunkt der Zahlung oder Veranlagung waren laut Gesetzestext der Steuerreform von 1986 und laut beabsichtigten Richtlinien zudem anrechenbare ausländische Steuern der QBU auf die jeweiligen Körbe aufzuteilen. ${ }^{191}$ Abgesehen hiervon ist aber auch für den Gewinn oder Verlust einer QBU, deren funktionale Währung nicht der U.S.-Dollar ist, die Anrechnung von im Ausland zu zahlenden Steuern in den USA nach den in Abschnitt I dargelegten Bestimmungen zu berechnen. ${ }^{192} \mathrm{Die}$ Beziehung der in dieses Anrechnungsverfahren eingehenden ausländischen Einkünfte zu den darauf im Ausland entrichteten Steuern wurde somit in doppelter Hinsicht verzerrt.

Mit der Steueränderung von 1997 wurde die Umrechnung anrechenbarer ausländischer Steuern einer QBU modifiziert. Für die Bestimmung der Anrechnungsgutschriften ist künftig ebenfalls der jahresdurchschnittliche Kurs zu verwenden. ${ }^{193}$ Hiernach können im Rahmen der Stichtagmethode ausländische Einkünfte und darauf im Quellenland zu entrichtende Steuern in der Regel zum gleichen Wechselkurs umgerechnet werden.

${ }^{188}$ Natürlich wäre, strenggenommen, die - aus theoretischer Sicht - beste Lösung die zeitkontinuierliche Errechnung der Einkommenszuwächse. Dann wäre diese Analyse überflüssig. Wenn aber diskret besteuert wird, dann ist der Stichtagskurs anzuwenden, um den erwarteten Grenzertrag in- und ausländischer Investitionsalternativen gleich zu behandeln - konkret: den Zinsvorteil durch Stundung der Steuern bis zum Periodenende nicht zu verzerren.

$189(1,028 \mathrm{~s} / \mathrm{Am}-1 \mathrm{~s} / \mathrm{AM}) \cdot 1 / 2+1 \mathrm{~s} / \mathrm{MM}=1,014 \mathrm{~s} / \mathrm{MM}$.

${ }^{190}$ In anderem Zusammenhang wird so auch argumentiert in: R. Reagan, The Presidents Tax Proposals, a.a.O., S. 415 .

191 IRC §986(a) u. Prop. Reg. §1.987-1(b)(3)(ii). Steuerrückzahlungen oder Abweichungen zwischen der veranlagten und den tatsächlich gezahlten Abgaben sind zu dem Kurs zu buchen, der bei der Anrechnung zugrunde lag.

192 Eine Ausnahme - die sogenannte „qualified business unit rule“ - betrifft passive Einkünfte: Gemäß Reg. $\S 1.904-4(c)(4)$ werden zur Prüfung, ob die passiven Erträge einer QBU einer Besteuerung im Ausland von mindestens $90 \%$ des Satzes der USA unterliegen, alle solche Erträge jeder einzelnen QBU getrennt zusammengefaßt, deren Quelle in deren Belegenheitsstaat (zu bestimmen nach dessen Recht) liegt. Liegt deren Quelle außerhalb des Belegenheitsstaates, gelten die allgemeinen Regelungen.

193 Tax Payer Relief Act of 1997, \$1102(a)(1). Ausgenommen von dieser Regel sind Steuern, (i) die mehr als zwei Jahre nach der Bilanzperiode ihrer Entstehung gezahlt werden, (ii) die im Voraus gezahlt wurden und (iii) die in einer hoch inflationären Währung zu zahlen sind. Ebda.; KPMG Peat Marwick LLP. (Hrsg.), a.a.O., Internet:http://www.us.kpmg.com/taxact/booklet/7foreign.html; V.K. Jacobs, a.a.O.; M. Cooper, A. Shapiro u.a., a.a.O., S. 414. 


\section{e) Zurechnung von Zinsaufwendungen}

Die Umrechnung der Gewinn- und Verlustrechnung einer QBU ist zur Bestimmung des steuerpflichtigen Gewinnes oder Verlustes allerdings nicht ausreichend. Ein Dilemma für das Konzept der Stichtagmethode zeigt sich nämlich, wenn nochmals die Vorschriften des U.S.-Steuerrechts über die Zurechnung von Zinsaufwendungen, die im Zusammenhang mit der Erzielung von Einkünften entstanden sind, betrachtet werden: Die Umrechnung eines Stromsaldos ist nicht kompatibel mit der Zurechnung der Aufwendungen auf indirektem Wege nach Maßgabe der geographischen Aufteilung der Bestände der Steuerpflichtigen.

Eine Bewertung der Vermögenswerte in U.S.-Dollar ist deshalb zum Zwecke der Allokation der Fremdkapitalkosten doch notwendig, und zwar - ganz gleich ob Buch- oder Marktwerte zugrunde gelegt werden - zum aktuellen Wechselkurs am Bilanzstichtag. ${ }^{194}$ Die Fremdkapitalkosten selbst sind dagegen zum jahresdurchschnittlichen Wechselkurs in die Aufstellung abziehbarer Kreditkosten einzubringen. Sie können direkt aus der Gewinn- und Verlustrechnung übernommen werden, die gemäß dem amerikanischem Steuerrecht zur Stichtagmethode in U.S.-Dollar aufgestellt wurde. ${ }^{195}$ Diese tatsächlich gezahlten Fremdkapitalzinsen sind freilich aus dem Erfolg der QBU danach herauszurechnen und durch den ermittelten Anteil der gesamten Zinszahlungen des Steuerpflichtigen zu ersetzen. ${ }^{196}$

Damit werden aber Währungsgewinne und -verluste, die durch die Kredite verursacht sind, nicht bei der Zurechnung der Fremdkapitalaufwendungen einer QBU einbezogen. Kapitalexport in Form einer wirtschaftlichen Einheit wird diskriminiert, wenn der risikofreie Zins in deren funktionaler Währung höher ist als im Inland. Denn durch die relative Zurechnung auf indirektem Wege werden nicht die ausländischen Kosten zugrunde gelegt, sondern der - in diesem Fall geringere - Durchschnitt aus in- und ausländischen Fremdkapitalkosten. Das heißt, die Wahrscheinlichkeit eines Anrechnungsüberhanges wird reduziert. Außerdem ist Finanzierungsneutralität verletzt: Einzige theoretische Möglichkeit, die Benachteiligung zu umgehen, wäre nämlich eine reine Fremdfinanzierung der QBU durch Dritte bei gleichzeitiger ausschließlicher Eigenfinanzierung der Aktivitäten in den USA - oder aber die Erweiterung um weitere QBU in einem Währungsraum mit niedrigerem Zinsniveau.

$\mathrm{Zu}$ beachten sind hierbei darüber hinaus natürlich auch die Regelungen bezüglich der Aufnahme von Fremdwährungskrediten, das heißt hier Krediten in einer anderen als der funktionalen Währung. ${ }^{197}$ Diese Fragestellung fällt indes in den Bereich der Behandlung von Einzeltransaktionen in fremden Währungen und wird dort erörtert.

\section{f) Kapitalherabsetzungen und Entnahmen \\ a) Bestimmung der Höhe des Währungsergebnisses}

Ein Währungserfolg wird durch die Stichtagmethode des U.S.-Steuerrechts bei der Umrechnung der Gewinn- und Verlustrechnung - soweit dieser nicht bei Transaktionen in Drittwährungen entstanden ist - nicht ausgewiesen. Wird aber das Kapital einer QBU herabgesetzt oder die Einheit aufgelöst, entsteht ein Währungsgewinn oder -verlust, wenn sich der Wechselkurs seit dem Zeitpunkt des Kapitalexports beziehungsweise der Entstehung noch nicht repatri-

\footnotetext{
194 Reg. $\$ 1.861-9 \mathrm{~T}(\mathrm{~g})(2)(\mathrm{ii})(\mathrm{A})(1)$ bei Bewertung zu Buchwerten und (2)(ii)(B) bei Marktwerten.

195 Reg. §1.861-9T(f)(2)(ii).

196 J. Isenbergh, International Taxation, 1994 Supplement, a.a.O., S. 523.

${ }^{197}$ Reg. §1.861-9T(b).
} 
ierter Gewinne geändert hat. ${ }^{198}$ Dieser so benannte „,section 987 gain or loss“ ist die Differenz zwischen dem Wert in U.S.-Dollar bei der Vermögensentnahme und einem historischen Wert. Ersterer resultiert direkt aus der Umrechnung zum Zeitpunkt der Entnahme - und zwar unabhängig davon, ob der Wert tatsächlich repatriiert oder im Ausland belassen wird. Letzterer ist dagegen nicht so einfach zu bestimmen. Denn es gilt, Veräußerungsgewinne und Währungsergebnis zu trennen. Die Richtlinien schreiben deshalb vor, während der gesamten Lebensdauer einer QBU laufend einen fiktiven Wert der Einheit in U.S.-Dollar zu quantifizieren.

Konkret bedeutet dies, daß für jede QBU zwei Konten zu führen sind: ein „equity pool“ in der funktionalen Währung der QBU und ein „basis pool“ in U.S.-Dollar. ${ }^{199}$ Zweck der Konten ist die Fortschreibung des Vermögensbestandes in beiden Währungen nach den steuerrechtlichen Bewertungsvorschriften der USA.

In der Ausgangssituation einer ersten Eröffnungsbilanz der QBU muß der Wert beider Konten übereinstimmen; er ergibt sich aus der Differenz zwischen der Summe der Aktiva und dem Fremdkapital von Dritten; ${ }^{200}$ Darlehen von beteiligten Steuerinländern sind nicht abzuziehen. $^{201}$ In jeder Periode ist dann das Ergebnis der Gewinn- und Verlustrechnung des Steuerjahres (ohne anrechenbare ausländische Steuern) zu addieren. Für den „basis pool“ ist hierfür der zuvor nach den Bestimmungen der Stichtagmethode in U.S.-Dollar umgerechnete Erfolg maßgeblich. Außerdem sind - neben anderem-Kapitalerhöhungen und -herabsetzungen sowie auch andere Kapitaltransfers zwischen der QBU und dem Steuerpflichtigen zu berücksichtigen. Wo notwendig, müssen diese Beträge jeweils zum Kassakurs zum Zeitpunkt des Transfers entsprechend umgerechnet werden. ${ }^{202}$

Mit Hilfe der beiden Konten ist nun bei jeder Kapitalherabsetzung ein anteiliger Währungserfolg zu quantifizieren. Er ergibt sich aus der Differenz zwischen (i) der Entnahme, konvertiert zum Wechselkurs am Tag des Transfers und (ii) dem Anteil dieses Kapitals am Konto „basis pool“ (das, wie gesagt, in U.S.-Dollar geführt wird). ${ }^{203}$ Letzterer wiederum ist einfach $\mathrm{zu}$ bestimmen: es ist der gleiche prozentuale Anteil, um den sich auch der "equity pool“" reduziert. ${ }^{204}$ Wird etwa ein Betrag aus der QBU entnommen, der zehn Prozent des Kapitals des Kontos „equity pool“ entspricht, ergibt sich dessen Anteil am „basis pool“ aus diesem Prozentsatz. ${ }^{205}$

Übrigens ist für den „basis pool“ auch ein negatives Vorzeichen nicht auszuschließen. ${ }^{206}$ Beispiel C6:

Ein U.S.-Steuerpflichtiger stattet eine QBU in einem fremden Währungsraum mit einem Dotationskapital von $\$ 10.000$, beziehungsweise 10.000 AM in der funktionalen Währung der QBU, aus. In den ersten beiden Jahren entsteht in der QBU ein Verlust von jeweils 4.000 AM. Andererseits steigt der Devisenkurs der AM auf 1,3\%/AM am Ende des ersten

\footnotetext{
198 Prop.Reg. §1.987-2(a)(1).

199 Prop.Reg. \$1.987-2(a)(1) u. Prop.Reg. \$1.987-2(c). Das System der Konten wurde nach der Steuerreform für Kapitalgesellschaften eingeführt, da in den USA die Anrechnung von ausländischen Steuern auch bei Ausschüttungen in späteren Perioden möglich ist. Unternehmen müssen für jeden Anrechnungskorb ein Konto für die einbehaltenen Gewinne und ein Konto für die darauf entrichteten Steuern führen. Bei einer Ausschüttung werden beide Kontenstände pro rata reduziert. M. Zarnitz, a.a.O., S.18-19 m.w.N..

200 Prop. Reg. $\$ 1.987-2$ (c)(1)(i)(B) für den „equity pool“ und 2(c)(2)(i)(B) für den „,basis pool“.

201 Prop.Reg. $\$ 1.987-2($ b)(2)(iv).

202 Prop.Reg. \$1.987-2(c)(1)(ii), (iii) für den „equity pool" und 2(c)(2)(ii), (iii) für den „basis pool“.

203 Prop. Reg. $\$ 1.987-2(d)(1)$.

204 Prop. Reg. \$1.987-2(d)(2).

205 Für eine genauere Darstellung der rechtlichen Einzelheiten vgl. J. Isenbergh, International Taxation, 1994 Supplement, a.a.O., S.513-519 und die Beispiele der Prop.Reg. §1.987-2(d)(3).

206 J. Isenbergh, International Taxation, 1994 Supplement, a.a.O., S.518.

Ist die QBU eine Personengesellschaft, ist auch ein negativer Saldo des Kontos „equity pool“ möglich. Vgl. Beispiel 4 in Prop. Reg. §1.987-2(d)(3).
} 
und auf 1,6\$ $\mathrm{\$ m}$ am Ende des zweiten Jahres; die zur Umrechnung der Verluste maßgeblichen Durchschnittskurse betragen 1,15\%/AM beziehungsweise 1,45\% $/ \mathrm{AM}$. Am Ende des zweiten Steuerjahres hat der ,basis pool“ demgemäß einen Wert von $\$ 10.000-\$ 4.600$ $\$ 5.800=-\$ 400$.

Für die oben beschriebene Vorgehensweise hat dies keine Auswirkungen.

Bemerkenswert ist aber vielleicht, daß es im Anschluß an die Steuerreform zunächst geheißen hatte, die nach der Stichtagmethode ermittelten Verluste einer QBU in einer Periode dürften den Gesamtbetrag des „basis pool“ nicht übersteigen. In diesem Beispiel bliebe demgemäß der Verlust in Höhe von $\$ 400$ im zweiten Jahr steuerlich unberücksichtigt. Die Richtlinien der Steuerbehörden müßten dies sicherstellen. ${ }^{207}$ Diese unverständliche Anforderung ist in den beabsichtigten Richtlinien jedoch nicht zu finden. Statt dessen wird ausdrücklich klargestellt, ein negativer „basis pool“ - und auch ein negativer „basis pool“ - habe keine Auswirkungen auf die Abziehbarkeit der Verluste einer QBU. ${ }^{208}$

Wird die QBU aufgelöst, ist zuvor für das laufende Steuerjahr bis zum Zeitpunkt der Auflösung (1) der Gewinn oder Verlust der Einheit nach der Stichtagmethode zu bestimmen und sind (2) die beiden Konten, wie soeben beschrieben, zu aktualisieren. In dem letzten Schritt (3) ist der Währungsgewinn oder -verlust zu errechnen. Er ist hier die gesamte Differenz zwischen dem „,equity pool“ - zum Kassakurs in U.S.-Dollar umgerechnet - und dem „basis pool“.209, 210 Wird die QBU in dem obigen Beispiel C5 am letzten Tag des zweiten Steuerjahres aufgelöst, ergeben die Richtlinien das folgende Resultat:

Der „equity pool“ weist zum Schluß des zweiten Jahres einen Wert von 10.000 AM $-4.000 \mathrm{AM}-4.000 \mathrm{AM}=2.000 \mathrm{AM}$ auf. Zum Stichtagskurs umgerechnet sind dies

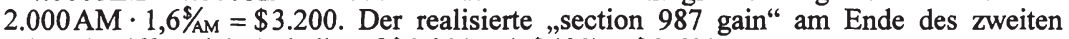
Jahres beziffert sich deshalb auf $\$ 3.200-(-\$ 400)=\$ 3.600$.

Gemäß der Stichtagmethode hat der inländische Steuerpflichtige außerdem negative Einkünfte von $\$ 4.600$ am Ende des ersten Jahres und von $\$ 5.800$ am Ende des zweiten Jahres. Unter Hinzuziehung des Währungsgewinnes beziffert sich der steuerrechtliche Gesamtverlust auf $\$ 6.800$. Wird ein Opportunitätskostensatz von $0 \%$ unterstellt, um die Problematik des Realisationsprinzips auszublenden, entspricht das Ergebnis exakt dem wirtschaftlichen Verlust aus dem Auslandsengagement in Form der QBU: $\$ 10.000-2.000 \mathrm{AM} \cdot 1,6 \$ \mathrm{AM}=\$ 6.800$.

Nicht überzeugend ist allerdings die gewählte Vorgehensweise, die zeitliche Struktur des Vermögens der QBU durch die schlichte Anteilsrechnung außer acht zu lassen. Besser wäre es einem umfassenden „first in - first out“ Prinzip der Bewertung von Lagerbeständen folgend davon auszugehen, jedweder Transfer würde zunächst eine Entnahme des jeweils am längsten in der QBU gebundenen Kapitals implizieren. Der Zeitraum zwischen Entstehung und Realisierung von Währungsgewinnen oder -verlusten würde so vermindert. Dadurch wird zwar dem Realisationsprinzip widersprochen, aber nicht ein Mehr an Ineffizienz begründet.

Im übrigen läßt sich auch das vom Finanzministerium gewählte Verfahren so interpretieren, daß es das Realisationsprinzip verletzt. Denn auch hierbei wird bei jedem Transfer von Gewinnen früherer Perioden anteilig auch der, ebenfalls nicht realisierte, Währungserfolg beim

${ }^{207}$ D. P.Zaiken u.a., Handling the Treatment of Foreign Currency under Tax Reform, a.a.O., S.171. Die Bezeichnung „basis pool" wurde allerdings noch nicht verwendet.

208 Prop. Reg. $\$ 1.987-1$ (b)(4).

209 Prop.Reg. $\S 1.987-3(\mathrm{~h})(1)-(3)$.

210 Um den Währungsgewinn oder -verlust bestimmen zu können, sehen die beabsichtigten Richtlinien im Falle eines negativen Endwertes im „equity pool“ konkret vor, einen fiktiven Transfer in Höhe dieses negativen Saldos des ersten Kontos zu unterstellen, der dann eine entsprechende Minderung des zweiten Kontos zur Folge hat. Ist danach der Betrag im „basis pool“ positiv, ist ein Währungsverlust entstanden. Prop.Reg. §1.987-3(h)(3)(ii). 
Dotationskapital einbezogen. Der Zeitraum zwischen Entstehung und Realisierung von Währungsgewinnen oder -verlusten wird vermindert. ${ }^{211}$

Eine andere naheliegende Alternative, nämlich zu unterstellen, der zuletzt angefallene Gewinn würde zunächst transferiert und erst an letzter Stelle das Dotationskapital - dies wurde in dem ersten Vorschlag des Finanzministeriums aus dem Jahr 1980 erwogen $^{212}$-, wäre demgegenüber weniger effizient. Wegen des längeren Zeitraums bis zur Realisierung von Währungserfolgen würden hierdurch in stärkerem Maße Investitionen in Ländern diskriminiert (begünstigt), von dessen Währung eine Abwertung (Aufwertung) erwartet würde. ${ }^{213}$

Dies wird durch die oben schon dargestellte Kritik bekräftigt, dernach Auslandsengagements in schwachen Währungsräumen diskriminiert werden, wenn ein Währungsverlust bis zum Zeitpunkt einer Entnahme steuerlich unberücksichtigt bleibt. Denn trotz der zeitlich weitreichenden Verlustverrechnungsmöglichkeiten im U.S.-Steuerrecht ist bei QBU mit einer längeren Lebensdauer nicht auszuschließen, daß dieser Aspekt zu einer entscheidungsrelevanten Größe wird.

\section{ß) Quelle und Art des Währungsergebnisses}

Nachdem die Höhe des Währungserfolgs bei einer Kapitalherabsetzung bekannt ist, stellt sich eine interessante Frage: Sollten Währungsgewinne und -verluste im Steuerrecht der USA nach Maßgabe der Quellenregeln oder der Bestimmungen über die Zurechnung von Aufwendungen in der Bemessungsgrundlage berücksichtigt werden?

Wie die Analyse in Teil B gezeigt hat, sind erwartete Währungserfolge aufgrund der Zinsparität der Art nach als integraler Bestandteil des erwarteten Ertrages einer Investition in einem fremden Währungsraum anzusehen. Antizipierte Währungsgewinne und -verluste könnten demnach der steuerlichen Bemessungsgrundlage der ausländischen Erträge zugerechnet werden. Es erscheint auf Grund dessen denkbar, diese im Sinne einer steuerrechtlichen Verwendung des Begriffs als Aufwendungen zu interpretieren, die im Zusammenhang mit der Erwirtschaftung von Einnahmen entstanden sind. Demnach wäre der ,section 987 gain or loss“ eine negative beziehungsweise positive Aufwendung, die im Zusammenhang mit der Erwirtschaftung der Gewinne der QBU entstanden ist. Da Aufwendungen zwar von Einnahmen abgezogen werden und nicht (negative) Einkünfte sind, wird auf diese Weise rechtssystematisch außerdem die Notwendigkeit umgangen, für Währungserfolge eine eigene Quelle festlegen zu müssen.

In den beabsichtigten Regelungen der Steuerbehörden wird der Währungserfolg zwar als Einkommen oder Verlust bezeichnet, es wird aber auf die Bestimmungen über die Zurechnung von Zinsaufwendungen zurückgegriffen. Im Wortlaut heißt es: „Source and character of section 987 gain or loss is allocated like interest“. 214,215

${ }^{211}$ Die Prop.Reg. §1.987-2 und 3 stehen aber, im Unterschied zu den anderen hier genannten Möglichkeiten, im Einklang mit dem Prinzip der Fungibilităt des Geldes, auf dem die Regelungen zur Zurechnung von Zinsaufwendungen fußen (siehe Seite 91 dieser Arbeit). Es ist ökonomisch natürlich irrelevant, zu welchem Zeitpunkt eine Währungseinheit erwirtschaftet oder exportiert wurde.

${ }^{212}$ U.S. Department of the Treasury, Foreign Exchange Discussion Draft, a.a.O., S.16.

${ }^{213}$ Darüber hinaus wäre dieser Weg mit größerem buchhalterischen Aufwand verbunden. T. Horst, Foreign Exchange Gains And Losses, a.a.O., S.1397.

214 Prop.Reg. §1.987-2(f) (Die kursive Akzentuierung wurde ergänzt). 
Die Methode wird im Text klargestellt und darüber hinaus weitergehend konkretisiert. Bei Währungsgewinnen oder -verlusten versagt nämlich der bei Fremdkapitalkosten allgemein gültige Ansatz der Zurechnung auf indirektem Wege nach Maßgabe aller in- und ausländischen einkommenerzeugenden Aktivitäten und Vermögenswerte des Steuerpflichtigen.216 Deshalb wurde - wie im übrigen auch im Gesetzestext selbst vorgeschrieben ${ }^{217}$ - die Zurechnung auf die Bruttoeinkünfte beziehungsweise die Aktiva der konkreten QBU beschränkt. ${ }^{218}$ Das heißt, das Währungsergebnis ist generell ausländischen Ursprungs, soweit nicht die QBU Einnahmen erwirtschaftet hat, die steuerrechtlich in den USA entstanden sind. ${ }^{219}$

Allerdings werden Wechselkursänderungen typischerweise nicht antizipiert.

Im Gegensatz zu dieser Regelung wäre es dann aber - wie in Teil B herausgefunden wurde bei beschränkter Anrechnung zweckmäßig, wechselkursbedingte Kapitalgewinne nicht explizit den ausländischen Einkünften der QBU zuzurechnen, um die diskriminierende Wirkung unsicherer erwarteter Anrechnungsüberhänge zu minimieren. Statt dessen würde Neutralität hinsichtlich des Einsatzortes von Kapital weniger verletzt, wenn das Steuerrecht die größtmöglichen Verrechnungsmöglichkeiten für diese Währungsverluste gewähren würde, da so ex ante der Wert einer Eventualforderung des inländischen Staates am geringsten wäre.

Dieser Aspekt wird durch das U.S.-Steuerrecht noch verstärkt, denn die Vor- und Rücktragsmöglichkeiten für Anrechnungsüberhänge betragen nur fünf beziehungsweise zwei, für Verluste dagegen 20 beziehungsweise zwei Jahre.

Hinzukommt: Ist der Gesamtbetrag der ausländischen Einkünfte negativ, wird zwar das Welteinkommen in der Periode und damit die Steuerlast in den USA gemindert. Doch müssen ja positive Einkünfte in späteren Perioden zur Bemessung des Anrechnungsbetrags bis zur Höhe des Verlustes als inländische Einkünfte umgedeutet werden. Das Ergebnis des Teils B, demnach die Möglichkeit des Abzugs ausländischer Verluste bei der Quantifizierung der im Inland steuerpflichtigen Welteinkünfte die Verzerrungen durch das Anrechnungsverfahren reduziert, hat hier kaum praktische Bedeutung.

Währungsgewinne oder -verluste sollten somit als ordentliches Einkommen im Inland der Besteuerung unterliegen. ${ }^{220}$

Ein solches Vorgehen wurde bei der Erarbeitung der Steuerreform tatsächlich erwogen. Der erste, vom Repräsentantenhaus vorgelegte Entwurf ließ die Frage noch offen; er sah lediglich die Charakterisierung als ordentliches Einkommen vor. ${ }^{221}$ Überlegt wurde indes auch, den Währungserfolg als separate Kategorie von Einkünften einem eigenen Korb zuzuweisen. ${ }^{222}$

215 Der Rückgriff auf die Quellen-Regeln für Zinseinkünfte wäre aber auch nicht möglich gewesen: Das U.S.-Steuerrecht knüpft - wie gesagt - in den Quellenregeln bei Zinseinkünften an dem Wohnsitz des Schuldners an. Der aber existiert bei einem Währungsgewinn nicht. J. Isenbergh, International Taxation, 1994 Supplement, a.a.O., S.518.

216 Vgl. Seite 91 dieser Arbeit.

217 IRC $\S 987(3)(b)$.

218 Prop. Reg. $\$ 1.987-2(f)(i)$ beziehungsweise (ii). Derzeit sind allerdings noch IRC $\S 987(3)(b)$ und Reg. §1.987-2(h) die Grundlage. In der Richtlinie heißt es schlicht: „Section 987 gain or loss is sourced and characterized as provided by section 987 and regulations issued under that section." Andere als die genannten beabsichtigten Richtlinien gibt es derzeit aber nicht.

219 International Bureau of Fiscal Documentation, a.a.O., S.135.

${ }^{220} \mathrm{Vgl}$. auch J. Bourne Wahl, Taxation of Foreign Exchange Gains and Losses, a.a.O., die aber - wie in Teil B dargestellt - zwischen antizipierten und nicht antizipierten Währungsergebnissen unterscheidet und deshalb auch nur letztere als inländisch qualifiziert wissen will.

${ }^{221}$ U.S. House Ways and Means Committee, Tax Reform Bill of 1985, a.a.O., Sp.471.

222 Vgl. M.J. Cooper, a.a.O., S.58f.. 
In dem vom Senat am 24. Juni 1986 verabschiedeten geänderten Text wurde demgegenüber schlicht die Qualifikation als inländische Einkünfte formuliert.223 Erst in der am 22. Oktober des Jahres verabschiedeten endgültigen Fassung des Gesetzestextes wurde festgelegt, sie pro rata den ausländischen Einnahmen zuzurechnen.

\section{g) Besonderheiten bei Ausschüttungen ausländischer Tochtergesellschaften}

Die Bestimmungen des Unterabschnitts J gelten, wie schon gesagt, für ausländische Kapitalgesellschaften, an denen U.S.-Steuerpflichtige beteiligt sind, vom Grundsatz her in gleicher Weise wie für Betriebstätten.

Bei Ausschüttungen von E\&P einer ausländischen Kapitalgesellschaft, die in früheren Perioden der Zugriffsbesteuerung nach Unterabschnitt F des IRC unterlagen, finden die oben beschriebenen Bestimmungen zur Repatriierung versteuerter Gewinne einer QBU Anwendung. Die Währungsgewinne sind ordentliche Einkünfte, deren Quelle sich auch hier aus dem schon versteuerten Einkommens selbst ableitet.224

Für das Anrechnungsverfahren ist das Währungsergebnis zu gleichen Teilen auf die Körbe aufzuteilen, in die auch die zugriffsteuerpflichtigen Einkünfte gehören. ${ }^{225}$ Allerdings kann der Währungserfolg auch in dem Korb für passive Erträge landen, obgleich die Einkünfte aufgrund hoher Besteuerung im Ausland anderen Körben zugewiesen wurden, weil er ja im Ausland nicht besteuert wird. ${ }^{226}$

$\mathrm{Ob}$ Währungsgewinne ordentliche Einkünfte sind, wenn (i) der Steuerpflichtige in den letzten fünf Jahren davor wenigstens $10 \%$ der Stimmrechte der Gesellschaft gehalten hat und (ii) die Gesellschaft eine abhängige Auslandsgesellschaft ist, ist unklar. ${ }^{227}$

Gewinne einer ausländischen Kapitalgesellschaft, die nicht der Zugriffsbesteuerung unterliegen, werden aber erst bei ihrer Ausschüttung beim Anteilseigner steuerpflichtig. Dadurch können der Zeitpunkt der Entstehung des Gewinnes und der Besteuerung im Inland auseinanderfallen. Die Möglichkeit von Wechselkursänderungen in diesem Zeitraum wirft Fragen auf bezüglich der Umrechnung von Ausschüttungen von E\&P und den hierauf im Ausland entrichteten Steuern.

Zwei Aspekte werden nachfolgend eingehender betrachtet: Zunächst wird abgewogen, wie Währungsgewinne und -verluste behandelt werden sollten, die durch eine Kursänderung zwischen der Entstehung und der Ausschüttung von Gewinnen ausländischer Kapitalgesellschaften anfallen.

Danach wird analysiert, ob die Umrechnung von im Ausland gezahlten Steuern zum Zwecke der indirekten Anrechnung im Inland mit dem historischen oder dem aktuellen Kurs, das heißt

223 In IRC $\$ 987(3)(B)$ des vom Senat verabschiedeten Gesetzestextes hieß es ,treating gain or loss [...] as ordinary income or loss, respectively, and sourcing such gain or loss by reference to the residence of the taxpayer as defined in section 988(a)(3)." o.V., Tax Reform Bill: Text of H.R. 3838 as Passed by the Senate on June 24, 1986, in: Standard Federal Tax Reports - Extra Edition-, 73.Jg. (1986), Sp.525. So auch in Senate Finance Committee, Report on H.R. 3838, a.a.O., S.470.

224 IRC $§ 986$ (c)(1).

225 Isenbergh, International Taxation, 1994 Supplement, a.a.O., S.524. Für einige Beispielrechnungen vgl. J.H. Shedivy u.a., E\&P Accounting for Distributions of Previously Taxed Income (PTI) of a CFC, in: Tax Management International Journal, 19.Jg. (1990), S.105-110.

${ }^{226}$ Reg. $\$ 1.904-4$ (c)(5)(iii).

${ }^{227}$ T.J. O'Neil, a.a.O., S. 190, Fn.34. Vgl. auch Seite 87 dieser Arbeit. 
mit dem Wechselkurs zum Zeitpunkt der Entstehung des Gewinnes oder zum Zeitpunkt der Ausschüttung und Konvertierung der Dividenden, sinnvoll ist.

Die Frage nach der Umrechnung ausländischer Steuern war auch Diskussionsgegenstand im Vorfeld der U.S.-amerikanischen Steuerreform von 1986. Kritisiert wurde die in jener Zeit geltende Rechtslage, die nach einem Urteil des Finanzgerichts in den USA mit dem Namen Bon $A m i^{228}$ verbunden wird und die generelle Umrechnung von Dividenden und anrechenbaren ausländischen Steuern mit dem Wechselkurs zum Zeitpunkt der Konvertierung vorsah.

\section{a) Währungsgewinne und -verluste bei der Ausschüttung von einbehaltenen Gewinnen}

Es würde naheliegen, daß sich durch Wechselkursänderungen bei der Umrechnung von Dividenden und anrechenbaren ausländischen Steuern keine zusätzlichen Probleme ergeben: Einbehaltene Gewinne, darauf im Ausland gezahlte Steuern und auch die inländische Steuerpflicht werden gleichermaßen verändert; ${ }^{229}$ die Relationen bleiben konstant, nur die Dimension wird durch eine Auf- oder Abwertung verändert. Demnach wäre Bon Ami die angebrachte Vorgehensweise. ${ }^{230}$

Andererseits ist aber die Einbehaltung von Gewinnen Selbstfinanzierung und bewirkt eine Aufstockung des Eigenkapitals. Das Kapital wird im Unternehmen - hier in der ausländischen Tochtergesellschaft - investiert; der Verzicht auf den Import der Kapitalerträge ist ökonomisch deshalb gleichbedeutend mit Kapitalexport durch inländische Kapitalgeber - hier der inländischen Muttergesellschaft.

Ein Währungsgewinn bei späterem Transfer der einbehaltenen Gewinne sollte demzufolge so behandelt werden wie Währungsgewinne oder -verluste bei der Repatriierung von einstmals tatsächlich exportiertem Kapital.

In dem ersten Diskussionsentwurf des Finanzministeriums wurde erwogen, einbehaltene Gewinne und darauf im Ausland gezahlte Steuern zum Zeitpunkt der Ausschüttung mit historischen Kursen umzurechnen. Diese Beträge sollten als ausländische Einkünfte betrachtet werden und bei der Anrechnung ausländischer Steuern einbezogen werden. Währungsgewinne oder -verluste, die sich danach aus einer Differenz zwischen der Umrechnung des ausländischen Gewinnes nach Abzug der darauf im Ausland gezahlten Steuern zum historischen und zum aktuellen Kurs ergeben, sollten als ordentliches Einkommen inländischen Ursprungs angesehen und als solches in den USA separat versteuert werden. ${ }^{231}$

${ }^{228}$ Die Bezeichnung „Bon Ami“ geht auf ein Finanzgerichtsurteil aus dem Jahre 1939 zurück. Bon Ami Company war eine U.S.-amerikanische Aktiengesellschaft, dessen 100-prozentige Tochtergesellschaft mit Sitz in Kanada im Jahr 1933 die zwischen 1926 bis 1932 angehäuften Gewinne an die Mutter ausschüttete. Streitpunkt war die Frage, ob die in Kanada gezahlten Körperschaftsteuern der Tochter zur indirekten Anrechnung in den USA mit den Kursen zum Zeitpunkt der Besteuerung in Kanada oder dem (niedrigeren) Kurs bei der Repatriierung 1933 umzurechnen sind. Die Gesellschaft hatte daneben die Ausschüttungen für die Besteuerung in den USA zum aktuellen Wechselkurs umgerechnet. Da diese Vorgehensweise in dem Urteil nicht in Frage gestellt wurde, hatte es als Anhaltspunkt zur Besteuerung von Währungsgewinnen und -verlusten bei Ausschüttungen von abhängigen Tochtergesellschaften von U.S.-Unternehmen bis 1986 Bedeutung. Vgl. D. R. Ravenscroft, a.a.O., S.101.

${ }^{229}$ Dies gilt uneingeschränkt natürlich nur bei gleichen Bemessungsgrundlagen.

${ }^{230}$ Dies wurde auch als Begründung für Bon Ami genannt. D.P. Zaiken u.a., Handling the Treatment of Foreign Currency under Tax Reform, a.a.O., S.172.

231 U.S. Department of the Treasury, Foreign Exchange Discussion Draft, a.a.O., S.4f.. 
Ziel war, die Entscheidung über die Repatriierung von Gewinnen von der Währungsentwicklung zu trennen. Der Praxis des Bon Ami wurde nämlich ein gravierender Nachteil zugeschrieben; die Argumentation lautete etwa folgendermaßen:

„Beispielsweise sei angenommen, eine ausländische Tochtergesellschaft zahlte 100 AM an

Steuern, als der Wechselkurs bei $1 \mathrm{AM}=\$ 1$ lag. Bei der sofortigen Repatriierung der entsprechenden E\&P würde die U.S.-Muttergesellschaft im Ausland gezahlte Steuern von $\$ 100$ aus der Tochtergesellschaft herausnehmen. Würden die E\&P jedoch erst repatriiert, nachdem die ausländische Währung auf $1,1 \mathrm{~s} / \mathrm{Am}$ aufwertete, würden zusammen mit der Dividendenzahlung potentiell anrechenbare ausländische Steuern von \$110 importiert. Würde andererseits die Ausschüttung verzögert, bis der Wert der ausländischen Währung zurückgegangen ist auf $\$ 1=1,1 \mathrm{AM}$, würden sich die anrechenbaren ausländischen Steuern auf $\$ 90,91$ reduzieren." 232

Daraus wurde der Schluß gezogen, „daß die Bon Ami Regel nicht ökonomisch effizient war. Es werden Investitionen in feste Währungen gegenüber solchen in schwachen Währungsräumen bevorzugt, da die potentiellen Gutschriften für im Ausland gezahlte Steuern in festen Währungsräumen vergrößert werden, wohingegen die potentiellen Gutschriften bei Tochtergesellschaften mit Sitz in schwachen Währungsräumen zusammenschrumpfen. “233 Dies wird offensichtlich verhindert, wenn der ausländische Gewinn und die darauf im Sitzland entrichteten Steuern unabhängig von der Währungsentwicklung zum historischen Kurs umgerechnet werden. ${ }^{234}$ Ein danach anfallender Währungserfolg hätte als inländischer Gewinn oder Verlust keinen Einfluß mehr auf das Anrechnungsverfahren.

Der Lösungsansatz entspricht auch der in Teil B hergeleiteten Vorgehensweise, nämlich Währungsgewinne beim exportierten Kapital - hier dem zur Selbstfinanzierung genutzten Gewinn - nicht in die Anrechnungsgrundlage einzubeziehen.

Aber auch Bon Ami ist hinsichtlich der steuerlichen Behandlung von Währungsgewinnen symmetrisch, solange weitere Einkünfte nicht berücksichtigt werden. Insoweit bestehen die Parallelen zwischen Selbst- und Eigenfinanzierung nicht. Bei Eigenfinanzierung werden zum Zeitpunkt des Kapitalexports die Anschaffungskosten festgestellt. Eine anschließende Wechselkursänderung hat einen Gewinn oder Verlust zur Folge, der im Ausland nicht besteuert wird und deshalb bei der Verrechnung mit positiven ausländischen Einkünften den Anrechnungshöchstbetrag verändert. Bei Selbstfinanzierung ergibt sich dieses Problem nicht, da die Vermögensmehrung durch den Gewinn der ausländischen Gesellschaft vor dem Zeitpunkt seiner Ausschüttung an die Muttergesellschaft in den USA nicht erfaßt wird.

Relevant ist aber ein anderer Aspekt, denn die effektive Steuerlast ist bei den beiden hier betrachteten Alternativen unterschiedlich. Dies wird am einfachsten sichtbar, wenn zunächst ein Anrechnungsüberhang unterstellt wird. Ein Kursanstieg oder -rückgang hat dann bei Bon Ami offensichtlich keine steuerlichen Auswirkungen im Inland. Bei der zweiten Variante führt dies indes zu einem steuerpflichtigen inländischen Gewinn beziehungsweise Verlust.

Wird ein konstanter Wechselkurs antizipiert, wird auf diesem Weg nur ein Teil des Währungsrisikos dem inländischen Staat übertragen; der Barwert bleibt davon unberührt. Kann indes ein Kursanstieg erwartet werden, resultiert ex ante eine effektive Mehrbelastung gegenüber Bon Ami; bei einem erwarteten Kursrückgang dagegen eine effektiv geringere Steuerlast. Ist die Steuerbelastung im Ausland geringer als im Inland, führt Bon Ami bei einem Währungsgewinn zu einer niedrigeren inländischen Steuerlast: Die anrechenbaren auslän-

${ }^{232}$ M. Zollo, a.a.O., S.983 (eigene Übersetzung).

${ }^{233}$ M. Zollo, a.a.O., S.983 (eigene Übersetzung); so auch U.S. Department of the Treasury, Foreign Exchange Discussion Draft, a.a.O., S.4f.; U.S. House Ways and Means Committee, House Ways and Means Committee Report, a.a.O., S.470; F.M. Horner u. K. E. Barge, Simplifying the Foreign Tax Translation Rules, in: Tax Notes, 51.Jg. (1981), S.1573.

${ }^{234}$ U.S. House Ways and Means Committee, House Ways and Means Committee Report, a.a.O., S.470. 
dischen Steuern und der ausländische Gewinn haben in inländischer Währung proportional an Wert gewonnen. Deshalb ist der Währungsgewinn hier im Ergebnis nur mit einem Steuersatz in Höhe der Differenz zwischen in- und ausländischem Tarif steuerpflichtig. Umgekehrt hat ein rückläufiger Kurs eine geringere Minderung der Belastung zur Folge. Wäre statt dessen der Gewinn zunächst ausgeschüttet und sofort in Form von Eigenkapital wieder eingezahlt worden, wäre der Währungsgewinn beziehungsweise -verlust im Inland voll zu versteuern.

Entscheidend ist aber, daß auch ein erwarteter Währungsgewinn oder -verlust nur mit dem geringeren Steuersatz belastet wird - und im Fall eines Anrechnungsüberhanges überhaupt nicht.

Damit werden durch Bon Ami tatsächlich tendenziell selbstfinanzierte Investitionen in festen Währungen gegenüber solchen in schwachen Währungsräumen bevorzugt. Die Wirkung ist bis zu dem Punkt eines Anrechnungsüberhanges umso größer, je höher der ausländische Steuersatz ist.

In der Reform entschied sich der Gesetzgeber am Ende aber für eine dritte Alternative: „Zu Zwecken der Bestimmung des Betrages der Anrechnungsgutschrift sind alle ausländischen Einkommensteuern unter Anwendung des Wechselkurses zum Zeitpunkt, zu dem die Steuern an das Ausland gezahlt wurden, in Dollar umzurechnen" 235 .

Die Ausschüttungen selbst sind dagegen mit dem aktuellen Devisenkurs zu konvertieren, nämlich mit dem ,angemessenen“ Kurs, ${ }^{236}$ der in diesem Fall der Kurs zu dem Zeitpunkt ist, an dem die Einkünfte in die Bemessungsgrundlage des inländischen Steuerpflichtigen einbezogen werden. ${ }^{237}$

Nach der Einführung dieses Gesetzes hatte auf Seiten der Praktiker insbesondere die Anknüpfung an den Zeitpunkt der Zahlung der Steuer im Ausland einige Irritationen hervorgerufen.238 Zum einen weicht der Termin regelmäßig von der Periode der Entstehung des Gewinnes ab. 239 $\mathrm{Da}$ aber Ausschüttungen mit dem aktuellen Kurs konvertiert werden müssen und damit in inländischer Währung keine Relation von Steuerlast zu Gewinn besteht, ist der Aspekt aus dem Blickwinkel dieser Arbeit nicht wesentlich. Für die Steuerpflichtigen entstehen aber außerdem erhebliche Kosten bei der Feststellung des genauen Datums der tatsächlichen Steuerzahlung. Obgleich dies einfach klingt, ,weiß jeder, der versucht hat, die exakten Daten der Steuerzahlungen einer multinationalen Kapitalgesellschaft mit mehreren ausländischen Tochtergesellschaften in verschiedenen Ländern festzustellen, daß der Vorgang nicht immer so unkompliziert ist, wie er erscheinen mag. Ausländische Steuerbescheinigungen sind oft nicht entzifferbar oder existieren gar nicht, und obgleich die Summe der Steuerzahlungen im

235 IRC $§ 986(\mathrm{a})(1)(\mathrm{A})$ (eigene Übersetzung).

236 IRC $\S 986(\mathrm{~b})(2)$.

${ }^{237}$ IRC $§ 989$ (b)(1). Der erste Gesetzesentwurf des Repräsentantenhauses sah noch vor, Dividenden von nicht abhängigen Tochtergesellschaften, an denen der Steuerpflichtige zu wenigstens zehn Prozent beteiligt ist, zu historischen Kursen umzurechnen. Wăhrungsgewinne oder -verluste sollten allerdings separat konvertiert und in einen eigenen Anrechnungskorb verwiesen werden. Dies hätte die steuerliche Berücksichtigung von Wăhrungsverlusten ebenfalls stark eingeschränkt, wohingegen Gewinne steuerpflichtig wären. U.S. House Ways and Means Committee, Tax Reform Bill of 1985, a.a.O., Sp.469, §986(a)(2)(B); dies., House Ways and Means Committee Report, a.a.O., S.477; M.J. Cooper, a.a.O., S. 58.

${ }^{238} \mathrm{Um}$ diese, auch als „date of payment rule“ bezeichnete Regelung, wurde zuvor nur innerhalb des Finanzministeriums und der gesetzgebenden Organe heftig gestritten. In der Öffentlichkeit wurde der Aspekt indes kaum beachtet. T. Horst, Foreign Exchange Gains and Losses, a.a.O., S.1398; F.M. Horner u. K. E. Barge, a.a.O., S. 1569.

${ }^{239}$ Die Analyse der Steuerzahlungen für 1988 der Tochtergesellschaften einer bedeutenden multinationalen Unternehmung in sechs Ländern ergab, daß 97\% innerhalb der ersten sechs Monate des Jahres 1989 und der Restbetrag in den anschließenden 18 Monaten gezahlt wurden. F.M. Horner u. K.E. Barge, a.a.O., S.1572. 
allgemeinen zwar bestätigt werden kann, ist dies für das genaue Zahlungsdatum manchmal nicht möglich." 240,241

Nicht zuletzt deswegen wurde wohl mit der Steueränderung von 1997 auch in diesem Zusammenhang der durchschnittliche Kurs der Bilanzperiode, auf die sich die ausländische Steuerzahlung bezieht, zur Umrechnung vorgeschrieben. ${ }^{242}$ Hier galt und gilt die gleiche gesetzliche Bestimmung wie für andere QBU.

Ungeachtet dieser Neuerung wurde aus allokativer Sicht mit der Entscheidung, anrechenbare Steuern zu einem historischen, die Ausschüttung dagegen zum aktuellen Kurs umzurechnen, die schlechteste Variante gewählt. Einerseits bleibt die Höhe der anrechenbaren Steuer unabhängig von der Währungsentwicklung konstant. Andererseits erhöht ein Währungsgewinn die Anrechnungsgrenze, ein Währungsverlust bringt die Gefahr zusätzlicher Überhänge mit sich. Ursache der Diskriminierung ist auch hier die Bestimmung des Auslands als Quelle des Währungsergebnisses. Das Problem liegt nicht in der Umrechnung der anrechenbaren Steuern zum historischen Kurs. Vielmehr wird dadurch Kapitalexport im Zusammenwirken mit dem Steueraufschub in den USA bis zum Zeitpunkt der Ausschüttung sogar eher begünstigt:

\section{ß) Anrechnung ausländischer Steuern}

Bei konstanten Wechselkursen kann die Besteuerung im Inland erst zum Zeitpunkt der Repatriierung durch die abschirmende Wirkung der rechtlichen Selbständigkeit einer Kapitalgesellschaft einen Steuervorteil gewähren. Ursache ist der zeitliche Aufschub der Zahlung einer Steuerpflicht, die im ökonomischen Sinne in der Vergangenheit entstanden ist. Die Verzögerung der Ausschüttung um eine Periode läßt beispielsweise bei einem inländischen Steuersatz von $\tau=0,55$ und einer Grenzproduktivität von $\mathrm{gp}=\mathrm{gp}^{*}=0,1$ am Ende der zweiten Periode einen Endwert von

$$
{ }_{\mathrm{t}} \mathrm{ge}_{\mathrm{t}+2}=\left(\left(1+\mathrm{gp}^{*}\right)^{2}-1\right) \cdot(1-\tau)=\left(1,1^{2}-1\right) \cdot 0,45=0,0945
$$

erwarten. Wird dagegen periodisch besteuert, beträgt der Wert:

$$
{ }_{\mathrm{ge}_{\mathrm{t}+2}}=\left(1+\mathrm{gp}^{*} \cdot(1-\tau)\right)^{2}-1=(1+0,1 \cdot 0,45)^{2}-1=0,0920
$$

Bei reiner Wohnsitzlandbesteuerung resultiert hier eine Differenz von 0,0025 zum Vorteil des Steuerpflichtigen. Im wesentlichen aus diesem Grund wurde die Zugriffbesteuerung entwickelt.

Der Wert des Steueraufschubs ist bis zu dem Punkt eines Anrechnungsüberhanges umso geringer, je höher der ausländische Steuersatz auf diese Gewinne ist. Erhebt das Ausland am Ende

${ }^{240}$ M.Zollo, a.a.O., S.984 (eigene Übersetzung). Problematisch ist auch, daß ausländische Steuerrückzahlungen mit dem Wechselkurs des Tages der ursprünglichen Zahlung der erstatteten Steuer umzurechnen sind. IRC §986(a)(1)(B)(iii). Denn es kann für einen Steuerpflichtigen, der im Verlauf des Steuerjahres periodische Zahlungen auf der Grundlage von Steuerschätzungen vornimmt, schwer sein, zu bestimmen, auf welche Steuerzahlung sich eine Erstattung bezieht. R.P. Keck u. J.F. Montgomery, a.a.O., S. 158.

Vgl. auch R. Henrey, H.R. 3838 and Foreign Currency Rules Reform, a.a.O., S. 176-181, dort werden außerdem detaillierte Einzelfallrechnungen zur Auswirkung von Bon Ami und Umrechnung mit historischen Kursen bei hoher und niedriger ausländischer Steuer sowie hohem und niedrigem Devisenkurs durchführt.

241 Viele multinationale Konzerne hielten diese Regelung für weit komplexer als andere Besonderheiten des U.S.Außensteuerrechts, etwa die Anrechnungskörbe oder die Abzugsbesteuerung. F.M. Horner u. K.E. Barge, a.a.O., S. 1569.

242 Tax Payer Relief Act of 1997, §1102(a)(1). Vgl. Fußnote 193 auf Seite 110 dieser Arbeit. 
jeder Periode eine Quellensteuer von $t^{*}=0,35$, ergäbe sich nach zwei Perioden ein Endwert von:

Abb. C1: Nettoertrag einer zweiperiodigen Auslandsanlage und periodischen Quellensteuerzahlungen, die im Inland bei der Repatriierung in Periode 2 angerechnet werden

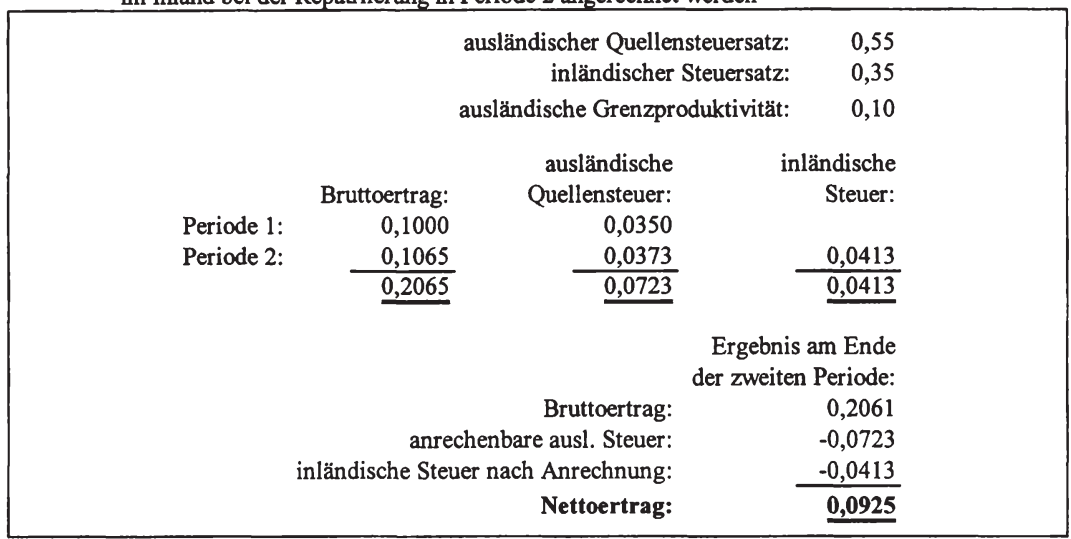

Quelle: Eigene Darstellung.

Bei einem ausländischen Steuersatz, der über dem des Inlands liegt, kann es schließlich - zumindest bei konstantem Wechselkurs - nicht zu einem Steueraufschub kommen. ${ }^{243}$

Welchen Einfluß hat aber die Berücksichtigung flexibler Wechselkurse auf den erwarteten Grenzertrag eines Auslandsengagements, wenn die Besteuerung im Inland erst bei der Repatriierung zugreift?

Ist die Grenzproduktivität im In- und Ausland nicht identisch, weil sie im Ausland nur beispielsweise $\mathrm{gp}^{*}=0,07$ beträgt, resultiert ein erwarteter Nettogrenzertrag von:

$$
\begin{aligned}
{ }_{t \text { e }_{t+2}} & =\left(\left(1+\mathrm{gp}^{*}\right)^{2} \cdot \Delta \mathrm{e}_{+2}-1\right) \cdot(1-\tau) \\
& =\left(1,07^{2} \cdot 1,057-1\right) \cdot 0,45=0,0945 ;
\end{aligned}
$$

wenn infolge der unterschiedlichen Grenzproduktivitäten eine Wechselkursänderung von $\Delta \mathbf{e}_{+2}$ $=1,057$ antizipiert wird.

Wie erwartet werden konnte, ist das Ergebnis identisch mit Gleichung [C2].

Aufschlußreicher ist die Analyse, wenn das Ausland am Ende jeder Periode eine Quellensteuer erhebt. Geprüft wird hier zum einen die Auswirkung des Steueraufschubs und zum anderen

243 Wie Sinn anmerkt, ist der Vorteil durch Einbehaltung von Gewinnen allerdings weiter geringer, wenn für den Kapitaleinsatz in der Kapitalgesellschaft abnehmende Grenzerträge unterstellt werden, weil dann die Steuerersparnis einer zusătzlichen Einheit nicht repatriierter Gewinne durch die zurückgehende Rendite innerhalb der Gesellschaft aufgezehrt werden kann. Zweite Voraussetzung ist, daß der gleiche Steuervorteil bei Anlagen außerhalb der Unternehmung nicht gewährt wird, beispielsweise infolge einer weitreichenden Zugriffsbesteuerung, wie in den USA. H.-W. Sinn, Taxation and the Birth of Foreign Subsidiaries, NBER Working Paper Series Nr. 3519, Cambridge, Mass. 1990, S.18-25. Vgl. auch G. Krause-Junk, Eine Thesaurierungsbegünstigung ist eher skeptisch zu beurteilen, in: Wirtschaftsdienst, 9. Jg. (1992), S.453. Der eigene Korb für passive Erträge hat deshalb zur Folge, daß der Steueraufschub durch das Einbehalten von Gewinnen weniger attraktiv ist, wenn Erweiterungsinvestitionen innerhalb der Gesellschaft nicht sinnvoll sind. Denn passiven Erträgen aus einbehaltenen Gewinnen ist die Verrechnungsmöglichkeit mit den Erträgen aus der gewöhnlichen Geschäftstätigkeit der Gesellschaft verwehrt. 
die Wahl des Umrechnungskurses zur Bemessung der anrechenbaren ausländischen Steuerzahlungen. Betrachtet wird eine Umrechnung (1) zum historischen Kurs des Zeitpunktes der Entstehung des Gewinns im Ausland und (2) zum Wechselkurs am Tag der Repatriierung der ausländischen Erträge.

Zur Veranschaulichung werden die ex ante erwarteten Endwerte bei beiden Alternativen graphisch in der folgenden Abbildung C2 gezeigt. Dafür wird der Grenzertrag eines zweiperiodigen Auslandsengagements in Abhängigkeit der dortigen Grenzproduktivität betrachtet, wenn für das Inland konstant gp $=0,1$ pro Periode möglich ist. Die Steuersätze sind $\tau=0,55$ im Inland und $t^{*}=0,35 \mathrm{im}$ Ausland. Unterstellt wird auch hier, daß die Erwartungen über die Wechselkursentwicklung aus der zinsparitätischen Beziehung der Grenzproduktivitäten zueinander abgeleitet werden:

Abb. C2: Einfluß des Steueraufschubs im Wohnsitzland auf den Endwert einer zweiperiodigen Anlage bei zinsparitätischer Beziehung der in- und ausländischen Grenzproduktivität

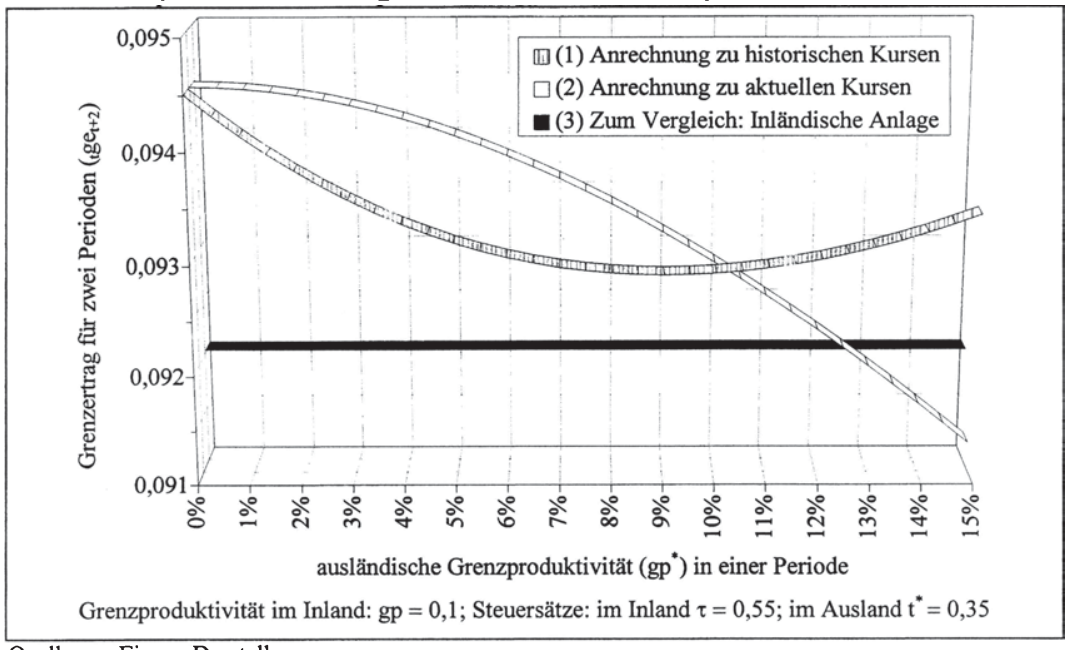

Quelle: Eigene Darstellung.

Die beiden Schnittpunkte der Funktionen leuchten unmittelbar ein: Ist die ausländische Grenzproduktivität null, stellt sich die Frage nach der Umrechnung zu historischen oder aktuellen Kursen nicht, da keine ausländische Steuer anfällt. Der gesamte Ertrag fällt in Form des Währungsgewinnes an und wird erst am Ende der zweiten Periode besteuert. ${ }^{244}$ Sind die in- und ausländischen Grenzproduktivitäten dagegen identisch $\left(\mathrm{gp}^{*}=\mathrm{gp}=0,1\right)$, wird ein konstanter Wechselkurs erwartet und es ist irrelevant, ob der historische oder der aktuelle Kurs zur Umrechnung herangezogen wird. ${ }^{245}$

Ist die Grenzproduktivität im Ausland positiv aber geringer als im Inland, wird ein steigender Devisenkurs antizipiert. Der erwartete Endwert der Investition muß infolgedessen bei Umrechnung zu historischen Kursen geringer sein, da die anrechenbare ausländische Steuerzahlung in inländischer Währung niedriger ist als bei Umrechnung zu aktuellen Kursen. Genau andersherum ist die Situation dagegen bei einer höheren Grenzproduktivität im Ausland, da ein Rückgang des Devisenkurses erwartet wird.

${ }^{244}$ Er entspricht dem in Gleichung [C2] auf Seite 120 ausgerechneten Wert.

245 Der Wert entspricht dem in Abb. 1 auf Seite 121 errechneten Nettoertrag. 
In Abbildung $\mathrm{C} 2$ zeigt eine dritte Funktion den Ertrag der alternativen inländischen Anlage, die der periodischen Besteuerung unterliegt. Bei Anrechnung zu historischen Kursen ist der erwartete Endwert der ausländischen Investition eindeutig höher. Wird dagegen zu aktuellen Kursen umgerechnet, ist auch die Erwartung eines geringeren Endwertes nicht ausgeschlossen, wenn die Grenzproduktivität im Inland erheblich niedriger als im Ausland ist. Die Ursache liegt darin, daß der Währungsverlust beim exportierten Kapital erst zum Zeitpunkt der Repatriierung - als inländische Einkünfte - steuerlich berücksichtigt wird. Der Steueraufschub dieses Währungsverlustes mindert den erwarteten Endwert.

Bei der Anrechnung der ausländischen Steuerzahlung zu historischen Kursen wird diese Wirkung überkompensiert durch den höheren Anrechnungsbetrag. Nicht so bei der Anrechnung mit dem aktuellen Devisenkurs: Der Vorteil des Aufschubs der inländischen Steuer auf den ausländischen Gewinn wird aufgezehrt durch den Nachteil des Aufschubs des Währungsverlustes beim exportierten Kapital.

Die isolierte Betrachtung der Wirkungen der Wahl des Umrechnungskurses führt somit nicht zu einer überzeugenden Aussage darüber, welche Form der Besteuerung überlegen ist. Die Ergebnisse beider Ansätze weichen von dem ökonomisch richtigen Endwert ab. Dabei ist zu bedenken, daß die Abweichungen, die in diesem Beispiel gering sind, bei längeren Zeiträumen entsprechend größer werden.

Eindeutig diskriminierend wirkt die Umrechnung mit dem aktuellen Kurs gegenüber Investitionen in Währungsräumen, dessen (nominale) Grenzproduktivität erheblich über der des Inlands liegt, wenn der Steuersatz im Quellenland niedriger ist als im Wohnsitzland. Mit gleicher Eindeutigkeit begünstigt die Umrechnung zu historischen Kursen in dieser Situation allerdings die Auslandsinvestition. ${ }^{246}$

\section{Eine Variante der „Net Worth Method“": Spezielle Rechtsverordnungen für stark inflationäre Währungen}

Steuerpflichtigen qualifizierten wirtschaftlichen Einheiten wird in IRC §985 gestattet, - soweit die Durchführungsverordnungen dies zulassen - den U.S.-Dollar als funktionale Währung zu wählen, wenn (A) die Bücher der Einheit in der amerikanischen Währung geführt werden oder (B) die Einheit eine Umrechnungsmethode anwendet, die in ihren Ergebnissen der Umsatzmethode nahekommt. 247

In den Verordnungen ist das im Gesetzestext formulierte Wahlrecht indessen inzwischen nicht mehr zu finden. ${ }^{248}$ Statt dessen wird einer QBU, deren nach den bisher genannten Kriterien ermittelte funktionale Währung einem besonders starken Kaufkraftverlust unterliegt, eine Gewinnermittlungsmethode verbindlich vorgeschrieben, die eine Buchhaltung in U.S.-Dollar näherungsweise abbilden soll. ${ }^{249}$

\footnotetext{
$246 \mathrm{Vgl}$. auch J. Bourne Wahl, Taxation of Foreign Exchange Gains and Losses, a.a.O., S. $14 \mathrm{f}$.

247 IRC $\S 985(\mathrm{~b})(3)$.

${ }^{248}$ Es war nicht die Intention der Gesetzgeber, dieses Wahlrecht generell einzuräumen. Die Option war nur auf QBU in hoch inflationären Währungsräumen ausgerichtet. o.V., Tax Reform Act of 1986; Conference Report to Accompany H.R. 3838, in: Standard Federal Tax Reports -Extra Edition-, 73.Jg. (1986), S.II-662.

${ }^{249}$ Reg. $\$ 1.985-1(b)(2)(i i)(A)$. Ein Wahlrecht bleibt gemäß Reg. $\$ 1.985-1(b)(2)(i i)(B)(2)$ nur für die „1050 corporations" und deren QBU in hochinflationären Währungsräumen, da nicht erwartet werden kann, daß den beteiligten Steuerinländern die notwendigen Informationen für die alternative Methode zur Verfügung stehen. C.W. Cope u. R.A. Katcher, Final DASTM Regulations: An Aid to Business Operating in Hyperinflationary Countries, in: Tax Notes, 64.Jg. (1994), S. 1361; o.V., New Rules Affecting Hyperinflationary Currency Accounting, in: Journal of Taxation, 80. Jg. (1994), S.274.
} 
Eine sogenannte hyperinflationäre Währung (,hyperinflationary currency") liegt im steuerrechtlichen Sinne vor, wenn der Geldwertschwund innerhalb der letzten drei aufeinanderfolgenden Jahre vor dem aktuellen Steuerjahr insgesamt mindestens 100 Prozent beträgt. ${ }^{250}$

Die Meinungsbildung zur Lösung der Problematik der Besteuerung von QBU, deren funktionale Währung starker Inflation unterliegt, nahm einige Zeit in Anspruch. Der Kongreß hielt sich zurück; Kritik an der Stichtagmethode wegen der verzögerten steuerlichen Anerkennung von Währungsverlusten wurde zwar zur Kenntnis genommen, ${ }^{251}$ die Lösung aber der Finanzverwaltung überlassen. Die ersten einstweiligen Richtlinien, die mit der Steuerreform 1986 einhergingen, wurden 1989 zurückgezogen. Die an ihre Stelle getretenen Verordnungen sind 1994 nochmals in wesentlichen Punkten verändert und vervollständigt worden. ${ }^{252}$

Schließlich steht noch eine weitere Ergänzung der Verordnungen im Raum, nämlich die Anleitung, wie zu verfahren ist, nachdem die Inflationsrate der funktionalen Währung in drei aufeinanderfolgenden Steuerjahren nicht mehr insgesamt 100 Prozent überschreitet. ${ }^{253} \mathrm{Da} \beta$ dieser Aspekt erst zehn Jahre nach der Steuerreform als regelungsbedürftig erkannt wurde, ist bemerkenswert. ${ }^{254}$ Der Grund liegt in der bislang gewährten Wahlmöglichkeit. Viele Unternehmen verzichteten auf die Gewinnermittlungsmethode in U.S.-Dollar wegen der damit verbundenen zusätzlichen Komplexität. ${ }^{255}$ Das bedeutet freilich entweder, die in den einstweiligen Richtlinien vorgegebene Methode konnte Verzerrungen durch eine starke Inflation nicht ausgleichen, oder eine Steuerersparnis gegenüber der Stichtagmethode war nicht groß genug, um den Aufwand zu rechtfertigen.

\section{a) Theoretische Überlegungen}

Was ist die besondere Schwierigkeit einer neutralen Besteuerung von Investitionen im Wohnsitzland, die in einem inflationierenden fremden Währungsraum getätigt werden?

In dem Analyserahmen des Teils B gleicht die erwartete Währungsentwicklung gerade die unterschiedlichen nominalen Grenzproduktivitäten der Währungsräume aus, wenn im Wohnsitzstaat sämtliches Einkommen mit dem einheitlichen Steuersatz belastet wird, ganz gleich, wie hoch die Geldentwertung in den Ländern ist. Die inländische Inflationsrate ist nur relevant, wenn Scheingewinne nicht besteuert werden sollen, die des Auslands ist überhaupt bedeutungslos. 256

${ }^{250}$ Dies entspricht bei konstanter Rate in den drei Jahren einer jährlichen Inflation von etwa $26 \%$. Auch diese Grenze wurde aus den durch FASB Statement No.52. für die Rechnungslegung vorgegebenen Werten übernommen. R. Henrey, International Tax Aspects, a.a.O., S.313. Als Inflationsrate ist zu diesem Zweck die Veränderung der Lebenshaltungskosten zugrunde $\mathrm{zu}$ legen, die in den monatlichen Statistiken des Internationalen Währungsfonds veröffentlicht wird. Reg. §1.985-1(b)(2)(ii)(D).

Sollte sich die Geldentwertung der U.S.-Wahrung allerdings einer solchen Rate nähem, würde der Effekt der in diesem Unterabschnitt beschriebenen Regelungen unterlaufen. J. Isenbergh, International Taxation, 1994 Supplement, a.a.O., S.503, Fn.12.

251 U.S. Senate Finance Committee, Report on H.R. 3838, a.a.O., S.459.

252 M. Zollo, a.a.O., S.977f.; C.W. Cope u. R.A. Katcher, a.a.O., S. 1358.

253 Prop. Reg. §1.985-1(b)(2)(ii)(E).

254 Bislang gelten die allgemeinen Richtlinien für den Wechsel der funktionalen Währung der Reg. $\$ 1.985-5$, denen zufolge die Bilanz zum Kurs am Stichtag in die neue funktionale Währung umzurechnen ist. Währungsgewinne und -verluste, die bis zu diesem Zeitpunkt aufgelaufen sind, müssen dabei realisiert werden. Unterschiede zwischen Buch- und Marktwert bleiben indes unberücksichtigt.

255 A. W. Cathcart, Hyperinflation Holiday To End, in: Tax Notes International, 9. Jg. (1994), S.303.

${ }^{256} \mathrm{Vgl}$. Abschnitt III des Teils B dieser Arbeit, insbesondere Seite $52 \mathrm{ff}$. . 
Doch gibt es im Steuerrecht keinen realistischen Ansatz zur Erfassung ökonomischen Einkommens. Zwei bekannte Problemfelder erlangen durch starke Geldentwertung deshalb besonderes Gewicht:257 die Abschreibung abnutzbaren Anlagevermögens zu historischen Anschaffungswerten - in der amerikanischen Literatur einprägsam als das Problem der verschwindenden Anlagen (,disappearing plant problem“) bezeichnet ${ }^{258}$ - und das Realisationsprinzip.

Die Stichtagmethode des U.S.-Steuerrechts ist in diesem Umfeld besonders ungeeignet. Zum einen wird die Realisation von Währungsgewinnen und -verlusten bis zum Zeitpunkt der Kapitalrückfuihrung hinausgeschoben. Zum anderen fußt die Gewinnermittlung in der funktionalen Währung auf U.S.-amerikanischem Recht, das heißt auf dem Nominalwertprinzip.

Die Wechselwirkungen des Rückgangs des Binnen- und des Außenwertes einer stark inflationären Währung auf die steuerliche Bemessungsgrundlage in dem Zahlungsmittel des Wohnsitzlandes veranschaulichen die folgenden drei kleinen Beispiele. Aus Vereinfachungsgründen wird dabei ein Gewinn im Rahmen der Stichtagmethode nicht mit dem Durchschnitts-, sondern dem Stichtagskurs umgerechnet.

Beispiel C8:

Ein amerikanisches Unternehmen kauft für 10.000 AM ein Grundstück in einem Land, dessen Währung AM einer jährlichen Inflationsrate von $\mathrm{i}^{*}=35 \%$ unterliegt. Zum Zeitpunkt des Kaufs liegt der Wechselkurs bei $\$ 1=1 \mathrm{AM}$; das Unternehmen investiert somit $\$ 10.000$. Die nominale Grenzproduktivität des Kapitals beträgt in dem Belegenheitsstaat $r^{*}=40 \%$ und in dem Wohnsitzland des Steuerpflichtigen $r=7 \%$. Unterstellt wird, daß die Einkünfte aus der Vermietung des Grundstücks gerade der realen Grenzproduktivität entsprechen; sie belaufen sich demnach auf 500AM. Bleibt der Wert des Grundstücks real konstant, hat es nominal am Ende des Jahres einen Marktpreis von 13.500 AM. Entspricht die Währungsentwicklung den Erwartungen, liegt der Devisenkurs am Ende der Periode bei $\$ 1=0,764$ AM. Gemäß der Stichtagmethode sind in den USA unter diesen Annahmen steuerpflichtig: $500 \mathrm{AM} \cdot 0,764 \mathrm{~S} / \mathrm{AM}=\$ 382$.

Durch die hohe Inflationsrate im Quellenland ergeben sich hier bei Anwendung der Stichtagmethode keine zusätzlichen Probleme. Entspricht die reale Grenzproduktivität des Kapitals in den USA nämlich der des betrachteten Auslands, würde in U.S.-Dollar die gleiche steuerpflichtige Mieteinnahme und der gleiche nominale Wertzuwachs anfallen, der bis zur Realisierung unberücksichtigt bleibt.

Natürlich kann es auch hier zu Marktwertänderungen in der fremden Währung oder infolge einer unerwarteten Wechselkursentwicklung kommen, die wegen des Realisationsprinzips nicht zeitnah der Besteuerung unterworfen wird. Die Auswirkungen sind aber nicht spezifisch von der Rate der Geldentwertung im Quellenland abhängig.

Eine Buchfuihrung in der Währung des Wohnsitzlandes führt in diesem Beispiel C8 offensichtlich zu dem gleichen Ergebnis wie die Stichtagmethode.

Beispiel C9:

Das U.S.-Unternehmen des Beispiels C8 kauft für 10.000 AM Anleihen in dem inflationären Ausland. Am Ende des Steuerjahres bezieht es daraus Zinseinkünfte in Höhe von 4.000 AM, die gemäß der Stichtagmethode in vollem Umfang in den USA steuerpflichtig sind.

Bei einer Buchführung in U.S.-Dollar wären ebenfalls 4.000 AM (=\$3.057) am Wohnsitz zu versteuern. Der Währungsverlust beim Nennwert würde erst zum Zeitpunkt der Realisierung, beziehungsweise wenn der Verlust durch eine QBU im Ausland erwirtschaftet wurde, sogar erst bei der Kapitalrückführung in den USA steuerlich erfaßt.

${ }^{257}$ Vgl. S.R. Lainoff u. T.Y. McArthur, a.a.O., S.586; C.W. Cope u. R.A. Katcher, a.a.O., S. 1359; G. Langenbucher, Umrechnung von Fremdwährungsabschlüssen, a.a.O., S. 451 f., Rz.987f. u. S.450f., Rz. 1009.

${ }^{258}$ M. Zollo, a.a.O., S.977; S.R. Lainoff u. T.Y. McArthur, a.a.O., S.586; J. Isenbergh, International Taxation, 1994 Supplement, a.a.O., S.502f.. 
Die Verzerrung der Kapitalanlage in Form der ausländischen Anleihe - die natürlich in gleicher Weise zur Begünstigung wird, wenn Fremdkapital in der inflationären Währung aufgenommen wird -, läßt sich aber leicht ausräumen, indem Nominalwerte zum Stichtagkurs umgerechnet werden. Augenscheinlich wären dann 14.000 AM zum Kurs am Periodenende umzurechnen, und es ergäbe sich ein steuerpflichtiger Gewinn von $14.000 \mathrm{AM} \cdot 0,764 \$ \mathrm{AM}-\$ 10.000=\$ 700$; das Kapitaleinkommen würde korrekt ermittelt.

Besondere Schwierigkeiten bereitet indes die Umrechnung einer Zahlungsreihe, die Aufwendungen für Abnutzung einschließt:

Beispiel C10:

Das U.S.-Unternehmen des Beispiels C8 kauft für 10.000 AM eine Maschine in dem Ausland. Am Ende des Jahres hat die Anlage infolge von Verschleiß die Hälfte des realen Wertes eingebüßt und deshalb nur noch einen Marktpreis von $10.000 \mathrm{AM} \cdot 1 / 2 \cdot 1,35=$ 6.750 AM. Durch ihren Einsatz konnten andererseits aber Umsatzerlöse von 7.250 AM erzielt werden. Der reale Gewinn beträgt demnach wiederum 500AM.

Angenommen wird, daß die Anlage eine Nutzungsdauer von zwei Jahren hat und daß steuerlich die lineare Abschreibung der Anschaffungskosten zulässig ist. Die Anwendung der Stichtagmethode ergibt unter diesen Bedingungen einen Bilanzgewinn von 7.250 AM 10.000 AM $\cdot 1 / 2=2.250$ AM.

Die Abschreibungen wären um 6.750 AM $-5.000 \mathrm{AM}=1.750 \mathrm{AM}$ zu niedrig.

Bei einer Buchführung in U.S.-Dollar würde demgegenüber ein Umsatzerlös in Höhe von $7.250 \mathrm{AM} \cdot 0,764 \mathrm{\$} / \mathrm{AM} \$ 5.541$ bilanziert. Zulässig wäre eine Abschreibung von $\$ 5.000$. Es verbleibt ein steuerpflichtiger Gewinn von $\$ 541$.

Würde die Maschine am Beginn der nachfolgenden Periode veräußert, würde zudem ein steuerpflichtiger Veräußerungsgewinn von $6.750 \mathrm{AM} \cdot 0,764 / \mathrm{AM}-\$ 5.000=\$ 159$ erzielt. Insgesamt wären dies $\$ 541+\$ 159=\$ 700$ - der ökonomische Gewinn.

Damit wird zwar der steuerpflichtige Gewinn in der ersten Periode zu gering ausgewiesen. Der Effekt ist aber nicht Folge der Wechselkursänderung. Der Betrag ist der nicht realisierte nominale Gewinn beim Restbuchwert der Anlage. Wenn die reale Grenzproduktivität des Kapitals im Wohnsitzland genauso hoch ist wie in dem inflationären Währungsraum, dann ergäbe sich ceteris paribus bei der Investition im Inland exakt die gleiche Zahlungsreihe. ${ }^{259}$

Als allgemeine Regel ist hiernach auch bei abnutzbarem Anlagevermögen die Bilanzierung in der Währung des Wohnsitzlandes sachgemäß.

Dem Anspruch der Quantifizierung des ökonomischen Gewinns können Abschreibungsregelungen, die der Realität entsprechend eine standardisierte Vorgehensweise vorschreiben, ohnehin nicht gerecht werden, wenn die Preisrelationen im In- und Ausland nicht identisch sind. Die wirtschaftliche Einheit wird ihre Entscheidungen unter den ökonomischen Bedingungen des ausländischen Währungsraumes - namentlich der in jenem Land erwarteten Preise für Güter und den Faktor Arbeit - treffen. Daher trifft die auf Seite 41 bezüglich der Gültigkeit der Kaufkraftparität genannte Einschränkung hier im besonderen zu: Auch die Möglichkeiten, Kapitalexportneutralität zu realisieren, sind umso mehr eingeschränkt, je stärker sich zwei betrachtete Volkswirtschaften in ihrer Struktur und ihrem Entwicklungsstand unterscheiden.

${ }^{259}$ Die nominale Grenzproduktivität des Kapitals im Quellenland beträgt 40\%, die Inflationsrate 35\%. Demnach beträgt die reale Grenzproduktivität $1,4 / 1,35-1=3,7 \%$. Die nominale Grenzproduktivität des Kapitals im Wohnsitzland beträgt 7\%. Bei einer realen Grenzproduktivität von 3,7\% ergibt sich eine Inflationsrate von $1,07 / 1,037-1=3,18 \%$. Bei linearer Abnutzung beläuft sich der Restmarktwert einer Anlage mit Anschaffungskosten von $\$ 10.000$ am Ende der Periode auf $\$ 10.000 \cdot 1 / 2 \cdot 1,037=\$ 5.159$. Daneben würden Umsatzerlöse in Höhe von $\$ 10.700-\$ 5.159=\$ 5.541$ erwirtschaftet. Bei linearer steuerlicher Abschreibung zu historischen Kosten von $\$ 5.000$ resultiert ein steuerpflichtiger Gewinn von $\$ 5.541-\$ 5.000=\$ 541$. 


\section{b) Die geltende Rechtslage}

Bei einer Gewinnermittlung in der Währung des Wohnsitzstaates besteht in der Realität allerdings das Problem eines erheblichen buchhalterischen Aufwands. Deshalb wurde in den Regelungen die sogenannte „dollar approximate separate transactions method" (DASTM) entwickelt, die eine Approximation einer Buchhaltung in U.S.-Dollar darstellen soll.

Eine Verpflichtung zur Bestimmung der Steuer nach dieser Gewinnermittlungsmethode gilt für Steuerjahre, die nach dem 24. August 1994 beginnen. Für die vorangegangenen Jahre besteht tatsächlich das im Gesetzestext gewährte Wahlrecht, anstelle der Ermittlung des steuerlichen Gewinns auf der Grundlage der inflationären Währung nach den in diesem Teil C beschriebenen Vorschriften, alternativ den U.S.-Dollar als funktionale Währung einzusetzen. ${ }^{260}$

Trotz einer Anzahl von Modifikationen, ist das Grundprinzip der DASTM seit 1986 identisch geblieben. Die Methode wird in den Verordnungen in vier Schritten beschrieben. ${ }^{261}$ Sie ist in der folgenden Weise sowohl zur Ermittlung des Einkommens von Betriebstätten als auch der E\&P ausländischer Gesellschaften anzuwenden:

(1) Es ist für die QBU eine Gewinn- und Verlustrechnung in der funktionalen Währung zu erstellen.

(2) Die Gewinn- und Verlustrechnung ist den Vorschriften des Steuerrechts der USA anzupassen.

(3) Die Aufstellung des Schrittes (2) ist in U.S.-Dollar umzurechnen. Als Wechselkurs ist zu diesem Zweck in den meisten Fällen ein einheitlicher Kurs für die Buchungen eines Monats heranzuziehen. ${ }^{262}$ Buchungszeitpunkt zur Bestimmung des Umrechnungskurses ist der Monat der Ein- oder Auszahlung, nicht das Datum der Einnahme beziehungsweise der Ausgabe. ${ }^{263}$ Vor allem aber: Abschreibungen auf nichtmonetäre Aktiva sind auf der Basis des historischen Wechselkurses des Stichtagsmonats der Anschaffung des abnutzbaren Aktivums umzurechnen, um dem „Verschwinden der Anlagen“ der QBU in der inflationären Währung zu begegnen. 264

(4) Die transformierte Gewinn- und Verlustrechnung der QBU für die Periode ist um eine Position zu ergänzen, die den getrennt zu quantifizierenden Währungsgewinn oder -verlust („DASTM gain or loss") ausweist.

Die Schritte (1) bis (3) entsprechen in der Vorgehensweise einer Variante der Stichtagmethode. Mit der DASTM soll die hyperinflationäre Währung der QBU als Meßgröße für relativ kurze Zeiträume erhalten bleiben, um den buchhalterischen Aufwand einzuschränken. Damit sich andererseits die verzerrenden Effekte der hohen Inflation in Grenzen halten, ist die Gewinnund Verlustaufstellung aber auf Zeiträume von höchstens einem Monat zu beziehen. ${ }^{265}$

Der Zweck dieser Erfolgsrechnung leitet sich aus den Vorschriften des U.S.-Außensteuerrechts ab: Die Ergebnisse des Schrittes (3) werden zugrunde gelegt, um die Einkünfte der QBU auf die diversen Anrechnungskörbe aufzuteilen. Ferner greifen die Quellenregeln und gegebenenfalls auch die Zugriffsbesteuerung nach Unterabschnitt F des IRC auf die Aufstellung zurück. ${ }^{266}$

\footnotetext{
${ }^{260}$ Reg. $\$ 1.985-2$ i.V.m. Reg. $\S 1.985-1(b)(2)(i)$. Das heißt entweder die DASTM in alter Form oder andere Methoden der Buchhaltung, die IRC $§ 988$ entsprechen, anzuwenden. Reg. $\S 1.985-2(d)(2)(i i)$.

Vgl. zur DASTM auch S.R. Lainoff u. T.Y. McArthur, a.a.O., S. 583-599.

${ }^{261}$ Reg. §1.985-3(b)(1)-(4); M. Zollo, a.a.O., S.978.

${ }^{262}$ Reg. §1.985-3(c)(1) i.V.m. Reg. §1.985-3(c)(6)-(7).

263 Reg. \$1.985-3(c)(5).

${ }^{264}$ Reg. $\$ 1.985-3(c)(4)$.

265 S.R. Lainoff u. T. Y. McArthur, a.a.O., S. 587, S. 590 f. .

266 M. Zollo, a.a.O., S. 978.
} 
Der eigentliche Währungsgewinn oder (hier wohl realistischer) Währungsverlust, um den die Gewinn- und Verlustrechnung in dem obigen Schritt (4) zu ergänzen ist, wird indessen mittels einer in U.S.-Dollar aufzustellenden Bilanz der QBU ermittelt. ${ }^{267}$ Auch die Bilanz muß zunächst in der inflationären Währung erstellt und den Vorschriften des Steuerrechts der USA angepaßt werden. ${ }^{268}$ Anschließend sind die Bilanzpositionen umzurechnen, und zwar Sachwerte mit historischen und Nominalwerte mit aktuellen Kursen. ${ }^{269}$ Die in den Steuerrichtlinien vorgegebenen Umrechnungsregeln werden in der rechten Spalte der nachfolgenden Abbildung C3 genannt. Einlagen oder Entnahmen sind zum Kurs zum Zeitpunkt der Einbeziehungsweise Auszahlung in U.S.-Dollar zu bilanzieren. ${ }^{270}$

Das gesuchte Währungsergebnis ist die Umrechnungsdifferenz, die verbleibt, wenn diese Bilanz um den Saldo der Gewinn- und Verlustrechnung im obigen Schritt (3) ergänzt wird. Es zählt auch hier zu den ordentlichen Einkünften.

Abb. C3: Entwicklung der Umrechnungsregeln im U.S.-Steuerrecht: Vorschriften für abhängige Auslandsgesellschaften vor der Reform, für qualifizierte Betriebseinheiten in stark inflationären Währungsräumen bis zum 24.9.1994 und heute gemäß „Dollar Approximate Separate Transactions Method“ (DASTM).

\begin{tabular}{|c|c|c|c|}
\hline Bilanzposition & $\begin{array}{c}\text { Regelung vor der } \\
\text { Steuerreform } 1986 \\
\text { „Full Section } 964 \text { Method“ }\end{array}$ & $\begin{array}{c}\text { DASTM } \\
\text { bis August } 1994\end{array}$ & $\begin{array}{c}\text { DASTM } \\
\text { aktuell }\end{array}$ \\
\hline $\begin{array}{l}\text { AKTIVA } \\
\text { Immaterielles Vermögen } \\
\text { Sachanlagen } \\
\text { Finanzanlagen } \\
\text { Vorräte } \\
\text { Sonstige Vermögensgegenstände } \\
\text { Kurzfristige Forderungen }{ }^{(2)} \\
\text { Anzahlungen } \\
\text { Liquide Mittel } \\
\text { in inflationärer Währung } \\
\text { in anderen Währungen } \\
\text { Termingeschäfte } \\
\text { PASsIVA } \\
\text { Langfristige Verbindlichkeiten } \\
\text { Kurzfristige Verbindlichkeiten }\end{array}$ & $\begin{array}{l} \\
\text { Stichtag } \\
\text { Stichtag } \\
\\
\text { Stichtag } \\
\text { Stichtag } \\
\text { Stichtag }\end{array}$ & $\begin{array}{c}\text { - historisch } \\
\text { - historisch } \\
\text { historisch } \\
\text { historisch } \\
\text { - historisch } \\
\text { historisch } \\
\text { historisch }\end{array}$ & $\begin{array}{c}\text { Stichtagsmonat } \\
\overline{\text { Stichtagsmonat }} \\
\text { onat } \\
\text { Wahlrecht } \\
\text { Stichtagsmonat }\end{array}$ \\
\hline
\end{tabular}

(1) Die Umrechnung zu historischen Kursen war zulässig, wenn die Nachweise erbracht wurden, daß die Verbindlichkeiten schon längere Zeit bestanden. ${ }^{271}$

(2) Unverzinsliche Forderungen aufgrund von gelieferten Gütern und Leistungen können, unverzinsliche Verbindlichkeiten aufgrund von gelieferten empfangenen Gütern und Leistungen müssen deflationiert werden. $^{272}$

Quellen: M. Zollo, The Search for Clarity And Consistency in Foreign Currency Translation, in: Taxes, 71.Jg. (1993), S.993; Reg. §1.985-3(d).

${ }^{267}$ Reg. $\S 1.985-3(d)(1)$.

268 Reg. $\$ 1.985-3(d)(2)(i),(i i)$.

${ }^{269}$ Deshalb wäre die deutsche Bezeichnung Fristigkeitmethode spätestens seit der revidierten Fassung der DASTM nicht korrekt. Da nunmehr auch langfristige Verbindlichkeiten mit dem Kurs des Stichtagsmonats umzurechnen sind, Umlaufvermögen indes zum historischen Kurs, gleicht das Verfahren der Nominal-/Sachwertmethode. Vgl. auch die Tabelle in W. Zillessen, a.a.O., S.536.

${ }^{270}$ Reg. §1.985-3(d)(3), (4).

${ }^{271}$ Reg. $\$ 1.985-3(d)(5)(v i i i)(B)$.

272 S.R. Lainoff u. T.Y. McArthur, a.a.O., S. 589. 
In Abbildung C3 werden neben den Bestimmungen der aktuellen DASTM außerdem die historische Entwicklung der vorgeschriebenen Umrechnungskurse gegenübergestellt: die Umrechnungsvorschriften, die vor der Steuerreform 1986 bestanden und DASTM in der ersten Variante. Zwar werden die Regelungen in dieser Arbeit nicht vorgestellt. Sinn und Zweck der Aufstellung ist vielmehr, zu verdeutlichen, in welchem Ausmaß in der aktuellen DASTM die Umrechnung wieder einer Methode aus der Zeit vor der Reform entspricht, namentlich der „full section 964 method“. Einziger Unterschied ist nämlich der Übergang zu monatsdurchschnittlichen Kursen anstelle von reinen Stichtagskursen (und ein Wahlrecht bei der Umrechnung von Kassenbeständen in Drittwährungen).

In der ersten Fassung der DASTM spielte hingegen die Bilanzierung zu historischen Kursen in Anlehnung an die Methodik des neuen Unterabschnitts J eine wesentlich stärkere Rolle. Bemerkenswert ist dies insbesondere für die Nominalwerte; sowohl Forderungen als auch Verbindlichkeiten waren zu Anschaffungswerten zu bilanzieren.

Auch die oben genannten Schritte zur Aufstellung von Gewinn- und Verlustrechnung und Bilanz wurden in enger Anlehnung an die vor 1986 gültige Methode formuliert, die damals allerdings nur für die Zugriffsbesteuerung abhängiger Auslandsgesellschaften galt. Eine Fortschreibung der Richtlinien war aber konsequent, weil Unterabschnitt F damals schon eine Aufgliederung der Erträge in die verschiedenen Anrechnungskörbe erforderte.

Die Parallelen der DASTM zu der ,full section 964 method“ sind insoweit nicht überraschend. Ziel letzterer war schon vor der Steuerreform von 1986 die getrennte Ermittlung nicht realisierter Währungsgewinne oder -verluste, um sie zur Anrechnung ausländischer Steuern im Verhältnis der Einkünfte auf die Körbe aufzuteilen und damit in den USA der sofortigen Besteuerung zu unterwerfen. ${ }^{273}$ Jetzt ist freilich der Anknüpfungspunkt die ausländische Geldentwertung und nicht die rechtliche Erscheinungsform des Auslandsengagements.

Überraschend sind die Änderungen in der Zwischenzeit. Vermutlich wurde hier versucht, mit dem konsequenten Zugrundelegen von historischen Kursen das Vorgehen stärker an der Stichtagmethode zu orientieren. Außerdem stand es den Steuerpflichtigen ja frei, auch die Stichtagmethode zu wählen - eine Option die, wie gesagt, vielfach genutzt wurde. Seitens der Finanzverwaltung gab es deshalb die Befürchtung, das Wahlrecht könne zu Lasten des Fiskus mißbraucht werden. ${ }^{274}$ Die endgültige DASTM gewährt nun die Anerkennung nicht realisierter Währungserfolge bei Fremdfinanzierungsinstrumenten, aber eben kein Wahlrecht mehr.

Aus allokativen Überlegungen ist dies vorteilhaft, da das Recht nicht Möglichkeiten bot, durch Vermeidung von Anrechnungsüberhängen die Steuerlast auf die Höhe inländischer Anlagen zu mindern. Vielmehr betraf die Wahl den Besteuerungszeitpunkt. Im übrigen entspricht die jetzt gegebene konsequente Trennung des Umrechnungskurses nach monetären Positionen und nichtmonetären Aktiva dem Ergebnis der theoretischen Überlegungen am Anfang dieses Unterabschnitts.

Neuerungen gegenüber der DASTM von 1989 und der „full section 964 method“ wurden vorrangig betreffend die Berechnung sowie die Zurechnung und Aufteilung des Währungsgewinns eingeführt. „Diese Bestimmung ist absichtlich umfangreich. Auf Einfachheit der Buchfuihrung wurde zugunsten von Zuordnungsvorschriften verzichtet, die den Inhalt des Einkommensteuergesetzes umsetzen und damit Verzerrungen reduzieren, die die vorangegangene DASTM belasteten." 275

273 U. Woywode, a.a.O., S.701.

274 S.R. Lainoff u. T.Y. McArthur, a.a.O., S.595.

275 S.R. Lainoff u. T.Y. McArthur, a.a.O., S. 591 (eigene Übersetzung). Für QBU, deren Gesamtkapital am Jahresende nicht mehr als $\$ 10$ Millionen beträgt, kann eine vereinfachte DASTM angewendet werden, 
Zur Zurechnung und Aufteilung des Währungserfolgs - und nur zu diesem Zweck - sind folgende neun Schritte vorgeschrieben:276

Gemäß Schritt (i) ist wenigstens alle drei Monate eine Bilanz nach dem im Text beschriebenen Verfahren zur Bestimmung des DASTM Währungserfolgs aufzustellen. Bei QBU mit saisonal stark schwankenden Aktivitäten würde die Aufteilung des Währungserfolgs nach Maßgabe der Bilanzpositionen nur eines Stichtags im Jahr zu ungenau sein.

Schritt (ii) schreibt vor, Finanzaktiva und -passiva - genau: die §988-Umsätze sowie Rückstellungen - aller Bilanzen des Steuerjahres zu markieren.

In den Schritten (iii) und (iv) ist der Währungsverlust zu berechnen, der Einkünften aus Finanzaktiva zuzurechnen ist. Die monetären Aktiva der QBU - nichtmonetäre Positionen werden nicht einbezogen, da sie ja zum historischen Wechselkurs umzurechnen sind - sind in Ertragskategorien beziehungsweise zu Gruppen zusammenzufassen; hierfür wird auf die Regeln zur Zurechnung und Aufteilung von Zinsaufwendungen zurückgegriffen. ${ }^{277}$ Der Währungsverlust jeder einzelnen Gruppe wird anschließend auf dem Weg einer einfachen Durchschnittsrechnung quantifiziert; bezüglich des Zeitraums, den sich die Vermögenswerte in den Büchern der QBU befanden, wird innerhalb der verkürzten Bilanzperioden nicht differenziert. In Schritt (v) ist der errechnete Währungsverlust schließlich auf die Einkünfte der Aktiva ${ }^{278}$ aufzuteilen.

So werden einerseits hohe nominale Zinseinkünfte einer Kategorie zum Zwecke der Besteuerung durch die USA direkt und ohne Obergrenze durch den Verlust infolge der Wechselkursentwicklung reduziert. Andererseits können dadurch erhebliche Anrechnungsüberhänge in einzelnen Körben entstehen, sollte das Steuersystem des Auslands keine Indexierung vorsehen. Aber auch, wenn dies nicht erwartet wird, diskriminiert die damit verbundene Eventualforderung des Staates gegenüber Kapitalexport, sofern ein Anrechnungsüberhang nicht ausgeschlossen ist. Allerdings kann die neutrale Alternative der Bestimmung des Inlands als Quelle des Währungserfolgs hier erhebliche Steuerausfälle bei anderen inländischen Einkünften zur Folge haben. Es würde hier besonders de facto die Erstattung der ausländischen Steuer durch den inländischen Fiskus bedeuten.

In den Schritten (vi) bis (viii) sind in gleicher Weise die Währungsgewinne zu kalkulieren, die den im zweiten Schritt markierten Verbindlichkeiten der QBU zuzurechnen sind und auf indirektem Wege nach Maßgabe der Aktiva des Steuerpflichtigen weltweit aufgeteilt oder zugerechnet werden. ${ }^{279,} 280$ Auch hier besteht keine Begrenzung bezüglich der Höhe des aufzuteilenden Währungsgewinns. Sollte ein Währungsgewinn in einer Periode die Fremdkapitalkosten der QBU übertreffen, hat dies im Ergebnis zur Folge, daß der QBU Aufwendungen aus Aktivitäten des Steuerpflichtigen in anderen Ländern zugerechnet werden.

dernach der Währungserfolg (das heißt der „DASTM gain or loss“) im Verhältnis der Einkünfte in den Anrechnungskörben aufgeteilt wird. Reg. $\$ 1.985-(\mathrm{e})(\mathrm{i})$, (iv).

${ }^{276}$ Reg. $\$ 1.985-3($ e)(3)(i)-(ix); S.R. Lainoff u. T.Y. McArthur, a.a.O., S.591-594; o.V., New Rules Affecting Hyperinflationary Currency Accounting, a.a.O., S. 274.

${ }^{277}$ Vgl. die Darstellungen auf den Seiten 90 f. dieser Arbeit. In Reg. §1.985-3(e)(3)(iii) wird direkt verwiesen auf die einstweiligen Regelungen zur indirekten Methode der Zurechnung und Aufteilung von Zinsaufwendungen, nämlich Reg. §1.961-9T(g)(3).

${ }^{278}$ Die Einkünfte resultieren aus den Schritten (1) bis (3) der oben dargestellten Erfolgsrechnungen für das Steuerjahr. Reg. $\$ 1.985-3(\mathrm{e})(3)(\mathrm{v})$

279 Unverzinsliche Verbindlichkeiten werden hier nicht einbezogen.

280 Unabhängig von möglicherweise kompensierenden Währungserfolgen bei Aktiva und Passiva ist diese Verrechnung notwendig. Andernfalls könnte Fremdfinanzierung von Aktivitäten einer QBU in dessen inflationärer Währung durch die indirekte Methode der Zurechnung von Zinsaufwendungen im U.S.-Steuerrecht attraktiv erscheinen: Hohe nominale Zinskosten würden auf die weltweiten Aktivitäten des Steuerpflichtigen verteilt und dadurch die Gewinne relativ zur Steuerlast erhöht werden. 
Währungsgewinne bei unverzinslichen Verbindlichkeiten aus empfangenen aber unbezahlten Gütern und Leistungen werden demgegenüber direkt mit dem Preis der Produkte verrechnet, denn es wird unterstellt, die Preiskalkulation beinhalte auch Kapitalkosten. Bliebe dies unberücksichtigt, würden die Kosten überzeichnet. ${ }^{281}$

In einem letzten Schritt (ix) kann es erforderlich sein, einen etwaigen Restbetrag aus den Bilanzen der globalen Rechnungen des ersten Schrittes auf die Gruppen anteilig aufzuteilen.282 Denn die Quantifizierung der Währungsgewinne beziehungsweise -verluste in den Schritten (iv) und (vi) bei den Einzelkategorien beziehungsweise Gruppen geschieht ohne bezug zu dem Ergebnis des Schrittes (i).

Zur Erinnerung: das beschriebene Verfahren ist eine Vereinfachung, nämlich gegenüber einer Buchfuhrung in U.S.-Dollar und der damit verbundenen Umrechnung jeder Einzelposition. Regelungen zur Buchführung in stark inflationären Währungsräumen bewegen sich immer im Spannungsfeld zwischen dem buchhalterischen Aufwand und den Kosten eines ungenauen Ergebnisses. Die Regelungen der Finanzverwaltung tragen dem Rechnung, indem die Bilanzierungszeiträume bis zu einer Obergrenze gewählt werden können. Die Wahl des optimalen Zeitraums ist aber auch eine Funktion der Höhe der Inflation. Die DASTM ist - wie gesagt ab einer Geldentwertung von 100 Prozent in drei aufeinanderfolgenden Jahren vorgeschrieben. Diese Rate wird von einzelnen Staaten weit überschritten.

Der Aufwand bei der Berechnung der Steuer ist indes zu einem wesentlichen Teil auf die übermäßig komplizierten Bestimmungen zur Anrechnung ausländischer Steuern zurückzuführen. Das Anrechnungsverfahren ist der Antrieb der Finanzverwaltung für die Formulierung genauer Regelungen zur Quantifizierung von Währungserfolgen. Es stellt die Ergebnisse aber zugleich in Frage.

\section{Umsatzmethode mit Neuerungen: "Section 988 Transactions“}

Die Umsatzmethode 283 ist seit 1987 für die Quantifizierung von Währungsgewinnen oder -verlusten aus bestimmten Transaktionen in anderen als der funktionalen Währung vorgeschrieben (,section 988 transactions"). ${ }^{284}$ Dies sind:

(i) die Veräußerung von Zahlungsmittelbeständen, Sicht- oder Terminguthaben in nichtfunktionaler Währung (,nonfunctional currency“285) im Tausch gegen andere Vermögenswerte oder gegen Zahlungsmittelbestände, Sicht- oder Terminguthaben in der funktionalen Währung ${ }^{286}$ und

(ii) das Eingehen von Positionen in Finanzierungsinstrumenten mit Fremdkapitalcharakter einschließlich der Buchung von Forderungen oder Verbindlichkeiten von Geschäften, bei

281 S.R. Lainoff u. T.Y. McArthur, a.a.O., S. 593.

282 Nach Maßgabe der relativen Anteile der Bruttoeinkünfte, die sich nach den Korrekturen durch die Schritte (ii) bis (viii) ergeben. Reg. §1.985-3(e)(3)(ix).

${ }^{283} \mathrm{Vgl}$. zu §988-Umsätzen insbesondere M. Dionne u. S. Orme, Foreign Currency Transactions Under the Section 988 Regulations, in: Taxes, 70.Jg. (1992), S.532-550, und auch T.J. O'Neil, a.a.O., S.186-197 sowie R.H. Dilworth u.a., U.S. Tax Treatment of Financial Transactions Involving Foreign Currency, in: Taxes, 66.Jg. (1988), S.1019-1061, die eine Reihe anschaulicher Beispiele beschreiben. Allerdings konnten die Regelungen unter IRC $\$ 988$ nicht berücksichtigt werden, da sie noch nicht existierten.

${ }^{284}$ IRC §988(c)(1)(A); vgl. auch U.S. Senate Finance Committee, Report on H.R. 3838, a.a.O., S. 460.

${ }^{285}$ IRC $\S 988$ (c)(1)(C)(ii); Reg. $\$ 1.988-1(\mathrm{c})$.

${ }^{286}$ Das heißt, ausgenommen sind der Umtausch von Zahlungsmittelbeständen, Sicht- oder Terminguthaben verschiedener nichtfunktionaler Währungen sowie Ein- und Auszahlungen von Sichtguthaben- und Termingeldkonten in nichtfunktionalen Währungen. Reg. §1.988-1(a)(1)(i) u. 2(a)(1)(iii). 
denen Einzahlung und Einnahme beziehungsweise Auszahlung und Ausgabe zeitlich auseinanderfallen und von Terminfestgeschäften, Optionen oder vergleichbaren Kontrakten. ${ }^{287}$

$\S 988$ des IRC und die darunter 1992 in endgültiger Form erlassenen Richtlinien des Finanzministeriums legen Quelle und Art von Einkünften aus §988-Umsätzen sowie zum Teil den Zeitpunkt der Realisierung von solchen Umsätzen fest. Fremdwährungstransaktionen werden, unabhängig davon, ob die qualifizierte wirtschaftliche Einheit ihren Sitz in den USA oder im Ausland hat und ob der U.S.-Dollar oder eine andere funktionale Währung einsetzt wird, in grundsätzlich gleicher Weise nach folgenden generellen Regeln erfaßt:288

Währungsgewinne oder -verluste

- zählen im allgemeinen zu den ordentlichen Einkünften; ${ }^{289}$

- haben ihre steuerrechtliche Quelle im Wohnsitzland des Steuerpflichtigen oder im Sitzland der QBU, in dessen Büchern und Geschäftspapieren die Transaktion ordnungsgemäß erfaßt wurde;290

- werden buchhalterisch getrennt von der Geschäftstätigkeit erfaßt, der Höhe nach aber begrenzt auf den Gewinn beziehungsweise Verlust der zugrundeliegenden Transaktion ${ }^{291}$ und

- werden im Falle eines Kurssicherungsgeschäfts - genau: einer „988 hedging transaction“ mit dem Währungsverlust beziehungsweise -gewinn aus der zu sichernden Position zusammengefaßt. ${ }^{292}$

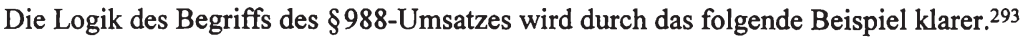

Beispiel C11:

Am 1.1.1989 erwirbt X, eine Kapitalgesellschaft mit Sitz in den USA, 100.000 AM. Die Gesellschaft kauft am 15.1. für die 100.000 AM Aktien, die sie am 1.8.1989 für 120.000 AM veräußert. Am 30.8.1989 schließlich tauscht X den Betrag von 120.000 AM in U.S.-Dollar um.

§988-Transaktionen sind einerseits der Erwerb der 100.000 AM am 1.1. und der Zugang der 120.000 AM am 1.8.1989 zur Quantifizierung der Basis in der ausländischen Währung. Es sind andererseits der Tausch von 100.000 AM am 15.1. und von 120.000 AM am 39.8.1989 zur Ermittlung der Höhe des Währungserfolgs.

Demgegenüber sind weder der Kauf noch der Verkauf der Aktien als §988-Umsätze anzusehen. ${ }^{294}$ Kauf und Verkauf der Aktien sind nämlich genau betrachtet wiederum jeweils zwei separate Transaktionen: Der Kauf ist zu interpretieren als (i) Umtausch des Betrags in nichtfunktionaler Währung gegen den Gegenwert in der funktionalen Währung und (ii) Kauf der Aktien in funktionaler Währung. Umgekehrt gilt für den Verkauf, daß er als (i) Verkauf der Aktien für funktionale Währung und (ii) Umtausch des Betrags in funktionaler Währung

${ }^{287}$ Reg. $§ 1.988-1$ (a)(2)(i), (ii) und (iii). Hierbei ist es hinreichend, daß der Wert einer Positionen bezugnehmend auf den Wechselkurs einer oder auch mehrerer nichtfunktionaler Währungen indexiert ist, auch wenn die Zahlungen selbst nur in der funktionalen Währung erfolgen. IRC §988(c)(1)(A)(ii); Reg. §1.988-1(a)(1)(ii). Ein Beispiel hierzu sind die Doppelwährungsanleihen (,dual currency issues“), bei der die Einzahlung der Anleger beim Kauf der Anleihe sowie die laufenden Zinszahlungen des Emittenten in einer anderen Währung erfolgen als sie Rückzahlung des Anleihebetrages bei Fälligkeit. H.E. Büschgen, Finanzinnovationen - Neuerungen und Entwicklungen an nationalen und internationalen Finanzmärkten, in: Zeitschrift für Betriebswirtschaftslehre, 56. Jg. (1986), S.315.

${ }^{288}$ M. Dionne u. S. Orme, a.a.O., S. 533.

289 IRC $\S 988(a)(1)(A)$.

${ }^{290}$ IRC $\S 988(a)(3)(A)$.

${ }^{291}$ IRC $\S 988(b)(1)$ und (2).

292 IRC $\$ 988(d)$.

293 Reg. $§ 1.988-1(a)(6)$ Beispiel 8.

${ }^{294}$ Laut Gesetzestext (IRC §988(c)(1)(B)(i) i.V.m. §988(c)(4)) können Finanzbehörden auch Vorzugsaktien in $\S 988-U m s a ̈ t z e$ einbeziehen. Dies ist aber nicht geschehen. M. Dionne u. S. Orme, a.a.O., S. 534. 
gegen den Gegenwert in der nichtfunktionalen Währung anzusehen ist. ${ }^{295}$ Das Gesetz geht deshalb zwar ,einen weiten Weg in Richtung der Klarstellung des Rechts in diesem Bereich, es geht aber nicht weit genug." 296

\section{a) Zu nichtmonetären Aktiva}

Ein Grund für diese Regelungen ist die steuerrechtliche Gleichrangigkeit von ausländischer Währung und anderen Aktiva. Die getrennte Ausweisung verschiedener Einflüsse der Änderung des Wertes eines Aktivums ist nicht vorgesehen. Es wird deshalb bei nichtmonetären Aktiva nicht in zwei Stufen separat die Preisentwicklung (i) in der nichtfunktionalen Währung und (ii) infolge einer Wechselkursänderung bestimmt. Lediglich im Rahmen der Stichtagmethode ist dies durch die Zwischenschaltung einer funktionalen Währung möglich.

Ökonomisch ist das Vorgehen indes fragwürdig. Bei handelbaren Gütern ließe sich mit gewissen Einschränkungen rechtfertigen, daß der Währungsraum nur geringen Einfluß auf den Preis eines Vermögenswertes hat. Die Ausfuihrungen zur Kaufkraftparitätentheorie am Anfang dieser Arbeit haben aber deutlich gemacht, wie realistisch diese Annahme im allgemeinen ist. ${ }^{297}$ Ist andererseits der Wert einer Investition in einem Währungsraum durch die diskontierten erwarteten Einzahlungsüberschüsse begründet, ist der dort erwartete Grenzertrag maßgeblich, gleichgültig ob dieser als Einkünfte in Form von Einzahlungen oder in Form eines Veräußerungsgewinnes anfällt. Wenn das Steuerrecht Neutralität hinsichtlich der Investitionsentscheidung nicht verletzten soll, impliziert dies auch gleiche steuerliche Behandlung des Währungsergebnisses aller Anlagealternativen.

Aber wie wäre ein Währungserfolg in diesem Zusammenhang zu quantifizieren?

Der Ertrag einer Auslandsanlage entspricht der Differenz aus dem Vermögen V am Anfang der Periode und am Ende der Periode $\left(\mathrm{V}_{+1}\right)$, jeweils mit dem aktuellen Devisenkurs e beziehungsweise $e_{+1}$ in der heimischen Währung bewertet: $V_{+1} \cdot e_{+1}-V \cdot e$. Dieser Ertrag kann in drei Komponenten aufgespalten werden:298

$$
\begin{aligned}
\mathrm{V}_{+1} \cdot e_{+1}-\mathrm{V} \cdot \mathrm{e}= & \left(\mathrm{V}_{+1}-\mathrm{V}\right) \cdot \mathrm{e} \\
& +\left(\mathrm{e}_{+1}-\mathrm{e}\right) \cdot \mathrm{V} \\
& +\left(\mathrm{e}_{+1}-\mathrm{e}\right) \cdot\left(\mathrm{V}_{+1}-\mathrm{V}\right)
\end{aligned}
$$

Der erste Summand der rechten Seite von Gleichung [C5] quantifiziert den Veräußerungsgewinn im Ausland, bewertet mit dem historischen Wechselkurs, der zweite Summand den Währungsgewinn oder -verlust, der auf das am Anfang der Periode eingesetzte Vermögen entfällt. In Frage steht der dritte Summand; er beziffert den Währungsgewinn oder -verlust beim ausländischen Veräußerungsgewinn. Doch sollte $\left(e_{+1}-e\right) \cdot\left(V_{+1}-V\right)$ nicht als Teil des Währungsergebnisses angesehen werden. Denn ex ante ist dieser Betrag bei einer Grenzinvestition die erwartete Kompensation für eine unterschiedliche Rendite in den beiden Währungsräumen. Es gilt $V_{+1}=\left(1+g p^{*}\right)$, wenn $V=1$. Vorausgesetzt alle Einkünfte werden steuerlich gleich behandelt, entspricht dieses Vorgehen der in Teil B unterstellten Form der

295 J. Isenbergh, International Taxation, 1994 Supplement, a.a.O., S. 526.

296 T.J. O'Neil, a.a.O., S. 188 (eigene Übersetzung).

${ }^{297}$ Schwierigkeiten bereitet eine Trennung von Wăhrungs- und Veräußerungsgewinn gewiß, wenn tatsächlich ein Marktwert in der nichtfunktionalen Währung nicht ermittelt wird; insbesondere wenn ein Vermögenswert - etwa eine gebrauchte Maschine - physisch importiert wird.

298 P.B. Musgrave, Exchange Rate Aspects, a.a.O., S.412. 
Besteuerung. ${ }^{299}$ Dabei ist es gleichgültig, ob der ausländische Bruttoertrag gp als Veräußerungsgewinn oder als ordentliches Einkommen anfällt.

Dies führt wieder zu der Überlegung aus Teil B, dernach Währungsgewinne und -verluste nicht in die Anrechnungsgrundlage einbezogen werden sollten. Demzufolge wäre $\left(e_{+1}-e\right) \cdot V$ als Währungsergebnis inländischen Einkünften zuzurechnen. Unter dieser Voraussetzung würden - unabhängig davon, ob es sich bei der Auslandsanlage um eine Grenzinvestition handelt - die Relationen ausländischer Quellen- und inländischer Einkommen- und Veräußerungsgewinnsteuern nicht verletzt, weil auch im Sitzstaat des Steuerpflichtigen der gleiche relative Zuwachs als Veräußerungsgewinn zugrunde gelegt würde.

Im übrigen würden bei diesem Vorgehen auch der Währungs- und Veräußerungsgewinn bei einzelnen Geschäftsvorfällen auf grundsätzlich gleiche Weise bemessen, wie bei der Stichtagmethode. ${ }^{300}$ Unterschiede ergäben sich dann nur bezüglich des Zeitpunktes der Besteuerung und möglicherweise der Quelle des Währungsergebnisses.

Im Steuerrecht der USA haben Veräußerungsgewinne aus beweglichem Vermögen regelmäßig ihre Quelle am Wohnsitz der verkaufenden Person. Ausländische Steuern sind damit nicht anrechenbar.

Für Gewinne aus dem Verkauf ausländischer Aktien kann ein Doppelbesteuerungsabkommen aber anderes vorsehen. $\mathrm{Da}$ in diesem Fall überdies der Höchstbetrag sowohl zur direkten als auch zur indirekten Anrechnung für einen solchen Gewinn getrennt zu ermitteln ist, ${ }^{301}$ ließe sich eine Diskriminierung dieser Anlageform gegenüber monetären Aktiva reduzieren, wenn das Währungsergebnis inländischen Ursprungs wäre.

Zudem ist auch die Quelle von Gewinnen und Verlusten aus dem Verkauf unbeweglicher Aktiva der Belegenheitsstaat.

Die Investitionen sind deshalb in doppeltem Sinne benachteiligt. Zum einen ist die Anrechnungsgrenze der ausländischen Steuer auf einen Veräußerungsgewinn eine Funktion der Devisenkursentwicklung. Zum anderen sind Veräußerungsverluste nur mit Veräußerungsgewinnen verrechenbar, ganz gleich ob eine Wechselkurs- oder eine Preisänderung im Ausland die Ursache ist.

\section{b) Anlage- und Finanzierungsinstrumente mit Fremdkapitalcharakter}

Im Unterschied zu den im letzten Unterabschnitt betrachteten nichtmonetären Aktiva ist bei Anlageformen mit Fremdkapitalcharakter wie auch bei Verbindlichkeiten eine getrennte Ausweisung von Währungsgewinnen und -verlusten im U.S.-Steuerrecht weniger problematisch, da das Wirtschaftsgut die Währung selbst ist.

Die Erfassung und Berechnung von Währungsgewinnen oder -verlusten von §988-Umsätzen knüpft auf Grund dessen an die Bestimmungen des Einkommensteuergesetzes betreffend den Verkauf oder Tausch von Vermögenswerten an. ${ }^{302}$ Dabei treten allerdings dann Schwierigkeiten auf, wenn zugleich Kursgewinne oder -verluste infolge einer Zinsänderung oder ein Forderungsausfall hinzukommen.

${ }^{299}$ Dies ist im übrigen auch der Betrag, der bei der Stichtagmethode als Periodengewinn ausgewiesen wird.

${ }^{300} \mathrm{Vgl}$. OECD, Tax Consequences of Foreign Exchange Gains and Losses, Issues in International Taxation Nr.3, Paris 1988, S.29; Rz. 88f..

${ }^{301}$ IRC $\S 865(\mathrm{~h})(1)(B)$. Wie in der Fußnote 104 auf Seite 94 des letzten Abschnitts I gesagt, wird durch die Steueränderung von 1997 in Zukunft eine Verrechnung möglich werden.

${ }^{302}$ Reg. $\S 1.988-2(a)(1)(i)$. Verwiesen wird auf IRC $\S 1001,1092$. 
Denkbar sind für monetäre Positionen prinzipiell mehre Ansatzpunkte der Besteuerung. Naheliegend ist - dem Realisationsprinzip entsprechend - die separate Erfassung des angefallenen Währungsergebnisses zum Rückzahlungszeitpunkt oder dessen jährliche Bemessung.

Daneben könnte aber auch zwischen erwarteten und unerwarteten Währungsgewinnen und -verlusten differenziert werden. Unter bestimmten Voraussetzungen sind Zinseinkünfte im U.S.-Steuerrecht zur Bemessung der jährlichen Steuerpflicht in Form eines fiktiven Zahlungsstroms zugrunde zu legen. Ein einfaches Beispiel: Bei einer Null-Kupon-Anleihe werden Zins und Zinseszins thesauriert. Die Verzinsung wird erst im Rückzahlungszeitpunkt zusammen mit dem ursprünglich gezahlten Kapitalbetrag zu einer Ein- beziehungsweise Auszahlung. Dessen ungeachtet schreibt das Steuerrecht der Vereinigten Staaten eine periodische Besteuerung der Verzinsung vor. ${ }^{303}$ Entsprechendes gilt für alle Finanzierungsinstrumente mit einem Ausgabeabschlag (,original issue discount"). ${ }^{304}$

Ein erwarteter Wechselkursanstieg oder -rückgang wird nicht im Sinne dieses Gesetzes interpretiert. Aus der Luft gegriffen ist der Gedanke einer getrennten Erfassung antizipierter Währungserfolge aber nicht. Wie in Teil B angesprochen, wurde diese Möglichkeit in den USA diskutiert. ${ }^{305}$ In den schon erwähnten Vorschlägen des Präsidenten zu der Steuerreform von 1986 hieß es etwa hierzu:

„Im allgemeinen werden Währungsfluktuationen dazu tendieren, Zinsniveauunterschiede zwischen zwei Währungen auszugleichen. [...] Der Mangel im gegenwärtigen Recht, diesen zugrundeliegenden ökonomischen Zusammenhang richtig $\mathrm{zu}$ reflektieren, führt $\mathrm{zu}$ denselben Formen des Nichtzusammenpassens von Einnahmen und Abzügen und der Veränderung des Rückzahlungsbetrages von Fremdkapital, die zu den Bestimmungen zur steuerlichen Behandlung von Ausgabeabschlägen im gegenwärtigen Recht geführt haben." 306

In dem Vorschlag wurde ein Weg zur Bestimmung des Gewinnes oder Verlustes, der antizipierten Wechselkursänderungen zuzurechnen sei, erwogen. Demnach könnte einer periodischen Besteuerung unterliegen: ${ }^{307}$ die Differenz zwischen

- der mit dem historischen Wechselkurs in die funktionale Währung umgerechneten nominalen Ertragsrate der ausländischen Anlage oder des Kredites - also deren interne Verzinsung in nichtfunktionaler Währung -, die zu diesem Zweck zunächst aus dem tatsächlichen Zahlungsstrom der Ein- und Auszahlungen der betreffenden Forderungen oder Verbindlichkeiten errechnet werden müßte und

- dem Marktzinsniveau der funktionalen Währung. Ist der U.S.-Dollar die funktionale Währung, wurde konkret die „Federal rate" ${ }^{308}$ für vergleichbare Anlagen oder Kredite in U.S.-Dollar genannt.

Doch ist es schwierig, einen erwarteten Re- oder Deport infolge unterschiedlicher Zinssätze in zwei Währungsräumen immer zweifelsfrei zu quantifizieren; darauf wurde schon hingewiesen. ${ }^{309}$ Genauso wird in dem zitierten Vorschlag eingeräumt, daß der vorgeschlagene Weg der Behandlung von Währungsgewinnen und -verlusten sehr komplexe Regelungen zur Folge

\footnotetext{
${ }^{303}$ Dies trifft jedenfalls auf Steuerpflichtige zu, die ihren Gewinn durch Betriebsvermögensvergleich (,accrual method") bestimmen. Bei Anwendung der Überschußrechnung („cash method") würde dagegen erst zum Zahlungszeitpunkt besteuert werden.

${ }^{304}$ IRC §1273(a). Ausgenommen sind solche Instrumente, bei denen der Ausgabeabschlag 0,25\% multipliziert mit der Gesamtlaufzeit in Jahren nicht übersteigt. IRC §1273(a)(3).

$305 \mathrm{Vgl}$. auch Teil B dieser Arbeit, Seiten $63 \mathrm{f}$. .

${ }^{306}$ R. Reagan, The Presidents Tax Proposals, a.a.O., S. 413 (eigene Übersetzung).

${ }^{307}$ R. Reagan, The Presidents Tax Proposals, a.a.O., S.418.

308 Definiert in IRC $\S 1274$ (d).

${ }^{309}$ Anderer Meinung sind J.Kay u. J.King, a.a.O., S.55.
} 
haben müßte. Die Vorschläge verschwanden deshalb in der Schublade. ${ }^{310}$ Dieser Entschluß wurde durch die Analyse des Teils B bestätigt.

Zudem sind die Bestimmungen zu den §988-Umsätze auch so schon komplex:

\section{ఎ) §988-Währungsgewinn oder -verlust}

Im Gesetzestext ist ein Währungsgewinn definiert als

,jeder Gewinn aus einem §988-Umsatz, soweit dieser Gewinn nicht den Gewinn übersteigt, der aufgrund von Veränderungen der Wechselkurse am oder nach dem Buchungsdatum und vor dem Zahldatum realisiert wurde".311

In entsprechender Weise wird daran anschließend ein Währungsverlust festgelegt. ${ }^{312}$ Unter dem Buchungsdatum ist in diesem Kontext der Tag zu verstehen, an dem eine offene Fremdwährungsposition in die Bücher aufgenommen oder, bei Termingeschäften, eingegangen wird; das Zahldatum ist der Zeitpunkt, an dem die Transaktion abgeschlossen wird. ${ }^{313}$

Währungserfolge aus $§ 988$-Umsätzen sind laut Gesetzestext ${ }^{314}$ separat zu berechnen. Das Ergebnis der Berechnung nach der oben zitierten Definition kann allerdings etwas eigenartig sein: Währungsgewinne und -verluste werden hierdurch - wie schon erwähnt - der Höhe nach begrenzt auf den Gewinn beziehungsweise Verlust der zugrundeliegenden Transaktion. ${ }^{315}$ Ein darüber hinausgehender Gewinn oder Verlust ist in bezug auf Quelle und Art der Position selbst zuzurechnen. ${ }^{316}$

Die Regelungen sehen vor, Währungsgewinne oder -verluste einzubeziehen bei dem Nennwert beziehungsweise der Zahlung am Buchungsdatum (,principal“") ${ }^{317}$ und gegebenenfalls auch bei aufgelaufenen, aber noch nicht fälligen Zinsen; besonders im Fall vorzeitiger Veräußerung eines Papiers. ${ }^{318,} 319$

Zinserträge oder -aufwendungen aus Fremdwährungskassapositionen zählen nicht zu den Gewinnen, die bei der Quantifizierung des Währungserfolges im Sinne des zitierten Gesetzestextes einzubeziehen sind. Sie werden zur Besteuerung mit dem aktuellen Kurs ${ }^{320}$ zum Zeitpunkt der Zahlung konvertiert. ${ }^{321}$ Ein Währungserfolg entsteht zumindest dann nicht, wenn

${ }^{310}$ R. Reagan, The Presidents Tax Proposals, a.a.O., S.418; U.S. House Ways and Means Committee, House Ways and Means Committee Report, a.a.O., S.467; J. Bourne Wahl, Tax Treatment of Foreign Exchange Gains and Losses and the Tax Reform Act of 1986, a.a.O., S.61. Vgl. auch OECD, a.a.O., S.19f.; Rz. 46.

311 IRC §988(b)(1) (eigene Übersetzung).

312 IRC $\$ 988(\mathrm{~b})(2)$.

313 IRC $\$ 988(c)(2)$. Für Forderungen und Verbindlichkeiten in nichtfunktionaler Währung, die im Rahmen des Kaufs und Verkaufs von Gütern und Leistungen bei der gewöhnlichen Geschäftstätigkeit entstehen, besteht die Möglichkeit einer (höchstens) vierteljährigen Pauschalermittlung der Währungserfolge des Zeitraums (,spot rate convention"). Reg. §1.988-1(d)(3).

314 IRC $\S 988(a)(1)(A)$.

315 IRC $\$ 988(b)(1)$ und (2); J. Isenbergh, International Taxation, Teil II, a.a.O., S.302; M. Dionne u. S. Orme, a.a.O., S.533.

${ }^{316}$ R.P. Keck u. J.F. Montgomery, a.a.O., S.154.

${ }^{317}$ Reg. §1.988-2(b)(5) für Gläubiger, Reg. §1.988-2(b)(6) für Schuldner.

${ }^{318}$ Reg. $\$ 1.988-2(b)(8)$.

${ }^{319} \mathrm{Da}$ Transaktionen von Aktien nicht erfaßt werden, ist es erforderlich, bei Wandelanleihen am Zeitpunkt der Wandlung einen Währungserfolg (aber nur einen Währungserfolg) bezogen auf den Nennwert der Anleihe bei Gläubigern und Schuldnern zu realisieren. Andernfalls würde unter Umständen auch ordentliches Einkommen aus einem §988-Umsatz dauerhaft in einen Kapitalgewinn oder -verlust gewandelt und darüber hinaus deren Quelle geändert. Reg. $\$ 1.988(b)(13)(i) ;$ M. Dionne u. S. Orme, a.a.O., S.540.

320 Der Begriff Kassakurs (,spot rate“) wird für IRC $\S 988$ in Reg. $\$ 1.988-1(d)(1)$ definiert.

${ }^{321}$ Reg. $§ 1.988-2$ (b)(2)(ii)(B). 
der tatsächliche und der zur Bemessung der jährlichen Steuer zugrunde zu legende Zahlungsstrom übereinstimmen.

Bei steuerlich zu antizipierenden Zinserträgen eines Gläubigers, wie etwa bei Null-KuponAnleihen, ist eine Differenz zwischen (i) dem Wert in funktionaler Währung der tatsächlichen und (ii) der antizipierten Beträge aber als Währungserfolg anzusehen. ${ }^{322}$

Entsprechend ist bei vorab als Aufwendung von den Bruttoeinkünften abgezogenen Fremdkapitalkosten eines Schuldners die Differenz zwischen dem Wert in funktionaler Währung der antizipierten und der tatsächlichen Zahlung ein Währungserfolg. ${ }^{323}$ Die antizipierten Zinszahlungen sind mit dem durchschnittlichen Kurs für den Zeitraum zu konvertieren, in dem sie wirtschaftlich entstanden sind. ${ }^{324}$

Zur Bestimmung des $§ 988$-Währungsergebnisses wird der Ausgabepreis der Anleihe oder des Kredits um die zum durchschnittlichen Kurs umgerechneten antizipierten Beträge korrigiert ${ }^{325}$ und der thesaurierte Zins und Zinseszins bei deren Fälligkeit oder Veräußerung einbezogen. 326

Die Ergebnisse dieser Bestimmungen des U.S.-Steuerrechts werden mit Hilfe der folgenden Beispiele veranschaulicht:

Beispiel C12:327

Am 1.1.1995 erwirbt die Kapitalgesellschaft X mit Sitz in den USA 10.000AM für $\$ 10.000$. X kauft am gleichen Tag für diesen Betrag 100 ausländische Anleihen mit einem Nennwert von 100AM, einer Laufzeit bis zum 31.12.1996 und einem jährlichen Kupon von $7 \mathrm{AM}$.

Auch dieses Mal werden die bekannten Wechselkurse unterstellt, nämlich 1,028 \$/AM am 31.12.1995 und 1,057\%/Am am 31.12.1996.

Als Zinseinkünfte steuerpflichtig sind

$\$ 719,60=700 \mathrm{AM} \cdot 1,028 \mathrm{~S} / \mathrm{AM}$ am $31.12 .1995^{328}$ und

$\$ 739,90=700 \mathrm{AM} \cdot 1,057 \mathrm{\$} / \mathrm{AM}$ am 31.12.1996.

Der Währungsgewinn, der am 31.12.1996 realisiert wird, beläuft sich auf

$\$ 570,00=10.000 \mathrm{AM} \cdot(1,057 \mathrm{~S} / \mathrm{AM}-1 \mathrm{~S} / \mathrm{AM})$ beim Nennwert. ${ }^{329}$

$\mathrm{Da}$ ein Kursgewinn oder -verlust in $\mathrm{AM}$ - etwa infolge einer Zinsänderung oder einer schlechteren Bonität des ausländischen Schuldners - nicht entstanden ist, übersteigt der gesamte Gewinn aus der Anleihe nicht den Gewinn, der aufgrund von Veränderungen der Wechselkurse am oder nach dem Buchungsdatum und vor dem Zahldatum realisiert wurde und ist infolgedessen als Währungsgewinn anzusehen.

${ }^{322}$ Reg. §1.988-2(b)(2)(ii)(C). Für Steuerpflichtige, die nach der Methode des Betriebsvermögensvergleiches ihre Bemessungsgrundlage ermitteln, sind auch bei periodischer Verzinsung unter Umständen Währungserfolge bei zwischenzeitlich antizipierten Zinszahlungen zu ergänzen. Auch diese antizipierten Zahlungen sind zunächst zum durchschnittlichen Kurs für den jeweiligen Zeitraum umzurechnen. Am effektiven Zinszahlungszeitpunkt wird steuerlich eine Differenz zwischen dem Durchschnitts- und dem Kassakurs als weiterer Währungsgewinn oder -verlust realisiert. Auf diesen Aspekt wird im Text der Arbeit aber nicht weiter eingegangen.

${ }^{323}$ Reg. §1.988-2(b)(3) für Gläubiger, Reg. §1.988-2(b)(4) für Schuldner.

${ }^{324}$ Reg. $\$ 1.988-2$ (b)(2)(ii)(C). Vgl. auch die kritischen Ausfuhrungen auf den Seiten 108f. dieser Arbeit.

325 Reg. §1.988-2(b)(7); vgl. auch Reg. §1.988-2(b)(9) Beispiel 10.

326 Reg. $\$ 1.988-2(\mathrm{~b})(8)$.

$327 \mathrm{Vgl}$. auch Reg. §1.988-2(b)(9) Beispiel 2.

${ }^{328}$ Im Falle einer Null-Kupon-Anleihe mit einem Rückzahlungsbetrag von $100 \cdot 1,07^{2}=11.449 \mathrm{AM}$, müßte die Gesellschaft am Ende des Jahres 1995 gemäß IRC §1272 eine fiktive Zinszahlung von 700AM zur Besteuerung zum durchschnittlichen Kurs in U.S.-\$ umrechnen, also nur $\$ 709,80$.

${ }^{329}$ Für die Null-Kupon-Anleihe der vorangegangenen Fußnote sähe die Rechnung etwas anders aus: Als Zins steuerpflichtig wäre ein Betrag von 749 AM $\cdot 1,057 \mathrm{~s} / \mathrm{AM}=\$ 791,69$ (darin ist eine Verzinsung des Zinsertrages der ersten Periode enthalten). Es entstünde außerdem ein zusätzlicher Währungsgewinn durch die fiktive Zinszahlung in 1995 in Höhe von $700 \mathrm{AM} \cdot(1,057 \mathrm{~s} / \mathrm{AM}-1,014 \mathrm{~S} / \mathrm{AM})=\$ 30,10$. Vgl. auch Reg. $\S 1.988-2($ b) $(9)$ Beispiel 7 für eine Rechnung zu Null-Kupon-Anleihen. 
Interessanter ist das Ergebnis in folgendem Fall: ${ }^{330}$

Beispiel C13:

$\mathrm{X}$ erwirbt am 1.1.1995 für 10.000 AM 100 ausländische Anleihen mit einem Nennwert von 100 AM, einer Laufzeit bis zum 31.12.1997 und einem jährlichen Kupon von 7AM. Schon am 31.12.1996 verkauft die Gesellschaft die Anleihen, direkt nach der Zinszahlung. Infolge eines Anstiegs des Zinsniveaus im Ausland beträgt der Erlös aber nur 98,06AM.

Angenommen wird außerdem, daß der Kassakurs zu diesem Zeitpunkt infolge einer nicht erwarteten Wechselkursänderung bei 1,03\%/M liegt.

Als Zinseinkünfte steuerpflichtig sind wiederum

$\$ 719,60=700 \mathrm{AM} \cdot 1,028 \mathrm{~s} / \mathrm{M}$ am 31.12.1995 und hier

$\$ 721,00=700 \mathrm{AM} \cdot 1,03 \mathrm{~s} / \mathrm{AM}$ am 31.12.1996.

Der Währungsgewinn, der am 31.12.1996 realisiert wird, beläuft sich auf

$\$ 300,00=10.000 \mathrm{AM} \cdot(1,03 \mathrm{~S} / \mathrm{AM}-1 \mathrm{~S} / \mathrm{AM})$ bezogen auf den Nennwert.

Der Veräußerungserlös beträgt aber nur $\$ 10.100(=9.806 \mathrm{AM} \cdot 1,03 \mathrm{~S} / \mathrm{AM})$, der Gewinn der Gesellschaft X mithin \$100. Das Steuerrecht schreibt vor, diesen Gewinn zur Gänze und ausschließlich als Währungsgewinn anzusehen, ${ }^{331}$ weil dies der gesamte Gewinn aus dem $§ 988$ Umsatz ist und die Summe nicht den Gewinn übersteigt, der aufgrund von Veränderungen der Wechselkurse am oder nach dem Buchungsdatum und vor dem Zahldatum realisiert wurde.

Das Ergebnis dieses Beispiels C13 ist in der folgenden Abbildung C4 in Zeile [7] zusammen mit anderen Kombinationen aus Währungs- und Veräußerungsergebnis eingetragen. Durch die Gegenüberstellung der verschiedenen Resultate wird die Systematik der Regelung zur Quantifizierung von §988-Währungsgewinnen sichtbar:

Abb. C4: Aufteilung eines Gewinnes oder Verlusts aus einem §988-Umsatz auf §988-Währungsgewinne und sonstige Verăußerungsgewinne.

\begin{tabular}{|c|c|c|c|c|c|}
\hline & $\begin{array}{l}\text { Ergebnis bei d } \\
\text { [A] } \\
\text { Währungsgewinn/ } \\
\text {-verlust }\end{array}$ & $\begin{array}{l}\text { Veräußerung } \\
\qquad \text { [B] } \\
\text { Veräußerungs- } \\
\text { gewinn/-verlust }\end{array}$ & $\begin{array}{c}{[C]} \\
\text { Summe } \\
{[A]+[B]=[D]+[E]}\end{array}$ & $\begin{array}{l}\text { Ergebnis na } \\
\text { [D] } \\
\text { §988-Wăhrungs- } \\
\text { gewinn/-verlust }\end{array}$ & $\begin{array}{c}\text { ch IRC } \$ 988 \\
\text { [E] } \\
\text { Restlicher Gewinn } \\
\text { oder Verlust }\end{array}$ \\
\hline [1] & $\$ 200$ & $\$ 200$ & $\$ 400$ & $\$ 200$ & $\$ 200$ \\
\hline [2] & $\$ 100$ & $\$ 200$ & $\$ 300$ & $\$ 100$ & $\$ 200$ \\
\hline [3] & $\$ 0$ & $\$ 200$ & $\$ 200$ & $\$ 0$ & $\$ 200$ \\
\hline [4] & $-\$ 100$ & $\$ 200$ & $\$ 100$ & $\$ 0$ & $\$ 100$ \\
\hline [5] & $-\$ 200$ & $\$ 200$ & $\$ 0$ & $\$ 0$ & $\$ 0$ \\
\hline [6] & $-\$ 300$ & $\$ 200$ & $-\$ 100$ & $-\$ 100$ & $\$ 0$ \\
\hline [7] & $\mathbf{\$ 3 0 0}$ & $-\$ 200$ & $\$ 100$ & $\$ 100$ & So \\
\hline [8] & $\$ 200$ & $-\$ 200$ & $\$ 0$ & $\$ 0$ & $\$ 0$ \\
\hline [9] & $\$ 100$ & $-\$ 200$ & $-\$ 100$ & $\$ 0$ & $-\$ 100$ \\
\hline [10] & $\$ 0$ & $-\$ 200$ & $-\$ 200$ & $\$ 0$ & $-\$ 200$ \\
\hline [11] & $-\$ 100$ & $-\$ 200$ & $-\$ 300$ & $-\$ 100$ & $-\$ 200$ \\
\hline [12] & $-\$ 200$ & $-\$ 200$ & $-\$ 400$ & $-\$ 200$ & $-\$ 200$ \\
\hline
\end{tabular}

Quelle: Eigene Darstellung.

Die Folgen dieser Abgrenzung eines Währungserfolges aus §988-Umsätzen können indes erst beurteilt werden, wenn auch deren steuerliche Behandlung bekannt ist. Es wird ja nicht die Höhe des Gewinns oder Verlustes insgesamt begrenzt, sondern nur der Teil identifiziert, der als Währungsgewinn oder -verlust angesehen werden muß.

${ }^{330} \mathrm{Vgl}$. auch das Beispiel 5 der Reg. $§ 1.988-2(\mathrm{~b})(9)$ in dem als Ursache für den Verlust Zahlungsunfähigkeit des Schuldners unterstellt wird.

331 Vgl. J. Isenbergh, International Taxation, Teil II, a.a.O., S.302f. . 


\section{ß) Quelle und Art des Währungsergebnisses}

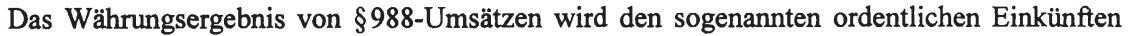
zugerechnet. ${ }^{332}$ Dies wurde abgeleitet aus der Erkenntnis, Währungserfolge seien mit Zinseinkünften vergleichbar (,interest equivalence“) und keine Veräußerungsgewinne und infolgedessen auch nicht so zu charakterisieren. ${ }^{333}$

Quelle ist das Sitzland des Steuerpflichtigen beziehungsweise der QBU des Steuerpflichtigen, in deren Büchern das Aktivum oder die Verbindlichkeit geführt wurde. ${ }^{334}$

Die Wirkungen der oben beschriebenen Einschränkung des Währungsgewinnes oder -verlustes werden damit erkennbar:

Soweit ein Währungs- und ein Veräußerungsgewinn in fremder Währung (Zeilen [1] bis [3] in Abbildung C4) oder ein Währungs- und ein Veräußerungsverlust (Zeilen [10] bis [12]) zusammentreffen, ist das Resultat im Sinne der Analyse des Teils B korrekt. Das Währungsergebnis wird richtig quantifiziert und zählt zu den inländischen Einkünften. Nur der Veräußerungserlös ist ausländischen Ursprungs, wie ein Vergleich der Spalten [B] und [E] zeigt.

Entsteht indes ein Währungsverlust und gleichzeitig ein Veräußerungsgewinn in fremder Währung, wird die Anrechnungsgutschrift verändert, da der Währungsverlust mit dem Veräußerungsgewinn verrechnet wird. Der ausländische Erlös ist gemäß U.S.-Steuerrecht geringer als der tatsächliche Veräußerungsgewinn, wie in Zeilen [4] bis [6] ablesbar. Die Gefahr eines Anrechnungsüberhangs wird tendenziell erhöht, soweit das Ausland diesen Gewinn besteuert. Allerdings kommt es auch nicht zu der indirekten effektiven Erstattung ausländischer Steuern durch die USA.

Spiegelbildlich ist die Situation für einen Währungsgewinn, der mit einem Verlust im Ausland zusammenfällt. So wird verhindert, daß im Inland ein Gewinn und im Ausland ein Verlust realisiert wird. In Beispiel $\mathrm{C} 13$ etwa würden andernfalls ausländische Einkünfte um $\$ 200$ (= $194 \mathrm{AM} \cdot 1,03 \mathrm{~S} / \mathrm{AM})$ gemindert, gleichzeitig aber das inländische Einkommen um $\$ 300$ erhöht. Statt dessen wird nun ein inländischer Gewinn von $\$ 100$ errechnet. $^{335}$ Sollte im Ausland die Möglichkeit eines Verlustabzugs gegeben sein, kann es hierbei allerdings zu einer Minderbesteuerung kommen.

Da die Quellenregel für monetäre Aktiva und Passiva in gleicher Weise gilt, fallen auch erwartete Währungserfolge, die durch Fremdfinanzierung verursacht werden, im allgemeinen - wie auch bei einer QBU - nicht unter die Bestimmungen über die Zurechnung von Zinsaufwendungen. ${ }^{336}$

Bei Finanzierung in einer Währung, für die ein Rückgang erwartet wird, stehen sich in diesem Fall aber zwei Effekte gegenüber, deren Nettowirkung einzelfallabhängig ist. Einerseits gehen gemäß der Zinsparitätentheorie hohe periodische Zinsaufwendungen mit einem zu erwartenden

332 IRC §988(a)(1)(A); Reg. §1.988-3(a).

${ }^{333}$ S.R. Lainoff u. T.Y. McArthur, a.a.O., S. 585.

${ }^{334}$ IRC §988(a)(3); Reg. §1.988-4(a), (b).

${ }^{335}$ Freilich entstehen zumindest bei einer Finanzierung mittels Fremdwährungskrediten -abgesehen vom Währungsergebnis - selten Verluste. Denkbar ist dies allenfalls bei einem Rückkauf selbstemittierter Anleihen oder bei einem Schuldenerlaß. Gängige Praxis war es vor der Steuerreform 1986 allerdings, einen Währungsgewinn bei Verbindlichkeiten als Schuldenerlaß zu interpretieren; so konnte dessen Besteuerung hinausgezögert werden. Die Definition von Währungsgewinnen und -verlusten in IRC §988 ist auch vor diesem Hintergrund zu sehen. Die Formulierung stellt diesbezüglich die Rangfolge jetzt eindeutig klar: nur ein Restbetrag kann als Schuldenerlaß angesehen werden. F.E. White, a.a.O., S.214.

${ }^{336}$ Ausgenommen können gemäß Temp. Reg. §1.961-9T Situationen sein, in denen monetäre Aktiva und Passiva oder Kurssicherungsinstrumente in der gleichen Währung vorliegen. Darauf wird in dem nachfolgenden Unterabschnitt eingegangen. 
Währungsgewinn einher, der erst am Ende der Laufzeit der Besteuerung unterliegt. ${ }^{337,} 338$ Auf der anderen Seite werden die Fremdkapitalkosten jedoch auf die weltweiten Aktivitäten des Steuerpflichtigen aufgeteilt. Auf diesem Weg werden Aufwendungen zum Teil ins Ausland geleitet. Der Währungsgewinn fällt indes im Inland an. Das heißt: dem Zinsvorteil des Steueraufschubs stehen geringere ausländische Einkünfte gegenüber.

Interessant erscheint hiernach vor allem die Finanzierung einer ausländischen QBU mit Fremdkapital aus einem inflationären dritten Währungsraum. So werden Währungsgewinne im Ausland realisiert, die Zinsaufwendungen aber möglicherweise teilweise dem Inland zugerechnet. Das heißt: es ist ein Zinsvorteil zu erwarten, und die ausländischen Einkünfte werden erhöht - und Kapitalexport durch die USA wird zugunsten ausländischer Fremdfinanzierung diskriminiert.

Denkbar ist auch die Finanzierung in einer Währung, deren Zinsniveau niedriger ist als die Fremdkapitalkosten in den USA. Dies ist der einfachste Weg, um ausländische Einkünfte zu erhöhen, da der gleichzeitig erwartete Währungsverlust im Inland anfällt. ${ }^{339}$ Angesichts des niedrigen Zinsniveaus und der geringen Inflationserwartungen in den USA ist es aber fraglich, ob dieser Möglichkeit derzeit nennenswerte Bedeutung zukommt. Dennoch wird nicht ausgeschlossen, daß die Bundessteuerbehörden die einstweiligen Richtlinien ${ }^{340}$ umschreiben, um Vorsorge zu treffen, daß Währungsverluste bei der Zurechnung von Aufwendungen wie Zinseinkünfte zu behandeln sind. ${ }^{341} \mathrm{Im}$ Gesetzestext wird dem Finanzminister die Möglichkeit dazu ausdrücklich eingeräumt. ${ }^{342}$

Übrigens hieß es in einem ersten Entwurf des Gesetzestextes noch, soweit Währungsgewinne und -verluste den ordentlichen Einkünften zugerechnet würden, seien diese generell wie Zinsen zu behandeln, und auch die Quelle sei in derselben Weise zu bestimmen. ${ }^{343}$ Der Weg wurde vorgeschlagen, um darauf verzichten zu können, erwartete und nicht erwartete Währungserfolge getrennt ermitteln zu müssen. ${ }^{344}$ Und: es ,ist eine pragmatische Antwort auf eine Frage, bei der Finanzwissenschaftler und Praktiker unterschiedlicher Auffassung sind." 345 Deren allgemeine Interpretation als inländische Einkünfte ist speziell im Rahmen des Steuerrechts der USA aber die bessere Lösung: Auswirkungen von Wechselkursänderungen auf ausländische Aktiva und Passiva werden auf einfache Weise gegeneinander verrechnet, ohne in verschiedenen Körben zu landen und entweder als zugerechnete Aufwendungen oder als Zinseinkünfte das ausländische Einkommen relativ zur ausländischen Steuerlast zu verändern. ${ }^{346}$

Wären andererseits Währungsverluste generell ausländischen Ursprungs, könnten große Schwankungen der Wechselkurse die ausländischen Gewinne eines Jahres relativ zu den anrechenbaren ausländischen Steuern stark reduzieren; „die Wirkung auf ein einzelnes Jahr

${ }^{337}$ ONeil schlägt deshalb vor, eine Amortisation des erwarteten Währungsgewinnes vorzuschreiben, wenn die Inflationsrate der Währung, in der finanziert wird, mehr als $15 \%$ beträgt. T.J. O'Neil, a.a.O., S.194.

${ }^{338}$ Die Attraktivität dieser Möglichkeit wird nur für Steuerpflichtige mit Einkünften in mehreren Ländern dadurch eingeschränkt, daß die Zinsaufwendungen pro rata auf alle Aktiva aufgeteilt werden, der Währungsgewinn demgegenüber nur in dem Land anfällt, für das das Fremdkapital aufgenommen wurde.

${ }^{339}$ M. Dionne u. S. Orme, a.a.O., S.543, Fn. 117.

340 Temp. Reg. §1.961-9T; IRC §864(e)(7).

${ }^{341}$ M. Dionne u. S. Orme, a.a.O., S.543, Fn.117. Dies ist bisher nicht geschehen.

342 IRC $\S 988(a)(1)(B)$. In IRC §988(a)(1)(A) wird der Steuerbehörde außerdem auch gestattet, Gewinne oder Aufwendungen nicht dem ordentlichen Einkommen zuzurechnen.

343 U.S. House Ways and Means Committee, Tax Reform Bill of 1985, a.a.O., Sp.472, §988(a)(2), (3).

344 U.S. House Ways and Means Committee, House Ways and Means Committee Report, a.a.O., S.467.

345 U.S. House Ways and Means Committee, House Ways and Means Committee Report, a.a.O., S.467 (eigene Übersetzung); so auch in U.S. Senate Finance Committee, Report on H.R. 3838, a.a.O., S. 452.

${ }^{346}$ R. Henrey, H.R. 3838 and Foreign Currency Rules Reform, a.a.O., S. 173. 
kann dramatisch sein“. ${ }^{347}$ Der Einfluß eines solches Steuersystems ex ante auf die Allokationsentscheidung von Kapitalanbietern in jedem Jahr wurde in Teil B analysiert. Demnach ist zwar der Effekt nicht so dramatisch wie die Beobachtung im ungünstigen Fall ex post vermuten lassen mag. Dennoch: würden Währungserfolge in die Anrechnungsgrundlage einbezogen, müßte die erwartete Rendite ausländischer Anlagen signifikant höher sein als bei inländischen Alternativen.

Die Legislative hat mit der gewählten Formulierung diesen Bedenken ${ }^{348}$ Rechnung getragen, letztendlich die Entscheidungen aber der Steuerbehörde überlassen. In den Regelungen des Finanzministeriums wurde von dieser Option bislang nur im Zusammenhang mit Kurssicherungstransaktionen Gebrauch gemacht. ${ }^{349,} 350$

\section{c) Währungstermingeschäfte}

Zu den § 988-Umsätzen zählen auch Terminfestgeschäfte, Optionen und weitere vergleichbare Kontrakte, wenn deren letztendlich zugrundeliegender Vermögenswert eine nichtfunktionale Währung ist.

Andere Instrumente - etwa ein Termingeschäft, das zum Kauf oder Verkauf von Waren oder Aktien in einer nichtfunktionalen Währung verpflichtet - werden ausdrücklich nicht einbezogen. ${ }^{351}$ Denn bei diesen Positionen ist der Gewinn oder Verlust nicht nur von der Entwicklung der Währung abhängig, sondern auch von dem Preis des zugrundeliegenden Wirtschaftsgutes.

Kapitalanbieter können mit solchen Finanzinstrumenten auf einfache Weise die Risikostruktur ihren individuellen Präferenzen anpassen, indem sie Teile des Risikos ihrer Fremdwährungspositionen abgeben. Beispielsweise kann das Währungsrisiko einer Fremdwährungsanleihe mit einem Termingeschäft abgesichert werden.

Kapitalnachfrager können demgegenüber, wie in Teil B dargestellt wurde, durch eine Veränderung der Kapitalstruktur ihre Kapitalkosten nicht senken, es sei denn, es ist möglich, dadurch Zahlungen an Dritte zu mindern. Dies sind neben Transaktionskosten namentlich Zahlungen an den Fiskus.

${ }^{347}$ R. Henrey, H.R. 3838 and Foreign Currency Rules Reform, a.a.O., S. 173 (eigene Übersetzung).

${ }^{348}$ Denkbar ist aber noch ein weiterer Grund: Durch die gewählte einheitliche Charakterisierung von Währungsgewinnen und -verlusten wird verhindert, daß Steuerpflichtige den Ort von Fremdwährungsgeschäften nach Maßgabe einer Quellenregel wählen und damit unter Umständen solche Geschäfte nicht an einem U.S.-Finanzplatz oder mit einer amerikanischen Bank abschließen. Die entwickelten Regelungen bewirken eher das Gegenteil, da es insbesondere bei unsicherem Ausgang - und damit dem Risiko eines Verlustes - im Zweifel sinnvoll ist, Einkünfte dort anfallen zu lassen, wo auch steuerlich deren Quelle ist.

${ }^{349}$ Temp. Reg. $\$ 1.961-9$ T und außerdem bei steuerbefreiten Anleihen durch Reg. $\$ 1.988-3(c)$. L.D. Yoder u. S.P. McGill, Subpart F: New Foreign Currency Hedging Exception, in: Taxes, 74.Jg. (1996), Heft 3, S. 150 f..

${ }^{350}$ Eine interessante Ausnahme von der Regel gilt indes für verbundene Unternehmen und hat das Ziel, Versuche einer Manipulation der Anrechnungsgrenzen durch das Ausnutzen solcher Erwartungen hinsichtlich der Währungsentwicklung zu verhindern. IRC §988(a)(3)(C); Reg. §1.988-4(e).

Betroffen sind Kredite von einem Steuerinländer der USA an eine ausländische Tochtergesellschaft, an der ersterer gemäß IRC §988(a)(3)(D) eine Beteiligung von mindestens zehn Prozent der Stimmrechte hält, das heißt deren im Ausland zu zahlende Steuern er indirekt anrechnen kann. Wenn die Kredite nicht in U.S.-Dollar gewährt wurden und wenn deren Verzinsung die mittelfristige „Federal rate“ um mindestens zehn Prozentpunkte übertrifft, ist zum Zwecke der Bestimmung der Anrechnungsgrundlage des Steuerinländers (i) an jedem Bilanzstichtag der Marktwert der Forderung in U.S.-Dollar zu bestimmen und (ii) ein Marktwertverlust - und nur ein Verlust - eines Steuerjahres von den Zinseinnahmen abzuziehen. Auf diesem Weg wird verhindert, daß ein hohes Zinsniveau in dem Sitzland einer QBU genutzt wird, um Erträge zu generieren, deren Quelle das Ausland ist, wenn zugleich damit in wirtschaftlichem Zusammenhang stehende Währungsverluste im Inland anfallen. F.E. White, a.a.O., S.214; J. Isenbergh, International Taxation, Teil II, a.a.O., S.305.

${ }^{351}$ Reg. $\$ 1.988-1$ (a)(2)(iii)(A). 
Die Umgehung von Steuern ist eine der wesentlichen Intentionen bei der Anwendung und der Entwicklung solcher Finanzierungsinstrumente. ${ }^{352}$ Denkbar sind insbesondere (i) die Variation des Realisierungszeitpunktes, (ii) die Veränderung der steuerlichen Quelle des Einkommens oder (iii) des Charakters als Veräußerungsgewinn beziehungsweise ordentliches Einkommen. ${ }^{353}$ Ein erfolgreicher Versuch des Steuerpflichtigen, die Belastung auf diesem Weg legal zu reduzieren, zeigt Schwächen eines Steuersystems auf.

Nicht weniger bedeutend ist aber auch der Umkehrschluß: Die Entwicklung und der Einsatz solcher Finanzierungsinstrumente führt durch die Senkung von Transaktionskosten zu einer Steigerung der Effizienz der Kapitalmärkte. ${ }^{354}$ Die Funktion der Märkte einer bestmöglichen Kapitalallokation wird infolgedessen eingeschränkt, wenn die Anwendung dieser Instrumente durch die Besteuerung diskriminiert wird. Dafür ist es nicht notwendig, daß die Folge eine ex post größere Steuerlast ist. Schon wenn ex ante Unsicherheit über Höhe der tatsächlichen Steuerlast besteht, kann der Einsatz diskriminiert werden - insbesondere, wenn die Intention des Steuerpflichtigen die Reduzierung anderer Risiken ist.

Die steuerliche Behandlung dieser Instrumente ist insbesondere dann interessant, wenn für bestimmte Kombinationen von Finanzierungsinstrumenten eigene Bestimmungen bestehen, wie hier etwa hinsichtlich $\S 988$-Kurssicherungstransaktionen. Denn es heißt, daß die Regelungen, die für die getrennte Besteuerung der Positionen gelten, zu einem nicht befriedigenden Ergebnis führen, das einer Korrektur bedarf.

Infolge der Komplexität dieses Themenbereichs und der andauernden Fortschreibung der Richtlinien durch die Steuerbehörden ${ }^{355}$ beschränken sich die folgenden Ausführungen allerdings auf Terminfestgeschäfte und die Darstellung der Systematik, soweit dies - auch mit Blick auf die in Teil D folgende Betrachtung des deutschen Steuerrechts - sinnvoll erscheint.

Der Zusammenhang zwischen einer Termin- und einer Kassaposition wurde schon in Teil B auf Seite 46 eingeführt. Anhand des folgenden Beispiels wird er zunächst noch einmal kurz veranschaulicht.

Beispiel C14a:

Am 1.1.1995 erwirbt die Kapitalgesellschaft X mit Sitz in den USA 10.000AM für $\$ 10.000$. X kauft am gleichen Tag für diesen Betrag 100 ausländische Anleihen mit einem Nennwert von 100AM, einer Restlaufzeit bis zum 31.12.1995 und einem jährlichen Kupon von 7AM.

$\mathrm{X}$ entscheidet sich, ein Währungsrisiko auszuschließen, indem sie die zu erwartende Einzahlung von 10.700 AM schon am 1.1.1995 mit einem Devisenterminfestgeschäft (,forward contract") mit Erfüllungstermin am 31.12.1995 verkauft. Eine Anleihe in U.S.-Dollar mit entsprechender Laufzeit und einem jährlichen Kupon von \$10 notiert am 1.1.1995 genau zu \$100.

Der Terminkurs zum Zeitpunkt t für den Tag $t+1\left(f_{t+1}\right)$ errechnet sich gemäß Gleichung [B9b] beziehungsweise [C6] aus dem aktuellen Devisenkurs $e_{t}=1 \mathrm{~S} / \mathrm{AM}$ sowie den Ertragsraten einer inländischen und einer ausländischen Anlage von $1+r_{t+1}=1,1$ beziehungsweise $1+r_{r}{ }^{*}{ }_{t+1}=1,07: 356$

352 Vgl. z.B. J.C. Van Horne, Of Financial Innovations and Excesses, in: Journal of Finance, 40.Jg. (1985), S.622-624; F.D. Finnerty, Financial Engineering in Corporate Finance: An Overview, in: Financial Management, 17.Jg. (1988), S.15f. u. S.24; R.A. Brealy u. S.C. Myers, a.a.O., S.322f..

353 O.H. Jacobs u. J. Haun, Financial Derivatives in International Tax Law - A Treatment of Certain Key Considerations, in: Intertax, o.Jg. (1995), S.405f..

354 J.C. Van Horne, a.a.O., S.621.

355 So sind z.B. neue Richtlinien für Kurssicherungstransaktionen im Rahmen des „Foreign Personal Holding Company“ Einkommen zu IRC $\S 954(c)(1)(D)$ eingeführt worden. Vgl. L.D. Yoder u. S.P. McGill, a.a.O., S. 147-167. Vgl. auch Fußnote 40 auf Seite 86 dieser Arbeit.

356 U.S. House Ways and Means Committee, House Ways and Means Committee Report, a.a.O., S.455f.. 


$$
{ }_{1.1} f_{31.12 .}=\frac{1+r_{t+1}}{1+r_{t} r_{t+1}^{*}} \cdot e_{t}=\frac{1,10}{1,07} \cdot 1 \mathrm{~S} / \mathrm{AM}=1,028 \mathrm{~S} / \mathrm{AM} \text {. }
$$

Der Erlös der Gesellschaft beträgt am Ende des Jahres unabhängig von der tatsächlichen Devisenkursentwicklung \$11.000: Aus dem Verkauf der Anleihen resultiert eine Einzahlung von $10.700 \mathrm{AM}$, die X aufgrund des Termingeschäfts zum Kurs von 1,028\$/AM in U.S.-Dollar umtauschen muß.

Liegt beispielsweise der Kassakurs am 31.12 .1995 bei $0,95 \mathrm{~S} / \mathrm{Am}$, erzielt die Gesellschaft zum einen nur $\$ 10.165=10.700 \mathrm{AM} \cdot 0,95 \mathrm{~S} / \mathrm{AM}$ aus der Rückzahlung der Anleihen. Die separate Betrachtung des Termingeschäfts ergibt indessen einen Gewinn von $\approx \$ 835$, weil der Vertragspartner verpflichtet ist, $10.700 \mathrm{AM}$ für $\$ 11.000 \mathrm{abzunehmen,} \mathrm{obgleich} \mathrm{deren} \mathrm{Marktwert} \mathrm{zu}$ dem Zeitpunkt nur $\$ 10.165$ beträgt.

Im Einkommensteuergesetz heißt es zu Währungsgewinnen oder -verlusten bei Termingeschäften, die einen §988-Umsatz darstellen: , jeder Gewinn oder Verlust aus einer solchen Transaktion ist als Währungsgewinn oder -verlust zu behandeln" . 357 In den Bestimmungen des Finanzministeriums wird dies umgesetzt, indem vom Grundsatz her der Unterschied zwischen dem Wert zum Zeitpunkt der Eröffnung und der Differenzabrechnung oder Lieferung einer solchen Position als Währungserfolg interpretiert wird. ${ }^{358}$

Die separate Definition für einen Währungserfolg bei Termingeschäften ist nachträglich in dem Gesetz ergänzt worden. Die allgemeine, auf Seite 136 zitierte, Formulierung erwies sich nämlich als problematisch, wenn Kassa- und Terminkurs zum Zeitpunkt des Eingehens der Position nicht identisch sind. Ändert sich beispielsweise der Kassakurs während der Haltedauer nicht, läge rechtlich kein Währungsgewinn oder -verlust vor, obgleich tatsächlich infolge der unerwarteten Stabilität des Wechselkurses ein Gewinn beziehungsweise Verlust entstanden ist. 359

Ansonsten werden Termingeschäfte behandelt, wie andere §988-Umsätze. Gewinne und Verluste sind ordentliche Einkünfte ${ }^{360}$, deren Quelle ist das Sitzland des Steuerpflichtigen beziehungsweise der QBU des Steuerpflichtigen.

In dem obigen Beispiel C14a wäre dieser Definition zufolge der Gewinn aus dem Termingeschäft in Höhe von $\$ 835$ als Währungsgewinn inländischen Ursprungs steuerpflichtig, weil dies die Differenz zwischen dem Wert der Position zum Zeitpunkt der Eröffnung $(\$ 11.000)$ und des Abschlusses (\$10.165) ist.

${ }^{357}$ IRC $\$ 988(b)(3)$ (eigene Übersetzung).

${ }^{358}$ Reg. §1.988-2(d)(4)(i); M. Dionne u. S. Orme, a.a.O., S.541.

${ }^{359}$ H.J. Levine u. H. Berger, TAMRA Amendments to the Foreign Currency Rules, in: Tax Management International Journal, 18.Jg. (1989), S.86.

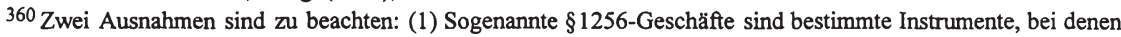
„marked to market“"möglich ist, das heißt, deren Buchwert jederzeit dem Marktwert angepaßt werden kann. Hier gilt das Realisationsprinzip nicht; auch unrealisierte (Währungs-)Gewinne oder Verluste sind steuerpflichtig, und zwar als Veräußerungsgewinne oder -verluste. Der Steuerpflichtige hat ex ante nach IRC $\S 988(\mathrm{c})(1)(D)(i i i)$ die Wahl, das (realisierte und unrealisierte) Währungsergebnis aus sämtlichen §1256-Geschäften als ordentliches Einkommen aus §988-Umsätzen zu versteuern. Vgl. zur Schnittmenge der Regelkreise der IRC §988 und $\S 1256$ R. Henrey, International Tax Aspects, a.a.O., S.315f.; C.D. Farias, Interaction of Foreign Currency Rules and Section 1256 Contracts After the New Section 988 Temporary Regulations, in: Journal of Taxation and Investments, 7.Jg. (1990), S.293-303 u. R.H. Dilworth u.a., a.a.O., S.1027-1030.

(2)Das Währungsergebnis aus einzelnen §988-Umsätzen, die (i) keine standardisierten Terminkontrakte und (ii) als Kapitalvermögen gemäß IRC $\$ 1221$ (,,capital asset") anzusehen sind (also nicht der Geschäftstätigkeit eines Handels oder Gewerbes zurechenbar sind), kann gemäß IRC §988(a)(1)(B) wahlweise als Veräußerungsgewinn oder -verlust versteuert werden.

$\mathrm{Da}$ es sich aber um Wahlrechte handelt, die zudem infolge der Komplexität „Steuerberater noch für viele Jahre glücklich und wohlgenährt am Leben halten" werden, werden die Ausnahmen im Text vernachlässigt. J.F. Chown, a.a.O., S.7 (eigene Übersetzung). 
Dabei sind Anleihenposition und Termingeschäft steuerrechtlich prinzipiell getrennte Transaktionen. Bei der Rückzahlung der 100 Anleihen des Beispiels entstünde demgemäß zugleich ein Währungsverlust von $10.000 \mathrm{AM} \cdot(1 \mathrm{~S} / \mathrm{AM}-0,95 \mathrm{~S} / \mathrm{AM})=\$ 500$.

Aber: Unter bestimmten Gegebenheiten, nämlich wenn das Termingeschäft die Voraussetzungen einer sogenannten §988-Kurssicherungstransaktion (,Section 988 Hedging Transaction") erfüllt, können zwei Geschäfte steuerrechtlich zusammengefaßt werden. Diese Möglichkeit wird indes im folgenden Text zunächst zurückgestellt (die Positionen des Beispiels würden die Voraussetzungen jedoch erfüllen).

Ansonsten sind aber auch Positionen, die sich gegenseitig ausgleichen, separat zu behandeln. ${ }^{361}$ Beispiel C14b:

Am 1.7.1995 entscheidet sich die Kapitalgesellschaft $\mathrm{X}$ des vorangegangenen Beispiels C14a dafür, die $\$ 11.000$ per 31.12 .1995 doch wieder zu verkaufen.

Das Zinsniveau liege im Ausland bei $7 \%$ und in den USA bei $10 \%$ pro Jahr für eine Laufzeit von sechs Monaten, der Devisenkurs sei inzwischen unerwartet auf 0,95\%/M gefallen.

Der Terminkurs für den 31.12. ist jetzt:

$$
{ }_{1.7 .} f_{31.12 .}=\frac{1+{ }_{1.7} r_{31.12}}{1+{ }_{1.7 .} r_{31.12}^{*}} \cdot e_{1.7 .}=\frac{1,0489}{1,0345} \cdot 0,95 \mathrm{~s} / \mathrm{AM} \approx 0,963 \mathrm{~s} / \mathrm{AM} \text {. }
$$

Der Verkauf von $\$ 11.000$ am Jahresende wird somit einen Erlös von 11.423 AM $=\$ 11.000$. $(0,963 \mathrm{~S} / \mathrm{AM})^{-1}$ erbringen. Da der Gewinn aus beiden Positionen zusammen am 31.12. des Jahres schon am 1.7. feststeht - es sind 723 AM - läßt sich diese Position auch interpretieren, als gleiche sie das Termingeschäft vom Jahresanfang aus beziehungsweise als würde ersteres am 1.7. verkauft.

Das Ergebnis wird dennoch steuerlich erst zum Zeitpunkt der Fälligkeit der Positionen realisiert; zumindest soweit nicht eine der folgenden Ausnahmen vorliegt: 362

- Erzielt der Steuerpflichtige schon vor dem Zeitpunkt der Realisierung einen ökonomischen Vorteil aus dem Gewinn, indem er die Positionen als Sicherheit hinterlegt, um in Form eines Kredites darüber zu verfügen, wird dies als Realisierung angesehen.

- Als realisiert gilt der Gewinn natürlich auch dann, wenn er tatsächlich realisiert wird. Dies ist bei Termingeschäften der Fall, die so weit standardisiert sind, daß sie an einer Börse gehandelt werden. Dies kann aber auch geschehen, wenn sich die Vertragspartner auf eine Differenzabrechnung vor der Lieferung einigen. ${ }^{363}$

Verbaut wurde außerdem eine der offensichtlichen Varianten der im letzten Unterabschnitt angesprochenen Möglichkeiten zur Minderung der Steuerlast durch Manipulation der zuzurechnenden Fremdkapitalaufwendungen: Nimmt der Steuerpflichtige einen Kredit in einer nichtfunktionalen Währung auf, in der das Zinsniveau niedriger ist als in den USA, dann wird jedes Termingeschäft, das das Währungsrisiko „wesentlich reduziert", mit der Verbindlichkeit zusammengefaßt. Positive und negative Zahlungen aus beiden Positionen werden den Zinsaufwendungen zugerechnet. ${ }^{364}$ Andernfalls könnte auf diesem Wege ein Währungsverlust im Inland erzeugt und gleichzeitig die weltweit zuzurechnenden Aufwendungen gemindert werden, das heißt die ausländischen Einkünfte erhöht werden. ${ }^{365}$

\footnotetext{
361 Reg. $§ 1.988-2(d)(2)(i i)(A)$.

362 Reg. $§ 1.988-2(d)(2)(i i)$.

${ }^{363}$ Dies könnte in dem obigen Beispiel bedeuten, daß die Gesellschaft X am 1.7.1994 einen Differenzbetrag von $723 \mathrm{AM} \cdot 1,0345^{-1}=700 \mathrm{AM}$ erhält. Vgl. Reg. $\S 1.988-2(\mathrm{~d})(2)(\mathrm{iv})$ Beispiel 1.

364 Temp. Reg. §1.961-9T(2).

365 Dabei ist es gleichgültig, ob das Geschäft tatsächlich zur Minderung des Risikos eingegangen wurde, solange nicht der Nachweis erbracht wird, daß die Terminposition durch die gewöhnliche Geschäftstätigkeit begründet ist. Temp. Reg. §1.961-9T(2); L.D. Yoder u. S.P. McGill, a.a.O., S.151.
} 


\section{d) \$988-Kurssicherungstransaktionen („Section 988 Hedging Transactions“)}

„Hedging“ heißt, zu einer Position ein zweite Position mit partiell negativ korrelierten Erwartungsstrukturen abzuschließen, durch deren Verbindung das Risiko der Gesamtposition vermindert wird. ${ }^{366}$ Ist das Deckungsgeschäft mit der zu sichernden ersten Position vollkommen negativ korreliert, besteht das Risiko für die Person nicht mehr (,perfect hedge").

§988-Kurssicherungsgeschäfte ("Section 988 Hedging Transactions") sind laut Gesetzestext definiert als Transaktionen, die von dem Steuerpflichtigen durchgeführt werden, um das eigene Währungsrisiko bei einem Aktivum oder einer Verbindlichkeit zu reduzieren. ${ }^{367}$ Einbezogen werden Positionen, die schon bilanzwirksam wurden, aber auch unerfuillte schwebende Geschäfte, die für den Steuerpflichtigen einen Anspruch oder eine Verpflichtung für einen zukünftigen Zeitpunkt darstellen. Alle Transaktionen, die Teil einer §988-Kurssicherungs-

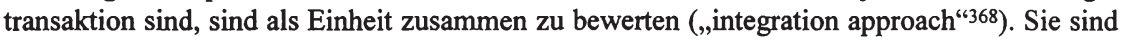
entweder als eine einzige Position zu interpretieren oder auf andere Weise konsistent zu behandeln. ${ }^{369}$ Das Prinzip separater Transaktionen wird für integrierte Geschäfte aufgehoben, und zwar nicht nur in bezug auf den Zeitpunkt der Besteuerung, sondern auch für Quelle und Charakter der Einkünfte.

Hinsichtlich der Identifikation einer Transaktion als §988-Kurssicherungsgeschäft besteht ein Wahlrecht seitens des Steuerpflichtigen. Bei mißbräuchlicher Anwendung kann indes auch die zuständige Steuerbehörde entscheiden: Erfaßt werden Transaktionen, die „durch den Finanzminister oder den Steuerpflichtigen als $\S 988$-Kurssicherungstransaktion erkannt wurden" ${ }^{370}$ In Erwartung stark zunehmenden Gebrauchs von Kurssicherungsgeschäften wurde die konkrete Gestaltung des gesetzlichen Rahmens der Finanzverwaltung überlassen, um Sicherheit bezüglich der steuerlichen Behandlung zu gewährleisten. ${ }^{371}$ In nahezu wörtlicher Umsetzung der Formulierung des Gesetzes können gemäß den Richtlinien ${ }^{372}$ derzeit Deckungsgeschäfte dann als §988-Kurssicherungstransaktion erklärt werden, wenn entweder

(a) alle Ein- oder Auszahlungen bestimmter §988-Umsätze (nahezu) vollständig gesichert werden; ${ }^{373}$ oder

(b) das Risiko durch Währungsfluktuationen bei schwebenden Geschäften verringert wird, die für den Steuerpflichtigen eine Verpflichtung zu einem zukünftigen Zeitpunkt darstellen (,executory contracts“"). ${ }^{374}$

Konkret muß eine synthetische Position des Typs (a) bestehen aus

- einem Grundgeschäft, das hier eine Anleihe oder Schuldurkunde („,qualifying debt instrument" $)^{375}$ sein muß, die die Voraussetzungen eines $§ 988$-Umsatzes ${ }^{376}$ erfüllt, und

\footnotetext{
${ }^{366}$ Vgl. z.B. H.-J. Krümmel, Finanzierungsrisiken und Kreditspielraum, in: Zeitschrift für Betriebswirtschaftslehre, 36.Jg. (1966), 1. Ergänzungsheft, S.138f..

${ }^{367}$ IRC $\S 988(d)(2)(A)$.

${ }^{368}$ T. Horst, Foreign Exchange Gains And Losses, a.a.O., S. 1395.

${ }^{369}$ IRC $\S 988(d)(1)$.

${ }^{370}$ IRC $§ 988(d)(2)(B)$ (eigene Übersetzung).

${ }^{371}$ U.S. Senate Finance Committee, Report on H.R. 3838, a.a.O., S.464; IRC §988(d)(1).

372 Die Trennung in diese beiden Typen wurde durch die Legislative in dieser Form schon nahegelegt. Vgl. o.V., Tax Reform Act of 1986; Conference Report to Accompany H.R. 3838, a.a.O., S.II-666; o.V. Explanation of Tax Reform Act of 1986. Chicago, Ill. 1986, S. 538, Abs. 1982.

Vgl. auch U.S. Department of the Treasury, Foreign Exchange Discussion Draft, a.a.O., S.9f., in dem ein sieben Punkte umfassender Katalog von Kurssicherungsgeschäften zusammengestellt wurde, der weitreichender war als die bislang gültigen und die beabsichtigten Regelungen.

${ }^{373}$ Reg. $\$ 1.988-5(a)$.

${ }^{374}$ Reg. $\$ 1.988-5$ (b).
} 
- einem Deckungsgeschäft „das bei Integration mit dem Grundgeschäft die Berechnung einer internen Verzinsung [...] in der Währung erlaubt, auf die die synthetische Position lautet." 377 Dies können Kassapositionen, Währungsswaps, Termingeschäfte einschließlich Optionen und vergleichbare Instrumente sein.

Durch diese Definition wird auf einfache Weise die Anforderung der vollkommenen Sicherung gewährleistet. Es bedeutet aber auch, daß eine synthetische Position mit dem Charakter einer Eventualforderung oder -verbindlichkeit nicht akzeptiert wird. Optionen können zwar Bestandteil der Position sein, die Rechte und Pflichten müssen sich aber gegenseitig aufheben. ${ }^{378}$ Grundgeschäft und §988-Kurssicherungstransaktion sind für den Zeitraum der Sicherung als vollkommen integrierter $§ 988$-Umsatz anzusehen. ${ }^{379}$ Das heißt: entspricht das Ergebnis der Kombination von Finanzierungsinstrumenten einer synthetischen Position in U.S.-Dollar, wird steuerlich kein Währungsergebnis anerkannt. Es können nur Zinseinkünfte entstehen, deren Quelle aus dem Grundgeschäft abgeleitet wird. Wird dagegen eine Position in nichtfunktionaler Währung synthetisiert, sind Währungsgewinne oder -verluste so zu behandeln wie bei anderen $\S 988$-Transaktionen. ${ }^{380}$

Der simultane Kauf und Verkauf aller Elemente einer solchen synthetischen Position wird steuerlich behandelt, wie Kauf und Verkauf der duplizierten Position; ${ }^{381}$ andernfalls gilt:

- Der Abschluß eines Deckungsgeschäfts („legging in“) für eine schon bestehende Position ist bezüglich der steuerlichen Bemessung eines Währungsgewinns oder -verlustes gleichzusetzen mit dem Verkauf der zu sichernden Position. Der Abschluß führt aber nicht zur Fälligkeit der Steuer. ${ }^{382}$

Die Bemessung ist erforderlich, da durch die steuerliche Bewertungseinheit rechtlich eine völlig neue Position entstanden ist. Es wird die Veräußerung des Grundgeschäfts fingiert. Durch den Aufschub der Fälligkeit ist aber die Möglichkeit verbaut, mittels Termingeschäften den Zeitpunkt der steuerlichen Berücksichtigung eines (inländischen) Währungsverlustes wählen zu können, ohne ihn tatsächlich zu realisieren.

Die Steuer wird erst zum Zeitpunkt der Veräußerung des Grundgeschäfts fällig.

- Das Öffnen der synthetischen Position (,legging out") durch Fälligkeit, Verkauf oder Ausübung eines ihrer Bestandteile hat Bemessung und Fälligkeit sämtlicher Steuern aus der integrierten Position zur Folge, namentlich für den Zeitraum zwischen dem „leg-in date“ und dem „leg-out date“. Zu diesem Zweck wird unterstellt, die in den Händen des Steuerpflichtigen verbleibende Position sei ebenfalls zu ihrem Marktwert verkauft worden. ${ }^{383}$

Eine sogenannte „timing option" ${ }^{384}$ wird somit verhindert. Das heißt, es ergibt sich für den Steuerpflichtigen nicht die Perspektive einer Reduzierung von Steuerzahlungen, indem mit der Öffnung der synthetischen Position nur ein Kursverlust realisiert wird, nicht aber der korrespondierende Gewinn bei dem zweiten Bestandteil.

375 Reg. $§ 1.988-5(a)(3)$.

${ }^{376}$ Es muß eine Position im Sinne der Reg. $\$ 1.988-1$ (a)(2)(i) sein.

${ }^{377}$ Reg. $§ 1.988-5$ (a)(4) (eigene Übersetzung). Zur Berechnung der internen Verzinsung wird auf IRC $§ 1272$ verwiesen. Dort wird die Ermittlung des „original issue discount“ vorgegeben.

${ }^{378}$ Reg. $\S 1.988-5(a)(5)(i)$ und die interessanten Beispiele 6 und 7 der Reg. §1.988-5(a)(9)(iv).

${ }^{379}$ Reg. §1.988-5(a)(9).

${ }^{380}$ Reg. $\$ 1.988-5(\mathrm{a})(1)$. Wird die integrierte Position über mehrere Perioden gehalten, wird ein am Laufzeitende anfallender Gewinn oder Verlust infolge des Auseinanderfallens von Kassa- und Terminkurs diskontiert und zur Besteuerung anteilig den Zinseinkünften während der Haltedauer zugerechnet. R. Henrey, International Tax Aspects of Foreign Currency Transactions, a.a.O., S.316.

${ }^{381}$ Reg. $\$ 1.988-5(a)(9)(i)(A)$.

382 Reg. $\S 1.988-5(a)(6)(i)(B)$.

${ }^{383}$ Reg. §1.988-5(a)(6)(ii)(B), (C).

384 Vgl. hierzu G.M. Constantinides, a.a.O., S.611-612. 
Infolge der Integration der Positionen und der damit einhergehenden steuerlichen Erfassung das Saldos aus Gewinnen und Verlusten bei Grund- und Sicherungsgeschäft ist nach dem Öffnen nur das Ergebnis steuerpflichtig, das wirtschaftlich durch die synthetische Anlage erzielt wurde.

Vermieden werden soll aber auch die Öffnung einer integrierten Position mit dem Ziel der frühzeitigen Realisierung eines Verlustes bei der Komponente, die nicht veräußert wird. Erzielt der Steuerpflichtige nämlich einen Gewinn aus dem Bestandteil des synthetischen Instruments, den er aus den Händen gibt, wird die Anerkennung als integrierte Position dann verwehrt, wenn während einer Periode von 30 Tagen vor oder nach dem Öffnen wenigstens die Hälfte des verbleibenden Währungsrisikos durch ein neues Geschäft gesichert wird. ${ }^{385}$ In diesem Fall wäre nur der Gewinn steuerpflichtig, der unrealisierte Verlust indes nicht.

In dem Beispiel C14a auf Seite 142 wurde eine integrierte Position beschrieben, die (wie

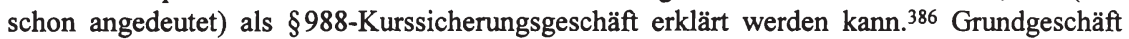
(100 Anleihen in AM) und Deckungsgeschäft (das Termingeschäft) erfüllen die hier genannten Voraussetzungen. Die Position dupliziert den Zahlungsstrom einer U.S.-Anleihe, denn die Gesellschaft X wird sichere Zinseinkünfte von $\$ 1.000$ erzielen. Da aber mit dem Grundgeschäft Kapital exportiert wurde, ist das Ausland die steuerrechtliche Quelle der Zinsen.

Deshalb schafft das Deckungsgeschäft auch bei Erklärung als §988-Kurssicherungstransaktion nicht völlige Sicherheit hinsichtlich eines Anrechnungsüberhangs. Selbst wenn das Währungsrisiko aus dem Grundgeschäft vollkommen ausgeräumt wird, ist ja die Höhe der ausländischen Steuer in U.S.-Dollar eine Funktion des Wechselkurses. In Beispiel C14a etwa würde, wenn der erwartete Wechselkurs von $1,028 \mathrm{\$} / \mathrm{AM}$ eintrifft und für die USA ein Steuersatz von $\tau=0,35$ angenommen wird, ab einem ausländischen Quellensteuersatz von $t^{*} \approx 0,49$ ein Anrechnungsüberhang entstehen. ${ }^{387}$ Wäre der Devisenkurs am Jahresende höher, wäre bei diesem Satz die Quellensteuer des Auslands nicht gänzlich anrechenbar.

Freilich würde es ohne die Integration schon bei einem ausländischen Steuersatz von $t^{*}=0,35$ zu einem Anrechnungsüberhang kommen, da das Währungsergebnis inländisches Einkommen wäre. Durch die Bewertungseinheit werden die ausländischen Zinșeinkünfte hier um den aus der Differenz zwischen dem Kassa- und dem Terminkurs resultierenden Gewinn erhöht.

Das heißt allerdings auch, daß eventuell die Bildung eines synthetischen Aktivums für den Steuerpflichtigen unvorteilhaft ist, wenn ein Währungsverlust erwartet werden kann, wenn also das Zinsniveau im Ausland höher ist als in den USA.

Bei einer integrierten Transaktion auf der Passivseite des Steuerpflichtigen beziehungsweise der QBU ist es im Unterschied zu der so gesicherten Forderung nicht erforderlich, eine Quelle zu bestimmen. Gewinne und Verluste aus Kredit und Deckungsgeschäft sind in dem Fall als Fremdkapitalkosten auf dem weiter oben beschriebenen indirekten Weg zuzurechnen. ${ }^{388}$

${ }^{385}$ Das Vorgehen in dieser Reg. §1.988-5(a)(6)(ii)(E) entspricht der sogenannten „wash sale rule“, IRC §1091. M. Dionne u. S. Orme, a.a.O., S. $547 \mathrm{f}$.

${ }^{386}$ Reg. $§ 1.988-5(\mathrm{a})(9)(\mathrm{iii})$.

${ }^{387}$ Der sichere Ertrag der synthetischen Position beträgt $\$ 1.000$. Aus einem Steuersatz von $\tau=0,35$ errechnet sich eine Steuer von $\$ 350$.

Das gleiche Ergebnis resultiert bei $t^{*} \approx 0,49: 700 \mathrm{AM} \cdot 0,49 \cdot 1,028 \mathrm{~s} / \mathrm{AM} \approx \$ 350$.

${ }^{388}$ Reg. $\S 1.988-5(a)(9)(i i i)$ oder, wie im Text schon gesagt, auch direkt aus Reg. $§ 1.861-9 T(b)$, wenn der Steuerpflichtige die Integration nicht von sich aus als §988-Kurssicherungsgeschäft erklärt. 
Als §988-Kurssicherungstransaktion können aber auch Deckungsgeschäfte anerkannt werden, wenn das Grundgeschäft die restriktiven Voraussetzungen des Typs (a) nicht erfüllt. Die integrierte Position vom Typ (b) muß bestehen aus ${ }^{389}$

- einem „executory contract", der definiert ist als Verpflichtung im Rahmen der gewöhnlichen Geschäftstätigkeit eines Steuerpflichtigen, die zwar ökonomisch aber noch nicht im buchhalterischen Sinne eine Einnahme oder Ausgabe darstellt, und

- einem Deckungsgeschäft, mit dem das Währungsrisiko der Verpflichtung reduziert wird. Dies kann hier ein Guthaben in nichtfunktionaler Währung sein, wenn es auf einem speziell deklarierten Konto hinterlegt wird; es können Terminkontrakte oder -geschäfte sein oder auch Optionen, soweit die Restlaufzeit vor der Fälligkeit der gesicherten Position endet.

Der grundlegende Unterschied der Typen (a) und (b) wird damit sichtbar: Bei ersterem wird die Zahlungsreihe einer bestehenden Bilanzposition verändert. Ergebnis ist die Duplikation einer anderen Position; der Zahlungsstrom in einer Währung wird in einen Zahlungsstrom in einer anderen Währung transformiert.

Typ (b) befaßt sich indessen mit Währungsrisiken aus noch nicht bilanzwirksamen Forderungen beziehungsweise Verbindlichkeiten. Es sind einmalige Zahlungen zu einem zukünftigen Zeitpunkt, ${ }^{390}$ die vorrangig im Rahmen der gewöhnlichen Geschäftstätigkeit einer QBU anfallen.

Darunter fallen im wesentlichen schwebende Geschäfte, die zur Abnahme oder zur Bereitstellung von Gütern oder Dienstleistungen zu einem in nichtfunktionaler Währung fest vereinbarten Preis verpflichten. ${ }^{391}$ Daneben wird aber auch eine vertragliche Verpflichtung zur Veräußerung von Aktien zu einem zukünftigen Zeitpunkt eingeschlossen, obgleich diese nicht zur gewöhnlichen Geschäftstätigkeit zählt. ${ }^{392}$

Folge der Erklärung einer integrierten Position dieses Typs ist, daß Beträge, die von dem Steuerpflichtigen aufgrund des Deckungsgeschäfts gezahlt oder empfangen werden, als aus dem Grundgeschäft resultierend behandelt werden. Da diese integrierte Position auf die funktionale Währung lautet, ${ }^{393}$ entsteht steuerlich kein Währungsergebnis. ${ }^{394}$ Das heißt, die Anschaffungskosten oder der Veräußerungspreis in U.S.-Dollar werden hiernach durch den Wechselkurs determiniert, zu dem das Kurssicherungsgeschäft abgeschlossen wurde.

Andernfalls würde die zu sichernde Position nach dem Prinzip separater Transaktionen mit dem Wechselkurs zum Zeitpunkt der Lieferung bilanziell erfaßt. Das Grundgeschäft ist kein §988-Umsatz, sondern ein schwebendes Geschäft in nichtfunktionaler Währung, bei dem ein Währungserfolg nicht ausgewiesen würde.

Das Kurssicherungsgeschäft wäre demgegenüber bei isolierter Betrachtung steuerpflichtig.

${ }^{389}$ Reg. §1.988-5(b)(2)(ii)(A). Für eine ausfuihrliche Darstellung vgl. R. Feinschreiber, Hedging Foreign Transactions Without Exposure to Currency Taxation, in: Journal of Taxation and Investments, 12.Jg. (1994), S. 100-105.

${ }^{390}$ Empfangene Zinsen auf ein Guthaben, das in nichtfunktionaler Währung zur Kurssicherung angelegt wurde, können in das Deckungsgeschäft einbezogen werden. Werden die Beträge auf dem Konto belassen, werden darauf anfallende Währungsgewinne oder -verluste mit dem Grundgeschäft verrechnet. Die steuerliche Realisierung der Zinserträge kann dadurch allerdings nicht hinausgezögert werden: Sie zählen im Steuerjahr der Zahlung zu den Bruttoeinkünften des Steuerpflichtigen. Reg. §1.988-5(b)(2)(iii)(E).

${ }^{391}$ Reg. $\S 1.988-5(\mathrm{~b})(2)(\mathrm{ii})(\mathrm{B})$.

${ }^{392}$ Reg. $§ 1.988-5$ (b)(2)(ii)(A). In den zunächst beabsichtigten Regelungen wurden diese Transaktionen nicht einbezogen. In Reaktionen darauf wurde eine mögliche Diskriminierung von Aktienkäufen oder -verkäufen kritisiert. R. Feinschreiber, a.a.O., S. 102.

Gedacht wird aber wohl vorrangig an Transaktionen, die zu der wirtschaftlichen Tätigkeit des Steuerpflichtigen beziehungsweise der QBU zu zählen sind. Zumindest ist in den Regelungen zur Veranschaulichung von einem Kontrakt die Rede, der zur Veräußerung von Anteilen einer Tochtergesellschaft verpflichtet. Die Rechenbeispiele der Reg. §1.988-5(b)(4)(iv) behandeln übrigens nur Geschäfte mit Maschinen, Wartungsdienstleistungen und Stahl.

393 R. Feinschreiber, a.a.O., S. 101.

${ }^{394}$ Reg. $§ 1.988-5(b)(4)(i)$. 
Allerdings stellt sich hier die Frage, ob nicht ein Währungsgewinn oder -verlust bei schwebenden Geschäften prinzipiell erfaßt werden könnte. Die ökonomische Situation des Steuerpflichtigen ist in beiden Fällen identisch.

\section{Privatvermögen}

Wie schon erwähnt, begründet eine Einzelperson keine QBU. ${ }^{395}$ Aktivitäten eines Steuerpflichtigen, die nicht Teil einer QBU sind, sind prinzipiell in U.S.-Dollar zu bewerten, ${ }^{396}$ wodurch die Stichtagmethode nicht angewendet werden kann.

Auch die Umsatzmethode im Sinne des IRC $§ 988$ gilt für Einzelpersonen nur unter bestimmten Voraussetzungen. Erforderlich ist entweder, ${ }^{397}$ daß eine Transaktion im Zusammenhang mit der Geschäftstätigkeit eines Handels oder Gewerbes des Steuerpflichtigen durchgeführt wird ${ }^{398}$, oder daß die Transaktion zu den gewöhnlichen und notwendigen Ausgaben gerechnet werden kann, die bei der Erzielung der Einkünfte in dem Steuerjahr anfielen. ${ }^{399}$ Quelle des Währungserfolgs ist dann der Ort, an dem der Steuerpflichtige oder dessen QBU domiziliert. ${ }^{400}$ In allen anderen Situationen behält für Einzelpersonen das bis zur Reform von 1986 gewachsene Recht Gültigkeit. ${ }^{401}$ Das heißt: ein Währungsergebnis wird als Veräußerungsgewinn oder -verlust charakterisiert, weil es nicht von anderen Gewinnen durch die Veräußerung eines betreffenden Vermögensgegenstand getrennt wird ${ }^{402}$ oder die veräußerte fremde Währung als selbst als Vermögensgegenstand anzusehen ist. ${ }^{403}$ De jure zählt dazu auch der Währungsgewinn, der bei dem weiter oben erwähnten Kauf des Cappuccinos in Lire durch den U.S.-Touristen entstehen kann. ${ }^{404}$ Erst durch die Steueränderung von 1997 werden künftig für Einzelpersonen Gewinne aus einem Währungsumtausch steuerfrei gestellt werden, wenn sie \$ 200 nicht überschreiten. ${ }^{405}$

Die wesentliche Neuerung durch die Steuerreform von 1986 war für Einzelpersonen deshalb die Entscheidung, Veräußerungsgewinne mit dem gleichen Satz zu besteuern, wie ordentliches Einkommen. Damit wurden Kapitalanlagen in Währungen, für die eine Aufwertung erwartet wird, durch die Tarifbelastung nicht mehr begünstigt und Anlagen in schwachen Währungen nicht mehr diskriminiert. Es blieb lediglich der Vor- beziehungsweise Nachteil eines Steueraufschubs als Folge des Realisationsprinzips. Allerdings wurde der Steuersatz für Veräußerungsgewinne ja unlängst wieder gesenkt.

\footnotetext{
${ }^{395}$ Reg. $§ 1.989(a)-1(b)(2)(i)$.

396 IRC $§ 985(B)(1)(a)$ wenn eine QBU vorliegt, Reg. 1.985-1(b)(1) bei Einzelpersonen.

397 IRC $§ 988(e)$.

398 Im Sinne des IRC $§ 162$.

399 Gemäß IRC §212(1) und (2).

${ }^{400}$ IRC $\S 988(a)(3)(B)(i)(I)$; der Wohnsitz ist im Sinne des IRC $\S 911$ (d)(3) zu verstehen.

401 Vgl. hierzu insbesondere T.J. ONeil u. C. Lee, a.a.O., S.9-18.

402 D.P. Zaiken u.a., Handling the Treatment of Foreign Currency under Tax Reform, a.a.O., S. 174.

${ }^{403}$ Das Prinzip separater Transaktionen gilt auch hier. Dies wurde in dem Urteil des Falles Carlos J. Quijano and Jean M. Quijano vs. United States of America bestätigt. Es wurde den Klagenden versagt, einen wechselkursbedingten Veräußerungsgewinn durch den Verkauf des eigenen Hauses in England um einem Währungsverlust bei dessen Finanzierung zu reduzieren. Daneben wurde es abgelehnt, das britische Pfund als funktionale Währung anzusehen, weil keine QBU vorliegt. Carlos J. Quijano, et ux. v. United States 78 AFTR2d Par.965295 No. 96-1053, zitiert nach: C.K. Cyr, Gain On Sale Of Foreign Residence Not Reduced By 'Exchange-Rate' Gain, in: Tax Analysts, Document Number: Doc 96-23603, 1996.

${ }^{404}$ Vgl. auch Beispiel 2 des Reg. §1.988-1(a)(9)(ii).

405 Taxpayer Relief Act of 1997, §1104(a). Verluste waren schon vorher nicht abziehbar.
} 
Ungeachtet dessen wird Kapitalexport aber durch die asymmetrische steuerliche Behandlung von Veräußerungsgewinnen und -verlusten benachteiligt, weil hiermit auch Währungsverluste nicht mit ordentlichem Einkommen verrechnet werden können. Dessen Wirkung auf den Barwert des Auslandsengagements ist hier größer als in den Rechnungen des Teils B, da im U.S.-Steuerrecht Veräußerungs- und Währungsverluste auch nicht mit anderen Einkünften aus dem Auslandsengagement verrechnet werden können. Das heißt beispielsweise, daß Währungsverluste nicht positive Zinseinkünften aus dem Quellenland mindern können. Zudem gewinnt der Aspekt mit einer längeren Haltedauer an Gewicht.

Überdies ist ein Veräußerungserfolg bei im Ausland belegenen immobilen Vermögenswerten und teilweise auch bei Aktien ausländischen Ursprungs. ${ }^{406}$ Falls ein quellensteuerpflichtiger Veräußerungsgewinn durch einen Währungsverlust reduziert oder gar aufgezehrt wird, ist die ausländische Steuer definitiv. ${ }^{407}$ Sie kann dann allenfalls noch auf dem Wege des Abzugsverfahrens bei der Bemessung der Steuerlast in den USA berücksichtigt werden.

Deshalb wurde Kapitalexport von Einzelpersonen durch die steuerliche Behandlung von Währungsgewinnen und -verlusten zumindest bis zur Steueränderung von 1997 diskriminiert. Begünstigend wirkte zwar die Möglichkeit eines Steueraufschubs, wenn ein Devisenkursanstieg erwartet werden kann. Dem stand aber das Risiko eines nicht abziehbaren Nettokapitalverlustes bei einem (unerwarteten) Kursrückgang gegenüber.

Die Benachteiligung wurde durch die Senkung der Tarifbelastung auf längerfristige Veräußerungsgewinne und -verluste bei Investitionen in Ländern mit schwachen Währungen offensichtlich verstärkt.

Die Wirkung auf Kapitalexport in Länder mit im Vergleich zum U.S.-Dollar festen Währungen ist vom Einzelfall abhängig. Eine Begünstigung ist umso wahrscheinlicher, je höher der erwartete Währungsgewinn und je geringer das Währungsrisiko.

\section{Zusammenfassende Beurteilung}

In den USA ist seit zehn Jahren die Besteuerung von Währungsgewinnen und -verlusten gesetzlich geregelt. Der neue Unterabschnitt J des IRC wurde vor dem Hintergrund der zuvor geltenden Vorschriften überwiegend als wirkliche Vereinfachung und Verbesserung begrüßt, ${ }^{408}$ da er ,wenigstens der Konzeption nach den Geist von Rationalität und Vernunft in das ganze Thema" ${ }^{409}$ bringe.

Mit dem Regelwerk, das von der Legislative vorgegeben und seither von der Exekutive ausgefüllt wurde, werden Währungsgewinne und -verluste vom Ansatz her angemessen erfaßt. Fragwürdig ist aus dem Blickwinkel ökonomischer Effizienz aber teilweise die steuerrechtliche Quelle des Währungsergebnisses und, speziell bei Direktinvestitionen, auch der Zeitpunkt der Besteuerung.

\footnotetext{
${ }^{406} \mathrm{Vgl}$. Seite 90 dieser Arbeit.

${ }^{407}$ Und zwar unabhängig von dem Vorliegen anderer ausländischer Einkünfte, da das Anrechnungsverfahren hier getrennt auf jeden einzelnen Veräußerungsgewinn angewendet wird. IRC $\S 865(\mathrm{~h})(1)(B)$. Hinzutreten kann zudem eine Minderung der ausländischen Einkünfte durch die anteilige Zurechnung abziehbarer Hypothekenzinsen.

408 J. Bourne Wahl, Tax Treatment of Foreign Exchange Gains and Losses and the Tax Reform Act of 1986, a.a.O., S.61; F.E. White, a.a.O., S.214; J.F. Chown, a.a.O., S.171; J. Isenbergh, International Taxation, Teil II, a.a.O., S.279.

409 J.F. Chown, a.a.O., S. 171 (eigene Übersetzung).
} 
Im einzelnen lassen sich anhand der in Teil B angestellten theoretischen Überlegungen folgende Ergebnisse für das in den USA seit der Steuerreform geschaffene Recht zusammenfassen:

Eines der erklärten Ziele des Außensteuerrechts der USA ist Kapitalexportneutralität. Demgemäß ist ausländisches Einkommen von Steuerinländern des Landes steuerpflichtig und eine Anrechnung im Ausland gezahlter Einkommensteuern zulässig. Durch die Begrenzung der Anrechnung wird das Ziel zwar in Frage gestellt; das ist aber nicht Thema der Arbeit. Gemäß Teil B sollten Währungsgewinne und -verluste in diesem Steuersystem grundsätzlich besteuert werden. Dies ist der Fall.

Infolge der Begrenzung der Anrechnung war aber zu prüfen, welche Auswirkungen nicht erwartete Wechselkursänderungen auf die erwartete Steuerlast bei grenzüberschreitendem Kapitaleinsatz haben können. Hier ist das Bild uneinheitlich.

Zur Ermittlung des Währungsergebnisses bei Direktinvestitionen ist seit der Steuerreform in der Regel die Stichtagmethode vorgeschrieben, wenn die Aktivitäten eine qualifizierte wirtschaftliche Einheit (QBU) begründen und hinreichend eng mit der ökonomischen Umwelt des ausländischen Standortes verbunden sind. Der steuerpflichtige Periodengewinn ist dann in der funktionalen Währung der QBU zu bemessen. Währungsgewinne oder -verluste werden getrennt quantifiziert, und zwar bezogen auf das zum Zeitpunkt des Kapitalexportes eingesetzte Vermögen.

Die methodischen Vorzüge, die das Stichtagverfahren damit im Hinblick auf die Ergebnisse der Analyse des Teils B bietet, wurden im U.S.-Steuerrecht indes nicht genutzt:

Zum einen ist der Gewinn und die darauf im Ausland entrichteten Steuern (zum Teil) zu unterschiedlichen Wechselkursen umzurechnen.

Ein Auseinanderfallen der Bemessungsgrundlagen ist zwar regelmäßig auch ohne die Einbeziehung von Währungsschwankungen allein durch die rechtlichen Unterschiede der Länder gegeben, letztere berühren aber zumeist nur die zeitliche Abgrenzung des Totaleinkommens. Die zulässigen Vor- und Rücktragsmöglichkeiten von Anrechnungsüberhängen im Steuerrecht der USA können diese Unterschiede - abgesehen von einem Zinsvorteil oder -nachteil - aber wenigstens teilweise auffangen. Im Unterschied dazu kann ein Währungsgewinn oder -verlust zu einem dauerhaften Auseinanderfallen des steuerpflichtigen Einkommens nach in- und ausländischem Recht führen. ${ }^{410}$ Damit ist auch der Anrechnungsüberhang dauerhaft.

Mit der Steueränderung von 1997 wird dies für rechtlich nicht selbständige QBU und für die Zugriffsbesteuerung korrigiert; Gewinn und ausländische Steuern sind zum durchschnittlichen Wechselkurs des Steuerjahres umzurechnen. Für die Gewinne ausländischer Tochtergesellschaften ist ansonsten indes weiterhin der Kurs bei deren Ausschüttung anzuwenden, für die ausländischen Steuern aber der Kurs des Jahres der Entstehung der Gewinne. Hier besteht nach wie vor das Risiko, daß deren Relationen im Anrechnungsverfahren durch Kursänderungen verändert werden.

Zum anderen werden die getrennt zu quantifizierenden Währungsgewinne durch eine QBU nicht den inländischen, sondern den ausländischen Einkünften zugerechnet.

Dieser Schritt wurde durch den U.S.-amerikanischen Gesetzgeber letztendlich nicht getan, obgleich - vielleicht aber auch, weil - die in der Analyse des Teils B ökonomisch beschriebene und quantifizierte Wirkung von Währungsgewinnen im Anrechnungsverfahren erkannt wurde. Denn eine Zurechnung zu den inländischen Einkünften hat zwar den Vorteil einer geringeren Diskriminierung von Kapitalexport, wirtschaftlich betrachtet werden damit aber unter Umständen auch ausländische Steuern durch die USA erstattet. Dies läuft jedoch dem Zweck des

${ }^{410}$ P. Malinski, Währungsschwankungen und Doppelbesteuerung, Herne u. Berlin 1992, S. 68. 
so überaus komplexen Anrechnungsverfahrens im U.S.-Steuerrecht zuwider, da die Sicherung des Steueraufkommens dem Ziel ökonomischer Effizienz untergeordnet würde.

Bemerkenswert ist deshalb die Gesetzgebung zu den sogenannten §988-Transaktionen. Währungsgewinne und -verluste bei Nominalwerten und Finanzierungsinstrumenten, die auf eine fremde Währung lauten, werden seither als ordentliche Einkünfte charakterisiert und sind zum Zeitpunkt der Realisierung steuerpflichtig.

Quelle dieser Einkünfte ist prinzipiell der Währungsraum der funktionalen Währung.

Allerdings sind die Quellensteuersätze bei diesen Formen des Kapitalexports in der Realität regelmäßig nicht so hoch. Gemäß dem Musterabkommen der OECD zur Vermeidung von Doppelbesteuerung sind dies für Zinseinkünfte $10 \%^{411}$, die jedoch stets auf den Bruttoertrag der Zinszahlung erhoben werden. Die Sätze liegen tatsächlich aber oft noch darunter oder die Steuer wird überhaupt nicht erhoben. ${ }^{412}$ Die Wirkung der Behandlung als inländische Einkünfte - und auch die Folge für das Steueraufkommen - ist insofern hier, zumindest bei isolierter Betrachtung, geringer als bei einer QBU. Doch ist sie nicht bedeutungslos. Auch bei einer niedrigen Quellensteuer kann ein Anrechnungsüberhang nicht ganz ausgeschlossen werden, wenn die Wechselkursentwicklung unsicher ist. Infolgedessen verringert sich die erwartete Rendite.

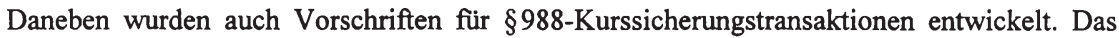
Gebot der Einzelbewertung wurde für synthetische Positionen und auch für bestimmte Deckungsgeschäfte im Rahmen der gewöhnlichen Geschäftstätigkeit des Steuerpflichtigen aufgehoben. Letztere umfassen insbesondere die Sicherung von noch nicht bilanzwirksamen vertraglichen Verpflichtungen. „Diese Richtlinien haben einen erheblichen Verwaltungsaufwand zur Folge, da sie den Steuerzahler nötigen, für zahlreiche Transaktionen nach unterschiedlichen und sehr spezifischen Regeln Buch zu fuihren."413 Gleichwohl sind sie interessant, weil sie die Probleme bei der Besteuerung aufzeigen, die aus dem Prinzip separater Transaktionen bei wirtschaftlich integrierten Positionen bezüglich der Quelle von Gewinnen und Verlusten und des Zeitpunktes der Besteuerung entstehen.

Im Unterschied zu Nominalwerten wird bei Sachwerten das Währungsergebnis nicht getrennt

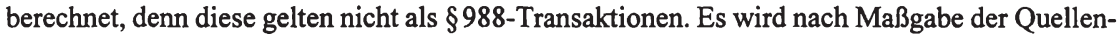
regeln wie Veräußerungsgewinne oder -verluste behandelt und zählt damit insbesondere bei unbeweglichen Aktiva und mit Einschränkungen auch bei Aktien zu den ausländischen Einkünften.

Eine gewisse kompensierende Wirkung gewährt das U.S.-Anrechnungsverfahren hier im Einzelfall, weil die Anrechnungshöchstbeträge nach Einkunftarten und nicht nach Währungsräumen getrennt berechnet werden. Ex ante besteht demnach ein Anreiz, Kapital auf mehrere Währungsräume aufzuteilen, da ausländische Währungsgewinne und -verluste aus verschiedenen Ländern gegeneinander verrechnet werden können. Zudem können mittels Vorund Rücktrag von Anrechnungsgutschriften auch (nicht erwartete) Kursgewinne und -verluste unterschiedlicher Steuerjahre ausgeglichen werden, bevor es zu einem Überhang kommt.

Allerdings ist aus den gleichen Gründen die Bedeutung der Möglichkeit, anstelle der Anrechnung ausländischer Steuern deren Abzug von der inländischen Bemessungsgrundlage zu wählen, von der geographischen Aufteilung der Einkünfte des Steuerpflichtigen abhängig, da sie nicht für jedes Land getrennt getroffen werden kann.

411 Art. 11 Abs. 2 OECD-MA.

${ }^{412}$ Die Quellensteuer auf Zinsen beträgt $0 \%$ z.B. für Deutschland, Frankreich und Groß Britannien und sie beträgt 10\% z.B. für Kanada und Japan. Vgl. Anhang V auf Seite 223.

${ }^{413}$ M. Dionne u. S. Orme, a.a.O., S. 550. 
Ein weiteres Problem bei der Besteuerung von Währungsgewinnen und -verlusten, das in Teil B ausgeklammert wurde, stellt in der Praxis der Zeitpunkt der Erhebung der Steuer und die damit in Zusammenhang stehende Abgrenzung der Bemessungsgrundlage dar.

Es ist in der Regel leicht, jährlich das Währungsergebnis bezogen auf Anschaffungskosten zu berechnen. Dies ist aber keine Lösung, wenn sich der Wert eines Wirtschaftsgutes, gemessen in dem ausländischen Zahlungsmittel, inflationär bedingt ändert, weil die Auswirkungen auf Nominal- und Sachwerte unterschiedlich sind. Eine realistische einkommensteuerliche Behandlung steht auf Grund dessen im Spannungsfeld der durch Veränderungen des Binnenund des Außenwertes der ausländischen Währung verursachten Gewinne oder Verluste.

Herrscht im Quellenland eine Inflationsrate, die von der des Wohnsitzlandes nur geringfügig abweicht, überwiegen Auswirkungen durch Schwankungen des Außenwertes der ausländischen Währung, insbesondere nicht erwartete Wechselkursänderungen. Es bestehen indes geringe Wechselwirkungen zwischen der Entwicklung des Binnen- und des Außenwertes des ausländischen Zahlungsmittels.

Eine zeitnahe Besteuerung von erwarteten Währungsgewinnen und -verlusten hat so keinen erheblichen Einfluß; vorrangig beeinflussen nicht antizipierte Kursänderungen die Allokationsentscheidung: Durch das Realisationsprinzip besteht ein Anreiz, den Kapitaleinsatz nach einem Kursanstieg zu verlängern und Verluste möglichst zeitnah zu realisieren.

Ist die Inflationsrate im Quellenland dagegen sehr viel höher als im Wohnsitzland, werden reale Wechselkursänderungen dominieren.

Hier ist ein differenziertes Vorgehen notwendig, da die Auswirkungen bei Nominal- und bei Sachwerten unterschiedlich sind. Bei Nominalwerten ist ex ante von der Erwartung auszugehen, daß die nominalen Zahlungen für die Überlassung von Kapital die Geldentwertung im Quellenland ausgleichen. Wird die Besteuerung des Währungsergebnisses bis zur Realisierung hinausgezögert, wird diese Form des Kapitalexports diskriminiert (und Kapitalaufnahme in solchen Währungen begünstigt).

Bei Sachwerten wird die Entscheidung über den Kapitaleinsatz in solchen Währungsräumen dagegen beeinflußt, wenn isoliert der Währungsgewinn zeitnah steuerpflichtig ist. Investitionen in nicht abnutzbares Vermögen werden begünstigt, da ein zu erwartender nominaler Veräußerungsgewinn hinausgezögert werden kann; bei abnutzbaren Aktiva sind die im Rahmen des Nominalwertprinzips in der Währung des Quellenlandes zulässigen Abschreibungen zu gering.

Das Steuerrecht der USA reflektiert diese unterschiedlichen Auswirkungen, indem für Direktinvestitionen eine Grenze gezogen wurde, und zwar bei einer Inflationsrate im Quellenland von insgesamt $100 \%$ in drei aufeinanderfolgenden Jahren.

Die DASTM Umrechnungsmethode für Investitionen in stark inflationären Währungsräumen schreibt vor, das Währungsergebnis wenigstens monatlich mittels einer dem Nominal-/Sachwertverfahren vergleichbaren Umrechnungsmethode zu berechnen. Das heißt Sachwerte sind zu historischen Kursen, Nominalwerte und Verbindlichkeiten demgegenüber zum Stichtagkurs umzurechnen.

Doch ist fraglich, ob es wirklich sinnvoll ist, unterschiedliche Umrechnungsmethoden vorzuschreiben. Der Aufwand der DASTM und auch der Aufwand eines Methodenwechsels sind erheblich. ${ }^{414}$ Insbesondere sind aber die allokativen Vorteile zweifelhaft, denn eine Unter-

${ }^{414}$ Es besteht die Vermutung, die Bundessteuerbehörde hätte bei der Entwicklung der Richtlinien zu der DASTM erwogen, die Methode als Wahlrecht für alle QBU zuzulassen, wenn der Steuerpflichtige eine Niederlassung in einem hochinflationären Wăhrungsraum unterhält, dies aber in der Befürchtung eines Mißbrauchs letztlich nicht umgesetzt. S.R. Lainoff u. T.Y. McArthur, a.a.O., S.595, Fn.163. 
scheidung nach Nominal- und Sachwerten führt auch bei geringerer Inflationsrate im Quellenland nicht zu Verzerrungen.

Eher trifft das Gegenteil zu. Der Gewinn der QBU ist nach U.S.-Vorschriften - also auf der Grundlage des Nominalwertprinzips in der Währung des Quellenlandes - zu bestimmen. Langfristig werden auf diese Weise auch Investitionen in Ländern mit nur geringfügig höherer Inflationsrate diskriminiert. Inflationär bedingte Gewinne werden zwar nicht zeitnah bilanziell erfaßt, Scheingewinne aber doch im Laufe der gewöhnlichen Geschäftstätigkeit steuerpflichtig, beispielsweise durch Abschreibungen zu Anschaffungskosten und nominal höhere Umsatzerlöse. Ein Währungsverlust wird dagegen erst zum Zeitpunkt der Veräußerung der QBU in voller Höhe realisiert.

Überdies sind die Folgen der Anwendung des Realisationsprinzips in der Währung des Belegenheitsstaates hier gering. Weitreichender sind die Konsequenzen einer realen Kursänderung auf die Entscheidung über die Verwendung von Gewinnen und die Fortführung einer QBU. Währungsgewinne und -verluste sind in der ausländischen wirtschaftlichen Einheit steuerfrei eingeschlossen, solange kein Kapital entnommen wird - oder sie durch eine erneute Kursänderung nivelliert werden.

Schließlich wurde ja, wie gesagt, der Vorteil der Stichtagmethode einer getrennten Ermittlung des Währungsergebnisses ohnehin nicht genutzt.

Im Handelsrecht wurde die Stichtagmethode auf Druck der Unternehmen eingeführt. ${ }^{415}$ An der jährlichen Bilanzierung von Währungsgewinnen und -verlusten im Rahmen der zuvor vorgeschriebenen Nominal-/Sachwertmethode „wurde vor allem kritisiert, daß die ausgewiesenen Jahres- und vor allem Quartalsergebnisse irreale, vom wirtschaftlichen Erfolg losgelöste Sprünge aufwiesen und daß Vergleichs- und Kennzahlen sowie Trends den wirtschaftlichen Realitäten nicht entsprächen und somit irreführend wären." $416 \mathrm{Ob}$ sich die Kapitalgeber von der Bilanzierungsform tatsächlich beeindrucken lassen, kann dahingestellt bleiben.

Der Reformentwurf des Finanzministeriums schreibt hierzu: „In einer Welt flexibler Wechselkurse ist es für Steuerpflichtige, die vorrangig in einer fremden Währung handeln, nicht angebracht, einen Währungsgewinn oder -verlust zu bilanzieren, solange er noch nicht realisiert wurde oder solange die Aktiva in diesem Währungsraum noch genutzt werden."417

Soweit die Devisenmärkte effizient sind, ist jedoch allein der zum Zeitpunkt der Gewinnfeststellung geltende Kurs richtig und somit entscheidungsneutral.

415 F.E. White, a.a.O., S. 207.

${ }^{416}$ G. Langenbucher, Umrechnung von Fremdwährungsabschlüssen, a.a.O., Rz.993. Ebenso F.E. White, a.a.O., S.207.

${ }^{417}$ R. Reagan, The Presidents Tax Proposals, a.a.O., S.414 (eigene Übersetzung). 


\section{Währungsgewinne und -verluste im deutschen Steuerrecht}

Die Besteuerung von Währungsgewinnen und -verlusten ist im deutschen Einkommen- und Körperschaftsteuergesetz, anders als in den USA, nicht geregelt. Das geltende Recht basiert hauptsächlich auf zum Teil ungeschriebenem Handelsrecht und Urteilen des Bundesfinanzhofs. Die Hintergründe der steuerlichen Behandlung in Deutschland wurden erst in den letzten Jahren in einigen Arbeiten systematisch beleuchtet, mit zum Teil differierenden Schlußfolgerungen. ${ }^{1}$

Unterschiede zum U.S.-amerikanischen Recht ergeben sich aber auch aus anderen Bereichen des Außensteuerrechts, wie im nachfolgenden Abschnitt I deutlich werden wird. Der Abschnitt bietet eine Beschreibung relevanter Grundlagen zum Verständnis des deutschen Steuerrechts. Es wird ein kurzer Überblick über die Ermittlung und Abgrenzung ausländischer Einkünfte und über die Steuersätze gegeben. Außerdem werden die Methoden zur Vermeidung doppelter Besteuerung dargestellt, die nämlich im Gegensatz zu den Vereinigten Staaten nicht nur das Anrechnungsverfahren sondern auch das Freistellungsverfahren umfassen.

Wegen des Nebeneinander der verschiedenen Verfahren zur Vermeidung von Doppelbesteuerung wird die Besteuerung des Währungsergebnisses in diesem Teil der Arbeit in zwei Abschnitten behandelt.

In Abschnitt II wird die Rechtslage in Deutschland dargestellt und hinsichtlich der Auswirkungen nicht erwarteter Wechselkursänderungen auf die Kapitalallokation analysiert. Formal läßt sich diese Einschränkung erreichen, indem die Erwartung eines konstanten Wechselkurses unterstellt wird.

Zunächst werden die für das Thema relevanten Grundsätze ordnungsmäßiger Buchführung des Handelsrechts benannt. Dabei wird eine dritte relevante Abweichung vom U.S.-Recht sichtbar werden. Als einer der „Eckpfeiler der Bilanz“2 nach deutschem Handelsrecht gilt das sogenannte Imparitätsprinzip auch im Steuerrecht. Das heißt, daß Verluste schon vor der Realisierung steuerlich zu berücksichtigen sind.

Wie lange dies noch der Fall sein wird, ist allerdings offen. In der kürzlich beschlossenen Steueränderung wurde das Prinzip erstmalig eingeschränkt: Rückstellungen für drohende Verluste aus schwebenden Geschäften dürfen seit 1997 nicht mehr gebildet werden.

Doch sind die Auswirkungen dieser asymmetrischen Bilanzierung von Währungsgewinnen und -verlusten durch das Imparitätsprinzip zumindest im Anrechnungsverfahren schwer abzuschätzen und nicht selten einzelfallabhängig.

Ausgangspunkt ist in diesem Teil die steuerliche Behandlung des Währungsergebnisses durch einzelne Geschäfte in fremden Währungen. Da im Einkommen- und Körperschaftsteuergesetz Währungsgewinne und -verluste nicht erwähnt werden, ist auch der Entstehungsort sowie der Zeitpunkt der Besteuerung dieser Einkünfte nicht explizit geregelt. Sie sind wohl überwiegend ausländischen Ursprungs. Bei Wertpapieren und Forderungen ist dies allerdings unklar.

1 G. Langenbucher, Die Umrechnung von Fremdwährungsgeschäften: Eine Untersuchung nach handels- und steuerrechtlichen Grundsätzen, Stuttgart 1988, zugl. Diss., Würzburg 1986; Institut „Finanzen und Steuern“ e. V. (Hrsg.), Heft 125, a.a.O.; U. Wlecke, Währungsumrechnung und Gewinnbesteuerung bei international tätigen deutschen Unternehmen, Düsseldorf 1989, zugl. Diss., Univ. Münster (Westf.) 1988; T. Finne, a.a.O.; P. Malinski, a.a.O.; N.-P. Schoss, a.a.O..

2 N. Herzig u. U. Rieck, Saldierungsbereich bei Drohverlustrückstellungen im Gefolge der Apothekerentscheidung, in: Der Betrieb, 50. Jg.(1997), S. 1881. 
Infolgedessen gibt es aber auch keine eindeutige Regel zur Besteuerung ausländischer Betriebstätten. Die Bilanzierung geschieht im wesentlichen analog zur Vorgehensweise bei einzelnen Fremdwährungspositionen. Auch hier steht indes der Ort der Entstehung des Währungsergebnisses nicht völlig zweifelsfrei fest.

Im Anschluß daran wird die einkommensteuerliche Behandlung von Währungsgewinnen und -verlusten bei Direktinvestitionen in Form von Zweigniederlassungen im Ausland und von wesentlichen Beteiligungen an Tochtergesellschaften untersucht und abschließend wiederum auch die Besteuerung von Privatvermögen kurz betrachtet.

In Abschnitt III werden Auswirkungen erwarteter Wechselkursänderungen analysiert. Zum einen wird der Frage nach den Auswirkungen der Charakterisierung von Währungsgewinnen und -verlusten als in- beziehungsweise ausländische Einkünfte im Rahmen des Freistellungsverfahrens nachgegangen. Zum anderen wird beleuchtet, welche Auswirkungen sich für Kapitalexport in inflationäre Währungsräume im Rahmen des Anrechnungsverfahrens ergeben. Das Imparitätsprinzip verhindert hier auf einfache Weise eine Diskriminierung solcher Auslandsengagements, eine gewisse Begünstigung ist jedoch nicht ausgeschlossen. Aber: sollte es tatsächlich zu einer (weitergehenden) Einschränkung dieses Prinzips im Steuerrecht kommen ${ }^{3}$, müßte die Besteuerung von Investitionen in hochinflationären Währungsräumen gesetzlich geregelt werden.

Abschnitt IV beschließt diesen Teil mit einer zusammenfassenden Beurteilung des deutschen Rechts im Vergleich zur Besteuerung in den USA.

\section{Grundlagen zur Besteuerung ausländischer Einkünfte}

\section{Steuersubjekte und Steuersätze}

Natürliche Personen, die ihren Wohnsitz oder gewöhnlichen Aufenthalt in Deutschland haben, sind hier mit ihren Welteinkünften unbeschränkt steuerpflichtig. ${ }^{4}$ Sie unterliegen der Einkommensteuer, die nach einem progressiven Tarif erhoben wird. Der Spitzensteuersatz beträgt $53 \% .^{5}$

Die Besteuerung juristischer Personen richtet sich nach dem Ort, an dem die Körperschaft ihre Geschäftsleitung oder ihren Sitz hat. ${ }^{6}$ Ist dies Deutschland, trifft auch sie hier grundsätzlich die unbeschränkte Steuerpflicht ihrer weltweiten Einkünfte. Das Körperschaftsteuergesetz baut auf den einkommensteuerlichen Gewinnermittlungsvorschriften auf und ergänzt sie in zahlreichen Punkten. Die Körperschaftsteuer wird proportional erhoben. Sie beträgt auf Ausschüttungen $30 \%$ des zu versteuernden Gewinnes. Einbehaltene Gewinne werden dagegen

3 Dies mutmaßt zumindest W.-P. Hoffmann, Anmerkungen zum bilanzrechtlichen Teil des Steuerreformgesetzes 1998, in: Betriebs-Berater, 52.Jg. (1997), S.1198f..

$4 \S 1$ Abs. 1 EStG i.V.m. $§ 8$ AO (Wohnsitz) bzw. §9 AO (gewöhnlicher Aufenthalt).

5 Die tarifliche Einkommensteuer beträgt, jeweils in Deutsche Mark für zu versteuernde Einkommen

1.bis 12.095 Deutsche Mark (Grundfreibetrag):

2.von 12.096 Deutsche Mark bis 55.727 Deutsche Mark:

$(86,63 \cdot y+2.590) \cdot y$

3. von 55.728 Deutsche Mark bis 120.041 Deutsche Mark:(151,94 $z+3.346) \cdot z+12.949$;

4. von 120.042 Deutsche Mark an:

$0,53 \cdot x-22.842$

„y“ ist ein Zehntausendstel des 12.042 Deutsche Mark übersteigenden Teils des abgerundeten zu versteuernden Einkommens. „z“ ist ein Zehntausendstel des 55.674 Deutsche Mark übersteigenden Teils des abgerundeten zu

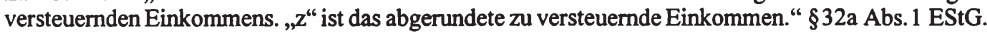

$6 \S 1$ Abs. $1 \mathrm{KStG}$ i.V.m. $§ 10 \mathrm{AO}$ (Geschäftsleitung) bzw. $\$ 11 \mathrm{AO}$ (Sitz). 
mit einem Satz von $45 \%$ belastet; ${ }^{7}$ der Unterschiedsbetrag wird aber zum Zeitpunkt der Ausschüttung erstattet. ${ }^{8}$

Da das deutsche Körperschaftsteuersystem für inländische Kapitalgesellschaften ein Vollanrechnungssystem ist, ist die gezahlte Körperschaftsteuer darüber hinaus zur Gänze auf die individuelle Einkommensteuer anrechenbar. ${ }^{9}$

Gewinne, die im Inland unbeschränkt Steuerpflichtige durch ausländische Kapitalgesellschaften erzielen, werden im allgemeinen im Inland erst zum Zeitpunkt der Ausschüttung steuerpflichtig. Dabei geschieht die Einordnung ausländischer Gesellschaften als Personenoder Kapitalgesellschaft im Einzelfall nach den leitenden Gedanken des Einkommen- und Körperschaftsteuergesetzes. ${ }^{10} \mathrm{Im}$ besonderen wird aber auch im deutschen Außensteuerrecht die Abschirmwirkung durch eine Aktivitätsklausel für Gewinne aus „passiven“ Tätigkeiten eingeschränkt. ${ }^{11}$ Ein solchen Gewinnen entsprechender Betrag wird der Bemessungsgrundlage des Steuerpflichtigen hinzugerechnet, wenn

- in Deutschland unbeschränkt Steuerpflichtige zusammen einen Anteil von über $50 \%$ des Eigenkapitals oder der Stimmrechte der ausländischen Gesellschaft halten; ${ }^{12}$

- die Gewinne als sogenannte Zwischeneinkünte anzusehen sind, das heißt wenn die Einkünfte der ausländischen Gesellschaft aus passivem Erwerb stammen, und

- auf die Einkünfte im Ausland ein Körperschaftsteuersatz von weniger als $30 \%$ zur Anwendung kommt. ${ }^{13}$

Zum Zeitpunkt der Ausschüttung der Gewinne wird dieser Hinzurechnungsbetrag mit der dann zu zahlenden Körperschaftsteuer verrechnet. ${ }^{14}$

Außer acht bleibt in dieser Arbeit die Gewerbesteuer, die die Gemeinden nach einheitlichem Recht, aber eigenen Sätzen erheben und die von der Bemessungsgrundlage der Einkommenbeziehungsweise Körperschaftsteuer abgezogen werden kann. ${ }^{15}$

\section{Arten von Einkünften}

Im deutschen Steuerrecht werden sieben Arten von Einkünften natürlicher Personen unterschieden: Einkünfte aus (1) Land- und Forstwirtschaft, (2) Gewerbebetrieb, (3) selbständiger und (4) nichtselbständiger Arbeit, (5) Kapitalvermögen, (6) Vermietung und Verpachtung und (7) sonstige Einkünfte. ${ }^{16}$ Davon sind Einkünfte der Arten (2), (5) und (6) für die Fragestellung dieser Arbeit von Interesse. Außerdem sind von den sonstigen Einkünften die sogenannten Spekulationsgewinne zu berücksichtigen. ${ }^{17}$

\footnotetext{
$\S 23 \mathrm{Abs} .1 \mathrm{KStG}$.

$\S 27$ Abs. $1 \mathrm{KStG}$.

$\S 20$ Abs. 1 Nr.3 EStG i.V.m. $\$ 36$ Abs. 2 Nr. 3 EStG.

BFH-Urteil v. 17.7.1968 I 121/64, in: BStBl. II 1968, S.695.

Vgl. hierzu die Negativaufzăhlung des $\S 8$ Abs. 1 AStG.

$\$ 7$ Abs. 2 AStG.

$\S 8$ Abs. 3 AStG.

$14 \S 10$ Abs. 2 AStG.

15 Auch der Solidaritätszuschlag wird nach einer Anmerkung am Ende dieses Abschnitts ausgeklammert.

$16 \S 2$ Abs. 1 EStG. Sonstige Einkünfte werden in $\S 22 \mathrm{EStG}$ als bestimmte Einkünfte aus wiederkehrenden Bezügen definiert.

$17 \S 22$ Nr. 2 EStG.
} 
Kapitalgesellschaften stellen einen einheitlichen Gewerbebetrieb dar. ${ }^{18}$ Sie erzielen daher auch nur Einkünfte aus Gewerbebetrieb, die sich errechnen aus der um Kapitalerhöhungen und herabsetzungen korrigierten Differenz zwischen dem Betriebsvermögen am Beginn und am Ende eines Wirtschaftsjahres. ${ }^{19}$ Maßgeblich für die Gewinnermittlung sind die handelsrechtlichen Grundsätze ordnungsmäßiger Buchführung und Bilanzierung. ${ }^{20}$ Die für diese Arbeit relevanten Grundsätze werden im Abschnitt II erläutert.

Veräußerungsgewinne oder -verluste sind, soweit die Aktiva oder Passiva für den Betrieb eines gewerblichen Unternehmens eingesetzt wurden, im deutschen Steuerrecht in gleicher Weise wie andere Gewinne oder Verluste als Einkünfte aus Gewerbebetrieb steuerpflichtig.

Natürliche Personen erzielen Einkünfte aus Gewerbebetrieb in erster Linie durch die Beteiligung an einer Personengesellschaft. ${ }^{21}$

Daneben zählen auch Gewinne oder Verluste aus der Veräußerung von Beteiligungen an Unternehmungen zu dieser Art von Einkünften. Soweit es sich dabei um eine Kapitalgesellschaft handelt ${ }^{22}$, ist aber Voraussetzung, daß der Steuerpflichtige (1) in den letzten fünf Jahren vor dem Verkauf wesentlich, das heißt zu mehr als $25 \%$, beteiligt war und sich (2) innerhalb eines Steuerjahres von mehr als einem Prozent des Kapitals der Gesellschaft trennt. ${ }^{23}$

Veräußerungsgeschäfte außerhalb der betrieblichen Sphäre sind ansonsten nur dann steuerpflichtig, wenn sie als Spekulationsgeschäfte anzusehen sind, wenn also der Zeitraum zwischen Anschaffung und Veräußerung (a) bei Grundstücken nicht mehr als zwei Jahre beziehungsweise (b) bei anderen Wirtschaftsgütern nicht mehr als sechs Monate beträgt ${ }^{24}$ oder aber, wenn der Verkauf zeitlich vor dem Kauf stattfindet. ${ }^{25}$ Spekulationsverluste können darüber hinaus nur innerhalb desselben Jahres und nur mit Spekulationsgewinnen verrechnet werden. ${ }^{26}$

Andere Veräußerungsgewinne und -verluste im Privatvermögen bleiben steuerfrei.

$\mathrm{Zu}$ den Einkünften aus Kapitalvermögen zählen insbesondere Zinsen und Dividenden. ${ }^{27} \mathrm{Sie}$ sind einkommensteuerpflichtig, falls der Freibetrag von 6.000 DM überschritten wird. ${ }^{28}$

Die positiven oder negativen Einkünfte der verschiedenen Arten ergeben zusammen das steuerpflichtige Einkommen des Steuerpflichtigen. Verluste sind zunächst horizontal mit positiven Einkünften der anderen Arten zu verrechnen. Ist das steuerliche Ergebnis in einer Periode negativ, ist ein steuerlicher Verlustausgleich oder -abzug zulässig. Verluste können zunächst bis zu zwei Jahre zurückgetragen werden. Für einen danach verbleibenden Teil ist

$18 \S 8$ Abs. 2 KStG.

$19 \S 4$ Abs. 1 EStG. Das deutsche Steuerrecht sieht neben der Methode des Betriebsvermögensvergleichs auch die Einnahmenüberschußrechnung, $§ 4 \mathrm{Abs} .3 \mathrm{EStG}$, vor.

$20 \S 5$ Abs. 1 EStG. Genau genommen ist zu unterscheiden zwischen Steuerpflichtigen, die zur Bilanzierung gemä $\beta$ $\S 5$ i.V.m. §4 Abs. 1 EStG verpflichtet sind, das heißt, die nach Handelsrecht Bücher führen ( $\$ 238 \mathrm{Abs} .1 \mathrm{HGB})$ und anhand dieser den steuerlichen Gewinn ermitteln müssen, und denen, die aufgrund von $\S 4$ Abs. 1 EStG die Steuerbilanz erstellen. Die Unterschiede implizieren aber keine gravierenden Rechtsfolgen und werden hier vernachlässigt. Blümich/R. Wacker, §4 EStG, Rz.9.

$21 \S 15$ Abs. 1 EStG.

22 Veräußerungsgewinne aus Beteiligungen an rechtlich nicht selbständigen Gewerbebetrieben sind gemäß 16 Abs. 1 EStG steuerpflichtig. Zu beachten sind aber Freibeträge beziehungsweise -grenzen. Sie werden in §16 Abs. 4 EStG genannt. Darüber hinaus wird unter Umständen der Steuersatz durch §34 EStG verringert.

$23 \S 17$ Abs. 1 EStG. Zu beachten sind aber wiederum Freibeträge beziehungsweise -grenzen, hier nach Maßgabe des $\$ 17$ Abs. 3 EStG, sowie $\$ 34$ EStG.

$24 \S 23$ Abs. 1 Nr. 1 EStG. Eine Freigrenze von 1.000DM pro Jahr wird durch $\S 23 \mathrm{Abs} .4$ EStG gewährt.

$25 \S 23$ Abs. 1 Nr. 2 EStG.

$26 \S 23$ Abs. 4 EStG.

$27 \S 20$ Abs. 1 Nr. 1 u. Nr.5 EStG.

$28 \S 20$ Abs. 4 EStG. 
der Abzug von positiven Einkünften der folgenden Perioden zulässig. ${ }^{29}$ Dabei gelten keine besonderen Regeln für gewerbliche Veräußerungsverluste. Im Unterschied zu den USA besteht auch eine zeitliche Beschränkung des Verlustvortrags nicht mehr.

Die Verlustvortrags- und Verlustrücktragsmöglichkeiten gelten in entsprechender Weise für Kapitalgesellschaften. ${ }^{30}$

\section{Arten von ausländischen Einkünften}

Ausländische Einkünfte werden im Einkommensteuergesetz der Art nach im wesentlichen wie inländische Einkünfte differenziert. Demnach sind für die Bemessung der Einkommen- und Körperschaftsteuer ${ }^{31}$ unter anderem ausländischen Ursprungs: ${ }^{32}$

- Einkünfte aus Gewerbebetrieb, wenn sie (a) durch eine im Ausland belegene Betriebstätte oder auch durch einen dort tätigen ständigen Vertreter erwirtschaftet werden, oder wenn sie (b) zu den drei nachfolgend genannten Einkünften gehören (außer Spekulationsgewinnen) und einem inländischen Gewerbebetrieb zufließen;

- Veräußerungsgewinne bei Aktiva, die im Ausland belegen sind und zum Anlagevermögen eines Betriebes zählen, sowie aus der Veräußerung von Beteiligungen an ausländischen Kapitalgesellschaften;

- Einkünfte aus Kapitalvermögen, wenn der Zahlungsverpflichtete seinen Wohnsitz beziehungsweise die Geschäftsleitung oder den Sitz im Ausland hat; ${ }^{33}$

- Veräußerungsgewinne aus dem Verkauf immobiler Aktiva, wenn das Realkapital im Ausland installiert ist und schließlich

- Spekulationsgewinne, wenn das Wirtschaftsgut im Ausland belegen ist.

Einkommen, das im Gesetzestext nicht ausdrücklich ausländischen Quellen zugewiesen wird, ist inländischen Ursprungs, ${ }^{34}$ auch wenn ein Bezug zum Ausland besteht. ${ }^{35}$ Die Qualifizierung der Art nach ist in gleicher Weise wie auch bei inländischen Gewinnen nach ihrem wirtschaftlichen Zusammenhang vorzunehmen. ${ }^{36}$ Das Steuerrecht liefert hierzu allerdings keine weiteren Hinweise. Der Ort des Anfalls - und auch die Währung, auf die er lautet - ist jedenfalls irrelevant. ${ }^{37}$

Die Bestimmung der Quelle gewerblicher Einkünfte geschieht im nationalen Steuerrecht zum einen nach Maßgabe der in der Abgabenordnung definierten Betriebstätte. Eine Betriebstätte ist hiernach ,jede feste Geschäftseinrichtung, die der Tätigkeit eines Unternehmens dient." ${ }^{38}$ Voraussetzung ist außerdem ein längerfristiges Engagement in dem Land. ${ }^{39}$ Ein konkreter Zeit-

$29 \S 10 d$ Abs. 1 u. Abs. 2 EStG.

$30 \S 10$ d Abs. 1 EStG i.V.m. §8 Abs. $1 \mathrm{KStG}$. Für Körperschaften wird gemäß $§ 8 \mathrm{Abs} .5 \mathrm{KStG}$ der Verlustrücktrag aber auf den nicht ausgeschütteten Teil des Gewinnes der Rücktragsjahre beschränkt.

31 Flick/Wassermeyer/Becker, §34d EStG, Rz. 8.

32 §34d EStG; Flick/Wassermeyer/Becker, §34d EStG, Rz.18-27.

33 Dies sind insbesondere Zinsen und Dividenden. Flick/Wassermeyer/Becker, §34d EStG, Rz. 156-168.

34 Flick/Wassermeyer/Becker, §34d EStG, Rz.13; Blümich/H. Krabbe, §34d EStG, Rz.1.

35 P. Malinski, a.a.O., S.43.

36 W. Heinicke, in: Einkommensteuergesetz, Kommentar, Hrsg. L. Schmidt, 15.Aufl., München 1996, §4 EStG, Rz.7.

37 Oberfinanzdirektion Frankfurt am Main, Rundverfügung v. 14. Oktober 1988, S 2293 A-55-St II 20, in: DStR, 27.Jg. (1989), S.508.

$38 \S 12 \mathrm{AO}$.

39 A. Fey, Betriebsstättenbesteuerung, in: Deutsches Steuerlexikon, Hrsg. J. Schaeberle u. H. Utech, München 1997, S. 2. 
raum wird allerdings im Steuerrecht und auch durch die Rechtsprechung im allgemeinen nicht vorgegeben. Nur für Bauausführungen wird eine zeitliche Bindung von wenigstens sechs Monaten genannt. ${ }^{40}$

Der Begriff wird im Gesetz aber durch eine Liste von Beispielen konkretisiert. ${ }^{41}$ Genannt werden unter anderem: eine Stätte der Geschäftsleitung, eine Zweigniederlassung, eine Geschäftsstelle, eine Fabrikations- oder Werkstätte, ein Warenlager oder eine Ein- oder Verkaufsstelle.

Ausländischen Ursprungs sind sämtliche Gewinne und Verluste, die der Betriebstätte zuzurechnen sind. Hierzu zählen nach dem sogenannten Betriebstättenvorbehalt auch Dividenden und Zinsen sowie Lizenzgebühren, die der Betriebstätte zufließen. ${ }^{42}$ Die Ermittlung des Betriebstättenergebnisses erfordert die Aufstellung einer eigenen Steuerbilanz nach den Vorschriften des deutschen Steuerrechts. ${ }^{43}$ Handelsrechtlich sind Betriebstätten aber keine selbständigen Einheiten. Infolgedessen ist das Gesamtunternehmen Träger der Steuerpflicht. Zum anderen liegen aber auch dann ausländische Einkünfte aus Gewerbebetrieb vor, wenn sie unter die anderen oben genannten Kriterien fallen, aber nicht einer Einzelperson, sondern einem Gewerbebetrieb zufließen. Ohne diese Erweiterung wären rechtssystematisch solche Gewinne zwangsläufig inländischer Herkunft: Sie werden einerseits im Inland als Einkünfte aus Gewerbebetrieb qualifiziert und fallen damit nicht unter die Quellenregeln für die übrigen Einkunftsarten. Sie sind aber andererseits nicht einer im Ausland belegenen Betriebstätte oder einen dort tätigen ständigen Vertreter zurechenbar. ${ }^{44}$

Grundsätzlich fällt, dem Welteinkommensprinzip folgend, auch ein ausländischer Verlust unter diese Bestimmungen. Die Zulässigkeit der Verrechnung ausländischer Verluste mit ausländischen oder inländischen Gewinnen für die Ermittlung der deutschen Steuerlast wird aber durch einen Aktivitätsvorbehalt für Verluste aus Aktivitäten eingeschränkt, die nach der Auffassung des Deutschen Bundestages nicht „im Interesse der deutschen Volkswirtschaft liegen". 45

Negative ausländische Einkünfte, die nicht im Zusammenhang mit aktiven gewerblichen Tätigkeiten entstehen, dürfen „nur mit positiven Einkünften der jeweils selben Art aus demselben Staat [...] ausgeglichen werden". 46 Ein Ausgleich mit positiven inländischen Einkünften ist demnach für derartige Verluste ausgeschlossen. Nicht zulässig ist außerdem ein Rücktrag. Eine zeitliche Beschränkung des Vortrags derartiger negativer Einkünfte zur Verrechnung mit positiven Einkünften zukünftiger Perioden derselben Art aus demselben Staat gibt es hingegen nicht mehr.

$40 \S 12 \mathrm{Nr} .8 \mathrm{AO}$. Die Frist wird in Doppelbesteuerungsabkommen auf bis zu zwölf Monate verlängert.

41 Die Beispiele sind nicht als abschließende Aufzählung anzusehen. A. Fey, Betriebsstättenbesteuerung, a.a.O., S. 2 .

42 H. Debatin, Probleme der internationalen Doppelbesteuerung, in: Handbuch der Finanzwissenschaft Band IV. Hrsg. Frank Neumark, 3.Aufl., Tübingen 1983, S.305f..

43 Abschn.212d 2. Satz EStR, August 1994; P. Malinski, a.a.O., S.45 m.w.N.

44 Blümich/J. Täske, §26 KStG, Rz23.

45 BT-Drucks.9/2074, S.62; zitiert nach R. Plückebaum, Verlustausgleichsbeschränkung, a.a.O., S.387. Gemeint waren hierbei insbesondere Investitionen von Verlustzuweisungsgesellschaften. BT-Drucks. 9/2074, S. 62.

$46 \S 2 \mathrm{a}$ Abs. 1 EStG. 


\section{Zurechnung von Betriebsausgaben}

„Betriebsausgaben sind die Aufwendungen, die durch den Betrieb veranlaßt sind.“47 Die Zurechnung dieser Aufwendungen ist nach deutschem Recht die vom Einzelfall abhängige Entscheidung des Steuerpflichtigen und der Finanzverwaltung. Maßstab ist immer die Frage nach der Veranlassung. Dafür ist auch hier der wirtschaftliche Zusammenhang entscheidend. ${ }^{48}$ Ein wirtschaftlicher Zusammenhang wird als gegeben angesehen, wenn die Entstehung der Aufwendungen ursächlich und unmittelbar auf wirtschaftliche Vorgänge zurückzuführen ist, welche die Einkünfte der jeweiligen Einkunftsart betreffen. Dabei ist eine unmittelbare Beziehung der Aufwendungen zu den Einkünften aber nicht notwendig. Nicht allein erheblich sind auch rechtliche, räumliche oder zeitliche Gegebenheiten ${ }^{49}$ und in welcher Währung die Aufwendungen angefallen sind. ${ }^{50}$ Es reicht, wenn ein wirtschaftlicher Zusammenhang mit dem Steuerobjekt - etwa der Betriebstätte - besteht. $^{51}$

Für Zinsaufwendungen bedeutet dies konkret, daß genau die Fremdkapitalkosten einer Betriebstätte zuzurechnen sind, die mit Krediten zusammenhängen, die für die Zwecke der Betriebstätte aufgenommen wurden. Ob sie durch die Betriebstätte aufgenommen wurden, ist unerheblich, wenn das Fremdkapital nachweislich an diese weitergeleitet wurde. ${ }^{52}$

\section{Anrechnungs-, Freistellungs- und Abzugsmethode}

Bei der Bemessung der Einkommensteuer wird als unilaterale Maßnahme die Anrechnung „einer der deutschen Einkommensteuer entsprechenden Steuer“, die im Ausland gezahlt wurde und keinem Ermäßigungsanspruch mehr unterliegt, gestattet. ${ }^{53}$

In gleicher Weise ist die direkte Anrechnung für inländische juristische Personen auf die deutsche Körperschaftsteuer zulässig. ${ }^{54}$

In indirekter Form ist eine Anrechnung dann möglich, wenn die inländische Kapitalgesellschaft in den zwölf Monaten vor dem Ende des Veranlagungszeitraums zu wenigstens zehn Prozent am Nennkapital einer ausländischen Tochtergesellschaft beteiligt war - allerdings nur dann, wenn Gewinne nicht durch die ausländische Gesellschaft einbehalten werden. Nach deutschen Recht kann die indirekte Steueranrechnung ausländischer Körperschaftsteuern in späteren Wirtschaftsjahren nicht beansprucht werden. ${ }^{55}$ Bei einer späteren Ausschüttung bleibt nur die direkte Anrechnung etwaiger ausländischer Quellensteuern offen.

Auch ein Vor- oder Rücktrag von Anrechnungsüberhängen ist nicht möglich. Außerdem gilt kraft Rechtsverordnung eine Pro-Staat-Begrenzung; ${ }^{56}$ wenn die ausländischen Einkünfte aus

$47 \S 4$ Abs. 4 EStG.

48 Abschn.R212b EStR; BFH-Urteil v. 16.3.1994 I R 42/93, in: BStBl. II 1994, S.799-802; Institut „Finanzen und Steuern" e. V. (Hrsg.), Heft 125, a.a.O., S.9-12 m.w.N..

49 Abschn. R212b EStR; Herrmann/Heuer/Raupach, §50 EStG, Rz.40f.; Blümich/H. Krabbe, §34d EStG, Rz49; P. Malinski, a.a.O., S.54.

50 Oberfinanzdirektion Frankfurt am Main, a.a.O., S.508; FG Hamburg Urteil v. 26.4.1995 VII 101/92 (n-rkr), in: EFG 1995, Entscheidung Nr.725, S.871.

51 P. Malinski, a.a.O., S.52- 55 mit Verweis auf G. Strutz, Kommentar zum Einkommensteuergesetz vom 10. August 1925 nebst Ausführungsbestimmungen, Berlin 1927, §15 EStG, Rz. 19 u. m.w.N..

52 BFH-Urteil v. 27.7.1965 I 110/63 S, in: BStBl. III 1966, S. 27 f..

$53 \S 34 \mathrm{c}$ Abs. 1 Satz 1 EStG.

$54 \S 26$ Abs. $1 \mathrm{KStG}$.

$55 \S 26$ Abs. 2 KStG.

56 Oberfinanzdirektion Frankfurt am Main, a.a.O., S.508. 
mehreren Staaten stammen, ist der Anrechnungshöchstbetrag für jedes Land getrennt zu ermitteln. ${ }^{57}$ Eine Unterscheidung nach der Art der Einkünfte wird demgegenüber nicht getroffen. Die Charakterisierung erfolgt nur zur Identifikation ausländischen Einkommens und der Zurechnung der damit in wirtschaftlichem Zusammenhang stehenden Aufwendungen.

Der Höchstbetrag errechnet sich somit gemäß:

[D1] $\begin{gathered}\text { Anrechnungs- } \\ \text { höchstbetrag für } \\ \begin{array}{c}\text { Einkünfte } \\ \text { aus einem Land }\end{array}\end{gathered}=\frac{\begin{array}{c}\text { steuerpflichtige } \\ \text { Einkünfte des Landes }\end{array}}{\text { steuerpflichtige }} \begin{gathered}\begin{array}{c}\text { Steuerschuld im } \\ \text { Wohnsitzland auf die } \\ \text { Welteinkünfte }\end{array} \\ \begin{array}{c}\text { Welteinkünfte vor der } \\ \text { Anrechnung der Steuern } \\ \text { des anderen Landes }\end{array}\end{gathered}$.

Daneben wurde aber in der Mehrzahl der von Deutschland abgeschlossenen Doppelbesteuerungsabkommen unter bestimmten Voraussetzungen die Freistellung ausländischer Einkünfte als Grunderleichterung verankert. ${ }^{58}$

Freigestellt werden regelmäßig Einkünfte, die durch unbewegliches Vermögen erzielt werden, das im anderen Vertragsstaat belegen ist. Freigestellt werden außerdem Gewinne aus der Veräußerung dieser Wirtschaftsgüter. ${ }^{59}$ Gleiches gilt beim Verkauf von Gesellschaftsanteilen. Zinseinkünfte und Dividenden werden indes zumeist nicht freigestellt. 60

Freigestellt werden Gewinne, die einer gewerblichen Betriebstätte nach Maßgabe der Definition im Abkommenstext ${ }^{61}$ - die regelmäßig nicht identisch ist mit der Abgrenzung nach nationalem Recht $^{62}$ - in einem Abkommenstaat zuzurechnen sind;63 dazu gehören auch Veräußerungsgewinne. ${ }^{64}$ Der Begriff im jeweiligen Abkommen dient aber nur der Zurechnung und nicht der Ermittlung der Einkünfte. Die Feststellung des Gewinns ist nach der Abgrenzung des nationalen Steuerrechts vorzunehmen. ${ }^{65}$

Auch Ausschüttungen ausländischer Kapitalgesellschaften werden in den Abkommen von der deutschen Steuerpflicht befreit, sofern der inländische Steuerpflichtige eine juristische Person ist und an der ausländischen Gesellschaft wesentlich - das heißt zu wenigstens zehn Prozent ${ }^{66}$ beteiligt ist. ${ }^{67}$ Gewinne aus der Liquidation, der Kapitalherabsetzung und der Veräußerung solcher Gesellschaften fallen nach Abkommensrecht dem Sitzland der Muttergesellschaft

$57 \S 34 \mathrm{c}$ Abs.7 Nr.1 EStG i.V.m. §68a EStDV. Dabei geht die direkte Anrechnung gemäß §26 Abs.2 Satz $6 \mathrm{KStG}$ der indirekten Anrechnung vor.

$58 \mathrm{H}$. Debatin, Das Betriebsstättenprinzip der deutschen Doppelbesteuerungsabkommen, in: Der Betrieb, 42.Jg. (1989), S. 1693. Vgl. auch die Aufstellung in Anhang IV auf Seite 222.

59 Art.13 OECD-MA i.V.m. Art.23A Abs.2 OECD-MA.

60 Vgl. K.Vogel, Doppelbesteuerungsabkommen der Bundesrepublik Deutschland auf dem Gebiet der Steuern vom Einkommen und Vermögen: Kommentar auf der Grundlage der Musterabkommen. 3., völlig neubearb. Aufl., München 1996, S.1428-1461.

61 Hier gilt der dem Art. 7 Abs. 1 OECD-MA entsprechende Abkommenstext.

62 Im Musterabkommen der OECD ist die Definition der Betriebstätte enger gefaßt als im deutschen Steuerrecht in $\S 12 \mathrm{AO}$. Die wichtigsten Unterschiede ergeben sich aus der negativen Aufzählung im Art. 5 Abs. 4 OECD-MA. Hiernach sind beispielsweise Zentren der Verkaufsförderung, Dienstleistungszentren, Verarbeitungslager, Einkaufs- und Dokumentationsbüros sowie Forschungslaboratorien keine Betriebstätten. In den meisten Abkommen, die von Deutschland abgeschlossen wurden, ist die Definition des Musterabkommens übernommen worden. A. Fey, Betriebsstättenbesteuerung, a.a.O., S.2f..; H. Debatin, Das Betriebsstättenprinzip der deutschen Doppelbesteuerungsabkommen, a.a.O., S. 1693 ff..

63 Art. 7 Abs. 2 OECD-MA.

64 Art. 13 Abs. 2 OECD-MA.

65 H. Debatin, Das Betriebsstättenprinzip der deutschen Doppelbesteuerungsabkommen, a.a.O., S. 1695.

66 H. Debatin, StÄndG 1992 und „Treaty Override“, in: Der Betrieb, 45.Jg. (1992), S.2160.

$67 \S 26$ Abs. 2 Satz 1 KStG. 
zu. ${ }^{68}$ Sie werden in Deutschland seit dem Inkrafttreten des Standortsicherungsgesetzes jedoch nicht mehr besteuert. 69

Zum Zeitpunkt der Ausschüttung durch die inländische Gesellschaft unterliegen die ausländischen Nettogewinne auf der Ebene der Anteilseigner aber in voller Höhe der persönlichen Einkommensteuer - der sogenannte Nachholeffekt der deutschen Körperschaftsteuer. ${ }^{70}$ Die Anrechnung der ausländischen Steuer auf die Einkommensteuer der Anteilseigner der inländischen Muttergesellschaft ist nicht vorgesehen. ${ }^{71}$

Ist die ausländische Steuer auf der Ebene der inländischen Kapitalgesellschaft dagegen nur anrechenbar, mindert die auf die ausländischen Einkünfte gezahlte inländische Körperschaftsteuer bei deren Ausschüttung in gleicher Höhe die persönliche Einkommensteuer. ${ }^{72}$

Die Gesamtbelastung errechnet sich aus Sicht der inländischen Aktionäre somit sowohl bei Freistellung als auch bei Anrechnung auf der Ebene der Gesellschaft nach dem Abzugsverfahren, vorausgesetzt die Anteilseigner sind steuerpflichtig.

Unterschiede können sich jedoch hinsichtlich der Zeitpunkte der Steuerzahlung ergeben. Auf Grund dessen ist es fraglich, ob bei Freistellung ausländischer Einkünfte auf der Ebene der inländischen Kapitalgesellschaft tatsächlich eine wirtschaftliche Doppelbelastung besteht. Sie ist zumindest dann nicht gegeben, wenn die ausländischen Gewinne niemals ausgeschüttet werden und Veräußerungsgewinne auf Seiten der Anteilseigner nicht steuerpflichtig sind. ${ }^{73}$ Unter diesen Umständen kann der Gewinn in Form eines Marktwertzuwachses der Beteiligung von dem einzelnen Aktionär jederzeit durch Veräußerung steuerfrei realisiert werden.

Welche quantitative Bedeutung der Effekt in der Realität hat, ist unklar. Immerhin wurde die Vermeidung doppelter Belastung bei freigestellten ausländischen Einkünften aber als Erklärung für die hohen Bestände an Finanzaktiva deutscher multinationaler Konzerne angeführt, als „Siemens-Effekt". ${ }^{74}$

Die Freistellung ist auf unterschiedliche Weise an einen Aktivitätsvorbehalt geknüpft: In den meisten deutschen Doppelbesteuerungsabkommen wird die Befreiung von der deutschen Besteuerung nur gewährt, wenn die Einnahmen der Betriebstätte oder Tochtergesellschaft ausschließlich oder zu einem festen Anteil aus aktiven Tätigkeiten stammen. ${ }^{75}$ Stammen die Einkünfte nicht, beziehungsweise nicht im erforderlichen Umfang aus einer solchen aktiven Tätigkeit, ist nur die Anrechnung der im Ausland gezahlten Steuern zulässig. ${ }^{76}$

Soweit die ausländische Gesellschaft eine Kapitalgesellschaft ist, greift hier außerdem die Hinzurechnungsbesteuerung. Auch ein Steuervorteil infolge eines zeitlichen Aufschubs der Besteuerung durch Thesaurierung im Ausland ist dann nicht gegeben.

68 Art. 13 Abs. 4 OECD-MA.

$69 \S 8$ b Abs. 2 KStG; O.H. Jacobs, a.a.O., S.619f..

$70 \mathrm{Vgl}$. A.J. Weichenrieder, Freistellungsverfahren und Nachholeffekt, Münchener wirtschaftswissenschaftliche Beiträge Nr. 93-12, München 1993, S.1-4 m.w.N..

71 O.H. Jacobs, a.a.O., S.395.

72 K.-M. Wilke, Die Besteuerung ausländischer Einkünfte im Körperschaftsteuersystem, in: IWB Fach 3 Gruppe 4 Deutschland, S. $343 \mathrm{f}$..

73 Vgl. A.J. Weichenrieder, Freistellungsverfahren und Nachholeffekt, a.a.O.; ders., Besteuerung und Direktinvestition, a.a.O., S.127-138. Möglicherweise ist die Annahme der dauerhaften Nichtausschüttung nicht notwendig, wenn die Marktteilnehmer erwarten, das zu einem zukünftigen Zeitpunkt die Rechtslage geändert wird. Schon im Rahmen des Standortsicherungsgesetz war ursprünglich geplant, die Einkünfte auch bei Weiterausschüttung freizustellen.

74 A.J. Weichenrieder, Freistellungsverfahren und Nachholeffekt, a.a.O., S. 16-18; ders. Besteuerung und Direktinvestition, a.a.O., S.135-138.

75 K. Vogel, Doppelbesteuerungsabkommen, a.a.O., S. 1487.

76 Für eine Zusammenstellung der aktiven und passiven Tätigkeiten in Doppelbesteuerungsabkommen Deutschlands vgl. K. Vogel, Doppelbesteuerungsabkommen, a.a.O., S.1428-1461. 
Bei einer Veräußerung der Gesellschaft können Hinzurechnungsbeträge vergangener Perioden mit der Veräußerungsgewinnbesteuerung verrechnet werden - allerdings nur, soweit die Zahlungen nicht mehr als vier Jahre zurückliegen. ${ }^{77}$

Bei der Bemessung der Zugriffbesteuerung sind aber die Bestimmungen der Doppelbesteuerungsabkommen anzuwenden. ${ }^{78}$ Deshalb ist diese Vorschrift praktisch bedeutungslos, wenn kraft Abkommen ausländische Gewinne freigestellt werden. ${ }^{79}$

Da in älteren Doppelbesteuerungsabkommen das Vorliegen aktiver Tätigkeiten noch nicht als Voraussetzung für die Freistellung im Inland vereinbart wurde, ist die Hinzurechnungsbesteuerung im nationalen Außensteuerrecht auf sogenannte Zwischeneinkünfte mit Kapitalanlagecharakter ausgedehnt worden. ${ }^{80}$ Dies sind unter anderem Gewinne der ausländischen Gesellschaft aus dem Halten oder der Werterhöhung von Zahlungsmitteln, Forderungen und Wertpapieren, soweit die Beteiligung an einer dritten Gesellschaft zehn Prozent nicht übertrifft. ${ }^{81}$

Derartige Einkünfte haben unabhängig von Abkommenstexten in der Periode ihrer Entstehung eine Steuerpflicht im Inland zur Folge ${ }^{82}$, wenn (i) die ausländische Niederlassung überwiegend solche Zwischeneinkünfte erzielt, (ii) der Steuersatz im Ausland unter 30\% liegt und (iii) der Steuerinländer zu mindestens zehn Prozent an der Gesellschaft beteiligt ist ${ }^{83}$. Bei der späteren Ausschüttung sind sie dann freigestellt. ${ }^{84}$

Die zuletzt genannten Einschränkungen gelten auch für ausländische Betriebstätten. Das heißt: wenn Einkünfte mit Kapitalanlagecharakter in der Betriebstätte anfallen, wird eine im Abkommen vereinbarte Freistellung verwehrt. Statt dessen ist nur die Anrechnung der auf diese Einkünfte erhobenen ausländischen Steuern zulässig. ${ }^{85}$

Ein Gewinn aus der Veräußerung der Gesellschaft wird durch die Zugriffbesteuerung für Zwischeneinkünfte mit Kapitalanlagecharakter nicht berührt. ${ }^{86}$ Er unterliegt den Abkommensregeln und ist deshalb im Inland von der Besteuerung freigestellt.

Die Abzugsmethode ist im deutschen Steuerrecht im allgemeinen nicht gestattet, weil auch ausländische Einkommen- und Körperschaftsteuern zu den nicht abziehbaren Personensteuern zählen. ${ }^{87} \mathrm{Im}$ besonderen ist der Abzug der ausländischen Steuer von der deutschen Bemessungsgrundlage aber als Wahlrecht dann möglich, wenn auch deren Anrechnung zulässig ist. ${ }^{88}$ Die Wahl zwischen Anrechnungs- und Abzugsmethode kann für jeden Staat und jedes Jahr separat getroffen werden, für alle Einkünfte aus einem Land aber nur einheitlich. ${ }^{89}$

$77 \S 11$ Abs. 3 AStG.

$78 \S 10$ Abs. 5 AStG. Besteht kein Abkommen, ist die Anrechnung zulässig kraft § 12 Abs. 1 AStG.

79 H. Debatin, StÄndG 1992 und „Treaty Override“, a.a.O., S.2160.

80 H. Debatin, StÄndG 1992 und „Treaty Override“, a.a.O., S.2162.

$81 \S 10$ Abs. 6 AStG.

82 Die Anrechnung ist hier gemäß $§ 12$ Abs. 3 AStG zulässig.

$83 \S 7$ Abs. 6 AStG.

$84 \S 11$ Abs. 6 AStG.

$85 \S 20$ Abs. 1 AStG.

$86 \S 11$ Abs. 4 AStG.

87 §12 Abs. 3 EStG; Institut „Finanzen und Steuern“ e.V., Heft 125, a.a.O., S.32.

$88 \S 34 \mathrm{c}$ Abs. 2 EStG beziehungsweise $\S 26$ Abs. $6 \mathrm{KStG}$. Abziehbar sind gemäß §34c Abs. 3 EStG außerdem noch ausländische Steuern, die nicht der deutschen Einkommensteuer entsprechen oder die in einem dritten Staat angefallen sind.

89 L. Fischer u. P. Warneke, a.a.O., S. 149. 


\section{Eine Anmerkung zum Solidaritätszuschlag}

Derzeit wird in Deutschland zudem ein Solidaritätszuschlag in Form einer Ergänzungsabgabe als Prozentsatz der nach den allgemeinen Regeln des deutschen Steuerrechts festgestellten Einkommen- oder Körperschaftsteuer erhoben. ${ }^{90}$ Der Satz beträgt derzeit 7,5\% und soll ab 1998 auf 5,5\% gesenkt werden. Steuersubjekte der Abgabe sind alle natürlichen und juristischen Personen, die im Inland unbeschränkt oder beschränkt steuerpflichtig sind. ${ }^{91}$

Ausländische Einkünfte unterliegen infolgedessen nicht dem Solidaritätszuschlag, wenn sie im Inland freigestellt sind. Bei Einkünften aus aktiven Tätigkeiten der meisten ausländischen Betriebstätten ist der Zuschlag deshalb gegenstandslos.

Anders ist die Situation, wenn im Ausland gezahlte Steuern im Inland lediglich anrechenbar sind. Hier kann infolge des Zuschlages Kapitalexport begünstigt werden. Warum? Die Höhe des Solidaritätszuschlages leitet sich nur aus der festgestellten inländischen Einkommen- oder Körperschaftsteuer ab. Da diese aber durch die Anrechnung vergleichbarer ausländischer Steuern gemindert wird, fällt der Zuschlag umso geringer aus, je höher die Anrechnungsgutschrift.

Die Gesamtsteuerlast auf ausländisches Einkommen ist am geringsten, wenn ausländische Steuer gerade der deutschen Einkommen- oder Körperschaftsteuer vor Berücksichtigung der Anrechnungsgutschrift entspricht. Sie ist in diesem Fall gerade um die Höhe des Solidaritätszuschlages geringer als die Belastung vergleichbarer inländischer Kapitaleinkünfte.

Aufgrund dieser zusätzlichen Schwierigkeit im Rahmen des Anrechnungsverfahrens wird der Solidaritätszuschlag - in der Vermutung, daß er nur eine vorübergehende Erscheinung ist - hier nicht weiter beachtet.

\section{Die einkommensteuerliche Behandlung von Währungsgewinnen und -verlusten}

\section{Elementare Grundsätze ordnungsmäßiger Buchführung}

Die einkommensteuerliche Behandlung von Gewinnen und Verlusten aus Wechselkursfluktuationen ist, wie schon erwähnt, in den deutschen Steuergesetzen nicht geregelt. Doch gilt in Deutschland das Maßgeblichkeitsprinzip, das heißt die Handelsbilanz ist maßgeblich für die Steuerbilanz, soweit das Steuerrecht nichts anderes vorschreibt. ${ }^{92}$ Nur beinhaltet das Handelsgesetzbuch ebenfalls keine expliziten Vorschriften zur Bilanzierung von Auswirkungen von Währungsfluktuationen auf Ertrag und Vermögen. Dort heißt es lediglich: „Der Jahresabschluß ist in deutscher Sprache und in Deutscher Mark aufzustellen."93 Es heißt aber auch: „Der Jahresabschluß ist nach den Grundsätzen ordnungsmäßiger Buchfuihrung aufzustellen“.94

$90 \S 4$ SolZG.

$91 \S 2$ SolZG.

92 Dies trifft gemäß $\S 5$ Abs. 1 EStG zu für Kaufleute und andere Gewerbetreibende, die aufgrund gesetzlicher Vorschriften zur Buchfuihrung verpflichtet sind. Vgl. auch U. Wlecke, a.a.O., S. $108 \mathrm{ff}$.

$93 \S 244$ HGB; G. Gebhardt u. N. Breker, a.a.O., S. 1529. Allerdings sprechen Tipke und Lang inzwischen auch von einer "Umkehrmaßgeblichkeit", da in neuerer Zeit steuerrechtliche Wahlrechte teilweise nur eingeräumt werden, wenn sie auch in der Handelsbilanz umgesetzt werden. Vgl. K. Tipke u. J. Lang, Steuerrecht, a.a.O., S.229f.; A.G. Coenenberg, a.a.O., S.74f..

$94 \S 243$ Abs. 1 HGB. 
Die Grundsätze ordnungsmäßiger Buchführung sind ein sogenannter unbestimmter Rechtsbegriff; sie werden auf dem Wege der Gesetzesauslegung unter Zuhilfenahme von außergesetzlichen Normen und Erkenntnisquellen ausgefullt. Ausschlaggebend zur Herleitung der Grundsätze sind die Zwecke des Jahresabschlusses. ${ }^{95}$ Dies ermöglicht es einerseits, flexibel auf Veränderungen der ökonomischen Umwelt zu reagieren. Es ist ein Spielraum gegeben für eine „sinnvolle Fortentwicklung der Grundsätze ordnungsmäßiger Buchführung und deren Anpassung an veränderte Verhältnisse" des Wirtschaftslebens und der Technik. ${ }^{96} \mathrm{Im}$ übrigen würde dadurch zugleich der Gefahr vorgebeugt, durch zu starke Theoretisierung die praktische Handhabung zu vernachlässigen. ${ }^{97}$

Bei Fragen hinsichtlich der Bilanzierung wird deshalb an erster Stelle geprüft, ob es möglich ist, die Grundsätze sinngemäß anwenden beziehungsweise weiterentwickeln zu können. ${ }^{98}$ Erst wenn auf diesem Weg keine Lösung sichtbar wird, richtet sich der Blick zum Gesetzgeber.

Andererseits sind aber die Ziele der Handelsbilanz nicht notwendigerweise kompatibel mit denen der Steuerbilanz. ${ }^{99}$ Das wesentliche Ziel der Handelsbilanz ist die Bereitstellung von Informationen. ${ }^{100}$ Für die Steuerbilanz trifft das so nicht zu. Das Ergebnis dieses Zahlenwerks hat eine unmittelbare Rechtsfolge, nämlich die Pflicht zur Zahlung der Steuer.

Die Maßgeblichkeit wird deshalb durch einen Bewertungsvorbehalt eingeschränkt. Handelsrechtliche Aktivierungs- und Passivierungsgebote und -verbote zwingen zu übereinstimmender Bilanzierung in der Steuerbilanz. Handelsrechtliche Aktivierungs- oder Passivierungswahlrechte implizieren für die Steuerbilanz indessen ebenfalls Ge- beziehungsweise Verbote, soweit nicht auch das Steuerrecht das Wahlrecht ausdrücklich einräumt. ${ }^{101}$ Steuerrechtliche Sondervorschriften ergänzen und modifizieren außerdem die Höhe der Bewertungsansätze, betreffend insbesondere die Zulässigkeit von Abschreibungen.

Für die Besteuerung von Währungsgewinnen und -verlusten sind folgende Grundsätze relevant: 102

Schon aus Teil C bekannt ist das Realisationsprinzip. Es fordert, Gewinne nicht vor der Realisierung zu bilanzieren. Statt dessen sind Aktiva höchstens mit den Anschaffungs- oder Herstellungskosten, vermindert um planmäßige Abschreibungen, ${ }^{103}$ und Passiva mit dem Rückzahlungsbetrag zu bewerten.

95 J. Baetge, Grundsätze ordnungsmäßiger Buchführung, In: Der Betrieb, 39.Jg. (1986), Beilage 26 zu Heft 45, S.2f.; H. Biener, W. Berneke, Bilanzrichtlinien-Gesetz, Düsseldorf, 1986, S. 59.

96 Rechtsausschuß des Deutschen Bundestages, Unterausschuß „Bilanzrichtlinien-Gesetz“, Entwurf eines Gesetzes. Zitiert nach J. Baetge, Grundsätze ordnungsmäßiger Buchführung, a.a.O., S.2.

97 T. Finne, a.a.O., S.50f.; H. Biener, W. Berneke, a.a.O., S.59.

98 M. Groh, Zur Bilanzierung von Fremdwährungsgeschäften, in: Der Betrieb, 39.Jg. (1986), S.875; J. Baetge, Grundsätze ordnungsmäßiger Buchführung, a.a.O., S.3.

$99 \mathrm{Vgl}$. Fußnote 22 auf Seite 84 dieser Arbeit.

${ }^{100}$ Aus der Informationsfunktion leiten sich die konkreten Zwecke des Vermögens- und Erfolgsausweises, des Gläubigerschutzes, der Kapitalerhaltung und Ausschüttungsbemessung sowie Rechenschaft ab. Vgl. hierzu U. Leffson, Die Grundsätze ordnungsmäßiger Buchführung, 7.Aufl., Düsseldorf 1987, S.38f.; J. Baetge, Grundsätze ordnungsmäßiger Buchfuihrung, a.a.O., S.5-15; B. Knobbe-Keuk, Bilanz- und Unternehmensteuerrecht, 9. Aufl., Köln 1993, S. 18. Vgl. auch W. Stützel, Bemerkungen zur Bilanztheorie, a.a.O., S.322-328.

Aus der Bilanz können sich Rechtsfolgen ableiten, etwa der Konkurs. Auch der Konkurs ist aber eine Entscheidung; nämlich die Entscheidung der Eigner, das Unternehmen nicht durch zusätzliche Einlagen selbst weiterzuführen sondern es den Gläubigern zu überlassen.

$101 \S 5$ Abs. 6 EStG. H. Weber-Grellet, in: Einkommensteuergesetz, Hrsg. L. Schmidt, a.a.O., §5, Rz.47f. m.w.N.; B. Knobbe-Keuk, a.a.O., S.23-25; K. Tipke u. J. Lang, a.a.O., S. 298.

102 Vgl. z.B. H. Langel, Auswirkungen von Wechselkursänderungen auf die Bilanzierung, in: IWB Fach 3 Gruppe 3 Deutschland, S.847-849; U. Wlecke, a.a.O., S.111-204; T.Finne, a.a.O., S.54-70; L. Fischer u. P. Warneke, a.a.O., S.387.

$103 \S 253$ Abs. 1 HGB. 
Anschaffungs- und Realisationsprinzip werden im deutschen Handelsrecht um das in der U.S.-amerikanischen Rechnungslegung unbekannte Imparitätsprinzip ergänzt, das zu einer asymmetrischen Berücksichtigung wertverändernder Einflüsse auf die Bestände verpflichtet. Denn „es ist vorsichtig zu bewerten"104; dem soll dadurch Rechnung getragen werden, daß drohende Verluste abweichend vom Realisationsprinzip schon in der Bilanzperiode ihres Bekanntwerdens zu berücksichtigen sind. ${ }^{105} \mathrm{Im}$ Einkommensteuergesetz kommt das Prinzip mittels der Definition des Teilwertes zum Tragen. ${ }^{106}$ Der Teilwert ist der Ertragswert eines Wirtschaftsgutes ${ }^{107}$ innerhalb der konkreten Unternehmung, soweit er unter den Anschaffungskosten liegt. Theoretisch ist dies der Barwert des Teils der erwarteten Einzahlungsüberschüsse des Unternehmens, der durch den einzelnen Vermögensgegenstand erzielt wird. ${ }^{108}$ Rechnerisch ist die Ermittlung eines Teilwertes in dieser Form allerdings nicht realisierbar. ${ }^{109}$

Ein Teilwert muß eingesetzt werden beim Anlagevermögen, wenn die Wertminderung voraussichtlich von Dauer ist, sowie beim Umlaufvermögen und bei Verbindlichkeiten. Er kann darüber hinaus eingesetzt werden beim Anlagevermögen, wenn die Wertminderung voraussichtlich nicht von Dauer ist. ${ }^{110}$ Erweist sich in einer folgenden Periode die Befürchtung, aufgrund der eine bilanzielle Wertminderung vorgenommen wurde, als gegenstandslos, kann eine Zuschreibung bis zur Höhe der Anschaffungskosten vorgenommen werden. Ein Wertaufholungsgebot besteht steuerrechtlich aber weder für Personen- noch für Kapitalgesellschaften. ${ }^{111}$

Wesentlich ist auch der Grundsatz der Einzelbewertung. Er schreibt vor, jeden Vermögensgegenstand separat zu bewerten. ${ }^{112}$ Das heißt, auch ein Währungsgewinn oder -verlust ist für

$104 \S 252$ Abs. 1 Nr. 4 HGB.

${ }^{105}$ Das Imparitätsprinzip hat zwei Ausprägungen. Gemäß §253 Abs. 2 u. Abs. 3 HGB sind gegebenenfalls Abschreibungen bei Vermögensgegenständen und Verbindlichkeiten vorzunehmen. Gemäß §249 Abs. 1 HGB sind außerdem in der Höhe drohender Verluste aus schwebenden Geschäften Rückstellungen zu bilden. A.G. Coenenberg, a.a.O., S.32.

$106 \S 6$ Abs. 1 Nr.1 Satz 3 EStG; G. Wöhe, Bilanzierung und Bilanzpolitik, 8. Aufl., München 1992, S. 476.

${ }^{107}$ Der im Steuerrecht verwendete Begriff des Wirtschaftsgutes ist nicht (vollständig) gleichbedeutend mit dem Begriff des Vermögenswertes. Die Unterschiede werden hier aber nicht berücksichtigt. Vgl. B. Knobbe-Keuk, a.a.O. S. 86-89 m.w.N.. In gleicher Weise wird nicht differenziert zwischen dem steuerrechtlichen Teilwert und der handelsrechtlichen Bezeichnung „beizulegender Wert“ des \$253 Abs. 2 HGB. „Beide Begriffe liegen sachlich beieinander, ohne identisch zu sein“. J.P. Müller-Dott, Teilwertabschreibungen auf Auslandsbeteiligungen, in: Steuerberater-Jahrbuch, 40.Jg. (198/89), S.169. Vgl. auch Adler/Düring/Schmaltz, a.a.O., §253 HGB, Rz.471 m.w.N..

108 „Die heutige Definition des Teilwertes in §6 EStG geht von drei Fiktionen aus:

(1) Ein fiktiver Käufer soll den Gesamtwert des Betriebes ermitteln;

(2) die Ermittlung des Gesamtwertes soll unter dem Gesichtspunkt der Fortführung des Betriebes - also unter Berücksichtigung der zukünftig zu erwartenden Erträge - erfolgen;

(3) der fiktive Käufer soll den Gesamtkaufpreis, den er zu zahlen bereit ist, auf die einzelnen Wirtschaftsgüter verteilen.“

G. Wöhe, a.a.O., S.421 f..

${ }^{109}$ Vgl. G. Wöhe, a.a.O., S. 423 f.. In den Einkommensteuerrichtlinien heißt es deshalb jetzt: „Der Teilwert ist ein ausschließlich objektiver Wert, der von der Marktlage am Bilanzstichtag bestimmt wird." Abschn. R35a Abs. 1 Satz 1 EStR. Vgl. auch BFH-Urteil v. 6.7.1995 IV R 30/93, in: BStB1. II 1995, S. 832.

${ }^{110}$ G. Wöhe, a.a.O., S.475-480; A.G. Coenenberg, a.a.O., S.75f.; K. Tipke u. J. Lang, a.a.O., S.315f..

111 §6 Abs. 1 Nr.1 Satz 4 u. Nr.2 Satz 3 EStG; G. Wöhe, a.a.O., S.479f.; Adler/Düring/Schmaltz, a.a.O., §253 HGB, Rz. 98.

112 Handelsrechtlich ist der Grundsatz in $\S 252$ Abs. $1 \mathrm{Nr} .3 \mathrm{HGB}$ verankert. Er wurde bislang nur für Kreditinstitute durch $\$ 340 \mathrm{~h}$ HGB eingeschränkt und zwar durch ein Wahlrecht zur Bildung von Bewertungseinheiten bei Posten gleicher Währung mit Ausnahme der Wirtschaftsgüter, die wie Anlagevermögen behandelt werden. J. Benne, Einzelbewertung und Bewertungseinheit, in: Der Betrieb, 44.Jg. (1991), S.2605. Steuerrechtlich ist der Grundsatz auch aber direkt aus der Formulierung §6 Abs. 1 EStG abzuleiten. P. Kupsch, Abgrenzung der Bewertungseinheit in Handels- und Steuerbilanz: Grenzbereich Einzelbewertung und Saldierungsverbot, in: Steuerberater-Jahrbuch, 46.Jg. (1994/95), S. 132. 
jede Fremdwährungsposition einzeln zu quantifizieren und einzeln zu bilanzieren. ${ }^{113}$ Der Grundsatz bekommt besonderes Gewicht in Kombination mit dem Imparitätsprinzip: wirtschaftlich ineinandergreifende Positionen müßten systematisch ungleich behandelt werden. ${ }^{114}$ Deshalb sind die Auswirkungen dieses Prinzips speziell bei Kurssicherungstransaktionen interessant, weil es isoliert betrachtet impliziert, Gewinne einer Bilanzposition nicht mit Verlusten einer anderen Position verrechnen zu dürfen.

Der Sinn dieses Verrechnungsverbotes ${ }^{115}$ ist handelsrechtlich, Dritten die Bilanz transparenter zu machen, also der Informationsfunktion - namentlich: den Grundsätzen der Vollständigkeit ${ }^{116}$ und der Klarheit ${ }^{117}$ der Bilanz - gerecht zu werden. ${ }^{118}$ Daher findet der Grundsatz dort seine Grenze, wo dieses Ziel durchkreuzt wird:

Die Eignung zur alleinstehenden Bewertung muß ,nach der allgemeinen Verkehrsauffassung" ${ }^{119}$ gegeben sein. Je kleiner die Bewertungsobjekte gefaßt werden, umso stärker wirkt sich die Vorwegnahme von Vermögensminderungen durch das Imparitätsprinzip aus. ${ }^{120}$ Deshalb soll die Dekomposition eines Aktivums oder einer Verbindlichkeit vermieden werden, wenn ein einheitlicher Nutzungs- und Funktionszusammenhang besteht. ${ }^{121}$

Auf der anderen Seite kann aber auch bei Wirtschaftsgütern, die nach diesem Kriterium einzeln zu bewerten sind, die Bildung von Bewertungseinheiten zulässig beziehungsweise geboten sein. Denn die imparitätische Einzelbewertung zweier Wirtschaftsgüter, deren Risiken sich gegenseitig ausgleichen, stellt das Ziel der Bilanz in Frage, ein den tatsächlichen Verhältnissen entsprechendes Bild zu vermitteln.

\section{Transaktionen von Steuerinländern}

Die einkommen- und körperschaftsteuerliche Erfassung von Währungsgewinnen und -verlusten leitet sich aus den genannten Grundsätzen ordnungsmäßiger Buchführung ab.

Das Währungsergebnis ist zum Zeitpunkt einer Veräußerung oder Rückzahlung grundsätzlich die wechselkursbedingte Differenz zwischen dem Buch- und dem Marktwert. Der Buchwert entspricht entweder den Anschaffungskosten oder gegebenenfalls auch einem geringeren Teilwert. Ist ein niedrigerer Wert beizulegen, kann es ebenfalls zur steuerlichen Erfassung eines Währungsergebnisses kommen, und zwar in Höhe der wechselkursbedingten Differenz zwischen Anschaffungskosten und Ertragswert einer Position.

113 H. Langel, a.a.O., S.847.

114 W. Pößl, Die Zulässigkeit von Saldierungen bei der Bilanzierung von wirtschaftlich ineinandergreifenden Vorgängen, in: Deutsches Steuerrecht, 22.Jg. (1984), S.428; E. Faller, Der Grundsatz der Einzelbewertung und die Notwendigkeit seiner Durchbrechung unter Berücksichtigung des Bilanzrichtlinien-Gesetzentwurfs, in: Betriebs-Berater, 40.Jg. (1985), S.2017; U. Wlecke, a.a.O., S.178f..

$115 \S 246$ Abs. 2 HGB.

$116 \S 146$ Abs. 1 AO u. $\S 246$ Abs. 1 HGB.

$117 \S 243$ Abs. 2 HGB.

118 E. Faller, a.a.O., S. 2017.

119 „Bei der Verkehrsauffassung handelt es sich [...] um die Auffassung desjenigen Personenkreises, der aufgrund seiner Tätigkeit im allgemeinen Wirtschaftsverkehr mit entsprechenden Problemen konfrontiert wird und über entsprechende Sachkunde verfügt."U. Wlecke, a.a.O., S.125. Vgl. B. Knobbe-Keuk, a.a.O., S.88f..

${ }^{120}$ P. Kupsch, a.a.O., S. 132.

121 BFH-Urteil v. 9.11.1976 VIII R 27/75, in: BStBl. II 1977, S.307. 


\section{a) Anschaffungskosten und Veräußerungszeitpunkt}

Die Anschaffungskosten einer Fremdwährungsposition sind einfach auszumachen, wenn die Umwechslung von DM damit unmittelbar einhergeht: sie errechnen sich aus dem Wechselkurs zum Zeitpunkt der Erstverbuchung. ${ }^{122}$ Dies gilt sowohl für monetäre Aktiva als auch für Sachwerte, wenn der Betrag zeitgleich beschafft wurde. ${ }^{123}$ Analog ist der Realisationszeitpunkt für Währungsgewinne und -verluste der Moment, in dem der Erlös in DM umgetauscht wird.

Ansonsten steht die Bestimmung von Anschaffungskosten und dem Veräußerungszeitpunkt bei Positionen, die auf fremde Währungen lauten, im deutschen Recht nicht zweifelsfrei fest.

Der Bundesfinanzhof hat hinsichtlich des Anschaffungswertes von Forderungen ${ }^{124}$ und Verbindlichkeiten festgelegt:

- „Bei einem Anschaffungsgeschäft in ausländischer Währung ist der Wechselkurs im Anschaffungszeitpunkt für die Berechnung der Anschaffungskosten maßgeblich". 125

- Als Nennwert einer Kapitalforderung, die auf eine ausländische Währung lautet, ist der Betrag anzusetzen, der sich in Anwendung des Umrechnungskurses für die ausländische Währung in DM zum Zeitpunkt des Entstehens der Forderung errechnet. ${ }^{126}$

Andernfalls würde „die Höhe der Anschaffungskosten allgemein von Umständen abhängig, die eine steuerliche Gleichbehandlung aller Anschaffungsgeschäfte in Fremdwährung nicht mehr gewährleisten würden."127 Dies bringt das Prinzip separater Transaktionen zum Ausdruck: Es handelt „sich bei den Anschaffungskosten einerseits und der zu passivierenden Kaufpreisverbindlichkeit andererseits um zwei selbständige Bilanzposten“; 128 entsprechendes trifft für Forderungen zu. ${ }^{129}$ Ein Währungserfolg wird in beiden Fällen bei der Rückzahlung der Positionen realisiert. 130

Doch trotz des bisher Gesagten sind die Anschaffungskosten von Fremdwährungspositionen in der Literatur umstritten, wenn eine Transaktion den Tausch von Nominalwerten in fremder Währung gegen andere, nicht auf DM lautende, monetäre Positionen oder gegen Sachwerte zum Inhalt hat. Genau gesagt: der Anschaffungszeitpunkt ist nicht geklärt. Denn es ist zweifelhaft, ob hier ein sogenannter Realtausch vorliegt ${ }^{131}$, der die Bewertung des erworbenen Gutes zum Zeitwert am Tag der Lieferung erfordern würde. ${ }^{132}$ Steuerrechtlich gilt zwar das Nominalwertprinzip in DM. Demnach wäre ein Tausch anzunehmen und die Umrechnung der Transaktion mit dem aktuellen Kurs geboten. Zivilrechtlich werden aber auch fremde Währungen als Zahlungsmittel anerkannt; sie sind damit kein Wirtschaftsgut. ${ }^{133}$ Wenn aber

122 T. Finne, a.a.O., S.71, S.86, S. 109

${ }^{123}$ Abschn.R37 Abs.2 EStR für Verbindlichkeiten; U. Wlecke, a.a.O., S.154f.; G. Gebhardt u. N. Breker, a.a.O., S. 1530 .

${ }^{124}$ Der Kaufpreis, der den Rückzahlungsbetrag der Forderung bestimmt, ist aber mit dem im Ausland geltenden Zinssatz abzuzinsen. Fraglich ist, ob hier der Terminkurs am Rückzahlungszeitpunkt zugrunde zu legen ist. Dies wäre richtig. M. Groh, a.a.O., S.8

125 BFH-Urteil v. 16.12.1977 III R 92/75, in: BStBl. II 1978, S.233; Abschn.R32a Abs.2 Satz 4 EStR; N. Harder, Die fremde Währung im Steuerrecht, in: Internationales Steuerrecht, 2.Jg. (1993), S. 300.

${ }^{126}$ BFH-Urteil v. 19.1.1978 IV R 61/73, in: BStBI. II 1978, S.297.

127 BFH-Urteil v. 16.12.1977 III R 92/75, a.a.O., S.233.

128 BFH-Urteil v. 16.12.1977 III R 92/75, a.a.O., S. 233 f..

${ }^{129}$ BFH-Urteil v. 19.1.1978 IV R 61/73, a.a.O., S.297; BFH-Urteil v. 16.12.1977 III R 92/75, a.a.O., S.234; T. Finne, a.a.O., S.90-98; G. Gebhardt u. N. Breker, a.a.O., S. 1531.

${ }^{130}$ BFH-Urteil v. 16.12.1977 III R 92/75, a.a.O., S.233; H. Langel, a.a.O., S.853f..

${ }^{131}$ Ausgenommen ist der Tausch zweier Sachwerte und die Beteiligung an einer ausländischen Niederlassung mittels Sacheinlage. H.J. Kleineidam, in: Herrmann/Heuer/Raupach, §6 EStG, Rz. 16.

132 Abschn. R32a Abs. 2 Satz 3 EStR; G. Gebhardt u. N. Breker, a.a.O., S.1530f..

${ }^{133}$ U. Wlecke, a.a.O., S.158f.; T. Finne, a.a.O., S.152f.. 
die Transaktion nicht als Tausch angesehen werden kann, besteht kein Anknüpfungspunkt für eine Realisierung von Währungsgewinnen und -verlusten. ${ }^{134}$

Konkret: werden Fremdwährungsbestände für den späteren Kauf eines Fremdwährungsaktivums erworben oder wird eine Anzahlung geleistet, so ist für die Anschaffungskosten nach überwiegender Meinung der Wechselkurs am Kauftag der Devisen maßgeblich. ${ }^{135}$ Das Vorgehen entspricht hier also dem integrierten Ansatz. Damit wird, im Unterschied zu den USA, in Deutschland das Währungsergebnis bei Fremdwährungstransaktionen nicht konsistent behandelt. ${ }^{136}$ Der Tatsache, daß die Höhe der Anschaffungskosten dadurch von Umständen abhängig wird, die eine steuerliche Gleichbehandlung aller Anschaffungsgeschäfte in Fremdwährung nicht mehr gewährleisten, ${ }^{137}$ wird entgegen gehalten: „Wirtschaftliche Gegenleistung ist hier die Vorauszahlung. Somit muß auch der Wert der Vorauszahlung die Höhe der Anschaffungskosten bestimmen."138

Sind die Fremdwährungsbestände allerdings vorhanden, bevor eine Entscheidung über deren Tausch gegen Sachwerte fällt, bemessen sich die Anschaffungskosten nach dem Wechselkurs zum Zeitpunkt der Lieferung. ${ }^{139}$ Deshalb ist dieser Aspekt für den Zeitpunkt der Realisierung von Währungsgewinnen bei Transaktionen einer ausländischen Betriebstätte ${ }^{140}$ bedeutungslos. Insbesondere läßt sich hieraus nicht die Anwendung der Stichtagmethode ableiten. Gleiches gilt bei der Umschichtung eines Portfolios mit auf fremde Währung lautenden Wertpapieren.

\section{b) Quelle des Währungsergebnisses}

Die Quelle des Währungsergebnisses aus einzelnen Transaktionen wird aus dem wirtschaftlichen Zusammenhang abgeleitet. Der Ursprung solcher Einkünfte ist deshalb nach der herrschenden Meinung dort zu suchen, wo nach Maßgabe des nationalen Rechts auch die sonstigen Einnahmen und Aufwendungen anfallen, die in besagtem wirtschaftlichen Zusammenhang mit dem betreffenden Wirtschaftsgut stehen. ${ }^{141}$

Demzufolge ist das Währungsergebnis bei der Veräußerung immobiler Aktiva und von Beteiligungen im deutschen Steuerrecht ausländischen Ursprungs. ${ }^{142}$ Der wechselkursbedingte

\footnotetext{
${ }^{134}$ Es ist infolgedessen von der Motivation des Steuerpflichtigen abhängig, was im Einzelfall richtig ist. Nur wenn die Nominalwerte nicht als Wertaufbewahrungsmittel genutzt werden, ist eine Realisation von Kurserfolgen am Zahlungszeitpunkt sachgemäß. „Dieses ist zwar unerfreulich, aber unvermeidlich“. U. Wlecke, a.a.O., S. 161 .

135 IDW, Geänderter Entwurf einer Verlautbarung zu Währungsumrechnung im Jahres- und Konzernabschluß, in: Die Wirtschaftsprüfung, 39.Jg. (1986), S.665; H. Langel, a.a.O., S.858; U. Wlecke, a.a.O., S.217f. u. S. 217 f.; T. Finne, a.a.O., S. 119 u. S.138f.; G. Gebhardt u. N. Breker, a.a.O., S.1530f..

136 G. Gebhardt u. N. Breker, a.a.O., S.1531 f..

${ }^{137}$ Anderer Auffassung ist Harder, der aus dem Urteil des BFH folgert, „daß vorzeitige Devisenbeschaffung für die geplante Anschaffung, Anzahlungen und Kaufpreisstundungen keine Auswirkungen auf die steuerlichen Anschaffungskosten haben." N. Harder, a.a.O., S.390; T. Finne, a.a.O., S.139.

138 U. Wlecke, a.a.O., S.224; G. Langenbucher, Umrechnung von Fremdwährungsgeschäften, in: Handbuch der Konzernrechnungslegung: Kommentar zur Bilanzierung und Prüfung. Hrsg. K. Küting und C.-P. Weber, 3.Aufl., Stuttgart, 1990, S.322, Rz.489 plädiert indes dafür, auch hier nach dem Niederstwertprinzip vorzugehen.

${ }^{139}$ H.J. Kleineidam, in: Herrmann/Heuer/Raupach, §6 EStG, Rz. 15.

140 U. Wlecke, a.a.O., S. 379.

141 Blümich/H. Krabbe, §34d EStG, Rz49; P. Malinski, a.a.O., S.56f.; FG Hamburg Urteil v. 26.4.1995 VII 101/92 (n-rkr), a.a.O., S.871. Aktenzeichen des BFH: I R 69/95.

142 International Bureau of Fiscal Documentation, a.a.O., S.46f.
} 
Gewinn oder Verlust wird, wie in den USA, als Teil des Veräußerungsgewinnes oder -verlustes angesehen und nicht getrennt ausgewiesen. ${ }^{143}$

Die Quelle von Währungsgewinnen oder -verlusten ist bei Forderungen und Wertpapieren nicht eindeutig geklärt. Ein koordinierter Ländererlaß aus dem Jahr 1974 schreibt bei Forderungen vor, sie den ausländischen Einkünften zuzurechnen. ${ }^{144,145}$

Der Erlaß ist in der Literatur mit Hinweis auf einen fehlenden wirtschaftlichen Zusammenhang mit den oben genannten Arten ausländischer Einkünfte, insbesondere den Einkünften aus Kapitalvermögen, kritisiert worden. ${ }^{146}$ Ein anderer Anknüpfungspunkt ist aber nicht erkennbar, um hier den ausländischen Ursprung des Währungsergebnisses zu begründen. Deshalb bleibt eine gewisse Unsicherheit. Zudem hat vor dem Hintergrund der Doppelbesteuerungsabkommen mit den Niederlanden und Spanien auch der Bundesfinanzhof entschieden, $\mathrm{da} ß$ die wechselkursbedingte Wertminderung von Fremdwährungsdarlehen nicht zu den Zinseinkünften, sondern zu den übrigen inländischen Einkünften aus Gewerbebetrieb gehört. Doch werden in den Abkommen die Einkünfte aus Kapitalvermögen explizit als „Einkünfte aus Zinsen und Dividenden" benannt. ${ }^{147}$

Soweit ausländische Einkünfte vorliegen, entscheidet über die Besteuerung in Deutschland das jeweils geltende Doppelbesteuerungsabkommen oder die unilateralen Maßnahmen zur Vermeidung doppelter Belastung, wie in Abschnitt I dieses Teils dargelegt.

Zu möglichen Auswirkungen von Währungsschwankungen im Anrechnungsverfahren heißt es in dem Ländererlaß: „Wenn sich dadurch der Höchstbetrag der deutschen Steuer, bis zu der die ausländische Steuer angerechnet werden kann, vermindert, muß dies als notwendige Folge in Kauf genommen werden. Eine Möglichkeit, diese Nebenwirkung zu vermeiden, ist nicht gegeben." 148

\section{c) Teilwertabschreibungen bei wechsel- kursbedingten Wertminderungen}

Erhebliche Unterschiede zu den USA können auch bei der Quantifizierung der Höhe des Währungserfolgs zum Zeitpunkt der Veräußerung auftreten, wenn infolge des Niederstwertprinzips der Buchwert geringer ist als die Anschaffungskosten. Für den Buchwert zum Bilanzstichtag ist für Sachwerte und Beteiligungen maßgeblich der niedrigere Wert in inländischer Währung, der sich ergibt aus

- den Anschaffungskosten, umgerechnet mit dem Kurs zum Zeitpunkt der Anschaffung des Wirtschaftsgutes und

- dem Ertragswert am Bilanzstichtag, umgerechnet mit dem Kurs zu jenem Zeitpunkt. ${ }^{149}$

${ }^{143}$ BFH-Urteil v. 16.12.1977 III R 92/75, a.a.O., S. 233; BFH-Urteil v. 19.1.1978 IV R 61/73, a.a.O., S. 297 f..

144 Finanzministerium Nordrhein-Westfalen, Erlaß v. 1. März 1974-S 2293 - 17 - V B 2, in: Der Betrieb, 27.Jg. (1974), Heft 12, S.557; H.-D. Höppner, Kursverluste bei Fremdwährungsdarlehen, in: Jahrbuch der Fachanwälte für Steuerrecht, 40.Jg. (1989/90), S. 166; Blümich/H. Krabbe, §34d EStG, Rz 49.

${ }^{145}$ Anderer Auffassung: K. Uhrmann, Zur bilanziellen Erfassung inländischer Devisengeschäfte, In: Der Betrieb, 45.Jg. (1992), S.1791.

${ }^{146}$ Institut „Finanzen und Steuern" e.V., Heft 125, a.a.O., S.25f.; T. Finne, a.a.O., S.253; P. Malinski, a.a.O., S.94; Flick/Wassermeyer/Becker, §34c EStG, Rz.115; O.H. Jacobs, a.a.O., S.241 f.; N. Harder, a.a.O., S. 300 .

${ }^{147}$ BFH-Urteil v. 16.3.1994 I R 42/93, a.a.O., S.801.

${ }^{148}$ Finanzministerium Nordrhein-Westfalen, a.a.O., S.557.

$149 \S 253$ Abs. 1 HGB; W. Zillessen, a.a.O., S.536; M. Groh, a.a.O., S.871; H-J.Kleineidam, in: Herrmann/Heuer/Raupach, §6 EStG, Rz.23; U. Wlecke, a.a.O., S.233-235. 
Durch diesen sogenannten erweiterten Niederstwerttest ${ }^{150}$ werden zur Prüfung der Möglichkeit einer wechselkursbedingten Teilwertabschreibung der Wettbewerbs- und der Umwechslungseffekt ${ }^{151}$ verknüpft. Nur wenn das Ergebnis beider Effekte negativ ist, liegt tatsächlich ein Verlust vor, und die Minderung des steuerpflichtigen Gewinnes durch eine Teilwertabschreibung ist zulässig beziehungsweise geboten. Beispielsweise wären bei börsengehandelten Wertpapieren Marktwert- und Wechselkursänderungen zu verrechnen. Bei Forderungen ist eine Abschreibung vorzunehmen, wenn die zu erwartende Rückzahlung in DM unter den Anschaffungskosten liegt. ${ }^{152}$ Für Verbindlichkeiten gilt gemäß dem sogenannten Höchstwertprinzip das Gegenteil.153

Nach einem Anstieg des Wechselkurses ist umgekehrt auch die Erhöhung des Buchwertes von Aktiva und des steuerpflichtigen Gewinnes denkbar. Die Zuschreibung ist aber nur dann zulässig, wenn in der Vergangenheit eine außerplanmäßige Abschreibung vorgenommen wurde ${ }^{154}$ und maximal bis zur Höhe der Anschaffungskosten. Überdies ist sie, wie gesagt, in der Regel ein Wahlrecht des Steuerpflichtigen.

Verluste aus dem Umwechslungseffekt umfassen hierbei Verluste infolge von bis zum Bilanzstichtag eingetreten Kursänderungen, die den Marktwert der Fremdwährungspositionen gegenüber ihrem Buchwert reduziert haben. ${ }^{155}$

Grundsätzlich können dies aber darüber hinaus auch drohende Verluste sein, die am Stichtag vorhersehbar, aber noch nicht eingetretenen sind. Voraussetzung ist allgemein, daß dadurch der voraussichtlich erzielbare Verkaufspreis der Position gemindert wird. ${ }^{156}$ Die Wiederbeschaffungskosten sind nicht allein maßgeblich, ${ }^{157}$ die Wertänderung muß am Stichtag nur objektiv schon im wesentlichen gegeben sein.

Wie in Teil B ausführlich dargestellt wurde, ist die zweite Möglichkeit auf effizienten Devisenmärkten nicht denkbar. Kursänderungen können nur insoweit erwartet werden, wie sich dies aus der Zinsparitätenbeziehung ableitet. Eine solche Differenz zwischen Kassa- und Terminkurs wird aber nicht als hinreichend angesehen, um eine Teilwertabschreibung in der

${ }^{150}$ G. Gebhardt, a.a.O., S.11 f.; O.H. Jacobs, a.a.O., S. 325 .

151 Vgl. die Seiten 28f. in Teil B dieser Arbeit.

152 A.J. Rädler, Deutsches Steuerrecht und inflationäre Entwicklungen im Ausland, in: Steuerberater-Jahrbuch, 27.Jg. (1975/76), S.452f.; H. Langel, a.a.O., S.851 f. u. S.853f.; U. Wlecke, a.a.O., S. 269 f..

${ }^{153}$ A.J. Rädler, a.a.O., S.455f.; L. Fischer u. P. Warneke, a.a.O., S.367; G. Langenbucher, Umrechnung von Fremdwährungsgüeschäften, a.a.O., S.322, Rz. 475 u. Rz. 480.

$154 \S 253$ Abs. 2 u. $\$ 280$ Abs. 1 HGB; H. Langel, a.a.O., S. 849.

${ }^{155}$ Nach §253 Abs. 3 HGB dürfen außerdem Abschreibungen vorgenommen werden für Wertänderungen, die zwischen Bilanzstichtag und Zeitpunkt der Bilanzerstellung aufgetreten oder bekannt geworden sind. Aufgrund des Bewertungsvorbehaltes sind sie aber für die Steuerbilanz nicht bindend. Es darf nur bei Waren mit stark schwankendem Preis für den Wert am Bilanzstichtag der Durchschnitt aus den in einem Intervall von bis zu sechs Wochen vor und nach dem Bilanzstichtag an den internationalen Märkten gehandelten Preisen eingesetzt werden. BFH-Urteil v. 17.7.1956 I 292/55 U, in: BStBl. III 1956, S.379; Abschn. H36 EStR; B. KnobbeKeuk, a.a.O., S.52f.. Für Wirtschaftsgüter, deren Preis auf Märkten ausgehandelt wird, die unvollkommen sind, mag dies eine angemessene Vorgehensweise darstellen. Da dies für die Devisenmärkte indes nicht zutrifft, ist eine solche Durchschnittsrechnung nicht sinnvoll, obgleich dies überwiegend anders gesehen wird. G. Langenbucher, Die Umrechnung von Fremdwährungsgeschäften: Eine Untersuchung nach handels- und steuerrechtlichen Grundsätzen, a.a.O., S. 43 u. S.52f.; Adler/Düring/Schmaltz, a.a.O., §253 HGB, Rz. 99; mit Einschränkungen auch U. Wlecke, a.a.O., S.151.

${ }^{156}$ U. Wlecke, a.a.O., S. 138 m.w.N. in Fn. 542.

${ }^{157}$ BFH-Urteil v. 27.10.1983 IV R 143/80, in: BStB1. II 1984, S.36. 
Gegenwart zu rechtfertigen. ${ }^{158}$ Dies ist ökonomisch plausibel, das angefuihrte Argument, die Qualität des Terminkurses als Prognosewert sei unzureichend, ${ }^{159}$ allerdings nicht. Denn der Unterschiedsbetrag ist kein drohender Verlust, sondern die erwartete Kompensation für zukünftige Mehreinnahmen durch die höhere Rendite von Anlagen und Investitionen in dem ausländischen Währungsraum. ${ }^{160}$ Würde das Wirtschaftsgut am Bilanzstichtag veräußert, käme es nicht zu dem Kursverlust, weil der Marktwert der Position zu diesem Zeitpunkt jedenfalls aufgrund der Währungsentwicklung (noch) nicht gesunken ist.

Der Terminkurs für einen Zeitpunkt nach dem Bilanzstichtag ist aus ökonomischen Gesichtspunkten für die Bemessung der Steuerlast von Kassapositionen unerheblich. Ein etwas anderes Bild ergibt sich für Wechselkursänderungen, die zum Bilanzstichtag erwartet worden sind. Dieser Aspekt wurde schon in den Teilen B und C erörtert; ${ }^{161}$ in diesem Zusammenhang wird darauf zudem in Abschnitt III noch einmal eingegangen werden, wo die Annahme der Erwartung konstanter Kurse aufgegeben wird.

Der oben beschriebene Niederstwerttest ist getrennt bei allen Bilanzpositionen und auch bei schwebenden Geschäften zum Stichtag des Jahresabschlusses durchzuführen. ${ }^{162}$ Gegebenenfalls sind die Positionen auf den niedrigeren Teilwert abzuschreiben. Für die nicht zu bilanzierenden schwebenden Geschäfte ist eine Rückstellung für drohende Verluste allerdings nicht mehr zu bilden. Pauschalwertberichtigungen für die Bilanzpositionen in fremden Währungen sind nicht zulässig. ${ }^{163}$ Abschreibung und Rückstellung mindern die ausländischen Einkünfte des Steuerpflichtigen.

Aus Vereinfachungsgründen werden in der Praxis ungeachtet des Realisations- und des Imparitätsprinzips kurzfristige Forderungen sowie Barbestände überwiegend mit dem Kurs am Bilanzstichtag umgerechnet. ${ }^{164}$ Dies wird in der Literatur zum Teil heftig kritisiert. ${ }^{165}$ Dabei wird unter anderem darauf verwiesen, daß gerade für Positionen des Umlaufvermögens das strenge Niederstwertprinzip gelten sollte. Anderer Auffassung war indes das Finanzgericht Münster, das nämlich das materielle Ergebnis der Umrechnung in den Vordergrund stellte. ${ }^{166}$

${ }^{158}$ U. Wlecke, a.a.O., S.143-150 u. S.212; T. Finne, a.a.O., S.101f.; G. Gebhardt u. N. Breker, a.a.O., S.1531. Anderer Meinung sind mit Einschränkungen G. Langenbucher, Umrechnung von Fremdwährungsgeschäften, a.a.O., S. 322, Rz. 434 u. Rz.445f.; ders., Die Umrechnung von Fremdwährungsgeschäften: Eine Untersuchung nach handels- und steuerrechtlichen Grundsätzen, a.a.O., S.48f.; A.J. Rädler, a.a.O., S.454; G. Gebhardt, a.a.O., S.9.

159 J.P. Müller-Dott, a.a.O., S.178f.; U. Wlecke, .a.a.O., S.143-150; T. Finne, a.a.O., S. 101 f..

${ }^{160}$ Analog werden deshalb Null-Kupon-Anleihen mit dem niedrigeren Ausgabepreis bewertet. Die Kosten der Kapitalüberlassung sind auf die Laufzeit verteilt mittels einer Effektivzinsberechnung dem Ausgabebetrag zuzuschreiben. Eine Bilanzierung zum Rücknahmebetrag vor dem Laufzeitende entspricht nicht der herrschenden Meinung. IDW, Zur Bilanzierung von Zero-Bonds, in: IDW, Die Fachgutachten und Stellungnahmen, S. 144; A.G. Coenenberg, a.a.O., S.189. Auch können unverzinsliche Darlehensforderungen des Anlagevermögens mit dem geringeren Teilwert bewertet werden. Ein Abwertungszwang ist allerdings umstritten. P. Kupsch, a.a.O., S. 137 u. S.146-148 m.w.N.. R.G. Bachem, Das Auszahlungsdisagio in Bilanz und Vermögensaufstellung des Darlehensnehmers, in: Betriebs-Berater, 46.Jg. (1991), S.1671 m.w.N. sowie §253 Abs. 1 HGB.

$161 \mathrm{Vgl}$. die Seiten 135f. dieser Arbeit.

162 Vgl. zu den einzelnen Bilanzpositionen L. Fischer u. P. Warneke, a.a.O., S.387-393.

163 H.J. Kleineidam, in: Herrmann/Heuer/Raupach, §6 EStG, Rz. 23.

164 Vgl. Adler/Düring/Schmaltz, a.a.O., §253 HGB, Rz.92-94 T. Finne, a.a.O., S.81-83 u. S.99; H.J.Kleineidam, in: Herrmann/Heuer/Raupach, §6 EStG, Rz. 22 m.w.N..

165 M. Groh, a.a.O., S.869f.; T. Finne, a.a.O., S. 82, S.99f.. Die generelle Umrechnung zum Stichtagskurs wird in der Literatur aber selbst für Barmittel abgelehnt und aus Vereinfachungsgründen nur akzeptiert, ,wenn dies zu keiner ins Gewicht fallenden Verletzung des Imparitätsprinzips führt." G. Langenbucher, Die Umrechnung von Fremdwährungsgeschäften: Eine Untersuchung nach handels- und steuerrechtlichen Grundsätzen, a.a.O., S.135; IDW, Geänderter Entwurf einer Verlautbarung zu Währungsumrechnung im Jahres- und Konzernabschluß, a.a.O., S.665. Kritisch: T. Finne, a.a.O., S.81-83.

${ }^{166}$ FG Münster Urteil v. 3.10.1995 9 K 5026/92 (n-rkr), in: DATEV-LEXinform-Nr. 127320. 
Welche Wirkung hat diese asymmetrische steuerliche Behandlung von Währungsgewinnen und -verlusten durch die Möglichkeit von Teilwertabschreibungen auf die Kapitalallokation?

Die Antwort liegt auf der Hand, wenn das Währungsergebnis inländischen Ursprungs ist: durch die zeitnahe steuerliche Berücksichtigung von Verlusten auf der einen Seite und die bis zur Realisation verzögerte Erfassung von Währungsgewinnen auf der anderen Seite wird die Anlage in fremden Währungen begünstigt, und zwar umso stärker, je volatiler der Wechselkurs ist.

Liegen jedoch ausländische Einkünfte vor, sind die Folgen von Teilwertabschreibungen nicht so offensichtlich:

\section{a) Freistellungsverfahren}

In Situationen, in denen Veräußerungsgewinne in Deutschland von der Besteuerung freigestellt werden, kann es nämlich infolge des Niederstwertprinzips zu einer ,völlig verfehlten steuerlichen Behandlung von Währungsgewinnen oder -verlusten" ${ }^{167}$ kommen. Freigestellt sind, wie gesagt, üblicherweise laufende Einkünfte und Gewinne aus der Veräußerung von im Ausland belegenem unbeweglichem Vermögen.

Ursache ist ein Qualifikationskonflikt: Die Formulierung der Doppelbesteuerungsabkommen macht die Veräußerung des Wirtschaftsgutes - im Musterabkommen der OECD wird der Begriff „Veräußerungsgewinn“ verwendet ${ }^{168}$ - für eine Freistellung zur Voraussetzung. Die nationalen Vorschriften sehen dagegen ausdrücklich auch die Teilwertabschreibung vor. ${ }^{169}$ Ein Verlust, der nicht realisiert wird, mindert deshalb die steuerpflichtigen Welteinkünfte nach Maßgabe des Niederstwertprinzips: ein Verlust oder Gewinn, der realisiert wird, unterliegt aber den Regeln des Doppelbesteuerungsabkommens.

Daraus folgt: Wird bei einem Wirtschaftsgut an einem Bilanzstichtag ein wechselkursbedingter Wertverlust sichtbar, der eine Teilwertabschreibung rechtfertigt, reduziert diese Abschreibung die ausländischen Einkünfte des Steuerpflichtigen ${ }^{170}$ und damit, zumindest bei isolierter Betrachtung, die inländische Steuerlast. Zum Zeitpunkt der Veräußerung hat das Ausland das alleinige Besteuerungsrecht. Der deutsche Fiskus kann die Steuerminderung infolge einer Teilwertabschreibung nicht zurückgewinnen, selbst wenn der Wechselkurs bis zur Veräußerung wieder angestiegen ist. ${ }^{171}$

167 P. Malinski, a.a.O., S. 102.

168 Art. 13 OECD-MA.

${ }^{169}$ BFH-Urteil v. 14.3.1989 I R 39/85, in: BStBI. II 1989, S.600f.. Dort ging es um eine Teilwertabschreibung auf die Einlage in einer indischen Kapitalgesellschaft. Anders in BFH-Urteil v. 23.3.1972 I R 128/70, in: BStB1 II 1972, S.948f. und BFH-Urteil v. 9.12.1981 I R 78/80, in: BStBl. II 1982, S.243f. nur aufgrund der spezifischen Wortwahl im Doppelbesteuerungsabkommen zwischen Deutschland und Italien. Durch das neue Abkommen mit Italien sind aber mittlerweile Teilwertabschreibungen überhaupt nicht mehr freigestellte (negative) Einkünfte. H-J. Kleineidam, in: Herrmann/Heuer/Raupach, §6 EStG, Rz. 18a. Vgl. hierzu aber insb. K. Manke, Teilwertabschreibungen an ausländischen Kapitalgesellschaften - BFH-Urteil vom 14.3.1989 -, in: Deutsche Steuer-Zeitung, 78.Jg. (1990), S.4-10. Vgl. auch BFH-Urteil v. 19.5.1993 I R 60/92, in: BStBI. II 1993, S.714-716. Blümich/J. Täske, §26 KStG, Rz24d; O.H. Jacobs, a.a.O., S.398-400. Kritisch: K. Vogel, Doppelbesteuerungsabkommen, a.a.O., S.1484, Rz. 84; F. Wassermeyer, Teilwertabschreibung auf die Beteiligung an einer indischen Kapitalgesellschaft, in: Finanz-Rundschau, 71.Jg. (1989), S.518-521; ders., Die Auslegung von Doppelbesteuerungsabkommen durch den Bundesfinanzhof, in: Steuer und Wirtschaft, 67. Jg. (1990), S.408.

${ }^{170}$ Blümich/J. Täske, §26 KStG, Rz24d.

${ }^{171}$ Einzige Ausnahme ist eine Situation, in der vor der Realisierung eine Wertaufholung geboten ist. P. Malinski, a.a.O., S.98f.. 
Nach einem eingetretenen Währungsverlust besteht daher ein erheblicher Anreiz, das Wirtschaftsgut wenigstens bis über den nächsten Bilanzstichtag hinaus zu halten, um die Möglichkeit einer Teilwertabschreibung auszunutzen.

Demgegenüber bleibt ein Währungsgewinn im Inland steuerfrei.

Die ex ante erwartete Gesamtsteuerlast wird infolgedessen durch Währungsschwankungen verringert beziehungsweise der erwartete Nettogewinn erhöht und Kapitalexport somit begünstigt - und zwar umso stärker, je volatiler der Wechselkurs ist.

Auch hier läßt sich die Optionstheorie nutzen, um die Wirkung zu präzisieren. Der inländische Staat verschenkt nämlich mit der Möglichkeit zur Teilwertabschreibung eine Position in Verkaufoptionen. Er wird zum Stillhalter: Im Falle eines Währungsverlustes ist der Fiskus verpflichtet, einen Anteil in Höhe des Steuersatzes an dem Wertverlust mitzutragen. Betragsmäßig entspricht dies einer Transaktion, bei der der Steuerpflichtige die Verkaufoption ausübt, den Teil des Wirtschaftsgutes in Höhe des Steuersatzes zu den Anschaffungskosten an den inländischen Staat verkauft und zum geringeren Teilwert zurückkauft. Bei einem Gewinn indes fällt der Vorteil nur dem Steuerpflichtigen zu.

Der Preis einer solchen Option kann wieder mit einem Beispiel konkretisiert werden.

Beispiel D1:

Eine inländische Personengesellschaft kauft am 1.1.1996 für 10.000 AM ein Grundstück in einem Staat, mit dem Deutschland die Freistellung von Veräußerungsgewinnen bei immobilen Wirtschaftsgütern vereinbart hat. Der Wechselkurs liegt zu diesem Zeitpunkt bei $1 \mathrm{AM}=1 \mathrm{DM}$. Es wird erwartet, daß der Kurs und auch der Marktwert des Grundstücks konstant bleiben. Die erwartete Standardabweichung des Wechselkurses beträgt $10 \%$. Bei einem Steuersatz von beispielsweise $45 \%$ und einem Zinsniveau von $6 \%$ in beiden Ländern bewirkt die Möglichkeit einer Teilwertabschreibung zum Ende des ersten Jahres eine Erhöhung des erwarteten Gewinnes der inländischen Personengesellschaft von bis zu 179,45 DM, ${ }^{172}$ also von knapp 1,8\% des investierten Kapitals beziehungsweise $30 \%$ des erwarteten Bruttogewinnes.

Andererseits ist aber das Nominalwertprinzip zu beachten, das die Wirkung bei Aktiva nicht unerheblich mindert. In dem Beispiel wurde ein konstantes Preisniveau unterstellt. Bei einer Inflationsrate von 3\% in beiden Ländern wäre demgegenüber nach $\mathrm{Maßgabe}$ des erweiterten Niederstwerttests eine Teilwertabschreibung erst ab einem Kurs von $\approx 0,97$ DM/AM am Ende der Periode geboten. Der erwartete Endwert erhöht sich hier bei analoger Berechnung um bis zu $119,95 \mathrm{DM}$ oder $1,2 \%$ des Kapitaleinsatzes. ${ }^{173}$ Ferner sind auch andere nicht realisierte

${ }^{172}$ Der Ausübungspreis der Optionen ist $1 \mathrm{AM}=1 \mathrm{DM}$, also ist $\mathrm{k}=1$. Liegt der Devisenkurs darunter, ist eine Teilwertabschreibung geboten; der inländische Staat ist daran in Höhe des Steuersatzes, also zur Hälfte beteiligt. Das Zinsniveau beträgt für den Steuerpflichtigen im Inland und bei Annahme der Zinsparitätentheorie auch im Ausland 6\%. Für diese Werte errechnet sich ein Optionspreis am 1.1.1996:

$$
\begin{aligned}
& \mathrm{P}=\mathrm{k} \cdot(1+\mathrm{r})^{-\mathrm{t}}(1-N(\mathrm{x}))-\mathrm{e}_{\mathrm{t}} \cdot\left(1+\mathrm{r}^{*}\right)^{-\mathrm{t}} \cdot(1-N(\mathrm{x}+\sigma \cdot \sqrt{\mathrm{t}})) ; \mathrm{x}=\frac{\ln \frac{\mathrm{e}_{\mathrm{t}}}{\mathrm{k}}+\left(\mathrm{r}-\mathrm{r}^{*}-\frac{\sigma^{2}}{2}\right) \cdot \mathrm{t}}{\sigma \cdot \sqrt{\mathrm{t}}} . \\
& \mathrm{P}=1,06^{-1} \cdot(1-N(-0,05))-1,06^{-1}(1-N(-0,05+0,1)) ; \mathrm{x}=\frac{\ln \frac{1}{1}+0,06-0,06-\frac{0,1^{2}}{2}}{0,1}=-0,05 . \\
& \mathrm{P}=0,0376 .
\end{aligned}
$$

Für eine Investition von 10.000 DM ergibt dies $0,45 \cdot 10.000 \mathrm{DM} \cdot 0,0373=169,29 \mathrm{DM}$.

Bezogen auf den 31.12.1996 sind dies 169,29DM $\cdot 1,06=179,45 \mathrm{DM}$.

Vgl. M.B. Garman u. S.W. Kohlhagen, Foreign Currency Option Values, in: Journal of International Money and Finance, 2.Jg. (1983), S.234; J. Kloy u. J. Welcker, Drei Arten von Währungsoptionen, in: Die Bank, o.Jg. (1986), S.298f..

173 Bei längerer Haltedauer kann die Wirkung nur größer sein, da der Steuerpflichtige ja in jedem der fünf Jahre eine Abschreibung vornehmen kann. Da hier deshalb bedingte Optionen vorliegen, ist eine rechnerisch genaue Quantifizierung aber sehr schwierig und aufgrund des Ermessensspielraums von Steuerpflichtigem und Finanzverwaltung auch nicht seriös. 
Gewinne bei einem Fremdwährungsaktivum zu berücksichtigen. Natürlich ist eine Teilwertabschreibung erst gerechtfertigt, nachdem diese stillen Reserven durch einen Währungsverlust aufgezehrt wurden. ${ }^{174}$

\section{ß) Anrechnungsverfahren}

Wie in Teil B gezeigt wurde, ist das Anrechnungsverfahren bei flexiblen Wechselkursen problematisch, da ein Währungsgewinn die inländische Steuerlast auf die ausländischen Einkünfte erhöht, ein Währungsverlust dagegen zu einem Anrechnungsüberhang führen kann.

Für Deutschland stellt sich in diesem Zusammenhang außerdem die Frage, ob durch die geltende Pro-Staat-Begrenzung Kapitalexport zusätzlich diskriminiert wird. Die Auswirkung für Steuerpflichtige mit Einkünften aus mehreren Ländern ist unklar: Einerseits können Währungsgewinne und Währungsverluste bei Aktivitäten in verschiedenen Ländern nicht verrechnet werden; ein Anrechnungsüberhang in einem einzelnen Land wird dadurch wahrscheinlicher. Andererseits steigt aber auch die Wahrscheinlichkeit eines insgesamt negativen Ergebnisses in diesem Land, wenn positive Einkünfte und Währungsverluste für jedes Land separat saldiert werden. Ein solcher Verlust beeinflußt nicht den Anrechnungshöchstbetrag bei Einkünften aus anderen Währungsräumen, sondern mindert dann unmittelbar die inländische Steuerlast. Dieser Aspekt gewinnt noch an Gewicht, da im deutschen Steuerrecht zugleich die Wahl der Abzugsmethode für jedes Quellenland separat zulässig ist.

Fraglich ist auch der Effekt des Niederstwertprinzips:

Offensichtlich kann zum Zeitpunkt der Veräußerung der steuerliche Gewinn - die Differenz zwischen Buchwert und Veräußerungserlös - größer, nicht aber kleiner sein als ohne Teilwertabschreibungen. Somit wird ex ante im Wohnsitzland eine höhere Steuerlast für diese Periode erwartet werden; ein Anrechnungsüberhang ist zum Zeitpunkt der Realisierung weniger wahrscheinlich.

Dies impliziert jedoch zugleich die Perspektive einer Minderung ausländischer Einkünfte während der Haltedauer. Dabei sind drei Situationen zu unterscheiden:

Bezieht der Steuerpflichtige ansonsten keine ausländischen Einkünfte aus dem betreffenden Land in der Periode, reduziert der Währungsverlust das im Inland steuerpflichtige Einkommen in voller Höhe.

Hat der Steuerpflichtige ungenutzte Anrechnungsgutschriften durch positive Einkünfte aus dem Land, so können diese auf die wechselkursbedingte Abschreibung angewendet werden. Insbesondere, wenn sich Kursrückgänge über mehrere Perioden verteilen, wird auf diesem Wege die Gesamtsteuerlast am Wohnsitz gesenkt. Das Ergebnis entspricht einem Rücktrag von währungsbedingten Überhängen.

Entsteht andererseits aufgrund des Kursrückgangs ein Anrechnungsüberhang während der Haltedauer, ist auch eine Erhöhung der Gesamtsteuerlast nicht auszuschließen. Besteht der Kursrückgang, der die Teilwertabschreibungen notwendig machte, zum Zeitpunkt der Realisierung (Veräußerung) nicht mehr, erhöht sich durch die Abschreibung nämlich der steuerpflichtige Währungsgewinn. Ist der Kursrückgang indessen von Dauer, kommt es lediglich zu einer Vorverlagerung von Anrechnungsüberhängen.

Die Überlegungen zeigen: Auch die Auswirkung des Niederstwertprinzips auf den ex ante erwarteten Nettogewinn ist vom Einzelfall abhängig. Doch überwiegt vermutlich der Nachteil, da bei mehrperiodigen Investitionen ein steuerlich zu berücksichtigender Währungsverlust und

174 Vgl. auch L. Fischer u. P. Warneke, a.a.O., S.387-390. 
damit ein Anrechnungsüberhang wahrscheinlicher wird. Das Risiko besteht nicht nur zum Realisationszeitpunkt, sondern bei jedem Jahresabschluß.

Doch ist $\mathrm{zu}$ bedenken, daß die steuerliche Berücksichtigung von Teilwertabschreibungen bei Sachwerten und Beteiligungen dem Aktivitätsvorbehalt unterliegt. ${ }^{175}$ Sie dürfen, ebenso wie realisierte Verluste, bei passiven Aktiva nur mit positiven Einkünften derselben Art aus demselben Land verrechnet werden. Das heißt: der Währungsverlust kann hier nicht von anderen Einkünften aus dem Wirtschaftsgut, wie etwa Zinseinkünften, Beteiligungserträgen oder Mieteinnahmen, sondern nur von Veräußerungsgewinnen abgezogen werden. Diese Möglichkeit wird aber dadurch geschmälert, daß ja ein Kursrückgang den Wert aller Aktiva in einem Land reduziert. Gleichwohl entstehen durch Teilwertabschreibungen keine zusätzlichen Auswirkungen, da der Verlust unbegrenzt vorgetragen werden kann. Kommt es zum Zeitpunkt der Veräußerung (und bei einer späteren Zuschreibung) infolge eines wieder angestiegenen Kurses zu einem Gewinn, ist eine Verrechnung möglich.

Bleibt es indes bei dem niedrigen Kurs, ist die definitive Nichtberücksichtigung wahrscheinlich. Währungsgewinne sind demgegenüber steuerpflichtig.

Bei der Beurteilung der allokativen Folgen ist zudem zu berücksichtigen, wer der inländische Steuerpflichtige ist. Ist es nämlich eine Kapitalgesellschaft, mindert eine Teilwertabschreibung auf im Ausland belegene Wirtschaftsgüter zwar beim Freistellungsverfahren und möglicherweise auch beim Anrechnungsverfahren das körperschaftsteuerpflichtige Einkommen. Der Vorteil aus Sicht eines inländischen Sparers, der die Anteile hält, ist aber abhängig von dem Ausschüttungsverhalten der inländischen Gesellschaft und seiner individuellen einkommensteuerlichen Situation. Unter Umständen verbleibt von der geringeren Körperschaftsteuer nur ein Zinsvorteil. Wie gesagt, sinkt die mit der Ausschüttung bei der individuellen Einkommensteuer anrechenbare Körperschaftsteuer in dem Maße, in dem die Kapitalgesellschaft Steuern spart.

Einen effektiven Vorteil aus dem Niederstwertprinzip in der in diesem Unterabschnitt dargestellten Form haben demnach in erster Linie zwei Gruppen: (i) die Beteiligten an einer inländischen Personengesellschaft und andere buchführende natürliche Personen sowie (ii) Sparer, die an Kapitalgesellschaften beteiligt sind, Kapitaleinkommen aber nicht versteuern müssen.

\section{d) Währungstermingeschäfte}

Termingeschäfte sind, isoliert betrachtet, wie andere schwebende Geschäfte nicht zu bilanzieren. Für einen absehbaren - das heißt wirtschaftlich schon eingetretenen - Verlust war bisher eine Drohverlustrückstellung zu bilden. ${ }^{176}$ Durch die 1997 verabschiedete Steueränderung ist dies ab dem Jahr 1997 steuerrechtlich nicht mehr zulässig. ${ }^{177}$ Nicht realisierte Erfolge werden demgemäß hier nicht mehr asymmetrisch besteuert.

Die Behandlung von börsengehandelten Devisenterminkontrakten ist demgegenüber von den Kontraktspezifikationen abhängig. In der Regel besteht hier die Verpflichtung zu einer Sicherheitsleistung vor und zu täglichen Ausgleichszahlungen während der Laufzeit. Die Kontrakte werden deshalb als einseitig teilweise erfulltes Geschäft bezeichnet. ${ }^{178}$ Die Sicherheitsleistung

\footnotetext{
175 Hier: $\S \S 2 a$ Abs. 1 Nr. 3a), Nr.5 u. Nr.6c) EStG.

${ }^{176}$ K. Uhrmann, a.a.O., S. 1791 f..

177 Vgl. Beschlußempfehlung des Ausschusses nach Artikel 77 des Grundgesetzes (Vermittlungsausschuß) zu dem Gesetz zur Fortsetzung der Unternehmenssteuerreform, BT-Drucks. 13/8325 v. 4.8.1997., S. 2.

178 U. Wlecke, a.a.O., S. 128.
} 
ist zu aktivieren, die laufenden Zahlungen entsprechend ihres Vorzeichens als Erlös oder Aufwendung zu buchen. Damit findet auch steuerrechtlich ein ,marking to market" statt; es ist eine symmetrische Besteuerung von Gewinnen und Verlusten gewährleistet, die zudem periodengerecht erfaßt wird.

\section{e) Einzelbewertungsgrundsatz, Bewertungseinheiten und Kurssicherungstransaktionen}

Für zwei Wirtschaftsgüter eines Steuerpflichtigen mit negativ korrelierten Erwartungsstrukturen können - unter ebenso restriktiven wie umstrittenen Voraussetzungen - Bewertungseinheiten gebildet werden.

Die Möglichkeit besteht, da der Inhalt des Einzelbewertungsprinzips nicht eindeutig festgelegt ist. Mit anderen Worten: „Es besteht ein Unbestimmtheitsbereich hinsichtlich Art und Umfang der einem Bewertungsobjekt zuzuordnenden positiven und negativen Bewertungsfaktoren und damit bezüglich des Saldierungsbereiches der relevanten Bewertungsdeterminanten."179

Konkret bedeutet dies, daß die einzige Auswirkung einer Bewertungseinheit die Aufhebung des Niederstwertprinzips für deren Bestandteile ist. Es „dürfen hier ausnahmsweise nichtrealisierte Gewinne zum Ausgleich nichtrealisierter Verluste verwendet werden." 180,181 Kurssicherungstransaktionen sind dieser Fragestellung unterzuordnen. Das deutsche Recht kennt keine expliziten Vorschriften für Positionen, die mit der Motivation einer Minderung des Risikos eingegangen werden.

Die Bildung einer Bewertungseinheit läßt - im Unterschied zum U.S.-Steuerrecht - die Integration zweier Bilanzpositionen nicht zu. Bezüglich des Zeitpunktes der Realisierung ist es nicht relevant, ob eine Bewertungseinheit vorliegt. Die steuerrechtliche Quelle von Währungsgewinnen und -verlusten aus einem Sicherungsgeschäft läßt sich allerdings gegebenenfalls aus einem wirtschaftlichen Zusammenhang mit dem Grundgeschäft ableiten.

Das Spektrum der Meinungen zu dieser Bilanzierungsfrage reicht von dem Standpunkt, ${ }^{182}$ eine korrespondierende Bewertung verknüpfter Wirtschaftsgüter sei mit dem Einzelbewertungsgrundsatz generell unvereinbar, ${ }^{183}$ bis zu der Auffassung sie sei erforderlich, um die richtige Darstellung des Gewinnes im Jahresabschluß zu gewährleisten. ${ }^{184}$

Der Hauptfachausschuß des Instituts der Wirtschaftsprüfer kam zu dem Ergebnis, es handele sich um ein Wahlrecht. Sowohl die Bewertung der Positionen als Einheit, als auch die strikte Einzelbewertung sei zulässig, weil sich ein Grundsatz ordnungsmäßiger Buchfuihrung dazu noch nicht herausgebildet habe. ${ }^{185}$ Ein solches Wahlrecht wäre steuerlich jedoch aufgrund des

179 P. Kupsch, a.a.O., S. 133.

180 M. Groh, a.a.O., S. 873.

${ }^{181}$ Groh hält deshalb auch den Begriff Bewertungseinheit für verfehlt. M. Groh, a.a.O., S.873. Und Wlecke spricht nur von ,korrespondierender Bewertung“. U. Wlecke, a.a.O., S.181.

182 Vgl. U. Wlecke, a.a.O., S. 179 m..w.N..

183 H. Langel, a.a.O., S.858f..

${ }^{184}$ Diese Argumentation beruft sich auf $\S 252$ Abs. 2 HGB, demnach von den Grundsätzen in begründeten Ausnahmefällen abgewichen werden darf. G. Langenbucher, Die Umrechnung von Fremdwährungsgeschäften: Eine Untersuchung nach handels- und steuerrechtlichen Grundsätzen, a.a.O., S.143. U. Schlick, Bewertung von Fremdwährungspositionen im handelsrechtlichen Jahresabschluß, in: Deutsches Steuerrecht, 31.Jg. (1993), S. 256 .

${ }^{185}$ IDW, Geänderter Entwurf einer Verlautbarung zu Währungsumrechnung im Jahres- und Konzernabschluß, a.a.O., S. 665 f.. So im Ergebnis auch Groh, der meint, es könne aus dem „Vorhandensein von Forderungen und Schulden mit gleicher Fälligkeit nicht gefolgert werden, es bestehe Kurssicherung und es müsse daher vom 
Bewertungsvorbehalts als Aktivierungs- beziehungsweise Passivierungsgebot zu übersetzen; die Positionen wären steuerrechtlich zwangsläufig als eine Bewertungseinheit anzusehen. ${ }^{186}$

Überwiegende Meinung ist aber, daß eine zu enge Auslegung des Einzelbewertungsgrundsatzes dann nicht zu einer Anwendung des Imparitätsprinzips führen darf, wenn dies dem tatsächlichen Risiko widerspricht. ${ }^{187}$ Wirtschaftlich zusammenhängende Bilanzpositionen sind deshalb - und auch aus Vereinfachungsüberlegungen ${ }^{188}$ - im Einklang mit dem Einzelbewertungsgrundsatz korrespondierend zu bewerten.

Der wirtschaftliche Zusammenhang ist aber eng auszulegen. Jede Verrechnung von nicht realisierten Gewinnen und Verlusten muß die Sicherheit der Ansprüche voraussetzten. 189 Deshalb wird eine korrespondierende Bewertung für Sachwerte grundsätzlich abgelehnt. 190,191 Auch eine mit einem Erfüllungsrisiko belastete Forderung kann hiernach nicht Bestandteil einer Bewertungseinheit sein. ${ }^{192}$

Die Dekomposition solcher Positionen in einen Bewertungsfaktor Wechselkursrisiko und andere Risiken zur Isolierung des Umwechslungseffekts ist gleichwohl eventuell zulässig. Denkbar ist, das Imparitätsprinzip zunächst einzeln auf die Bewertung eines Aktivums in ausländischer Währung anzuwenden und anschließend den verbleibenden Teilwert bei korrespondierender Bewertung einzubeziehen. Der Bilanzansatz einer Forderung würde in diesem Fall nur den Wert umfassen, der nach Abzug eines Ausfallrisikos verbleibt. ${ }^{193}$

Nach den bisherigen Ausfuihrungen sind zur Bildung von Bewertungseinheiten noch (sichere) Forderungen und Verbindlichkeiten übrig; Sachwerte scheiden aus. ${ }^{194}$ Einbezogen werden darüber hinaus schwebende Geschäfte in der Weise, daß entweder eine Rückstellung für drohende Verluste aus einem solchen Geschäft in Fremdwährung oder eine Teilwertabschreibung bei den kompensierenden Bilanzpositionen unterbleibt. ${ }^{195}$ Für Termingeschäfte ist das Bild differenziert.

Börsengehandelte Devisenterminkontrakte sind in der Regel ebenfalls nicht geeignet, da sie infolge der börsentäglichen Nachschußverpflichtung einer zweiten Voraussetzung für die korrespondierende Bewertung nicht genügen können: der Kongruenz der Laufzeiten. ${ }^{196}$

Grundsatz der strikten Einzelbewertung abgewichen werden“. Vielmehr komme es auch auf die Bereitschaft und den Willen dazu an. M. Groh, a.a.O., S.873.

186 N. Harder, a.a.O., S. 300.

187 G. Langenbucher, Die Umrechnung von Fremdwährungsgeschäften: Eine Untersuchung nach handels- und steuerrechtlichen Grundsätzen, a.a.O., S.139 m.w.N.; U. Wlecke, a.a.O., S.179f.m.w.N..

188 W. Pößl, a.a.O., S.429; G. Langenbucher, Die Umrechnung von Fremdwährungsgeschäften: Eine Untersuchung nach handels- und steuerrechtlichen Grundsätzen, a.a.O., S.140.

${ }^{189}$ P. Kupsch, a.a.O., S. 135.

${ }^{190} \mathrm{IDW}$, Geänderter Entwurf einer Verlautbarung zu Währungsumrechnung im Jahres- und Konzernabschluß, a.a.O., S.665. U. Wlecke, a.a.O., S. 186; N. Shelton, Corporate Taxation of Foreign Currency Gains and Losses and Financial Instruments - Part I: Germany, in: Tax Planning International Review, 16. Jg. (1989), S.7.

${ }^{191}$ Auch gerichtlich ist der Grundsatz der Einzelbewertung bislang eng ausgelegt worden. Grundlage ist das BFH-Urteil vom 29.7.1965, der sogenannte Hopfen-Fall, wo entschieden wurde, daß bei einem Vorrat an Handelswaren und einem Deckungsgeschäft in Form eines Verkaufskontraktes das Niederstwertprinzip getrennt anzuwenden sei. BFH-Urteil v. 29.7.1965 IV 164/63 U, in: BStBl. III 1965, S.649. Bei Kurssicherungsgeschäften in größerem Umfang muß hierdurch die Aufgabe von Handels- und Steuerbilanz, ein den tatsächlichen Verhältnissen entsprechendes Bild der Vermögens-, Finanz- und Ertragslage zu vermitteln, bezweifelt werden. J. Benne, a.a.O., S. 2604.

${ }^{192}$ Adler/Düring/Schmaltz, a.a.O., §253 HGB, Rz.95ff.; U. Schlick, a.a.O., S.257; J. Benne, a.a.O., S.2604 m.w. N..

193 Adler/Düring/Schmaltz, a.a.O., \$253 HGB, Rz.110.; J. Benne, a.a.O., S. 2065.

194 G. Langenbucher, Umrechnung von Fremdwährungsgeschäften, a.a.O., S.349f., Rz. 533.

195 IDW, Geänderter Entwurf einer Verlautbarung zu Währungsumrechnung im Jahres- und Konzernabschluß, a.a.O., S.665.

196 G. Langenbucher, Umrechnung von Fremdwährungsgeschäften, a.a.O., S.356, Rz. 551 . 
Ansonsten ist dies bei Terminfestgeschäften kein Problem, da nur am Laufzeitende eine einmalige und zwingende Zahlung resultiert. ${ }^{197}$

Auch über die Reichweite dieses zweiten Anspruchs besteht indessen keine Einigkeit. Ein gewisser - kurzer - zeitlicher Unterschied wird teilweise als hinnehmbar angesehen, wenn die Lücke mit Sicherheit durch ein weiteres Deckungsgeschäft überbrückt werden kann. ${ }^{198}$

In jedem Fall ist aber der Abschluß eines Geschäfts zur Sicherung einer schon bestehenden Position dann kein Problem, wenn die Identität der Restlaufzeiten gegeben ist. ${ }^{199}$ Wird für eine solche Position ein Deckungsgeschäft abgeschlossen und bei der Bewertung der Position berücksichtigt, so ist der Unterschied zwischen dem bei der Erstverbuchung verwendeten Umrechnungskurs und einem niedrigeren Sicherungskurses als Kursverlust zu behandeln. Bei Vorliegen eines höheren Sicherungskurses darf handels- und steuerrechtlich bis zur Höhe des Anschaffungswertes eine Zuschreibung vorgenommen werden. ${ }^{200}$

Betragsidentität ist indessen nicht notwendig. ${ }^{201}$ Sind die sonstigen Voraussetzungen gegeben, ist es unproblematisch, die Minderung des Risikos durch schlichte Anteilsrechnung zu quantifizieren und zu berücksichtigen. ${ }^{202,203}$

Zusammenfassend kann an dieser Stelle festgestellt werden, daß die Identifikation von Bewertungseinheiten für Fremdwährungspositionen in der Praxis auf die Höhe der Steuerlast eines gegebenen Jahres keinen relevanten Einfluß haben muß. Der Steuerpflichtige kann eine Verpflichtung zu korrespondierender Bewertung umgehen. Die asymmetrische Wirkung des Imparitätsprinzips besteht dann selbst bei einer Kurssicherung, zumindest soweit auf eine vollkommene Sicherung verzichtet wird.

Freilich hat die Frage nach korrespondierender Bewertung zumindest bei Termingeschäften inzwischen keine Folgen mehr für die Höhe der Steuerlast, da aufgrund der oben erwähnten Steueränderung ein drohender Verlust aus einem schwebenden Geschäft ohnehin nicht abziehbar ist.

Sind aber in der Bilanz sowohl Aktiva als auch Passiva in einer fremden Währung enthalten, die nicht als Bewertungseinheit zusammengefaßt werden (können), wird eine Wechselkursänderung regelmäßig einen bilanziellen und steuerlichen Verlust zur Folge haben: Steigt der Devisenkurs, sind die Passiva mit dem höheren Rückzahlungskurs zu bilanzieren; sinkt der Kurs, sind die Aktiva mit dem niedrigeren Stichtagkurs umzurechnen. ${ }^{204}$

${ }^{197}$ Hessisches FG Urteil v. 24.11.1982 IV 359/79, in: EFG 1983, Entscheidung Nr.337, S.337; U. Wlecke, a.a.O., S.P. Kupsch, a.a.O., S.142.

${ }^{198}$ M. Groh, a.a.O., S. 874 m.w.N.; G. Langenbucher, Die Umrechnung von Fremdwährungsgeschäften: Eine Untersuchung nach handels- und steuerrechtlichen Grundsätzen, a.a.O., S.147f.; IDW, Geänderter Entwurf einer Verlautbarung zu Währungsumrechnung im Jahres- und Konzernabschluß, a.a.O., S.665; Adler/Düring/Schmaltz, a.a.O., §253 HGB, Rz.109. Anderer Auffassung ist Wlecke, da es in Abhängigkeit der Kursentwicklung zwischenzeitlich zur Realisation erheblicher Kursverluste kommen kann, denen nur unrealisierte Kursgewinne gegenüberstehen. U. Wlecke, a.a.O., S.195-199.

${ }^{199}$ G. Langenbucher, Umrechnung von Fremdwährungsgeschäften, a.a.O., S.349, Rz. 530.

200 IDW, Geänderter Entwurf einer Verlautbarung zu Währungsumrechnung im Jahres- und Konzernabschluß, a.a.O., S. 665.

${ }^{201}$ G. Langenbucher, Die Umrechnung von Fremdwährungsgeschäften: Eine Untersuchung nach handels- und steuerrechtlichen Grundsätzen, a.a.O., S.148; U. Wlecke, a.a.O., S.194.

202 Vgl. U. Wlecke, a.a.O., S. 189-193 mit einer ausführlichen Beispielrechnung.

${ }^{203}$ Eine weitere Bedingung, die kausale Beziehung der wertbeeinflussenden Faktoren der Positionen einer Bewertungseinheit, ist hier selbstredend gegeben, da nur das Währungsrisiko betrachtet wird. W. Pöß1, a.a.O., S.434; P. Kupsch, a.a.O., S.135f..

${ }^{204}$ M. Groh, a.a.O., S.870; S. Pomrehn, Handelsrechtliche Bewertung bei zu bilanzierenden Fremdwährungsgeschäften und Rückführung auf die durch das Steuerrecht gezogenen Grenzen, in: Der Betrieb, 43.Jg. (1990), S. 1102 f.; N. Harder, a.a.O., S. 300 . 
Eine willkürliche Ausnutzung dieses Unbestimmtheitsbereiches des Rechts wird allerdings durch das Gebot der Methodenstetigkeit eingeengt, demnach von einmal gewählten Bewertungsverfahren nur in begründeten Ausnahmefällen abgewichen werden darf. ${ }^{205}$ Trotzdem bleiben für den Steuerpflichtigen, insbesondere im Hinblick auf die erforderliche Kongruenz der Fälligkeiten, Gestaltungsspielräume bestehen. ${ }^{206}$

Deren Tragweite ist jedoch unbestimmt:

Im allgemeinen besteht der steuerliche Vorteil durch einen Verzicht auf korrespondierende Bewertung für Unternehmen mit positiver Erfolgslage in einen Zinsvorteil durch die gewinnmindernde Abschreibung beziehungsweise Rückstellung vor dem Zeitpunkt der Realisierung. ${ }^{207}$

Im besonderen kann bei grenzüberschreitendem Kapitaleinsatz diesem Vorteil des Steueraufschubs aber die Gefahr eines Anrechnungsüberhangs im Jahr der Abschreibung gegenüberstehen, vorausgesetzt es liegen ausländische Einkünfte vor. Die Auswirkungen wurden weiter oben in Unterabschnitt c) aufgezeigt. Zwar ist der Quellensteuersatz auf die zur Bildung von Bewertungseinheiten zulässigen Formen des Kapitalexports in der Realität regelmäßig nicht so hoch, soweit sie überhaupt erhoben wird. ${ }^{208,} 209$ Die Quellensteuer wird aber zumeist auf den Bruttoertrag erhoben. Zudem kann, wie in Teil B gezeigt wurde, schon bei einem niedrigen Steuersatz im Quellenland ein signifikanter Barwert einer zusätzlichen Steuerlast entstehen. Die Wirkung ist umso stärker, je größer die Schwankungen der Fremdwährung.

Auch die Perspektive eines Zinsvorteils bei Verzicht auf korrespondierende Bewertung nimmt aber mit dem Wechselkursrisiko zu, da eine Teilwertabschreibung wahrscheinlicher wird.

Der Effekt auf den ex ante erwarteten Nettogewinn ist also auch hier vom Einzelfall abhängig. Soweit im Quellenland Steuern gezahlt werden müssen, reduziert die Möglichkeit zu korrespondierender Bewertung wohl in erster Linie die durch das Anrechnungsverfahren bestehende Diskriminierung.

Welche quantitative Bedeutung haben Stille Reserven als Folge währungsbedingter Teilwertabschreibungen in der Praxis? Diese Frage muß hier unbeantwortet bleiben. Publikumsgesellschaften sind lediglich zur Angabe der Grundlagen für die Umrechnung in ihrem - handelsrechtlichen - Jahresabschluß verpflichtet. ${ }^{210}$ Die Bilanzen der Unternehmen weisen Fremdwährungspositionen weder nach Aktiva und Passiva noch nach Währungen getrennt aus. Untersuchungen $\mathrm{zu}$ dieser Frage sind dementsprechend auch in der Literatur nicht $\mathrm{zu}$ finden. Allerdings wird in der Bilanzierungspraxis ,in nicht unerheblichem Ausmaß aus Gründen der Bilanzoptik unter Berufung auf die wirtschaftliche Betrachtungsweise" - und auch nach eigenem Belieben - korrespondierend bewertet. 211

Steuerliche Überlegungen werden auf Grund des Maßgeblichkeitsprinzips dann diesem Bilanzziel untergeordnet.

\footnotetext{
$205 \S 252$ Abs. 1 Nr. 6 HGB; §252 Abs. 2 HGB.

206 T. Finne, a.a.O., S.302f..

207 G. Gebhardt, a.a.O., S.19f.; N. Harder, a.a.O., S.300f..

$208 \mathrm{Vgl}$. Anhang V auf Seite 223.

${ }^{209}$ Dabei ist aber zu bedenken, daß das Sicherungsgeschäft auch inländische Gewinne oder Verluste generieren kann, beispielsweise wenn es mit einer inländischen Bank abgeschlossen wurde.

$210 \S 284$ Abs. 2 Nr. 2 HGB.

${ }^{211}$ H. Langel, a.a.O., S.859.
} 


\section{Ausländische Betriebstätten}

Die Charakterisierung und Quantifizierung von Währungsgewinnen oder Verlusten, die im Zusammenhang mit der Existenz einer Betriebstätte entstehen können, ist im deutschen Steuerrecht nicht zweifelsfrei geklärt. In der Literatur wurden sehr unterschiedliche Auffassungen vertreten, deren Konsequenzen ganz konkret die Höhe der Steuerlast beeinflussen. Nach und nach schließen sich aber die bestehenden rechtlichen Lücken durch Urteilssprüche des Bundesfinanzhofes.

Im Steuerrecht der USA werden Auslandsaktivitäten, die den Voraussetzungen einer qualifizierten wirtschaftlichen Einheit genügen, zum Zwecke der Bestimmung von Zeitpunkt und Höhe der Währungserfolge als wirtschaftliche Einheit angesehen. Die Ermittlung des Gewinnes der QBU - und damit auch die Bewertung der Bilanzpositionen - geschieht nach den Vorschriften des U.S.-Steuerrechts in der funktionalen Währung. Die Währungsumrechnung ist lediglich eine Maßnahme der Ergebnisübernahme. ${ }^{212}$ Zur Quantifizierung des Währungserfolges - und nur dafür - wird die QBU als eine integrierte Position interpretiert. So ist es möglich, den Währungsgewinn oder -verlust bezogen auf das Reinvermögen in den Händen der inländischen Steuerpflichtigen zu quantifizieren.

\section{a) Zulässigkeit der Umrechnungsmethoden}

Im Unterschied dazu wird in Deutschland die Betriebstätte auch für diese Frage vom Grundsatz her als unselbständiger Teil des inländischen Steuerpflichtigen angesehen. Das Betriebstättenprinzip, demnach von einem selbständigen Unternehmen auszugehen ist, dient nur der geographischen Aufteilung von Einkünften, um die Zuordnung von Besteuerungsansprüchen zwischen den Staaten zu regeln. Der Gewinn ist nach deutschen Vorschriften zu quantifizieren, ${ }^{213}$ und es ist dabei unzulässig, die ausländische Währung zur Bemessung des steuerlichen Gewinnes heranzuziehen. ${ }^{214}$ Die Währungsumrechnung wird als Teil der Bewertung angesehen; 215 eine Kursänderung ist nur einer von möglicherweise mehreren Bewertungsfaktoren.

Die Meinungen hinsichtlich der Anwendbarkeit der Umrechnungsmethoden im deutschen Steuerrecht ist differenziert und wurde in der Literatur ausgiebig diskutiert. ${ }^{216}$ Die Widersprüche werden hier deshalb im wesentlichen in einer kurzen, zusammenfassenden Form wiedergegeben:

Natürlichen Personen, die Gesellschafter einer ausländischen Personengesellschaft sind, ist es ohne Frage gestattet, zur Bemessung der inländischen Steuerpflicht auf die Bilanz der ausländischen Gesellschaft zurückzugreifen. Zur Ergebnisumrechnung können diese Personen

${ }^{212} \mathrm{M}$. Eisenach, Währungsumrechnung beim Verlustabzug nach $\S 2$ Auslandsinvestitionsgesetz, in: Der Betrieb, 39. Jg. (1986), S.2280.

${ }^{213}$ L. Fischer u. P. Warneke, a.a.O., S.384; K.-H. Baranowski, Zur Ermittlung und Umrechnung ausländischer Einkünfte, in: Der Betrieb, 45.Jg. (1992), S.240; Blümich/J. Täske, §26 KStG, Rz22.

${ }^{214}$ D. Grützner, Die Umrechnung ausländischer Besteuerungsgrundlagen, in: IWB, Fach 3 Deutschland, Gruppe 3, S. 870 .

${ }^{215} \mathrm{M}$. Eisenach, Währungsumrechnung beim Verlustabzug nach $§ 2$ Auslandsinvestitionsgesetz, a.a.O., S.2280. Vgl. auch W. Ossadnik, a.a.O., S.1395-1397.

${ }^{216}$ Vgl. D. Grützner, a.a.O., S. 868f. m.w.N.; M. Eisenach, Währungsumrechnung beim Verlustabzug nach $\S 2$ Auslandsinvestitionsgesetz, a.a.O., S.2279-2284; Institut „Finanzen und Steuern“ e.V. (Hrsg.), Heft 125, a.a.O., S.16-19; T. Finne, a.a.O., S.167-175; U. Wlecke, a.a.O., S.56-62; P. Malinski, a.a.O., S.16-27. 
aus verschiedenen Verfahren wählen - soweit nur die deutschen Grundsätze ordnungsmäßiger Bilanzierung eingehalten werden. ${ }^{217}$

Im Unterschied zu Einzelpersonen unterliegen inländische Kapitalgesellschaften einer Buchführungs- und Bilanzierungspflicht im Inland. Da Betriebstätten handelsrechtlich unselbständiger Teil des Vermögens der Gesellschaft sind, sind sie in die Buchführungspflicht des inländischen Stammhauses einbezogen. ${ }^{218}$

Um den Grundsätzen ordnungsmäßiger Buchführung gerecht zu werden, ist es erforderlich, alle Transaktion separat mit dem jeweils aktuellen Kurs in der oben genannten Weise in Deutscher Mark zu bewerten. Es dürfte genau genommen nur die Umsatzmethode anwendbar sein. ${ }^{219}$ In der Abgabenordnung wird zur Buchführungspflicht von Betriebstätten aber gesagt, diese könnten im Geltungsbereich des ausländischen Gesetzes geführt und aufbewahrt werden, soweit nach dem Recht des Belegenheitsstaates

„eine Verpflichtung besteht, Bücher und Aufzeichnungen zu führen, und diese Verpflichtung erfüllt wird. In diesem Falle [...] müssen die Ergebnisse der dortigen Buchführung in die Buchführung des hiesigen Unternehmens übernommen werden, soweit sie für die Besteuerung von Bedeutung sind. Dabei sind die erforderlichen Anpassungen an die steuerrechtlichen Vorschriften im Geltungsbereich dieses Gesetzes vorzunehmen und kenntlich zu machen." 220

Je nach der Interpretation des Wortes „Ergebnisse“,221 könnten sowohl Stichtag- als auch Fristigkeitmethode zulässig sein, wenn die Buchfuihrung den deutschen Vorschriften angepaßt wird. Bei beiden Verfahren werden die Bücher in der Sitzlandwährung geführt und nur das Ergebnis in die inländische Währung umgerechnet.

Das Problem bleibt aber, daß sowohl die Stichtag- als auch die Fristigkeitmethode im Widerspruch zu Imparitäts- und Realisationsprinzip und die Stichtagmethode darüber hinaus im Widerspruch zum Einzelbewertungsgrundsatz stehen. ${ }^{222}$ Nur die Umsatzmethode genügt diesen Anforderungen. ${ }^{223} \mathrm{Da}$ sich die Prinzipien direkt aus dem Einkommensteuergesetz ableiten, sind sie als Spezialvorschriften gegenüber der Abgabenordnung vorrangig.

217 J. Viegener, Umrechnung der nach ausländischen Rechtsordnungen ermittelten Ergebnisse zur Anwendung des Auslandsinvestitionsgesetzes, in: Steuerberater-Jahrbuch, 35.Jg. (1983/84), S.401 f.; BFH-Urteil v. 13.9.1989 I R 117/87, in: BStGl. II 1990, S.58f.; L. Fischer u. P. Warneke, a.a.O., S.385; K.-H. Baranowski, a.a.O., S.243; K. Tipke u. H.W. Kruse, Abgabenordnung, Finanzgerichtsordnung: Kommentar, 16. Aufl., Köln 1996, $\S 146$ AO, Tz. 11 .

${ }^{218}$ Vgl. G. Langenbucher, Die Umrechnung von Fremdwährungsgeschäften: Eine Untersuchung nach handelsund steuerrechtlichen Grundsätzen, a.a.O., S.178f. und die dort angegebene Literatur.

${ }^{219}$ Eine andere Auffassung vertritt allerdings Baranowski mit Verweis auf das Realisationsprinzip. Thm zufolge ist es ein „Unterschied, ob der Unternehmer in einem ausländischen Währungsgebiet über eine dort vorhandene Betriebsstätte am dortigen Wirtschaftsverkehr teilnimmt oder ob er in seinem inländischen Unternehmensbereich ausländische Zahlungsmittel hält". Erwirbt die ausländische Betriebstätte Aktiva, ergäben sich Anschaffungskosten in der Landeswährung. Einer Umrechnung zum Zeitpunkt des Erwerbs bedürfe es nicht. „Das Verlangen nach einer solchen Umrechnung unterstellt einen Vorgang, der gar nicht stattgefunden hat; denn das Wirtschaftsgut, dessen Wert in DM umgerechnet werden soll, befindet sich in einer Betriebsstätte außerhalb des DM-Währungsgebietes.“ Eine Umrechnung sei nur zu rechtfertigen bei Veräußerung der Betriebstätte oder „wenn die handelsrechtliche oder steuerrechtliche Periodenabgrenzung dem Unternehmen aufgibt, auf das Ende des Geschäftsjahres das Vermögen der ausländischen Betriebsstätte und damit auch deren Geschäftsergebnis in DM auszuweisen“. K.-H. Baranowski, a.a.O., S. $241 \mathrm{f}$..

$220 \S 146$ Abs. 2 Sätze 2 bis 4 AO.

${ }^{221}$ U. Wlecke, a.a.O., S.61; N.-P. Schoss, a.a.O., S. 101 f..

${ }^{222}$ Zudem wird eingewendet, die Abschreibung auf der Grundlage der Anschaffungskosten nach $§ 7$ EStG sei inkompatibel mit einer Umrechnung zum Stichtagkurs. M. Eisenach, Währungsumrechnung beim Verlustabzug nach §2 Auslandsinvestitionsgesetz, a.a.O., S.2282.

${ }^{223}$ G. Gebhardt, a.a.O., S.156f.; T. Finne, a.a.O., S.173f.. Unstreitig ist, daß die Grundsätze auf die Positionen in ausländischer Wăhrung anzuwenden sind. 
Allerdings läßt die Annahme, „daß der Gesetzgeber im Zweifel keine Nonsens-Vorschriften schafft" 224 , sondern mit der Regelung eine Vereinfachung der Buchfuihrung beabsichtigt habe, einige Autoren an der alleinigen Zulässigkeit der Umsatzmethode zweifeln und auf ein Wahlrecht bezüglich der Umrechnungsmethode schließen. ${ }^{225} \mathrm{Ihr}$ Zweck ist aber, einen Konflikt zwischen dem Recht des Betriebstättenstaates und Deutschlands zu vermeiden, der darin bestehen könnte, daß grundsätzlich beide Länder die Aufbewahrung der Originalbelege fordern; es handelt sich um eine reine Ordnungsvorschrift. ${ }^{226}$

Dennoch: die oben zitierte Passage stellt den einzigen unmittelbaren Ansatzpunkt für die Rechtfertigung der Anwendung einer vereinfachenden Umrechnungsmethode dar. ${ }^{227}$ Die Verfahrensweisen werden in der Literatur deshalb vielfach abgelehnt. ${ }^{228}$ Einigkeit besteht nur über die Zulässigkeit der Umsatzmethode. Andererseits merkt Jacobs an, „für umfangsmäßig bedeutende Zweigniederlassungen stellt diese Ausnahmevorschrift faktisch den Regelfall dar." 229

Zweifelsfrei kann hier folglich nur eines festgestellt werden: Die Stichtagmethode ist in der derzeit in den USA vorgeschriebenen Form in Deutschland nicht zulässig,, ${ }^{230}$ da Auswirkungen von Kursänderungen auf die Bilanzpositionen unberücksichtigt bleiben. Werden die Auswirkungen auf die Bestände einbezogen, kann die Methode indes akzeptiert werden, wenn „das relativ einfache Stichtagkursverfahren nicht zu materiell falschen Ergebnissen“ führt. ${ }^{231}$

Die Zeitbezugmethode wurde demgegenüber in mehreren Urteilen vom Bundesfinanzhof akzeptiert. ${ }^{232}$ Die Methode wird oft als Weiterentwicklung des Nominal-/Sachwertverfahrens

224 Institut „Finanzen und Steuern“ e.V. (Hrsg.), Heft 125, a.a.O., S.17. Indes hat der Bundesfinanzhof in seinen bisherigen Urteilen zur Währungsumrechnung einen Zusammenhang zwischen der Vorschrift des §146 AO und der Umrechnung des Betriebstättenergebnisses ,noch nicht einmal in Erwägung gezogen“. P. Malinski, a.a.O., S. $25 \mathrm{f}$.

225 So z.B. Institut „Finanzen und Steuern“ e.V. (Hrsg.), Heft 125, a.a.O., S.19; J. Viegener, a.a.O., S.405-409; G. Langenbucher, Die Umrechnung von Fremdwährungsgeschäften: Eine Untersuchung nach handels- und steuerrechtlichen Grundsätzen, a.a.O., S.184f.; O. H. Jacobs, a.a.O., S.324. K.-H. Baranowski, a.a.O., S.240; Flick/Wassermeyer/Becker, §34c EStG, Rz.116b. Vgl. auch H.-J. Kleineidam, Gewinnermittlung bei Auslandsbetriebstätten (Teil II), in: Internationales Steuerrecht, 2.Jg. (1993), S.398 für einen ,Forderungskatalog" an eine den Grundsätzen ordnungsmäßiger Buchführung entsprechende Währungsumrechnung.

${ }^{226} \mathrm{Vgl}$. M. Eisenach, Währungsumrechnung beim Verlustabzug nach $\S 2$ Auslandsinvestitionsgesetz, a.a.O., S. 2283; K. Tipke u. H.W. Kruse, a.a.O., §146 AO, Tz.11; P. Malinski, a.a.O., S.26f..

227 U. Wlecke, a.a.O., S.68.

${ }^{228}$ So z.B. A. Rädler, a.a.O., S.457; S. Schröder, Die Betriebstätte im deutschen Außensteuerrecht, in: Steuerliche Betriebsprüfung, 18.Jg. (1978), S.180f. demzufolge es aber genügt, „wenn als ,Betriebstättengewinn“ zum Ende eines Monats jeweils die Salden der Bestands- und Erfolgskonten aus der Betriebstättenbuchhaltung über ein Verrechnungskonto in die Buchführung des Stammhauses übernommen werden."; D. Grützner, a.a.O., S.871; T. Finne, S.172f. u. S.175; P. Malinski, a.a.O., S.22f., der dann, wenn eine relativ stabile Wechselkursentwicklung vorliegt, aus Vereinfachungsgründen auch die Fristigkeitmethode für zulässig hält; ebenso Blümich/H. Krabbe, §34d EStG, Rz.48; N.-P. Schoss, a.a.O., S. 106.

229 O. H. Jacobs, a.a.O., S. 324.

${ }^{230}$ BFH-Beschluß v. 9.8.1989 I B 118/88, in: BStBl. II 1990, S.177; P. Malinski, a.a.O., S.22; N. Harder, a.a.O., S. 298.

${ }^{231}$ FG Münster Urteil v. 3.10.1995 9 K 5026/92 (n-rkr), a.a.O., unter II.2. Es handelte sich um eine Betriebstätte, die ausschließlich Umlaufvermögen hatte.

Eine Auswertung der Anhangsangaben von 100 Konzernabschlüssen des Jahres 1993 ergab, daß von 85 Konzernen, die Angaben gemacht hatten, die Stichtagmethode in 67 Fällen für die handelsrechtliche Bilanz gewählt wurde. Vgl. W. Gelhausen u. R. Mujkanovic, Auswertung zur Währungsumrechnung im Konzernabschluß, in: Deutsches Steuerrecht, 30. Jg. (1992), S.1724-1726.

232 So zur Ermittlung des Gewinns von im Ausland belegenen Gewerbebetrieben für den Progressionsvorbehalt: BFH-Beschluß v.9.8.1989 I B 118/88, a.a.O., S.175-177; BFH-Urteil v. 13.9.1989 I R 117/87, a.a.O., S.59f.; BFH-Urteil v. 16.2.1996 I R 43/95, in: Der Betrieb, 49. Jg. (1996), S. 1801. So außerdem: FG Baden-Württemberg-Beschluß v. 15.6.1988 XII V 7/87, anders indes zuvor: FG Baden-Württemberg-Urteil v. 3.7.1987 XII K 
bezeichnet. Im Hinblick auf das Vorgehen bei der steuerrechtlichen Gewinnermittlung verwirrt diese Bezugnahme aber mehr als sie klarstellt. Denn, den oben genannten Grundsätzen folgend, besteht der Kern der Zeitbezugmethode in der Umrechnung sämtlicher Bestände mit den historischen Kursen zum Zeitpunkt ihrer Erstverbuchung, ergänzt um den - hier vom Umfang her umstrittenen - Niederstwerttest. ${ }^{233}$

Die Parallelen zum Nominal-/Sachwertverfahren sind insofern gering. In der Literatur ist zwar teilweise die Auffassung zu finden, Nominalwerte könnten generell mit dem Stichtagkurs umgerechnet werden. ${ }^{234}$ Überwiegend wird dies aber mit Hinweis auf das Realisationsprinzip abgelehnt, oder allenfalls für nominelle Wirtschaftsgüter mit kurzen Restlaufzeiten als akzeptabel angesehen. ${ }^{235}$

Materielle Unterschiede zur Umsatzmethode ergeben sich allenfalls durch eine Vereinfachung der Buchführung bei der Umrechnung des Erfolgs der ausländischen Niederlassung. Die Konvertierung der Gewinn- und Verlustrechnung mit einem einheitlichen Kurs ist aber nach dem bisher Gesagten nicht möglich und wird abgelehnt. ${ }^{236}$

Der Niederstwerttest ist auch hier - abgesehen von Positionen, die korrespondierend zu bewerten sind - auf jede Bilanzposition separat anzuwenden. ${ }^{237}$ Das heißt, es besteht der bemerkenswerte Effekt, daß sowohl ein Rückgang als auch ein Anstieg des Kurses zu einem Verlust führen kann - entweder auf der Aktiv- oder der Passivseite der Bilanz. ${ }^{238}$

$\mathrm{Ob}$ aus der Teilwertabschreibung für den Steuerpflichtigen ein Vorteil in Form einer dauerhaften Minderung oder eines zeitlichen Aufschubs der Steuerlast erwächst, hängt aber von weiteren Faktoren ab, insbesondere von der Rechtsform des Steuerpflichtigen und der Quelle von Währungserfolgen durch Betriebstätten.

\section{b) Quelle des Währungsergebnisses}

In der Literatur wird die grundsätzliche Frage, ob Währungsgewinne oder -verluste überhaupt besteuert werden sollten, nicht gestellt. Umstritten ist deren Ursprung und die Frage, ob sie nach Maßgabe des Betriebstättenprinzips zuzurechnen sind.

Drei Positionen wurden vertreten:239

(1) Währungsgewinne und -verluste sind ausländische Einnahmen oder Betriebsausgaben und deshalb steuerfrei, wenn Deutschland in einem Doppelbesteuerungsabkommen mit dem Belegenheitsstaat die Freistellung der Betriebstätteneinkünfte vereinbart hat.

759/85. Vgl. hierzu M. Eisenach, Abzug von Währungsverlusten - Ernstliche Zweifel an der Nichtberücksichtigung von Wechselkursverlusten, in: Der Betrieb, 41.Jg. (1988), S. 1827.

233 In diesem Fall wird auch der Begriff der Äquivalenzmethode verwendet. D. Ordelheide, a.a.O., S.797.

$234 \mathrm{Vgl}$. zur handelsrechtlichen Bilanzierung auch IDW, Geänderter Entwurf einer Verlautbarung zu Währungsumrechnung im Jahres- und Konzernabschluß, a.a.O., S.665f. .

235 A. G. Coenenberg, a.a.O., S.382f.

${ }^{236}$ U. Wlecke, a.a.O., S.364f.; H.-J. Kleineidam, Gewinnermittlung bei Auslandsbetriebstätten (Teil II), a.a.O., S.398; vgl. auch N.-P. Schoss, a.a.O., S.97f..

${ }^{237}$ Dabei ist bei abnutzbaren Aktiva der ausländischen Betriebstätte eine Teilwertabschreibung natürlich nur zulässig, falls der Wăhrungsverlust eine Differenz zwischen steuerlicher planmäßiger Absetzung für Abnutzung und dem tatsächlichen wirtschaftlichen Wertverlust übertrifft. Analog sind - wie im Text weiter oben erwähnt sonstige bilanziell entstandene Stille Reserven zunächst zu verrechnen. L. Langel, a.a.O., S.849; G. Wöhe, a.a.O., S.478f.. Vgl. auch das Beispiel in T. Finne, a.a.O., S.131.

238 Vgl. T. Finne, a.a.O., S.275-284 mit zahlreichen Beispielrechnungen; K. Uhrmann, a.a.O., S.1793, der deshalb fordert, die Abschreibungen für Währungsrisiken auf den Kapitalsaldo zu begrenzen; U. Schlick, a.a.O., S.254f..

${ }^{239}$ Vgl. auch die Literaturzusammenfassung in N.-P. Schoss, a.a.O., S.108-111 sowie auch S.112-123. 
(2) Währungsgewinne und -verluste sind inländische Einkünfte und deshalb in jedem Fall steuerpflichtig.

(3) Währungsgewinne und -verluste sind - gesetzt den Fall, es sind ausländische Einnahmen auch dann nicht freizustellen, wenn das Betriebstättenergebnis freigestellt wird.

Die erste Position ist die überwiegende Auffassung der Finanzverwaltung 240 und auch der Rechtsprechung ${ }^{241}$. Begründet wird dies schlicht damit, daß der Währungsgewinn oder -verlust ohne die Errichtung und Existenz der Betriebstätte nicht eingetreten wäre.

Dabei wird entweder argumentiert, es seien Ausgaben, die deshalb dem Veranlassungsprinzip unterliegen: Die Betriebsausgaben stünden in wirtschaftlichem Zusammenhang mit der Betriebstätte und seien durch sie veranlaßt. ${ }^{242}$ Oder es wird gesagt, Währungserfolge seien Einnahmen, die ohne die Existenz der Betriebstätte in einem fremden Währungsraum nicht entstanden wären und deshalb ausländischen Ursprungs. ${ }^{243}$ Die Unterscheidung zwischen Aufwendung und Einnahme ist im deutschen Steuerrecht für das Ergebnis hier unwesentlich, da der Währungserfolg im Gesetz nicht als eigene Einkunftart kodifizert wurde. Bei beiden Varianten ist nach dem wirtschaftlichen Zusammenhang mit Umständen, durch den sie veranlaßt sind, zu suchen. 244

Auf der Grundlage geltenden Rechts wurden aber auch die beiden anderen Positionen vertreten.

Das Institut „Finanzen und Steuern“ e. V. begründete die zweite Möglichkeit wie folgt:

Es sei ,nicht zu verkennen, daß die Währungsgewinne und -verluste in der nach dem ausländischen Steuerrecht erstellten Betriebstättenbilanz nicht in Erscheinung treten. Sie treten ausschließlich in der inländischen Bilanz des Stammhauses auf, weil dort aufgrund gesetzlicher Anordnung in Deutscher Mark bilanziert werden muß. Wenn das inländische Steuerrecht auch eine Bilanzierung in Fremdwährung zulassen würde, käme es zu dem Problem nicht. Es ist demzufolge der gesetzliche Umrechnungszwang in Deutsche Mark, der überhaupt erst zum Auftreten dieser Währungsgewinne und -verluste in der inländischen Bilanz führt." 245

Damit handele es sich um einen unternehmensexternen Faktor; die Einkünfte würden deshalb auch nicht von der Betriebstätte ,erzielt“. ${ }^{246}$ Sie entstünden zwar durch die Existenz, nicht jedoch durch die Tätigkeit der Betriebstätte und ,sind daher nach der Legaldefinition des Betriebsstättengewinns nicht dessen Bestandteile".247 Ist ein wirtschaftlicher Zusammenhang aber nicht zu begründen, fallen sie nicht unter die im Einkommensteuergesetz als ausländisch definierten Einkünfte und sind damit zwangsläufig inländischen Ursprungs.

Der Standpunkt ist jedoch zweifelhaft. In Teil B wurde zwar gezeigt, daß ein unmittelbarer Zusammenhang des Währungsrisikos - und damit ex post des Währungsergebnisses - mit der Form der Auslandsaktivität nicht besteht. Der Währungserfolg entsteht somit nicht durch die Tätigkeit der Betriebstätte. Eine unmittelbare Verbindung mit Kapitalexport als solchem ist aber gegeben. Die Verneinung eines (mittelbaren) wirtschaftlichen Zusammenhangs ist aus

240 Institut „Finanzen und Steuern“ e.V. (Hrsg.), Heft 125, a.a.O., S.20; K.-H. Baranowski, a.a.O., S.242.

241 BFH-Beschluß v. 9.8.1989 I B 118/88, a.a.O., S.175-157; BFH-Urteil v. 13.9.1989 I R 117/87, a.a.O., S.5760; BFH-Urteil v. 16.2.1996 I R 43/95, a.a.O., S.1801, P. Malinski, a.a.O., S.82.

242 O.H. Jacobs, a.a.O., S.238f. u. S. 331 f..

${ }^{243}$ D. Grützner, a.a.O., S. 870 ff.; Flick/Wassermeyer/Becker, §2 AIG, Rz.120b; Blümich/H. Krabbe, §34dEStG, Rz49.

244 O.H. Jacobs, a.a.O., S. 331 f.. $\$ 4$ Abs. 4 u. $\$ 9$ Abs. 1 EStG.

245 Institut „Finanzen und Steuern“ e.V. (Hrsg.), Heft 125, a.a.O., S.20f. .

$246 \S 34$ d Abs. 2a) EStG; Institut ,Finanzen und Steuern“ e.V. (Hrsg.), Heft 125, a.a.O., S. 20 f..

247 W. Pering, Auswirkungen von Wăhrungskursschwankungen auf den Betriebstättengewinn, in: Der Betrieb, 39.Jg. (1986), S.2301. So auch T. Finne, a.a.O., S.267f.; K. Uhrmann, a.a.O., S.1792; N.-P. Schoss, a.a.O., S. 123 u. S. 113. 
diesem Grund nicht überzeugend, und eine Interpretation als ausländische Gewinne oder Verluste nach derzeitigem nationalen Recht ist plausibel. ${ }^{248}$ Im übrigen hat der Bundesfinanzhof in anderem Zusammenhang klargestellt, daß Gewinne einer Betriebstätte sowohl durch ihre Existenz als auch durch ihre Tätigkeit erwirtschaftet werden können. ${ }^{249}$

Die dritte Position schließlich beruft sich auf dem Musterabkommen der OECD entsprechende Vorschriften der deutschen Doppelbesteuerungsabkommen. ${ }^{250}$ In dem Musterabkommen heißt es zur Freistellungsmethode:

„Bezieht eine in einem Vertragstaat ansässige Person Einkünfte oder hat sie Vermögen und können diese Einkünfte [...] nach diesem Abkommen in einem anderen Vertragstaat besteuert werden, so nimmt der erstgenannte Staat [...] diese Einkünfte [...] von der Besteuerung aus." 251

Weil aber das Ausland Währungserfolge nicht besteuern könne, ${ }^{252}$ da sie in der nach dessen Steuerrecht erstellten Bilanz nicht existieren, wären sie auch nicht von der deutschen Steuer befreit, wenn sie ausländischen Ursprungs sind. ${ }^{253}$ Dem widersprach das Finanzgericht Münster: ,ausschlaggebend ist [...] die Zuordnung der maßgeblichen Geschäftsvorfälle, nicht aber die Zuordnung der für die Gewinnermittlung maßgeblichen Vorschriften". 254

Der Bundesfinanzhof hat diese Position in zwei Urteilen von 1996 bestätigt. 255

Auch aus dem Blickwinkel dieser Arbeit wäre das Ergebnis der Interpretation nicht befriedigend:256

248 So auch P. Malinski, a.a.O., S.57.

249 BFH-Urteil v. 20.7.1988 I R 49/84, in: BStBl. II 1989, S. 142 m.w. N.; O.H. Jacobs, a.a.O., S. 332.

${ }^{250} \mathrm{Vgl}$. Institut „Finanzen und Steuern“ e.V. (Hrsg.), Heft 125, a.a.O., S.45f.

${ }^{251}$ Art.23A Abs. 1 OECD-Musterabkommen. Zu einer genaueren Analyse der Formulierungen in Doppelbesteuerungsabkommen Deutschlands vgl. P. Malinski, a.a.O., S.82-85; N.-P. Schoss, a.a.O., S. 120 f..

252 Anderer Auffassung ist Malinski. Er ist der Meinung, der mit der Ermittlung der Einkünfte verbundene Arbeitsaufwand läge ,noch im Rahmen des Vertretbaren“ und die Argumentation sei deshalb so nicht stichhaltig. P. Malinski, a.a.O., S. 84. So auch FG Münster Urteil v. 3.10.1995 9 K 5026/92 (n-rkr), a.a.O. unter II. 3.c), das in diesem Zusammenhang von virtueller Doppelbesteuerung spricht.

253 Institut „Finanzen und Steuern“ e. V. (Hrsg.), Heft 125, a.a.O., S. 46.

${ }^{254}$ FG Münster Urteil v. 3.10.1995 9 K 5026/92 (n-rkr), a.a.O. unter II.3.b). So auch FG Hamburg Urteil v. 26.4.1995 VII 101/92 (n-rkr), a.a.O., S.871 f..

${ }^{255}$ Zum einen ging es um die Berücksichtigung von Währungsverlusten aus der Rückführung von Dotationskapital einer belgischen Betriebstätte bei dem Betriebsergebnis der inländischen Kapitalgesellschaft. BFH-Urteil v. 16.2.1996 I R 43/95, a.a.O., S.1801 f.. Zum anderen hatte der BFH zu entscheiden, ob Währungsverluste, die auf U.S.-Dollar Guthaben bei einer in den USA gelegenen Betriebstätte beruhen, den inländischen Gewinn einer deutschen GmbH mindern. BFH-Urteil v. 16.2.1996 I R 46/95, in: Deutsche Steuer-Zeitung, 85.Jg. (1997), S.92.

${ }^{256}$ Einerseits ist die Gewinnermittlung - wie im Text gesagt - nicht Inhalt der Abkommen, sondern lediglich die Gewinnzurechnung. Die Frage, ob der andere Vertragsstaat die Gewinne besteuern kann, wäre demgemäß nicht zulässig. Andererseits heißt es in Art. 7 Abs. 2 OECD-MA, der Betriebstätte sind die Gewinne zuzurechnen, die „sie hätte erzielen können, wenn sie eine gleiche oder ähnliche Tätigkeit unter gleichen oder ähnlichen Bedingungen als selbständiges Unternehmen ausgeübt hätte." Damit wird in doppelter Weise ein unmittelbarer $\mathrm{Zu}$ sammenhang herausgestellt. Es kommt auf die Tätigkeit der Betriebstätte an. Die Formulierung ist präziser als die Wortwahl im nationalen Recht, wo es in §34d Nr.2a) EStG lediglich heißt: „durch eine [...] Betriebstätte [...] erzielt werden“. Hiernach könnte die Existenz als Begründung genügen. Die mittelbare Verknüpfung ist demgegenüber nach dem Wortlaut des Musterabkommens wohl nicht hinreichend. Währungsgewinne und -verluste wären somit tatsächlich ausländische Einkünfte (nach nationalem Recht), die aber nicht freigestellt werden (nach Abkommensrecht). Daß diese Einkünfte nach Abkommensrecht nicht freigestellt sind, meint auch Schoss, der die Formulierungen des Art. 7 Abs. 2 OECD-MA in den einzelnen deutschen Doppelbesteuerungsabkommen analysiert. N.-P. Schoss, a.a.O., S.112-119.

Die Freistellung wird indes auch mit Hinweis auf Art.13 Abs. 2 OECD-MA begründet, wonach auch die Besteuerung eines Veräußerungsgewinnes bei einer ausländischen Betriebstätte dem Belegenheitsstaat zusteht. D. Grützner, a.a.O., S.872. O.H. Jacobs, a.a.O., S.332. 
Erstens hilft die Position nicht weiter, wenn kraft Doppelbesteuerungsabkommen oder als unilaterale Maßnahme nur die Anrechnung ausländischer Steuern gestattet ist. Denn die Argumentation geht ja davon aus, daß die Quelle von Währungserfolgen im Ausland ist; sie werden damit beim Anrechnungsverfahren einbezogen.

Zweitens könnte bei Freistellung des Betriebstättenergebnisses im Falle einer Qualifizierung als ausländischen Ursprungs der Anrechnungshöchstbetrag für weitere (passive) Einkünfte aus dem betreffenden Land verändert werden. Ein Währungsverlust erhöht die Wahrscheinlichkeit eines Anrechnungsüberhangs, ein Währungsgewinn reduziert sie. Es werden solche weiteren Anlagen im gleichen Land diskriminiert, die nicht ebenfalls im Inland freigestellt sind.

Drittens wäre, soweit ausländisches Einkommen von der Besteuerung im Inland freigestellt wird - zumindest im Rahmen der Analyse des Teils B - das Gegenteil anzustreben, nämlich die Freistellung des Währungsergebnisses. Auf diesen Aspekt wird aber weiter unten in Abschnitt III noch einmal eingegangen.

\section{c) Wechselkursbedingte Wertminderungen \\ a) Freistellungsverfahren}

Ist das Währungsergebnis ausländischen Ursprungs und wird durch die Betriebstätte erwirtschaftet, dann gelten bezüglich der Höhe von Teilwertabschreibungen bei den Bilanzpositionen einer Betriebstätte die bisher angestellten Überlegungen analog.

Wechselkursbedingte Wertminderungen haben hier allerdings keine unmittelbaren Auswirkungen auf die inländische Bemessungsgrundlage des Steuerpflichtigen, soweit der Betriebstättengewinn von der Besteuerung in Deutschland freigestellt ist. ${ }^{257} \mathrm{Da}$ in der auf Seite 187 zitierten Passage des Musterabkommens von Einkünften gesprochen wird, besteht kein Qualifikationskonflikt, denn Abschreibungen stehen in wirtschaftlichem Zusammenhang mit der Erzielung von Einkünften. Sie mindern infolgedessen nicht die inländische Steuerlast.

Dennoch sind Teilwertabschreibungen auch an dieser Stelle nicht ohne Bedeutung. Nach deutschem Steuerrecht besteht nämlich auf Antrag die Möglichkeit, Verluste auch dann von der inländischen Bemessungsgrundlage abzuziehen, wenn die Gewinne kraft Abkommen von einer Besteuerung durch Deutschland befreit werden. Voraussetzung ist, daß der Gesamtbetrag der gewerblichen Einkünfte in dem betreffenden Land und Jahr negativ ist. ${ }^{258}$ $\mathrm{Da}$ der Verlust bei der Ermittlung des Gesamtbetrags der Einkünfte abgezogen wird, kann er darüber hinaus auch zurück- oder vorgetragen werden. Auch Währungsverluste fallen unter diese Regelung. 259,260

Isoliert betrachtet läßt sich die Wirkung auf die Allokationsentscheidung inländischer Kapitalanbieter für ein gegebenes Jahr wiederum als Optionsposition interpretieren, und zwar als Verkaufoptionen in den Händen des Steuerpflichtigen, da sich der inländische Staat zur Erstattung eines Teils des Verlustes verpflichtet hat. Ex ante wird Kapitalexport in Form ausländischer Betriebstätten infolgedessen begünstigt.

${ }^{257}$ F. Wassermeyer, Teilwertabschreibung auf die Beteiligung an einer indischen Kapitalgesellschaft, a.a.O., S. $518 \mathrm{f}$..

258 §2a Abs. 3 EStG.

259 A.J. Rädler, a.a.O., S.458; G. Langenbucher, Die Umrechnung von Fremdwährungsgeschäften: Eine Untersuchung nach handels- und steuerrechtlichen Grundsätzen, a.a.O., S.199.

${ }^{260}$ Dies würde bei der Stichtagmethode nicht gelten, da Währungsverluste dort nicht in die Bemessungsgrundlage einfließen. M. Eisenach, Abzug von Wăhrungsverlusten, a.a.O., S.1827. 
Der Effekt wird durch die Vernachlässigung kompensierender Werterhöhungen bei den Verbindlichkeiten als Folge des Einzelbewertungsgrundsatzes noch verstärkt. Damit besteht allerdings auch ein gewisser steuerlicher Anreiz, die Betriebstätte nicht durch inländisches Kapital, sondern mit Krediten in der Währung des Belegenheitsstaates zu finanzieren.

Ergebnis der Bestimmung ist zudem ex post ein Anreiz, das Auslandsengagement nach einem Jahr mit Verlusten zu beenden, ${ }^{261}$ sprich: die Option auch tatsächlich auszuüben. Denn sind in einer folgenden Periode - ohne zeitliche Begrenzung - die gesamten gewerblichen Einkünfte des Steuerpflichtigen aus diesem Land positiv, sind sie im Inland bis zur Höhe des Verlustes steuerpflichtig. ${ }^{262}$ Maßgeblich ist hierfür der Betrag in DM, der tatsächlich als Verlust abgezogen wurde, unabhängig von der Währungsentwicklung. Dem Steuerpflichtigen bleibt danach nur der Zinsvorteil. ${ }^{263}$

\section{ß) Anrechnungsverfahren}

Ist dagegen nur die Anrechnung ausländischer Steuern zulässig und die Quelle von Währungsverlusten der Belegenheitsstaat, kann es aus steuerlichen Gesichtspunkten vorteilhaft sein, Teilwertabschreibungen möglichst gering zu halten.

Dies gilt insbesondere für die Passiva. Bei wirtschaftlicher Betrachtung ist eine unmittelbare Wertminderung infolge eines Devisenkursanstiegs hier nicht gegeben. Damit steht der gebotenen Rückstellung für drohende Verluste aus der Finanzierung ein Gewinn bei den Aktiva gegenüber. Es ist infolge der Vorwegnahme des korrespondierenden Verlusts zu erwarten, daß der Gewinn in einer späteren Periode zu einem Anrechnungsüberhang und zur Steuerpflicht in Deutschland führt.

Deshalb kann hier ein gewisser steuerlicher Anreiz bestehen, die Betriebstätte soweit wie möglich durch direkten Kapitalexport oder Fremdkapital in inländischer Währung zu finanzieren. Auf diese Weise erhöht sich zwar das Währungsrisiko der inländischen Kapitalgeber, doch sinkt die Gefahr von Verlusten auf der Passivseite, die wirtschaftlich nicht bestehen.

Im Ergebnis wird somit durch Währungsschwankungen Kapitalexport aufgrund der damit verbundenen Veränderung des Anrechnungshöchstbetrages diskriminiert, für eine bestehende Betriebstätte die Finanzierung mit inländischem Kapital indes zumindest tendenziell begünstigt.

${ }^{261}$ Deshalb wird in §2a Abs. 4 EStG die Rückzahlung einer solchen Steuerminderung auch dann verlangt, wenn die betreffende Betriebstätte in eine Kapitalgesellschaft umgewandelt wird.

$262 \S 2 \mathrm{a}$ Abs. 3 Satz 3 EStG. Die ausländische Steuer wird sowohl im Verlustjahr, als auch in den anschliessenden Jahren mit positiven Nettoeinkünften aus derselben Quelle nicht beachtet. K.-M. Wilke, a.a.O., S.350f.. Die Gesamtsteuerlast auf diese Einkünfte kann dadurch erheblich sein.

Die Wăhrungsentwicklung in den anschließenden Jahren ist für die Bewertung des Verlusts in DM unerheblich; dies ergibt sich aus der Formulierung des §2a Abs. 3 EStG. Die zu verrechnenden Gewinne sind zum aktuellen Kurs umzurechnen. F. Pach-Hanssenheimb, §2a Abs. 3 und 4 EStG fuihren bei sinkendem Wechselkurs der ausländischen Währung zu Doppelbesteuerungen, in: Internationales Steuerrecht, 2. Jg. (1993), S. 508. Hier von Doppelbesteuerung zu reden, ist allerdings abwegig. Schon der Begriff Steuer ist nicht korrekt; passender ist es, von einer vorübergehenden Investitionshilfe zu sprechen. So W. Heinicke, in: Einkommensteuergesetz, Hrsg. L. Schmidt, a.a.O., §2a EStG, Rz.50.

${ }^{263}$ Die praktische Bedeutung des Verlustabzugs wird dadurch eingeschränkt, daß es hier keinen Progressionsvorbehalt gibt, daß also der Verlust nicht bei der Bemessungsgrundlage für den Steuersatz berücksichtigt wird. Die Minderung des Steuersatzes hat aber eine dauerhafte Steuerminderung zur Folge, wohingegen der Verlustabzug nur eine Steuerstundung bewirkt, wenn in den folgenden Perioden positive Einkünfte in dem betreffenden Land erzielt werden. N. Harder, a.a.O., S.299. Voraussetzung hierfür ist natürlich der Fortbestand der Betriebstätte. 
Auch hier gelten die dargestellten Zusammenhänge uneingeschränkt aber nur für die oben schon genannten beiden Gruppen von Kapitalgebern, nämlich (i) natürliche Personen, die direkt an einer ausländischen Betriebstätte beteiligt sind und (ii) Steuerinländer, die Kapitaleinkommen nicht versteuern müssen. Für steuerpflichtige Beteiligte an einer inländischen Kapitalgesellschaft, die die ausländische Betriebstätte betreibt, unterscheiden sich Freistellungs- und Anrechnungsverfahren im Ergebnis nur durch den Zeitpunkt der Besteuerung von der Abzugsmethode.

\section{Wesentliche Beteiligungen an ausländischen Kapitalgesellschaften}

Die Bilanzierung von wesentlichen Auslandsbeteiligungen im Betriebsvermögen ist prinzipiell in der gleichen Weise durchzuführen wie schon oben im Unterabschnitt II.2 für einzelne Positionen beschrieben. Anschaffungskosten der Beteiligung sind die bei Gründung, Kapitalerhöhung oder Kauf aufgewendeten Summen, umgerechnet in inländische Währung zu jenem Zeitpunkt. ${ }^{264}$ Realisiert werden Währungsgewinne oder -verluste entsprechend bei der Veräußerung der Beteiligung, bei einer Kapitalherabsetzung oder der Liquidation der ausländischen Tochtergesellschaft.

Eine Teilwertabschreibung auf eine Auslandsbeteiligung kann nach einem Rückgang des Devisenkurses gerechtfertigt sein, wenn zum Bilanzstichtag der ,innere Wert“ der Beteiligung niedriger ist als der Wert in den Büchern des Steuerpflichtigen. ${ }^{265}$

Der innere Wert ist entsprechend der Systematik des Begriffes des Teilwertes der Beitrag, den die Auslandsbeteiligung zu dem Ertragswert der inländischen Muttergesellschaft leistet. Ausschlaggebend ist deshalb die funktionale Bedeutung der Tochtergesellschaft im Rahmen des Gesamtunternehmens. ${ }^{266}$ Das heißt, es ist nicht nur der Ertragswert zu berücksichtigen, der sich aus den diskontierten erwarteten Einzahlungsüberschüssen der ausländischen Gesellschaft errechnet beziehungsweise gegebenenfalls ein höherer Substanzwert. ${ }^{267}$ Einzubeziehen ist darüber hinaus ein sogenannter Zusatzwert, der die spezifische Funktion der Beteiligung für das beteiligte inländische Unternehmen quantifizieren soll. Die Quantifizierung der Auswirkungen einer Wechselkursänderung auf den Zusatzwert ist allerdings eine Ermessensfrage in jedem Einzelfall. ${ }^{268}$

Im Vergleich zu einer ausländischen Betriebstätte sind Kurseinflüsse nicht so groß, da sich der Niederstwerttest auf den Wert des Eigenkapitals in inländischer Währung bezieht. Aktiva und

${ }^{264}$ H. Langel, a.a.O., S.850; G.Langenbucher, Umrechnung von Fremdwährungsgeschäften, a.a.O., S.343, Rz.507.

265 H.J. Kleineidam, in: Herrmann/Heuer/Raupach, §6 EStG, Rz. 14.

266 BFH-Urteil v. 27.7.1988 I R 104/84, in: BStB1. II 1989, S. 274 f..

${ }^{267}$ Dabei fließen auch hier stille Reserven ein, die in anderen Zusammenhängen entstanden sein können.

Außerdem sind gemäß § 8b Abs. 6 KStG (zwischen dem 23.6.1988 und dem 31.12.1992 §26 Abs. 8 KStG) sogenannte ausschüttungsbedingte Teilwertabschreibungen unzulässig. In der Praxis bedeutet dies, daß eine $A b$ schreibung erst dann zulässig ist, wenn der Teilwert die Anschaffungskosten der Beteiligung abzilglich der seit dem 23.6.1988 aufgelaufenen kumulierten Ausschüttungen der Tochter- an die inländische Muttergesellschaft unterschreitet. „Eine Kausalität zwischen Gewinnausschüttung und Teilwertabschreibung kann weder von der Finanzverwaltung bewiesen, noch vom Steuerpflichtigen widerlegt werden. Jedoch wie bei anderen Betriebsvermögensminderungen trägt auch hier der Steuerpflichtige die objektive Beweislast." N.-P. Schoss, a.a.O., S. 180f.; BFH-Urteil v. 24.6.1976 IV R 101/75, in: BStB1. II 1976, S.207.

${ }^{268}$ Vgl. RFH-Urteil v. 18.8.1943 VI 152/43, in: RStBl. 1943, S.710f.; A.J. Rädler, a.a.O., S.462-465; Institut „Finanzen und Steuern“e.V., Teilwertabschreibungen auf Beteiligungen an Kapitalgesellschaften, Heft 123, Bonn 1985, S.113-116 m.w.N. H. Langel, a.a.O., S.850f.; T. Finne, a.a.O., S.142f.; J.P. Müller-Dott, a.a.O., S. 172-177. O. Jacobs, a.a.O., S.398-400; N.-P. Schoss, a.a.O., S.157-161. 
Passiva der Gesellschaft werden im Ergebnis saldiert. Aus dem Umwechslungseffekt kann unter sonst gleichen Umständen bei einem Auslandsengagement in Form einer Kapitalgesellschaft nur bei einem Devisenkursrückgang und nicht bei einem Kursanstieg eine Teilwertabschreibung möglich oder notwendig werden.

Der Stellenwert solcher Abschreibungen ist zudem geringer, weil die ausländische Tochtergesellschaft aufgrund ihrer Eigenschaft als juristische Person als wirtschaftliche Einheit behandelt wird. Damit wird der innere Wert auch durch den Wettbewerbseffekt bestimmt. Steigen infolge des Kursrückgangs die erwarteten Gewinne durch die geänderten relativen Preise auf den spezifischen Beschaffungs- und Absatzmärkten der ausländischen Tochtergesellschaft, besteht für eine Teilwertabschreibung im Wohnsitzland unter Umständen kein Grund. Bei einer Betriebstätte ist dagegen die Wirkung einer Kursänderung auf die Bilanzpositionen - das heißt auf die Bestände und nicht auf die diskontierten Ströme - stärker, weil jede Position einzeln bewertet wird.

Im übrigen unterliegt auch die Teilwertabschreibung auf Auslandsbeteiligungen dem Aktivitätsvorbehalt. Das heißt, es gilt das Abzugsverbot für passive Verluste. ${ }^{269}$ Die Abschreibung wird in der Steuerbilanz nur nachvollzogen, wenn der Steuerpflichtige dokumentiert, daß die ausländische Kapitalgesellschaft wenigstens fast ausschließlich aktiv tätig ist.

\section{a) Freistellungsverfahren}

Währungsgewinne und -verluste, die durch wesentliche Beteiligungen an einer ausländischen Kapitalgesellschaft entstehen, sind in Deutschland steuerfrei, soweit sie bei der Veräußerung realisiert werden. Währungsverluste, die im Inland zuvor durch Teilwertabschreibungen Eingang in die Steuerbilanz finden, haben demgegenüber infolge des oben dargelegten Qualifikationskonflikts ${ }^{270}$ grundsätzlich eine dauerhafte Minderung der Steuerlast in Deutschland zur Folge.

Aber: die Steuerbefreiung von Gewinnen oder Verlusten aus der Reduzierung der Beteiligung an der ausländischen Unternehmung wird nur gewährt, ,soweit sich nicht in früheren Jahren eine bei der Gewinnermittlung berücksichtigte Gewinnminderung durch Ansatz des niedrigeren Teilwerts des Anteils ergeben hat und soweit diese Gewinnminderung nicht durch den Ansatz eines höheren Teilwerts ausgeglichen worden ist." 271 Das Zuschreibungswahlrecht wird also zum Zeitpunkt der Abgabe der Beteiligung steuerlich quasi zum Zuschreibungsgebot. Nur der danach verbleibende Unterschiedsbetrag zwischen Veräußerungserlös und Anschaffungskosten kann effektiv die deutsche Körperschaftsteuer mindern.

Wenn der Veräußerungserlös aber höher ist als die Anschaffungskosten, bleibt diese Differenz in Deutschland effektiv körperschaftsteuerfrei.

Doch ist die Freistellung auch hier nur auf der Ebene der inländischen Gesellschaft wirksam. Für in Deutschland steuerpflichtige beteiligte natürliche Personen wird die geringere Körperschaftsteuer durch den verminderten Anrechnungsbetrag bei der individuellen Einkommensteuer aufgefangen. ${ }^{272}$ Eine asymmetrische Belastung verbleibt infolge der zeitnahen Berück-

${ }^{269}$ H.J. Kleineidam, in: Herrmann/Heuer/Raupach, §6 EStG, Rz. 18 a.

$270 \mathrm{Vgl}$. Seite 174 dieser Arbeit und die in Fußnote 169 angegebene Literatur.

$271 \S 8 \mathrm{~b}$ Abs. $2 \mathrm{KStG}$.

272 Das Ziel der zitierten Passage ist es auch, zu verhindern, daß eine ausländische Muttergesellschaft aus einer Teilwertabschreibung, die eine deutsche Tochtergesellschaft bei einer ausländischen Enkelgesellschaft vornimmt, einen effektiven Vorteil durch die Steuerentlastung in Deutschland ziehen kann. 
sichtigung von Währungsverlusten gegenüber der bis zum Zeitpunkt der Ausschüttung durch die Muttergesellschaft hinausgezögerten Erfassung von Währungsgewinnen.

\section{b) Anrechnungsverfahren}

Sind die Gewinne einer ausländischen Tochtergesellschaft nicht von der Besteuerung in Deutschland befreit, ist auf der Ebene der Muttergesellschaft eine effektive zusätzliche Belastung durch die Unsicherheit über einen Anrechnungsüberhang zu erwarten.

Hinsichtlich der Auswirkung der Pro-Staat-Begrenzung des Anrechnungsverfahrens einerseits und des Effektes des Niederstwertprinzips gelten die ab Seite 176 angestellten Überlegungen zu einzelnen grenzüberschreitenden Transaktionen von Steuerinländern analog.

Theoretisch könnte bei einer wesentlichen Beteiligungen die inländische Muttergesellschaft zwar den Zeitpunkt einer Ausschüttung mit Blick auf die Steuerlast planen. Doch ist zu bedenken, daß die indirekte Anrechnung im Ausland gezahlter Abgaben im deutschen Steuerrecht - abgesehen von einer zumeist geringen Quellensteuer - nur bei sofortiger Ausschüttung gestattet ist. $^{273}$

Die Zugriffsbesteuerung bildet in diesem Zusammenhang nur bei der Frage nach der Quantifizierung der laufenden Gewinne eine besondere Problematik. Im Gesetzestext heißt es, der Hinzurechnungsbetrag sei nach den deutschen Vorschriften zu ermitteln, ${ }^{274}$ also wie der Betriebstättengewinn. Intention der Hinzurechnungsbesteuerung war es indes, eine Ausschüttung zu fingieren, ${ }^{275}$ demnach wäre der nach ausländischen Vorschriften festgesetzte Gewinn im Inland zu versteuern. Deshalb ist es einheitliche Meinung in der Literatur, daß der Steuerpflichtige diesbezüglich ein Wahlrecht hat. ${ }^{276}$ Allenfalls kann es geboten sein, den Gewinn in ausländischer Währung nach deutschen Vorschriften zu ermitteln und dann zum Stichtagkurs umzurechnen. ${ }^{277}$

Veräußerungserfolge und auch Wertminderungen der Beteiligung werden durch diese Besteuerung indes nicht berührt, dies ist auch nicht das Ziel der Abzugsbesteuerung. Dies ist indes das Ziel des Aktivitätsvorbehaltes bei der Verrechnung ausländischer Verluste mit inländischen und ausländischen Einkünften anderer Arten, der sowohl Verluste durch Ansatz des niedrigeren Teilwerts als auch aus der Veräußerung umfaßt und damit eine asymmetrische Besteuerung dieser Formen des Kapitalexports bewirkt. ${ }^{278}$

Der zentrale Aspekt der Diskussion in den USA um die Ergebnisumrechnung bei Beteiligungen an ausländischen Kapitalgesellschaften ist für das deutsche Steuerrecht indessen ohne Bedeutung. Die Frage danach, zu welchem Kurs einbehaltene Gewinne und darauf im Ausland entrichtete ausländische Steuern bei ihrer Ausschüttung in einem späteren Jahr umzurechnen sind, stellt sich nämlich so nicht, wenn Beteiligungserträge auf der Ebene der Gesellschaft von der deutschen Steuer freigestellt werden oder die Anrechnung der im Ausland gezahlten Steuern nur innerhalb derselben Bilanzperiode zulässig ist.

273 Auch die Annahme, daß es niemals zur Ausschüttung durch die ausländische Tochtergesellschaft kommen wird, hilft hier nicht weiter, da ein Gewinn aus der Veräußerung der Beteiligung ebenfalls in Deutschland steuerpflichtig ist.

$274 \S 10$ Abs. 3 AStG.

275 P. Malinski, a.a.O., S.36.

${ }^{276}$ U. Wlecke, a.a.O., S.388f.; P. Malinski, a.a.O., S.37f. m.w.N..

277 A.J. Rädler, a.a.O., S.465f..

278 §2a Abs. 1 Nr. 3 EStG. 


\section{Zur Umrechnung ausländischer Steuern im Anrechnungsverfahren}

Unbeantwortet ist noch die Frage nach der Umrechnung der ausländischen Steuerzahlungen im Anrechnungsverfahren des deutschen Steuerrechts. Zur direkten Anrechnung ist laut Gesetzestext die ,festgesetzte und gezahlte und keinem Ermäßigungsanspruch mehr unterliegende ausländische Steuer" zugrunde zu legen.279 Das gleiche gilt bei der zulässigen indirekten Anrechnung von der inländischen Körperschaftsteuer entsprechenden ausländischen Steuerzahlungen. ${ }^{280}$ Nach Ansicht der Finanzverwaltung ist deshalb die ausländische Steuerlast - wie bisher auch in den USA - zu dem Kurs am Tag der Zahlung ${ }^{281}$ der Steuer umzurechnen. ${ }^{282}$

Intention der Finanzverwaltung war es, eine Vereinfachungsregelung zu schaffen. ${ }^{283}$ Das Vorgehen wird aber auch direkt aus dem oben zitierten Gesetzestext abgeleitet. ${ }^{284}$ Diese Lesart des Gesetzestextes wurde vom Bundesfinanzhof in einem neueren Urteil betreffend die Umrechnung ausländischer Erbschaftsteuern allerdings nicht nachvollzogen. Dort heißt es wörtlich:

„Zwar ist nur die gezahlte Erbschaftsteuer anzurechnen, hieraus folgt aber nicht zwingend, daß sich der anzurechnende Wert in Deutscher Mark nach dem Zeitpunkt der Zahlung an die ausländische Behörde richtet; ebenso konnte [...] mit der Einfügung des Wortes ,gezahlte ${ }^{\prime}$ in $\S 21$ Abs. 1 ErbStG 1974 vom Gesetzgeber lediglich beabsichtigt gewesen sein, sicherzustellen, daß die anzurechnende ausländische Erbschaftsteuer überhaupt gezahlt worden ist. Es entspricht aber dem Sinn des $§ 21$ Abs. 1 ErbStG 1974, die anzurechnende ausländische Steuer nach dem amtlichen Devisenkurs umzurechnen, der im Zeitpunkt der Entstehung der - deutschen - Erbschaftsteuer gegolten hat, denn durch die Anrechnung der ausländischen Steuer soll nur die Doppelbelastung bei der inländischen Steuer beseitigt werden, nicht aber die inländische Besteuerung als solche berührt werden. [...] Würde die anzurechnende Steuer dagegen nach einem abweichenden [...] Devisenkurs umgerechnet, so würden die zu erhebende und anzurechnende Steuer nach unterschiedlichen Maßstäben ermittelt [...]. Das Argument [...], bei einem Ansatz des Kurswertes im Zeitpunkt der Entstehung der Steuer würden Kurssteigerungen oder ein Kursverfall der Deutschen Markt zu ungerechtfertigten Entlastungen oder Belastungen des Steuerpflichtigen im Zeitpunkt der Zahlung der ausländischen Steuer führen, hat rein spekulativen Charakter". ${ }^{285}$

Der Wortlaut der zugrundeliegenden Passage des Erbschaftsteuergesetzes entspricht im wesentlichen der Formulierung im Einkommen- und im Körperschaftsteuergesetz.

Die Frage nach dem Umrechnungskurs für ausländische Steuern ist damit allerdings noch nicht beantwortet, weil unklar ist, welcher Kurs für Ausschüttungen zugrunde zu legen ist. Dividenden sind regelmäßig dann zu aktivieren, wenn der Gewinnverwendungsbeschluß der ausschüttenden Kapitalgesellschaft vorliegt. ${ }^{286} \mathrm{Da}$ die Einkünfte zu diesem Zeitpunkt entstehen, erscheint es plausibel, bei der Umrechnung der ausländischen anrechenbaren Steuern

\footnotetext{
279 §26 Abs. $1 \mathrm{KStG}$.

$280 \S 34$ c Abs. 1 EStG i.V.m. $\$ 26$ Abs. 2 KStG.

281 Genau: Zu dem amtlich festgestellten Devisenkurs, der im Bundesanzeiger veröffentlicht wird.

282 Abschn.R212a EStR; K.-H. Baranowski, a.a.O., S.241; Blümich/J. Täske, §26 KStG, Rz.45; Flick /Wassermeyer/Becker, §26 KStG, Rz.65. Steuernachzahlungen sind ebenfalls zum Kurs ihrer Zahlung umzurechnen und in das Anrechnungsverfahren einzubeziehen. Blümich/J. Täske, §26 KStG, Rz46. Für Steuererstattungen ist die Meinung differenziert. Vgl. Blümich/J. Täske, §26 KStG, Rz.24d; Flick /Wassermeyer/Becker, $\S 26 \mathrm{KStG}, \mathrm{Rz} .66$.

283 N. Harder, a.a.O., S. 300.

284 Institut „Finanzen und Steuern“ e.V. (Hrsg.), Heft 125, a.a.O., S. 31 f.; P. Malinski, a.a.O., S. 70.

285 BFH-Urteil v. 19.3.1991 II R 134/88, in: BStBI. II 1991, S.522.

${ }^{286}$ BFH-Urteil v. 2.4.1980 I R 75/76, in: BStBI. II 1980, S. 703.
} 
auf den gleichen Kurs zurückzugreifen. Dies setzt aber voraus, daß Gewinne oder Verluste aus Wechselkursänderungen zwischen dem Zeitpunkt der Entscheidung über die Ausschüttung und der Repatriierung und Konvertierung den inländischen Einkünften zugerechnet werden. ${ }^{287}$ Nur so werden auch bei wirtschaftlicher Betrachtung die zu erhebende und die anzurechnende Steuer nicht nach unterschiedlichen Maßstäben ermittelt.

In gleicher Weise sollten anrechenbare ausländische Steuern bei anderen Einkünften konvertiert werden, um eine wechselkursbedingte Veränderung des Anrechnungshöchstbetrages zu verhindern.

Dies ist allerdings bei der Umrechnung des Betriebstättenergebnisses unrealistisch. Es hieße, die Steuer anteilig mit differenzierten Kursen umzurechnen. Bei den in Deutschland zulässigen Umrechnungsmethoden ist es infolgedessen nicht möglich, die im Ausland gegebene Beziehung zwischen Betriebstättenergebnis und darauf zu entrichtende Steuern in inländischer Währung zu erhalten.

\section{Einnahmenüberschußrechnung und Privatvermögen}

Steuerpflichtige, die nicht aufgrund gesetzlicher Verpflichtung oder freiwillig Bücher führen, können ihre steuerpflichtigen Einkünfte nach der Einnahmenüberschußrechnung quantifizieren. Steuerpflichtig ist dann als Einkünfte aus Gewerbebetrieb der Überschuß der Einnahmen über die Betriebsausgaben ${ }^{288}$ und bei den anderen Einkunftarten der Überschuß der Einnahmen über die Werbungskosten. ${ }^{289}$

Ein wesentlicher materieller Unterschied zu dem bisher Gesagten liegt in dem Zeitpunkt der Bemessung von Einkünften. ${ }^{290}$ Entscheidend sind hier nur die Zeitpunkte des Zuflusses der Einnahmen und des Abflusses der Ausgaben. Zugeflossen sind Einnahmen, sobald der Steuerpflichtige über sie verfügen kann; abgeflossen sind sie, wenn der Steuerpflichtige die Verfügungsmacht verloren hat. ${ }^{291}$ Eine periodische Bewertung der Bestände findet nicht statt. ${ }^{292}$ Damit entfällt insbesondere die Möglichkeit beziehungsweise Notwendigkeit von Teilwertabschreibungen. ${ }^{293}$

Die Umrechnung und die Quantifizierung von Währungserfolgen ist hier deshalb unproblematisch: Werden die Beträge am Anschaffungs- und Veräußerungszeitpunkt sofort konvertiert, ist der Umtauschkurs, ansonsten der Kurs bei Ab- beziehungsweise Zufluß maßgeblich. ${ }^{294}$ Analog

287 Vgl. Seite 171 dieser Arbeit.

$288 \S 4$ Abs. 3 EStG i.V.m. §2 Abs. 2 Nr.1. EStG u. §11 EStG.

$289 \S 2$ Abs. 2 Nr.2. EStG i.V.m. §11 EStG.

290 Herrmann/Heuer/Raupach, $\$ 4$ EStG, Rz.46a-b.

291 Blümich / H. Glenk, §11 EStG, Rz.10f.; D. Birk, in: Herrmann/Heuer/Raupach, §11 EStG, Rz.3; Blümich/J. Täske, §26 KStG, Rz25; A. Bordewin, Das Fremdwährungsdarlehen in der Überschußrechnung, in: Deutsches Steuerrecht, 30.Jg. (1992), S. 244.

292 Herrmann/Heuer/Raupach, §4 EStG, Rz.46a-b; Blümich/B. Thürmer, §9 EStG, Rz. 125.

Abweichungen von dem Prinzip der Einnahmenüberschußrechnung bestehen im betrieblichen Bereich durch die Möglichkeit der Erfassung von Sacheinnahmen und -aufwendungen, von Abschreibung für Abnutzung und ähnlichem. W. Heinicke, in: Einkommensteuergesetz, Hrsg. L. Schmidt, a.a.O., §4 EStG, Rz.373-399. Die Unterschiede sind hier aber nicht interessant, da hinsichtlich der Umrechnung grundsätzlich vorzugehen ist wie beim Betriebsvermögensvergleich. G. Langenbucher, Die Umrechnung von Fremdwährungsgeschäften: Eine Untersuchung nach handels- und steuerrechtlichen Grundsätzen, a.a.O., S.227; U. Wlecke, a.a.O., S.99-101 m.w.N..

293 BFH-Urteil v. 9.11.1993 LX R 81/90, in: BStB1. II 1994, S.290.

294 §8 Abs. 2 EStG; G. Langenbucher, Die Umrechnung von Fremdwährungsgeschäften: Eine Untersuchung nach handels- und steuerrechtlichen Grundsätzen, a.a.O., S.225 u. S.230f.; U. Wlecke, a.a.O., S.102; P. Malinski, 
sind auch Zinsen und Dividenden - im Einklang mit dem erwähnten koordinierten Ländererlaß - mit dem Wechselkurs beim Zufluß umzurechnen. Es besteht also auch hier das Risiko einer Veränderung des Anrechnungshöchstbetrages als Folge nicht erwarteter Währungsverluste. Der Zufluß muß mit der Zahlung und nicht mit der Entstehung angenommen werden.295

Währungsgewinne oder -verluste unterliegen als Betriebsausgabe der inländischen Besteuerung. Nach Maßgabe des Veranlassungsprinzips sind sie aber nicht den Einkünften aus einem Wirtschaftsgut, sondern dem Wirtschaftsgut selbst zuzuordnen. ${ }^{296}$

Die Quelle von Währungserfolgen ist bei Sachwerten hier generell das Ausland, wenn die zugrundeliegenden Einkünfte ebenfalls nicht im Inland anfallen. ${ }^{297}$

Die Zurechnung zu den Zinseinkünften wird für Nominalwerte prinzipiell verneint. Begründet wird dies damit, daß die Fremdwährungsposition auf eigenes Risiko eingegangen wurde und daß währungsbedingte Gewinne oder Verluste nicht zwischen Darlehensgeber und -nehmer vereinbart ${ }^{298}$ und nicht ausgetauscht werden. ${ }^{299}$

Währungsgewinne oder -verluste werden deshalb im Privatvermögen als Werbungskosten sowohl bei Sach- wie auch bei Nominalwerten nicht anerkannt, denn auch Veräußerungsgewinne gehören in Deutschland nicht zu den steuerpflichtigen Einkünften, soweit sie nicht in wirtschaftlichem Zusammenhang mit einem Gewerbebetrieb stehen. Wertänderungen führen nur bei den Gewinneinkunftarten zu steuerlichen Auswirkungen, ansonsten bleiben sie auch zum Zeitpunkt ihrer Realisation unberücksichtigt. ${ }^{300}$ Auch Währungserfolge sind damit steuerfrei, wenn sie außerhalb der betrieblichen Sphäre anfallen.

Die Ausnahme bilden unter Umständen Veräußerungsgewinne, die das Ergebnis von Spekulationsgeschäften sind. Dabei müssen aber die Regelungen von Doppelbesteuerungsabkommen beachtet werden. Die Abkommenstexte kennen keine Spekulationsgeschäfte, sondern nur Veräußerungsgewinne. Soweit diese freigestellt sind, können sie auch innerhalb der Spekulationsfristen nicht besteuert werden. Dies ist regelmäßig bei im Ausland belegenen unbeweglichen Wirtschaftsgütern der Fall. Das Währungsergebnis bei Anleihen und anderen Wertpapieren ist demgegenüber innerhalb der Frist von sechs Monaten steuerpflichtig. ${ }^{301,} 302$

a.a.O., S.29; W. Heinicke, in: Einkommensteuergesetz, Hrsg. L. Schmidt, a.a.O., §8 EStG, Rz.52; FG München Urteil v. 18.7.1996 10 K843/92, in: Der Betrieb, 50.Jg. (1997), S.850.

295 Flick/Wassermeyer/Becker, §34c EStG, Rz.115; O.H. Jacobs, a.a.O., S.241; K.-H. Baranowski, a.a.O., S. 241 .

${ }^{296}$ Abschn. R212b EStR; BFH-Urteil v. 16.3.1994 I R 42/93, a.a.O., S.800f.; A. Bordewin, a.a.O., S.245; BFHUrteil v. 15.11.1990 IV R 103/89, in: BStB1. II 1991, S.229. Für Einkünfte aus Vermietung und Verpachtung: BFH-Urteil v. 9.11.1993 DX R 81/90, a.a.O., S.290; Hessisches FG. Urteil v. 19.8.1985 V 261/79 (rkr), in: EFG 1985, S.600. Für Einkünfte aus Kapitalvermögen: FG Baden-Württemberg-Urteil v. 5.6.1984 VIII K 419/83 (rkr), in: EFG 1985, Entscheidung Nr. 682, S.601.

297 P. Malinski, a.a.O., S.62.

${ }^{298}$ FG Baden-Württemberg-Urteil v. 5.6.1984 VIII K 419/83 (rkr), a.a.O., S.601; BFH-Urteil v. 9.11.1993 IX R 81/90, a.a.O., S.291.

${ }^{299}$ Hessisches FG. Urteil v. 19.8.1985 V 261/79 (rkr), a.a.O., S.600.

${ }^{300}$ BFH-Urteil v. 15.9.1990 IV R 103/89, a.a.O., S.229f.; FG München Urteil v. 18.6.1991 16 K 4505/88 (nrkr), in: EFG 1992, S.66; FG Baden-Württemberg-Urteil v. 5.6.1984 VIII K 419/83 (rkr), a.a.O., S.601; BFH-Urteil v. 9.10.1979 VIII R 67/77, in: BStBl. II 1980, S.116.

301 P. Malinski, a.a.O., S.97f..

302 Nach Auffassung von Wellmann ist zwischen Währungsgewinnen und Veräußerungsgewinnen in der fremden Währung zu differenzieren. Die Spekulationsfrist für Währungsgewinne beginne mit dem Zeitpunkt der Konvertierung des DM-Betrages in die fremde Währung; die Frist für Veräußerungsgewinne in der ausländischen Währung mit jeder Transaktion von neuem. Würde beispielsweise eine Fremdwährungsanleihe mit einem schon mehr als sechs Monate bestehenden Fremdwährungsguthaben angeschafft, könne es keinen währungsbedingten Spekulationsgewinn mehr geben. Bei Veräußerung des Wertpapiers innerhalb der Spekulationsfrist dürfe der Spekulationsgewinn nur in der fremden Währung festgestellt und das Ergebnis umgerechnet werden. U. Wellmann, Währungsgewinne im Privatvermögen, in: Deutsche Steuer-Zeitung, 85.Jg. (1997), S. 254. 


\section{Wirkung der deutschen Besteuerung bei erwarteten Wechselkursänderungen}

Bei der Analyse des deutschen Steuerrechts wurde die Bedeutung von Wechselkurserwartungen für die Allokationsentscheidung inländischer Kapitalanbieter bisher vernachlässigt. Es wurde unterstellt, es werde ein konstanter Kurs antizipiert.

Die Annahme wird in diesem Abschnitt aufgehoben und die Wirkungen der Erwartung von Kursänderungen auf grenzüberschreitenden Kapitaleinsatz im allgemeinen und auf Investitionen in stark inflationären Währungsräumen im besonderen werden untersucht.

Infolge der im letzten Abschnitt betrachteten Sachlage der Behandlung von Währungsgewinnen und -verlusten in Deutschland lassen sich die Überlegungen des Teils B nicht ohne weiteres auf die Realität übertragen. Bei dem „Welteinkommensprinzip handelt es sich um einen bloßen Programmsatz, der in der Rechtswirklichkeit weitgehend eingeschränkt ist" . ${ }^{303}$ Denn es sind gleichsam alle denkbaren Formen der Besteuerung anzutreffen:

(1) Ausländische Einkünfte und Währungsgewinne und -verluste werden besteuert

- bei passiven Einkünften und

- wenn kein Doppelbesteuerungsabkommen besteht oder in dem Abkommen nur das Anrechnungsverfahren vereinbart wurde.

(2) Ausländische Einkünfte und Währungsgewinne und -verluste bleiben steuerfrei

- bei ausländischen Betriebstätten mit Einkünften aus aktiven Tätigkeiten, wenn diese in Deutschland kraft Doppelbesteuerungsabkommen freigestellt sind und

- unter Aktivitätsvorbehalt auch bei unbeweglichen Wirtschaftsgütern, die im Ausland belegen sind sowie

- bei ausländischen Aktiva in den Händen von Einzelpersonen, deren Einkünfte aus Kapitalvermögen den Freibetrag nicht übersteigen und soweit die Aktiva mehr als sechs Monate gehalten werden.

(3) Ausländische Einkünfte werden besteuert, Währungs- und Veräußerungsgewinne dagegen nicht

- bei ausländischen Aktiva in den Händen von Einzelpersonen, deren Einkünfte aus Kapitalvermögen den Freibetrag übersteigen, soweit die Aktiva mehr als sechs Monate gehalten werden.

(4) Und schließlich: Ausländische Einkünfte und das Währungsergebnis werden auf der Ebene der Kapitalgesellschaft nicht besteuert, bei Ausschüttung an inländische Anteilseigner aber in voller Höhe mit dem persönlichen Einkommensteuersatz.

Deshalb stellt sich insbesondere die Frage neu, ob bei der Freistellung ausländischer Erträge Währungsgewinne oder -verluste auf Seiten der inländischen Kapitalanbieter ebenfalls nicht besteuert werden sollten. Die Analyse in Teil B hat ein „Ja“ auf diese Frage ergeben, wenn beide Länder sämtliches Kapitaleinkommen nur an der Quelle besteuern. Dies ist aber im deutschen Steuerrecht nicht der Fall.

\section{Zur erwarteten Währungsentwicklung}

In Teil B wurde gesagt, daß die Besteuerung allenfalls vorübergehend den Wechselkurs beeinflussen kann. ${ }^{304}$ Langfristig wird die Kaufkraftparität die Kursentwicklung begrenzen, die als Arbitragebeziehung der Gütermärkte durch eine Kapitaleinkommensteuer zumindest direkt nicht veränderbar ist.

${ }^{303}$ FG Münster Urteil v. 3.10.1995 9 K 5026/92, (n-rkr), a.a.O..

$304 \mathrm{Vgl}$. die Seiten 57f. dieser Arbeit. 
Infolgedessen wird eine Steuer auf das Währungsergebnis im Inland langfristig nur die Kapitalkosten oder die Kapitalerträge beeinflussen. Einige Argumente sprechen dafür, daß ein Vor- oder Nachteil einer Besteuerung von wechselkursbedingten Gewinnen oder Verlusten langfristig und kurzfristig auf Seiten der Kapitalanbieter wirksam wird; in dem Fall ergäben sich keine Auswirkung für die inländischen Kapitalkosten:

Zum einen ist auch in Deutschland das Freistellungsverfahren nur für bestimmte aktive Einkünfte einer ausländischen Betriebstätte gestattet. Für diese Gruppe der Marktteilnehmer wird die erwartete Währungsentwicklung aber nur indirekt in die Investitionsentscheidung einfließen. Insbesondere können sie auf geänderte Umweltumstände erst mit zeitlicher Verzögerung reagieren.

Außerdem wird die Freistellung ausländischer Einkünfte nur von deutscher Seite aus regelmäßig in Doppelbesteuerungsabkommen eingeräumt. Die Mehrzahl der Vertragspartner gestattet dessen ungeachtet lediglich die Anrechnung der deutschen Steuer. ${ }^{305}$ Andererseits: ist die effektive Steuerlast in Deutschland im internationalen Vergleich tatsächlich eher hoch, ${ }^{306}$ sind Anrechnungsüberhänge auf Seiten ausländischer Kapitalanbieter bei Investitionen wahrscheinlich. ${ }^{307}$ Hinzukommt auf deren Seite möglicherweise der diskriminierende Effekt ex ante unsicherer Anrechnungsüberhänge durch volatile Wechselkurse, so daß die antizipierte Belastung oberhalb der Tarifbelastung am Wohnsitz liegt. Es müßte im Einzelfall geprüft werden, wie das Währungsergebnis in dem betreffenden Land steuerlich charakterisiert wird.

Zum anderen sind Einkünfte aus passivem Erwerb auch in Deutschland steuerpflichtig. Dieses Kapitalangebot wird wohl eher die Entwicklung der Preise auf den Kapitalmärkten determinieren, da es schnell und zu geringen Transaktionskosten mit Portfolioumschichtungen auf neue kursbeeinflussenden Informationen reagieren kann.

Hier ist zudem die verzerrende Wirkung des Anrechnungsverfahrens gering. Für ausländische Kapitalanbieter besteht das Risiko eines Überhangs überhaupt nicht, weil Zinseinkünfte in Deutschland quellensteuerfrei sind. Für deutsche Kapitalanbieter ist diese Gefahr aber ebenfalls regelmäßig nicht groß, denn Zinseinkünfte unterliegen auch in anderen Ländern allenfalls einer niedrigeren (derivate Finanzierungsinstrumente in der Regel keiner ${ }^{308}$ ) Quellensteuer. ${ }^{309}$ Und: Kapitalanbieter, die weder im Quellen- noch im Wohnsitzland Steuern auf Kapitaleinkommen zahlen, werden gegenüber Anlagen in verschiedenen Währungsräumen dann indifferent sein, wenn der erwartete Kursverlauf einer Parität nach Maßgabe des Wohnsitzlandprinzips folgt.

Welche Auswirkungen hat im Rahmen des Freistellungsverfahrens die Freistellung beziehungsweise Besteuerung von Währungsgewinnen und -verlusten im Wohnsitzland, wenn der Voroder Nachteil die Kapitalanbieter trifft - konkret: welche Auswirkungen hat deren Charakterisierung als in- oder ausländische Einkünfte?

${ }^{305}$ Anhang IV auf Seite 222 bietet eine Gegenüberstellung der in den Abkommen vereinbarten Methode von deutscher Seite und von Seiten der Vertragstaaten.

306 Vgl. z.B. D. Schneider, Hochsteuerland Deutschland 1994/95, in: Der Betrieb, 47. Jg. (1994), S. 541 -549.

${ }^{307}$ Berücksichtigt werden müßten darüber hinaus Auswirkungen der internationalen Besteuerung auf die sogenannten „cross rates“, das heißt die Wechselkurse zwischen zwei fremden Währungsräumen, die untereinander und mit dem Inland Kapital ausgetauscht haben.

${ }^{308}$ Vgl. OECD, Taxation of New Financial Instruments, Paris 1994, S.48, Rz.40, S.63 u. S.53, Rz.69, S.70; H.O. Jacobs u. J. Haun, a.a.O., S.408f..

${ }^{309}$ Einen Überblick zu den Quellensteuern auf Zinsen und Dividenden ausgewählter Länder bietet Anhang V auf Seite 223. 


\section{Zur Quelle von Währungsgewinnen und -verlusten im Freistellungsverfahren}

Die Auswirkungen der Charakterisierung des Währungsergebnisses als in- oder ausländische Einkünfte lassen sich mit Hilfe der folgenden Gleichung [D1] darstellen. Sind die internationalen Verhältnisse der Grenzproduktivitäten maßgeblich für die Währungsentwicklung, sind inländische Kapitalanbieter nämlich nur indifferent gegenüber inländischen und ausländischen Investitionen, sofern gilt

$$
\begin{aligned}
1+\mathrm{gp} \cdot(1-\tau)=1+(\Delta \mathrm{e}-1) & \left(1-\tau_{\mathrm{e}}\right)+\Delta \mathrm{e} \cdot \mathrm{gp}^{*} \cdot\left(1-\mathrm{t}^{*}\right) \\
& \text { unter der Nebenbedingung } 1+\mathrm{gp}=\Delta \mathrm{e} \cdot\left(1+\mathrm{gp}{ }^{*}\right)
\end{aligned}
$$

Der Nettoertrag der inländischen Investition entspricht der mit dem Steuersatz $\tau$ zu versteuernden Grenzproduktivität. Der Nettoertrag des ausländischen Kapitaleinsatzes ergibt sich aus der Summe aus einem - eventuell mit dem Satz $\tau_{e}$ im Wohnsitzland zu versteuernden - Währungsgewinn oder -verlust und dem ausländischen, dort mit $t^{*}$ steuerpflichtigen, Ertrag. Nebenbedingung ist, daß die Grenzproduktivitäten des Faktors in einer Beziehung zueinander stehen sollen, die durch die Zinsparität beschrieben wird. ${ }^{310}$ Nichtsteuerliche Einflüsse werden dabei wieder vernachlässigt.

Wird das Währungsergebnis im Wohnsitzland besteuert $\left(\tau_{\mathrm{e}}=\tau\right)$, ist der erwartete Ertrag durch eine Grenzinvestition im Ausland geringer, falls der ausländische Steuersatz über dem des Inlands liegt beziehungsweise höher, falls der Quellensteuersatz geringer ist als der des Inlands. Dies leuchtet unmittelbar ein: ist der Gewinn beider Alternativen bei gleichem Steuersatz identisch, dann wird die Auslandsinvestition begünstigt, wenn ein Teil deren Ertrags relativ geringer belastet wird.

Nicht so leicht fällt die Aussage, wenn das Währungsergebnis zusammen mit anderen ausländischen Einkünften freigestellt ist $\left(\tau_{\mathrm{e}}=0\right)$. Wird ein konstanter Wechselkurs erwartet und stimmen außerdem die Steuersätze beider Länder überein, dann muß auch der Grenzertrag der in- und ausländischen Investitionsalternativen identisch sein. Ist der Quellensteuersatz höher und wird ein rückläufiger Devisenkurs erwartet, dann wird Kapitaleinsatz im Ausland benachteiligt. Ist umgekehrt der ausländische Steuersatz geringer und wird ein ansteigender Devisenkurs erwartet, wird die Auslandsinvestition begünstigt.

Für die anderen möglichen Zustände läßt sich das Ergebnis nicht eindeutig ableiten. Deshalb wird anhand des folgenden Beispiels einer einperiodigen Auslandsinvestition eine Indifferenzkurve graphisch dargestellt.

Beispiel D2:

Im Inland beträgt die Grenzproduktivität $\mathrm{gp}=6 \%$ und der Steuersatz auf Kapitaleinkommen $\tau=45 \%$. Die folgende Abbildung D1 zeigt die Funktion der Kombinationen aus ausländischem Steuersatz und ausländischer Grenzproduktivität gemäß Gleichung D1, bei denen der inländische Kapitalanbieter indifferent ist gegenüber der Investition im eigenen Land oder im Ausland, vorausgesetzt der Währungsgewinn oder -verlust ist nicht steuerpflichtig:

${ }^{310}$ Vgl. Teil B dieser Arbeit, Seite $48 f$. 
$\mathrm{Abb}$. D1: Indifferenzkurve inländischer Kapitalanbieter bei Quellenbesteuerung nach dem Nominalwertprinzip und Verzicht des Wohnsitzlandes auf die Besteuerung von Währungsgewinnen oder -verlusten, wenn der Wechselkursentwicklung der Parität der Grenzproduktivitäten folgt.

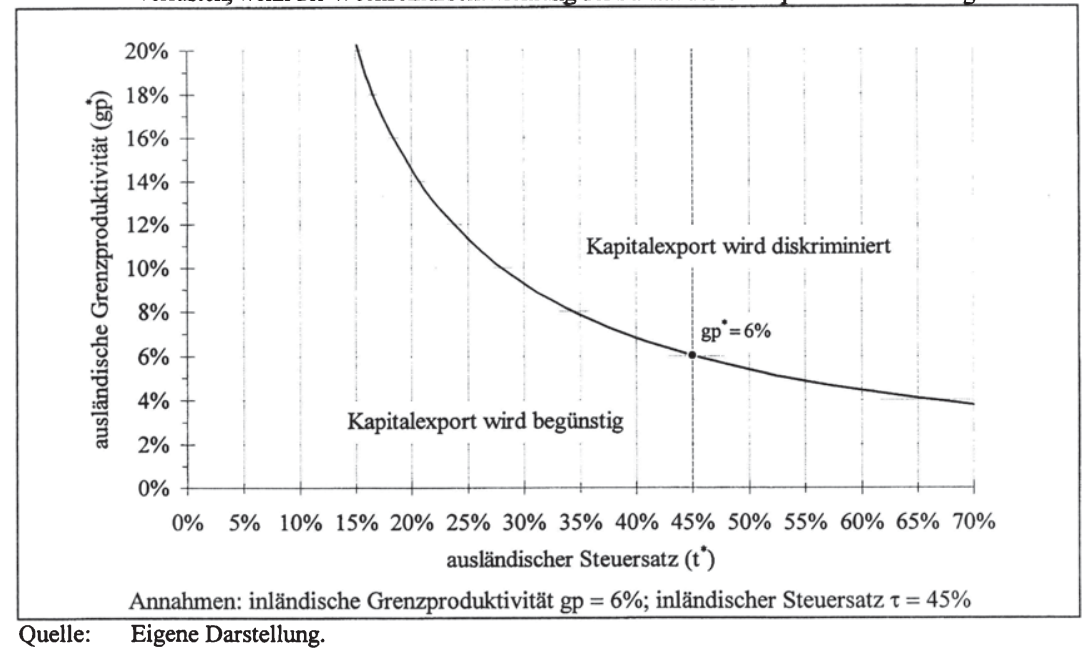

Die Graphik zeigt, wann der Vorteil einer geringeren Quellensteuer durch einen Währungsverlust aufgezehrt wird. Bei einer ausländischen Grenzproduktivität von $10 \%$ ist unter diesen Annahmen schon bei einer Steuerbelastung von mehr als $28 \%$ eine Bevorzugung durch Freistellung nicht mehr gegeben. Schon bei einer um einen Prozentpunkt höheren nominalen Grenzproduktivität im Ausland bedarf es einer um über sechs Prozentpunkte niedrigeren effektiven Grenzsteuerbelastung im Quellenland, damit der ausländische Standort aus steuerlichen Gesichtspunkten ex ante tatsächlich günstiger ist. ${ }^{311}$

Andererseits wird selbst bei einem Quellensteuersatz von $60 \%$ eine Benachteiligung dann noch nicht erwartet, wenn die Grenzproduktivität in dem Belegenheitsstaat nicht mehr als 4,4\% beträgt und die Währung des Einsatzortes entsprechend aufwertet.

Wäre das Währungsergebnis andererseits inländischen Ursprungs, würde eine Begünstigung des Auslandsengagements gegeben sein, wenn der Steuersatz im Quellenland unter dem des Inlands liegt, also für alle Punkte links von der Marke eines Quellensteuersatzes von $45 \%$.

Die Auswirkungen bei Charakterisierung von Währungsgewinnen und -verlusten als entweder inländische oder ausländische Einkünfte sind damit gänzlich unterschiedlich. $\mathrm{Ob}$ aus allokativen Überlegungen im Rahmen der Freistellung von bestimmten ausländischen Einkünften auch Währungsgewinne oder -verluste im Wohnsitzland von der Besteuerung ausgenommen werden sollten, muß hiernach unbestimmt bleiben. Dafür wären die in- und ausländischen Steuersätze und der erwartete Wechselkursverlauf im Einzelfall zu betrachten.

Ein Urteil wird aber vermutlich aus fiskalischen Überlegungen nicht schwerfallen. Zählt das Währungsergebnis zu den inländischen Einkünften, werden nämlich bei einem sinkenden Devisenkurs im Ergebnis im Ausland gezahlte Steuern durch den inländischen Staat erstattet,

${ }^{311}$ Bei allen Vorbehalten hinsichtlich der Annahmen, die dieser sehr einfachen Rechnung zugrunde liegen, ist das Ergebnis vor dem Hintergrund der aktuellen Standortdiskussion in Deutschland doch bemerkenswert, wenn berücksichtigt wird, daß in den letzten Jahren die Inflationsraten in einer Reihe von Ländern relativ zu Deutschland zurückgegangen sind. 
denn die Höhe des steuerpflichtigen ausländischen Gewinnes und des erwarteten Währungsverlustes stehen in ökonomischem Zusammenhang zueinander.

In Deutschland bekommt diese Überlegung besonderes Gewicht: Zumindest historisch sind die Devisenkurse gegenüber der Deutschen Mark eindeutig rückläufig. Seit 1975 ist der nominale effektive Außenwert der DM um über $70 \%$ gestiegen. ${ }^{312}$

Außerdem würde es bei Investitionen in Ländern mit hoher Inflation regelmäßig zur Erstattung eines Währungsverlustes in Höhe des inländischen Steuersatzes kommen.

Hinzukommt: Speziell in stark inflationären Währungsräumen sind Scheingewinne möglicherweise von der Besteuerung ausgenommen. Abbildung D1 bildet demgegenüber den ausländischen Steuersatz auf der Grundlage des Nominalwertprinzips ab. Soweit das Steuerrecht des Quellenlandes eine Indexierung bei der Bemessung der Steuer zuläßt, reduziert sich der effektive Steuersatz dort entsprechend:

Beispiel D3:

Die Grenzproduktivität betrage in Beispiel D2 im Ausland nominal 20\%, real aber nur $6 \%$.

Eine Tarifbelastung von $45 \%$ entspricht bei Indexierung in der Darstellung einem effektiven Steuersatz von $13,5 \% .313$

Mit dem Freistellungsverfahren ist deshalb eine Förderung von Kapitalexport in Staaten, deren Zahlungsmittel einer starken Geldentwertung unterliegt, allgemein dann zu vermuten, wenn dort Scheingewinne nicht steuerpflichtig sind. ${ }^{314}$ Der reale ausländische Gewinn macht infolge des Kursrückgangs aus inländischer Sicht nur einen geringen Teil des Kapitaleinkommens aus. Entsprechend geringer ist die tatsächliche Belastung am Einsatzort.

Wird das Währungsergebnis den inländischen Einkünften zugerechnet, wird infolge der Erwartung eines Devisenkursrückgangs darüber hinaus noch eine Minderung der inländischen Steuerlast erwartet werden. Bei einer hohen Inflationsrate im Quellenland ist unter diesen Umständen sogar eine negative effektive Gesamtsteuerlast nicht auszuschließen. ${ }^{315}$

Die Lokalisierung des Währungsergebnisses im Wohnsitzland ist deshalb hier unsinnig.

Mit Blick auf die gegenwärtige Rechtslage läßt sich das bisher Gesagte für realistische Steuersätze im Quellenland in zwei Aussagen zusammenfassen:

- Kapitalexport in Länder, für deren Währung ein Rückgang erwartet wird, wird diskriminiert, wenn der Quellensteuersatz auf nominelle Gewinne in diesem Währungsraum nicht wesentlich niedriger ist als die Besteuerung bei Kapitaleinsatz im Wohnsitzland.

- Kapitalexport in Länder mit höherer Inflationsrate wird dann begünstigt, wenn der Quellensteuersatz Scheingewinne ausnimmt. Aus Sicht des Wohnsitzlandes ist die Geldentwertung im Quellenland dann infolge der erwarteten Währungsentwicklung nachrangig.

312 Vgl. Abbildung B5 auf Seite 28 dieser Arbeit.

313 Die Steuerlast beträgt im Quellenland $0,06 \cdot 0,45=0,027$. Bezogen auf einen nominalen Gewinn von 0,2 ergibt $\operatorname{dies} 0,2 \cdot t^{*}=0,027 \Leftrightarrow t^{\circ}=13,5 \%$.

${ }^{314}$ Schon die Freistellung von Veräußerungsgewinnen im Rahmen der gewerblichen Einkünfte im Quellenland würde hier eine Begünstigung solcher Formen des Kapitaleinsatzes in dem betreffenden Währungsraum bewirken.

315 In Beispiel D3 ergibt sich eine erwartete effektive Gesamtsteuerlast von 6,4\%: Antizipiert wird ein Wechselkursrückgang um 1,06/1,20=0,883. Die ausländische Steuer beträgt in inländischer Währung dann 0,0135 . $0,883=0,11925$. Hinzukommt die negative Steuer am Wohnsitz von $(1-0,883) \cdot 0,45=0,0525$. Zusammen ergibt dies $-0,0525+0,11925=0,064=6,4 \%$. 


\section{Anrechnungsverfahren und stark inflationäre Währungen}

Die Ermittlung der steuerlichen Bemessungsgrundlage bei Direktinvestitionen in stark inflationären Währungsräumen wird in Deutschland - im Unterschied zu den USA - im Rahmen des Anrechnungsverfahrens nicht kritisiert.

Tatsächlich muß es im deutschen Recht durch die Gewinnermittlung nicht zu einer Diskriminierung kommen. Aus den Grundsätzen ordnungsmäßiger Buchführung leitet sich für Einzelpositionen wie auch für ausländische Betriebstätten eine der Umsatzmethode nahekommende Bilanzierung ab, und zwar in Deutscher Mark.

Sachwerte sowie auch Abschreibungen für Abnutzung werden somit angemessen erfaßt, soweit dies praktisch möglich ist. ${ }^{316} \mathrm{Zu}$ Anschaffungskosten sind indessen auch Nominalwerte zu bilanzieren. Doch besteht im Fall eines Währungsverlustes die Möglichkeit einer Teilwertabschreibung. Kursverluste können damit zeitnah berücksichtigt werden. Im Gegensatz dazu ist bei Sachwerten eine solche Abschreibung nicht zulässig, falls der Wert des Aktivums in der ausländischen Währung nur infolge der inflationären Entwicklung im Quellenland an Wert zugenommen hat.

Bei den Aktiva sind folglich systematische Verzerrungen durch eine starke Inflation im Belegenheitsstaat nicht zu erwarten.

Entsprechend ist allerdings auch bei den Passiva zu verfahren. Das bedeutet bei Fremdfinanzierung im Quellenland, daß ein Währungsgewinn als Folge eines zurückgehenden Devisenkurses erst zum Zeitpunkt der Rückzahlung des Kredites realisiert wird. Die Fremdkapitalaufwendungen sind aber in Höhe des im Quellenland vorherrschenden Zinsniveaus abziehbar. ${ }^{317}$

Insofern besteht zumindest steuerlich ein Anreiz, eine Betriebstätte durch längerfristiges Fremdkapital in der inflationären Währung des Quellenlandes zu finanzieren.

Ein solches Auslandsengagement würde begünstigt, Kapitalexport jedoch diskriminiert. Dem Zinsvorteil des Steueraufschubs steht aber wiederum ein möglicher Nachteil durch einen Anrechnungsüberhang als Folge der Minderung des ausländischen Einkommens gegenüber.

Die praktische Bedeutung der Finanzierung in einer inflationären Währung ist aber fraglich, da das erhebliche Risiko einer Änderung der Rate der Geldentwertung wie auch politischer Unsicherheiten die Vorteilhaftigkeit langfristiger Fremdfinanzierung stark einschränken. Andererseits war das Ausräumen solcher Anreize zur Steuerumgehung der vorrangige Grund für das Finanzministerium der USA, die komplizierten Gewinnermittlungsvorschriften der DASTM vorzuschreiben.

\section{Exkurs: Freistellungsverfahren weltweit}

Dem in Teil B dargestellten Gleichgewicht bei weltweiter Anwendung des Quellenlandprinzips kommt nach dem in dieser Arbeit Gesagten keine praktische Bedeutung zu.

Dabei ist das Freistellungsverfahren zumindest in Bezug auf die Einfachheit des Steuersystems überlegen. Schon in Teil B wurde gezeigt, warum es in einem einperiodigen Modell optimal ist, Währungsgewinne und -verluste im Quellenlandprinzip auf Seiten der Kapital-

${ }^{316} \mathrm{Vgl}$. die theoretischen Überlegungen auf den Seiten 124 bis 126 dieser Arbeit.

${ }^{317}$ Vgl. allgemein BFH-Urteil v. 19.1.1994 I R 93/93, in: Internationales Steuerrecht, 3.Jg. (1994), S. 332. 
anbieter nicht der Besteuerung zu unterwerfen. ${ }^{318}$ Dieses Ergebnis hat auch Bestand, wenn mehrere Perioden betrachtet werden und eine periodengerechte Abgrenzung des Einkommens nicht möglich ist:

Werden Gewinne und Verluste steuerlich zu spät oder auch zu früh berücksichtigt, hat dies für Steuerpflichtige bekanntlich einen Zinsvorteil beziehungsweise -nachteil durch den Steueraufschub zur Folge. Ein solcher Vor- oder Nachteil wird bei reiner Quellenbesteuerung aber immer auf Seiten des Kapitalnachfragers wirksam, denn Kapitalanbieter unterliegen direkt keiner Besteuerung und konkurrieren weltweit um die günstigsten Anlagemöglichkeiten. Im Gleichgewicht ist der Grenzertrag der Kapitalanbieter mithin identisch, beziehungsweise wird - bei flexiblen Wechselkursen - durch eine zinsparitätische Beziehung determiniert. Kapitalnachfrager eines jeden Landes sind infolgedessen indifferent gegenüber Kapital in- und ausländischen Ursprungs. Die Quellensteuer erhöht die Kapitalkosten nur in Abhängigkeit vom Einsatzort des Kapitals, nicht aber von dessen Herkunft. Entsprechend muß auch ein Vorteil, etwa durch die Möglichkeit einer geringeren Gesamtsteuerlast durch das Hinauszögern der Besteuerung, zumindest direkt nur den Kapitalnachfragern zufallen.

Für jeden Zeitraum existiert deshalb genau eine erwartete Wechselkursänderung, die die erwartete Rendite in- und ausländischer Anbieter für Anlagealternativen in den Ländern angleicht. Wie in Teil B gezeigt wurde, ist das weltweite Arbitragegleichgewicht bei nicht identischen Quellensteuersätzen aber nur dann möglich, wenn das Währungsergebnis nicht besteuert wird. ${ }^{318}$

Damit sind die Probleme des Periodisierungszwangs und der Quantifizierung nicht realisierter Vermögensänderungen im Quellenland nicht gelöst. ${ }^{319}$ Ebenso wenig ist dies eine Begründung für oder gegen Kapitalimport- und Kapitalexportneutralität. Die Argumente hierzu wurden am Anfang der Arbeit skizziert.

Beide Aspekte sind aber nicht Thema dieser Arbeit, da sie nicht abhängig sind von der Frage nach der optimalen einkommensteuerlichen Behandlung von Währungsgewinnen und -verlusten. Es bleibt deshalb hier nur festzuhalten, daß das Ziel der Kapitalimportneutralität weniger Schwierigkeiten bei der Erhebung der Steuer bereitet, da das Währungsergebnis nicht der Besteuerung unterliegen sollte.

318 Wie schon in Fußnote 139 auf Seite 55 des Teils B dieser Arbeit gesagt, sind Kursgewinne und -verluste bei der Besteuerung des Kapitalnachfragers gleichwohl zu berücksichtigen, falls (Fremd-)Kapital in einer ausländischen Währung aufgenommen wurde. Dabei kann es auch zu nicht realisierten Kursgewinnen oder -verlusten kommen. Insoweit ist Kapitalimportneutralität doch verletzt. Diese sind aber steuerlich leichter zu erfassen, da es sich regelmäßig um nominelle Bilanzpositionen handeln wird.

${ }^{319}$ Dies trifft auch auf die Problematik der Wechselwirkungen von Inflation und Außenwert sowie auf (Fremd-)Finanzierung in einer ausländischen Währung zu. Die Entscheidung über das Ausmaß der Besteuerung von Scheingewinnen obliegt aber einzig dem Quellenland. 


\section{Zusammenfassende Beurteilung im Vergleich zu der Besteuerung in den USA}

Die steuerliche Behandlung von Währungsgewinnen und -verlusten wird im deutschen Einkommen- und Körperschaftsteuergesetz nicht ausdrücklich erwähnt. Maßgeblich für den Zeitpunkt der Besteuerung und die Höhe des Währungsergebnisses sind im wesentlichen die handelsrechtlichen Grundsätze ordnungsmäßiger Buchführung. Die Quelle entscheidet sich danach, ob ein wirtschafticher Zusammenhang mit den im Einkommensteuergesetz als ausländisch definierten Einkünften besteht. Eine Anzahl strittiger Fragen bei der Auslegung von Handels- und Steuerrecht wurden in den vergangenen Jahren durch Urteile des Bundesfinanzhofs und der Finanzgerichte der Länder geklärt. In einigen Teilbereichen besteht aber weiterhin Unklarheit.

Doch obgleich kein geschriebenes Recht existiert, läßt sich die in der Einleitung dieser Arbeit zitierte Kritik von P. Musgrave an der U.S.-amerikanischen Besteuerungspraxis vor der Gesetzesreform von 1986 nicht auf Deutschland übertragen. Das Maßgeblichkeitsprinzip zwingt zu einer systematischen Analyse bei Entscheidungen, und der Bewertungsvorbehalt schränkt dabei handelsrechtliche Wahlrechte ein. Es bedarf deshalb im Unterschied zu den USA nicht des Gesetzgebers, um „der Konzeption nach den Geist von Rationalität und Vernunft“ 320 in diesem Teil des Steuerrechts zu gewährleisten.

Eine Konkretisierung des deutschen Steuerrechts erscheint dennoch in einigen Punkten sinnvoll. Das trifft allerdings vor allem dort $\mathrm{zu}$, wo das Handelsrecht keine Hilfe bietet, nämlich bei der Bestimmung der Quelle von Währungsgewinnen und -verlusten. Auch hier ist aber eine angemessene Klärung durch den Bundesfinanzhof denkbar. ${ }^{321}$

Aus allokativem Blickwinkel ist außerdem das Imparitätsprinzip fraglich. Im allgemeinen werden riskante Investitionen begünstigt, wenn Verluste schon vor der Realisierung steuerlich $\mathrm{zu}$ berücksichtigen sind. Im besonderen ist das Bild für die Besteuerung von Währungsgewinnen und -verlusten im Rahmen des Anrechnungsverfahrens jedoch differenziert. Einerseits ist auch eine zusätzliche Diskriminierung nicht auszuschließen, wenn das Währungsergebnis ausländischen Ursprungs ist. Andererseits verhindert oder reduziert das Imparitätsprinzip auf einfache Weise eine Benachteiligung von Auslandsengagements in inflationären Währungsräumen. Eine Einschränkung dieses Prinzips würde hier eine gesetzliche Regelung notwendig machen, die die zeitnahe Berücksichtigung von Kursgewinnen und -verlusten bei Nominalwerten festlegt. Die komplizierten Regelungen der USA bieten dabei aber keine konkrete Hilfestellung.

$\mathrm{Da}$ die in diesem Teil beleuchtete Situation der Behandlung von Währungsgewinnen und -verlusten dennoch ein uneinheitliches Bild ergibt, liegt in erster Linie an dem Nebeneinander verschiedener Methoden zur Vermeidung von Doppelbesteuerung. Dadurch ist eine Beurteilung des deutschen Rechts sowohl anhand der in Teil B angestellten theoretischen Überlegungen als auch im Vergleich zu den USA schwierig.

Im einzelnen lassen sich folgende Ergebnisse zusammenfassen:

${ }^{320} \mathrm{Vgl}$. Seite 150 dieser Arbeit.

${ }^{321}$ Die Entscheidung des Bundesfinanzhofes zur Quelle des Währungsergebnisses bei Wertpapieren und Forderungen in der Bilanz inländischer Steuerpflichtiger bezog sich zwar explizit auf Einkünfte aus Kapitalvermögen, die in einem Doppelbesteuerungsabkommen als Einkünfte aus Zinsen und Dividenden präzisiert werden. Doch läßt die Formulierung der Begründung vermuten, daß auch auf Basis des Einkommensteuergesetzes entsprechend entschieden würde. BFH-Urteil v. 16.3.1994 I R 42/93, a.a.O., S.801.

Ebenso ist die Zulässigkeit einer Umrechnung von Gewinnen und darauf im Ausland entrichteten Steuern bei wesentlichen Beteiligungen zum gleichen Kurs denkbar. Vgl. die Seiten 193f. dieser Arbeit. 
Im Unterschied zu den USA kommt in Deutschland neben dem Anrechnungsverfahren auch die Freistellungsmethode zur Anwendung. Die Überlegungen des Teils B zur Besteuerung erwarteter Währungsgewinne und -verluste lassen sich deshalb nicht auf die deutsche Realität übertragen.

Die Freistellung wird in Deutschland kraft Doppelbesteuerungsabkommen im wesentlichen für aktive Einkünfte durch ausländische Betriebstätten und Tochtergesellschaften sowie durch im Ausland belegene unbewegliche Wirtschaftsgüter eingeräumt. Werden die ausländischen Einkünfte von einer inländischen Kapitalgesellschaft erzielt, wird der Vorteil einer Freistellung auf der Ebene der Gesellschaft durch das körperschaftsteuerliche Anrechnungsverfahren bei einer sofortigen Ausschüttung an inländische Steuerpflichtige nivelliert. Bei späterer Ausschüttung bleibt ein Zinsvorteil durch die Steuerstundung.

Aufgrund der Einschränkungen wird in dieser Arbeit vermutet, daß sich eine Begünstigung oder Diskriminierung durch die Freistellung auf Seiten der inländischen Kapitalanbieter auswirkt. Trifft dies zu, ist auch für Deutschland die Besteuerung von Währungsgewinnen oder -verlusten im Rahmen des Freistellungsverfahrens abzulehnen. Das heißt konkret: das Währungsergebnis sollte hier den ausländischen Einkünften zugerechnet werden. Dies ist der Fall.

Das Ergebnis läßt sich allerdings nicht aus allokativen Überlegungen ableiten. Die Freistellung hat tendenziell zur Folge, daß Kapitalexport in solche Länder behindert wird, für die ein zurückgehender Devisenkurs erwartet wird. Die Höhe des Steuersatzes (bezogen auf den nominalen ausländischen Gewinn) spielt im Vergleich zur erwarteten Währungsentwicklung eine eher nachrangige Rolle. Wäre das Währungsergebnis statt dessen steuerpflichtig, würde die Grenzinvestition im Ausland begünstigt, wenn der Steuersatz im Quellenland unter dem des Inlands liegt.

Das Urteil fällt aber aus fiskalischen Überlegungen nicht schwer. Zählt das Währungsergebnis zu den inländischen Einkünften, werden nämlich bei einem sinkenden Devisenkurs im Ergebnis im Ausland gezahlte Steuern durch den inländischen Staat erstattet. Eindeutig ist zudem, daß die Zurechnung zu den inländischen Einkünften dann unsinnig ist, wenn die Inflationsrate im Quellenland höher ist und das Ausland Scheingewinne von der Besteuerung ausnimmt. In diesem Fall würden nämlich im Inland sogar Steuern erstattet, die im Ausland gar nicht gezahlt wurden.

Für die Analyse von Auswirkungen nicht erwarteter Wechselkursänderungen sind neben den Methoden zur Vermeidung von Doppelbesteuerung insbesondere folgende Unterschiede im Vergleich zum U.S.-Steuerrecht relevant:

- Bei der Ermittlung des steuerpflichtigen Gewinns durch Direktinvestitionen ist die Stichtagmethode in Deutschland (in der Regel) unzulässig.

- Das Imparitätsprinzip ist bei der Besteuerung von Währungsgewinnen und -verlusten in den USA unbekannt.

- Das Anrechnungsverfahren ist in Deutschland für jedes Land und nicht für verschiedene Arten von ausländischen Einkünften separat anzuwenden. Außerdem ist die Anrechnung ausländischer Steuern nur im Jahr ihrer Entstehung gestattet und ein Vor- oder Rücktrag von Anrechnungsüberhängen nicht zulässig.

In Deutschland muß der Gewinn einer ausländischen Betriebstätte in einer der Umsatzmethode zumindest nahekommenden Weise bestimmt werden. Daher ist es nicht möglich, die im Ausland gegebene Beziehung zwischen Betriebstättenergebnis und darauf zu entrichtende Steuern in inländischer Währung zu erhalten. Soweit dieses Einkommen nicht freigestellt ist, wird Kapitalexport diskriminiert, weil das Währungsergebnis auch in Deutschland zu den ausländischen Einkünften zählt.

Das Imparitätsprinzip reduziert unter Umständen diesen Effekt. Einerseits kann hierdurch der zum Realisationszeitpunkt im Inland steuerpflichtige Gewinn zwar größer, nicht aber kleiner 
sein. Ein wechselkursbedingter Anrechnungsüberhang ist für diesen Zeitpunkt weniger wahrscheinlich. Andererseits entstehen aber im Jahr der Abschreibung negative ausländische Einkünfte. Es hängt von der jeweiligen Situation ab, ob diese die Steuerlast im Wohnsitzland mindern.

Das Imparitätsprinzip ist auf alle Bilanzpositionen separat anzuwenden. Das heißt, sowohl ein Rückgang als auch ein Anstieg des Kurses kann einen währungsbedingten Verlust zur Folge haben - entweder bei den Aktiva oder bei den Passiva.

Eine Begünstigung ist im Vergleich zu einer Investition im Inland jedoch nur realistisch, falls ein Anrechnungsüberhang ex ante (nahezu) ausgeschlossen ist, und zwar nur aufgrund eines Zinsvorteils. Demgegenüber kann es aber zu einer zusätzlichen Steuerlast kommen, wenn durch eine solche Abschreibung die Anrechnung ausländischer Steuern verhindert wird. Im allgemeinen wird das Imparitätsprinzip deshalb im Anrechnungsverfahren nicht aufgrund des Währungsrisikos zu einer Förderung von Kapitalexport führen, wenn eine Quellensteuer erhoben wird und Kursgewinne oder -verluste ausländisches Einkommen sind.

Bei bestimmten Formen des Kapitalexportes gehört aber auch in Deutschland das Währungsergebnis wohl zu den inländischen Einkünften. Dabei handelt es sich um ausländische Wertpapiere und Forderungen in der Bilanz inländischer Steuerpflichtiger. Zumindest trifft dies gemäß einer Entscheidung des Bundesfinanzhofes für Darlehen zu, wenn in einem Doppelbesteuerungsabkommen Einkünfte aus Kapitalvermögen als Einkünfte aus Zinsen und Dividenden präzisiert werden.

Diese Einkünfte sind regelmäßig nicht von der Besteuerung in Deutschland freigestellt. Die Zurechnung von Kursgewinnen und -verlusten $\mathrm{zu}$ den inländischen Einkünften entspricht deshalb dem Ergebnis der Analyse des Teils B.

Hier lassen sich Parallelen zu den §988-Geschäften des U.S.-Steuerrechts feststellen. Entsprechende Kurssicherungstransaktionen sind in Deutschland aber nicht vorgesehen. Die Quelle des Währungsergebnisses wird bei Grund- und Sicherungsgeschäft separat oder nach dem Veranlassungsprinzip ermittelt. Soweit nicht korrespondierende Bewertung geboten ist, kommt es zudem durch die jüngste Steueränderung zu einem „Systembruch“322: Ein wirtschaftlich gleicher (Währungs-)Verlust begründet bei einem Grundgeschäft eine Teilwertabschreibung, bei einem Termingeschäft dagegen keine Drohverlustrückstellung mehr.

Werden ausländische Einkünfte dagegen in Deutschland kraft Doppelbesteuerungsabkommen nicht besteuert, fördert die Perspektive wechselkursbedingter Teilwertabschreibungen den Kapitaleinsatz im Ausland in Form unbeweglicher Wirtschaftsgüter. Teilwertabschreibungen sind in den Abkommen nämlich nicht vorgesehen. Dem Verlustabzug durch eine Abschreibung stehen hier steuerfreie Gewinne gegenüber.

In geringerem Maße werden auch Investitionen durch ausländische Betriebstätten und Tochtergesellschaften begünstigt. Bei Betriebstätten sind jedoch bis zur Höhe des Verlustes positive Einkünfte späterer Perioden im Inland steuerpflichtig; bei Tochtergesellschaften ist effektiv nur eine negative Differenz zwischen Anschaffungskosten und Veräußerungserlös abziehbar.

Bei einer Beurteilung der Wirkung von Teilwertabschreibungen ist aber zu bedenken, daß die Bewertung von Wirtschaftsgütern in nicht unerheblichem Ausmaß einzelfallabhängig ist und im Ermessen der Entscheidungsträger liegt - des Steuerpflichtigen sowie gegebenenfalls auch dem Finanzamt und dem Betriebsprüfer.

Einzelfallabhängig sind auch die Folgen der Pro-Staat-Begrenzung des deutschen Rechts beim Anrechnungsverfahren für Steuerpflichtige mit Einkünften aus mehreren Staaten:

322 Vgl. W.-P. Hoffmann, Anmerkungen zum bilanzrechtlichen Teil des Steuerreformgesetzes 1998, a.a.O., S.1198, der dies auch an anderen Beispielen verdeutlicht. 
Währungsgewinne und -verluste können bei Aktivitäten in verschiedenen Ländern nicht miteinander verrechnet werden. Folglich ist ein Anrechnungsüberhang in einem einzelnen Land wahrscheinlicher.

Damit steigt aber auch die Wahrscheinlichkeit eines insgesamt negativen Ergebnisses in diesem Land. Der ausländische Verlust beeinflußt nicht den Anrechnungshöchstbetrag bei Einkünften aus anderen Währungsräumen, sondern mindert unmittelbar die inländische Steuerlast. Dieser Aspekt gewinnt noch an Gewicht, da in Deutschland zugleich die Wahl der Abzugsmethode für jedes Quellenland separat zulässig ist.

Die erste Folge ist im U.S.-Steuerrecht weniger gewichtig, weil gleiche Einkünfte aus verschiedenen Ländern miteinander verrechnet werden können und mehr noch durch die Vorund Rücktragsmöglichkeiten von Überhängen.

Die kompensierende Wirkung des zweiten Effektes ist dagegen nur sehr eingeschränkt gegeben. Es ist zwar zulässig, negative ausländische Einkünfte einer Periode vom inländischen Einkommen abzuziehen. Positive ausländische Einkünfte späterer Jahre werden dann aber zur Bemessung des Anrechnungsbetrags bis zur Höhe des Verlustes als inländische Einkünfte angesehen. Die Diskriminierung durch das Anrechnungsverfahren wird deshalb kaum reduziert. 


\section{E. Zusammenfassung}

Durch die internationale Kapitalallokation entstehen bei flexiblen Wechselkursen Währungsgewinne und Währungsverluste. Diese müssen bei der einkommensteuerlichen Behandlung grenzüberschreitend eingesetzten Kapitals berücksichtigt werden.

Als Maßstab zur Beurteilung einer effizienten Besteuerung von Währungsgewinnen und -verlusten wurden in dieser Arbeit zunächst alternativ Kapitalexport- und Kapitalimportneutralität zugrunde gelegt. Unterstellt wurden dabei effiziente Devisenmärkte, die Zinsparität und die langfristige Gültigkeit der Kaufkraftparität.

Es zeigte sich, daß das Währungsergebnis unter der Zielsetzung der Kapitalexportneutralität wie anderes Kapitaleinkommen im Wohnsitzland besteuert werden muß. Im Rahmen von Kapitalimportneutralität ist es aber von der Besteuerung freizustellen, wenn es auf Seiten der Kapitalanbieter anfällt.

In der Realität wird das Ziel der Kapitalexportneutralität regelmäßig mit Hilfe des Anrechnungsverfahrens angestrebt. Ausländische Steuern sind dabei im Inland jedoch nur bis zur Höhe der inländischen Steuerlast anrechenbar. Bei unsicherer Wechselkursentwicklung ist die Besteuerung unter diesen Umständen nicht symmetrisch, wenn das Währungsergebnis als ausländisches Einkommen beim Anrechnungsverfahren einzubeziehen ist. Einerseits besteht die Gefahr von Anrechnungsüberhängen als Folge nicht erwarteter Währungsverluste. Andererseits erhöhen Währungsgewinne die Steuerlast, soweit der Anrechnungshöchstbetrag überschritten wird.

Die Begrenzung der Anrechnung läßt sich für ein gegebenes Jahr als Optionsposition interpretieren, und die Wirkung kann damit bestimmt werden. Der inländische Staat ist „Käufer“ von Kaufoptionen, der Steuerpflichtige „Stillhalter" der Position. Der Kaufpreis der Optionsposition stellt den entscheidungsrelevanten Barwert der Steuerforderung des inländischen Staates dar. Er ergibt zusammen mit der ausländischen Steuer die erwartete Gesamtbelastung.

Die erwartete Steuerlast wurde in dieser Arbeit anhand von Beispielen berechnet. Dabei ergab sich durch die Berücksichtigung von Währungsrisiko eine zum Teil erhebliche zusätzliche Diskriminierung von Kapitalexport.

Wird die Möglichkeit des Verlustabzugs oder das Recht zur Wahl der Abzugsmethode eingeräumt, können Währungsverluste ab einer bestimmten Höhe die Steuerlast im Inland reduzieren. Dadurch werden auch die negativen Auswirkungen des Anrechnungsverfahrens auf die erwartete Steuerlast gemindert.

Die Resultate der Berechnungen wurden verglichen mit dem Gegenwartswert der Steuerlast, der sich ergibt, wenn Währungsgewinne und -verluste steuerrechtlich als inländisches Einkommen angesehen werden. In diesem Fall ist die Besteuerung symmetrisch, zumindest soweit Währungsverluste mit anderen inländischen Einkünften des Steuerpflichtigen verrechnet werden können.

Dabei zeigte sich, daß die diskriminierende Wirkung eines Anrechnungshöchstbetrags bei Zurechnung des Währungsergebnisses zu den inländischen Einkünften überwiegend geringer ist. Nur falls ein Währungsgewinn erwartet wird und außerdem die Steuer im Quellenland höher ist als im Wohnsitzland, kann die Benachteiligung größer sein.

Im Hinblick auf die Auswirkungen auf die internationale Kapitalallokation ist es deshalb bei der Formulierung einer allgemeinen Regel vorzuziehen, das Währungsergebnis dem inländisches Einkommen zuzurechnen. 
In den Vereinigten Staaten ist ausländisches Einkommen von Steuerinländern grundsätzlich steuerpflichtig. Zur Vermeidung von Doppelbesteuerung wird unter bestimmten Voraussetzungen die direkte und die indirekte Anrechnung im Ausland gezahlter Steuern gestattet. Ein Währungsergebnis wird generell besteuert.

Im Rahmen der umfassenden Steuerreform von 1986 wurde das Einkommensteuergesetz der USA um einen Unterabschnitt J ergänzt, der sich ausschließlich mit der steuerlichen Behandlung von Währungsgewinnen und -verlusten befaßt.

Seit dieser Steuerreform ist als Umrechnungsverfahren für Direktinvestitionen im Ausland die Stichtagmethode vorgeschrieben, wenn eine sogenannte qualifizierte wirtschaftliche Einheit (QBU) vorliegt und wenn deren funktionale Währung nicht der U.S.-Dollar ist.

Die funktionale Währung wird aus der ökonomischen Bindung an einen Währungsraum abgeleitet. Maßgeblich sind unter anderem die Dauer des Auslandsengagements und die Dominanz des Zahlungsmittels bei den Geschäftsvorfällen.

Die Rechtsform ist demgegenüber unerheblich. Die Vorschriften gelten vom Grundsatz her sowohl für Niederlassungen als auch zur Ermittlung des steuerpflichtigen Gewinns ausländischer Tochtergesellschaften, die einer Zugriffsbesteuerung unterliegen.

Die in den USA steuerpflichtigen Einkünfte einer QBU sind das Ergebnis der in der funktionalen Währung nach U.S.-Vorschriften erstellten Gewinn- und Verlustrechnung, das zum Durchschnittskurs des Veranlagungszeitraumes umzurechnen ist.

Währungsgewinne oder -verluste sind steuerpflichtig, wenn Gewinne oder Einlagen entnommen werden beziehungsweise bei Ausschüttungen oder Kapitalherabsetzungen oder wenn die wirtschaftliche Einheit ganz oder teilweise veräußert wird. Er wird den ausländischen Einkünften zugerechnet und beim Anrechnungsverfahren einbezogen.

Die Stichtagmethode ist auf den ersten Blick interessant, die Rechtslage in den USA aber aufgrund der Wirkungen auf die Kapitalallokation nicht überzeugend:

Interessant ist, daß ein Auslandsengagement als wirtschaftliche Einheit angesehen wird. Das Währungsergebnis ist unabhängig von den wirtschaftlichen Aktivitäten und den Erträgen im Quellenland. Es bemißt sich nur nach der Höhe des im Ausland eingesetzten Kapitals eines inländischen Steuerpflichtigen.

Die sich daraus ergebende Möglichkeit, Währungsgewinne und -verluste den inländischen Einkünften zuzurechnen, ist - obgleich ursprünglich geplant - indessen nicht genutzt worden. Außerdem verzögert die Methode in den USA die Realisierung des Währungsergebnisses ungerechtfertigt lange. Das erklärte Ziel, ein Währungsergebnis steuerlich nicht zu berücksichtigen, solange das Kapital in der QBU eingesetzt wird, ist zumindest in Währungsräumen ohne Kapitalverkehrsbeschränkungen fraglich.

Auf den zweiten Blick zeigt sich zudem, daß die Neutralität in bezug auf die Betätigung im Quellenland nicht gewährleistet ist, wenn sich auch der Binnenwert der funktionalen Währung ändert und der Periodengewinn wegen des Nominalwert- und des Realisationsprinzips nicht korrekt ermittelt wird. Die Probleme des Stichtagverfahrens werden besonders deutlich bei Direktinvestitionen in stark inflationären Währungsräumen.

In den USA wurden für diese Fälle abweichende Rechtsverordnungen erlassen. Diese, in ihrer jetzigen Form Mitte 1994 in kraft getretenen Bestimmungen, fußen zwar auf der Stichtagmethode. Hinsichtlich der Quantifizierung des Währungsverlusts wurde indes festgelegt, er sei wenigstens monatlich mittels einer dem Nominal-/Sachwertverfahren vergleichbaren Umrechnungsmethode zu berechnen; Nominalwerte sind zum aktuellen, Sachwerte zum historischen Wechselkurs umzurechnen. 
Die geltende Rechtslage in den USA zur Umrechnung bei Direktinvestitionen ist deshalb vor dem Hintergrund der theoretischen Ergebnisse zwar bemerkenswert. Sie ist aber infolge des gebotenen Methodenwechsels bei starker Inflation im Quellenland sowie der Komplexität und des damit verbundenen Aufwands unbefriedigend.

In Unterabschnitt J wurden zum anderen sogenannte §988-Transaktionen definiert. Währungsgewinne und -verluste bei Nominalwerten und Finanzierungsinstrumenten, die auf eine andere als die funktionale Währung lauten, sind seither ordentliches Einkommen und zum Zeitpunkt der Realisierung steuerpflichtig. Quelle dieser Einkünfte ist prinzipiell der Währungsraum der funktionalen Währung.

Außerdem wurde das Gebot der Einzelbewertung für synthetische Positionen und für bestimmte Deckungsgeschäfte im Rahmen der gewöhnlichen Geschäftstätigkeit des Steuerpflichtigen aufgehoben. Letztere umfassen insbesondere die Sicherung von noch nicht bilanzwirksamen vertraglichen Verpflichtungen. Grund- und Deckungsgeschäft sind bezüglich des Zeitpunktes und der Quelle des Währungsergebnisses als integrierte Positionen zu behandeln. Die Quelle leitet sich aus dem Grundgeschäft ab.

Die Gesetzgebung zu §988-Transaktionen ist überzeugender. Es ist lediglich zu überlegen, auch bei Sachwerten Währungserfolge getrennt zu ermitteln und als inländische Einkünfte einzustufen. So würden zudem Gewinne bei beweglichen Wirtschaftsgütern und unbeweglichen Aktiva, die keine QBU begründen, steuerlich gleichgestellt.

In Deutschland wird ausländisches Einkommen von Steuerinländern kraft Doppelbesteuerungsabkommen oder nach nationalem Recht regelmäßig freigestellt, wenn es durch die aktive Tätigkeit oder die Veräußerung ausländischer Betriebstätten oder Tochtergesellschaften, oder durch ausländisches unbewegliches Vermögen erzielt wird. In diesem Fall sind grundsätzlich auch Währungsgewinne und -verluste von der Besteuerung ausgenommen. Ansonsten ist nach nationalem und teilweise auch nach Abkommensrecht die direkte und indirekte Anrechnung im Ausland gezahlter Steuern zulässig. Das Währungsergebnis ist dann ebenfalls steuerpflichtig.

Die Besteuerung von Währungsgewinnen und -verlusten ist aber im Einkommen- und Körperschaftsteuergesetz nicht ausdrücklich geregelt, sondern aus dem Handelsrecht und dem allgemeinen Steuerrecht abzuleiten.

Da das Freistellungs- und das Anrechnungsverfahren parallel zur Anwendung kommen, kann das oben genannte theoretische Ergebnis, demzufolge Währungsgewinne und -verluste auf Seiten der Kapitalanbieter im Rahmen des Quellenlandprinzips freigestellt werden sollten, nicht auf die deutsche Realität angewendet werden.

In dieser Arbeit wird angenommen, daß sich ein Vor- oder Nachteil durch das Freistellungsverfahren auf Seiten der inländischen Kapitalanbieter auswirkt. Unter dieser Voraussetzung sollte das Währungsergebnis, der Realität entsprechend, den ausländischen Einkünften zugerechnet und damit freigestellt werden.

Die Schlußfolgerung läßt allerdings nicht in erster Linie aus allokativen, sondern aus fiskalischen Überlegungen ableiten. Die Auswirkungen auf den erwarteten Nettoertrag sind je nach Höhe der Besteuerung am Einsatzort und erwarteter Kursentwicklung unterschiedlich. Wäre das Währungsergebnis jedoch Teil der inländischen Einkünfte, würden besonders bei Investitionen in hochinflationären Währungsräumen mit dem zu erwartenden Devisenkursrückgang erhebliche Steuerausfälle einhergehen.

Dessen ungeachtet würde aber auch hier die Diskriminierung von Kapitalexport im Rahmen des Anrechnungsverfahrens reduziert, wenn Währungsgewinne und -verluste dem inländischen Einkommen zugerechnet werden. Eine Differenzierung der Quelle in Abhängigkeit der zur 
Vermeidung von Doppelbesteuerung zur Anwendung kommenden Methode ist indes im allgemeinen nicht realistisch.

Im besonderen ist sie bei bestimmten Formen des Kapitalexportes aber wohl doch gegeben. Gemäß einer Entscheidung des Bundesfinanzhofes können Kursgewinne oder -verluste bei Darlehen durch die Formulierung in Doppelbesteuerungsabkommen zu den inländischen Einkünften gehören. Diese Einkünfte sind regelmäßig nicht freigestellt.

Eine asymmetrische Besteuerung von Währungsgewinnen und -verlusten resultiert in Deutschland außerdem aus dem Imparitätsprinzip.

Als indirekte Folge dieses Prinzips können trotz Freistellung ausländischen Einkommens unter Umständen Währungsverluste die Steuerlast im Inland mindern, wenn sie vor ihrer Realisierung sichtbar werden: Bei ausländischen unbeweglichen Wirtschaftsgütern kann ein zwischenzeitlich eintretender Verlust eine Teilwertabschreibung begründen und abziehbar sein, obgleich Veräußerungsgewinne und -verluste in Deutschland nicht besteuert werden. Bei Tochtergesellschaften ist im Ergebnis eine negative Differenz zwischen Anschaffungskosten und Veräußerungserlös abziehbar. Schließlich können bei Investitionen durch Betriebstätten ausländische Verluste das steuerpflichtige inländische Einkommen mindern, Gewinne späterer Perioden sind dann aber bis zur Höhe des Verlusts im Inland steuerpflichtig.

Kapitalexport wird hierdurch umso stärker gefördert, je höher das Währungsrisiko ist.

Demgegenüber ist die Begünstigung im Anrechnungsverfahren zweifelhaft, weil durch eine vorzeitige Abschreibung von Verlusten auch ein Anrechnungsüberhang entstehen kann.

$\mathrm{Zu}$ beachten ist aber: Wird das ausländische Einkommen durch eine inländische Kapitalgesellschaft erwirtschaftet, reduzieren sich die genannten Begünstigungen oder Diskriminierungen für steuerpflichtige inländische Kapitalanbieter zu einem Zinsvorteil oder -nachteil durch eine Steuerstundung bis zur Ausschüttung. Aufgrund des körperschaftsteuerlichen Anrechnungsverfahrens sinkt bei einer geringeren Steuerbelastung der Gesellschaft entsprechend auch die Anrechnungsgutschrift.

Insgesamt ergibt die gegenwärtige Rechtslage in Deutschland bezüglich der einkommensteuerlichen Behandlung von Währungsgewinnen und -verlusten ein uneinheitliches Bild. Die Ursache liegt aber in erster Linie in dem Nebeneinander unterschiedlicher Verfahren zur Vermeidung von Doppelbesteuerung und im allgemeinen Steuerrecht.

Zweifelhaft ist aus dem Blickwinkel dieser Arbeit das Imparitätsprinzip. Daneben gibt es im gegenwärtigen deutschen Steuerrecht keinen realistischen Ansatzpunkt, um infolge flexibler Wechselkurse bestehende Probleme isoliert zu reduzieren. 


\section{Anhang}

Anhang I: Quantifizierung beschränkter Anrechnung 212

Anhang II: Quantifizierung des Ausschlusses von

Verlustausgleichsmöglichkeiten im Wohnsitzland 216

Anhang III: Quantifizierung der Abzugmethode als Wahlrecht im Rahmen des Anrechnungsverfahrens

Anhang IV: Freistellung und Anrechnung in deutschen Doppelbesteuerungsabkommen

Anhang V: Quellensteuersätze auf Zinsen und Dividenden für Kapitalanbieter aus den USA oder aus Deutschland

AnhangVI: Internal Revenue Code—Subtitle A Ch. 1N, Part III Subpart J-Foreign Currency Transactions 


\section{Beispielrechnung zur Quantifizierung der Bedeutung beschränkter Anrechnung bei Unsicherheit über die Wechselkursentwicklung}

\section{Inland}

Unterstellt werden:

- inländisches Zinsniveau:

- ausländisches Zinsniveau:

$$
\begin{aligned}
r & =0,10 \\
r^{*} & =0,07
\end{aligned}
$$

Daraus errechnet sich gemäß der Zinsparitätenbeziehung der erwartete Devisenkurs:

$$
E\left[\frac{\mathrm{e}_{+1}}{\mathrm{e}}\right]=\frac{1+\mathrm{r}}{1+\mathrm{r}^{*}}=\frac{1,1}{1,07}=1,02804 .
$$

Unterstellt werden weiterhin:

- Inländischer Steuersatz auf

- ausländische Einkünfte und auf

- Währungsgewinne:

- Ausländischer Quellensteuersatz:

- Standardabweichung des erwarteten Devisenkurses: $\quad \sigma\left[e_{+1} / e\right]=0,10$

Ein Anrechnungsüberhang entsteht, wenn die inländische Steuerlast auf ausländische Einkünfte höher ist als die in die inländische Währung umgerechnete ausländische Steuerzahlung. Die Steuerlast bei reiner Quellensteuer betrüge:

$$
T\left(\frac{e_{+1}}{e}\right)=r^{*} \cdot t^{*} \cdot \frac{e_{+1}}{e}
$$

der Nettoertrag:

$$
\begin{aligned}
\mathrm{R}_{1}\left(\frac{\mathrm{e}_{+1}}{\mathrm{e}}\right) & =\left[1+\mathrm{r}^{*} \cdot\left(1-\mathrm{t}^{*}\right)\right] \cdot \frac{\mathrm{e}_{+1}}{\mathrm{e}}-1 \\
& =[1+0,07 \cdot(1-0,55)] \cdot 1,02804-1=0,0604 .
\end{aligned}
$$

Die Steuerlast bei Besteuerung nur im Belegenheitsstaat beliefe sich auf:

$$
T\left(\frac{e_{+1}}{e}\right)=\left[\left(1+r^{*}\right) \cdot \frac{e_{+1}}{e}-1\right] \cdot \tau
$$

und der Nettoertrag auf

$$
\begin{aligned}
R_{2}\left(\frac{e_{+1}}{e}\right) & =\left[\left(1+r^{*}\right) \cdot \frac{e_{+1}}{e}-1\right] \cdot(1-\tau) \\
& =[(1+0,07) \cdot 1,02804-1] \cdot(1-0,35)=0,65 .
\end{aligned}
$$

Der tatsächliche Nettoertrag inländischer Anleger bei ausländischen Anlagen errechnet sich aus den ausländischen Einkünften - bewertet in inländischer Währung - abzüglich des größeren Betrages aus Gleichungen [I1] und [I3] beziehungsweise:

$$
\text { [I5] } R\left(\frac{e_{+1}}{e}\right)=\left[1+r^{*} \cdot\left(1-t^{*}\right)\right] \cdot \frac{e_{+1}}{e}-1-\max \left\{\left[\left(1+r^{*}\right) \frac{e_{+1}}{e}-1\right] \cdot \tau-r^{*} \cdot t^{*} \cdot \frac{e_{+1}}{e} ; 0\right\} \text {. }
$$

Die Ergebnisfunktion dieses Nettoertrags am Periodenende in Abhängigkeit der Wechselkursänderung ist im Text auf Seite 61 abgebildet; Gleichung [I5] entspricht Gleichung [B14].

Der Erwartungswert des Nettoertrags zum Entscheidungszeitpunkt läßt sich nun optionstheoretisch ermitteln, indem die Anlage in die beiden Komponenten zerlegt wird, in:

- eine ausländische Anleihe, deren Ertrag um die Quellensteuer gemindert wird, und

- eine Eventualforderung des inländischen Staates in Höhe der Differenz aus ausländischer Steuerpflicht und der inländischen Steuerlast im Falle ausschließlicher Wohnsitzlandbesteuerung. 
Die Eventualforderung des inländischen Staates ist aus der Sicht des Anlegers gleichbedeutend mit der Position als Stillhalter in einer zu ermittelnden Anzahl von Kaufoptionen. Denn nur wenn der Ertrag infolge der Währungsentwicklung eine bestimmte Höhe erreicht hat - den Ausübungspreis -, entsteht eine Steuerpflicht im Inland. Eine negative Steuer des Wohnsitzstaates wird hier annahmegemäß ausgeschlossen.

Ausübungspreis der Option $\mathrm{k}$ ist der Devisenkurs, bei dem die ausländische Steuerlast der inländischen Zahlungspflicht entspricht, bei dem also der Anrechnungshöchstbetrag erreicht wird. Er kann durch Gleichsetzen von [I 1] und [I 2] ermittelt werden, indem nach $\left(\mathrm{e}_{+1} / \mathrm{e}\right)$ aufgelöst wird:

$$
\mathrm{k}=\left[\mathrm{r}^{*} \cdot\left(1-\frac{\mathrm{t}^{*}}{\tau}\right)+1\right]^{-1}=\left[0,07 \cdot\left(1-\frac{0,55}{0,35}\right)+1\right]^{-1}=1,0417
$$

Soweit der Devisenkurs den Wert k am Periodenende überschreitet, errechnet sich die Grenzsteuerbelastung im Inland bei einer marginalen Wechselkursänderung aus der Differenz der Steigungen der Nettoerträge bei reiner Wohnsitz- und bei reiner Quellenbesteuerung. Die Steigungen resultieren aus der ersten Ableitung der Funktionen [I 2] und [I 3] nach der Wechselkursänderung:

$$
\frac{\partial R_{1}}{\partial \frac{e_{+1}}{e}}=1+r^{*} \cdot\left(1-t^{*}\right) \text { und [I4'] } \frac{\partial R_{2}}{\partial \frac{e_{+1}}{e}}=\left(1+r^{*}\right) \cdot(1-\tau) \text {. }
$$

\section{Die Differenz beträgt:}

[I7] $1+\mathrm{r}^{*} \cdot\left(1-\mathrm{t}^{*}\right)-\left(1+\mathrm{r}^{*}\right) \cdot(1-\tau)=1+0,07 \cdot 0,45-1,07 \cdot 0,65=0,336$.

Dies ist die effektive inländische Grenzsteuerbelastung je Einheit Währungsgewinn, wenn der Kurs den Wert $\mathrm{k}$ übersteigt und damit auch die gesuchte Zahl von Kaufoptionen, die der Steuerpflichtige infolge der asymmetrischen Steuer im Inland hält. Der Wert ist geringer als die Tarifbelastung, da der ausländische Steuersatz höher ist als der Satz des Wohnsitzlandes. Bei einem marginal höheren Kurs steigt infolgedessen die ausländische Belastung auf den ausländischen Ertrag stärker als die des Inlands. Der Anrechnungsüberhang mindert die zusätzliche inländische Belastung des Währungsgewinns.

Die Quantifizierung der Eventualforderung des inländischen Staates wird hier mit Hilfe der 1973 von Black und Scholes allgemein und von Garman und Kohlhagen für Währungsoptionen entwickelten Bewertungsformel durchgeführt: ${ }^{1}$

$$
\text { [I8] } \mathrm{C}=\mathrm{e} \cdot\left(1+\mathrm{r}^{*}\right)^{-\mathrm{t}} \cdot N(\mathrm{x}+\sigma \cdot \sqrt{\mathrm{t}})-\mathrm{k} \cdot(1+\mathrm{r})^{-\mathrm{t}} \cdot N(\mathrm{x}) ; \mathrm{x}=\frac{\ln \frac{\mathrm{e}}{\mathrm{k}}+\left(\mathrm{r}-\mathrm{r}^{*}-\frac{\sigma^{2}}{2}\right) \cdot \mathrm{t}}{\sigma \cdot \sqrt{\mathrm{t}}} \text {, }
$$

wobei $N($.) die kumulative Normalverteilung des Wertes in den Klammern ausdrückt.

Demnach muß der Preis für eine Option betragen:

$$
\begin{gathered}
\mathrm{x}=\frac{\ln \frac{1}{1,0417}+\left(0,1-0,07-\frac{0,1^{2}}{2}\right)}{0,1}=-0,158 ; \\
\mathrm{C}=1,07^{-1} \cdot 0,4768-1,0417 \cdot 1,1^{-1} \cdot 0,4371=0,0316 .
\end{gathered}
$$

Der Preis der Eventualforderung des Staates beträgt in $t=0: 0,336 \cdot 0,0316=0,0106$. Um die Erträge für in- und ausländische Anlagealternativen vergleichbar zu machen, ist es schließlich erforderlich, den Optionspreis mit dem Zins für inländische Anlagen aufzuzinsen. Dieser Betrag

1 F. Black u. M. Scholes, The Pricing of Options and Corporate Liabilities, in: Journal of Political Economy, 81.Jg. (1973), S.637-640; M.B. Garman u. S. W. Kohlhagen, Foreign Currency Option Values, a.a.O., S.232234; J. Kloy u. J. Welcker, Drei Arten von Wăhrungsoptionen, a.a.O., S.298f.. 
ist von dem Nettoertrag bei reiner Quellenbesteuerung abzuziehen. Denn das Recht des Staates, ab einem bestimmten Ertrag zu partizipieren, wird Anlegenden natürlich nicht vergütet.

Das Ergebnis lautet bezogen auf das Periodenende: $0,0604-0,0106 \cdot 1,1=\underline{0,0487}$.

Der Aufzinsungsfaktor ist nicht der Opportunitätszinssatz, also der Nachsteuerzinssatz im Inland, da die Option selbst die Steuerlast ist. Die durch die Position zum Ausdruck kommende Steuer wird aber erst am Ende der Periode und nicht zeitkontinuierlich fällig.

Zum Vergleich: Würde hinsichtlich der Devisenkursentwicklung Sicherheit unterstellt, verspräche die Auslandsanlage einen Nettoertrag von 0,0604; es entstünde - wie aus den Ergebnissen der Gleichungen [I2] und [14] ersichtlich - ein geringer Anrechnungsüberhang von $0,065-0,0604=0,0046$.

Die Nettoverzinsung im Inland liegt annahmegemäß bei 0,065 .

\section{Ausland}

Es werden die gleichen Daten unterstellt wie in der Rechnung für inländische Anleger. Hergeleitet wird folgend die erwartete Nettorendite von Anlagen ausländischer Anleger im Inland. Ausländische Anleger werden demgemäß einen Devisenkurs von

$$
E\left[\frac{\mathrm{e}}{\mathrm{e}_{+1}}\right]=\frac{1+\mathrm{r}^{*}}{1+\mathrm{r}}=\frac{1,07}{1,1}=0,973
$$

für das Ende der Periode erwarten.

Unterstellt werden weiterhin:

- Steuersatz im Wohnsitzland (,Ausland") auf

- ausländische Einkünfte und auf

- Währungsgewinne:

$$
\begin{aligned}
\tau^{*} & =0,55 \\
t & =0,35
\end{aligned}
$$

- Quellensteuersatz (im „Inland“):

- Standardabweichung des erwarteten Devisenkurses: $\quad \sigma\left[\mathrm{e} / \mathrm{e}_{+1}\right]=0,10$

Der Nettoertrag bei ausschließlicher Quellensteuer betrüge:

$$
\begin{aligned}
R_{1}^{*}\left(\frac{e}{e_{+1}}\right) & =[1+r \cdot(1-t)] \cdot \frac{e}{e_{+1}}-1 \\
& =[1+0,1 \cdot(1-0,35)] \cdot 0,973-1=0,036 .
\end{aligned}
$$

Der Nettoertrag bei Besteuerung nur im Belegenheitsstaat beliefe sich auf:

$$
\begin{aligned}
\mathbf{R}_{2}^{*}\left(\frac{e}{e_{+1}}\right) & =\left[(1+r) \cdot \frac{e}{e_{+1}}-1\right] \cdot\left(1-\tau^{*}\right) \\
& =[(1+0,1) \cdot 0,973-1] \cdot(1-0,55)=0,0315 .
\end{aligned}
$$

Der tatsächliche Nettoertrag der ausländischen Anleger bei grenzüberschreitenden Anlagen kann wiederum ermittelt werden, indem von dem Nettoertrag bei Quellenbesteuerung aus [I2"] die Steuerforderung des Wohnsitzstaates abgezogen wird:

$$
\left[I 5^{*}\right] R^{*}\left(\frac{e}{e_{+1}}\right)=[1+r \cdot(1-t)] \cdot \frac{e}{e_{+1}}-1-\max \left\{\left[(1+r) \cdot \frac{e}{e_{+1}}-1\right] \cdot \tau-r \cdot t \cdot \frac{e}{e_{+1}} ; 0\right\} \text {. }
$$

Die Ergebnisfunktion dieses Nettoertrags zum Periodenende in Abhängigkeit der Wechselkursänderung ist wiederum im Text - auf Seite 65 - abgebildet.

Die Eventualforderung des Wohnsitzstaates ist aus der Sicht des Anlegers gleichbedeutend mit der Position als Stillhalter in einer zu ermittelnden Anzahl von Kaufoptionen. 
Ausübungspreis der Option $\mathbf{k}^{*}$ ist auch hier der Devisenkurs, bei dem die Steuerlast im Quellenstaat der Zahlungspflicht im Wohnsitzland entspricht und deshalb die Anrechnungsgrenze erreicht wird:

$$
\mathrm{k}^{*}=\left[\mathrm{r}^{*} \cdot\left(1-\frac{\mathrm{t}}{\tau^{*}}\right)+1\right]^{-1}=\left[0,1 \cdot\left(1-\frac{0,35}{0,55}\right)+1\right]^{-1}=0,9649
$$

Die Steuerpflicht des Ausländers ist sowohl gegenüber dem inländischen Staat als auch gegenüber dem ausländischen Staat eine Funktion des Devisenkurses. Die Anzahl von Optionen ist aus dem Verhältnis der Steigungen der Nettoerträge bei reiner Wohnsitz- und bei reiner Quellenbesteuerung zu ermitteln. Die Steigungen betragen:

$$
\frac{\partial \mathrm{R}_{1}^{*}}{\partial \frac{\mathrm{e}}{\mathrm{e}_{+1}}}=1+\mathrm{r} \cdot(1-\mathrm{t}) \text { und }\left[14^{*}\right] \frac{\partial \mathrm{R}_{2}^{*}}{\partial \frac{\mathrm{e}}{e_{+1}}}=(1+\mathrm{r}) \cdot\left(1-\tau^{*}\right) \text {. }
$$

Daraus folgt die erforderliche Zahl von Kaufoptionen für eine Einheit:

$$
1+r \cdot(1-t)-(1+r) \cdot\left(1-\tau^{*}\right)=1+0,1 \cdot 0,65-1,1 \cdot 0,45=0,57
$$

Auf eine Einheit zusätzlichen Währungsgewinnes werden im Inland effektiv 0,57\% zusätzliche Steuern erhoben. Der Wert ist hier höher als die Tarifbelastung im Wohnsitzland, da der ausländische Steuersatz niedriger ist als der Satz des Wohnsitzlandes. Bei einem marginal höheren Kurs steigt infolgedessen sowohl die inländische Belastung des ausländischen Ertrags als auch die inländische Belastung des Währungsgewinns.

Die Quantifizierung der Eventualforderung des Wohnsitzstaates mit der Optionsbewertungsformel von Black und Scholes ergibt:

$$
\mathrm{C}^{*}=\mathrm{e}^{-1} \cdot(1+\mathrm{r})^{-\mathrm{t}} \cdot N(\mathrm{x}+\sigma \cdot \sqrt{\mathrm{t}})-\mathrm{k}^{*} \cdot\left(1+\mathrm{r}^{*}\right)^{-\mathrm{t}} \cdot N(\mathrm{x})
$$

$$
x=\frac{\ln \frac{e_{1}^{-1}}{k^{*}}+\left(r^{*}-r-\frac{\sigma^{2}}{2}\right) \cdot t}{\sigma \cdot \sqrt{t}} .
$$

Demnach muß der Preis für eine Option betragen:

$$
\begin{gathered}
x=\frac{\ln \frac{1}{0,9649}+\left(0,07-0,1-\frac{0,1^{2}}{2}\right)}{0,1}=0,0072 ; \\
C^{*}=1,1^{-1} \cdot 0,5427-0,9649 \cdot 1,07^{-1} \cdot 0,5029=0,0399 .
\end{gathered}
$$

Da nur 0,57 Optionen erforderlich sind, beträgt der Preis der Eventualforderung $0,57 \cdot 0,0399=0,0228$ am Anfang beziehungsweise $0,0228 \cdot 1,07=0,0244$ am Ende der Periode.

Das Ergebnis lautet also: $0,036-0,0244=\underline{0,0116}$.

Auch hier noch einmal der Vergleich: Würde hinsichtlich der Devisenkursentwicklung Sicherheit unterstellt, verspräche die Auslandsanlage für Ausländer den gleichen Nettogewinn wie eine Anlage im Wohnsitzstaat, denn es entstünde hier kein Anrechnungsüberhang; also 0,0315. 


\section{Beispielrechnung zur Quantifizierung der Bedeutung des Ausschlusses von Verlustausgleichsmöglichkeiten im Wohnsitzland bei Unsicherheit über die Wechselkursentwicklung}

\section{Inland}

Unterstellt werden auch hier:

- inländisches Zinsniveau:

- ausländisches Zinsniveau:

$$
\begin{aligned}
r & =0,10 \\
r^{*} & =0,07
\end{aligned}
$$

- Inländischer Steuersatz auf

- ausländische Einkünfte und auf

- Währungsgewinne:

$$
\tau=0,35
$$

- Standardabweichung des erwarteten Devisenkurses: $\quad \sigma\left[\mathrm{e}_{+1} / \mathrm{e}\right]=0,10$

Der erwartete Devisenkurs beträgt:

$$
E\left[\frac{e_{+1}}{e}\right]=\frac{1,1}{1,07}=1,02804
$$

Die Ermittlung des entscheidungsrelevanten Endwertes einer Auslandsanlage in einem Steuersystem ohne Verlustausgleich im Wohnsitzland erfolgt durch optionstheoretische Interpretation der Steuerforderung. Da der Staat sich bei einem Verlust schadlos hält, ist ein inländischer Kapitalgeber quasi Stillhalter in einer Anzahl von Währungs-Kaufoptionen. Die Ergebnisfunktion - Gleichung [B17] im Text - lautet:

$$
\mathrm{R}\left[\frac{e_{+1}}{\mathrm{e}}\right]=\left(1+\mathrm{r}^{*}\right) \cdot \frac{\mathrm{e}_{+1}}{\mathrm{e}}-1-\max \left\{\left(\frac{\mathrm{e}_{+1}}{\mathrm{e}}-1+\frac{\mathrm{e}_{+1}}{\mathrm{e}} \cdot \mathrm{r}^{*}\right) \cdot \tau ; 0\right\} .
$$

Bei einem ausländischen Zinsniveau von $r^{*}=0,07$ ist der Ausübungspreis der Optionen

$$
\begin{gathered}
\left(1+r^{*}\right) \cdot \frac{e_{+1}}{e}=1 \\
\Leftrightarrow \quad k=\frac{e_{+1}}{e}=1,07^{-1}=0,935 .
\end{gathered}
$$

Bei diesem Wechselkurs am Periodenende wäre der Gesamtertrag des Auslandsengagements null; es entstünde kein Verlust und auch kein steuerpflichtiger Gewinn.

Wird dieser Wert zusammen mit dem jeweiligen Marktzinsniveau der Länder in die Berechnungsformel für eine Währungs-Kaufoption eingesetzt, die schon für die beschränkte Anrechnung angewendet wurde (vgl. Anhang I, Seiten 213f.), errechnet sich der Preis für eine Option aus

$$
\mathrm{C}=\mathrm{e} \cdot\left(1+\mathrm{r}^{*}\right)^{-\mathrm{t}} \cdot N(\mathrm{x}+\sigma \cdot \sqrt{\mathrm{t}})-\mathrm{k} \cdot(1+\mathrm{r})^{-\mathrm{t}} \cdot N(\mathrm{x})
$$

$$
\mathrm{x}=\frac{\ln \frac{\mathrm{e}}{\mathrm{k}}+\left(\mathrm{r}-\mathrm{r}^{*}-\frac{\sigma^{2}}{2}\right) \cdot \mathrm{t}}{\sigma \cdot \sqrt{\mathrm{t}}},
$$

wobei $N($.) die kumulative Normalverteilung des Wertes in den Klammern ausdrückt.

Demnach muß der Preis für eine Option betragen:

$$
\begin{gathered}
x=\frac{\ln \frac{1}{0,935}+\left(0,1-0,07-\frac{0,1^{2}}{2}\right)}{0,1}=0,927 ; \\
C=1 \cdot 1,07^{-1} \cdot 0,848-0,935 \cdot 1,1^{-1} \cdot 0,823=0,0930 .
\end{gathered}
$$

Die Anzahl der Optionen entspricht

$$
\tau \cdot\left(1+r^{*}\right)=0,35 \cdot 1,07=0,3745 \text {. }
$$


Warum? Der sichere ausländische Endwert beträgt hier 1,07 der Währung des Auslands. Ein Rückgang des Devisenkurses um eine Einheit bewirkt einen Rückgang des Ertrags in inländischer Währung um 1,07 Einheiten. Der Staat ist daran mit seinem Steuersatz $\tau=0,35$ beteiligt - beziehungsweise im Falle eines Verlustes nicht beteiligt.

Der Barwert des verwehrten Verlustausgleichs - der Stillhalterposition des Kapitalgebers beläuft sich demnach auf 0,093 $0,3745=0,0349$.

Zur Bestimmung des erwarteten Nettoendwertes ist diese Steuerforderung mit dem inländischen risikofreien Zinssatz aufzuzinsen: $0,0349 \cdot 1,1=0,0384$.

Die inländische Steuer reduziert infolgedessen den erwarteten Endwert der Auslandsanlage aufgrund des Ausschlusses von Verlustausgleichsmöglichkeiten auf 0,1-0,0384 $=\underline{0,0616}$ gegenüber 0,065 bei symmetrischer Belastung.

Der Wert wird durch den Ausschluß des Verlustausgleichs nur um 0,0034 gemindert. Die Ursache hierfür liegt in der geringen Wahrscheinlichkeit eines Verlustes. Erwartet wird ja ein Devisenkurs von 1,028; ein Verlust würde indes bei einem Kurs von weniger als 0,935 entstehen.

\section{Ausland}

Unterstellt werden auch hier weiterhin:

- Steuersatz auf

- ausländische Einkünfte und auf

- Währungsgewinne im Ausland: $\quad \tau^{*}=0,55$

- Standardabweichung des erwarteten Devisenkurses: $\quad \sigma\left[e / e_{+1}\right]=0,10$

Der erwartete Devisenkurs

aus der Sicht des Auslands ist:

$$
E\left[\frac{\mathrm{e}}{\mathrm{e}+1}\right]=\frac{1,07}{1,1}=0,9727
$$

Die Ermittlung des entscheidungsrelevanten Endwertes einer grenzüberschreitenden Anlage in einem Steuersystem ohne Verlustausgleich im Wohnsitzland ist optionstheoretisch möglich.

Ein Kapitalgeber des Auslands ist in der Position eines Stillhalters in einer Anzahl von Währungs-Kaufoptionen. Bei einem Zinsniveau im Quellenland von $r=0,1$ ist der Ausübungspreis der Optionen

$$
\begin{gathered}
(1+\mathrm{r}) \cdot \frac{\mathrm{e}}{\mathrm{e}_{+1}}=1 \\
\Leftrightarrow \quad \mathbf{k}^{*}=\frac{\mathrm{e}}{\mathrm{e}_{+1}}=1,1^{-1}=0,910 .
\end{gathered}
$$

Ist dies der tatsächliche Wechselkurs am Ende der Periode, wäre der Gesamtertrag des Engagements ausländischer Kapitalgeber im Inland null; es entstünde kein Verlust und auch kein steuerpflichtiger Gewinn.

Wird der Wert zusammen mit dem jeweiligen Marktzinsniveau der Länder und der Standardabweichung der erwarteten Währungsentwicklung in die Berechnungsformel für eine Währungs-Kaufoption eingesetzt, resultiert ein Preis für eine Option in $t=0$ in Höhe von

[II $\left.8^{*}\right]$

$$
\mathrm{C}^{*}=\mathrm{e}^{-1} \cdot(1+\mathrm{r})^{-\mathrm{t}} \cdot N(\mathrm{x}+\sigma \cdot \sqrt{\mathrm{t}})-\mathrm{k}^{*} \cdot\left(1+\mathrm{r}^{*}\right)^{-\mathrm{t}} \cdot N(\mathrm{x})
$$

$$
x=\frac{\ln \frac{e_{1}^{-1}}{k^{*}}+\left(r^{*}-r-\frac{\sigma^{2}}{2}\right) \cdot t}{\sigma \cdot \sqrt{t}} .
$$


Einsetzen der Werte ergibt:

$$
\begin{gathered}
x=\frac{\ln \frac{1}{0,91}+\left(0,07-0,1-\frac{0,1^{2}}{2}\right)}{0,1}=0,603 ; \\
C^{*}=1,1^{-1} \cdot 0,759-0,91 \cdot 1,07^{-1} \cdot 0,7268=0,0725 .
\end{gathered}
$$

Die Anzahl der Optionen entspricht

[II9"]

$$
\tau^{*} \cdot(1+r)=0,55 \cdot 1,1=0,605,
$$

denn der sichere ausländische Endwert beträgt 1,1 in der Währung des Inlands. Ein Rückgang des Devisenkurses um eine Einheit bewirkt also einen Rückgang des Ertrags in ausländischer Währung um 1,1 Einheiten. Der ausländische Staat partizipiert daran im Falle eines Verlustes mit seinem Steuersatz von $\tau^{*}=0,55$ nicht.

Der Barwert des verwehrten Verlustausgleichs - der Stillhalterposition des Kapitalgebers beläuft sich demnach auf $0,0725 \cdot 0,605=0,0438$.

Zur Bestimmung des erwarteten Nettoendwertes ist diese Steuerforderung aufzuzinsen: $0,0438 \cdot 1,07=0,047$.

Die Steuer im ausländischen Wohnsitzstaat reduziert den erwarteten Endwert der Anlage im Inland deshalb aufgrund des Ausschlusses von Verlustausgleichsmöglichkeiten auf 0,07$0,047=\underline{0,023}$ gegenüber 0,0315 bei symmetrischer Belastung.

Der Wert wird durch den Ausschluß des Verlustausgleichs hier stärker gemindert als in der Beispielrechnung für das Inland, nämlich um 0,0085. Erwartet wird ein Devisenkurs von 0,973; ein Verlust würde bei einem Kurs von weniger als 0,910 entstehen. 


\section{Beispielrechnung zur Quantifizierung der Abzugmethode als Wahl- recht im Rahmen des Anrechnungsverfahrens bei Unsicherheit über die Wechselkursentwicklung}

\section{Inland}

Unterstellt wird wiederum:

- inländisches Zinsniveau:

- ausländisches Zinsniveau:

$$
\begin{aligned}
r & =0,10 \\
r^{*} & =0,07
\end{aligned}
$$

- Inländischer Steuersatz auf

- ausländische Einkünfte und auf

- Währungsgewinne:

- Ausländischer Quellensteuersatz:

$$
\tau=0,35
$$$$
\mathrm{t}^{*}=0,55
$$

- Standardabweichung des erwarteten Devisenkurses: $\quad \sigma\left[\mathrm{e}_{+1} / \mathrm{e}\right]=0,10$

Der erwartete Devisenkurs ist:

$$
E\left[\frac{e_{+1}}{\mathrm{e}}\right]=\frac{1,1}{1,07}=1,02804
$$

Die Ermittlung des entscheidungsrelevanten erwarteten Endwertes der Abzugmethode entspricht prinzipiell dem Vorgehen der Rechnung im Anhang II für eine einfache Kaufoption. Nur sind hier nicht Kauf-, sondern Verkaufoptionen zugrunde zu legen, da der Staat gerade nur im Fall eines Verlustes beteiligt ist. Ein inländischer Kapitalgeber ist deshalb hier quasi Käufer einer Anzahl von Währungs-Verkaufoptionen.

Hier wird die Wirkung des Rechts auf die Wahl der Abzugmethode isoliert berechnet. In Entsprechung der Gleichung [B20] im Text lautet der erwartete Endwert der Steuer in Abhängigkeit des Wechselkurses $\mathrm{A}\left[\mathrm{e}_{+1} / \mathrm{e}\right]$ :

$$
A\left[\frac{e_{+1}}{e}\right]=\min \left\{\left(\frac{e_{+1}}{e}-1+\frac{e_{+1}}{e} \cdot r^{*} \cdot\left(1-t^{*}\right)\right) \cdot \tau ; 0\right\} .
$$

Bei einem ausländischen Zinsniveau von $r^{*}=0,07$ ist der Ausübungspreis der Optionen

$$
\begin{gathered}
\left(1+\mathrm{r}^{*} \cdot\left(1-\mathrm{t}^{*}\right)\right) \cdot \frac{e_{+1}}{\mathrm{e}}=1 \\
\Leftrightarrow \quad \mathrm{k}=\frac{\mathrm{e}_{+1}}{\mathrm{e}}=(1+0,07 \cdot 0,45)^{-1}=0,969 .
\end{gathered}
$$

Bei diesem Wechselkurs am Periodenende wäre der Gesamtertrag des Auslandsengagements nach Abzug der ausländischen Steuern null. Ist der Devisenkurs höher, ist das Anrechnungsverfahren attraktiver, da es zur Freistellung im Wohnsitzland führt.

Eine einfache Berechnungsformel für eine Währungs-Verkaufoption lautet: ${ }^{2}$

[III 8]

$$
\mathrm{P}=\mathrm{k} \cdot(1+\mathrm{r})^{-\mathrm{t}} \cdot(1-N(\mathrm{x}))-\mathrm{e} \cdot\left(1+\mathrm{r}^{*}\right)^{-\mathrm{t}} \cdot(1-N(\mathrm{x}+\sigma \cdot \sqrt{\mathrm{t}}))
$$

$$
x=\frac{\ln \frac{\mathrm{e}}{\mathrm{k}}+\left(\mathrm{r}-\mathrm{r}^{*}-\frac{\sigma^{2}}{2}\right) \cdot \mathrm{t}}{\sigma \cdot \sqrt{\mathrm{t}}},
$$

wobei $N($.$) , wie gesagt, die kumulative Normalverteilung des Wertes in den Klammern$ ausdrückt.

2 Vgl. M.B. Garman u. S.W. Kohlhagen, Foreign Currency Option Values, in: Journal of International Money and Finance, 2.Jg. (1983), S.234; J. Kloy u. J. Welcker, Drei Arten von Währungsoptionen, in: Die Bank, o.Jg. (1986), S.298f.. 
Das Einsetzen der Werte ergibt den Preis für eine Verkaufoption:

$$
\begin{gathered}
\mathrm{x}=\frac{\ln \frac{1}{0,969}+\left(0,1-0,07-\frac{0,1^{2}}{2}\right)}{0,1}=0,560 ; \\
\mathrm{P}=0,969 \cdot 1,1^{-1} \cdot(1-0,7123)-1 \cdot 1,07^{-1} \cdot(1-0,7454)=0,0156 .
\end{gathered}
$$

Die Anzahl der Optionen entspricht hier

$$
\tau \cdot\left(1+\mathrm{r}^{*} \cdot\left(1-\mathrm{t}^{*}\right)\right)=0,35 \cdot 1,0315=0,361
$$

denn die ausländische Steuer wird hier nicht von der inländischen Steuer, sondern von der Bemessungsgrundlage abgezogen. Der Wechselkurs beeinflußt infolgedessen die Einkünfte und die Abgabe in gleicher Weise: Der sichere ausländische Endwert beträgt 1,0315 der Währung des Auslands. Ein Rückgang des Devisenkurses um eine Einheit bewirkt einen Rückgang des Gewinns in inländischer Währung um 1,0315 Einheiten.

Der Staat ist daran im Falle eines Verlustes mit seinem Steuersatz $\tau=0,35$ beteiligt.

Der Barwert des Rechts der Wahl der Abzugmethode- der Position in Währungs-Verkaufoptionen des Kapitalgebers - beläuft sich demnach auf 0,0156 0,361 =0,00564.

Zur Bestimmung der Wirkung auf den erwarteten Nettoendwert ist dieser Betrag mit dem inländischen risikofreien Zinssatz aufzuzinsen: $0,00564 \cdot 1,1=\underline{0,00621}$.

\section{Ausland}

Unterstellt werden:

- Steuersatz auf

- ausländische Einkünfte und auf

- Währungsgewinne im Ausland:

- Quellensteuersatz:

- Standardabweichung des erwarteten Devisenkurses: $\quad \sigma\left[\mathrm{e} / \mathrm{e}_{+1}\right]=0,10$

Der erwartete Devisenkurs aus der Sicht des Auslands ist:

$$
E\left[\frac{\mathrm{e}}{e_{+1}}\right]=\frac{1,07}{1,1}=0,9727
$$

Analog zur Rechnung für das Inland ist der Ausübungspreis der Position in WährungsVerkaufoptionen durch das Recht auf die Wahl der Abzugmethode hier:

[III6"]

$$
\begin{aligned}
& (1+\mathrm{r} \cdot(1-\mathrm{t})) \cdot \frac{\mathrm{e}}{e_{+1}} \stackrel{!}{=} 1 \\
& \Leftrightarrow \quad \mathbf{k}^{*}=\frac{e}{e_{+1}}=(1+0,1 \cdot 0,65)^{-1}=0,939 .
\end{aligned}
$$

Der Preis einer Verkaufoption beträgt

[III7"]

$$
\mathrm{P}^{*}=\mathrm{k}^{*} \cdot\left(1+\mathrm{r}^{*}\right)^{-\mathrm{t}} \cdot(1-N(\mathrm{x}))-\mathrm{e}^{-1} \cdot(1+\mathrm{r})^{-\mathrm{t}} \cdot(1-N(\mathrm{x}+\sigma \cdot \sqrt{\mathrm{t}}))
$$

$$
x=\frac{\ln \frac{e^{-1}}{k^{*}}+\left(r^{*}-r-\frac{\sigma^{2}}{2}\right) \cdot t}{\sigma \cdot \sqrt{t}} .
$$

Für die Werte des Beispiels errechnet sich daraus

$$
\begin{gathered}
x=\frac{\ln \frac{1}{0,939}+\left(0,07-0,1-\frac{0,1^{2}}{2}\right)}{0,1}=0,280 ; \\
P^{*}=0,939 \cdot 1,07^{-1} \cdot(1-0,6102)-1 \cdot 1,1^{-1} \cdot(1-0,6479)=0,022 .
\end{gathered}
$$


Die Anzahl der Optionen entspricht

$$
\text { [III") }
$$

$$
\tau^{*} \cdot(1+\mathrm{r} \cdot(1-\mathrm{t}))=0,55 \cdot 1,0455=0,575 \text {. }
$$

Der sichere ausländische Endwert beträgt hier 1,0455 der Währung des Quellenlandes. Ein Rückgang des Wechselkurses um eine Einheit bewirkt einen Rückgang des Ertrags in der Währung des Wohnsitzlandes um 1,0455 Einheiten. Der Staat ist daran im Falle eines Verlustes mit seinem Steuersatz $\tau^{*}=0,55$ beteiligt.

Der Barwert des Rechts auf die Wahl der Abzugmethode- der Position in Währungs-Verkaufoptionen des Kapitalgebers - beträgt somit 0,022 $0,575=0,0127$.

Zur Bestimmung der Wirkung auf den erwarteten Nettoendwert ist dieser Betrag mit dem inländischen risikofreien Zinssatz aufzuzinsen: $0,0127 \cdot 1,07=\underline{0,0136}$. 


\section{Freistellung und Anrechnung in deutschen Doppelbesteuerungsabkommen}

Abb. 1: Freistellung und Anrechnung in deutschen Doppelbesteuerungsabkommen

\begin{tabular}{|c|c|c|}
\hline Land & D & V \\
\hline Ägypten & $x$ & $x$ \\
\hline Argentinien & $\bullet$ & $x$ \\
\hline Australien & $x$ & $\bullet$ \\
\hline Bangladesch & $x$ & $x$ \\
\hline Belgien & $x$ & $x$ \\
\hline Bolivien & $\bullet$ & $x$ \\
\hline Brasilien & $\bullet$ & $\bullet$ \\
\hline Bulgarien & $x$ & $x$ \\
\hline China & $x$ & $\bullet$ \\
\hline Costa Rica & $x$ & $x$ \\
\hline Dänemark & $x$ & $\bullet$ \\
\hline Equador & $\bullet$ & $\bullet$ \\
\hline Elfenbeinküste & $x$ & $x$ \\
\hline Finnland & $x$ & $\bullet$ \\
\hline Frankreich & $x$ & $x^{*}$ \\
\hline Griechenland & $x$ & $\bullet$ \\
\hline Großbritannien & $x$ & $\bullet$ \\
\hline Indien & $x$ & $\bullet$ \\
\hline Indonesien & $x$ & $\bullet$ \\
\hline Iran & $x$ & $\bullet$ \\
\hline Irland & $x$ & $\bullet$ \\
\hline Island & $x$ & $x$ \\
\hline Israel & $x$ & $\bullet$ \\
\hline Italien & $x$ & $\bullet$ \\
\hline Jamaika & $x$ & $\bullet$ \\
\hline Japan & $x$ & $\bullet$ \\
\hline
\end{tabular}

\begin{tabular}{|c|c|c|c|c|c|}
\hline Land & D & V & Land & $\mathrm{D}$ & V \\
\hline Jugoslavien & $x$ & $x$ & Schweiz & $\bullet$ & $x$ \\
\hline Kanada & $x$ & $\bullet$ & Simbabwe & $x$ & $\bullet$ \\
\hline Kenia & $x$ & $\bullet$ & Polen & $x$ & $x$ \\
\hline Korea & $x$ & $\bullet$ & Portugal & $x$ & $\bullet$ \\
\hline Kuwait & $x$ & & Rumänien & $x$ & $\bullet$ \\
\hline Liberia & $x$ & $x$ & Sambia & $x$ & $\bullet$ \\
\hline Luxemburg & $x$ & $x$ & Schweden & $x$ & - \\
\hline Malaysia & $x$ & $\bullet$ & Schweiz & $\bullet$ & $x$ \\
\hline Malta & $x$ & $\bullet$ & Simbabwe & $x$ & $\bullet$ \\
\hline Marokko & $x$ & $x$ & Singapur & $x$ & - \\
\hline Mauritius & $x$ & $x$ & Spanien & $x$ & \\
\hline Mexiko & $x$ & $\bullet$ & Sri Lanka & $x$ & $x$ \\
\hline Mongolei & $x$ & $\bullet$ & Südafrika & $x$ & $x / 0$ \\
\hline Namibia & $x$ & $x / 0$ & Thailand & $x$ & $x$ \\
\hline Neuseeland & $x$ & $\bullet$ & Trinidad und Tobago & $x$ & - \\
\hline Niederlande & $x$ & $x^{*}$ & Tschechoslowakei & $x$ & $x$ \\
\hline Norwegen & $x$ & $x$ & Türkei & $x$ & $x$ \\
\hline Östereich & $x$ & $x$ & Tunesien & $x$ & $\bullet$ \\
\hline Pakistan & $x$ & $\bullet$ & Ukraine & $x$ & $\bullet$ \\
\hline Papua-Neuguinea & $x$ & $\bullet$ & Ungarn & $x$ & $x$ \\
\hline Philippinen & $x$ & $\bullet$ & Uruguay & $\bullet$ & $\bullet$ \\
\hline Polen & $x$ & $x$ & USA & $x$ & - \\
\hline Portugal & $x$ & $\bullet$ & USSR & $x$ & \\
\hline Rumänien & $x$ & $\bullet$ & Venezuela & $x$ & $x$ \\
\hline Sambia & $x$ & $\bullet$ & Ver. Arab. Emirate & $x$ & \\
\hline Schweden & $x$ & $\bullet$ & Zypern & $x$ & $\bullet$ \\
\hline \multicolumn{3}{|c|}{$x^{*}$ modifizierte Freistellung ${ }^{l}$} & - Anrechnung & & \\
\hline
\end{tabular}

${ }^{1}$ Die Freistellung wird in fast keinem Fall für Dividenden gewährt, für die nicht das Schachtelprivileg gilt, und überwiegend nicht für Zinsen.

Quelle: K. Vogel, Doppelbesteuerungsabkommen der Bundesrepublik Deutschland auf dem Gebiet der Steuern vom Einkommen und Vermögen: Kommentar auf der Grundlage der Musterabkommen, 3.Aufl., München 1996, S.1428-1461. 


\section{Quellensteuersätze auf Zinsen und Dividenden für Kapitalanbieter aus den USA oder aus Deutschland}

Abb. 2: Quellensteuern auf Zinsen und Dividenden in Prozent in 1995

\begin{tabular}{|l||c|c||c|c|}
\hline \multicolumn{1}{|c||}{ Wohnsitzland: } & \multicolumn{2}{c||}{ USA } & \multicolumn{2}{c|}{ Deutschland } \\
\cline { 2 - 5 } Quellenland: & Zinsen & Dividenden & Zinsen & Dividenden $^{1}$ \\
\hline \hline Australien & 10 & 15 & 10 & 15 \\
Belgien & $0 / 10$ & $5 / 15$ & $0 / 10$ & $0 / 15$ \\
Dänemark & 0 & $5 / 15$ & 0 & $10 / 15$ \\
Deutschland & 0 & $5 / 15$ & $\bullet$ & 0 \\
Frankreich & 0 & $5 / 15$ & 0 & 0 \\
Großbritannien & 0 & 0 & 0 & 0 \\
Irland & 0 & 0 & 0 & $10 / 15$ \\
Italien & 15 & $5 / 10 / 15$ & $0 / 10$ & $10 / 15$ \\
Japan & 10 & $10 / 15$ & 10 & 15 \\
Kanada & 10 & $6 / 15$ & $0 / 15$ & $10 / 15$ \\
Luxemburg & 0 & $5 / 7,5$ & 0 & 0 \\
Malaysia & 0 & 0 & $0 / 15$ & $0 / 10 / 15$ \\
Niederlande & 10 & $5 / 15$ & 0 & $5 / 15$ \\
Schweden & 0 & $5 / 15$ & 0 & $5 / 15$ \\
Schweiz & 5 & $5 / 15$ & 0 & $10 / 15$ \\
Spanien & 10 & $10 / 15$ & 10 & $10 / 15$ \\
USA & $\bullet$ & $\bullet$ & 0 & \\
\hline
\end{tabular}

${ }^{1}$ Bei zwei Zahlen gilt die erste bei Schachtelbeteiligungen und die zweite bei Streubesitz.

Quelle: $\quad$ G. J. Yost, III, 1996 International Tax Summaries, New York u.a. 1996. 


\section{Internal Revenue Code-Subtitle A Ch. 1N, Part III Subpart J-Foreign Currency Transactions}

[Sec. 985]

\section{SEC. 985. FUNCTIONAL CURRENCY.}

[Sec. 985(a)]

(a) IN GENERAL.-Unless otherwise provided in regulations, all determinations under this subtitle shall be made in the taxpayer's functional currency.

[Sec. 985(b)]

(b) FUnCTIONAL CURRENCY.-

(1) IN GENERAL.-For purposes of this subtitle, the term "functional currency“ means-

(A)except as provided in subparagraph (B), the dollar, or

(B) in the case of a qualified business unit, the currency of the economic environment in which a significant part of such unit's activities are conducted and which is used by such unit in keeping its books and records.

(2) FUNCTIONAL CURRENCY WHERE ACTIVITIES PRIMARILY CONDUCTED IN DOLLARS. - The functional currency of any qualified business unit shall be the dollar if activities of such unit are primarily conducted in dollars.

(3) ELECTION.-To the extent provided in regulations, the taxpayer may elect to use the dollar as the functional currency for any qualified business unit if-

(A) such unit keeps its books and records in dollars, or

(B) the taxpayer uses a method of accounting that approximates a separate transactions method.

Any such election shall apply to the taxable year for which made and all subsequent taxable years unless revoked with the consent of the Secretary.

(4) CHANGE IN FUNCTIONAL CURRENCY TREATED AS A CHANGE IN METHOD OF ACCOUNTING.-Any change in the functional currency shall be treated as a change in the taxpayer's method of accounting for purposes of section 481 under procedures to be established by the Secretary.

[Sec. 986]

\section{SEC. 986. DETERMINATION OF FOREIGN TAXES AND FOREIGN CORPORATION'S EARNINGS AND PROFITS.}

[Sec. 986(a)]

(a) FOREIGN TAXES.-

(1) IN GENERAL.-For Purposes of determining the amount of foreign tax credit-

(A) any foreign income taxes shall be translated into dollars using the exchange rates as of the time such taxes were paid to the foreign country or possession of the United States, and

(B) any adjustment to the amount of foreign income taxes shall be translated into dollars using-

(i) except as provided in clause (ii), the exchange rate as of the time when such adjustment is paid to the foreign country or possession, or 
(ii) in the case of any refund or credit of foreign income taxes, using the exchange rate as of the time of original payment of such foreign income taxes.

(2) FOREIGN INCOME TAXES.-For purposes of paragraph (1), „foreign income taxes“ means any income, war profits, or excess profits taxes paid to any foreign country or to any possession of the United States.

[Sec. 986(b)]

(b) EARNINGS AND PROFITS AND DISTRIBUTIONS-For purposes of determining the tax under this subtitle-

(1) of any shareholder of any foreign corporation, the earnings and profits of such corporation shall be determined in the corporation's functional currency, and

(2) in the case of any United States person, the earnings and profits determined under paragraph (1) (when distributed, deemed distributed, or otherwise taken into account under this subtitle) shall (if necessary) be translated into dollars using the appropriate exchange rate.

[Sec. 986(c)]

(c) Previously TaXed Earnings and Profits-

(1) IN GENERAL.-Foreign currency gain of loss with respect to distributions of previously taxed earnings and profits (as described in section 959 of 1293(c)) attributable to movements in exchange rates between the times of deemed and actual distribution shall be recognized and treated as ordinary income of loss from the dame source as the associated income inclusion.

(2) DistRIBUTIONS THROUGH TIERS.-The Secretary shall prescribe regulations with respect to the treatment of distributions of previously taxed earnings and profits through tiers of foreign corporations.

Ergänzt und verändert durch den Taxpayer Relief Act 1997 (Public Law 105-32) wie folgt:

SEC. 1102. EXCHANGE RATE USED IN TRANSLATING FOREIGN TAXES.

(a) ACCRUED TAXES TRANSLATED BY USING AVERAGE RATE FOR YEAR TO WHICH TAXES RELATE-

(1) IN GENERAL.-Subsection (a) of section 986 (relating to translation of foreign taxes) is amended to read as follows:

'(a) FOREIGN INCOME TAXES.--

'(1) TRANSLATION OF ACCRUED TAXES.-

'(A) IN GENERAL.- - For purposes of determining the amount of the foreign tax credit, in the case of a taxpayer who takes foreign income taxes into account when accrued, the amount of any foreign income taxes (and any adjustment thereto) shall be translated into dollars by using the average exchange rate for the taxable year to which such taxes relate.

'B) EXCEPTION FOR CERTAIN TAXES.-Subparagraph (A) shall not apply to any foreign income taxes-

'(i) paid after the date 2 years after the close of the taxable year to which such taxes relate, or

'(ii) paid before the beginning of the taxable year to which such taxes relate.

'(C) EXCEPTION FOR INFLATIONARY CURRENCIES.-Subparagraph (A) shall not apply to any foreign income taxes the liability for which is denominated in any inflationary currency (as determined under regulations).

'(D) CROSS REVERENCE.-CROSS REFERENCE

'For adjustments where tax is not paid within 2 years, see section 905 (c).

'(2) TRANSLATION OF TAXES To WhICH PARAGRAPH (1) DOES NOT APPLY.-For purposes of determining the amount of the foreign tax credit, in the case of any foreign income taxes to which subparagraph (A) of paragraph (1) does not apply-

(A) such taxes shall be translated into dollars using the exchange rates as of the time such taxes were paid to the foreign country or possession of the United States, and

'(B) any adjustment to the amount of such taxes shall be translated into dollars using-

'(i) except as provided in clause (ii), the exchange rate as of the time when such adjustment is paid to the foreign country or possession, or 
'(ii) in the case of any refund or credit of foreign income taxes, using the exchange rate as of the time of the original payment of such foreign income taxes.

'(3) FOREIGN INCOME TAXES.-For purposes of this subsection, the term 'foreign income taxes' means any income, war profits, or excess profits taxes paid or accrued to any foreign country or to any $[\ldots]$. possession of the United States.'.

(b) AUTHORITY TO USE AVERAGE RATES.-

(1) IN GENERAL.- -Subsection (a) of section 986 (as amended by subsection (a)) is amended by redesignating paragraph (3) as paragraph (4) and inserting after paragraph (2) the following new paragraph:

'(3) AUTHORITY TO PERMIT USE OF AVERAGE RATES.-To the extent prescribed in regulations, the average exchange rate for the period (specified in such regulations) during which the taxes or adjustment [...]. is paid may be used instead of the exchange rate as of the time of such payment.'.

(c) EFFECTIVE DATES.-

(1) IN GENERAL. - The amendments made by subsections (a)(1) and (b) shall apply to taxes paid or accrued in taxable years beginning after December 31, 1997.

(2) SUBSECTION (a)(2).-The amendment made by subsection (a)(2) shall apply to taxes which relate to taxable years beginning after December 31, 1997.

[Sec. 987]

\title{
SEC. 987. BRANCH TRANSACTIONS.
}

In the case of any taxpayer having 1 or more qualified business units with a functional currency other than the dollar, taxable income of such taxpayer shall be determined-

(1) by computing the taxable income or loss separately for each such unit in its functional currency,

(2) by translating the income of loss separately computed under paragraph (1) at the appropriate exchange rate, and

(3) by making proper adjustments (as prescribed by the Secretary) for transfers of property between qualified business units of the taxpayer having different functional currencies, including -

(A) treating post-1986 remittances from each such unit as made on a pro rata basis out of post-1986 accumulated earnings, and

(B) treating gain or loss determined under this paragraph as ordinary income or loss respectively, and sourcing such gain or loss by reference to the source of the income giving rise to post-1986 accumulated earnings.

[Sec. 988]

\section{SEC. 988. TREATMENT OF CERTAIN FOREIGN CURRENCY TRANSACTIONS.}

\author{
[Sec. 988(a)]
}

(a) GENERAL RULE-Notwithstanding any other provisions of this chapter-

(1) TREATMENT AS ORDINARY INCOME OR LOSS.-

(A) IN GENERAL.-Except as otherwise provided in this section, any foreign currency gain or loss attributable to a section 988 transaction shall be computed separately and treated as ordinary income or loss (as the case may be).

(B) SPECIAL RULE FOR FORWARD CONTRACTS, ETC.-Except as provided in regulations, a taxpayer may elect to treat any foreign currency gain of loss attributable to a forward contract, a futures contract, or option described in subsection (c)(1)(B)(iii) which is a capital asset in the hands of the taxpayer and which is not a part of a straddle (within the meaning of section 1092(c), without regard to paragraph (4) thereof) as capital gain or loss (as the case may be) if the taxpayer makes such election and 
identifies such transaction before the close of the day on which such transaction is entered into (or such earlier time as the Secretary may prescribe).

(2) GAIN OR LOSS TREATED AS INTEREST FOR CERTAIN PURPOSES.-To the extent provided in regulations, any amount treated as ordinary income or loss under paragraph (1) shall be treated as interest income or expense (as the case may be).

(3) SOURCE.-

(A) IN GENERAL.-Except as otherwise provided in regulations, in the case of any amount treated as ordinary income or loss under paragraph (1) (without regard to paragraph (1)(B)), the source of such amount shall be determined by reference to the residence of the taxpayer or the qualified business unit of the taxpayer on whose books the asset, liability, or item of income or expense is properly reflected.

(B) RESIDENCE.-For purposes of this subpart-

(i) IN GENERAL.-The residence of any person shall be-

(I) in the case of an individual, the country in which such individual's tax home (as defined in section 911(d)(3)) is located,

(II) in the case of any corporation, partnership, trust, or estate which is a

United States person (as defined in section 7701(a)(30)), the United States, and

(III) in the case of any corporation, partnership, trust, or estate which is not a

United States person, a country other than the United States.

If an individual does not have a tax home (as so defined), the residence of such individual shall be the United States if such individual is a United States citizen or a resident alien and shall be the country in which the principal place of business of such qualified business unit is located.

(ii) EXCEPTION.- In the case of a qualified business unit of any taxpayer (including an individual), the residence of such unit shall be the country in which the principal place of business of such qualified business unit is located.

(iii) SPECIAL RULE FOR PARTNERSHIPS.-To the extent provided in regulations, in the case of a partnership, the determination of residence shall be made at the partner level.

(C) SPECIAL RULE FOR CERTAIN RELATED PARTY LOANS.-Except to the extent provided in regulations, in the case of a loan by a United States person or a related person to a 10-percent owned foreign corporation which is denominated in a currency other than the dollar and bears interest at a rate at least 10 percentage points higher than the Federal mid-term rate (determined under section 1274(d)) at the time such loan is entered into, the following rules shall apply:

(i) For purposes of section 904 only, such loan shall be marked toe market on an annual basis.

(ii) Any interest income earned with respect to such loan for the taxable year shall be treated as income from sources within the United States to the extent of any loss attributable to clause (i).

For purposes of this subparagraph, the term ,related person“ has the meaning given such term by section 954(d)(3), except that such section shall be applied by substituting "United States person" for „controlled foreign corporation" each place such term appears.

(D) 10-PERCENT OWNED FOREIGN CORPORATION.-The term „10-percent owned foreign corporation" means any foreign corporation in which the United States person owns directly or indirectly at least 10 percent of the voting stock.

[Sec. 988(b)]

(b) FOREIGN CURRENCY GAIN OR LOSS-For purposes of this section-

(1) FOREIGN CURRENCY GAIN.-The term „foreign currency gain“ means any gain from a section 988 transaction to the extent such gain does not exceed the gain realized by 
reason of changes in exchange rates on or after the booking date and before the payment date.

(2) FOREIGN CURRENCY LOSS.-The term „foreign currency loss“ means any loss from a section 988 transaction to the extent such loss does not exceed the loss realized by reason of changes in exchange rates on or after the booking date and before the payment date.

(3) SPECIAL RULE FOR CERTAIN CONTRACTS, ETC.-In the case of any section 988 transaction described in subsection (c)(1)(B)(iii), any gain or loss from such transaction shall be treated as foreign currency gain or loss (as the case may be).

\section{[Sec. 988(c)]}

(c) OTHER DEFINITIONS-For purposes of this section-

(1) SECTION 988 TRANSACTION.-

(A) IN GENERAL.- The term „section 988 transaction“ means any transaction described in subparagraph (B) if the amount which the taxpayer is entitled to receive (or is required to pay) by reason of such transaction-

(i) is denominated in terms of a nonfunctional currency, or

(ii) is determined by reference to the value of 1 or more nonfunctional currencies.

(B) DESCRIPTION OF TRANSACTIONS.-For purposes of subparagraph (A), the following transactions are described in this subparagraph:

(i) The acquisition of a debt instrument or becoming the obligor under a debt instrument.

(ii) Accruing (or otherwise taking into account) for purposes of this subtitle any item of expense or gross income or receipts which is to be paid or received after the date on which so accrued or taken into account.

(iii) Entering into or acquiring any forward contract, futures contract, option, or similar financial instrument.

The Secretary may prescribe regulations excluding from the application of clause (ii) any class of items the taking into account of which is not necessary to carry out the purposes of this section by reason of the small amounts or short periods involved, or otherwise.

(C) SPECIAL RULES FOR DISPOSITION OF NONFUNCTIONAL CURRENCY.-

(i) IN GENERAL.- - In the case of any disposition of any nonfunctional currency-

(I) such disposition shall be treated as a section 988 transaction, and

(II) any gain or loss from such transaction shall be treated as foreign currency gain or loss (as the case may be).

(ii) NONFUNCTIONAL CURRENCY.-For purposes of this section, the term „nonfunctional currency“ includes coin or currency, and nonfunctional currency denominated demand or time deposits or similar instruments issued by a bank or other financial institution.

(D) EXCEPTION FOR CERTAIN INSTRUMENTS MARKED TO MARKET.-

(i) IN GENERAL.-Clause (iii) of subparagraph (B) shall not apply to any regulated futures contract or nonequity option which would be marked to market under section 1256 if held on the last day of the taxable year.-

(ii) ELECTION OUT.-

(I) IN GENERAL.- The taxpayer may elect to have clause (i) not apply to such taxpayer. Such an election shall apply to contracts held at any time during the taxable year for which such election is made or any succeeding taxable year unless such election is revoked with the consent of the Secretary.

(II) TIME FOR MAKING ELECTION.-Except as provided in regulations, an election under subclause (I) for any taxable year shall be made on or before the 
1st day of such taxable year (or, if later, on or before the 1st day during such year on which the taxpayer holds a contract described in clause (i)).

(III) SPECIAL RULE FOR PARTNERSHIPS, ETC.--In the case of a partnership, an election under subclause (I) shall be made by each partner separately. A similar rule shall apply in the case of an S corporation.

(iii) TREATMENT OF CERTAIN PARTNERSHIPS.-This subparagraph shall not apply to any income or loss of a partnership for any taxable year if such partnership made an election under subparagraph $(E)(i i i)(V)$ for such year or any preceding year.

(E) SPECIAL RULES FOR CERTAIN FUNDS.-

(i) IN GENERAL.- In the case of a qualified fund, clause (iii) of subparagraph (B) shall not apply to any instrument which would be marked to market under section 1256 if held on the last day of the taxable year (determined after the application of clause (iv)).

(ii) SPECIAL RULE WHERE ELECTING PARTNERSHIP DOES NOT QUALIFY.-If any partnership made an election under clause (iii)(V) for any taxable year and such partnership has a net loss for such year of any succeeding year from instruments referred to in clause (i), the rules of clauses (i) and (iv) shall apply to any such loss year whether or not such partnership is a qualified fund for such year.

(iii) QUALIFIED FUND DEFINED.-For purpose of this subparagraph, the term "qualified fund" means any partnership if -

(I) at all times during the taxable year (and during each preceding taxable year to which an election under subclause (V) applied), such partnership has at least 20 partners and no single partner owns more than 20 percent of the interests in the capital or profits of the partnership,

(II) the principal activity of such partnership for such taxable year (and each such preceding taxable year)consists of buying and selling options, futures, or forwards with respect to commodities,

(III) at least 90 percent of the gross income of the partnership for the taxable year (and for each such preceding taxable year) consisted of income or gains describes in subparagraph, (A), (B), or (G) of section 7704(d)(1) of gain form the sale or disposition of capital assets held for the production of interest or dividends,

(IV) no more than a de minimis amount of the gross income of the partnership for the taxable year (and each such preceding taxable year) was derived from buying and selling commodities, and

(V) an election under this subclause applies to the taxable year.

An election under subclause (V) for any taxable year shall be made on or before the 1st day of such taxable year (or, if later, on or before the 1st day during such year on which the partnership holds an instrument referred to in clause (i)). Any such election shall apply to the taxable year for which made and all succeeding taxable years unless revoked with the consent of the Secretary.

(iv) TREATMENT OF CERTAIN CURRENCY CONTRACTS.--

(I) IN GENERAL.-Except as provided in regulations, in the case of a qualified fund, any bank forward contract, and foreign currency futures contract traded on a foreign exchange, of to the extent provided in regulations any similar instrument, which is not otherwise a section 1256 contract shall be treated as a section 1256 contract for purposes of section 1256 .

(II) GAINS AND LOSSES TREATED AS SHORT-TERM.-In the case of any instrument treated as a section 1256 contract under subclause (I), subparagraph (A) of section 1256(a)(3) shall be applied by substituting "100 percent" for "40 percent" (and subparagraph (B) of such section shall not apply).

(v) SPECIAL RULES FOR CLAUSE (iii)(I).-

(I) CERTAIN GENERAL PARTNERS.- - The interest of a general partner in the partnership shall not be treated as failing to meet the 20-percent ownership requirements of clause (iii)(I) for any taxable year of the partner in which such partnership taxable year ends, such partner (and each corporation filing a 
consolidated return with such partner) had no ordinary income or loss from a section 988 transaction which is foreign currency gain or loss (as the case may be).

(II) TREATMENT OF INCENTIVE COMPENSATION.-For purpose of clause (iii)(I), any income allocable to a general partner as incentive compensation based on profits rather than capital shall not be taken into account in determining such partner's interest in the profits of the partnership.

(III) TREATMENT OF TAX-EXEMPT PARTNERS.-Except as provided in regulations, the interest of a partner in the partnership shall not be treated as failing to meet the 20-percent ownership requirements of clause (iii)(I) if none of the income of such partner from such partnership is subject to tax under this chapter (whether directly or through 1 or more pass-thru entities).

(IV) LOOK-THRU RULE.-In determining whether the requirements of clause (iii)(I) are met with respect to any partnership, except to the extent provided in regulations, any interest in such partnership held by another partnership shall be treated as held proportionately by the partners in such other partnership.

(vi) OTHER SPECIAL RULES.-For purposes of this subparagraph-

(I) RELATED PERSONS.- - Interest in the partnership held by persons related to each other (within the meaning of sections 267 (b) and 707(b)) shall be treated as held by 1 person.

(II) PREDECESSORS.- - References to any partnership shall include reference to any predecessor thereof.

(III) INADVERTENT TERMINATIONS.-Rules similar to the rules of section 7704(e) shall apply.

(IV) TREATMENT OF CERTAIN DEBT INSTRUMENTS.-For purpose of clause (iii)(IV), any debt instrument which is a section 988 transaction shall be treated as a commodity.

(2) BOOKING DATE.-The term "booking date" means-

(A) in the case of a transaction described in paragraph (1)(B)(i), the date of acquisition of on which the taxpayer becomes the obligor, or

(B) in the case of a transaction described in paragraph (1)(B)(ii), the date on which accrued or otherwise taken into account.

(3) PAYMENT DATE.-The term "payment date" means the date on which the payment is made or received.

(4) DEBT INSTRUMENT.-The term "debt instrument" means a bond, debenture, note, or certificate of other evidence of indebtedness. To the extent provided in regulations, such term shall include preferred stock.

(5) SPECIAL RULES WHERE TAXPAYER TAKES OR MAKES DELIVERY.--If the taxpayer takes or makes delivery in connection with any section 988 transaction described in paragraph (1)(B)(iii), any gain or loss (determined as if the taxpayer sold the contract, option, or instrument on the date on which he took or made delivery for its fair market value on such date) shall be recognized in the same manner as if such contract, option, or instrument were so sold.

[Sec. 988(d)]

\section{(d) TREATMENT OF 988 HEDGING TRANSACTIONS.--}

(1) IN GENERAL.- To the extent provided in regulations, if any section 988 transaction is part of a 988 hedging transaction, all transactions which are part of such 988 hedging transaction shall be integrated and treated as a single transaction or otherwise treated consistently for purposes of this subtitle. For purposes of the preceding sentence, the determination of whether any transaction is a section 988 transaction shall be determined without regard to whether such transaction would otherwise be marked-to-market under section 475 or 1256 and such term shall not include any transaction with respect to which 
an election is made under subsection (a)(1)(B). Sections 475, 1092, and 1256 shall not apply to a transaction covered by this subsection.

(2) 988 HEDGING TRANSACTION.-For purposes of paragraph (1), the term "988 hedging transaction" means any transaction-

(A) entered into by the taxpayer primarily-

(i) to reduce risk of currency fluctuations with respect to property which is held or to be held by the taxpayer, or

(ii) to reduce risk of currency fluctuations with respect to borrowings made or to be made, or obligations incurred or to be incurred, by the taxpayer, and

(B) identified by the Secretary or the taxpayer as being a 988 hedging transaction.

[Sec. 988(e)]

(e) APPLiCATION TO INDIVIDUALS. - This section shall apply to section 988 transactions entered into by an individual only to the extent expenses properly allocable to such transactions meet the requirements of section 162 or 212 (other than that part of section 212 dealing with expenses incurred in connection with taxes).

Ergänzt und verăndert durch den Taxpayer Relief Act 1997 (Public Law 105-32) wie folgt:

SEC. 1104. TREATMENT OF PERSONAL TRANSACTIONS BY INDIVIDUALS UNDER FOREIGN CURRENCY RULES.

(a) GENERAL RULE.-Subsection (e) of section 988 (relating to application to individuals) is amended to read as follows:

'(e) APPLICATION TO INDIVIDUALS.-

'(1) IN GENERAL.- The preceding provisions of this section shall not apply to any section 988 transaction entered into by an individual which is a personal transaction.

'(2) EXCLUSION FOR CERTAIN PERSONAL TRANSACTIONS.--If-

'(A) nonfunctional currency is disposed of by an individual in any transaction, and

'(B) such transaction is a personal transaction, no gain shall be recognized for purposes of this subtitle by reason of changes in exchange rates after such currency was acquired by such individual and before such disposition. The preceding sentence shall not apply if the gain which would otherwise be recognized on the transaction exceeds $\$ 200$.

'(3) PERSONAL TRANSACTIONS.--For purposes of this subsection, the term 'personal transaction' means any transaction entered into by an individual, except that such term shall not include any transaction to the extent that expenses properly allocable to such transaction meet the requirements of--

'(A) section 162 (other than traveling expenses described in subsection (a)(2) thereof), or

'(B) section 212 (other than that part of section 212 dealing with expenses incurred in connection with taxes).'.

(b) EFFECTIVE DATE.-The amendments made by this section shall apply to taxable years beginning after December 31, 1997.

[Sec. 989]

SEC. 989. OTHER DEFINITIONS AND SPECIAL RULES.

[Sec. 989(a)]

(a) QUALIFIED BUSINESS UNIT.-For purposes of this subpart, the term "qualified business unit" means any separate and clearly identified unit of a trade or business of a taxpayer which maintains separate books and records.

[Sec. 989(b)]

(b) APPROPRIATE EXCHANGE RATE.-Except as provided in regulations, for purposes of this subpart, the term "appropriate exchange rate" means-

(1) in the case of an actual distribution of earnings and profits, the spot rate on the date such distribution is included in income, 
(2) in the case of an actual or deemed sale or exchange of stock in a foreign corporation treated as a dividend under section 1248, the spot rate on the date the deemed dividend is included in income,

(3) in the case of any amounts included in income under section 951(a)(1)(A), 551(a), or 1293(a), the weighted averaged exchange rate for the taxable year of the foreign corporation, or

(4) in the case of any other qualified business unit of a taxpayer, the weighted average exchange rate for the taxable year of such qualified business unit.

For purposes of the preceding sentence, any amount included in income under subparagraph (B) or (C) of section 951(a)(1) shall be treated as an actual distribution made on the last day of the taxable year for which such amount was so included.

\section{[Sec. 989(c)]}

(c) REgULATIONS.- The Secretary shall prescribe such regulations as may be necessary or appropriate to carry out the purposes of this subpart, including regulations-

(1) setting forth procedures to be followed by taxpayers with qualified business units using a net worth method of accounting before the enactment of this subpart,

(2) limiting the recognition of foreign currency loss on certain remittances from qualified business units,

(3) providing for the recharacterization of interest and principal payments with respect to obligations denominated in certain hyperinflationary currencies,

(4) providing for alternative adjustments to the application of section 905(c), and

(5) providing for the appropriate treatment of related party transactions (including transactions between qualified business units of the same taxpayer).

Ergänzt und verändert durch den Taxpayer Relief Act 1997 (Public Law 105-32) wie folgt:

SEC. 1102. EXCHANGE RATE USED IN TRANSLATING FOREIGN TAXES.

[...].

(B) AUTHORITY TO USE AVERAGE RATES.-

[...].

(2) DETERMINATION OF AVERAGE RATES.-Subsection (c) of section 989 is amended by striking 'and' at the end of paragraph (4), by striking the period at the end of paragraph (5) and inserting ', and', and by adding at the end thereof the following new paragraph:

'(6) setting forth procedures for determining the average exchange rate for any period.'.

(3) CONFORMING AMENDMENTS.-Subsection (b) of section 989 is amended by striking 'weighted' each place it appears.

(c) EFFECTIVE DATES.-

(1) IN GENERAL. - The amendments made by subsections (a)(1) and (b) shall apply to taxes paid or accrued in taxable years beginning after December 31, 1997.

$[\ldots]$. 


\section{Literaturverzeichnis}

\section{Literaturverzeichnis}

\section{Adler, Hans, Walther DÜRIng UNd Kurt Schmaltz (Hrsg.)}

Rechnungslegung und Prüfung der Unternehmen: Kommentar zum HGB, AktG, GmbHG, PublG nach den Vorschriften des Bilanzrichtlinien-Gesetzes. Teilband 1, 6. neubearb. Aufl., Stuttgart 1995.

\section{ADler, Michael UND Bernard DUMAS}

Should Exposure Management Depend on Translation Accounting Methods?

In: Euromoney, o. Jg. 1981, Heft 6, S. $132-138$.

\section{Alworth, Julian S.}

The Finance, Investment and Taxation Decisions of Multinationals. New York 1988.

\section{american Institute of Certified Public Accountants (AICPA)}

Foreign Exchange Losses. In: The Bulletin of the American Institute of (Certified Public) Accountants, Nr. 92 vom 15. Dezember 1931.

\section{APELT, Michael}

Der abkommensrechtliche Nutzungsberechtigte aus US-Sicht-Neue Quellensteuerrichtlinien des IRS. In: Internationales Steuerrecht, , 6. Jg. (1997), Heft 8, S. 234 - 238.

\section{ARROW, KENNETH J.}

The Theory of Risk Taking. In: Essays in The Theory of Risk Bearing. Hrsg. K. J. Arrow, Amsterdam u.a. 1970, S. 90 - 120.

Arthur ANDersen \& Co. (Hrsg.)

Tax Reform 1986. Analysis and Planning. Chicago 1986.

AtKinson, ANThoNy B. UND Joseph E. STIEglitz

Lectures on Public Economics. London u.a. 1980.

\section{BACHEM, ROLF GEORG}

Das Auszahlungsdisagio in Bilanz und Vermögensaufstellung des Darlehensnehmers.

In: Der Betriebs-Berater, 46. Jg. (1991), Heft 24, S. 1671 - 1678.

BAETGE, JöRG (1986)

Grundsätze ordnungsmäßiger Buchfuihrung.

In: Der Betrieb, 39. Jg. (1986), Beilage 26 zu Heft 45.

BAETGE, JöRG (1995)

Konzernbilanzen. 2. überarb. u. aktualisierte Aufl., Düsseldorf 1995.

\section{BALASSA, BELA}

The Purchasing-Power-Parity Doctrine: A Reappraisal.

In: Journal of Political Economy, 72. Jg. (1964), S. 584 - 596.

BARANOWSKI, KARL-HEINZ

Zur Ermittlung und Umrechnung ausländischer Einkünfte.

In: Der Betrieb, 45. Jg. (1992), Heft 5, S. 240 - 243.

BENNE, JÜRGEN

Einzelbewertung und Bewertungseinheit.

In: Der Betrieb, 44. Jg. (1991), Heft 51/52, S. 2601 - 2610.

BERGSTRAND, JEFFREY $H$.

Structural Determinants of Real Exchange Rates and National Price Levels: Some Empirical Evidence. In: The American Economic Review, 81. Jg. (1991), Heft 1, S. 325 - 334. 


\section{Black, Fischer und MYron Scholes}

The Pricing of Options and Corporate Liabilities.

In: Journal of Political Economy, 81. Jg (1973), S. 637 - 654.

BLÜMICH, WALTER

Einkommensteuergesetz, Körperschaftsteuergesetz, Gewerbesteuergesetz. Kommentar.

Hrsg. Klaus Ebling u. Wolfgang Freericks, 15. Aufl., München 1995, Loseblatt,

Stand: 56. Ergänzungslieferung (Juni 1997).

\section{BOLES, ERNEST}

Gesellschaften im US-Einkommensteuerrecht.

Münchner Schriften zum Internationalen Steuerrecht, Heft 16, München 1993.

\section{BORDEWIN, ARNO}

Das Fremdwährungsdarlehen in der Überschußrechnung.

In: Deutsches Steuerrecht, 30. Jg. (1992), Heft 8, S. 244 - 245.

\section{BÖRNER, DIETRICH}

Bilanzpolitik und Unternehmenserhaltung bei geltendem Steuerrecht. In: Die Unternehmung in ihrer gesellschaftlichen Umwelt. Hrsg. Peter Mertens, Wiesbaden 1975, S. 225 - 280.

BREALEy, RichaRd A. UND STEWART C. MYerS

Principles of Corporate Finance. 4. Aufl., International Edition 1991.

BREEDEN, Douglas T.

An Intertemporal Asset Pricing Model with Stochastic Consumption and Investment

Opportunities. In: The Journal of Financial Economics, 7. Jg. (1979), S. 265 - 296.

BRINER, ERNST K.

Änderungen im amerikanischen Steuerrecht. In: Steuer Revue, 43. Jg. (1988), Heft 1, S. 17 - 36.

BROENEN, DARVIN, C. u. a.

Foreign Corporation Earnings and Profits. Tax Management Portfolio Nr. 932.

Washington, D.C. 1990.

\section{BUCKLEY, ADRIAN}

Multinational Finance. Oxford 1986.

BüSCHGEN, HANS E. (1986)

Finanzinnovationen - Neuerungen und Entwicklungen an nationalen und internationalen Finanzmärkten.

In: Zeitschrift für Betriebswirtschaftslehre, 56. Jg. (1986), Heft 4/5, S. 299 - 336.

BüsCHGEN, HANS E. (1993)

Internationales Finanzmanagement. 2. Überarb. Aufl., Frankfurt am Main 1993.

\section{CALMeS, JACKIE}

Tax Cuts Aplenty Are to Be Pledged In GOP's Manifesto.

In: The Wall Street Journal vom 22.09.1994.

CathCart, Alan W.

Hyperinflation Holiday To End. In: Tax Notes International, 9. Jg. (1994), Heft 5, S. 303 - 304.

Chown, JoHn F.

Tax Efficient Foreign Exchange Management. New York u. a. 1990.

COENENBERG, AdOLF G.

Jahresabschluß und Jahresabschlußanalyse: Betriebswirtschaftliche, handels- und steuerrechtliche Grundlagen. 14., überarb. Aufl., Landsberg/Lech 1993.

CONNOR, JOSEPH E.

Accounting for the Upward Float in Foreign Currencies.

In: The Journal of Accountancy, 133. Jg. (1972), Heft 6, S. 39 - 44. 
CONStaNtinides, George M.

Capital Market Equilibrium with Personal Taxes.

In: Econometrica, 51. Jg. (1983), Heft 3, S. 611 - 636.

CoOper, Michael J.

Proposed Tax Reform Act of 1985 Changes Rules for Taxing Exchange Gains or Losses.

In: Tax Management International Journal, 15. Jg. (1986), S. 57 - 59.

Cooper, Michael, Alan Shapiro u.a.

Tax Payer Relief Act of 1997 Introduces Changes to International Tax Provisions.

In: Tax Notes International, 15. Jg. (1997), Heft 6, S. 413.

Cope, Charles W. und Robert A. Katcher

Final DASTM Regulations: An Aid to Business Operating in Hyperinflationary Countries.

In: Tax Notes, 64. Jg. (1994), S. 1357 - 1363.

Copeland, Thomas E. und J. Fred Weston

Financial Theory and Corporate Policy. 3. Aufl. Reading, Mass. u. a. 1988.

Corey, William S., Leonard B. Terr, Dennis l. Allen, Clifford E. Muller

UND G. GARNER PRILAMAN, JR.

Tax Treatment of Foreign Currency Under $\S \S 985$ - 989. In: The Tax Management

International Journal, 16. Jg. (1987), S. 375 - 99 (Teil I) und S. 127 - 146 (Teil II).

Costello, JoHN J.

Tax Impact of Currency Exchange Rate Fluctuations.

In: Tax Lawyer, 26. Jg. (1973), S. 399 - 434.

COX, JoHn C. UND MARK RUBINSTEIN

Option Markets. Englewood Cliffs, NJ. 1985.

Cumby, Robert E. und MAURice ObSTFEld

A Note on Exchange-Rate Expectations and Nominal Interest Differentials: A Test of the

Fisher Hypothesis. In: Journal of Finance, 36. Jg. (1981), Heft 3, S. 697 - 703.

CYR, CoNRad K.

Gain On Sale Of Foreign Residence Not Reduced By 'Exchange-Rate' Gain.

In: Tax Analysts, Document Number: Doc 96-23603, 1996.

Debatin, Helmut (1983)

Probleme der internationalen Doppelbesteuerung. In: Handbuch der Finanzwissenschaft

Band IV. Hrsg. Frank Neumark, 3. gänzlich neubearb. Aufl., Tübingen 1983.

Debatin, Helmut (1987)

Reagans Steuerreform: Ein Experiment - kein Vorbild.

In: Frankfurter Allgemeine Zeitung vom 28.2.1987.

Debatin, Helmut (1989)

Das Betriebsstättenprinzip der deutschen Doppelbesteuerungsabkommen. In: Der Betrieb, 42. Jg. (1989), Heft 34, S. 1692 - 1697 (Teil I) und Heft 35, S. 1739 - 1744 (Teil II).

Debatin, Helmut (1992)

StÄndG 1992 und „Treaty Override“. In: Der Betrieb, 45. Jg. (1992), Heft 43, S. 2159 -2163.

DELOITTE \& TOUCHE LLP (HRSG.)

Promises Kept: The 1997 Tax Act, A Tax News \& Views Special Report. 1997.

Internet: http://www.dtonline.com/promises/cover.htm. Ausdruck vom 7.9.1997.

DEUTSCHE BUNDESBANK

Finanzmarktvolatilität und ihre Auswirkungen auf die Geldpolitik.

In: Monatsbericht, April 1996, S. 53 - 70.

DICHTEL, ERWIN UND OTMAR Issing (Hrsg.)

Vahlens großes Wirtschaftslexikon, Band I (A - K). München 1987. 
Dilworth, Robert H., Joseph L. ANDRus und L. G. HARTer

U.S. Tax Treatment of Financial Transactions Involving Foreign Currency.

In: Taxes, 66. Jg. (1988), S. 1019 - 1061,

DIONNE, MARYLOUISE UND STEPHEN ORME

Foreign Currency Transactions Under the Section 988 Regulations.

In: Taxes, 70. Jg. (1992), S. 532 - 550.

Dixit, Avinash K. UND Robert S. PINDYCK

The Options Approach to Capital Investment.

In: Harward Business Review, 73. Jg. (1995), Nr. 3, S. 105 - 115.

Domar, Evsley D. UNd RichaRd A. Musgrave

Proportional Income Taxation and Risk-Taking.

In: The Quarterly Journal of Economics, 59. Jg. (1944), S. 388 - 422.

DORNBUSCH, RÜDIGER (1976)

Expectations and Exchange Rate Dynamics.

In: Journal of Political Economy, 84. Jg. (1976), S. 1161-1176.

DORNBUSCH, RÜDIGER (1988)

Purchasing Power Parity. In: Rüdiger Dornbusch. Exchange Rates and Inflation.

Cambridge, Mass. u. London 1988, S. 265-292.

DORNBUSCH, RÜDIGER (1988)

The Dollar and the Deficit. In: Internationales Währungssystem und weltwirtschaftliche

Entwicklung. Hrsg. Christian Dräger u. Lothar Späth, Baden-Baden 1988, S.91 - 107.

DRUKARCZYK, JOCHEN

Theorie und Politik der Finanzierung. 2., völlig neugestaltete Aufl., München 1993.

DUKES, RolaND E.

The Empirical Investigation of the Effects of FASB Statement No. 8 on Security Return

Behaviour. Financial Accounting Standards Board, Dezember 1978.

Edison, Hali J. und B. Dianne Pauls

A Re-assessment of the Relationship Between Real Exchange Rates and Real Interest Rates:

1974 - 1990. In: Journal of Monetary Economics, 31. Jg. (1993), S. 165 - 187.

EISENACH, MANFRED

Währungsumrechnung beim Verlustabzug nach §2 Auslandsinvestitionsgesetz.

In: Der Betrieb, 39. Jg. (1986), Heft 45, S. 2279 - 2284.

EisenACH, MANFRED

Abzug von Währungsverlusten - Ernstliche Zweifel an der Nichtberücksichtigung von

Wechselkursverlusten. In: Der Betrieb, 41. Jg. (1988), Heft 36, S. 1827.

Eiteman, DAVID K. UND ARThUR I. STONEHILL

Multinational Business Finance. 5. Aufl., Reading, Mass. 1989.

Engel, Charles

Real Exchange Rates and Relative Prices.

In: Journal of Monetary Economics, 32. Jg. (1993), S. 35 - 50.

ESTACHE, ANTONIO UND SWEDER VAN WIJNBERGEN

Evaluating the Minimum Asset Tax on Corporations: An Option Pricing Approach.

CEPR Discussion Paper Series Nr. 684, London 1992.

EUROPÄISCHE KOMMISSION, BERATENDES FORUM FÜR RECHNUNGSLEGUNG

Umrechnung von Fremdwährungsposten.

Hrsg. Europäische Kommission, Brüssel u. Luxemburg 1995. 


\section{FALLer, Eberhard}

Der Grundsatz der Einzelbewertung und die Notwendigkeit seiner Durchbrechung unter Berücksichtigung des Bilanzrichtlinien-Gesetzentwurfs.

In: Der Betriebs-Berater, 40. Jg. (1985), Heft 31, S. 2017 - 2023.

FAMA, Eugene F. (1970)

Efficient Capital Markets: A Review of Theory and Empirical Work.

In: The Journal of Finance, 25. Jg. (1970), Nr. 2, S. 383 - 417.

FAMA, EUGENE F. (1991)

Efficient Capital Markets: II. In: The Journal of Finance, 46. Jg. (1991), Heft 5, S. 1575 - 1617.

Farias, Christopher D.

Interaction of Foreign Currency Rules and Section 1256 Contracts After the New Section 988

Temporary Regulations. In: Journal of Taxation and Investments, 7. Jg. (1990), S. 293 - 303.

\section{FEINSCHREIBER, ROBERT}

Hedging Foreign Transactions Without Exposure to Currency Taxation.

In: Journal of Taxation and Investments, 12. Jg. (1994), S. $100-105$.

FELdSTEIn, MARTIN

Why Capital Gains Taxes Are Unfair. In: The Wall Street Journal vom 21.11.1994.

FEY, ACRMM

Betriebsstättenbesteuerung. In: Deutsches Steuerlexikon. Hrsg. Jürgen Schaeberle u. Hans

Utech, München 1997, Loseblatt, Stand: 11. Ergänzungslieferung (Juni 1997).

Filc, WolfGaNG

Anmerkungen zur Effizienz des Devisenmarktes. In: Aspekte der Geldpolitik in offenen

Volkswirtschaften. Hrsg. C. Köhler und R. Pohl, Berlin 1987, S. 77 - 98.

Financial ACCounting Standards BoARd (1974)

An Analysis of Issues Related to Accounting of Foreign Currency Translation;

FASB-Discussion Memorandum. Stamford 1974.

FinaNCIAL ACCOUNTING STANDARDS BoARd (1975)

Statement of Financial Accounting Standards No. 8.: Accounting for the Translation of Foreign Currency Transactions and Foreign Currency Financial Statements. Stamford 1975.

Financial ACCOUNTINg Standards Board (1982)

Statement of Financial Accounting Standards No. 52.: Foreign Currency Translation.

In: Dies., Accounting Standards, Original Pronouncemants. Stamford 1982, S. 1390 - 1422 , Abgedruckt in: Heinrich H. Jonas. Der Konzernabschluß: Grundlagen und Anwendung in der Praxis nach neuem Handelsrecht. Stuttgart 1986, S. 495 - 527.

FINK, ELI H.

Final 'Check-the-Box' Regulations Issued. In: Intertax, 25. Jg. (1997), Heft 3, S. 106.

Finne, Thomas

Bilanzierung von Fremdwährungsgeschäften und internationale Doppelbesteuerung. Baden-

Baden 1991, zugl. Diss., Univ. Hamburg 1990.

FINNERTY, JOHN D.

Financial Engineering in Corporate Finance: An Overview.

In: Financial Management, 17. Jg. (1988), Heft 4, S. 14 - 31.

FISCHER, LUTZ UND PERYGRIN WARNEKE

Internationale Betriebswirtschaftliche Steuerlehre. 3., überarb. Aufl. 1988.

FISHER, IRVING

The Theory of Interest. New York 1930. 
Flick, Hans, Franz WASSERMEYer und HeLMUT BECKER

Kommentar zum Außensteuerrecht. 5. Auf., Köln 1994, Stand: 39. Ergänzungslieferung (Juni 1997).

FLOOD, Eugene JR. UND DONALD R. LESSARD

On the Measurement of Operating Exposure to Exchange Rates: A Conceptual Approach.

In: Financial Management, 15. Jg. (1986), Heft 1, S. 25 - 36.

FRANKE, GÜNTER

Währungsrisiken. In: Handwörterbuch Export und Internationale Unternehmung. Hrsg. Klaus Macharözina und Martin K. Welge, Stuttgart 1989, Sp. 2196 - 2213.

Frenkel, JaCob A. UNd Michael L. MuSSA

The Efficiency of Foreign Exchange Markets and Measures of Turbulence. In: The American Economic Review, Papers and Proceedings, 70. Jg. (1980), Heft 2, S. 374 - 381.

FrENKEL, JACOB A. UND MORRIS GOLDSTEIN

A guide to target zones.

In: International Monetary Fund Staff Papers, 33. Jg. (1986), S. 633 - 673.

Friedman, Muton

U.S. Tax Bill Won't Reform U.S. Politics. In: Wall Street Journal Europe vom 8.7.1986.

Froot, KenNeth A.

Multinational Corporations, Exchange Rates, and Direct Investment.

In: International Policy Coordination and Exchange Rate Fluctuations. Hrsg. William H.

Branson, Jacob A. Frenkel und Morris Goldstein, Chicago und London 1990, S. 307 - 345.

Froot, KENNETH A.

Comment. Kommentar zu: Joel Slemrod. The Impact of the Tax Reform Act of 1986 on

Foreign Direct Investment to and from the United States. In: Do Taxes Matter?: The Impact of the Tax Reform Act of 1986. Hrsg. Joel Slemrod, Cambridge, Mass. 1990.

Froot, KenNeth A. UND Jeffrey A. Frankel

Forward Discount Bias: Is it an Exchange Risk Premium?

In: The Quarterly Journal of Economics, 104. Jg. (1989), S. 139 - 161.

GAAB, WERNER

Möglichkeiten und Grenzen des Erkennens spekulativer Bubbles an den Devisenmärkten.

In: Kooperation, Autonomie und Devisenmarkt. Veröffentlichungen des Instituts für

Empirische Wirtschaftsforschung Bd. 26, Hrsg. Wolfgang Filc und Claus Köhler,

Berlin 1990, S. 67 - 97.

GANDENBERGER, OtTo (1983)

Kapitalexportneutralität versus Kapitalimportneutralität. Allokative Überlegungen zu einer Grundfrage der internationalen Besteuerung.

In: Aufsätze zur Wirtschaftspolitik Nr. 7, Mainz 1983.

GANDENBERGER, OTTO (1985)

Der Einfluß der Einkommen- und Körperschaftsteuer auf die internationalen

Wirtschaftsströme.

In: Grundfragen des Internationalen Steuerrechts. Hrsg. Klaus Vogel, Köln 1985, S. 33 - 48.

GaRman, MaRk B. und SteVen W. KohlHagen

Foreign Currency Option Values.

In: The Journal of International Money and Finance, 2. Jg. (1983), S. 231 - 237.

GEBHARDT, GüNTHER

Währungsumrechnung im Einzelabschluß und bei der Aufstellung konsolidierter Abschlüsse. Arbeitsbericht Nr. 39 des Instituts für Unternehmensführung und Unternehmensforschung der Ruhr-Universität Bochum, Bochum 1986. 


\section{GEBHARDT, GÜNTHER UND NORBERT BREKER}

Bilanzierung von Fremdwährungstransaktionen im Handelsrechtlichen Einzelabschluß - unter Berücksichtigung von §340h HGB. In: Der Betrieb, 44. Jg. (1991), Heft 30, S. 1529 - 1538.

Gelhausen, Wolf und Robin MuJKanovic

Auswertung zur Währungsumrechnung im Konzernabschluß.

In: Deutsches Steuerrecht, 30. Jg. (1992), Heft 44, S. 1724 - 1726.

\section{GiovannetTi, Giorgia}

A Survey of Recent Empirical Tests of the Purchasing Power Parity Hypothesis.

In: BNL Quarterly Review, 1992, Heft 180, S. 81 - 97.

\section{GiovanNini, Alberto}

National Tax Systems versus the European Capital Market.

In: Economic Policy, 8. Jg. (1989), Heft 9, S. 346 - 386.

GleckMan, Howard UND BARBaRa STARR,

The Minimum Tax: It's the Bottom Line that Counts. In: Business Week vom 16.6.1986.

Gordon, Richard A. UND DANIEL S. LANGE

International Effects of the Corporate AMT Book Income Regulations.

In: Tax Management International Journal, 16. Jg. (1987), S. 365 - 375.

GORDON, ROGER H.

R.H. Gordon, Taxation of Investment and Savings in a World Economy.

In: The American Economic Review, 76. Jg. (1986), Heft 5, S. 1086 - 1102.

GrabBe, J. OrLIN

The Pricing of Call and Put Options on Foreign Exchange.

In: The Journal of International Money and Finance, 2. Jg. (1983), S. 231 - 237.

Graetz, Michael J.

Federal Income Taxation. 2. Aufl. 1988, Westbury, NY. 1988.

GrahaM, GeORGE

Republican Tax Plans Challenged. In: The Financial Times vom 12.1.1995.

GroH, MANFRED

Zur Bilanzierung von Fremdwährungsgeschäften.

In: Der Betrieb, 39. Jg. (1986), Heft 17, S. 869 - 877.

GRÜTZNER, DIETER

Die Umrechnung ausländischer Besteuerungsgrundlagen.

In: IWB, Fach 3 Deutschland, Gruppe 3, S. 867 - 872.

Gurtner, Peter

Inflation, Nominalwertprinzip und Einkommensteuerrecht. 1. Aufl. Bern, Stuttgart 1980.

HaAse, KLaus DitTmaR

Geldentwertung und Ertragsbesteuerung der Unternehmung. In: Die Unternehmung in ihrer gesellschaftlichen Umwelt. Hrsg. P. Mertens, Wiesbaden 1975, S. 281 - 299.

\section{HARDER, NIELS}

Die fremde Währung im Steuerrecht.

In: Internationales Steuerrecht, 2. Jg. (1993), Heft 7, S. 297 - 303.

HENREY, ROBERT (1986)

H.R. 3838 and Foreign Currency Rules Reform: Comments and Recommendations.

In: Tax Management International Journal, 15. Jg. (1986), S. 172 - 181.

HENREY, ROBERT (1989)

International Tax Aspects of Foreign Currency Transactions. In: International Bureau of Fiscal Documentation Bulletin, 43. Jg. (1989), Heft 7, S. 312 - 326. 
Herrmann, Carl, Gerhard Heuer und ARndt Raupach

Einkommensteuer- und Körperschaftsteuergesetz. Kommentar.

20. Aufl., Köln 1995, Loseblatt, Stand: 189. Ergänzungslieferung (September 1997).

HERZIG, NORBERT UND ULRICH RIECK

Saldierungsbereich bei Drohverlustrückstellungen im Gefolge der Apothekerentscheidung,

- Anmerkung zu dem Beschluß des Großen Senats vom 23. 6.1997 GrS 2/93 -.

In: Der Betrieb, 50. Jg. (1997), Heft 19, S. 1881 - 1885.

HÖPPNER, HORST-DIETER

Kursverluste bei Fremdwährungsdarlehen.

In: Jahrbuch der Fachanwälte für Steuerrecht, 40. Jg. (1989/90), S. 164 - 172.

Horner, Frances M. UND Kathleen E. BARge

Simplifying the Foreign Tax Translation Rules.

In: Tax Notes, 51. Jg. (1981), S. 1569 - 1573.

Horst, Thomas (1980)

A Note on the Optimal Taxation of International Investment Income.

In: The Quarterly Journal of Economics, 95. Jg. (1980), S. 793 - 798.

Horst, THOMAS (1985)

Foreign Exchange Gains And Losses: What are the Issues?

In: Tax Notes, 28. Jg. (1985), S. 1393 - 1398.

HufbaUer, GaRY ClYde und JoanNa M. VAN ROOIJ

U.S. Taxation of International Income: Blueprint für Reform. Washington, DC. 1992.

InSTITUT „Finanzen UND STeUERN“ E. V. (Hrsg.) (1985)

Teilwertabschreibungen auf Beteiligungen an Kapitalgesellschaften.

Heft 123, Bearb.: Detlev Jürgen Piltz, Bonn 1985.

INSTITUT „FINANZEN UND STEUERN“ E. V. (Hrsg.) (1988)

Währungsschwankungen und die Methoden zur Vermeidung der Internationalen

Doppelbesteuerung. Heft 125, Bearb.: Detlev Jürgen Piltz, Bonn 1988.

INSTITUT DER WIRTSCHAFTSPRÜFER IN DEUTSChLAND E. V., HAUPTFACHAUSSCHUB

Zur Bilanzierung von Zero-Bonds.

In: DWW, Die Fachgutachten und Stellungnahmen, Düsseldorf 1995, Loseblatt,

Stand: 50. Ergänzungslieferung (Dezember 1995) S. 143 - 144.

INSTITUT DER WIRTSCHAFTSPRÜFER IN DEUTSChLAND E. V., HAUPTFACHAUSSCHUß

Geänderter Entwurf einer Verlautbarung zu Währungsumrechnung im Jahres- und

Konzernabschluß. In: Die Wirtschaftsprüfung, 39. Jg. (1986), Heft 23, S. 664 - 667.

InTERnational BUREAU of Fiscal Documentation

Tax Treatment of Exchange Gains and Losses. Amsterdam, 1988.

ISARD, PETER

Unvcovered Interest Parity. IMF Working Paper Nr. 51, 1991.

ISENBERGH, JOSEPH (1990)

International Taxation. U.S. Taxation of Foreign Taxpayers and Foreign Income.

Volume I and II, Boston u.a. 1990.

ISENBERGH, JOSEPH (1994)

International Taxation. U.S. Taxation of Foreign Taxpayers and Foreign Income.

1994 Supplement, Boston u.a. 1994.

JACOBS, OTTO (Hrsg.)

Internationale Unternehmensbesteuerung. 3. neubearb. und erw. Aufl., München 1995. 


\section{JACOBS, OTto H. UND JÜRgen HAUN}

Financial Derivatives in International Tax Law - A Treatment of Certain Key

Considerations. In: Intertax, o. Jg. (1995), Heft 8 - 9, S. 405 - 420.

JACOBS, VERNON K.

Taxpayer Relief Act: Statement of the Managers.

Internet: http://www.rpifs.comt/t97index.htm, Stand: 29.7.1997. Ausdruck vom 7.9.1997.

JOHANSSON, SVEN-ERIK

Income Taxes and Investment Decisions.

In: The Swedish Journal of Economics, 71. Jg. (1969), S. 104 - 110.

KAY, JoHN A. UND JoHn KING

Taxing Currency Fluctuation?: The Tax Treatment of Foreign Exchange Gains and Losses. Institute for Fiscal Studies Report Series Nr. 18, London 1985.

KECK, RICHARD P. UND JEFFREY F. MONTGOMERY

US Federal Tax Aspects of Foreign Currency Transactions.

In: Intertax, o. Jg. (1994), Heft 4, S. 149 - 158.

KEYNES, JOHN MEYNARD

The General Theory of Employment, Interest, and Money.

London, New York u.a., 1936.

KLEINEDAM, HANS-JoCHEN

Gewinnermittlung bei Auslandsbetriebstätten (Teil II).

In: Internationales Steuerrecht, 2. Jg. (1993), Heft 8, S. 395 - 400.

KLOY, JöRg UND JOHANNES WELCKER

Drei Arten von Währungsoptionen. In: Die Bank, o. Jg. (1986), Heft 6, S. 298 - 302.

KNOBBE-KEUK, BRIGITTE

Bilanz- und Unternehmensteuerrecht. 9., völlig überarb. und erw. Aufl., Köln 1993.

KONRAD, KaI ANDREAS

Kapitaleinkommensteuer und beschleunigte Abschreibungen bei Unsicherheit.

Münchener wirtschaftswissenschaftliche Beiträge Nr. 89-08, München 1989.

KPMG PEAT MARWick LLP. (Hrsg.)

Taxpayer Relief Act of 1997 Booklet. 1997.

Internet: http://www.us.kpmg.com/taxact/tra1997/home.html. Ausdruck vom 7.9.1997.

KRASKER, WHLIAM S.

The „Peso" Problem in Testing the Efficiency of Forward Exchange Markets.

In: Journal of Monetary Economics, 6. Jg. (1980), S. 269 - 276.

KRAUSE-JUNK, GEROLD (1984)

Die Bedeutung der Steuerharmonisierung für die Errichtung eines Gemeinsamen Marktes.

Vortrag gehalten auf dem Seminar des Arbeitskreises Europäische Integration über Probleme der Steuerharmonisierung, am 4. Oktober 1984 in Hauenstein/Pfalz. Institut für ausländisches und Internationales Finanz- und Steuerwesen. Hamburg 1984.

KRAUSE-JUnK, GeROLD (1988)

Außenwirtschaftliche Konsequenzen beschleunigter Abschreibung.

In: Finanzarchiv, 46. Jg. (1988), S. 252 - 267.

KRAUSE-JUnK, Gerold (1992)

Eine Thesaurierungsbegünstigung ist eher skeptisch zu beurteilen.

In: Wirtschaftsdienst, 9. Jg. (1992), Heft 9, S. 452 - 453.

KRAUSE-JUNK, Gerold (1993)

Körperschaftsteuerharmonisierung in Europa.

Unveröffentlichte Notizen zur Vorlesung im Sommersemester 1993. 


\section{Krugman, PaUl R.}

Equilibrium Exchange Rates.

In: International Policy Coordination and Exchange Rate Fluctuations.

Hrsg. William H. Branson u.a., Chicago u. London 1990, S. 159 - 187.

KRÜMMEL, HANS-JACOB

Finanzierungsrisiken und Kreditspielraum.

In: Zeitschrift für Betriebswirtschaftslehre, 36. Jg. (1966), 1. Ergänzungsheft, S. 134 - 157.

Wiederabgedruckt in: Die Finanzierung der Unternehmung. Hrsg. Herbert Hax und

Helmut Laux, Köln 1975, S. 200 - 223.

\section{KuPsCh, Peter}

Abgrenzung der Bewertungseinheit in Handels- und Steuerbilanz: Grenzbereich Einzel-

bewertung und Saldierungsverbot. In: Steuerberater-Jahrbuch, 46. Jg. (1994/95), S. 131 - 155.

KÜTING, KARLHEINZ UND ClAUS-PETER WEBER

Der Konzernabschluß. 3. grundlegend überarb. u. wesentlich erw. Aufl., Stuttgart 1991.

LAINOFF, STEVEN R. UND TODD Y. MCARTHUR

The Final Functional Currency Regime for U.S. Taxpayers Operating in Hyperinflationary

Environments: Mandatory DASTM.

In: The Tax Management International Journal, 23. Jg. (1994), S. 583 - 599.

LANGE, KLAUS

Die Bedeutung des Grundsatzes der Steuergerechtigkeit für die Erfolgsbesteuerung der Aktien- und der Zinsanlage unter dem Einfluß der Inflation und Konsequenzen für das geltende Steuerrecht. Diss., Univ. Hamburg 1982.

\section{LANGEL, HORST}

Auswirkungen von Wechselkursänderungen auf die Bilanzierung.

In: IWB Fach 3 Gruppe 3 Deutschland, S. 845 - 860.

\section{LANGENBUCHER, GÜNTHER (1986)}

Die Umrechnung von Fremdwährungsgeschäften: Eine Untersuchung nach handels- und steuerrechtlichen Grundsätzen. Stuttgart 1988, zugl. Diss., Würzburg 1986.

\section{LANGENBUCHER, GÜNTHER (1989)}

Umrechnung von Fremdwährungsabschlüssen.

In: Handbuch der Konzernrechnungslegung: Kommentar zur Bilanzierung und Prüfung. Hrsg.

Karlheinz Küting und Claus-Peter Weber, Stuttgart, 1989, S. 447 -485, Rz. 969 - 1144.

LANGENBUCHER, GÜNTHER (1990)

Umrechnung von Fremdwährungsgeschäften. In: Handbuch der Konzernrechnungslegung:

Kommentar zur Bilanzierung und Prüfung. Hrsg. Karlheinz Küting und Claus-Peter Weber, 3. grundlegend überarb. u. wesentlich erw. Aufl., Stuttgart, 1990, S. 317 - 364, Rz. 423 - 574.

\section{LAUX-MEISELBACH, WOLFGANG}

Ein einfaches Modell der optimalen Besteuerung internationaler Kapitalerträge.

Hefte zur internationalen Besteuerung, Institut für Ausländisches und Internationales

Finanz- und Steuerwesen Nr. 34, Hamburg 1987.

\section{LEFFSON, ULRICH}

Die Grundsätze ordnungsmäßiger Buchführung. 7. rev. u. erw. Aufl., Düsseldorf 1987.

\section{LeVi, MAURICE D.}

Taxation and "Abnormal" International Capital Flows.

In: The Journal of Political Economy, 85. Jg. (1977), S. 635 - 646. 


\section{LEVICH, RICHARD M.}

Empirical Studies of Exchange Rates: Price Behavior, Rate Determination and Market Efficiency. In: Handbook of International Economics, Bd. II.. Hrsg. R. W. Jones und P. B. Kenen, Amsterdam u.a. 1985, S. 979 - 1040.

\section{LEVINE, HOWARD J. UND HOWARD BERGER}

TAMRA Amendments to the Foreign Currency Rules.

In: Tax Management International Journal, 18. Jg. (1989), S. 85 - 88.

LiNDER, STAFFAN B.

An Essay on Trade and Transformation. New York 1961.

Littmann, Eberhard, Horst Bitz und Jens Peter Meincke

Das Einkommensteuerrecht, Kommentar. 15. Aufl., Stuttgart 1989, Loseblatt, Stand: 27. Ergänzungslieferung (März 1996).

\section{LORENSEN, LEONARD}

Reporting Foreign Operations of U.S. Companies in U.S. Dollars.

Accounting Reseach Study No. 12, New York 1972.

MAJd, SAMAN UNd STEWART MYERS

Valuing the Government's Tax Claim on Risky Corporate Assets.

NBER Working Paper Series Nr. 1553, Cambridge, Mass. 1985.

MALINSKI, Peter

Währungsschwankungen und Doppelbesteuerung. Herne u. Berlin 1992, zugl. Diss., Univ. Mannheim 1991.

MANKE, KLAUS

Teilwertabschreibungen an ausländischen Kapitalgesellschaften - BFH-Urteil vom 14.3.1989 -. In: Deutsche Steuer-Zeitung, 78. Jg. (1990), Heft 1-2, S. 4 - 10.

Marcuse, Steven R. Und David L. Paul

The U.S. Foreign Tax Credit - A Practical Handbook -. London 1993.

Marston, Richard C.

Real and Nominal Exchange Rate Variability.

In: Empirica - Austrian Economic Papers, 16. Jg. (1989), Heft 2, S. 147 - 160.

MCCulloch, J. Huston

Operational Aspects of the Siegel Paradox.

In: The Quarterly Journal of Economics, 89. Jg. (1975), S. 170 - 172.

McDaniel, Paul R, Hugh J. Ault, Martin J. McMahon, JR. und Daniel L.

Simmons

Federal Income Taxation of Business Organizations. Westbuy, NY. 1991.

MCDONALD, RONALD

Floating Exchange Rates. Theories and Evidence. London u.a. 1988.

MCDONALD, RONALD UND MARK P. TAYLOR

Exchange Rate Economics: A Survey.

In: International Monetary Fund Staff Papers, 39. Jg. (1992), S. 1-52.

Meese, RichaRd A. UND KenNeth RogofF

Was it Real? The Exchange Rate-Interest Differential Relation, 1973 - 1984.

NBER Working Paper Series Nr. 1732, Cambridge, Mass. 1985.

MENKHAUS, HEINRICH

Der oberste Gerichtshof nimmt Stellung zum Verhältnis von Handels- und Steuerrecht. In: Juristenzeitung, 34. Jg. (1979), Heft 10, S. 359. 


\section{Mertens, Jo Beth}

Translation Rules And Tax Neutrality: The Effects of The Foreign Exchange Gains and Losses on the Profit Maximizing Decisions of Firms, Diss., Emroy Univ. 1992.

\section{Modigliani, Franco}

Debt, Dividend Policy, Taxes, Inflation and Market Valuation.

In: The Journal of Finance, 37. Jg. (1982), S. 255 - 273.

Modigliani, Franco und Merton H. Miller (1958)

The Cost of Capital, Corporation Finance and the Theory of Investment.

In: American Economic Review, 48. Jg. (1958), Heft 3, S. 261 - 297. Übersetzt in: Die

Finanzierung der Unternehmung. Hrsg. H. Hax und H. Laux, Köln 1975, S. 86 - 119.

Modigliani, Franco Und Merton H. Miller (1963)

Corporate Income, Taxes and the Cost of Capital: A Correction.

In: American Economic Review, 53. Jg. (1963), S. 433 - 443. Übersetzt in: Die Finanzierung der Unternehmung. Hrsg. H. Hax und H. Laux, Köln 1975, S. 120 - 132.

Modigliani, Franco UNd Merton H. Miller (1969)

Reply to Heins and Sprenkle.

In: The American Economic Review, 59. Jg. (1969), S. 592 - 595.

MÖSSNER, JöRG

Die Methoden zur Vermeidung der Doppelbesteuerung - Vorzüge, Nachteile, aktuelle

Probleme.

In: Grundfragen des Internationalen Steuerrechts. Hrsg. Klaus Vogel, 1985, S. 135 - 170.

MÜLleR-DotT, JohanNes PETER

Teilwertabschreibungen auf Auslandsbeteiligungen

In: Steuerberater-Jahrbuch, 40. Jg. (198/89), S. 163 - 185.

Muller, Clifford E., G. Garner Prillaman, JR. und David A. Golden

Foreign Currency Regulatory Guidance: Qualified Business Units, Functional Currency, Net Worth Method Transition Rules and Distributions of Previously Taxed Income.

In: The Tax Management International Journal, 17. Jg. (1988), S. 371 - 393.

Musgrave, Peggy B. (1969)

United States Taxation of Foreign Investment Income. Issues and Arguments.

Cambridge, Mass. 1969.

Musgrave, Peggy B. (1975)

Exchange Rate Aspects in the Taxation of Foreign Income.

In: National Tax Journal, 28. Jg. (1975), Heft 4, S. 405 - 413.

MUSGRAVE, RichaRd A.

Fiscal Systems. New Haven und London 1969.

Musgrave, Richard A., Peggy B. Musgrave und Lore Kullmer (1992)

Die öffentlichen Finanzen in Theorie und Praxis.

3. Band, 4. völlig überarb. Aufl., Tübingen 1992.

Musgrave, Richard A., Peggy B. Musgrave und Lore Kullmer (1993)

Die öffentlichen Finanzen in Theorie und Praxis.

2. Band, 5. völlig überarb. Aufl., Tübingen 1993.

MÜSSENER, INGO

Vereinigte Staaten von Amerika. In: Steuern in Europa, USA, Kanada und Japan, Herne u.

Berlin, Hrsg. Annemarie Mennel, Loseblatt, Stand 32. Ergänzungslieferung (Mai 1997).

Muth, JoHn F.

Rational Expectations and the Theory of Price Movements.

In: Econometrica, 29. Jg. (1961), S. 315 - 335. 
O'NeI, Timothy J.

Federal Income Tax Treatment of Foreign Currency Transactions after the

Tax Reform Act of 1986. In: Tax Notes, 33. Jg. (1986), S. 186-197.

O'Nen, TMMOTHY J. UND CHSOON LEE

Federal Income Tax Treatment of Foreign Currency Denominated Debt.

In: The International Tax Journal, 12. Jg. (1986), Heft 1, S. 9 - 28.

o. V.

Tax Reform Act of 1986, Conference Report to Accompany H.R. 3838: Statement of the

Managers. In: Standard Federal Tax Reports -Extra Edition—, 73. Jg. (1986), Teil II, Heft 41.

o. V.

Explanation of Tax Reform Act of 1986. Chicago, Ill. 1986.

o. V.

New Rules Affecting Hyperinflationary Currency Accounting.

In: The Journal of Taxation, 80. Jg. (1994), Heft 5, S. 274.

o. V.

Die Wirtschaftsprüfer sehen das Vorsichtsprinzip gefährdet.

In: Frankfurter Allgemeine Zeitung vom 6.10.1997

OECD

Taxation of New Financial Instruments. Paris 1994.

ORDELHEIDE, DIETER

Gefährdung der Nominalkapitalerhaltung durch die Währungsumrechnung von

Auslandsinvestitionen.

In: Zeitschrift für betriebswirtschaftliche Forschung, 46. Jg. (1994), Heft 10, S. 795 - 818.

OSSADNIK, WOLFGANG

Umrechnung von Fremdwährungsposten bei der Konzernrechnungslegung.

In: Deutsches Steuerrecht, 32. Jg. (1994), Heft 38, S. 1393 - 1397.

Pach-Hanssenheimb, Ferdinand

§2a Abs. 3 und 4 EStG führen bei sinkendem Wechselkurs der ausländischen Währung zu

Doppelbesteuerungen. In: Internationales Steuerrecht, 2. Jg. (1993), Heft 11, S. 508 - 512.

PaUsenberger, EBrenfried und Martin Glaum

Management von Währungsrisiken. In: Handbuch des Finanzmanagements: Instrumente und Märkte der Unternehmensfinanzierung. Hrsg. Günther Gebhardt, Wolfgang Gerke und Manfred Steiner, München 1993, S. 763 - 785.

Peffekoven, RolF

Probleme der internationalen Finanzordnung.

In: Handbuch der Finanzwissenschaft, Bd. IV, Tübingen 1983, S. 219 - 268.

PERING, Wilfried

Auswirkungen von Währungskursschwankungen auf den Betriebstättengewinn.

In: Der Betrieb, 39. Jg. (1986), Heft 45, S. 2299 - 2302.

PoHLe, KLAUS

Management von Währungsrisiken.

In: Finanzierungshandbuch. Hrsg. F. W. Christians, 2. Aufl., Wiesbaden 1988, S. 769 - 780.

POMrehn, SIEGFRIEd

Handelsrechtliche Bewertung bei zu bilanzierenden Fremdwährungsgeschäften und

Rückführung auf die durch das Steuerrecht gezogenen Grenzen.

In: Der Betrieb, 43. Jg. (1990), Heft 22, S. 1102 - 1103. 


\section{Pöвl, Wolfgang}

Die Zulässigkeit von Saldierungen bei der Bilanzierung von wirtschaftlich ineinandergreifenden Vorgängen. In: Deutsches Steuerrecht, 22. Jg. (1984), Heft 14/15, S. 428 - 435.

\section{RÄDLER, ALBERT}

Deutsches Steuerrecht und inflationäre Entwicklung im Ausland.

In: Steuerberater-Jahrbuch, 27. Jg. (1975/76), S. 449 - 472.

RAVENSCROFT, DONALD R.

Taxation and Foreign Currency: The Income Tax Consequences of Foreign Exchange Transactions and Exchange Rate Fluctuations. Cambridge, Mass. 1973.

\section{REAGAN, RONALD}

The Presidents Tax Proposals to the Congress for Fairness, Growth and Simplicity. Washington, DC. 1985.

\section{Richman, Peggy B.}

Taxation of Foreign Investment Income. An Economic Analysis. Baltimore 1963.

\section{Rodrigues, Rita M. UND E. EUGENE CARTER}

International Financial Management. 2. Aufl., Englewood Cliffs 1979.

ROSE, KLAUS UND KaRLHANS SAUERNHEIMER

Theorie der Außenwirtschaft. 11., völlig überarb. und erw. Aufl., München 1992.

\section{SACHVERSTÄNDIGENRAT ZUR BEGUTACHTUNG DER}

GESAMTWIRTSCHAFTLICHEN ENTWICKLUNG

Gegen Pessimismus. Jahresgutachten 1982/83. Stuttgart 1982.

SCHAUMBURg, HaRALd

Internationales Steuerrecht: Außensteuerrecht, Doppelbesteuerungsrecht. Köln 1993.

SCHLICK, UWE

Bewertung von Fremdwährungspositionen im handelsrechtlichen Jahresabschluß.

In: Deutsches Steuerrecht, 31. Jg. (1993), Heft 7, S. 254 - 460.

\section{SCHMIDT, HARTMUT}

Liquidität von Finanztiteln als integrierendes Konzept der Bankbetriebslehre.

In: Zeitschrift für Betriebswirtschaft, 49. Jg. (1979), Heft 8, S. 713.

SCHMIDT, LUDWIG (Hrsg.)

Einkommensteuergesetz: Kommentar. 14. völlig neubearb. Aufl., München 1995.

SCHNABEL, JACQUES A. UND EBRAHIM ROUMI

A Contingent Claims Analysis of Partial Loss Offset Taxation and Risk-Taking.

In: Public Finance, 45. Jg. (1990), Heft 2, S. 304 - 320.

SCHNEIDER, DIETER (1977)

Gewinnbesteuerung und Risikobereitschaft: Zur Bewährung quantitativer Ansätze in der Entscheidungstheorie.

In: Zeitschrift für betriebswirtschaftliche Forschung, 29. Jg. (1977), S. 433 - 466.

SCHNEIDER, DIETER (1994)

Hochsteuerland Deutschland 1994/95. In: Der Betrieb, 47. Jg. (1994), Heft 11, S. 541 - 549.

\section{SCHRÖDER, SIEGFRIED}

Die Betriebstätte im deutschen Außensteuerrecht.

In: Die Steuerliche Betriebsprüfung, 18. Jg. (1978), Heft 8, S. 169 - 181.

Shapiro, Alan C.

Financial Structure and Cost of Capital in the Multinational Corporation.

In: Journal of Financial and Quantitative Analysis, 13. Jg. (1974), S. 211 - 226. 


\section{SHARPE, WiLliaM F.}

Discussion. Kommentar zu: Eugene F. Fama. Efficient Capital Markets: A Review.

In: Journal of Finance, 25. Jg. (1970), Nr. 2, S. 418 - 420.

Shedivy, James H., AUdry S. DitTer, Daniel S. LaNGe UND

DARIVN C. BROENEN

E\&P Accounting for Distributions of Previously Taxed Income (PTI) of a CFC.

In: Tax Management International Journal, 19. Jg. (1990), S. 99 - 116.

SHELTON, NED

Corporate Taxation of Foreign Currency Gains and Losses and Financial Instruments - Part

I: Germany. In: Tax Planning International Review, 16. Jg. (1989), Heft 6, S. 3 - 8.

SIEGEL, JEREMY J.

Interest Rates and the Forward Exchange.

In: Quarterly Journal of Economics, 86. Jg. (1972), S. 303 - 309.

Sievert, OLAF

Gibt es eine Alternative zu flexiblen Wechselkursen?

In: Wirtschaftsdienst, 66. Jg. (1986), Heft 7, S. 335 - 344.

SinN, HANS-WERNER (1984)

Die Bedeutung des Accelerated Cost Recovery System für den internationalen

Kapitalverkehr. In: KYKLOS, 37. Jg. (1984), Heft 4, S. 542 - 576.

SINN, HANS-WERNER (1985)

Kapitaleinkommensbesteuerung. Tübingen 1985.

SinN, HANS-WERNER (1990)

Taxation and the Cost of Capital: The „Old“ View, the „New“ View, and Another View.

NBER Working Paper Series Nr. 3501, Cambridge, Mass. 1990.

SINN, HANS-WERNER (1990)

Taxation and The Birth of Foreign Subsidiaries.

NBER Working Paper Series Nr. 3519, Cambridge, Mass. 1990.

STÜTZEL, WOLFGANG (1966)

Entscheidungstheoretische Elementarkategorien als Grundlage einer Begegnung von

Wirtschaftswissenschaft und Rechtswissenschaft.

In: Zeitschrift für Betriebswirtschaft, 36. Jg. (1966), S. 765 - 789.

STÜTZEL, WOLFGANG (1967)

Bemerkungen zur Bilanztheorie. Wiesbaden 1967.

(Sonderdruck der Zeitschrift für Betriebswirtschaft.)

TANZI, VITO

Inflation and the Personal Income Tax: An International Perspective. Cambridge, Mass. 1980.

TIPKE, KLAUS UND HEINRICH WILHELM KRUSE

Abgabenordnung, Finanzgerichtsordnung: Kommentar. 16. Aufl., Köln 1996, Loseblatt,

Stand: 78. Ergänzungslieferung (Mai 1996).

TIPKE, KLAUS UND JOACHIM LANG

Steuerrecht. 14. völlig überarb. Aufl., Köln 1994.

Treumann, Walter, Martin Peltzer und AngeldKa M. Kuehn

US Business Law: Ein zweisprachiger Grundriß für den deutschen Geschäftsmann und Investor sowie seine Berater. 2. neubearb. u. erw. Aufl., Köln 1990.

UHRMANN, KARL

Zur bilanziellen Erfassung inländischer Devisengeschäfte.

In: Der Betrieb, 45. Jg. (1992), Heft 36, S. 1791 - 1794. 


\section{United States Department OF The Treasury}

Foreign Exchange Discussion Draft. Washington, DC. 1980.

United States House Ways and Means Committee (1985)

House Ways and Means Committee Report.

In: Standard Federal Tax Reports - Extra Edition-, 72. Jg. (1985), Heft 53.

\section{United States Senate Finance Committee}

Senate Finance Committee Report on H.R. 3838, General Explanation.

In: Standard Federal Tax Reports-Extra Edition-, 73. Jg. (1986), Heft 25.

VAN HoRNe, JAMES C.

Of Financial Innovations and Excesses.

In: Journal of Finance, 40. Jg. (1985), Heft 3, S. 621 - 624.

VIEGENER, JOHANNES

Umrechnung der nach ausländischen Rechtsordnungen ermittelten Ergebnisse zur

Anwendung des Auslandsinvestitionsgesetzes.

In: Steuerberater-Jahrbuch, 35. Jg. (1983/84), S. 393 - 420.

VoGEL, KLAUS (1982)

Ausländische Entscheidungen als Anregung für den deutschen Steuerrechtler.

In: Steuer und Wirtschaft, 59. Jg. (1982), Heft 1, S. 66 - 70.

VOGEL, KLAUS (1988)

„Source“ und „Jurisdiction“ im Steuerrecht der Vereinigten Staaten und im deutschen Recht.

In: Aktuelle Themen im U.S.-Deutschen Steuer- und Handelsrecht. Festschrift zu Ehren von

Otto L. Walter. Hrsg. Henry S. Conston, Osnabrück 1988, S. 101 - 114.

VOGEL, KLAUS (1990)

Doppelbesteuerungsabkommen der Bundesrepublik Deutschland auf dem Gebiet der Steuern vom Einkommen und Vermögen: Kommentar auf der Grundlage der Musterabkommen.

3., völlig neubearb. Aufl., München 1996.

VOGEL, KLAUS (1993)

Harmonisierung des Internationalen Steuerrechts in Europa als Alternative zur

Harmonisierung des (materiellen) Körperschaftsteuerrechts.

In: Steuer und Wirtschaft, 70. Jg. (1993), Heft 4, S. 380 - 388.

WAHL, JENNY BOURNE (1987)

Taxation of Foreign Exchange Gains and Losses. Office of Tax Analysis Papers Nr. 57,

Washington, DC. 1987 (US Treasury Department).

WAHL, JENNY BOURNE (1989)

Tax Treatment of Foreign Exchange Gains and Losses and the Tax Reform Act of 1986.

In: National Tax Journal, 42. Jg. (1989), Heft 1, S. 59 - 68.

WALMSLEY, JULIAN

The Foreign Exchange Handbook: A Users Guide. New York u.a. 1983.

WASSERMEYER, FranZ (1989)

Teilwertabschreibung auf die Beteiligung an einer indischen Kapitalgesellschaft.

In: Finanz-Rundschau, 71. Jg. (1989), Heft 17, S. 518 - 521.

WASSERMEYER, FranZ (1990)

Die Auslegung von Doppelbesteuerungsabkommen durch den Bundesfinanzhof.

In: Steuer und Wirtschaft, 67. Jg. (1990), Heft 4, S. 404 - 412.

WEICHENRIEDER, ALFONS J. (1993)

Freistellungsverfahren und Nachholeffekt.

Münchener wirtschaftswissenschaftliche Beiträge Nr. 93 - 12, München 1993. 
WEICHENRIEdER, ALFONS J. (1995)

Besteuerung und Direktinvestition.

Schriften zur angewandten Wirtschaftsforschung Nr. 70, Tübingen 1995.

WELLMANN, Udo

Währungsgewinne im Privatvermögen.

In: Deutsche Steuer-Zeitung, 85. Jg. (1997), Heft 8, S. 253 - 255.

White, Frederic E.

Taxation of Foreign Currency Transactions under the Tax Reform Act of 1986.

In: International Bureau of Fiscal Documentation Bulletin, 41. Jg. (1987), Heft 5, S. 206 - 214.

WILENSKY, ALAN J.

Future Directions of U.S. International Tax Policy.

In: Taxes, 70. Jg. (1992), Heft 12, S. 998 - 1007.

WILKE, KAY-MICHAEL

Die Besteuerung ausländischer Einkünfte im Körperschaftsteuersystem.

In: IWB Fach 3 Gruppe 4 Deutschland, S. 339 - 374.

WLECKE, ULRICH

Währungsumrechnung und Gewinnbesteuerung bei international tätigen deutschen Unternehmen: ertragsteuerliche Währungsumrechnung unter Berücksichtigung außensteuerlicher Besonderheiten. Düsseldorf 1989, zugl. Diss., Univ. Münster (Westfalen) 1988.

WÖHE, GÜNTER unter Mitarbeit von Ulrich Döring

Bilanzierung und Bilanzpolitik. 8. völlig neubearb. und erw. Aufl., München 1992.

WoYwoDe, UwE

Fremdwährungsumrechnung nach US-Steuerrecht.

In: Recht der Internationalen Wirtschaft, 37. Jg. (1991), Heft 8, S. 695 - 704.

Yoder, LOWELL D. UND SANDRA P. MCGILL

Subpart F: New Foreign Currency Hedging Exception.

In: Taxes, 74. Jg. (1996), Heft 3, S. 147 - 167.

Yost, GeORGe J. III (Hrsg.)

1996 International Tax Summaries: A Guide for Planing and Decisions.

Coopers \& Lybrand International Tax Network, New York u.a. 1996.

ZaIken, DAVid P., Frederic E. White UNd Frederick E. Wooldridge

Handling the Treatment of Foreign Currency under Tax Reform.

In: The Journal of Taxation, 54. Jg. (1987), S. 168 - 178.

ZaIKEN, DaVID P., Frederick E. Wooldridge und Diane L. RenFroe

Revisions to Income-Sourcing Rules Likely to Increase U.S. Tax on Foreign Income.

In: The Journal of Taxation, 68. Jg. (1988), Heft 1, S. $120-125$.

ZARNITZ, MONIKA

Die Wirkung der Einführung der separaten Limitierung in das US-amerikanische

Außensteuerrecht auf die internationale Kapitalallokation. Diss., Univ. Hamburg 1994.

ZILLESSEN, WolfGaNG

Zur Praxis der Währungsumrechnung deutscher Unternehmen. Ergebnisse einer empirischen Untersuchung, bewertet unter besonderer Berücksichtigung der aktuellen Entwicklung in den USA. In: Die Betriebswirtschaft, 42. Jg. (1982), Heft 4, S. 533 - 552.

Zollo, Thomas M.

The Search for Clarity And Consistency in Foreign Currency Translation.

In: Taxes, 71. Jg. (1993), S. 971 - 995. 


\section{Sonstige Quellen}

\section{Federal Reserve Bank of Chicago}

Economic Information: Financial Markets Data: Foreign Exchange Rates.

Internet: http://www.frbchi.org/econinfo/finance/for-exchange/welcome.html.

Überspielt am 1.9.1997.

INTERNATIONAL MONETARY FUND (1995)

International Financial Statistics Yearbook 1995. Washington, D.C. 1995.

INTERNATIONAL MONETARY FUND (1996)

International Financial Statistics, July 1996. Washington, D.C. 1996.

INTERNATIONAL MONETARY FUND (1997)

International Financial Statistics, June 1997. Washington, D.C. 1997.

\section{INTERNAL REVENUE CODE, VOLUME I AND II}

Including all 1996 Amendments, Chicago, Ill. 1996.

TAXPAYER RELIEF ACT OF 1997

Hand enrollment pursuant to Public Law 105-32. - H.R.2014-

In: Thomas Legislative Information on The Internet, Internet:

ftp://ftp.loc.gov/pub/thomas/c105/h2014.enr.txt. Überspielt am 1.9.1997.

\section{Commerce Clearing House (Hrsg.)}

CCH Standard Federal Tax Reporter 1996. 83. Aufl. Chicago, Il. 1995.

Federation OF TAX ADMinistrators

State Tax Rates \& Structure. Washington, D. C. 1997.

Internet: http://sso.org/fta/ind_inc.html u. http://sso.org/fta/corp_inc.html.

Ausdruck vom 11.9.1997.

UNITED States Senate

Tax Reform Bill: Text of H.R. 3838 as Passed by the Senate on June 24, 1986.

In: Standard Federal Tax Reports -Extra Edition-, 73. Jg. (1986) Heft 30.

UNITED States House OF REPRESENTATIVES (1997)

Taxpayer Relief Act of 1997: Text of H.R. 2014 as Passed by the House of Representatives on June 26, 1997. In: Thomas Legislative Information on The Internet, Internet: ftp://ftp.loc.gov/pub/thomas/c105/h2014.eh.txt. Ausdruck vom 9.10.1997.

United States House Ways and Means Committee (1985)

Tax Reform Bill of 1985. In: Standard Federal Tax Reports -Extra Edition-,

72. Jg. (1985), Heft 52.

\section{BUNDESFINANZHOF}

Beschluß vom 9.8.1989 I B 118/88. In: BStBI. II 1990, S. 175 - 177.

Urteil vom 17.7.1956 I 292/55 U. In: BStBl. III 1956, S. 379 - 380.

Urteil vom 27.7.1965 I 110/63 S. In: BStBl. III 1966, S. 24 - 28

Urteil vom 29.7.1965 IV 164/63 U. In: BStBl. III 1965, S. 648 - 650.

Urteil vom 17.7.1968 I 121/64. In: BStB1. II 1968, S. 695.

Urteil vom 23.3.1972 I R 128/70. In: BStBl. II 1972, S. 948 - 949.

Urteil vom 9.11.1976 VIII R 27/75. In: BStB1. II 1977, S. 306 - 309.

Urteil vom 16.12.1977 III R 92/75. In: BStBI. II 1978, S. 233 - 234.

Urteil vom 19.1.1978 IV R 61/73. In: BStBl. II 1978, S. 295 - 299.

Urteil vom 9.10.1979 VII R 67/77. In: BStB1. II 1980, S.116 - 117. 
Urteil vom 2.4.1980 I R 75/76. In: BStB1. 1980 II, S. 702 - 704.

Urteil vom 9.12.1981 I R 78/80. In: BStB1. II 1982, S. 243 - 245.

Urteil vom 27.10.1983 IV R 143/80. In: BStBl. II 1984, S. 35 - 37.

Urteil vom 20.7.1988 I R 49/84. In: BStB1. II 1989, S. 140 - 143.

Urteil vom 27.7.1988 I R 104/84. In: BStB1. II 1989, S. 274 - 276.

Urteil vom 14.3.1989 I R 39/85. In: BStBl. II 1989, S. 600 - 602.

Urteil vom 13.9.1989 I R 117/87. In: BStB1. II 1990, S. 57 - 60.

Urteil vom 15.11.1990 IV R 103/89. In: BStBl. II 1991, S. 228 - 230.

Urteil vom 19.3.1991 II R 134/88, in: BStBl. II 1991, S. 521 - 522.

Urteil vom 19.5.1993 I R 60/92. In: BStBl. II 1993, S. 714 - 716.

Urteil vom 9.11.1993 IX R 81/90. In: BStBl. II 1994, S. 289 - 292.

Urteil vom 19. 1.1994 I R 93/93. In: Internationales Steuerrecht, 3. Jg. (1994),

Heft 7, S. 331 - 332.

Urteil vom 16.3.1994 I R 42/93. In: BStBl. II 1994, S. 799 - 802.

Urteil vom 6.7.1995 IV R 30/93. In: BStB1. II 1995, S. 831 - 833.

Urteil vom 16.2.1996 I R 43/95. In: Der Betrieb, 49. Jg. (1996), Heft 36, S. 1801 - 1803.

Urteil vom 16.2.1996 I R 46/95. In: Deutsche Steuer-Zeitung, 85. Jg. (1997), Heft 3, S. 92.

REICHSFINANZHOF

Urteil vom 18.8.1943 VI 152/43. In: RStB1. 1943, S. 710 - 711.

FINANZGERICHT BADEN-WÜRTTEMBERG

Urteil vom 5. 6.1984 VIII K 419/83. In: EFG 1985, Entscheidung Nr. 682, S. 600 - 601.

FinANZGERICHT HAMBURg

Urteil vom 26.4.1995 VII 101/92 (nicht rechtskräftig). In: EFG 1995, Entscheidung Nr. 725, S. $870-872$.

FINANZGeRICHT MÜNCHEN

Urteil vom 18.7.1996 10 K843/92. In: Der Betrieb, 50. Jg. (1997), Heft 17, S. 850.

FINANZGERICHT MÜNSTER

Urteil v. 3.10.1995 9 K 5026/92 (nicht rechtskräftig). In: DATEV-LEXinform-Nr. 127320.

FINANZMINISTERIUM NORDRHEIN-WESTFALEN

Erlaß vom 1. März 1974 - S 2293 - 17 - V B 2. In: Der Betrieb, 27. Jg. (1974), Heft 12, S. 557.

HESSISCHES FINANZGERICHT

Urteil vom 24.11.1982 IV 359/79. In: EFG 1983, Entscheidung Nr. 337, S. 337 - 338.

HESSISCHES FINANZGERICHT

Urteil vom 19.8.1985 V 261/79. In: EFG 1985, Entscheidung Nr. 681, S. 600.

OBERFINANZDIREKTION FraNKFURT AM MAIN

Rundverfügung vom 14. Oktober 1988, S 2293 A-55-St II 20.

In: Deutsches Steuerrecht, 27. Jg. (1989), Heft 15/16, S. 508 - 509.

o. V.

Beschlußempfehlung des Ausschusses nach Artikel 77 des Grundgesetzes (Vermittlungs ausschuß) zu dem Gesetz zur Fortsetzung der Unternehmenssteuerreform.

Bundestags-Druchsache 13/8325 vom 4.8.1997. 


\section{FINANZWISSENSCHAFTLICHE SCHRIFTEN}

Band 1 Werner Steden: Finanzpolitik und Einkommensverteilung. Ein Wachstums- und Konjunkturmodell der Bundesrepublik Deutschland. 1979.

Band 2 Rainer Hagemann: Kommunale Finanzplanung im föderativen Staat. 1976.

Band 3 Klaus Scherer: Maßstäbe zur Beurteilung von konjunkturellen Wirkungen des öffentlichen Haushalts. 1977.

Band 4 Brita Steinbach: "Formula Flexibility" - Kritische Analyse und Vergleich mit diskretionärer Konjunkturpolitik. 1977.

Band 5 Hans-Georg Petersen: Personelle Einkommensbesteuerung und Inflation. Eine theoretisch-empirische Analyse der Lohn- und veranlagten Einkommensteuer in der Bundesrepublik Deutschland. 1977.

Band 6 Friedemann Tetsch: Raumwirkungen des Finanzsystems der Bundesrepublik Deutschland. Eine Untersuchung der Auswirkungen der Finanzreform von 1969 auf die Einnahmenposition der untergeordneten Gebietskörperschaften und ihrer regionalpolitischen Zieladäquanz. 1978.

Band 7 Wilhelm Pfähler: Normative Theorie der fiskalischen Besteuerung. Ein methodologischer und theoretischer Beitrag zur Integration der normativen Besteuerungstheorie in der Wohlfahrtstheorie. 1978.

Band 8 Wolfgang Wiegard: Optimale Schattenpreise und Produktionsprogramme für öffentliche Unternehmen. Second-Best Modelle im finanzwirtschaftlichen Staatsbereich. 1978.

Band 9 Hans P. Fischer: Die Finanzierung des Umweltschutzes im Rahmen einer rationalen Umweltpolitik. 1978.

Band 10 Rainer Paulenz: Der Einsatz finanzpolitischer Instrumente in der Forschungs- und Entwicklungspolitik. 1978.

Band 11 Hans-Joachim Hauser: Verteilungswirkungen der Staatsverschuldung. Eine kreislauftheoretische Inzidenzbetrachtung. 1979.

Band 12 Gunnar Schwarting: Kommunale Investitionen. Theoretische und empirische Untersuchungen der Bestimmungsgründe kommunaler Investitionstätigkeit in NordrheinWestfalen 1965-1972. 1979.

Band 13 Hans-Joachim Conrad: Stadt-Umland-Wanderung und Finanzwirtschaft der Kernstädte. Amerikanische Erfahrungen, grundsätzliche Zusammenhänge und eine Fallstudie für das Ballungsgebiet Frankfurt am Main. 1980.

Band 14 Cay Folkers: Vermögensverteilung und staatliche Aktivität. Zur Theorie distributiver Prozesse im Interventionsstaat. 1981.

Band 15 Helmut Fischer: US-amerikanische Exportförderung durch die DISC-Gesetzgebung. 1981.

Band 16 Günter Ott: Einkommensumverteilungen in der gesetzlichen Krankenversicherung. Eine quantitative Analyse. 1981.

Band 17 Johann Hermann von Oehsen: Optimale Besteuerung. (Optimal Taxation). 1982.

Band 18 Richard Kössler: Sozialversicherungsprinzip und Staatszuschüsse in der gesetzlichen Rentenversicherung. 1982.

Band 19 Hinrich Steffen: Zum Handlungs- und Entscheidungsspielraum der kommunalen Investitionspolitik in der Bundesrepublik Deutschland. 1983.

Band 20 Manfred Scheuer: Wirkungen einer Auslandsverschuldung des Staates bei flexiblen Wechselkursen. 1983. 
Band 21 Christian Schiller: Staatsausgaben und crowding-out-Effekte. Zur Effizienz einer Finanzpolitik keynesianischer Provenienz. 1983.

Band 22 Hannelore Weck: Schattenwirtschaft: Eine Möglichkeit zur Einschränkung der öffentlichen Verwaltung? Eine ökonomische Analyse. 1983.

Band 23 Wolfgang Schmitt: Steuern als Mittel der Einkommenspolitik. Eine Ergänzung der Stabilitätspolitik? 1984.

Band 24 Wolfgang Laux: Erhöhung staatswirtschaftlicher Effizienz durch budgetäre Selbstbeschränkung? Zur Idee einer verfassungsmäßig verankerten Ausgabengrenze. 1984.

Band 25 Brita Steinbach-van der Veen: Steuerinzidenz. Methodologische Grundlagen und empirisch-statistische Probleme von Länderstudien. 1985.

Band 26 Albert Peters: Ökonomische Kriterien für eine Aufgabenverteilung in der Marktwirtschaft. Eine deskriptive und normative Betrachtung für den Allokationsbereich. 1985.

Band 27 Achim Zeidler: Möglichkeiten zur Fortsetzung der Gemeindefinanzreform. Eine theoretische und empirische Analyse. 1985.

Band 28 Peter Bartsch: Zur Theorie der längerfristigen Wirkungen 'expansiver' Fiskalpolitik. Eine dynamische Analyse unter besonderer Berücksichtigung der staatlichen Budgetbeschränkung und ausgewählter Möglichkeiten der öffentlichen Defizitfinanzierung. 1986.

Band 29 Konrad Beiwinkel: Wehrgerechtigkeit als finanzpolitisches Verteilungsproblem. Möglichkeiten einer Kompensation von Wehrungerechtigkeit durch monetäre Transfers. 1986.

Band 30 Wolfgang Kitterer: Effizienz- und Verteilungswirkungen des Steuersystems. 1986.

Band 31 Heinz Dieter Hessler: Theorie und Politik der Personalsteuern. Eine Kritik ihrer Einkommens- und Vermögensbegriffe mit Blick auf die Leistungsfähigkeitstheorie. 1994.

Band 32 Wolfgang Schert: Die beschäftigungspolitische und fiskalische Problematik der Arbeitgeberbeiträge zur Rentenversicherung. Eine Auseinandersetzung mit der Kritik an der lohnbezogenen Beitragsbemessung. 1987.

Band 33 Andreas Mästle: Die Steuerunion. Probleme der Harmonisierung spezifischer Gütersteuern. 1987.

Band 34 Günter Ott: Internationale Verteilungswirkungen im Finanzausgleich der Europäischen Gemeinschaften. 1987.

Band 35 Heinz Haller: Zur Frage der zweckmäßigen Gestalt gemeindlicher Steuern. Ein Diskussionsbeitrag zur Gemeindesteuerreform. 1987.

Band 36 Thomas Kuhn: Schlüsselzuweisungen und fiskalische Ungleichheit. Eine theoretische Analyse der Verteilung von Schlüsselzuweisungen an Kommunen. 1988.

Band 37 Walter Hahn: Steuerpolitische Willensbildungsprozesse in der Europäischen Gemeinschaft. Das Beispiel der Umsatzssteuer-Harmonisierung. 1988.

Band 38 Ulrike Hardt: Kommunale Finanzkraft. Die Problematik einer objektiven Bestimmung kommunaler Einnahmemöglichkeiten in der gemeindlichen Haushaltsplanung und im kommunalen Finanzausgleich. 1988.

Band 39 Jochen Michaelis: Optimale Finanzpolitik im Modell überlappender Generationen. 1989.

Band 40 Bernd Raffelhüschen: Anreizwirkungen der sozialen Alterssicherung. Eine dynamische Simulationsanalyse. 1989.

Band 41 Berend Diekmann: Die Anleihe- und Darlehenstransaktionen der Europäischen Gemeinschaften. 1990.

Band 42 Helmut Kaiser: Konsumnachfrage, Arbeitsangebot und optimale Haushaltsbesteuerung. Theoretische Ergebnisse und mikroökonometrische Simulation für die Bundesrepublik Deutschland. 1990. 
Band 43 Rüdiger von Kleist: Das Gramm-Rudman-Hollings-Gesetz. Ein gescheiterter Versuch der Haushaltskonsolidierung. 1991.

Band 44 Rolf Hagedorn: Steuerhinterziehung und Finanzpolitik. Ein theoretischer Beitrag unter besonderer Berücksichtigung der Hinterziehung von Zinserträgen. 1991.

Band 45 Cornelia S. Behrens: Intertemporale Verteilungswirkungen in der gesetzlichen Krankenversicherung der Bundesrepublik Deutschland. 1991.

Band 46 Peter Saile: Ein ökonomischer Ansatz der Theorie der intermediären Finanzgewalten Die Kirchen als Parafisci. 1992.

Band 47 Peter Gottried: Die verdeckten Effizienzwirkungen der Umsatzsteuer. Eine empirische allgemeine Gleichgewichtsanalyse. 1992.

Band 48 Andreas Burger: Umweltorientierte Beschäftigungsprogramme. Eine Effizienzanalyse am Beispiel des "Sondervermögens Arbeit und Umwelt". 1992.

Band 49 Jeanette Malchow: Die Zuordnung verteilungspolitischer Kompetenzen in der Europäischen Gemeinschaft. Eine Untersuchung aufgrund einer Fortentwicklung der ökonomischen Theorie des Föderalismus. 1992.

Band 50 Barbara Seidel: Die Einbindung der Bundesrepublik Deutschland in die Europäischen Gemeinschaften als Problem des Finanzausgleichs. 1992.

Band 51 Ralph Wiechers: Markt und Macht im Rundfunk. Zur Stellung der öffentlich-rechtlichen Rundfunkanstalten im dualen Rundfunksystem der Bundesrepublik Deutschland. 1992.

Band 52 Klaus Eckhardt: Probleme einer Umweltpolitik mit Abgaben. 1993.

Band 53 Oliver Schwarzkopf: Die Problematik unterschiedlicher Körperschaftsteuersysteme innerhalb der EG. 1993.

Band 54 Thorsten Giersch: Bergson-Wohlfahrtsfunktion und normative Ökonomie. 1993.

Band 55 Li-Fang Chou: Selbstbeteiligung bei Arzneimitteln aus ordnungspolitischer Sicht. Das Beispiel der Bundesrepublik Deutschland. 1993.

Band 56 Harald Schlee: Einkommensteuerliche Behandlung von Transferzahlungen. Zur Neuordnung der Familienbesteuerung sowie der Besteuerung von Versicherungsleistungen und Sozialtransfers. 1994.

Band 57 Alexander Spermann: Kommunales Krisenmanagement. Reaktionen baden-württembergischer Stadtkreise auf steigende Sozialhilfekosten und Einnahmenausfälle (198092). 1993.

Band 58 Otto Roloff / Sibylle Brander / Ingo Barens / Claudia Wesselbaum: Direktinvestitionen und internationale Steuerkonkurrenz. 1994.

Band 59 Claudia Wesselbaum-Neugebauer: Internationale Steuerbelastungsvergleiche. 1994.

Band 60 Stephanie Miera: Kommunales Finanzsystem und Bevölkerungsentwicklung. Eine Analyse des kommunalen Finanzsystems vor dem Hintergrund der sich abzeichnenden Bevölkerungsentwicklung am Beispiel Niedersachsens unter besonderer Berücksichtigung des Landkreises Wolfenbüttel und seiner Gemeinden. 1994.

Band 61 Wolfgang Scherf: Die Bedeutung des kaldorianischen Verteilungsmechanismus für die gesamtwirtschaftlichen Wirkungen der staatlichen Neuverschuldung. 1994.

Band 62 Rainer Volk: Vergleich der Vergünstigungseffekte der verschiedenen investitionsfördernden Maßnahmen. 1994.

Band 63 Hans-Georg Napp: Kommunale Finanzautonomie und ihre Bedeutung für eine effiziente lokale Finanzwirtschaft. 1994. 2., unveränderte Auflage 1994.

Band 64 Bernd Rahmann / Uwe Steinborn / Günter Vornholz: Empirische Analyse der Autonomie lokaler Finanzwirtschaften in der Europäischen Gemeinschaft. 1994. 
Band 65 Carsten Kühl: Strategien zur Finanzierung der Altlastensanierung. 1994.

Band 66 Stephan Boll: Intergenerationale Umverteilungswirkungen der Fiskalpolitik in der Bundesrepublik Deutschland. Ein Ansatz mit Hilfe des Generational Accounting. 1994.

Band 67 Karl Justus Bernhard Neumärker: Finanzverfassung und Staatsgewalt in der Demokratie. Ein Beitrag zur konstitutionellen Finanztheorie. 1995.

Band 68 Christian Haslbeck: Zentrale versus dezentrale Internalisierung externer Effekte bei unvollständiger Information. 1995.

Band 69 Regina Müller: Horizontale oder vertikale Transfers zur Durchsetzung eines horizontalen Finanzausgleichs. 1995.

Band 70 Christian Hockenjos: Öffentliche Sportförderung in der Bundesrepublik Deutschland. Darstellung und finanztheoretische Analyse. 1995.

Band 71 Manfred Rosenstock: Die Kontrolle und Harmonisierung nationaler Beihilfen durch die Kommission der Europäischen Gemeinschaften. 1995.

Band 72 Christian Rüsch: Wohnungsbau- und Wohneigentumspolitik im Rahmen der Einkommensteuer. Eine Analyse unter steuersystematischen, verteilungspolitischen und fiskalischen Aspekten. 1996.

Band 73 Stephan Winters: Die kollektive Vorsorge für den Pflegefall im Alter. Eine Untersuchung am Beispiel der gesetzlichen Pflegeversicherung in den Niederlanden. 1996.

Band 74 Knut Blind: Allokationsineffizienzen auf Sicherheitsmärkten: Ursachen und Lösungsmöglichkeiten. Fallstudie: Informationssicherheit in Kommunikationssystemen. 1996.

Band 75 Barbara Petrick-Rump: Ökonomische Wirkungen von Steueramnestien. Untersuchung konkreter Erfahrungen ausgewählter Länder mit dem Einsatz von Steueramnestien anhand eines effizienten Steueramnestieprogramms. 1996.

Band 76 Georg Hirte: Effizienzwirkungen von Finanzausgleichsregelungen. Eine Empirische Allgemeine Gleichgewichtsanalyse für die Bundesrepublik Deutschland. 1996.

Band 77 Ulrike Kirchhoff: Die rheinland-pfälzischen Gemeinden im System des Finanzausgleichs. 1996.

Band 78 Kerstin Keil: Der soziale Mietwohnungsbau: Mängel und Alternativen. 1996.

Band 79 Bernhard Manzke: Kinderlastenausgleich versus verstärkte Einwanderung. Alternative Ansätze zur langfristigen Sicherung der Gesetzlichen Rentenversicherung. 1997.

Band 80 Hariolf M. Wenzler: Institutionenökonomik und öffentliche Finanzkontrolle. Eine Analyse am Beispiel der Europäischen Union. 1997.

Band 81 Joachim Nagel: Supply-Side Policy in den USA. Eine theoretische und empirische Analyse der angebotsorientierten Wirtschaftspolitik Reagans unter besonderer Berücksichtigung steuerlicher Aspekte. 1997.

Band 82 Heinz Lampert: Krise und Reform des Sozialstaates. 1997.

Band 83 Monika Hanswillemenke / Bernd Rahmann: Zwischen Reformen und Verantwortung für Vollbeschäftigung. Die Finanz- und Haushaltspolitik der sozial-liberalen Koalition von 1969 bis 1982.1997.

Band 84 Berthold Fürst: Die Maastrichter Budgetkriterien im Konflikt mit der Verschuldungsautonomie der deutschen Gebietskörperschaften. 1997.

Band 85 Burkhard Pahnke: Einkommensorientierte Förderung des sozialen Mietwohnungsbaues. Bestandsaufnahme und Kritik. 1998.

Band 86 Judith Safford: Staatsverschuldung im Vereinigten Königreich. Die öffentliche Verschuldung unter der Konservativen Regierung von 1979-1994. Ursachen und Auswirkungen. 1998. 
Band 87 Ralf Oberheide: Die Bekämpfung der Steuerumgehung. 1998.

Band 88 Achim Truger: Die neue Finanzwissenschaft zwischen Realitätsferne und Irrelevanz der Annahmen. Eine methodologische Analyse potentieller Verteidigungsstrategien der neuen Finanzwissenschaft gegen den Vorwurf der Realitätsferne ihres entscheidungstheoretischen Fundamentes. 1998.

Band 89 Karin Bickel: Familienbezogene Elemente im System der gesetzlichen Rentenversicherung. Unter besonderer Berücksichtigung von Ein-Eltern-Familien. 1998.

Band 90 Wolfgang Scherf: Schlüsselzuweisungen und Kreisumlage. Die Problematik der Finanzierung der Landkreise am Beispiel des kommunalen Finanzausgleichs von RheinlandPfalz. 1998.

Band 91 Sandra Ehmann: Familienpolitik in Frankreich und Deutschland - ein Vergleich. 1999.

Band 92 Hendrik Suermann: Einkommensteuerliche Behandlung von Währungsgewinnen und -verlusten. Eine finanzwissenschaftliche Analyse des Steuerrechts in den USA und in Deutschland. 1999. 